magitan magrasta

ENVIRONMENTAL RESTORATION PROGRAM

\title{
Data Evaluation Technical Memorandum on the K-1407-C Retention Basin at the Oak Ridge K-25 Site, Oak Ridge, Tennessee

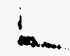

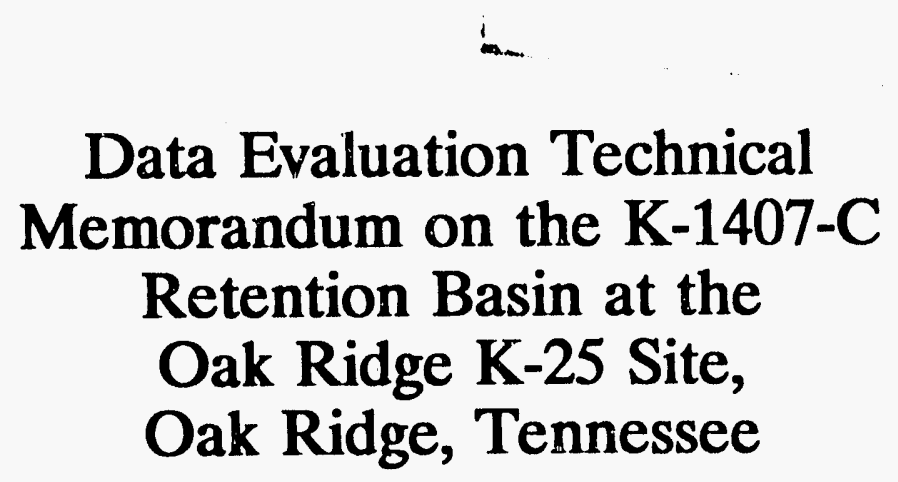

En

JAN 221992

Diat by L. D. Bates, K-1330, MS-7200, 480905

n
0
蒠

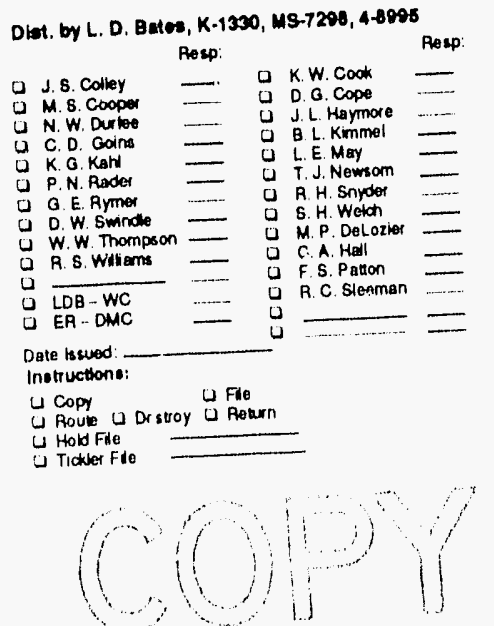


This report has been reproduced directly from the best avallable copy.

Avallable to DOE and DOE contractors from the Office of Scientific and Technical Information, P.O. Box 62, Oak Ridge, TN 37831; prices avallable from 615-576-8401, FTS 626-8401.

Available to the public from the National Technical Information Service, U.S. Department of Commerce, 5285 Port Royal Rd., Springfleld, VA 22161. 
Environmental Restoration Division K-25 Environmental Restoration Program

\section{Data Evaluation Technical Memorandum on the K-1407-C Retention Basin at the Oak Ridge K-25 Site, Oak Ridge, Tennessee}

Date Issued-October 1991

Prepared for

U.S. Department of Energy

Office of Environmental Restoration and Waste Management under budget and reporting codes CD 1072 and EW 20

OAK RIDGE K-25 SITE

Oak Ridge, Tennessee 37831-7101 managed by

MARTIN MARIETTA ENERGY SYSTEMS, INC.

for the

U.S. DEPARTMENT OF ENERGY

under contract DE-AC05-84OR21400

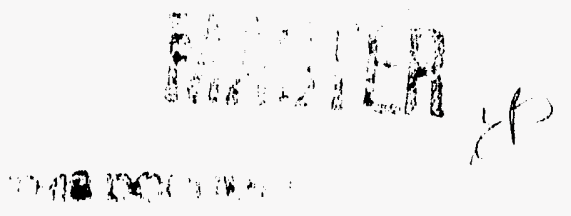




\section{Participating Authors}

Dennis Beal, Statistics

Jeff Bock, Statistics

Terry Hatmaker, Chemistry

Jack Zolyniak, Statistics

Technical Divisiom, Oak Ridge K-25 Site

Patty Goddard

Environmental Restoration Division, Oak Ridge K-25 Site

Dan Kucsmas

Engineering, Oak Ridge National Laboratory

Miriam L. Land, Data base nanagement

David C. Landguth, Industrial hygiene/field sampling

C. Wilson McGinn, Hydrogeology/risk analysis

Denise Miller, Geology/risk analysis

Peggy Tiner, Field sampling

Mary Uziel, Technical author, Chap. 3

Health and Safety Research Division, Oak Ridge National Laboratory 


\section{CONTENTS}

TABLES $\ldots \ldots \ldots \ldots \ldots \ldots \ldots \ldots \ldots \ldots \ldots \ldots \ldots \ldots \ldots \ldots \ldots, v$

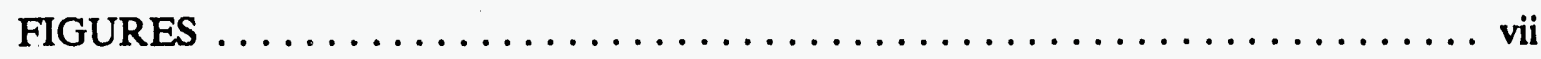

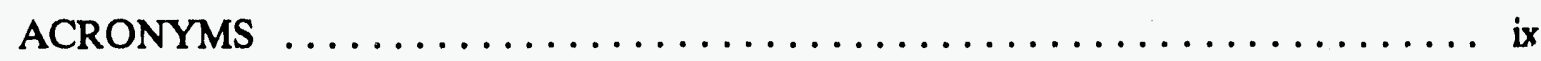

EXECUTTVE SUMMARY $\ldots \ldots \ldots \ldots \ldots \ldots \ldots \ldots \ldots \ldots \ldots \ldots \ldots \ldots \ldots$

1. INTRODUCTION $\ldots \ldots \ldots \ldots \ldots \ldots \ldots \ldots \ldots \ldots \ldots \ldots \ldots \ldots \ldots \ldots$

$1.1 \mathrm{~K}-25$ SITE REGULATORY HISTORY $\ldots \ldots \ldots \ldots \ldots \ldots \ldots \ldots \ldots \ldots \ldots \ldots$

$1.2 \mathrm{~K}$-1407-C RETENTION BASIN REGULATORY HISTORY $\ldots \ldots \ldots, 2$

1.3 PURPOSE OF THE DATA EVALUATION

TECHNICAL MEMORANDUM $\ldots \ldots \ldots \ldots \ldots \ldots \ldots \ldots, 2$

1.4 PREVIOUS DOCUMENTATION $\ldots \ldots \ldots \ldots \ldots \ldots \ldots \ldots \ldots, 2$

2. DESCRIPTION OF THE STUDY AREA $\ldots \ldots \ldots \ldots \ldots \ldots \ldots \ldots \ldots, 4$

2.1 PHYSICAL CHARACTERISTICS $\ldots \ldots \ldots \ldots \ldots \ldots \ldots \ldots \ldots, 4$

2.1.1 Geographic Location ...................... 4

2.1 .2 Climatology $\ldots \ldots \ldots \ldots \ldots \ldots \ldots \ldots \ldots \ldots \ldots, 4$

2.1.3 General Regional Demography ................. 4

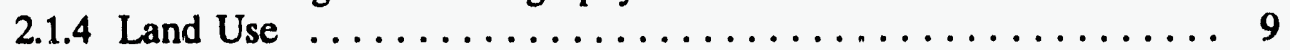

2.1.5 Hydrogeology ......................... 10

2.1.6 Data Limitations Related to Physical Characterization ....... 12

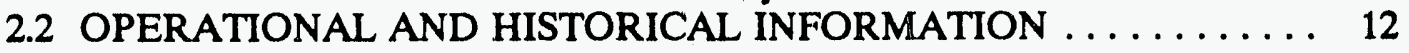

2.3 PREVIOUS INVESTIGATIONS $\ldots \ldots \ldots \ldots \ldots \ldots \ldots \ldots \ldots \ldots$

3. FIELD INVESTIGATION $\ldots \ldots \ldots \ldots \ldots \ldots \ldots \ldots \ldots \ldots \ldots \ldots \ldots \ldots \ldots \ldots$

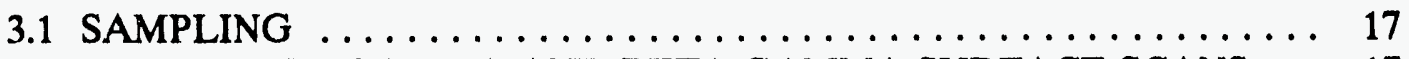

3.2 RESULTS OF GAMMA AND BETA-GAMMA SURFACE SCANS $\ldots \quad 17$

3.3 GAMMA EXPOSURE RATES AND BETA-GAMMA DOSE

RATES AT SAMPLING POINTS $\ldots \ldots \ldots \ldots \ldots \ldots \ldots \ldots, 18$

3.4 ALPHA RADIATION $\ldots \ldots \ldots \ldots \ldots \ldots \ldots \ldots \ldots \ldots \ldots \ldots \ldots \ldots \ldots \ldots$

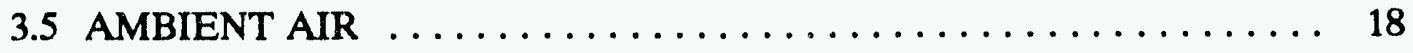

3.6 SIGNIFICANCE OF FIELD MEASUREMENTS $\ldots \ldots \ldots \ldots \ldots \ldots, 28$

3.7 DATA LIMITATIONS $\ldots \ldots \ldots \ldots \ldots \ldots \ldots \ldots \ldots \ldots \ldots \ldots \ldots \ldots \ldots \ldots$

4. QUALITY ASSURANCE/QUALITY CONTROL $\ldots \ldots \ldots \ldots \ldots \ldots \ldots 29$

4.1 DATA QUALITY OBJECTIVES ..................... 29

4.2 ANALYTICAL METHODOLOGY $\ldots \ldots \ldots \ldots \ldots \ldots \ldots \ldots, 29$

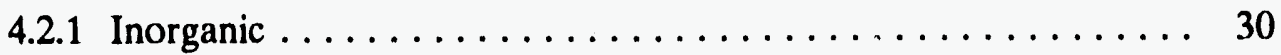

4.2.2 Radiochemical ........................ 30 
4.3 HOLDING TIMES $\ldots \ldots \ldots \ldots \ldots \ldots \ldots \ldots \ldots \ldots, 30$

4.4 EQUIPMENT RINSATES $\ldots \ldots \ldots \ldots \ldots \ldots \ldots \ldots \ldots \ldots, 31$

4.4.1 Radiochemical ............................. 31

4.4.2 Inorganic $\ldots \ldots \ldots \ldots \ldots \ldots \ldots \ldots \ldots \ldots \ldots, 31$

4.5 FIELD BLANKS $\ldots \ldots \ldots \ldots \ldots \ldots \ldots \ldots \ldots \ldots \ldots, 44$

4.6 MATRIX SPIKE RECOVERIES $\ldots \ldots \ldots \ldots \ldots \ldots \ldots \ldots \ldots \ldots, 44$

4.6.1 Inorganic Matrix Spikes ..................... 44

4.6.2 Radiochemical Matrix Spikes .................. 46

4.7 SUMMARY OF RESULTS $\ldots \ldots \ldots \ldots \ldots \ldots \ldots \ldots \ldots \ldots \ldots, 46$

4.7 .1 Inorganic $\ldots \ldots \ldots \ldots \ldots \ldots \ldots \ldots \ldots \ldots \ldots \ldots \ldots \ldots, 46$

4.7.2 Radiochemical .......................... 46

5. PRELIMINARY RISK ASSESSMENT . .................... 47

5.1 DATA EVALUATION/POTENTIAL CONTAMINANTS OF

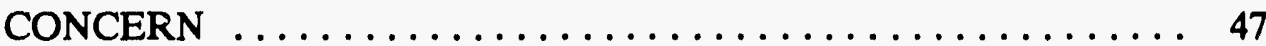

5.2 DOSE/RESPONSE INFORMATION EMPLOYED IN SCREENING .. 48

5.3 CONTAMINANT SCREENING $\ldots \ldots \ldots \ldots \ldots \ldots \ldots \ldots \ldots, 51$

5.3.1 Exposure Pathways ........................ 52

5.3 .2 Radionuclide Screening $\ldots \ldots \ldots \ldots \ldots \ldots \ldots \ldots \ldots \ldots, 53$

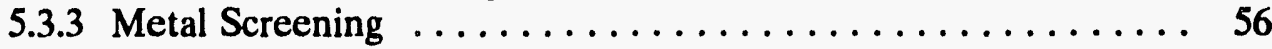

5.4 DATA LIMITATIONS $\ldots \ldots \ldots \ldots \ldots \ldots \ldots \ldots \ldots \ldots \ldots \ldots \ldots \ldots \ldots$

6. STATISTICAL EVALUATION OF DATA $\ldots \ldots \ldots \ldots \ldots \ldots \ldots \ldots \ldots$

6.1 DATA SUMMARY $\ldots \ldots \ldots \ldots \ldots \ldots \ldots \ldots \ldots \ldots \ldots \ldots \ldots, \quad 59$

6.1.1 Summary by Analyte $\ldots \ldots \ldots \ldots \ldots \ldots \ldots \ldots \ldots \ldots, 60$

6.1.2 Summary by Analyte and Sample Depth $\ldots \ldots \ldots \ldots \ldots \ldots 60$

6.1.3 Significant Differences Between Sample Depths .......... 60

6.2 DATA PRESENTATION . ....................... 69

6.2.1 Three-Dimensional Sample Concentration Plots ........ 72

6.2.2 Illustration of Contamination Probability Contours ....... 72

KRIGING REFERENCES $\ldots \ldots \ldots \ldots \ldots \ldots \ldots \ldots \ldots \ldots \ldots, \quad 89$

7. CONCLUSIONS AND RECOMMENDATIONS $\ldots \ldots \ldots \ldots \ldots \ldots \ldots \ldots$

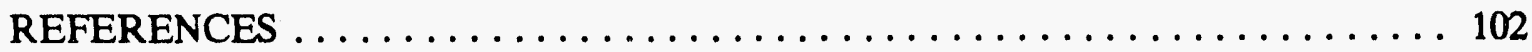

Appendix A: GAMMA EXPOSURE RATES AND BETA-GAMMA DOSE

RATES ............................... 105

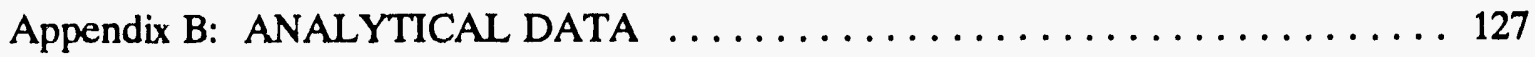

Appendix C: CALCULATIONS EMPLOYED IN THE STATISTICAL

EVALUATION OF DATA $\ldots \ldots \ldots \ldots \ldots \ldots \ldots \ldots \ldots \ldots$

Appendix D: DIMENSIONAL CONCENTRATION PLOTS $\ldots \ldots \ldots \ldots \ldots \ldots 183$ 


\section{TABLES}

1. Hydraulic conductivities in the K-1407-C are ${ }^{2} \ldots \ldots \ldots \ldots \ldots \ldots \ldots \ldots$

2. Summary of findings from surface gamma and beta-gamma scans at the K-1407-C Retention Basin ..................... 22

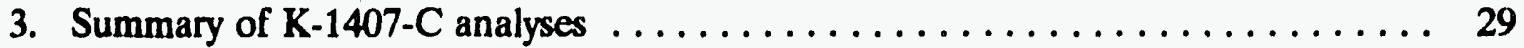

4. Radiochemical analysis methodologies $\ldots \ldots \ldots \ldots \ldots \ldots \ldots \ldots \ldots \ldots \ldots$

5. Mercury analyses exceeding holding times $\ldots \ldots \ldots \ldots \ldots \ldots \ldots \ldots \ldots \ldots \ldots \ldots$

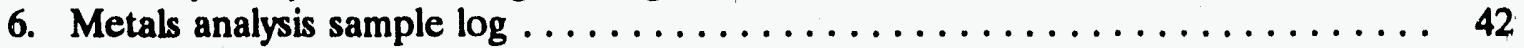

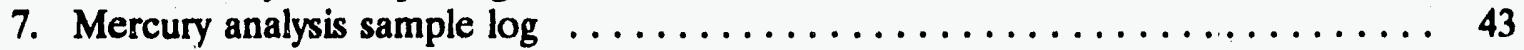

8. Slope factors for radionuclides detected in K-1407-C Retention Basin soil . . . . . 50

9. Available slope factors for nonradioactive metals detected in $\mathrm{K}-1407-\mathrm{C}$ Retention Basin soil $\ldots \ldots \ldots \ldots \ldots \ldots \ldots \ldots \ldots \ldots$

10. Available reference doses for K-1407-C

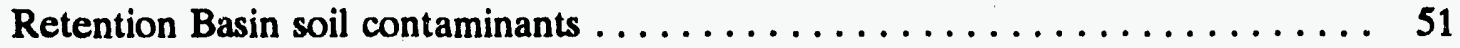

11. Guideline values for radionuclide screening $\ldots \ldots \ldots \ldots \ldots \ldots \ldots \ldots \ldots \ldots$

12. Frequency of radioactive soil samples exceeding carcinogenic toxicity guideline values $\ldots \ldots \ldots \ldots \ldots \ldots \ldots \ldots$

13. Guideline values for nonradioactive metals $\ldots \ldots \ldots \ldots \ldots \ldots \ldots \ldots \ldots \ldots$

14. Frequency of nonradioactive soil analytes

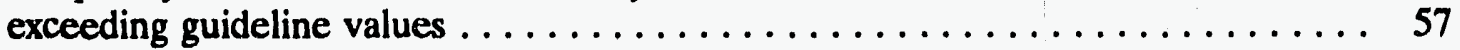

15. Summary statistics on all K-1407-C soil data by analyte $\ldots \ldots \ldots \ldots \ldots \ldots \ldots$

16. Summary statistics on all K-1407-C soil data by analyte and sample depth $\ldots \ldots 63$

17. A statistical comparison of the mean concentration per sample depth of all analytes at the Kk-1407-C Retention Basin . . . . . . . . . . 70 


\section{FIGURES}

1. Regional location of the K-25 Site .................... 5

2. Location of the K-25 Site with respect to the city of Oak Ridge $\ldots \ldots \ldots \ldots \ldots$

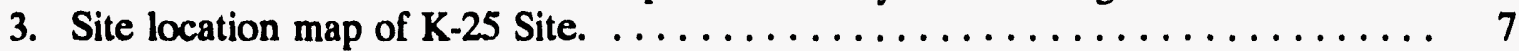

4. Communities within a 30 -mile radius of the $K-25$ Site $\ldots \ldots \ldots \ldots \ldots \ldots$

5. Geology in the vicinity of the K-25 Site $\ldots \ldots \ldots \ldots \ldots \ldots \ldots \ldots \ldots$

6. K-1407-C Retention Basin areal water table contour map and unconsolidated zone monitoring wells $\ldots \ldots \ldots \ldots \ldots \ldots \ldots \ldots$

7. Bedrock groundwater flow in K-1407-C Retention Basin area

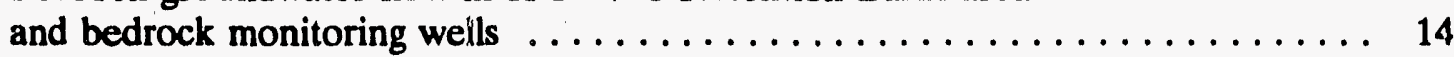

8. Sample location grid for the K-1407-C Retention Basin . . . . . . . . . . 19

9. Ranges of surface gamma exposure rates $(\mu \mathrm{R} / \mathrm{h})$ measured at the $\mathrm{K}-1407-\mathrm{C}$ Retention Basin (September 1989 to January 1990) . . . . . . . . . . . 20

10. Ranges of beta-gamma dose rates $(\mathrm{mrad} / \mathrm{h})$ measured at the K-1407-C Retention Basin (September 1989 to January 1990) . . . . . . . . . . . . . . .

11. Elevated surface gamma exposure rates $(\mu R / h)$ and beta-gamma dose rates (mrad/h in parentheses) at the $\mathrm{K}-1407-\mathrm{C}$ Retention Basin (September 1989 to January 1990)

12. Surfa'se gamma exposure rates $(\mu R / h)$ at sampling points at the K-1. 07-C Retention Basin (September 1989 to January 1990) . . . . . . . . . . 26

13. Surface beta-gamma dose rates $(\mathrm{mrad} / \mathrm{h})$ at sampling points at the K-1407-C Retention Basin (September 1989 to January 1990) . . . . . . . . . . . 27

14. Comparison of alpha results for rinsates, blanks, and samples $\ldots \ldots \ldots \ldots \ldots \ldots$

15. Comparison of beta results for rinsates, blaniks, and samples $\ldots \ldots \ldots \ldots \ldots \ldots$

16. Comparison of ${ }^{99} \mathrm{Tc}$ results for rinsates, blanks, and samples $\ldots \ldots \ldots \ldots \ldots \ldots$

17. Comparison of ${ }^{234} U$ results for rinsates, blanks, and samples $\ldots \ldots \ldots \ldots \ldots \ldots$

18. Comparison of ${ }^{238} U$ results for rinsates, blanks, and samples $\ldots \ldots \ldots \ldots \ldots$

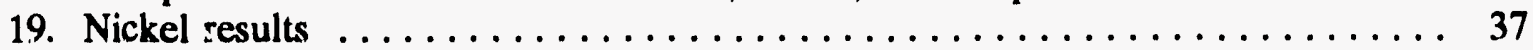

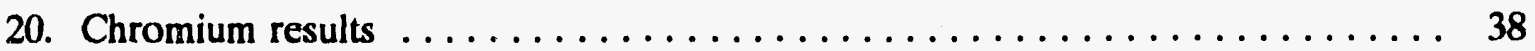

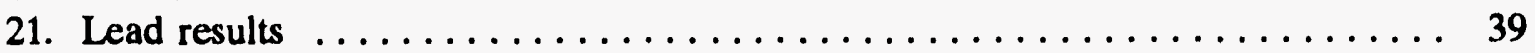

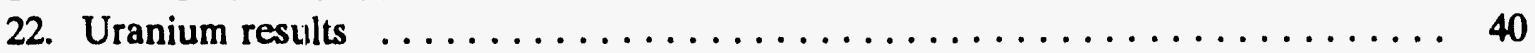

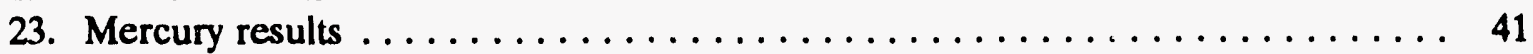

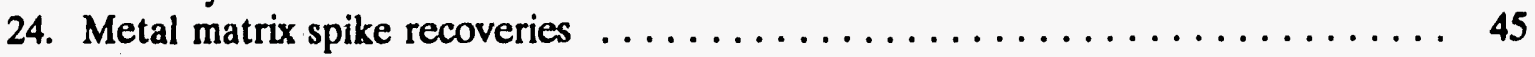

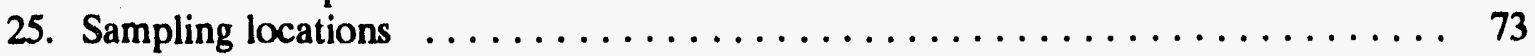

26. Three-dimensional perspective of the K-1407-C Retention Basin . . . . . . 74

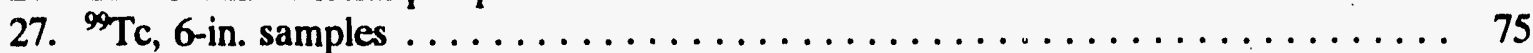

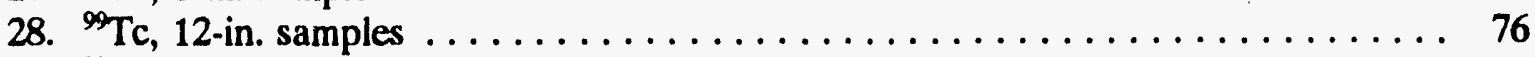

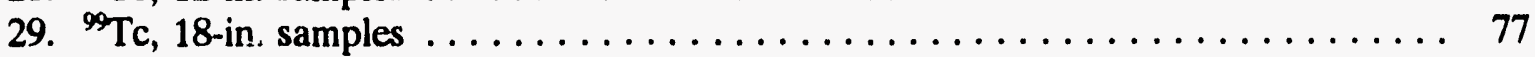

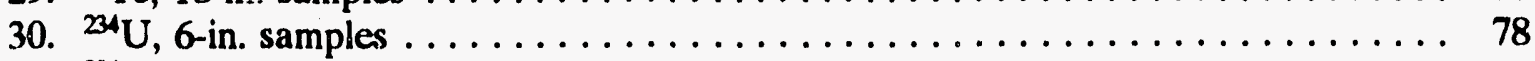

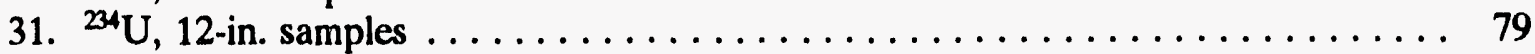

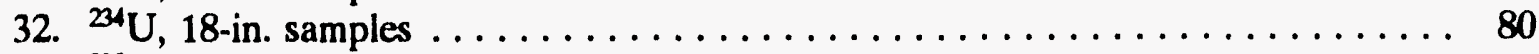

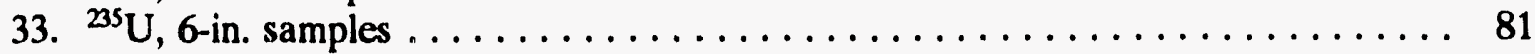




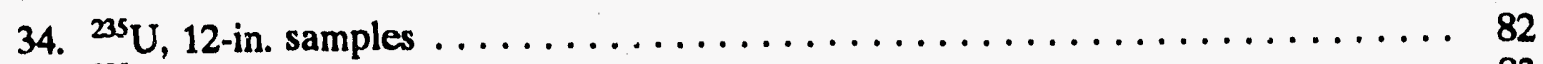

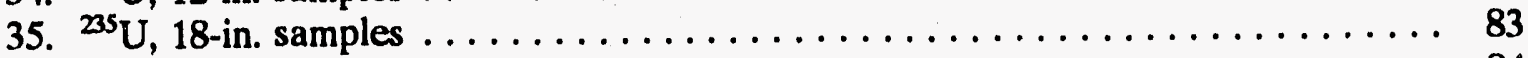

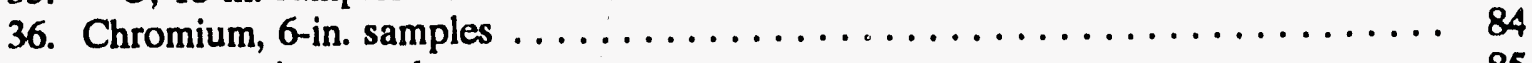

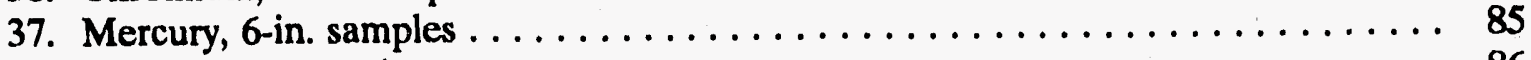

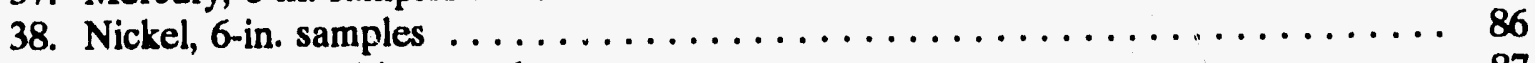

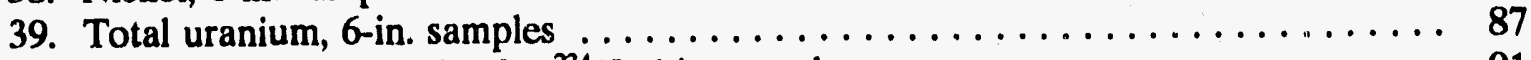

40. Probability contour plot for ${ }^{234} \mathrm{U}$, 6-in. samples $\ldots \ldots \ldots \ldots \ldots \ldots \ldots \ldots \ldots$

41. Probability contour plot for ${ }^{234} \mathrm{U}, 12$-in. samples $\ldots \ldots \ldots \ldots \ldots \ldots \ldots \ldots \ldots$

42. Probability contour plot for ${ }^{234} U$, 18 -in. samples $\ldots \ldots \ldots \ldots \ldots \ldots \ldots \ldots \ldots$

43. Probability contour plot for ${ }^{238} U$, 6-in. samples $\ldots \ldots \ldots \ldots \ldots \ldots \ldots \ldots \ldots . \ldots \ldots$

44. Probability contour plot for ${ }^{238} U$, 12 -in. samples $\ldots \ldots \ldots \ldots \ldots \ldots \ldots \ldots \ldots$

45. Probability contour plot for ${ }^{238} \mathrm{U}$, 18-in. samples $\ldots \ldots \ldots \ldots \ldots \ldots \ldots \ldots \ldots . \ldots 6$

46. Probability contour plot for ${ }^{237} \mathrm{~Np}$, 6-in. samples $\ldots \ldots \ldots \ldots \ldots \ldots \ldots \ldots \ldots$

47. Probability contour plot for ${ }^{235} \mathrm{U}$, 6-in. samples $\ldots \ldots \ldots \ldots \ldots \ldots \ldots \ldots \ldots$

48. Probability contour plot for ${ }^{241} \mathrm{Am}, 6$-in. samples $\ldots \ldots \ldots \ldots \ldots \ldots \ldots \ldots$ 


\section{ACRONYMS}

BRW bedrock well

CERCLA Comprehensive Environmental Response, Compensation, and Liability Act

DETM Data Evaluation Technical Mernorandum

EPA Environmental Protection Agency

ICP inductively coupled plasma

IT International Technology (Corporation)

$\mathrm{mrad} / \mathrm{h} \quad$ millirads per hour

$\mu \mathrm{R} / \mathrm{h} \quad$ microrontgens per hour

ORR Oak Ridge Reservation

ORNL Oak Ridge National Laboratory

QA quality assurance

QC quality control

RCRA Resource Conservation and Recovery Act

RFI R.CRA Facility Investigation

RfD reference dose

SEG Scientific Ecology Group

SWMU solid waste management unit

TDHE Tennessee Department of Health and Environment (now Tennessee Department of Environment and Conservation)

TSD treatment, storage, or disposal

UNW unconsolidated well 


\section{EXECUTIVE SUMMARY}

The K-1407-C Retention Basin was a surface impoundment at the Oak Ridge K-25 Site. The basin was used primarily for storing potassium hydroxide scrubber sludge generated at the K-25 Sitc. In addition, from 1960 to 1973, metal hydroxide sludges that were removed from the K-1407-B Holding Pond were discharged to the K-1407-C Retention Basin. The sludge in the K-1407-B Pond contained discharge from the K-1420 Decontamination and Uranium Recovery, the K-1501 Steam Plant, the K-1413 Laboratory, and the K-1401 Maintenance Building. Radioactive material is also present in the K-1407-C Retention Basin, probably the result of cleaning and decontamination activities at some of the aforementioned facilities. The discharge of waste materials to K-1407-C was discontinued before November of 1988, and all sludge was removed from the retention basin. Some of the sludge was stored, and the remainder was fixed in concrete.

This Data Evaluation Technical Memorandum is specific to the K-1407-C Retention Basin and includes information pertinent to the evaluation of soil contamination. The focus of this evaluation is the effectiveness of the Phase 1 investigation of the K-1407-C Retention Basin to define site conditions adequately to support decisions regarding appropriate closure alternatives. This includes the physical characterization of the site area and the characterization of the nature and extent of contamination at the site in relation to risk characterization and statistical evaluation.

The present evaluation has concluded that the investigation of the K-1407-C Retention Basin has not characterized the site well enough to support decisions regarding closure activities. Information regarding the physical characterization and the extent of contamination at the site is deficient. The health-based screening of contaminants detected in soil at the K-1407-C Retention Basin indicates that a majority of the samples taken from a 12- to 18-in. interval contain radioactive contaminant concentrations exceeding guideline values. Because the 18-in. samples contained radionuclides, the depth of contamination is not fully characterized at this site. Therefore, additional sampling is recommended to determine the depth and lateral extent of radioactive contamination. 


\section{INTRODUCTION}

\subsection{K-25 STTE REGULATORY HISTORY}

The Oak Ridge K-25 Site was built as part of the Manhattan Project during World War II to supply uranium-enriched material for nuclear weapons production. Construction of the K-25 Site started in 1943, and the K-25 Building, the first diffusion facility for large-scale separation of ${ }^{235} \mathrm{U}$, was fully operable by August 1945 . Additional buildings involved in the enrichment process, K-27, K-29, K-31, and K-33, were operable by 1956. In response to the nation's postwar nuclear emphasis, plant operations were modified to include the production of uranium compatible with reactors used to generate electric power. The K-25 Site continued to provide enriched uranium until 1985.

The separation process along with associated decontamination, maintenance, and fabrication processes resulted in the generation of various hazardous and radioactive waste by-products. Hazardous waste treatment, storage, and disposal (TSD) facilities, such as the K-1407-C Retention Basin, were created at the K-25 Site to handle such by-products. Some of these facilities continue to receive hazardous wastes, while others have been decommissioned. These TSD facilities are currently subject to the requirements of several laws:

- Resource Conservation and Recovery Act (RCRA): created in 1976 as a management system for hazardous wastes that mandates permitting currently operating TSD facilities.

- Hazardous and Solid Waste Amendment: amendments to RCRA (1984) which extended the authority of the Environmental Protection Agency (EPA) to correct releases to all media from all solid waste management units (SWMUs) at RCRA facilities.

Under RCRA a SWMU is defined as any "discernible waste management unit at a RCRA facility from which hazardous waste or hazardous constituents might migrate, irrespective of whether the unit was intended for the management of solid or hazardous waste. Such units include any area at a facility at which hazardous wastes or hazardous constituents have been routinely and systematically released."1

- Comprehensive Environmental Response, Compensation, and Liability Act (CERCLA, also referred to as Superfund): created in 1980 to establish a program to (1) identify sites (operable units) from which environmental releases of hazardous substances have occurred or might occur, (2) ensure that they are cleaned up by responsible parties or the government, (3) evaluate damages to natural resources, and (4) create a claims procedure for parties who have cleaned up sites or spent money to restore natural resources. Sites identified by CERCLA are evaluated and then placed on the National Priorities List if appropriate.

- Superfund Amendments and Reauthorization Act: signed into law in 1986 as a 5-year extension of the Superfund/CERCLA program to clean up hazardous releases at uncontrolled or abandoned hazardous waste sites. 
- National Environmental Policy Act (NEPA): directs public officials to consider the impacts of their actions (e.g., construction, remediation) on the human environment as a part of all decision-making processes.

\subsection{Y.-1407-C RETENTION BASIN REGULATORY HISTORY}

The K-1407-C Retention Basin is a surface impoundment at the K-25 Site which received waste streams from 1972 to 1988 . This basin is a RCRA Interim Status unit; a closure plan for the impoundment was submitted (May 1988) to the Tennessee Department of Heaith and Environment (TDHE, now the Tenricssee Department of Environment and Conservation). ${ }^{2}$ This plan was approved, and removal ot sludge was undertaksil at that time. Verification sampling as required by the closure plan was then conducted. However, the results of this sampling indicated the presence of unsuspected radionuclide contamination. Although radionuclides are not regulated under RCRA, a revised closure plan was submitted (April 1990) which addressed the radionuclide concerns and called for additional sampling prior to the completion of closure activities. ${ }^{3}$

Chapter 3 of the revised closure plan states that "the results of the investigation will be compared to the guideline values contained in the Data Analysis Approach Report for $K-1407-B$ Holding Pond and K-1407-C Retention Basin (KER-023) [sic.] . . . Based on the result of the comparisons, three closure scenarios are possible: no action, excavation, or another option." Therefore, the objectives of the investigation were to (1) determine if all RCRA hazardous constituents had been removed from the basin, (2) further define the nature of the radionuclide contamination, (3) determine is the radionuclide contamination was local or areal in extent, and (4) determine if concentrations were decreasing with depth. Subsequently, the sampling and analysis activities were outlined in the "Sampling Work Plan: K-1407-C Retention Basin," K/ER-21, and implemented. ${ }^{5}$ The analytical results werz analyzed, and the data evaluation is contained within this report.

\subsection{PURPOSE OF THE DATA EVALUATION TECHNICAL MEMORANDUM}

This Data Evaluation Technical Memorandum (DETM) is specific to the K-1407-C Retention Basin and includes the findings of a inultidisciplinary team that evaluated analytical data from the soil samples. The DETM will serve to provide an appraisal of the Phase 1 data in terms of their ability to meet the proposed objectives of the samplin $\tilde{E}$ work plan. Additionally, the data are evaluated in relation to their validity and representativeness with respect to human-health risk assessment.

\subsection{PREVIOUS DOCUIMENTATION}

Several documents rilevant to the investigation of the K-1407-C Retention Basin have been previously prepared. These documents are listed below with a brief explanation of their content and relevance to this project. 
- Closure Plan: K-1407-C Retention Basin, K/HS-221. The original closure plan which was submitted to TDHE (now the Tennessee Department of Environment and Conservation) for approval. ${ }^{2}$

- Closure Plan: K-1407-C Retention Basin, K/ER-27 and K/HS-221/R2. The revised closure plan which addresses the presence of radionuclide contamination in the basin. ${ }^{3}$

- "Sampling Work Plan: K-1407-C Retention Basin," K/ER-21 (Appendix 5 of the Closure Plan: K-1407-C Retention Basin). The sampling work plan contains the justification and rationale for the sampling locations and parameters. Also included within this report are the health and safety procedures implemented during the sampling activities and a description of the analytical procedures. ${ }^{5}$

- Site Characterization Summary, K-1407-C Retention Basin, K/ER-33. This document (1) summarizes all preexisting data, (2) summarizes the analytical results from the sampling outlined in K/ER-21, (3) addresses the development and initial screening of remedial alternatives, and (4) addresses potential applicable or relevant and appropriate requirements. ${ }^{6}$

- Data Analysis Approach Report for K-1407-B Holding Pond and K-1407-C Retention Basin, K/ER-23. This report contains information describing the cata evaluation process conducted prior to the generation of the DETM.?

- RCRA Facility Investigation Plan General Document, K/HS-132, Revision 1. This plan, referred to as the "General Document," serves as a comprehensive reference for individual RCRA facility investigation (RFI) plans as well as for other K-25 Site RFI documentation. The General Document characterizes the K-25 Site environment, locates all known SWMUs, and provides a perspective of the scope of the K-25 operation. Sampling strategies, quality assurance (QA), and quality control (QC) associaied with sampling and analysis and data management are discussed, along with procedures established to protect the health and safety of employees and the public. ${ }^{8}$ 


\section{DESCRIPTION OF THE STUDY AREA}

\section{PHYSICAL CHARACTERISTICS}

\subsubsection{Geographic Location}

The K-25 Site is located in east Tennessee $\sim 20$ miles northwest of Knoxville, Tennessee (Fig. 1), and 6 miles west of the city of Oak Ridge (Fig. 2). The K-1407-C Retention Basin is located in the northeast corner of the K-25 Site. Figure 3 is a site location map.

\subsubsection{Climatology}

Weather patterns in Oak Ridge are generally temperate, with warm, humid summers and cool winters. Extreme temperatures are uncommon because of the moderating influences of the adjacent mountain ranges. Annual average precipitation is $1.36 \mathrm{~m}$, including $-0.25 \mathrm{~m}$ of snowfall. ${ }^{9}$ Heavy precinitation occurs mostly in January, February, and July, while spring and autumn are relatively dry.

Although wind conditions in the Oak Ridge area are some of the calmest in the United States, an investigation of the wind patterns in the Oak Ridge Reservation (ORR) area confirmed good ventilation up and down the valleys. This ventilation helps circulate the air masses over Oak Ridge. Prevailing winds blow up-valley from the southwest during the day and down-valley from the northeast in the early evening and at night. This effect, which is due to the channeling of wind by the regional ridge and valley topography, is not as evident in the vicinity of the K-25 Site, which is in a relatively open area. ${ }^{\circ}$ Poor air dilution typically occurs in October because of slow-moving high-pressure cells. Severe electrical storms, wind storms, and tornadoes rarely occur in the Oak Ridge area. The major contributor to this stability of air movement is the Cumberland Plateau. In addition, the area is protected by the Appalachian Mountains from the hot southeasterly winds and tropical storms which sometimes develop along the Atlantic coast.

\subsubsection{General Regional Demography}

The K-25 Site is part of the 63,000-acre federally owned ORR, which is located in Anderson and Roane counties. There are five counties surrounding the Reservation: Anderson, Knox, Loudon, Morgan, and Roane. The combined population of these five counties is slightly greater than 500,000 .

The two major population centers within 30 miles of the site are Oak Ridge $(\sim 28,000)$, which lies 6 miles east of the plant, and Knoxville $(\sim 183,000)$, which is $\sim 20$ miles southeast of the site. Several smaller cities are located within the nearby counties: Clinton $(-5200)$, Harriman ( $\sim 8300)$, Kingston $(\sim 4500)$, Lenoir City $(-5500)$, Loudon $(\sim 4000)$, Oliver Springs $(-3600)$, and Rockwood $(-5800) .{ }^{11}$ The locations of these cities are given in Fig. 4. The largest population $(-2400)$ within a 2-mile "adius of the K-25 Site is composed of the on-site employees of the facility. In addition, a small number of visitors are present at the site at any 


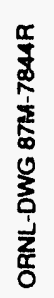

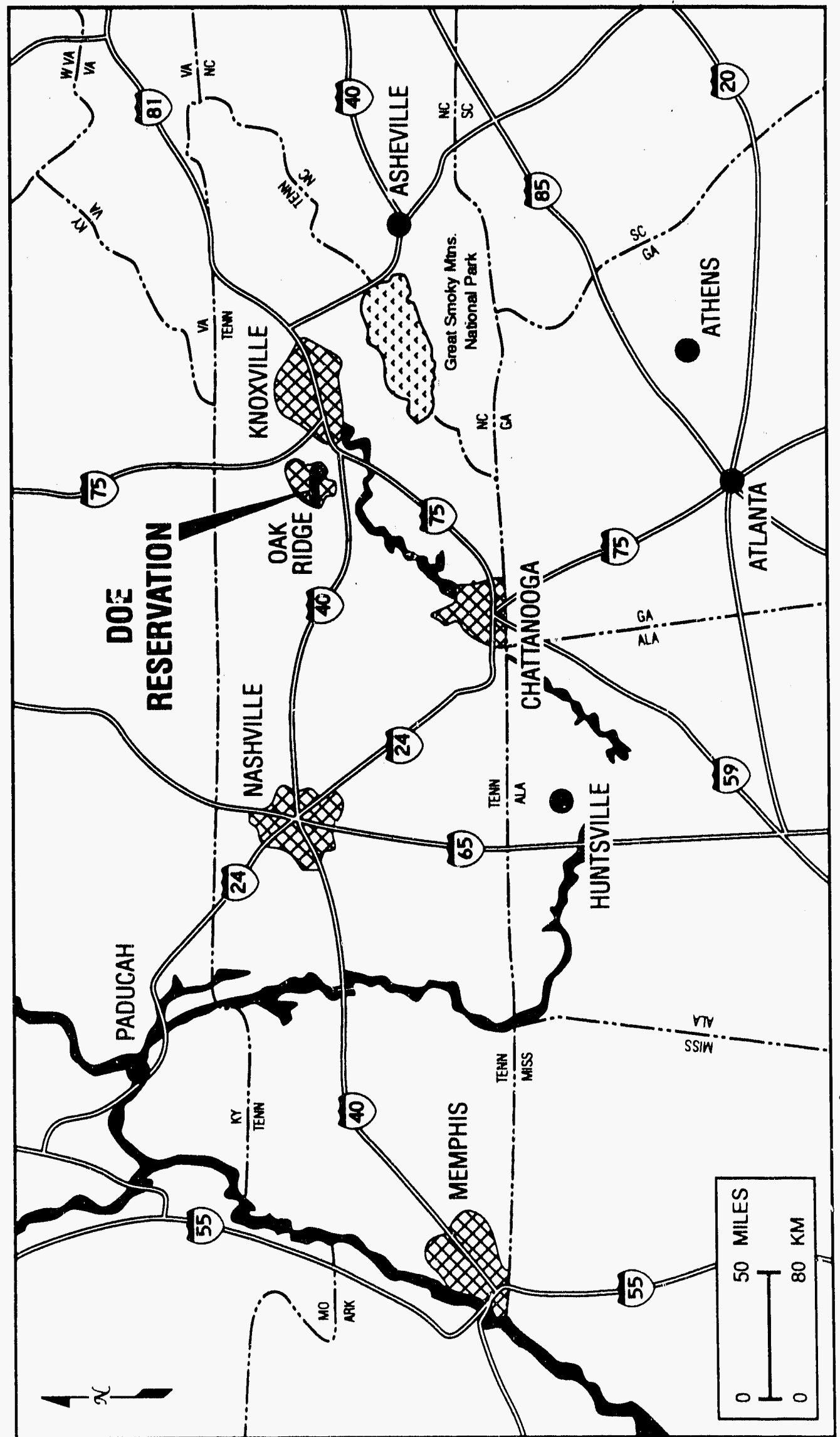

岁 


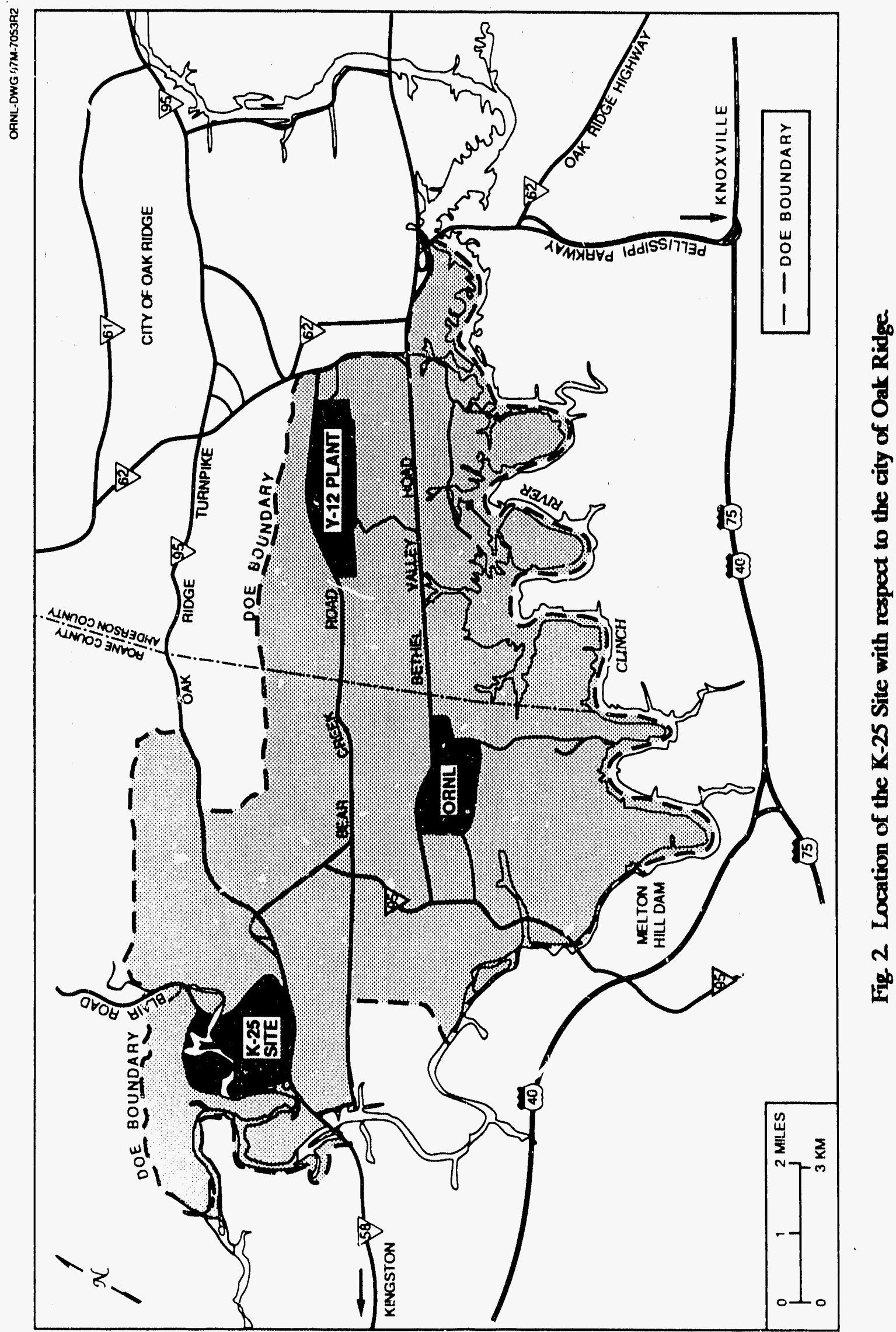




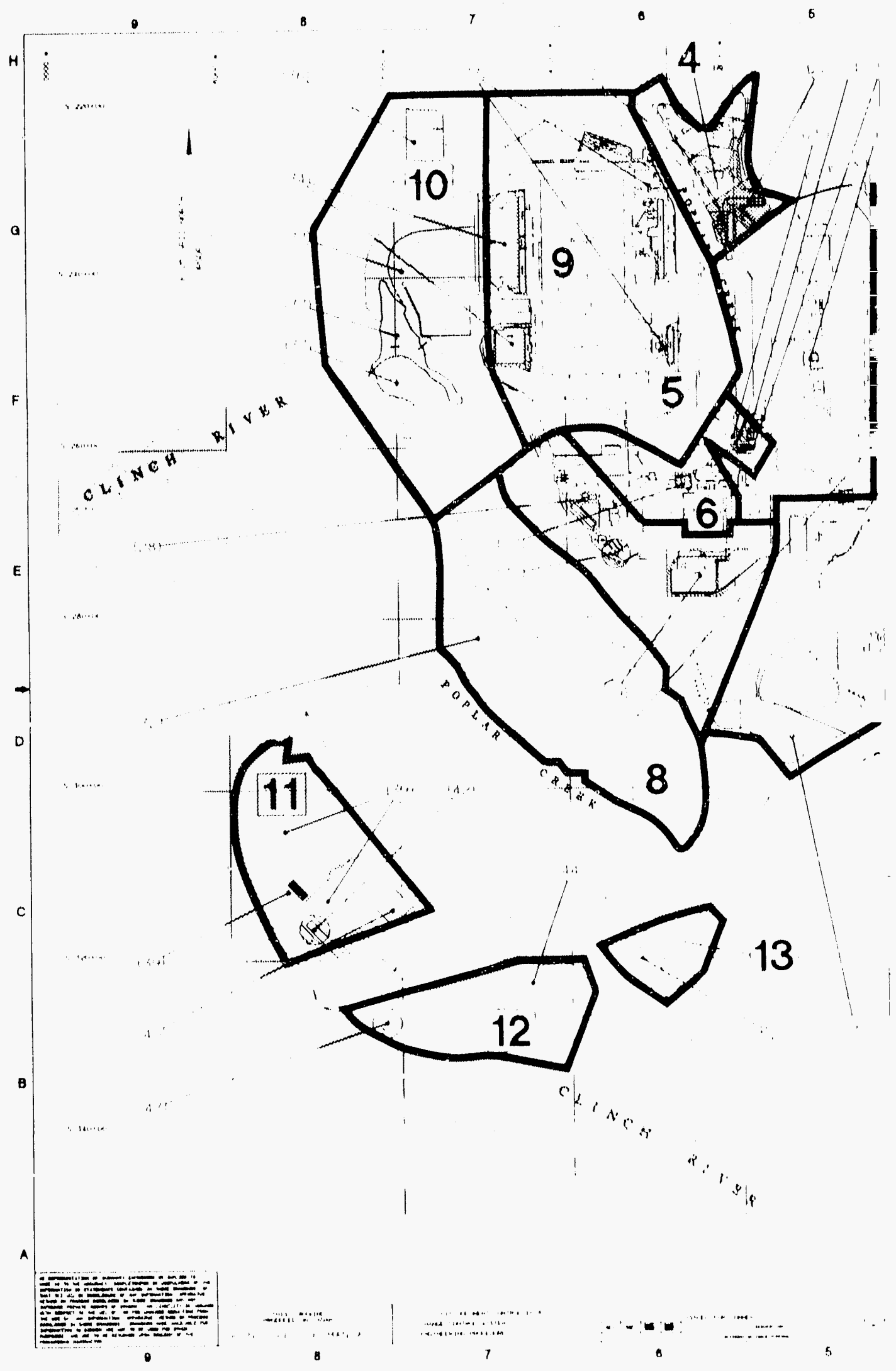

Fig. 3. Sitc loxati 


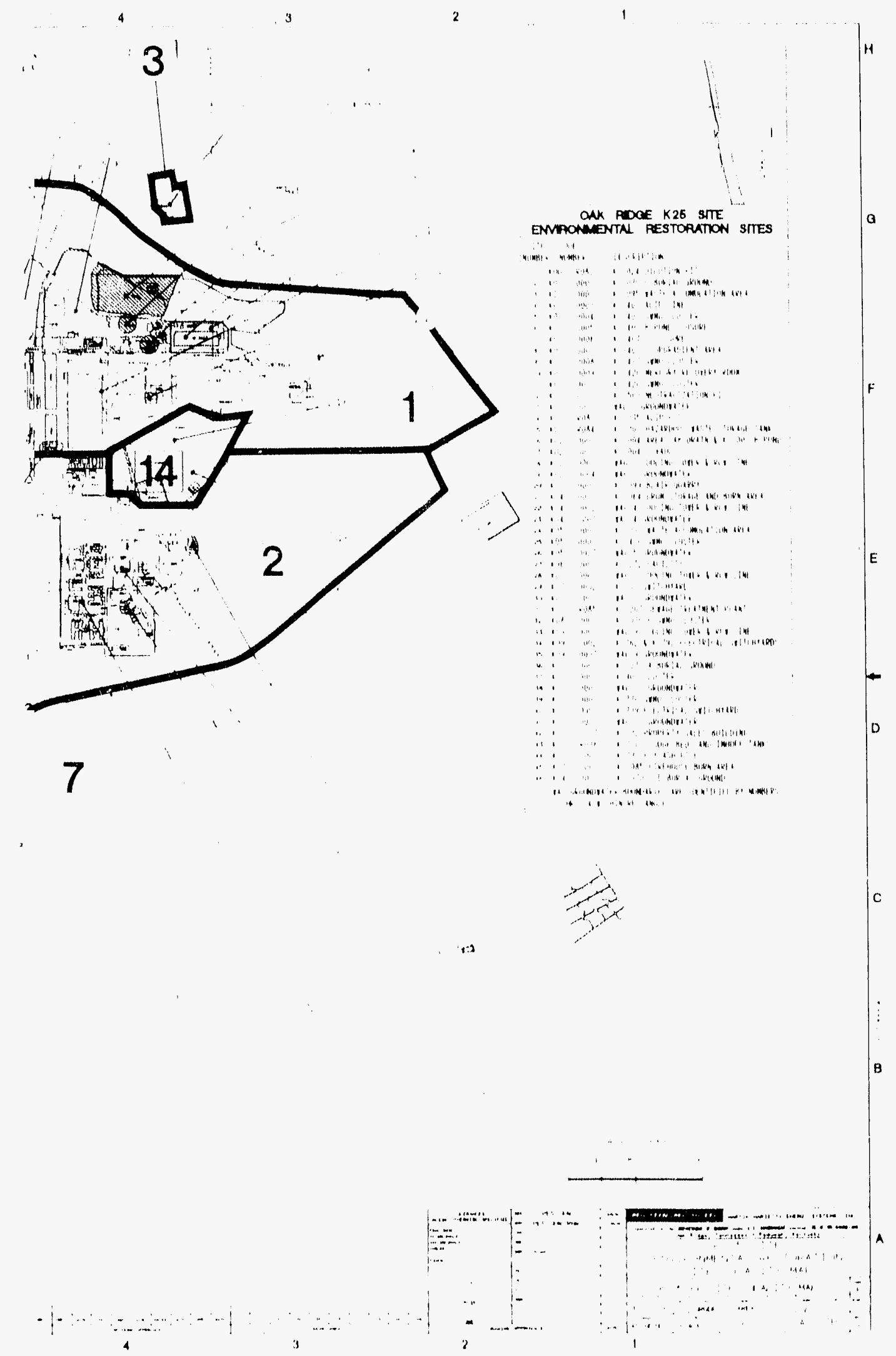

on map of K 25 Site. 
OANL.DWG 90M-10430R

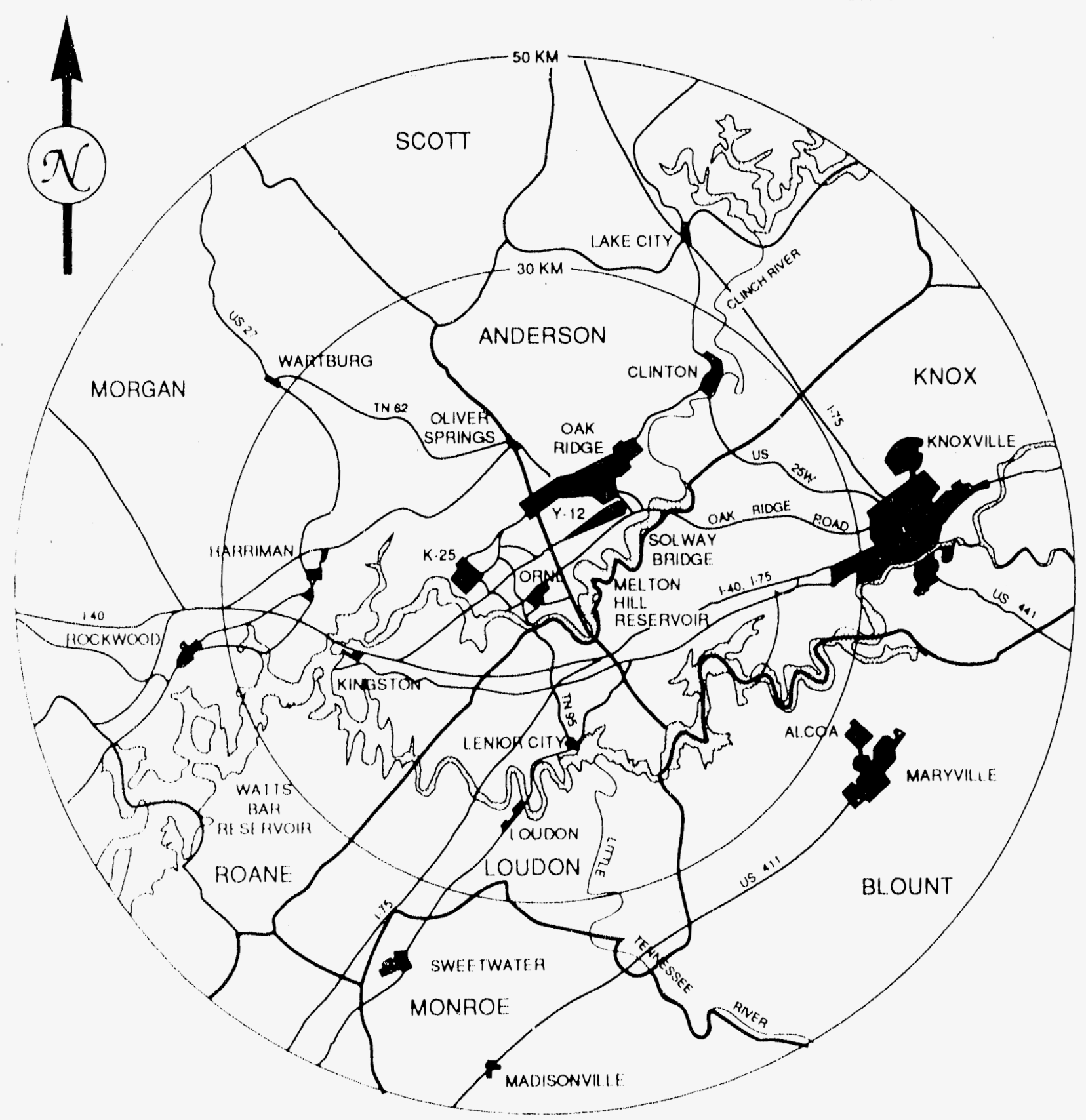

KILOMETERS

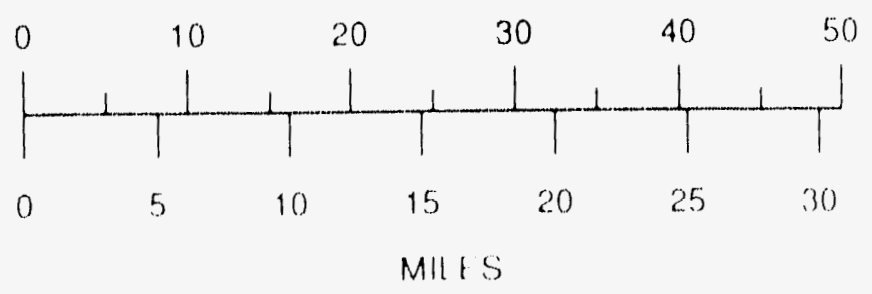

Fig. 4. Communities within a 30 mik: radius of the K 25 Site. 
given time. Other nearby facilities where local residents may be employed include the two industrial sites in the Clinch River Industrial Park and the Security Guard Training Facility on Bear Creek Road. One of the industrial iacilities is operated by the International Technology (IT) Corporation and employs 70 workers; the other is operated by the Scientific Ecology Group (SEG) and employs 150 workers. The population present at the Security Guard Training Facility is dependent upon the ongoing activities.

The nearest privately owned residential properties are in the Sugar Grove Valley, Dyllis, and Poplar Springs communities. The three communities are comprised of $\sim 50$ homes. The majority of these are located $\sim 1.5$ miles north of the K-25 Site in the Sugar Grove Valley and Dyllis communities. A smaller number of homes are located 2 miles west-southwest of the p'ant area and west of the Clinch River, us part of the Poplar Springs community. If an average of four occupants per dwelling is assumed, the residential population represented within a 2-mile radius is less than 200 . Other residential areas near the K-25 Site are Bradbury, which is located $\sim 5$ miles to the south, across the Clinch River, and Edgewood and Lawnville, which are located immediately west-northwest of the Poplar Springs community.

\subsubsection{Land Use}

According to Chap. 5 of the General Document, the region around the K-25 Site contains areas of agricultural, residential, industrial, and recreational uses. Because the land immediately surrounding the plant is a federal reservation, it is primarily undeveloped. ${ }^{12}$

Agricultural uses of nearby land include: limited-scale private gardening; raising of tobaccn, corn, wheat, and soybeans as cash crops; raising of beef cattle; and dairy farming. Some areas are also used for commercial logging. ${ }^{12}$

Nearby industrial use of the land includes the Oak Ridge National Laboratory (ORNL), the Oak Ridge Y-12 Plant, Phyton Technologies, Inc., SEG, and IT Corporation's Bear Creek Radiological Laboratory. Only the SEG and IT Corporation laburatories are within 2 miles of the K-25 Site. Tennessee Valley Authority facilities near the plant are the Melton Hill Dam, the Bull Run Steam Plant, and the Kingston Steam Plant. None of these is within 6 miles of the plant. ${ }^{13}$

The nearby Watts Bar Lake Embayment/Clinch River waterway is used as a recreational area by both pleasure boaters and fishermen. There are a number of small camping areas and boat launching ramps in the vicinity; one of the ramps is located slightly more than a mile upstream of the K-25 Site. There are no other recreational facilities within 2 miles of the K-25 Site. A small dirt-surface racetrack is located $\sim 4$ miles south of the plant and attracts several thousand spectators during the racing season. There is a public swimming area at Melton Hill Dam, 7 miles southeast and upstream of the plant. Sport hunting of game birds and game animals occurs seasonally in the region surrounding the plant. Also, deer hunting is authorized on some parts of the ORR as a population control measure; some of these seasonal hunting areas are within 2 miles of the K-25 Site. ${ }^{13}$ All harvested animals are screened for beta and gamma radiation contamination, and those animals with high radiation readings are confiscated. 


\subsubsection{Hydrogeology}

The K-1407-C Retention Basin lies in a small valley located between McKinney Ridge and Pine Ridge. Both groundwater and surface runoff in the area flow toward the southsouthwest to the K-1700 Stream (also known as Mitchell Branch), which flows $\sim 1500 \mathrm{ft}$ before discharging into Poplar Creek. Groundwater flow in this area occurs mainly in the limestone bedrock within a system of interconnecting, solution-enlarged fractures and bedding planes. The geologic feature that may have the greatest influence on the migration of site contamination is a branch fault of the Whiteoak Mountain Fault. The extensive fractures and brecciation associated with faulting could serve a preferable pathway if contamination is transported via groundwater. The exact location of the fault relative to the K-1407-C Retention Basin has not been determined.

\subsubsection{Geology}

The unconsolidated material in the area of the K-1407-C Retention Basin ranges in thickness from 11 to $40 \mathrm{ft}$. The thickness of the unconsolidated zone decreases along the axis of the valley and increases along the hillsides to the north and south. The unconsolidated material is comprised of clay and lithic fragments. The $\mathrm{K}-1407-\mathrm{C}$ area is underlain by rocks of the upper part of the Conasauga Group, which typically consists of massive limestone or limestone interbedded with calcareous shale. The limestones are generally gray to blue-gray, fine-grained, and oolitic, and the shale is gray to blue to green-gray with minor amounts of chert. The upper Conasauga, which may contain some dolomite or dolomitic limestone, grades stratigraphically downward (to the south) into predominantly calcareous shale.

The structural attitude of bedrock strata in the K-1407-C area is inferred from field measurements in nearby areas by $\mathrm{R}$. H. Ketelle of ORNL (unpublished geologic m?p). The areal geology of the K-25 Site is shown in Fig. 5. The strike of the bedding in the area of the $\mathrm{K}-1407-\mathrm{C}$ Retention Basin is roughly east-west. The bedding is very steeply inclined, probably dipping mainly to the south, although some bedding may dip to the north. The steep and variable dips are the result of structural deformation associated with the Whiteoak Mountain Fault. The predominant geologic feature in the area is a splay fault associated with the Whiteoak Mountain Fault. This north-south trending fault transverses the area of the site. This fault is the result of tectonic activities which have thrust the Conasauga Group over the Chickamauga limestone to the west. The faulting has caused extensive fracturing and jointing within the affected bedrock strata, in particular the more competent limestones and dolostones. The fault may influence the migration of contaminants from the site via groundwater. The exact location of the fault has not been determined.

\subsubsection{Hydrology}

The K-1407-C Retention Basin is located in the K-1700 watershed, which drains the northeastern corner of the plant first in a westerly direction and then northward to Poplar Creek. Downgradient from the site, surface runoff is collected into subsurface drains along with storm drains from other parts of the plant and considerable groundwater effluent. This water then flows through the K-1700 National Pollutant Discharge Elimination System station. There are no perennial streams [other than K-1700 (Mitchell Branch)] or springs on this site. According to data generated by the Tennessee Valley Authority, the K-1407-C area is above the 100-year flood level. 


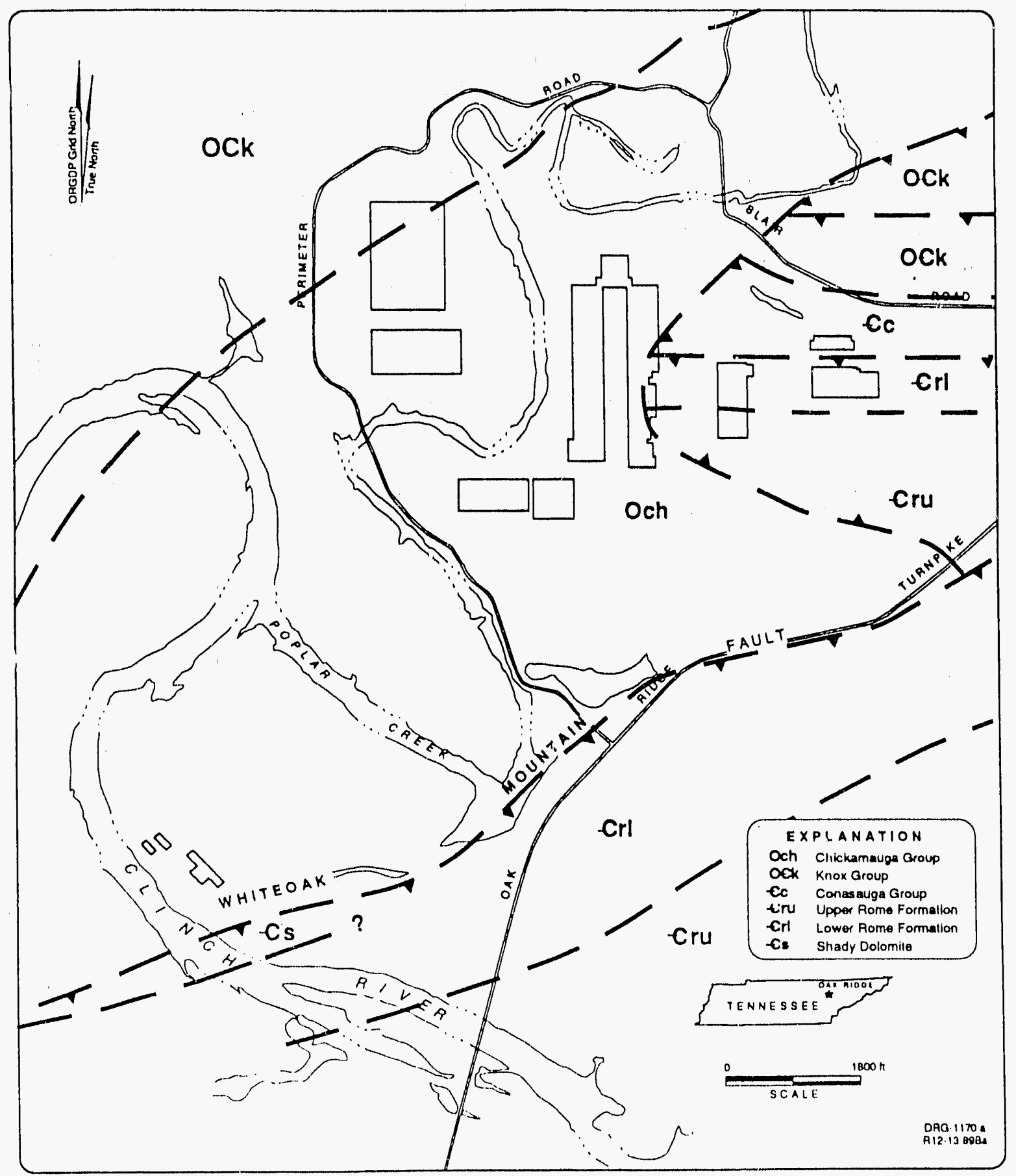

Fig. 5. Geology in the vicinity of the K-25 Site. Source: Geraghty and Miller, Inc., Hydrogeology of the Oak Ridge Gaseous Diffusion Plant, K/Sub/85-22224/12, Martin Marietta Energy Systems, Inc., Oak Ridge Gaseous Diffusion Plant, Oak Ridge, Tennessee, December 1989. 
Groundwater flow in the unconsolidated and bedrock zones is toward the valley where it discharges to the K-1700 Stream, as illustrated in Figs. 6 and 7. Bedrock wells (BRWs) BRW-13 and BRW-14 are paired with unconsolidated wells (UNWs) UNW-11 and UNW-10, respectively. (See Figs. 6 and 7.) Water elevations from these paired wells indicate a downward vertical groundwater flow gradient in the area of the retention basin. Hydraulic head measurements from unconsolidated wells in the vicinity indicate that the water table is relatively close to the bottom of the retention basin. The bottom of the retention basin has an elevation of $\sim 758$ to $760 \mathrm{ft}$, and the elevation of the water tatle in September 1990 was $\sim 750$ to $755 \mathrm{ft}$ in the area of the retention basin. The relationship of the groundwater is likely to have a significant influence on the migration potential of contamination from the soil in the retention basin.

Groundwater storage and flow in the K-1407-C area occurs mainly in the limestone bedrock within a system of interconnecting, solution-enlarged fractures and bedding planes. The shales are more subject to plastic deformation, and their fractures tend to be relatively tight and restrictive to groundwater flow. Hydraulic conductivity of the unconsolidated material ranges from $10^{-7}$ to $10^{-3} \mathrm{~cm} / \mathrm{s}$. Most of the tests produced values in the $10^{-5}-$ to $10^{-4}-\mathrm{cm} / \mathrm{s}$ range. Hydraulic conductivity measured in BRW-7 and BRW-8 was $10^{-4}$ and $10^{-5}$ $\mathrm{cm} / \mathrm{s}$, respectively. The hydraulic conductivity determined for wells in the vicinity is listed in Table 21.

\subsection{Data Limitations Related to Physical Characterization}

Additional characterization of the hydrogeology of the area is needed to determine the potential for contaminant transport via groundwater. The relationship of groundwater to the retention basin and the exact location of the fault in the area of the K-1407-C Retention Basin are not known. These factors could have a significant influence on the groundwater regime and transport pathways from the retention basin. Additionally, to quantify the migration potential of contaminants via the groundwater or surface water, soil parameters influencing transport, such as particle-size distribution, porosity, soil $\mathrm{pH}$ and oxidationreduction potential, cation-exchange capacity, mineralogy, and organic carbon fraction must be determined.

\section{OPERATIONAL AND HISTORICAL INFORMATION}

Until September 1985, the K-25 Site was involved in the enrichment of ${ }^{235} \mathrm{U}$ using uranium hexaflouride. This material was then processed and used as fuel in nuclear power reactors for electrical power generation. The $\mathrm{K}-1407-\mathrm{C}$ Retention Basin is a surface impoundment at the K-25 Site. The basin has a storage volume of $\sim 4$ million gal and was used primarily for storing potassium hydroxide scrubber sluuge generated at the K-25 Site. In addition, from 1960 to 1973 metal hydroxide sludges that were removed from the K-1407-B Holding Pond were discharged to the K-1407-C Retention Basin. The sludge in the K-1407-B Pond contained discharge from the K-1420 Decontamination and Uranium Recovery Unit, the K-1501 Steam Plant, the K-1413 Laboratory, and the K-1401 Maintenance Building. In addition, radioactive material in the K-1407-C Retention Basin may be the result of cleaning and decontamination activities at the aforementioned facilities. 


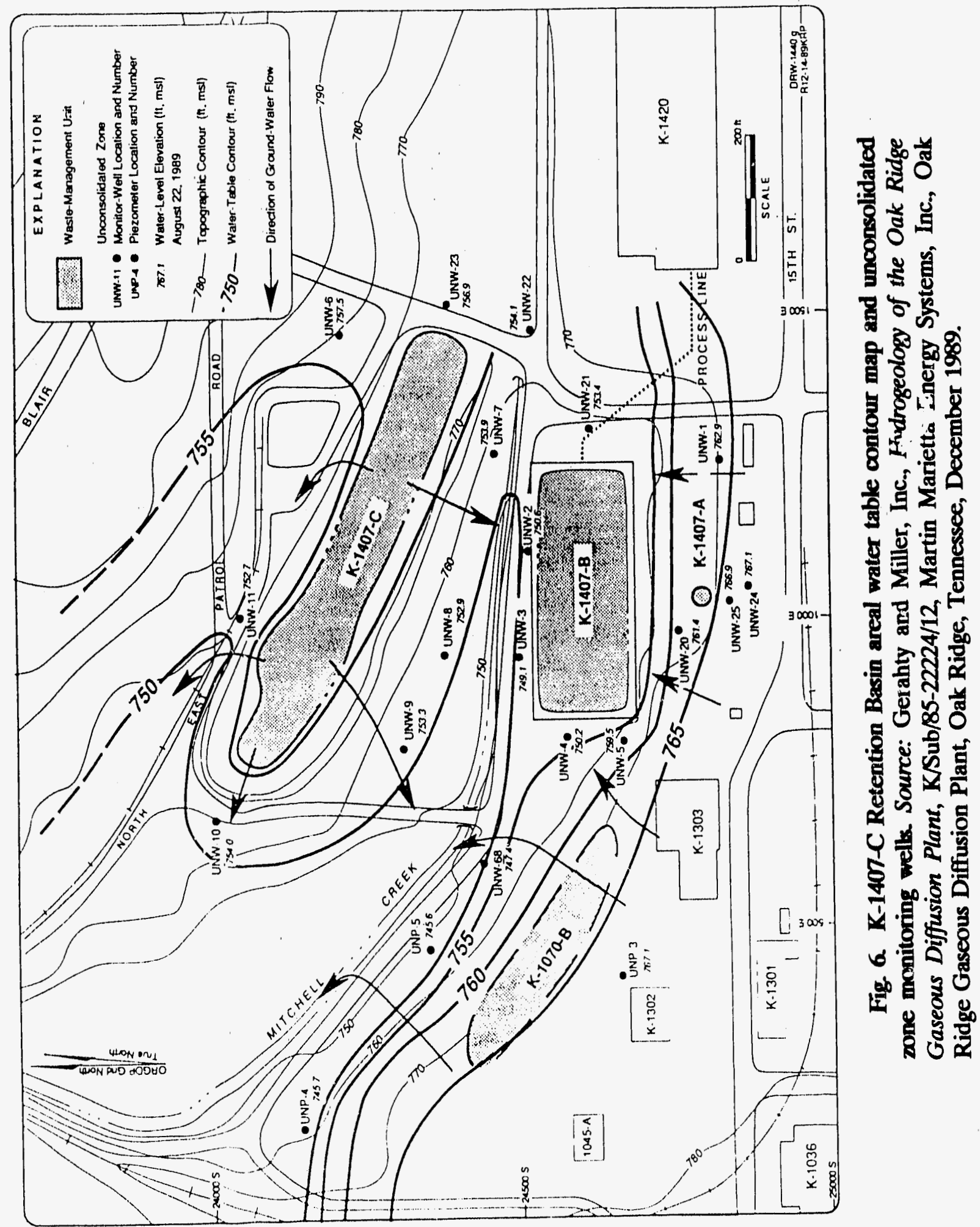




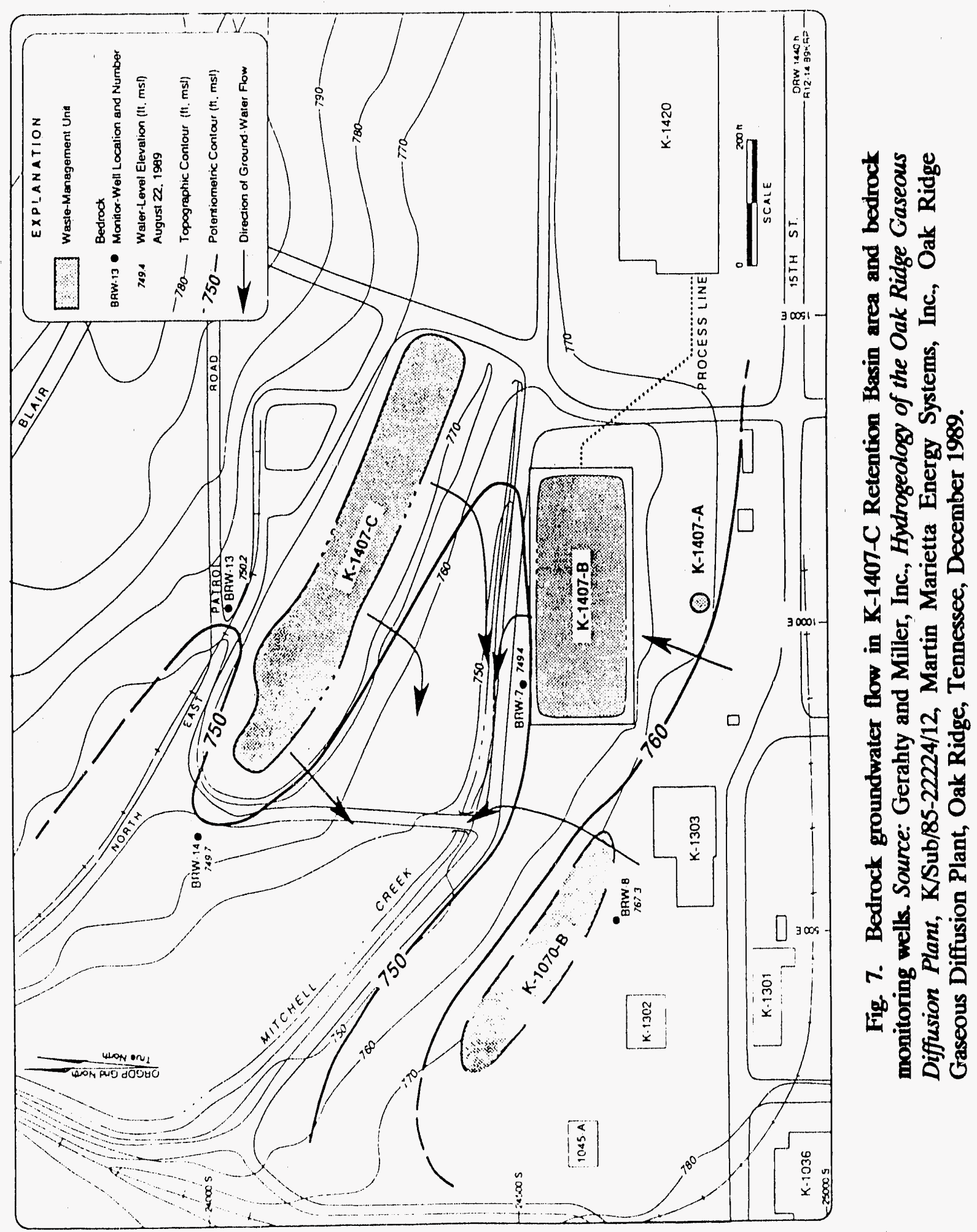


Table 1. Hydraulic conductivities in the K-1407-C area

\begin{tabular}{ccc}
\hline \multirow{2}{*}{ Well designation } & \multicolumn{2}{c}{ Method of analysis } \\
\cline { 2 - 3 } & Bouwer $(\mathrm{cm} / \mathrm{s})$ & Hvorslov $(\mathrm{cm} / \mathrm{s})$ \\
\hline UNP-3 & $5.40 \times 10^{-6}$ & $1.66 \times 10^{-5}$ \\
UNP-4 & $2.79 \times 10^{-6}$ & $8.19 \times 10^{-6}$ \\
UNP-5 & $3.23 \times 10^{-6}$ & $4.28 \times 10^{-6}$ \\
UNW-1 & $3.56 \times 10^{-4}$ & $4.21 \times 10^{-4}$ \\
UNW-2 & $1.44 \times 10^{-4}$ & $6.11 \times 10^{-4}$ \\
UNW-3 & $2.33 \times 10^{-4}$ & $4.83 \times 10^{-4}$ \\
UNW-4 & $1.08 \times 10^{-4}$ & $4.01 \times 10^{-4}$ \\
UNW-5 & $2.38 \times 10^{-5}$ & $2.16 \times 10^{-4}$ \\
UNW-6 & $3.72 \times 10^{-3}$ & $3.47 \times 10^{-5}$ \\
UNW-7 & $1.08 \times 10^{-4}$ & $6.51 \times 10^{-3}$ \\
UNW-8 & $1.01 \times 10^{-4}$ & $3.60 \times 10^{-4}$ \\
UNW-9 & $2.56 \times 10^{-3}$ & $8.23 \times 10^{-3}$ \\
UNW-10 & $1.06 \times 10^{-7}$ & $3.08 \times 10^{-7}$ \\
UNW-11 & $5.43 \times 10^{-7}$ & $2.51 \times 10^{-7}$ \\
BRW-1 & $1.34 \times 10^{-3}$ & \\
BRW-7 & $3.58 \times 10^{-5}$ & \\
BRW-8 & $6.71 \times 10^{-5}$ & \\
\hline & & \\
\hline
\end{tabular}

The discharge of waste materials to $\mathrm{K}-1407-\mathrm{C}$ was discontinued before November of 1988 , and all sludge was removed and stored or fixed in concrete. $I$ iquid waste and the sludge layer in the retention basin were removed using a portable hydraulic dredge that was mounted on a pontoon. To facilitate the sludge removal, berms were constructed to subdivide the retention basin by mounding the soil and sludge from the retention basin bottom. If possible, liquid and sludge were pumped through a discharge line to the K-1419 Sludge Fixation Plant. In the event the material would not pass through the discharge line, it was hauled with a clam shell from the northeast end of the retention basin and transported to the K-1419 facility. 
Removal of material was continued until indigenous soil was encountered and the retention basin was visibiy clean.

\section{PREVIOUS INVESTIGATIONS}

A waste-sampling program to characterize the sludge in the $\mathrm{K}-1407-\mathrm{C}$ Retention Basin was conducted in May 1985. In addition to sludge sampling, the investigation included sampling the soil beneath the sludge in 6-in. intervals to a depth of 18 in. The sampling method and analytical results are included in the Closure Plan: K-1407-C Retention Basin (K/ER-27). ${ }^{3}$ Evaluation of the data resulting from this sampling program indicated that the concentrations of hazardous waste constituents in the soil below the sludge layer did not exceed the proposed toxicity characteristic leaching procedure limits. Additionally, the organic constituents present in the sludge layer were not detected in the soil layers, and the extraction procedure toxicity constituents which were detected in the sludge and soil were not in the groundwater. Based on these results, a clean closure of K-1407-C Retention Basin was proposed.

After the removal of sludge from the K-1407-C Retention Basin, preliminary soil sampling was performed to ascertain if contamination had migrated into the soil beneath the sludge. This sampling effort consisted of five samples taken along the long axis of the retention basin. The results indicated that no organics or other RCRA hazardous constituents were present, but radionuclides were detected in all samples. The analytical results of the preliminary soil samples are included in the Closure Plan: K-1407-C Retention Basin $(\mathrm{K} / \mathrm{ER}-27){ }^{3} \quad$ Based on the radionuclide contamination detected in the five exploratory samples, a large-scale soil sampling operation was conducted, the results of which are the subject of the current evaluation. 


\section{FIELD INVESTIGATION}

\subsection{SAMPLING}

The most recent attempt to determine the extent of soil contamination in the K-1407-C Retention Basin was initiated in 1989. Fifty-seven sample locations were based on a 75- by 29-ft grid overlay of the retention basin, shown in Fig. 8. In addition, 23 samples were collected at locations of anomalously high radiation indicated during a walking radiation survey of the retention basin (Fig. 8). The samples taken as a result of the radiation survey are designated as biased samples. The biased samples were taken in an attempt to account for radioactive contamination at locations which are not included in the sampling grid. The use of biased and grid sampling should ensure the thorough characterization of the horizontal extent of radionuclide contamination in the retention basin. Samples at these locations were taken in 6-in. intervals to a depth of 18 in. Samples were analyzed for gross alpha, beta, and gamma radioactivity; for the radioactive isotopes americium, cesium, cobalt, curium, europium, neptunium, plutonium, potassium, strontium, technetium, and uranium; and for metals.

\subsection{RESULTS OF GAMMA AND BETA-GAMMA SURFACE SCANS}

Surface gamma scan ranges in accessible areas of individual grid blocks at the K-1407-C Retention Basin are shown in Fig. 9. Typical exposure rates generally ranged from 11 to 15 $\mu \mathrm{R} / \mathrm{h}$ outside the rope boundary and from 11 to $29 \mu \mathrm{R} / \mathrm{h}$ inside the rope boundary. Highest scan ranges reached $120 \mu \mathrm{R} / \mathrm{h}$ in grid block $10 \mathrm{C}$ and $79 \mu \mathrm{R} / \mathrm{h}$ in grid blocks $6 \mathrm{E}, 8 \mathrm{E}$, and $18 \mathrm{E}$. Gamma exposure rates exceeded $40 \mu \mathrm{R} / \mathrm{h}$ in more than half of the grid blocks and exceeded typical levels of the immediate vicinity (11 to $15 \mu \mathrm{R} / \mathrm{h}$ ) in all grid blocks.

The beta-gamma scan was conducted primarily to identify areas contaminated with radionuclides that are not strong gamma emitters (such as ${ }^{99} \mathrm{Tc}$ and strontium). Surface betagamma scan ranges in accessible areas of individual grid blocks are shown in Fig. 10. Typical beta-gamma dose rates in uncontaminated areas inside the rope boundary generally ranged from 0.036 to $0.072 \mathrm{mrad} / \mathrm{h}$; highest dose rates reached $1.9 \mathrm{mrad} / \mathrm{h}$ in grid block $10 \mathrm{C}, 1.6$ $\mathrm{mrad} / \mathrm{h}$ in $8 \mathrm{E}$, and $1.4 \mathrm{mrad} / \mathrm{h}$ in $2 \mathrm{G}$ and $16 \mathrm{G}$. Beta-gamma radiation levels exceeded typical background levels in 17 grid blocks. Details of the gamma and beta-gamma surface scans are summarized in Table 2.

Figure 11 shows the approximate locations of specific contaminated spots and areas identified during the surface scan. Gamma exposure rates ranged from 17 to $120 \mu R / \mathrm{h}$, and beta-gamma dose rates ranged from 0.036 to $1.9 \mathrm{mrad} / \mathrm{h}$. Radiation levels were generally higher on the north side of the basin at the base of the bank and extending up the bank and on the earthen dike that projects from the north bank to near the south bank at the center of the basin along grid line 7. Typical gamma levels on the road north of the basin (not shown on Fig. 11) ranged from 12 to $15 \mu \mathrm{R} / \mathrm{h}$. Typical gamma levels along the top of the south bank generally ranged from 11 to $15 \mu \mathrm{R} / \mathrm{h}$ and increased to 17 to $23 \mu \mathrm{R} / \mathrm{h}$ as the surveyor descended the bank toward the bottom of the pond. Nine contaminated spots with gamma 
exposure rates ranging from 36 to $85 \mu \mathrm{R} / \mathrm{h}$ were identified outside the rope boundary. In addition, a spot $-1 \mathrm{~m}^{2}$ measuring 17 to $36 \mu \mathrm{R} / \mathrm{h}$ and $0.18 \mathrm{mrad} / \mathrm{h}$ (not shown on Fig. 11) was identified on the road in the area north of grid line 5.

\subsection{GAMMA EXPOSURE RATES AND BETA-GAMMA DOSE RATES ATSAMPLING POINTS}

Gamma exposure rates and beta-gamma dose rates measured at the surface and at depths of 6,12 , and 18 in. are given in Appendix A, along with sample numbers, stake numbers, locations, dates, times, analyses, and comments. Gamma radiation levels fluctuated with increasing depth in $38 \%$ of the sampling holes, decreased with depth in $30 \%$, remained constant in $18 \%$, and showed slight increases in $14 \%$. Beta-gamma radiation levels decreased with increasing depth in $60 \%$ of the sampling holes and fluctuated with increasing depth in $38 \%$. Gamma exposure rates of samples ranged from 11 to $130 \mu \mathrm{R} / \mathrm{h}$; beta-gamma dose rates ranged from 0.014 to $1.7 \mathrm{mrad} / \mathrm{h}$. Figure 12 shows surface gamma exposure rates at sampling points ranging from 11 to $110 \mu \mathrm{R} / \mathrm{h}$, and Fig. 13 shows surface beta-gamma dose rates at the same points ranging from 0.030 to $1.7 \mathrm{mrad} / \mathrm{h}$. Sampling points that appear to be covered with water were sampled during dry periods when the water pools were smaller.

\subsection{ALPHA RADIATION}

On September 19, 1989, alpha contamination measuring $\left\langle 100 \mathrm{dpm} / 100 \mathrm{~cm}^{2}\right.$ was detected on a pair of field work gloves. The gloves were discarded. On September 20, 1989, alpha contamination measuring $-100 \mathrm{dpm} / 100 \mathrm{~cm}^{2}$ was detected on the soles of a pair of kneelength rubber boots. The boots were decontaminated by scrubbing with soap and water. On October 3,1989, alpha contamination measuring $400 \mathrm{dpm} / 100 \mathrm{~cm}^{2}$ was detected on a pair of plastic safety glasses. In this case, the contamination could not be removed by scrubbing with soap and water; the glasses were disposed of according to the rules and regulations governing radioactive wastes.

\subsection{AMBIENT AIR}

No radiological contamination was detected when the filters from personal air samplers worn by site personnel during dry, dusty conditions were analyzed for alpha- and beta-emitting radionuclides.

HNU ${ }^{m}$ and $O V M^{m m}$ readings in the breathing zone were consistently less than $1.0 \mathrm{ppm}$. On November 9, 1989, a fluctuating OVM reading of 0.0 to $1.4 \mathrm{ppm}$ was measured at the top of the sample hole during the collection of sample BH056ASO12A; the OVM reached $6.0 \mathrm{ppm}$ very briefly during this sample interval. A fluctuating OVM reading of 0.0 to $1.6 \mathrm{ppm}$ was measured when another sample (BH056ASO18A) was collected from the same hole. OVM readings in the breathing zone ranged from 0.0 to $0.3 \mathrm{ppm}$ during the collection of these two samples. 
$6 \quad 5 \quad 1$
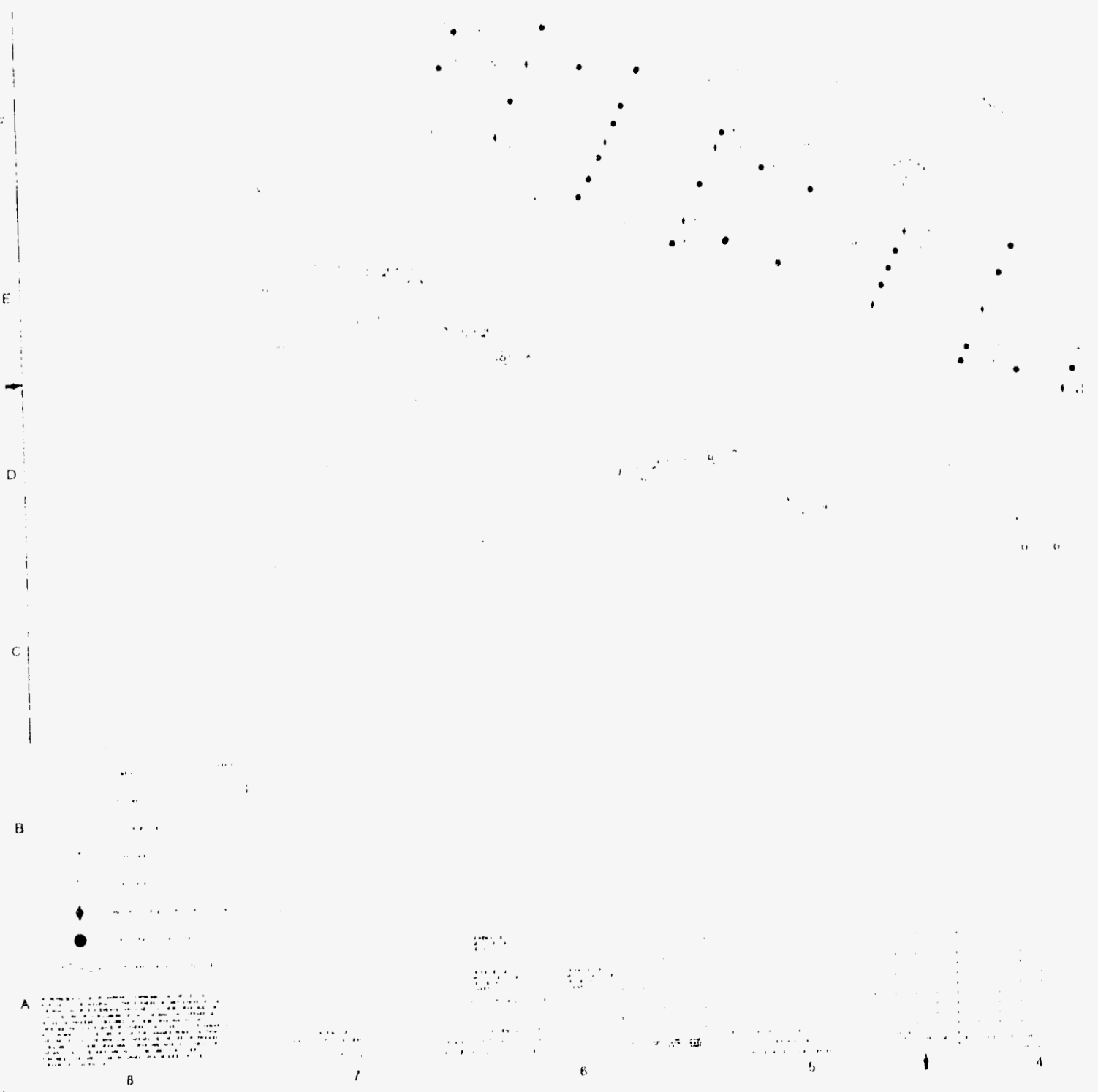

Fig. 8. Sample keation grid for the K-14077-C 


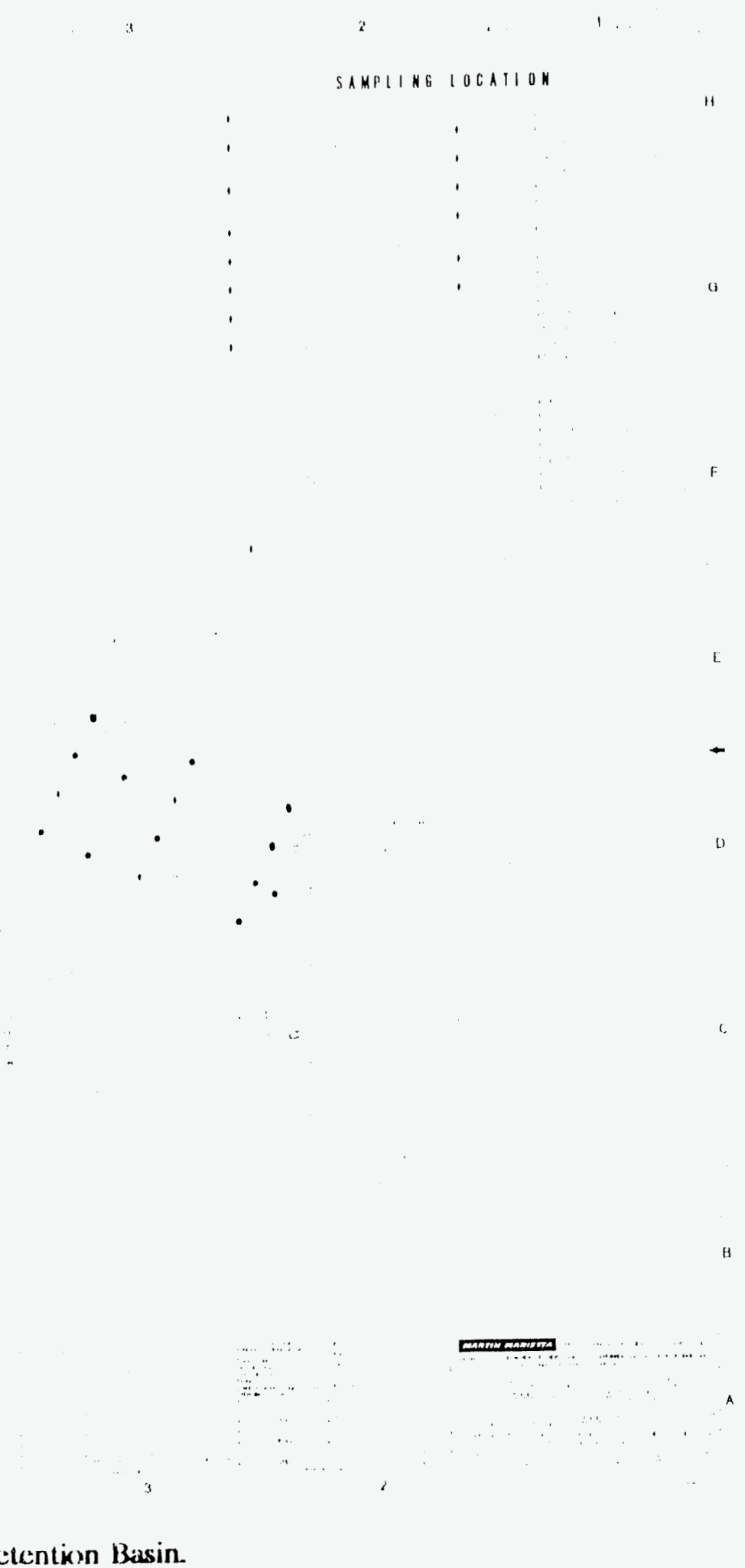

Relention Basin. 

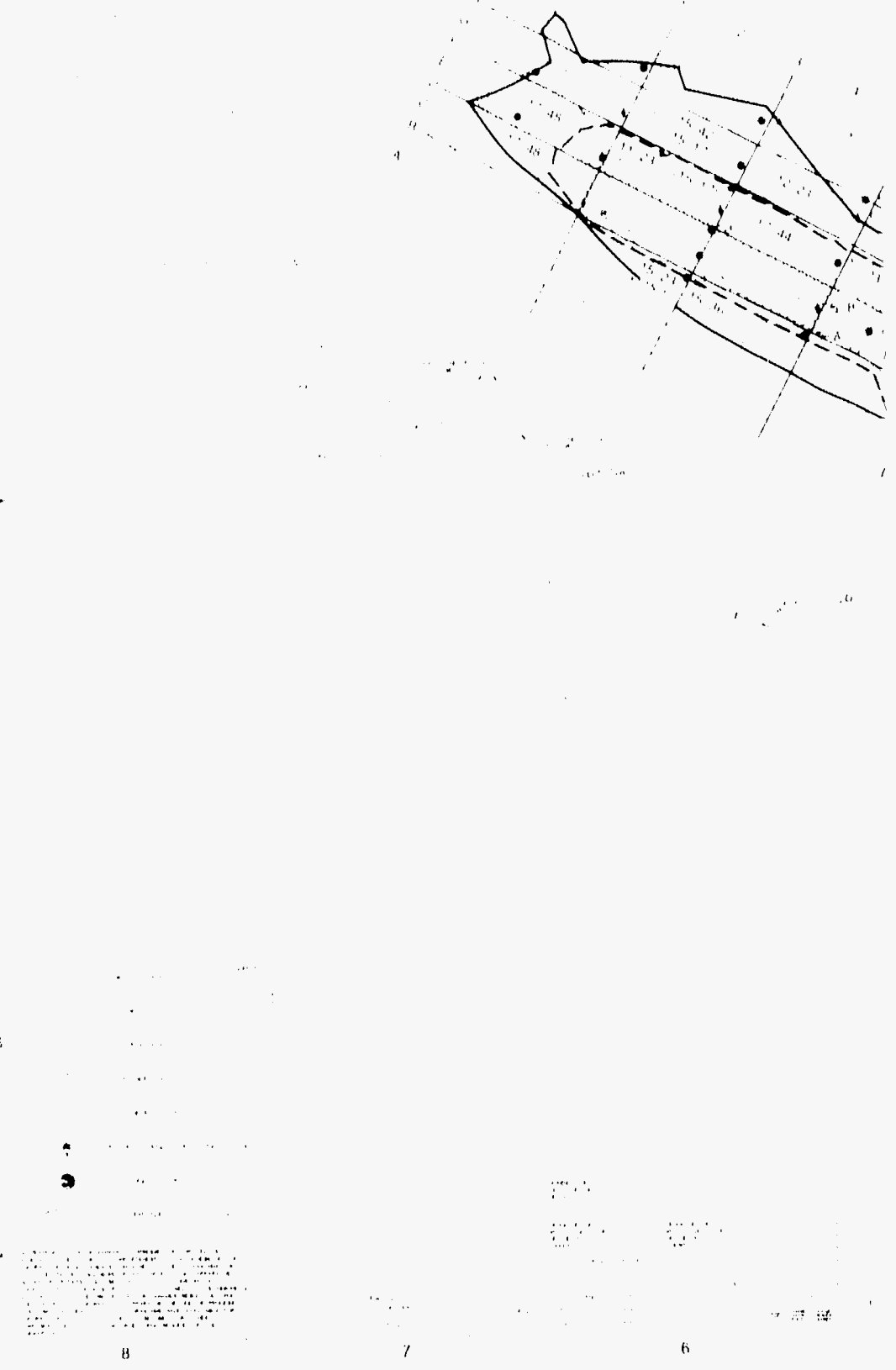

Fig. 9. Ranges of surface Retention Basin (September 19 
5

1

4

3

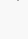

SAMPLING LOCATIOH

$1.1+1$
$\vdots$
$\vdots$
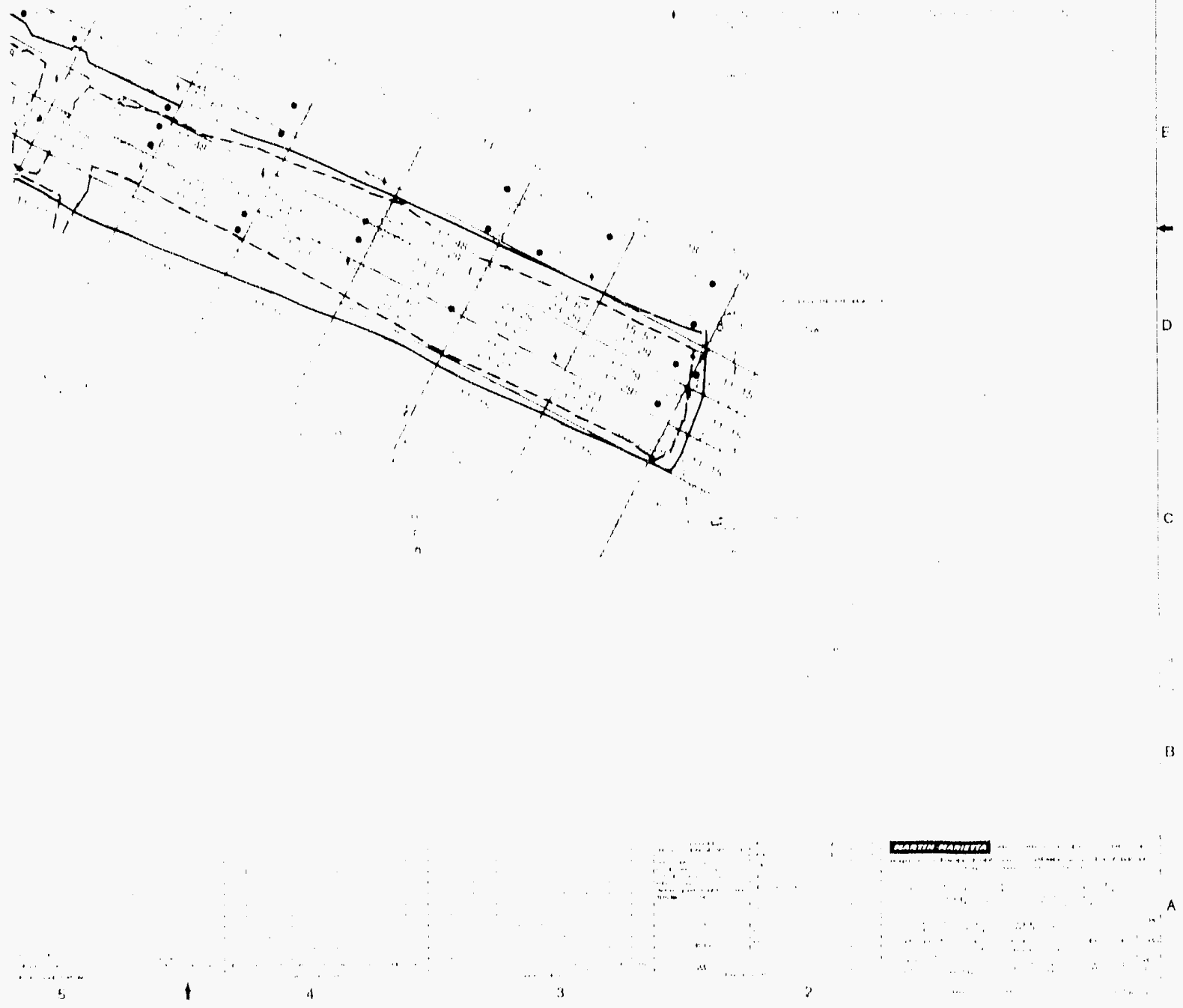

gamma exposure rates $(\mu \mathrm{K} / \mathrm{h})$ measured at the $\mathrm{K} \cdot 1 \mathrm{H}(97-\mathrm{C}$ 99 to January $19(x)$ ). 

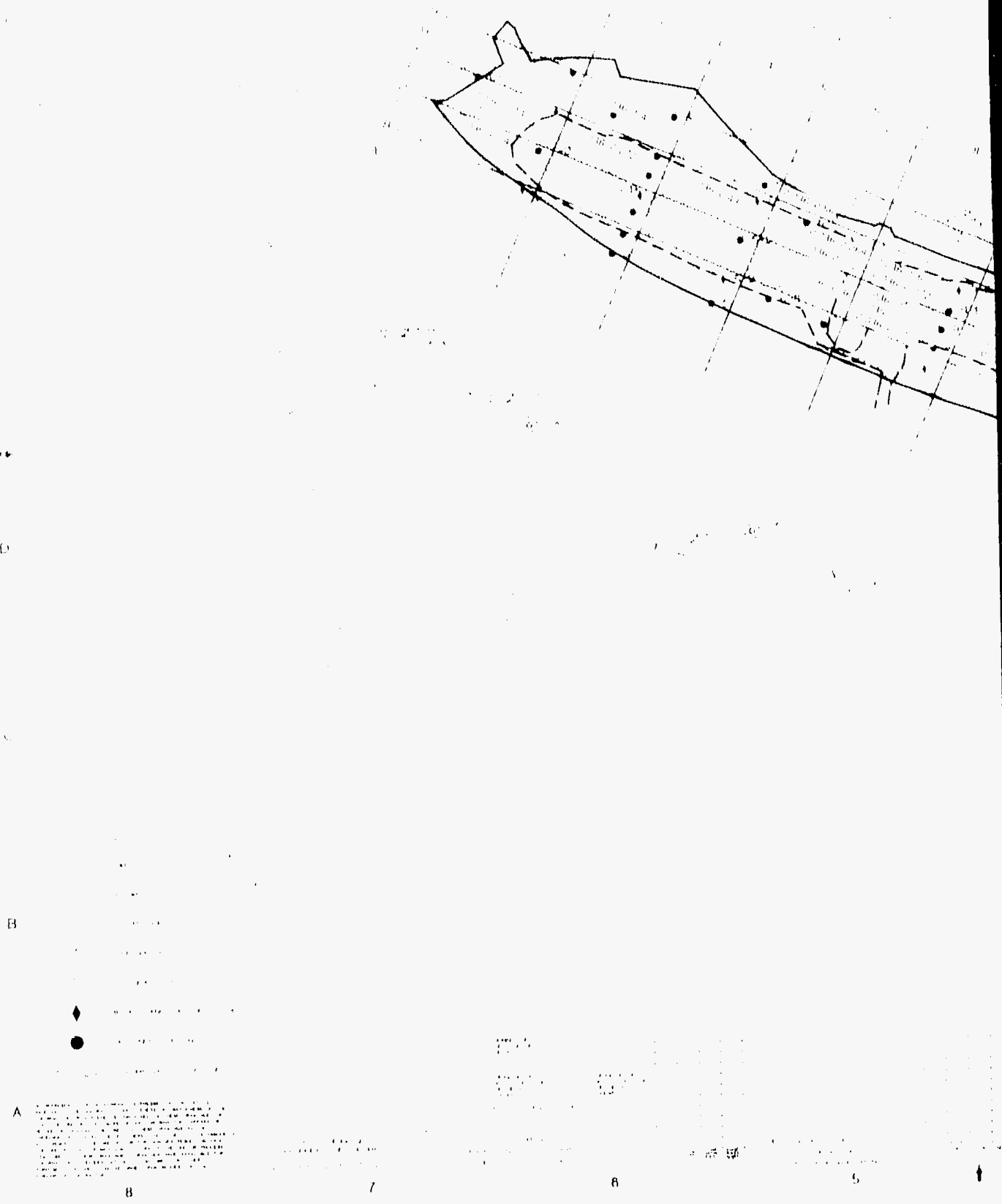

Fig. 10. Rangess of beta gamma dosc: rates (n Basin (Sx:ptember 1(x) to January $I(x)$ )). 


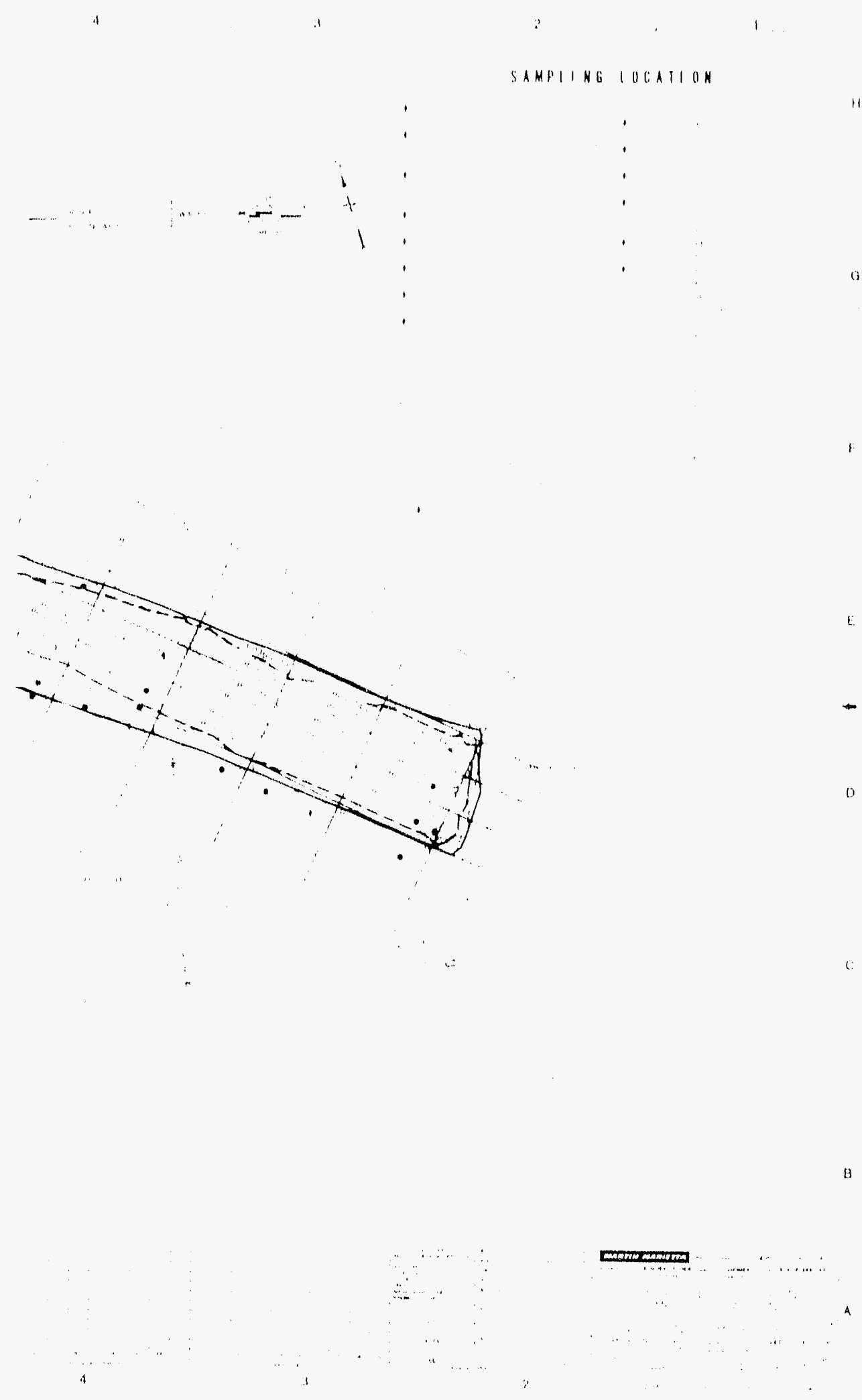

$\mathrm{rad} / \mathrm{h})$ measured at the $K \cdot 14(97$ C. Retcontion 
Tabke 2. Summary of findings from surface gamma and beta-gamma scans at the K-1407-C Retention Basin

\begin{tabular}{|c|c|c|c|c|}
\hline \multirow[b]{2}{*}{$\begin{array}{l}\text { Cirid } \\
\text { block }\end{array}$} & \multicolumn{2}{|r|}{ Gamma exposure rales } & \multicolumn{2}{|c|}{ Beta-gamma dose rates } \\
\hline & $\begin{array}{l}\text { Surface } \\
\text { scan } \\
\text { range } \\
(\mu R / h)\end{array}$ & Comments on gamma scan & $\begin{array}{l}\text { Surface } \\
\text { scan } \\
\mathrm{range} \\
(\mathrm{mrad} / \mathrm{h})\end{array}$ & $\begin{array}{c}\text { Comments on beta-gamma } \\
\text { scan }\end{array}$ \\
\hline 180 & $15-57$ & $\begin{array}{l}\text { Generally } 17-29 \mu \mathrm{R} / \mathrm{h} \text {; spets } \\
\text { up } 10.54 \mu \mathrm{R} / \mathrm{h} \text { along line } \\
\text { between } 17 \mathrm{H} \text { and } 19 \mathrm{H} \text {; } \\
\text { highest measurement } \\
(54 \mu \mathrm{R} / \mathrm{h} \text { at surface, } 23 \mu \mathrm{R} / \mathrm{h} \\
\text { at } 1 \mathrm{~m}) \text { found }-15: \mathrm{W} \text { of } \\
19 \mathrm{H} \text { at center of } 10-\times 10-\mathrm{ft} \\
\text { area measuring } 29-54 \mu \mathrm{R} / \mathrm{h}\end{array}$ & $\begin{array}{c}0.018 \\
0.89\end{array}$ & $\begin{array}{l}\text { Gencrally } 0.036-0.072 \mathrm{mrad} / \mathrm{h} \text {; } \\
\mathrm{spots} \text { along bottom of bank } \\
(0.11-(0.68 \mathrm{mrad} / \mathrm{h} \text {; area } 15 \mathrm{ft} \\
\mathrm{W} \text { of } 19 \mathrm{H} \mathrm{measured} \\
0.89 \mathrm{mrad} / \mathrm{h} \text { at surface and } \\
0.058 \mathrm{mrad} / \mathrm{h} \text { at } 1 \mathrm{~m}\end{array}$ \\
\hline $18 \mathrm{E}$ & $17 . .79$ & $\begin{array}{l}\text { Generally } 17.29 \mu \mathrm{R} / \mathrm{h} \text { with } \\
\text { one small area }\left(<1 \mathrm{~m}^{2}\right) \\
\text { ranging from } 29.79 \mu \mathrm{R} / \mathrm{h} \text { at } \\
19 \mathrm{~F} \text {; highest measurements: } \\
79 \mu \mathrm{R} / \mathrm{h} \text { at surface, } 32 \mu \mathrm{R} / \mathrm{h} \text { at } \\
1 \mathrm{~m}\end{array}$ & $\begin{array}{c}(0.0136- \\
0.32\end{array}$ & $\begin{array}{l}\text { Generally }(0.0 .36-(0.072 \mathrm{mrad} / \mathrm{h} \text {; } \\
\text { highest measurements at } 19 \mathrm{~F} \text {; } \\
0.32 \mathrm{mrad} / \mathrm{h} \text { at surface, } \\
0.072 \mathrm{mrad} / \mathrm{h} \text { at } 1 \mathrm{~m}\end{array}$ \\
\hline 180 & 11.23 & $\begin{array}{l}\text { Gencrally } 17-23 \mu \mathrm{R} / \mathrm{h}, \\
11.17 \mu \mathrm{R} / \mathrm{h} \text { along bank }\end{array}$ & $\begin{array}{l}0.0 .36 \\
0.072\end{array}$ & Generally (0.0.36-().072 mrad/h \\
\hline $160 \mathrm{i}$ & $23-6,7$ & $\begin{array}{l}\text { Cicnerally } 23-29 \mu \mathrm{R} / \mathrm{h} \text {; } \\
\text { clevated region }(-35 \times 5 \mathrm{fi}) \\
\text { with spots }(29-67 \mu \mathrm{R} / \mathrm{h}) \\
\text { extending from line }-5 \mathrm{fl} \therefore \text { of } \\
1.5 \mathrm{H}-17 \mathrm{H} \mathrm{N} \text { up slecp bank; } \\
\text { st snd clevated region } \\
(29 \mu \mathrm{R} / \mathrm{h}) \text { extending }-1.5 \mathrm{ft} \mathrm{W} \\
\text { and } 10 \mathrm{ft} \mathrm{N} \text { of } 17 \mathrm{H}\end{array}$ & $\begin{array}{l}(1.0 .36- \\
1.4\end{array}$ & $\begin{array}{l}\text { Generally } 0.0 .36-(0.072 \mathrm{mrad} / \mathrm{h} \text {; } \\
\text { spolty contamination in } \mathrm{N} \\
\text { part of grid bleck ranging } \\
\text { from } 0.11 .1 .4 \mathrm{mrad} / \mathrm{h} \text {; region } \\
\mathrm{W} \text { and } \mathrm{N} \text { of } 17 \mathrm{~F} \text { measured } \\
\text { ().11-(0.29 } \mathrm{mrad} / \mathrm{h}\end{array}$ \\
\hline $16 \mathrm{E}$ & 23.20 & $\begin{array}{l}\text { Cencrally } 23-27 \mu R / h \text {; } \\
\text { elevaled region at NE corner } \\
\text { described in Block } 10 \mathrm{G} \text {; spots } \\
\text { along } 155 \mathrm{D} \text { measuring } \\
29 \mu \mathrm{R} / \mathrm{h}\end{array}$ & $\begin{array}{l}(1.1) .36- \\
(1.1 .3\end{array}$ & $\begin{array}{l}\text { Gencrally (0.0)36-(0.072 } \mathrm{mrad} / \mathrm{h} \text {; } \\
\text { spots along } 15 \mathrm{~F} . \mathrm{D} \text { measuring } \\
(1.13 \mathrm{mrad} / \mathrm{h}\end{array}$ \\
\hline 160 & 11.27 & Generally $23-27 \mu R / h$ & $\begin{array}{l}0.018 \\
0.072\end{array}$ & Gencrally (0.0)18-(0.072 mrad/h \\
\hline 146 & 17.48 & $\begin{array}{l}\text { Generally } 17-29 \mu \mathrm{R} / \mathrm{h} \text {; } \\
17.48 \mu \mathrm{R} / \mathrm{h} \text { on bank; walcr } \\
\text { standing al } \mathrm{W} \text { end }\end{array}$ & $\begin{array}{l}(0.0) 36 \\
(0.43\end{array}$ & $\begin{array}{l}\text { (icnerally } 0 .() .36-() .(072 \mathrm{mrad} / \mathrm{h} \text {; } \\
(0 .(1) 72-() .4 .3 \mathrm{mrad} / \mathrm{h} \text { on hank; } \\
\text { water standing } \mathrm{W} \text { end }\end{array}$ \\
\hline $141:$ & $1.3-3.3$ & $\begin{array}{l}\text { Generally }-2.3 \mu \mathrm{R} / \mathrm{h} \text {; ranging } \\
\text { to } 29 \mu \mathrm{R} / \mathrm{h} \text { in elevated region } \\
\text { near center of block }\end{array}$ & $\begin{array}{l}\text { (1). (1).36- } \\
\text { (1).16 }\end{array}$ & $\begin{array}{l}\text { (iencrally }(0.036-(0.072 \mathrm{mrad} / \mathrm{h} \text {, } \\
\text { ranging } 100.16 \mathrm{mrad} / \mathrm{h} \mathrm{in} \\
\text { clevaled region near center of } \\
\text { bleck }\end{array}$ \\
\hline
\end{tabular}


Table 2 (continued)

\begin{tabular}{|c|c|c|c|c|}
\hline \multirow[b]{2}{*}{$\begin{array}{l}\text { Grid } \\
\text { block }\end{array}$} & \multicolumn{2}{|r|}{ Gamma exposure rates } & \multicolumn{2}{|r|}{ Beta-gamma dose rates } \\
\hline & $\begin{array}{l}\text { Surface } \\
\text { scan } \\
\text { range } \\
(\mu \mathrm{R} / \mathrm{h})\end{array}$ & Comments on gamma scan & $\begin{array}{l}\text { Surface } \\
\text { scan } \\
\text { range } \\
(\mathrm{mrad} / \mathrm{h})\end{array}$ & $\begin{array}{l}\text { Comments on beta-gamma } \\
\text { scan }\end{array}$ \\
\hline $14 C$ & $23-67$ & $\begin{array}{l}\text { Generally } 23-27 \mu R / h ; \text { spoi } 67 \\
\mu R / h\end{array}$ & $\begin{array}{c}0.036- \\
0.27\end{array}$ & $\begin{array}{l}\text { Generally } 0.036-0.072 \mathrm{mrad} / \mathrm{h} \text {; } \\
\text { spot } 0.27 \mathrm{mrad} / \mathrm{h}\end{array}$ \\
\hline $12 \mathrm{G}$ & & $\begin{array}{l}\text { Almost entirely covered by } \\
\text { water; spots } 32 \text { and } 36 \mu R / h \text {. }\end{array}$ & & \\
\hline $12 \mathrm{E}$ & $13-29$ & $\begin{array}{l}\text { Generally } 17 \mu R / h \text {; water } \\
\text { covering most of } N \text { side }\end{array}$ & $\begin{array}{c}0.029 \\
0.12\end{array}$ & $\begin{array}{l}\text { Generally } 0.036-0.072 \mathrm{mrad} / \mathrm{h} \text {; } \\
\text { water covering most of } \mathrm{N} \text { side }\end{array}$ \\
\hline $12 \mathrm{C}$ & $11-23$ & Generally $11-23 \mu R / h$ & $\begin{array}{c}0.018- \\
0.072\end{array}$ & Generally $0.018-0.072 \mathrm{mrad} / \mathrm{h}$ \\
\hline $10 G$ & $17-61$ & Generally $17-23 \mu R / h$ & & $\begin{array}{l}\text { Beta-gamma scan impossible } \\
\text { because of overgrown } \\
\text { vegetation }\end{array}$ \\
\hline $10 \mathrm{E}$ & $17-48$ & $\begin{array}{l}\text { Generally } 17-29 \mu R / h \text {; } \\
48 \mu R / h \text { in erosion runnels } N \\
\text { of washout channel }\end{array}$ & $\begin{array}{c}0.036- \\
0.30\end{array}$ & $\begin{array}{l}\text { Generally } 0.036-0.072 \mathrm{mrad} / \mathrm{h} \text {; } \\
0.072-0.29 \mathrm{mrad} / \mathrm{h} \text { south of } \\
\text { drainage channel with highest } \\
\text { levels in erosion runs }\end{array}$ \\
\hline $10 \mathrm{C}$ & $11-120$ & $\begin{array}{l}\text { Generally } 11-17 \mu \mathrm{R} / \mathrm{h} \text {; spot } \\
120 \mu \mathrm{R} / \mathrm{h} \text { near } 9 \mathrm{~B} ; \text { elevated } \\
\text { levels along south edge of } \\
\text { block at base of bank }\end{array}$ & $\begin{array}{c}0.036- \\
1.9\end{array}$ & $\begin{array}{l}\text { Generally } 0.036-0.072 \mathrm{mrad} / \mathrm{h} \text {; } \\
\text { spot near } 9 \mathrm{~B} \text { measured } \\
1.9 \mathrm{mrad} / \mathrm{h}\end{array}$ \\
\hline $8 \mathrm{E}$ & $17-79$ & $\begin{array}{l}\text { Generally } 17-23 \mu R / h \text { on flat } \\
\text { area } S \text { of slope, } 29-79 \mu R / h \\
\text { on } N \text { side of block in erosion } \\
\text { runs; water in } S E \text { corner }\end{array}$ & $\begin{array}{c}0.036- \\
1.6\end{array}$ & $\begin{array}{l}0.036-0.072 \mathrm{mrad} / \mathrm{h} \text { on } \mathrm{S} \text { side } \\
\text { of block; } 1.6 \mathrm{mrad} / \mathrm{h} \text { at } \\
54-\mu \mathrm{R} / \mathrm{h} \text { spot on berm; water } \\
\text { in } \mathrm{SE} \text { corner }\end{array}$ \\
\hline $8 \mathrm{C}$ & $11-58$ & $\begin{array}{l}\text { Generally } 11-17 \mu R / h ; \text { high } \\
58 \mu R / h\end{array}$ & $\begin{array}{c}0.036 \\
0.35\end{array}$ & $\begin{array}{l}\text { Generally } 0.036-0.072 \mathrm{mrad} / \mathrm{h} \text {; } \\
\text { elevated levels along berm at } \\
\mathrm{W} \text { end of block; } 0.35 \mathrm{mrad} / \mathrm{h} \\
\text { at } 58-\mu \mathrm{R} / \mathrm{h} \text { spot }\end{array}$ \\
\hline $6 \mathrm{G}$ & $12-85$ & Generally $12-23 \mu R / h$ & $\begin{array}{c}0.036 \\
0.56\end{array}$ & \\
\hline $6 \mathrm{E}$ & $23-92$ & $\begin{array}{l}\text { Generally } 23-29 \mu R / h \text { S of } \\
\text { slope on flat area; elevated } \\
\text { levels on berm at } E \text { end of }\end{array}$ & $\begin{array}{c}0.036 \\
0.68\end{array}$ & $\begin{array}{l}\text { Generally } 0.036-0.072 \mathrm{mrad} / \mathrm{h} \text {; } \\
0.072-0.68 \mathrm{mrad} / \mathrm{h} \text { in elevated } \\
\text { area }\end{array}$ \\
\hline
\end{tabular}
block and on slope at $\mathrm{N}$ end of block 
Table 2 (continued)

\begin{tabular}{|c|c|c|c|c|}
\hline \multirow[b]{2}{*}{$\begin{array}{l}\text { Grid } \\
\text { block }^{a}\end{array}$} & \multicolumn{2}{|r|}{ Gamma exposure rates } & \multicolumn{2}{|r|}{ Beta-gamma dose rates } \\
\hline & $\begin{array}{l}\text { Surface } \\
\text { scan } \\
\text { range } \\
(\mu R / h) \\
\end{array}$ & Comments on gamma scan & $\begin{array}{l}\text { Surface } \\
\text { scan } \\
\text { range } \\
(\mathrm{mrad} / \mathrm{h})\end{array}$ & $\begin{array}{l}\text { Comments on beta-gamma } \\
\text { scan }\end{array}$ \\
\hline $6 \mathrm{C}$ & $11-73$ & $\begin{array}{l}\text { Generally } 11-23 \mu R / h \text {, with } \\
\text { several elevated spots on } \\
\text { berm at } E \text { end; highest spot, } \\
73 \mu \mathrm{R} / \mathrm{h} \text {; water and mud } \\
\text { covered } \mathrm{W} \text { end of block }\end{array}$ & $\begin{array}{c}0.036 \\
0.36\end{array}$ & $\begin{array}{l}0.11-0.36 \mathrm{mrad} / \mathrm{h} \text { on berm; } \\
0.11-0.25 \mathrm{mrad} / \mathrm{h} \text { in } 15-\mathrm{ft} \text { strip } \\
\text { beside berm; water and mud } \\
\text { covered } \mathrm{W} \text { end of block }\end{array}$ \\
\hline $4 G$ & $12-23$ & $\begin{array}{l}\text { Generally } 12-13 \mu R / h \text { in flat } \\
\text { area, } 13-17 \mu R / h \text { on slope, } \\
23 \mu R / h \text { in erosion runs }\end{array}$ & & $\begin{array}{l}0.040 \mathrm{mrad} / \mathrm{h} \text { at } 23-\mu \mathrm{R} / \mathrm{h} \mathrm{spot} \\
\text { in erosion run }\end{array}$ \\
\hline $4 \mathrm{E}$ & $17-44$ & $\begin{array}{l}\text { Generally } 17-23 \mu R / h ; \\
\text { elevated region, } 23-44, \alpha R / h \text {, } \\
\text { along bottom of slope; water } \\
\text { and mud covering } S \text { part of } \\
\text { block prevented thorough } \\
\text { survey }\end{array}$ & $\begin{array}{c}0.036 \\
0.49\end{array}$ & \\
\hline $4 \mathrm{C}$ & $15-36$ & $\begin{array}{l}\text { Block almost entirely covered } \\
\text { with water and mud; surveyed } \\
\text { area generally } 15-17 \mu R / h \text {, } \\
\text { with elevated spots } \\
21-36 \mu R / h\end{array}$ & & $\begin{array}{l}\text { No beta-gamma survey } \\
\text { because of water and mud }\end{array}$ \\
\hline $2 G$ & $15-42$ & $\begin{array}{l}\text { Generally } 15-17 \mu \mathrm{R} / \mathrm{h} \text {, with } \\
\text { elevated spots up to } 42 \mu \mathrm{R} / \mathrm{h} \text {; } \\
\text { vegetation prevented } \\
\text { thorough survey }\end{array}$ & $0.036-1.4$ & \\
\hline $2 \mathrm{E}$ & $11-23$ & $\begin{array}{l}\text { Generally } 15-17 \mu R / h \text {; heavy } \\
\text { vegetation prevented } \\
\text { thorough survey }\end{array}$ & $\begin{array}{l}0.036 \\
0.072\end{array}$ & $\begin{array}{l}\text { Very limited beta-gamma } \\
\text { survey because of vegetation }\end{array}$ \\
\hline $2 \mathrm{C}$ & $15-23$ & $\begin{array}{l}\text { Mostly covered by water and } \\
\text { mud. Generally } 15-17 \mu R / h \text {, } \\
\text { with one spot } 23 \mu R / h\end{array}$ & & $\begin{array}{l}\text { No beta-gamma survey } \\
\text { because of mud and water }\end{array}$ \\
\hline $\begin{array}{l}\text { West } \\
\text { end }\end{array}$ & & $\begin{array}{l}\text { Slope at west end generally } \\
29-42 \mu R / h \text {, with some spots } \\
48 \mu R / h\end{array}$ & & \\
\hline
\end{tabular}

${ }^{a}$ Grid blocks are shown in Figs. 9 and 10. 

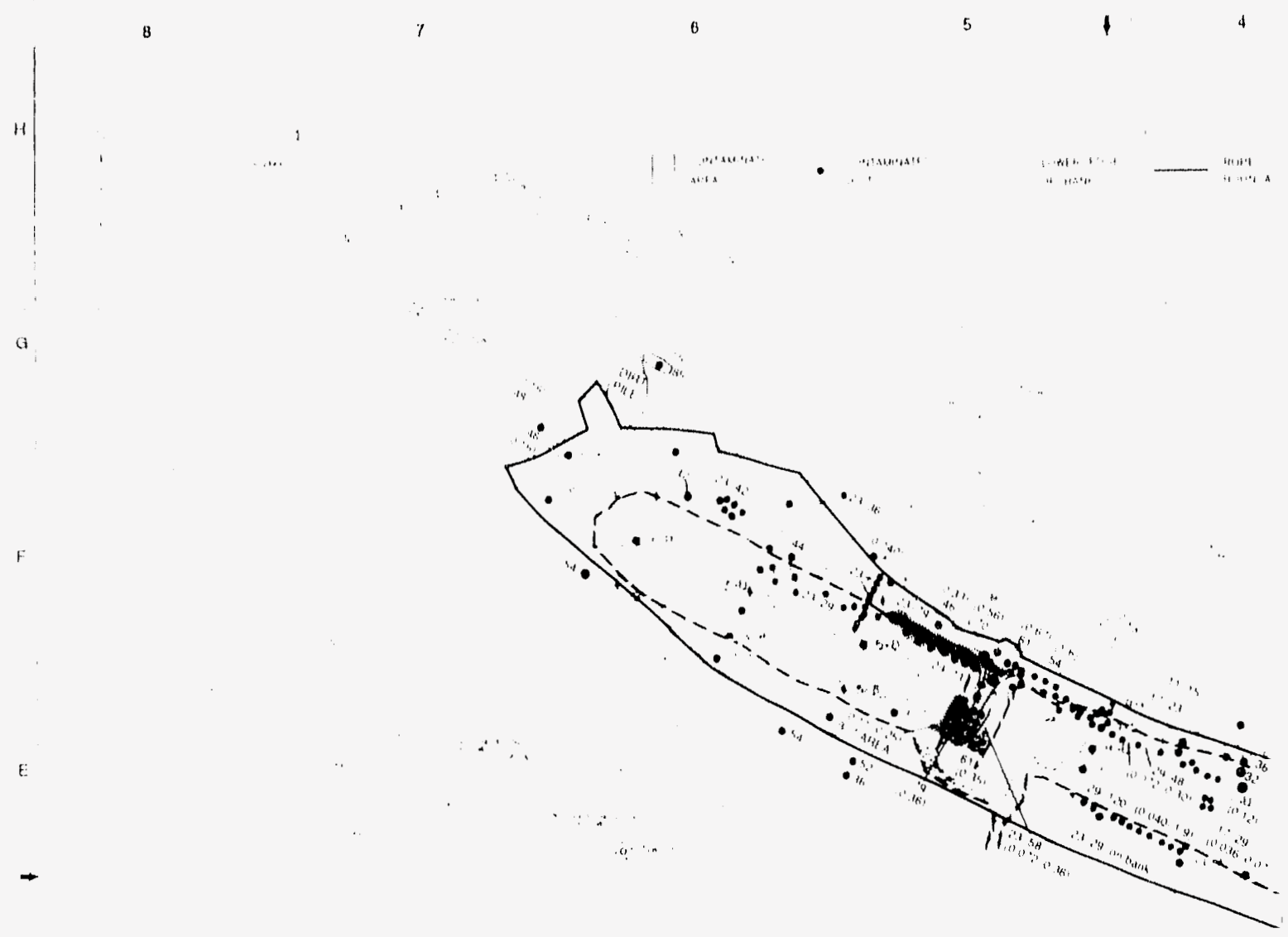

0
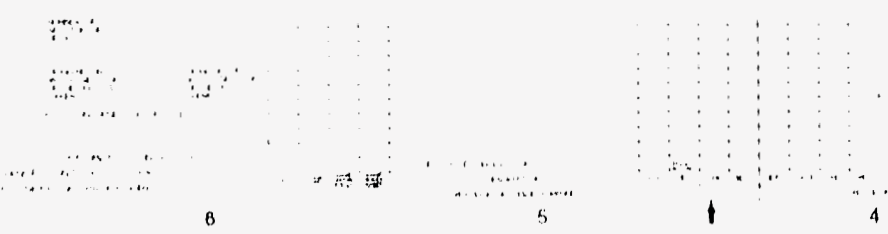

Fig. 11. Ekevated surface gamma exposure rates 1 (mrad/h in parentheses) at the $\mathrm{K} 1407$ C Retention Basin 


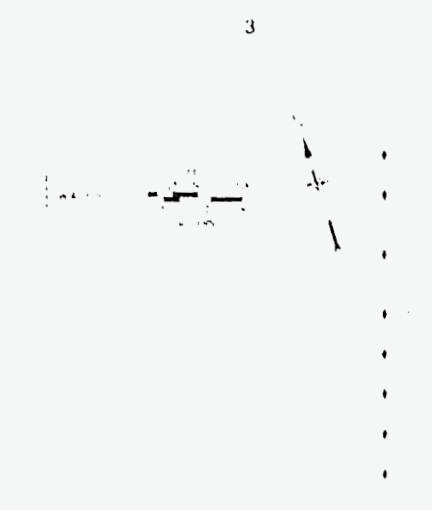

SAMPLING LOCAIIOA

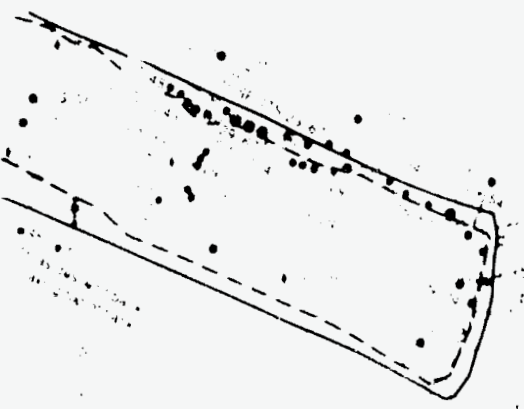

(R/1) and beta-gamma dose rates _September 1968 to January $19(x)$ ). 
- Anin in
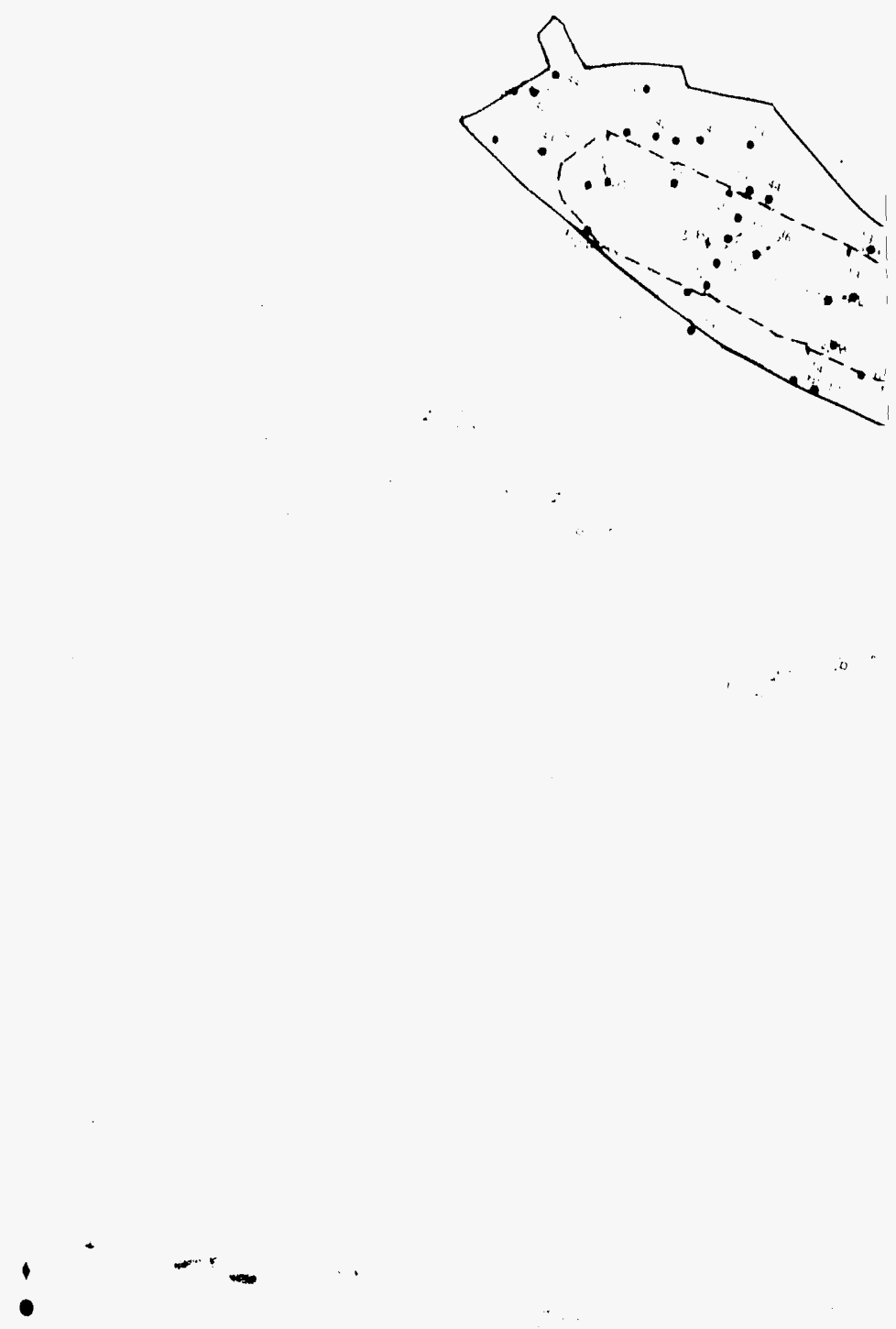

Fig. 12 Surface gamma e Retention Basin (September 1) 


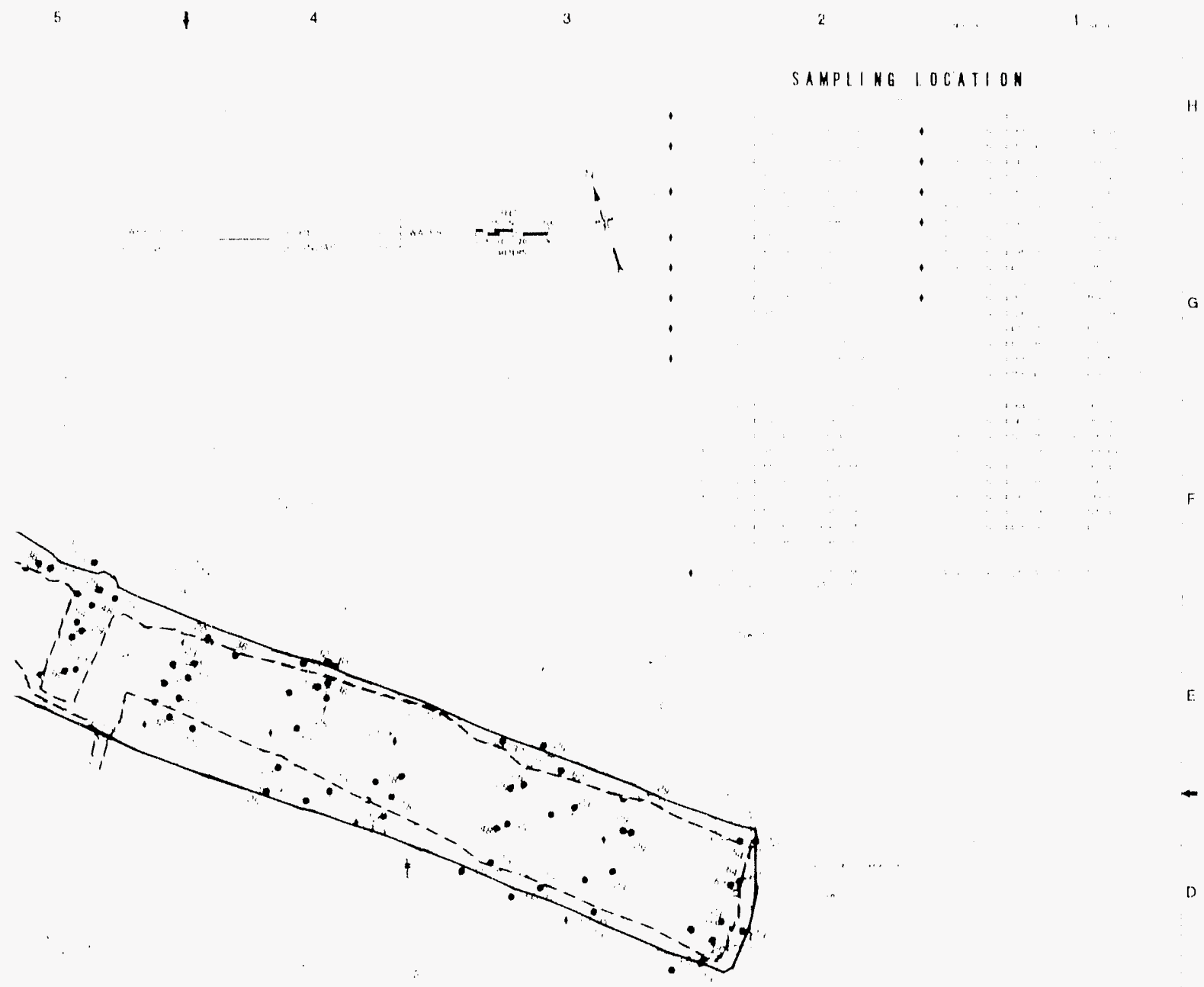



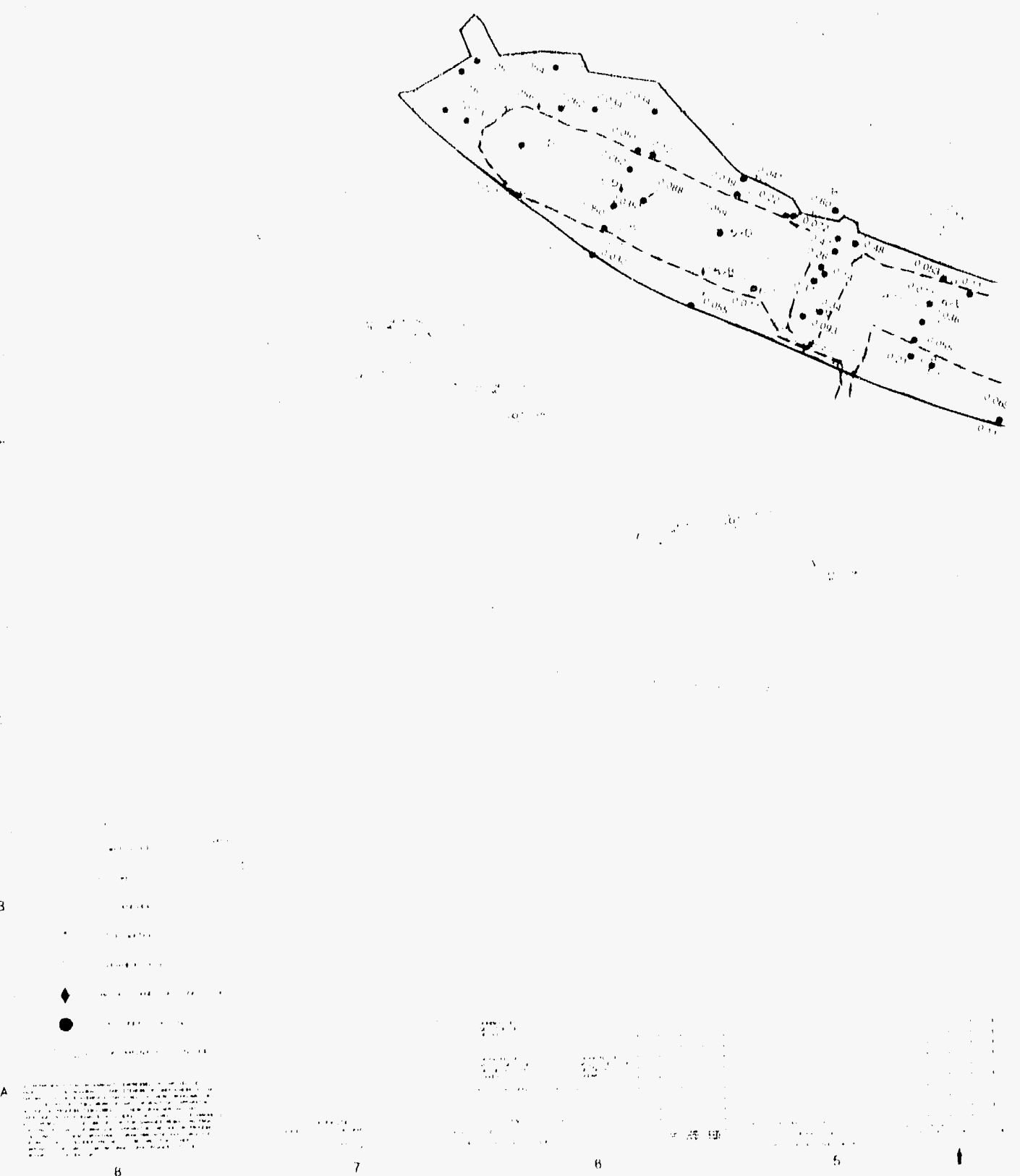


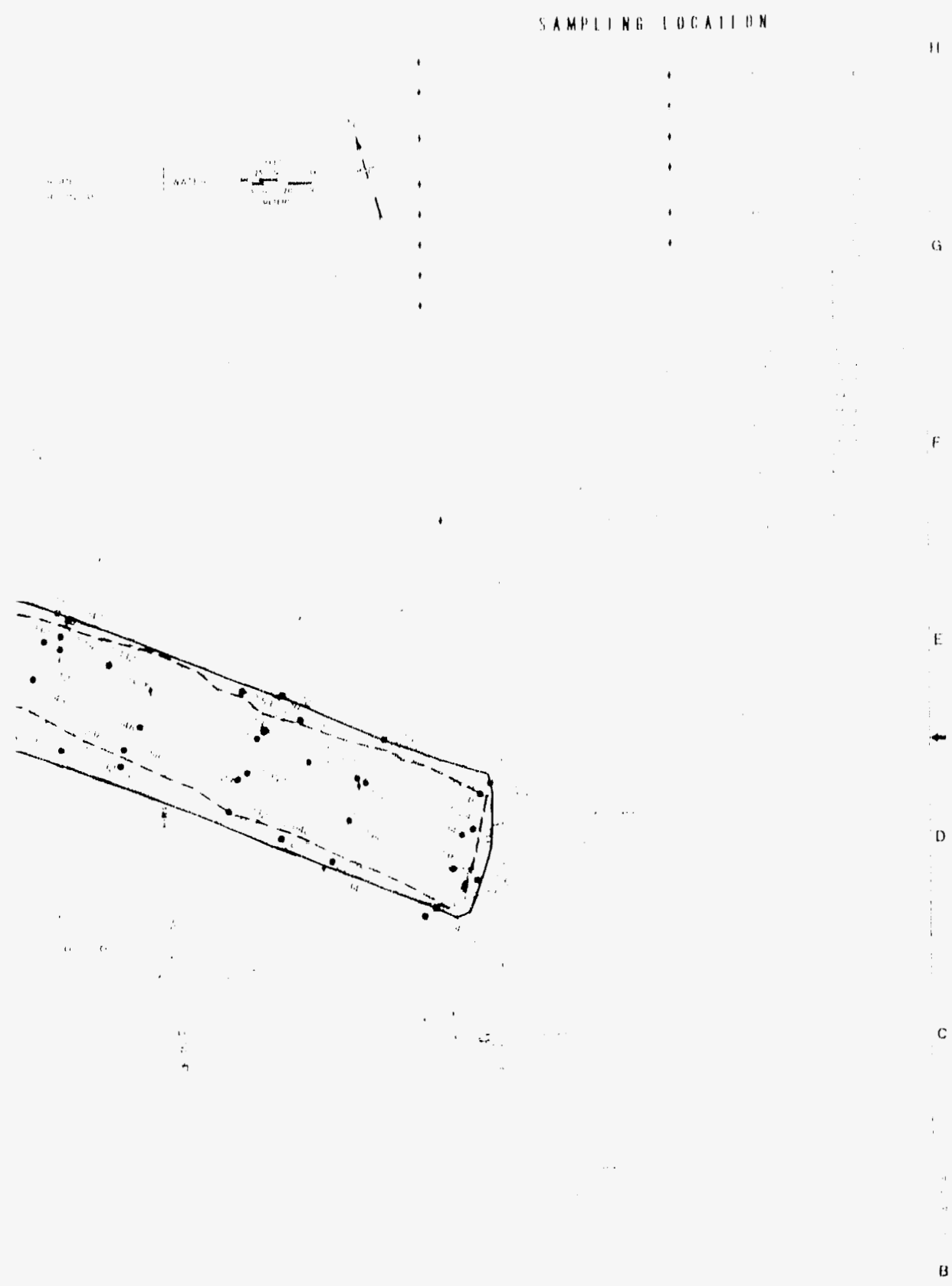

th) at sampling points at the $K 1407 C$ ). 


\subsection{SIGNIFICANCE: OF FIELD MEASUREMENIS}

Survey results show widespread residual radioactivity at the K-14017.C Retention Basin site. Typical surlace gamma exposure rates in the vicinity of the basin ranged from 11 to $15 \mu \mathrm{R} / \mathrm{h}$, while aceessible areas in the basin ranged from 11 to $120 \mu \mathrm{R} / \mathrm{h}$, with all grid blocks exceeding typical background levels. Numerous spots of surface contamination ranging from 23 to $79 \mu \mathrm{R} / \mathrm{h}$ were primarily concentrated on the north side of the basin at the base of the bank, extending up the bank, and along the top of the earthen dike that bisects the basin. Contaminants consisted of alpta, beta, and gamma emitters; at least a part of the alpha contamination was transferable to boxts and equipment.

Typical surface beta-gamma dose rates ranged from $0.0136 \mathrm{to} 0.072 \mathrm{mrad} / \mathrm{h}$, with highest measured levels reaching $1.9 \mathrm{mrad} / \mathrm{h}$ (25 io 50 times typical levels). Surface beta-gamma scan ranges exceeded typical background levels in $80 \%$ of the grid blocks surveyed.

Contamination in the area is not entirely confined to the basin. Nine contaminated spots ranging from 36 to $85 \mu \mathrm{R} / \mathrm{h}$ were identified outside the rope boundary. Another spot measuring $1710.36, \mathrm{R} / \mathrm{h}(0.18 \mathrm{mrad} / \mathrm{h})$ was identified on the road north of the basin.

Approximately $25 \%$ of the basin was inacessible during the period of this survey because of standing water, heavy vegetation, or steep terrain. It is highly probable that additional contamination is located in the inacessible areas.

\subsection{DATA LIMITATIONS}

Limitations associated with the sampling of the K-1407-C Retention Basin are related 10) the ability of the investigation to represent adequatcly the distribution of contaminants in the soil. One of the herms constructed during the sludge removal remains across the west end of the retention basin. This berm was produced by mounding soil from the floor of the retention basin; therefore, it is not reasonable to assume a correlation between samples taken from the berm and other locations. In addition, it should be noted that sample depth does not correlate to the soil's original depth beneath the bottom of the sludge. During removal of the sludge, the amount of material excavated relative to the original retention basin bottom varied; therefore, samples of the same depth cannot be strictly correlated in relation to their proximity to the source of contamination. Because samples were not taken below 18 in., the depth to which contamination extends is unknown. Finally, because no background samples are available, it is difficult to differentiate between naturally occurring regional background metal concentrations and metal concentrations related to site operations. 


\section{QUALITY ASSURANCE/QUALITY CONTROL}

\subsection{DATA QUALTY OBJECTIVES}

The data quality objectives for the K-1407-C Retention Basin are to obtain samples representative of the soil beneath the site. A review of the operations conducted at the site revealed that the site was used for storing sludge containing metallic or radioactive compounds. Although the sludge was removed, there was insufficient information on the site to determine the completeness of the sludge removal process or the effects of leaching from the sludge prior to removal. There is no evidence of organic contamination at the site; thus no organic analyses were necessary. Because of the nature of the site, soil was the only medium sampled. In addition to the soil samples, various QA samples were analyzed. These samples included equipment rinsates used to determine the adequacy of field cleaning procedures and field blanks to assure that water used in the field was not contaminated. Matrix spike samples were analyzed to determine the effectiveness of analytical preparation methodology. The samples were collected, prepared, and shipped following accepted EPA methodology. The metal analyses were performed according to accepted EPA protocol. There is no established EPA protocol for radiological samples. The analytical data for $\mathrm{K}-1407-\mathrm{C}$ Retention Basin soil is presented in Appendix B.

\subsection{ANALYTICAL METHODOLOGY}

Samples were analyzed for metals (including mercury) by the Analytical Chemistry Department of the Oak Ridge K-25 Site and for radiological components by the ORNL Analytical Chemistry Division. Table 3 is a summary of the number and the types of analyses performed on samples as part of the K-1407 Retention Basin investigation.

Table 3. Summary of K-1407-C analyses

\begin{tabular}{lccccc}
\hline & \multicolumn{2}{c}{ Soil samples } & & \multicolumn{2}{c}{ Water samples } \\
\cline { 2 - 3 } \cline { 5 - 7 } Analysis & Samples & $\begin{array}{c}\text { Matrix } \\
\text { samples }\end{array}$ & & $\begin{array}{c}\text { Equipment } \\
\text { rinsates }\end{array}$ & $\begin{array}{c}\text { Field } \\
\text { blanks }\end{array}$ \\
\hline ICP metals & 44 & 7 & & 0 & 0 \\
Mercury & 47 & 4 & & 0 & 0 \\
Radiochemical & 222 & 0 & & 16 & 14 \\
\hline
\end{tabular}




\subsubsection{Inorganic}

As stated in Sect. 4.1, the site was used for the storage of metal-contaminated sludge; consequently, the presence of metallic contamination was a concern in the site investigation. The analytical method EPA-6010 (SW-846) was used for the determination of all metals of concern except mercury. Mercury was determined by the analytical method EPA-7471 (also SW-846).

\subsection{Radiochemical}

Radiochemical contamination was determined to be the major concern for the K-1407-C site because of the storage of major quantities of potassium hydroxide scrubber sludge that contained radiochemical contamination; therefore, all samples collected were analyzed for radiochemical contamination. The aqueous QA samples (equipment rinsates and field blanks) were preserved by lowering the $\mathrm{pH}$ of the samples to $<2.0$ using $\mathrm{HNO}_{3}$. The procedures for specific radiochemical analytes are given in Table 4 . Since there are no EPA-approved procedures for most of the specific radiochemical analytes, the samples were analyzed using ORNL radiochemical methods.

Table 4. Radiochemical analysis methodologies

\begin{tabular}{|c|c|}
\hline Analyte & Analytical method \\
\hline${ }^{241} \mathrm{Am}$ & ORNL 231034 \\
\hline${ }^{137} \mathrm{Cs}$ & EPA 905.0 \\
\hline${ }^{60} \mathrm{Co}$ & EPA 905.0 \\
\hline${ }^{244} \mathrm{Cm}$ & ORNL 231034 \\
\hline${ }^{237} \mathrm{~Np}$ & ORNL 231535 \\
\hline${ }^{238} \mathrm{Pu}$ & ORNL 231625 \\
\hline${ }^{209} \mathrm{Pu}$ & ORNL 231625 \\
\hline${ }^{9} \mathrm{Sr}$ & EPA 905.0 \\
\hline Tc & ORNL 221833 \\
\hline${ }^{24} \mathrm{U}$ & ORNL 231933 \\
\hline${ }^{208} \mathrm{U}$ & ORNL 231933 \\
\hline Alpha & EPA 900 \\
\hline Beta & EPA 900 \\
\hline Gamma & EPA 901.1 \\
\hline
\end{tabular}

\subsection{HOLDING TTMES}

Samples analyzed for metals by inductively coupled plasma (ICP) have holding times of 6 months. None of the samples for ICP metals exceeded holding time limitations. Because mercury is a volatile metal, the holding time for samples scheduled for .isercury analyses is 28 days. Of the 47 samples analyzed for mercury, 6 were analyzed beyond the 28-day holding time. These samples are identified in Table 5. 
Table 5. Mercury analyses ercoeding holding times

\begin{tabular}{lc}
\hline \multicolumn{1}{c}{ Sample location } & Holding time (days) \\
\hline $09 \mathrm{~F}, 0-6$ in. & 29 \\
$09 \mathrm{~F}, 6-12$ in. & 29 \\
$09 \mathrm{~F}, 12-18$ in. & 29 \\
$07 \mathrm{D}, 0-6$ in. & 30 \\
$07 \mathrm{D}, 6-12$ in. & 30 \\
$07 \mathrm{D}, 12-18$ in. & 30 \\
\hline
\end{tabular}

\subsection{EQUIPMENT RINSATES}

Equipment rinsates are QA samples designed to demonstrate the cleanliness of equipment used for sampling. They are used to determine the potential for crosscontamination of samples. These samples are water samples obtained by washing equipment with clean water immediately after the completion of the cleaning process. These samples are preserved according to EPA guidelines for aqueous samples and are then analyzed for all parameters of interest. For samples taken from the K-1407-C Retention Basin, equipment rinsates were collected for radiochemical analyses. No equipment rinsates were collected for samples submitted for metals analyses.

\subsubsection{Radiochemical}

Only five of the radiochemical analytes showed sample activity at levels which could indicate potential problems from contamination between samples (cross-contamination). They are gross alpha, gross beta, ${ }^{99} \mathrm{Tc},{ }^{238} \mathrm{U}$, and ${ }^{234} \mathrm{U}$. Equipment rinsate results and the corresponding sample results for those radiochemical analytes are presented in Figs. 14 to 18. The data are plotted chronologically in order of sampling. The figures show that equipment rinsate data are only available for a limited number of samples analyzed for ${ }^{99} \mathrm{Tc},{ }^{238} \mathrm{U}$, and ${ }^{234} \mathrm{U}$. Data are available for alpha and beta throughout the sampling process. The figures show that radiochemical activity in the equipment rinsates is insignificant relative to radiochemical levels in the samples, so no sample-to-sample contamination is indicated.

\subsubsection{Inorganic}

As stated previously, no equipment rinsates were collected for samples analyzed for metals. For five metals (nickel, chromium, lead, uranium, and mercury) there were some samples at elevated levels following samples at higher levels. The possibility of crosscontamination due to the previous high sample cannot be ruled out without the presence of rinsate data. The sample data for these five metals are shown in Figs. 19 to 23. The data are plotted chronologically in order of sampling. The correlation between sample order number and sample identification is given in Table 6 for nickel, chromium, lead, and uranium and in Table 7 for mercury. 


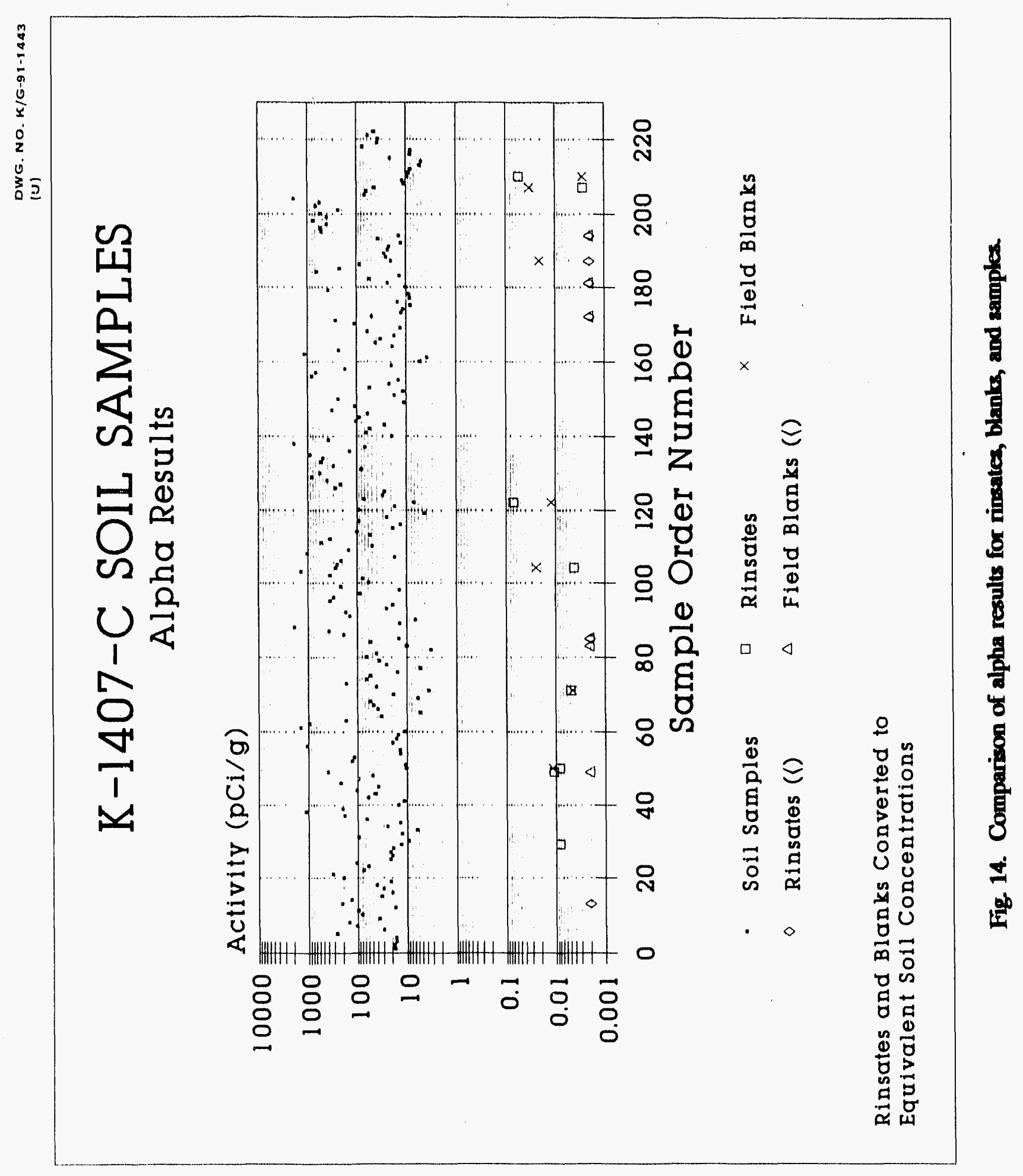




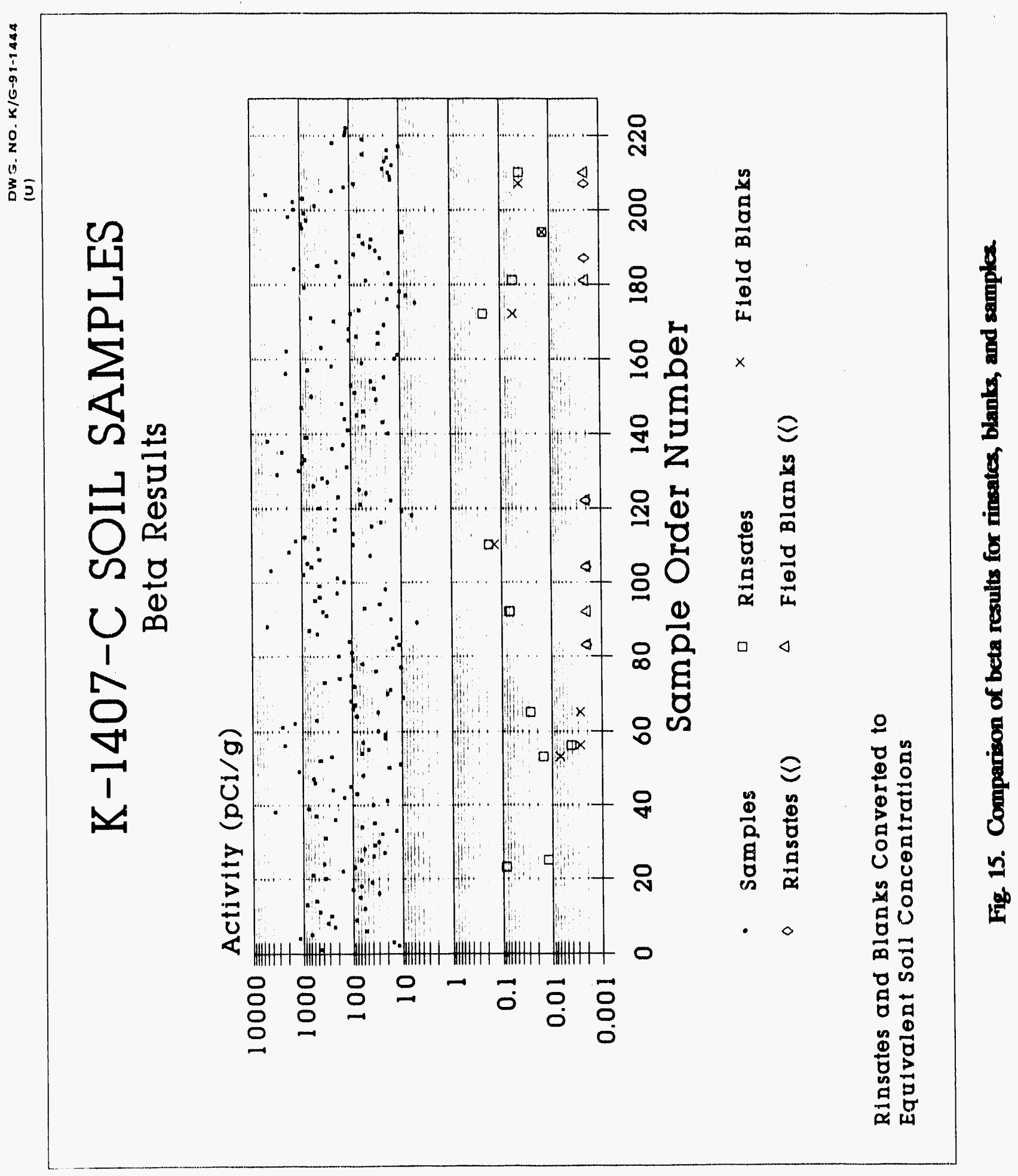




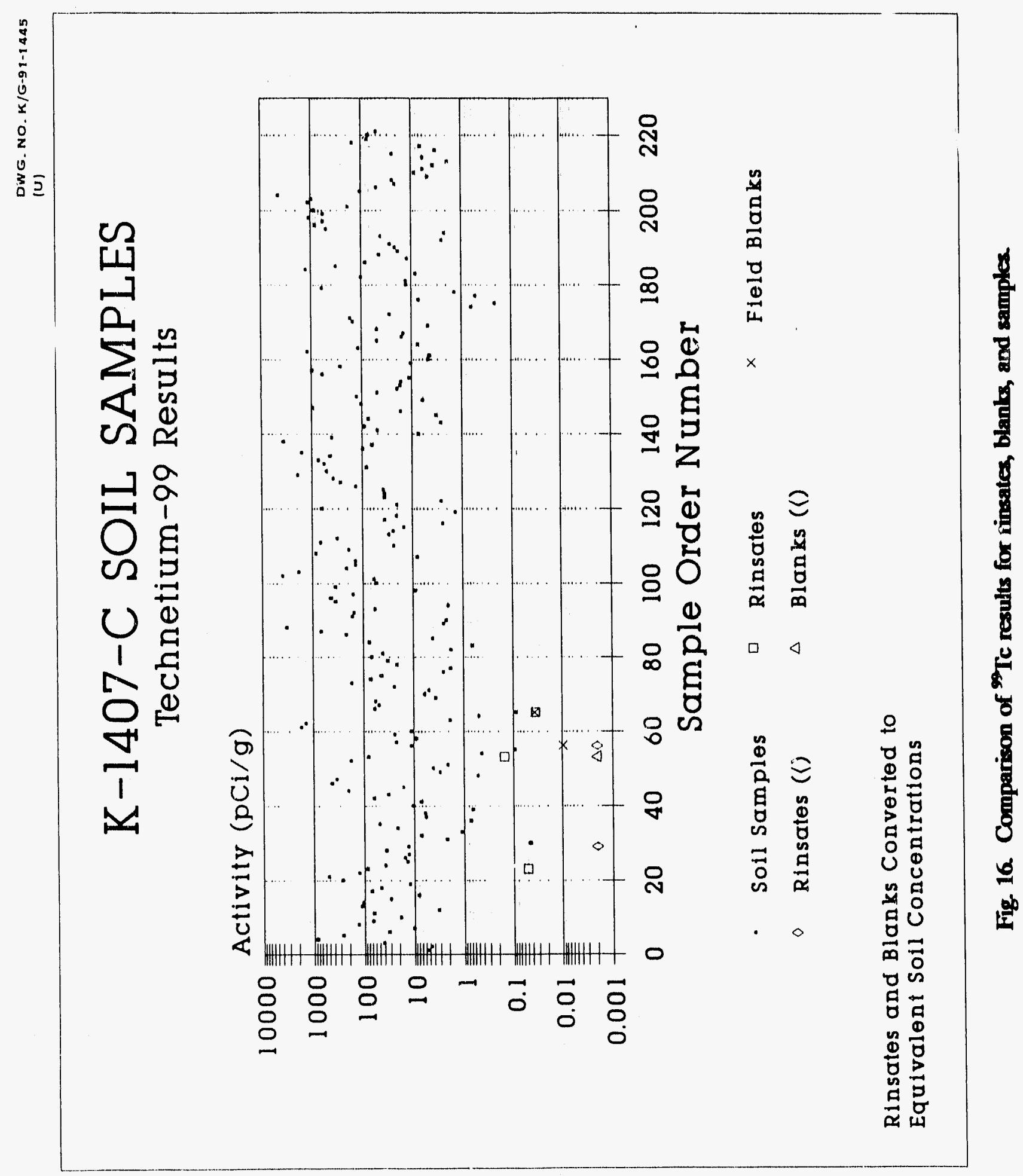




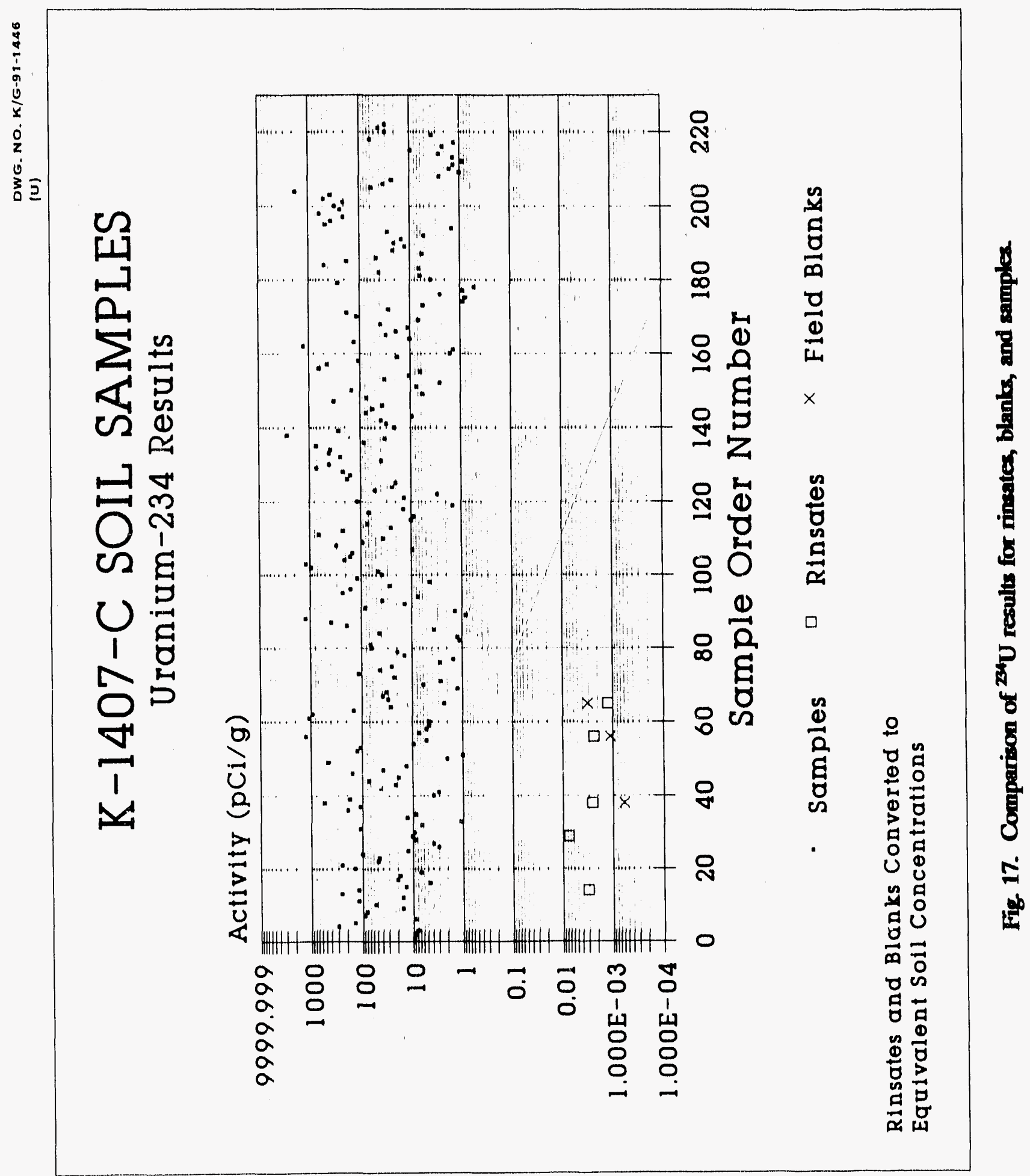




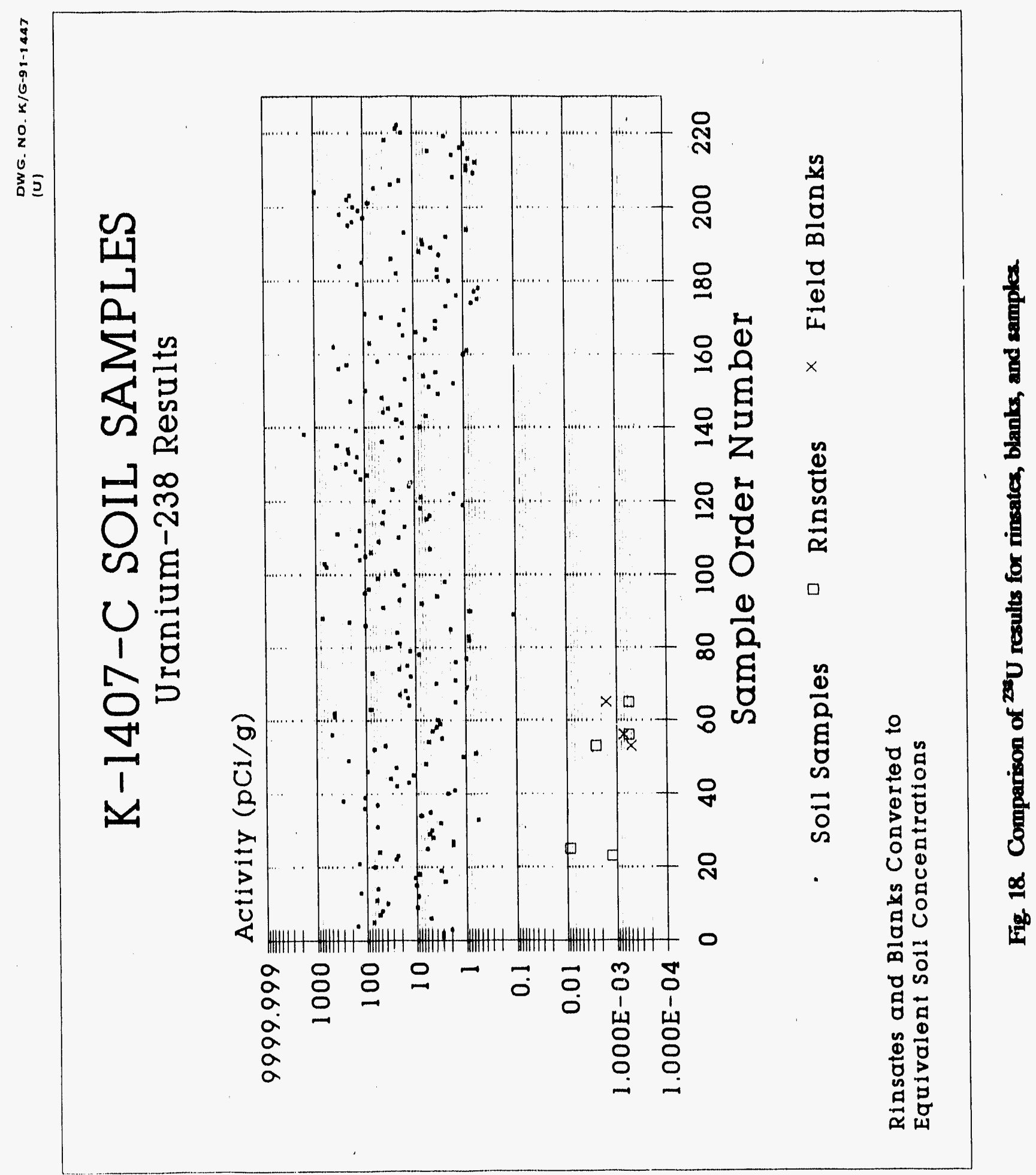


DWG. NO. K/G.81-1462

(U)

\section{K-1407-C SEDIMENT \\ NICKEL RESULTS}

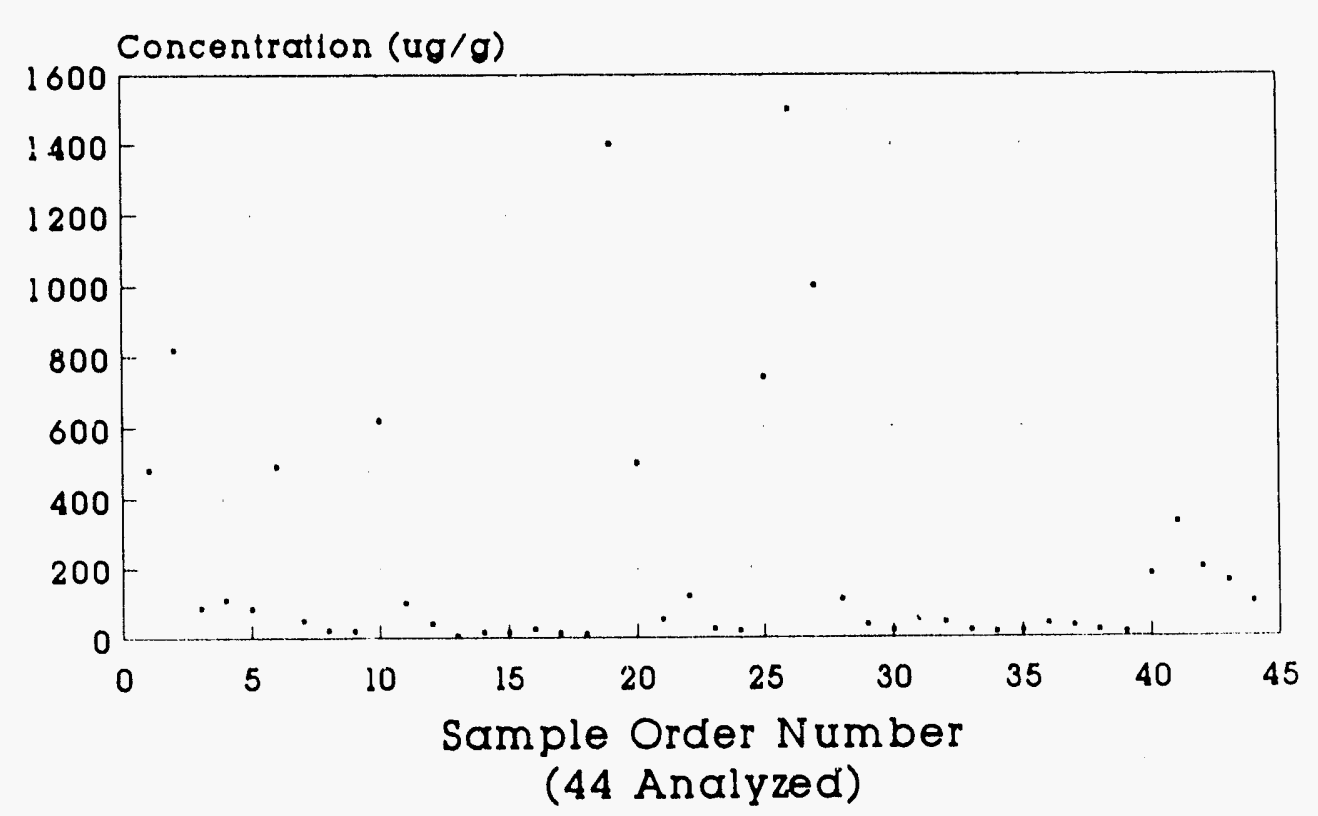

Fig. 19. Nickel results. 


\section{K-1407-C SEDIMENT CHROMIUM RESULTS}

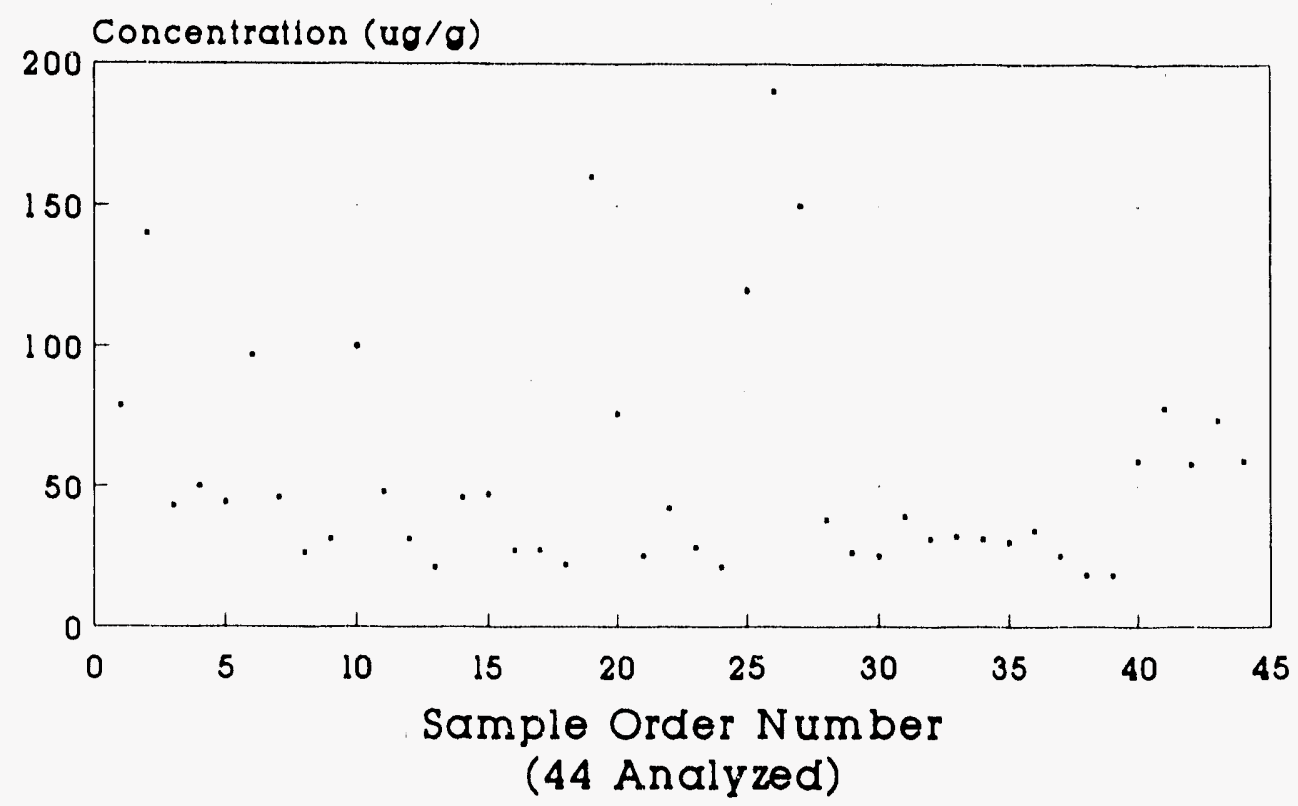

Fig. 20. Chromium results. 
DWG, NO, K/G-91-1464 (U)

\section{K-1407-C SEDIMENT LEAD RESULTS}

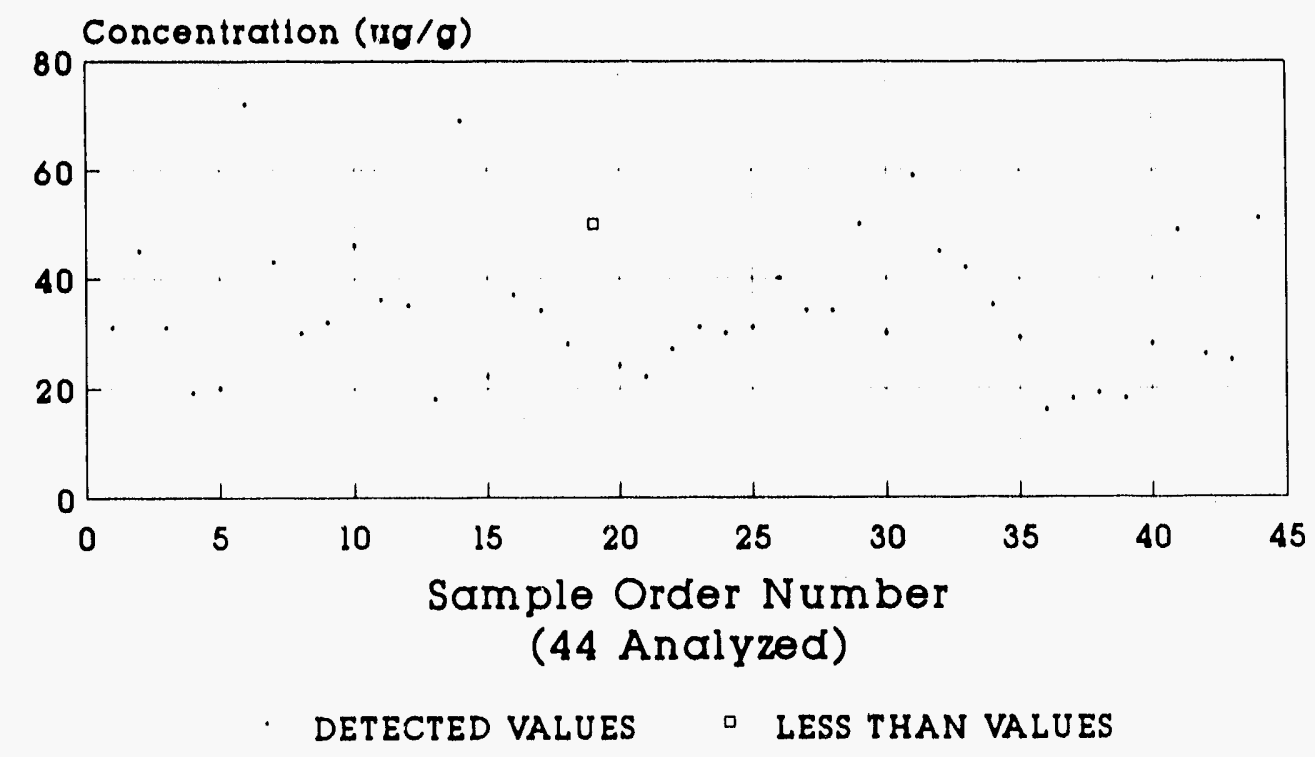

Fig. 21. Lead results. 
DWG. NO. K/G-91-1465 (v)

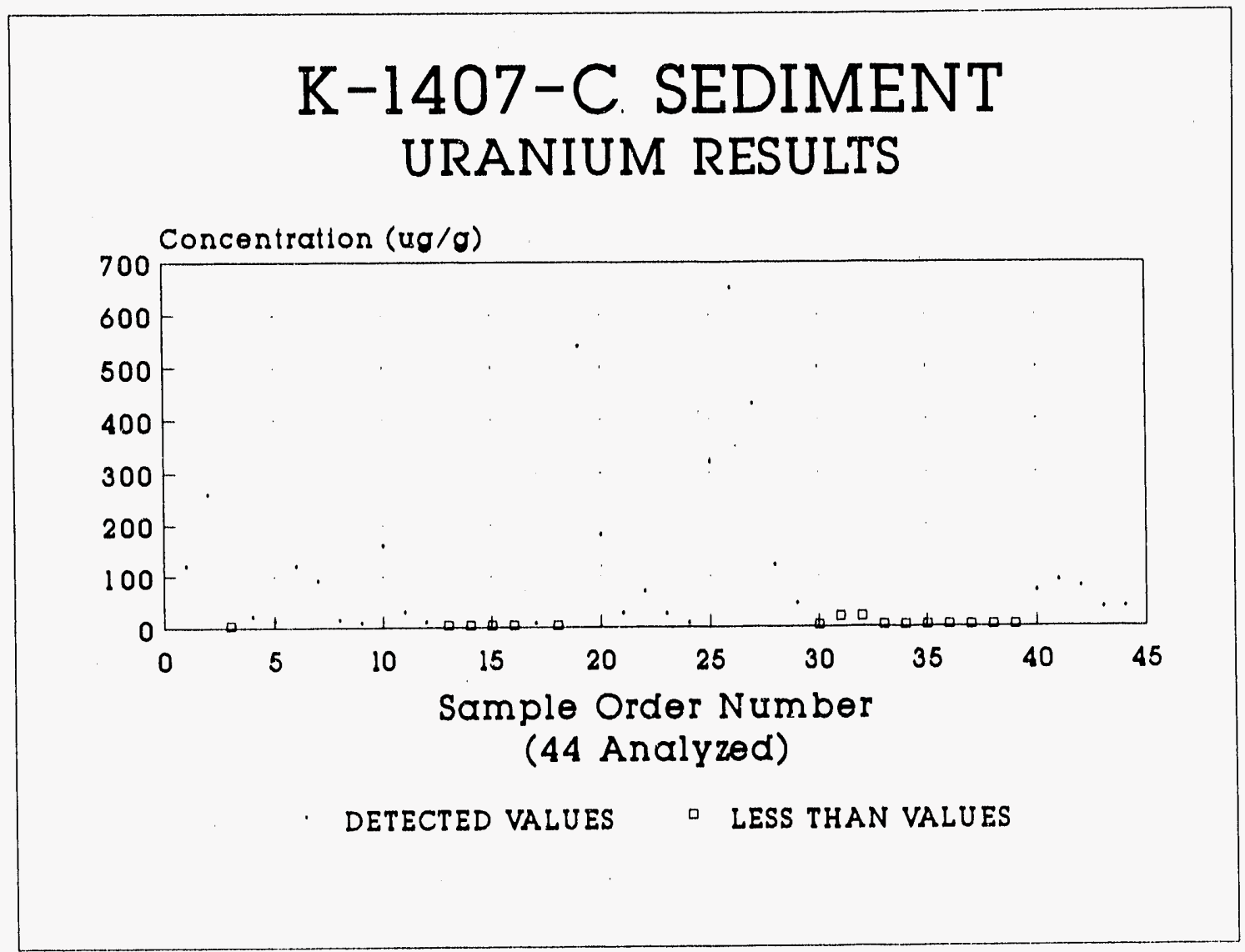

Fig. 22. Uranium results. 


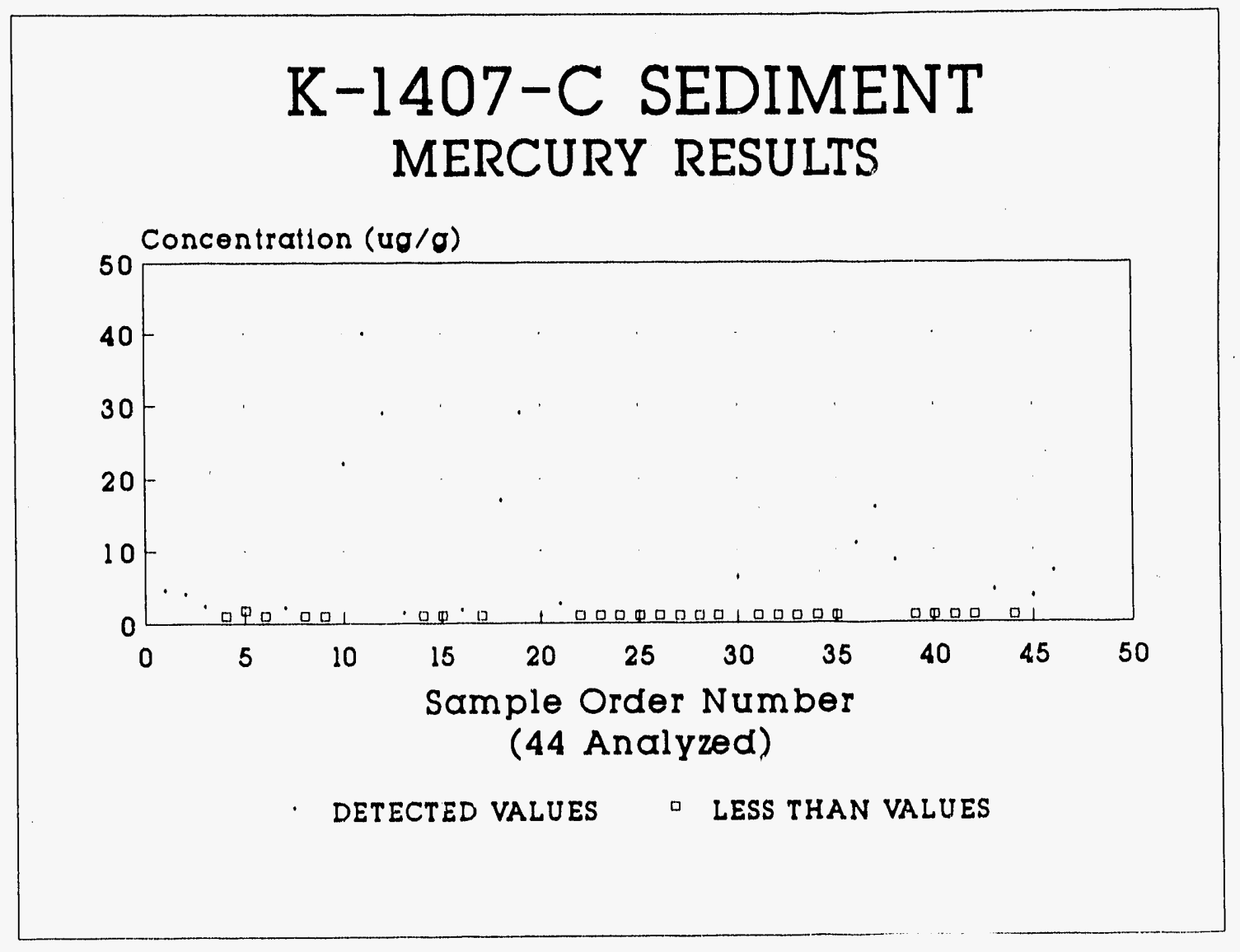

Fig. 23. Mercury results. 
42

Table 6. Metals analysis sample log

\begin{tabular}{|c|c|c|}
\hline Order number & Sample location & $\begin{array}{l}\text { Sample depth } \\
\text { (in.) }\end{array}$ \\
\hline 1 & 19D & 6 \\
\hline 2 & $17 \mathrm{~F}$ & 6 \\
\hline 3 & $17 \mathrm{~B}$ & 6 \\
\hline 4 & 19D & 12 \\
\hline 5 & 19D & 18 \\
\hline 6 & $17 \mathrm{~F}$ & 12 \\
\hline 7 & $17 \mathrm{~F}$ & 18 \\
\hline 8 & $17 \mathrm{~B}$ & 12 \\
\hline 9 & 17B & 18 \\
\hline 10 & $15 \mathrm{D}$ & 6 \\
\hline 11 & 11D & 6 \\
\hline 12 & 11D & 12 \\
\hline 13 & 11D & 18 \\
\hline 14 & 15D & 18 \\
\hline 15 & 15D & 12 \\
\hline 16 & $13 B$ & 6 \\
\hline 17 & $13 B$ & 12 \\
\hline 18 & $13 \mathrm{~B}$ & 18 \\
\hline 19 & 9B & 6 \\
\hline 20 & $9 \mathrm{~B}$ & 12 \\
\hline 21 & $9 B$ & 18 \\
\hline 22 & $9 \mathrm{~F}$ & 6 \\
\hline 23 & $9 \mathrm{~F}$ & 12 \\
\hline 24 & $9 F$ & 18 \\
\hline 25 & 7D & 6 \\
\hline 26 & 7D & 12 \\
\hline 27 & 7D & 18 \\
\hline 28 & $5 \mathrm{~F}$ & 6 \\
\hline 29 & $5 \mathrm{~F}$ & 12 \\
\hline 30 & $5 \mathrm{~F}$ & 18 \\
\hline 31 & $1 \mathrm{~F}$ & 6 \\
\hline 32 & $1 \mathrm{~F}$ & 12 \\
\hline 33 & 13B & 6 \\
\hline 34 & 13B & 12 \\
\hline 35 & $13 B$ & 18 \\
\hline 36 & $3 \mathrm{D}$ & 6 \\
\hline 37 & $5 B$ & 6 \\
\hline 38 & $5 B$ & 12 \\
\hline 39 & $5 B$ & 18 \\
\hline 40 & $2 \mathrm{E}$ & 6 \\
\hline 41 & $2 \mathrm{E}$ & 12 \\
\hline 42 & 1D & 6 \\
\hline 43 & $13 \mathrm{E}$ & 18 \\
\hline 44 & $13 F$ & 18 \\
\hline
\end{tabular}




\section{3}

Table 7. Mercury analysis sample log

\begin{tabular}{|c|c|c|}
\hline Order number & Sample location & $\begin{array}{l}\text { Sample depth } \\
\text { (in.) }\end{array}$ \\
\hline 1 & 19D & 12 \\
\hline 2 & 19D & 18 \\
\hline 3 & $17 \mathrm{~F}$ & 12 \\
\hline 4 & $17 \mathrm{~F}$ & 18 \\
\hline 5 & $17 \mathrm{~B}$ & 12 \\
\hline 6 & $17 \mathrm{~B}$ & 18 \\
\hline 7 & $9 \mathrm{~F}$ & 6 \\
\hline 8 & $9 \mathrm{~F}$ & 12 \\
\hline 9 & $9 \mathrm{~F}$ & 18 \\
\hline 10 & $7 \mathrm{D}$ & 6 \\
\hline 11 & 7D & 12 \\
\hline 12 & $7 \mathrm{D}$ & 18 \\
\hline 13 & $5 \mathrm{~F}$ & 6 \\
\hline 14 & $5 \mathrm{~F}$ & 12 \\
\hline 15 & $5 F$ & 18 \\
\hline 16 & $1 \mathrm{~F}$ & 6 \\
\hline 17 & $1 \mathrm{~F}$ & 12 \\
\hline 18 & 19D & 6 \\
\hline 19 & $17 \mathrm{~F}$ & 6 \\
\hline 20 & $17 \mathrm{~B}$ & 6 \\
\hline 21 & $15 \mathrm{~F}-\mathrm{B}$ & 6 \\
\hline 22 & $15 \mathrm{~F}-\mathrm{B}$ & 12 \\
\hline 23 & $15 F-B$ & 18 \\
\hline 24 & $13 \mathrm{~B}$ & 6 \\
\hline 25 & $13 B$ & 12 \\
\hline 26 & $13 B$ & 18 \\
\hline 27 & 11D & 6 \\
\hline 28 & 11D & 12 \\
\hline 29 & 11D & 18 \\
\hline 30 & $9 \mathrm{~B}$ & 6 \\
\hline 31 & 9B & 12 \\
\hline 32 & $9 \mathrm{~B}$ & 18 \\
\hline 33 & $9 \mathrm{~F}^{\circ}$ & 6 \\
\hline 34 & $9 \mathrm{~F}^{\infty}$ & 12 \\
\hline 35 & $9 \mathrm{~F}^{a}$ & 18 \\
\hline 36 & $7 D^{a}$ & 6 \\
\hline 37 & $7 D^{a}$ & 12 \\
\hline 38 & $7 D^{a}$ & 18 \\
\hline 39 & 3D & 6 \\
\hline 40 & 5B & 6 \\
\hline 41 & $5 B$ & 12 \\
\hline 42 & 5B & 18 \\
\hline 43 & $2 \mathrm{E}$ & 6 \\
\hline 44 & $2 E$ & 12 \\
\hline 45 & 1D & 6 \\
\hline 46 & $13 \mathrm{E}$ & 18 \\
\hline 47 & $13 \mathrm{~F}$ & 18 \\
\hline
\end{tabular}

${ }^{a}$ Field duplicate. 
The following show the possibility of contamination from preceding samples, which can be noted from the plots:

1. Nickel samples with order numbers 20 (BH038ASO12B) and 27 (BH045SO18B).

2. Chromium samples with order numbers 20 (BH038ASO12B) and 27 (BH045SO18B).

3. Lead several samples exhibiting the pattern described above with levels above Table 2.2 of the General Document. ${ }^{14}$

4. Uranium samples with order numbers 20 (BH038ASO12B) and 27 (BH045SO18B).

5. Mercury sample with order number 12 (BH045SO18B), somewhat elevated and following a high sample, but below guideline values of Table 2.2 of the General Document and thus of no significance.

\subsection{FIELD BLANKS}

Field blanks are used during an investigation to determine if contamination found in equipment rinsates resulted from the use of contaminated rinse water. As with equipment rinsates, field blank data are only available for radiochemical analytes.

The field blank data for radiochemical analytes are shown in Figs. 14 to 20 along with the corresponding equipment rinsate data and sample data. No radiochemical contamination is present in any of the field blank samples.

\subsection{MATRIX SPIKE RECOVERIES}

Matrix spikes are added to samples that require some form of extraction as a preparation for analysis. Matrix spikes are solutions of known concentrations of specific representative compounds added to samples in specific amounts. Comparison of the measured concentration of the compounds in the spiked samples and the corresponding original samples is used to determine the effect of the sample matrix on the extraction efficiency.

\subsubsection{Inorganic Matrix Spikes}

Inorganic matrix spike solutions were added to samples to check the recovery of the metallic analytes analyzed by ICP. Matrix spikes of cadmium, chromium, copper, lead, manganese, nickel, and zinc were added although not every matrix spike sample was analyzed for all seven elements. Matrix spikes were analyzed on 4 of the 47 samples collected for mercury analysis. Figure 24 shows the matrix spike recoveries for both ICP metals and mercury. Tr: sample order number on the plot is the order number correlated to the sample identification in Table 6 for ICP metals or Table 7 for mercury. All matrix spikes for ICP metals and mercury were within the acceptable limits of 75 to $125 \%$ recovery. 


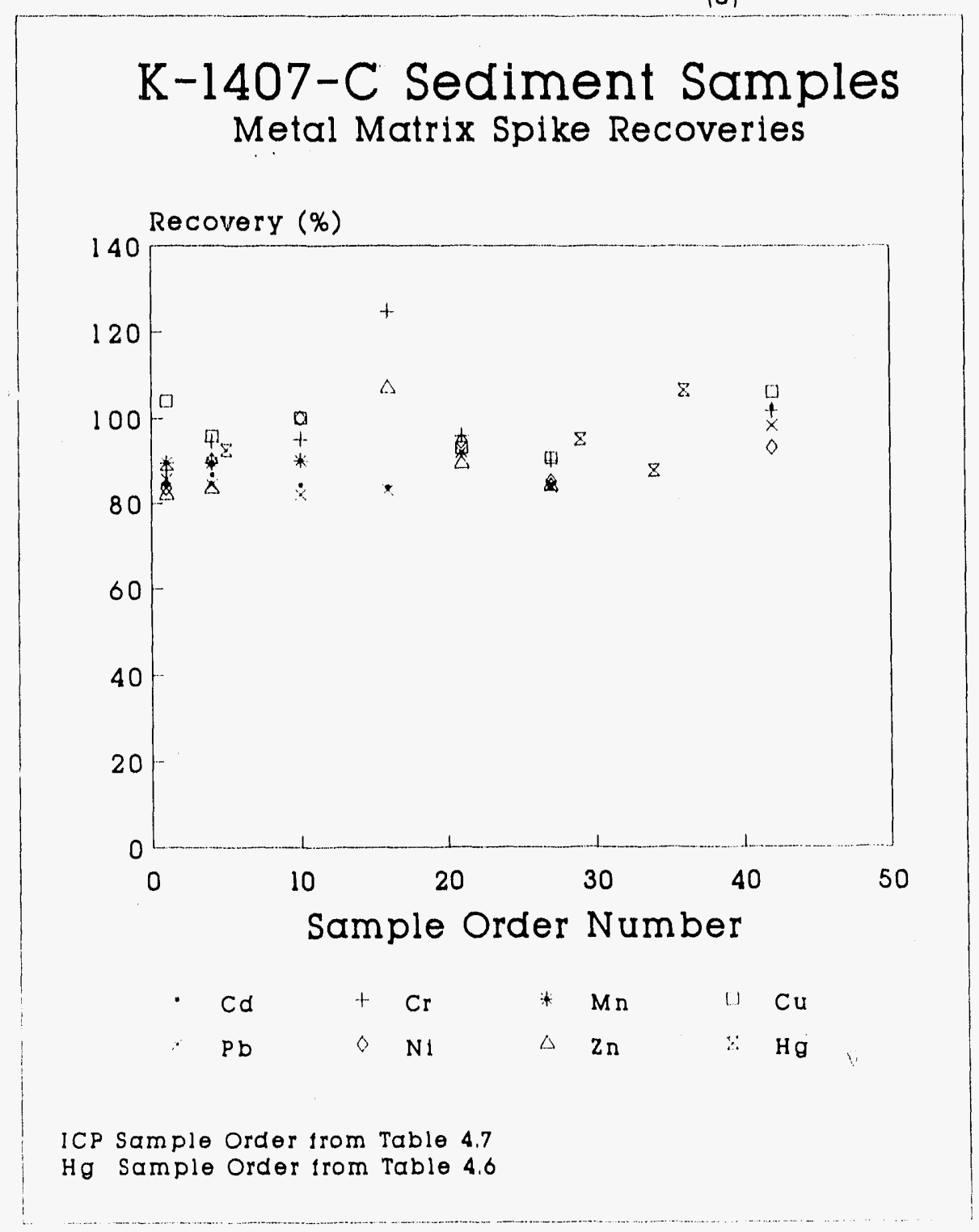

Fig. 24. Metal matrix spike recoveries. 


\subsubsection{Radiochemical Matrix Spikes}

No matrix data exist for radiochemical analytes, and thus no estimate of matrix effects on the extraction of the analytes can be determined.

\subsection{SUMMARY OF RESULTS}

\subsubsection{Inorganic}

All metal analyses (excluding mercury) were performed within recognized holding times, and matrix spike data were within acceptable limits. Six of the 47 mercury analyses were performed outside the est ablished holding times. However, they were only 2 or 3 days past the 28-day holding time, and the quality of the data would not be expected to be reduced. The mercury matrix spike data are within acceptable limits. Because of the absence of equipment rinsate data for metal and mercury samples, contamination of samples from incompletely cleaned equipment is a possibility, as described in Sect. 4.2.4.1. Those data are of questionable quality and should be used only as estimated concentrations if other information is available which indicates the measurements to be correct.

\subsubsection{Radiochemical}

A complete evaluation of the K-1407-C site is impossible because of the lack of complete radiochemical data. Although there are no established holding times for radiochemical analyses, some holding times have approached or exceeded 1 year, and data from those analyses should be used cautiously. Equipment rinsates collected for the early samples show no evidence of sample-to-sample contamination for any of the radiochemical analytes. Data were not present for each individual analyte for the entire sampling period. The alpha and beta activity data for equipment rinsate samples collected over the entire sampling period, however, indicate no sample-to-sample contamination for any of the alpha- or beta-emitting radiochemical analytes. Since no radiochemical matrix spike data are available, there is no way to determine whether preparation procedures for the analytes are free from matrix interference effects. Because of the length of time for analysis and the lack of any data that would show matrix effects on the radiochemical analyses, the data should be considered as estimates only. They could be used for determining general trends or potential locations to concentrate on in future sampling, but they should not be used for determining exact concentrations. 


\section{PRELIMINARY RISK ASSESSMENT}

This chapter examines the ability of the Phase 1 investigation to provide the data necessary to conduct a comprehensive assessment of the potential adverse human health effects from exposure to soil contamination at the K-1407-C Retention Basin. A conservative human health-based screening of soil contaminant concentrations is employed to indicate the contaminants that pose the greatest potential for producing adverse human health effects. This screening method is used to evaluate contaminant distribution and the effectiveness of the Phase 1 investigation to adequately characterize the extent of contamination at the site. Additionally, this chapter includes an evaluation of the ability of the data to characterize contamination as it relates to the environmental and exposure pathways that influence the nature of exposure. This chapter is concluded with a summarization of the Phase 1 data limitations affecting the production of a baseline risk assessment.

\subsection{DATA EVALUATION/POTENTIAL CONTAMINANTS OF CONCERN}

The evaluation of data for risk assessment is an iterative process that involves not only following set procedures, but also making decisions and assumptions concerning the data based on historical information, disposal records, and "best professional judgment." Soil data for the K-1407-C Retention Basin were compiled by the data base manager in accordance with the specifications outlined in the Oak Ridge Gaseous Diffusion Plant Remedial Action Program Data Management Plan, K/HS-232, Revision $1 .^{15}$ The following discussion addresses the primary steps in the evaluation of data for use in a risk assessment, with regard to the appropriateness of the data and identification of data limitations. Also, as a result of the data evaluation, a list of chemicals of potential concern has been compiled.

Evaluation of the analytical methods was the first step in the data evaluation process. Specificity, sensitivity, accuracy, and precision of the instruments and methods used for sample analysis were factors considered in determining the appropriateness and validity of the laboratory data. For Contract Laboratory Program analytical results, qualifiers and codes were attached to data by either the laboratory or by data validation personnel. These codes are related to QAVQC controls or question the reported chemical identities and concentrations. All qualifiers and codes were addressed before a chemical was included in the screening assessment.

The potential for the adulteration of soil samples due to collection practices or laboratory preparation is evaluated prior to the use of data in risk assessment. The assessment of the likelihood of sample contamination during collection is addressed in Chap. 4. Contamination of samples during laboratory procedures is not applicable to the K-1407-C soil data because organics that are the most common laboratory contaminants were not analyzed for in soil samples.

A comparison of sample concentrations to background concentrations is essential to identify indigenous constituents detected in site samples. The operational history of the 
K-1407-C Retention Basin indicates that it is the likely source of radionuclides detected in soil samples. However, the source of the nonradioactive metals detected in soil from the retention basin cannot be absolutely determined because most of the metals are indigenous in regional soils. The concentrations of chromium, mercury, and nickel are highest in samples taken from the east end, where flow entered the retention basin, suggesting site activities as the source. However, there is no indication of a correlation between metal and radionuclide distributions, which might be expected if metals were site-related. The inability to distinguish between site-related and naturally occurring metal concentrations should not have a significant influence on the present evaluation. Additionally, because the source of radionuclides can be related to site operations and because the source of nonradioactive metals has not been definitively identificd, it is logical to place a greater emphasis on the screening of radionuclides.

A primary goal of the Phase 1 review is to determine the ability of the analytical data to represent accurately the nature (contaminants and their concentrations) and extent of the contaminants in soil at the K-1407-C Retention Basin. The sampling array is believed to have been adequate to identify the analytes present in K-1407-C soil. However, because there are no data below a depth of 18 in., the assessment of potential health hazards is limited.

The potential contaminants of concern for the K-1407-C Retention Basin were derived using the methodology outlined in Chap. 5 of Risk Assessment Guidance for Superfund, Volume I: Human Health Evaluation Manual, EPA/540/1-89/002, December $1989 .{ }^{16}$ The following is a list of potential contaminants of concern detected in the soil at K-1407-C.

\section{Radionuclides}

Americium-241

Cesium-137

Cobalt-60

Curium-244

Europium-154
Neptunium-237

Plutonium-238

Plutonium-239

Potassium-40

\section{Metals}

Antimony

Arsenic

Barium

Beryllium

Boron

Cadmium

Chromium
Cobalt

Lead

Manganese

Mercury

Molybdenum

Nickel
Technetium-99

Uranium-234

Uranium-235

Uranium-238

Of the analytes detected in the soil samples, calcium, copper, iron, magnesium, silicon, and sodium are naturally occurring essential nutrients that have little or no toxic effects at the detected levels and consequently are not considered potential contaminants of concern.

\subsection{DOSE/RESPONSE INFORMATION EMPLOYED IN SCREENING}

The screening of soil contamination at the K-1407-C Retention Basin involves a comparison of contaminant concentrations with guideline values that are based on chemicalor element-specific dose/response information. Potential carcinogenic effects are characterized 
by estimating the probability that an individual will develop cancer over a lifetime of exposure from projected intakes and chemical-specific dose/response data or slope factors. Potential noncarcinogenic effects are characterized by comparing projected intakes of contaminants to reference doses (RfDs). The following discussion is a brief explanation of the significance of slope factors and REDs in the context of the screening assessment.

For carcinogens, risks are estimated as the incremental probability of an individual developing cancer over a lifetime as a result of exposure to the carcinogen (i.e., incremental or excess individual lifetime cancer risk). Cancer risk from the exposure to contamination is expressed as excess cancer risk, that is, cancer incurred in addition to normally expected rates of cancer development. An excess cancer risk of $1 \times 10^{-6}$ indicates that one person in $1,000,000$ is predicted to develop cancer from exposure to this contamination level. Excess cancer risks falling between $1 \times 10^{-4}$ and $1 \times 10^{-6}$ are within the range of concern, and cancer risks above $1 \times 10^{-4}$ are considered unacceptable by $\mathrm{EPA}^{17}$

The excess cancer risk is determined by the application of a slope factor, which is a chemical-specific value based on carcinogenic dose/response data. The slope factors and the estimated daily intake of site constituents, averaged over a lifetime of exposure, are used to estimate the incremental risk of an individual's developing cancer. Because the slope factors are the upper 95th percentile confidence limit on the probability of a carcinogenic response, the carcinogenic risk estimate represents an upper-bound estimate. The screening of the carcinogenic toxicity of contaminants is based on determining the samples in which concentrations producing a risk of $1 \times 10^{.5}$ or greater were detected.

Slope factors used in the evaluation of risk from exposure to contaminants in K-1407-C soil are listed in Tables 8 and 9. Slope factors for the radionuclides are from Health Effects Assessment Summary Tables. ${ }^{17}$ The slope factors for nonradioactive carcinogens are from the Integrated Risk Information System data base. ${ }^{18}$ Slope factors are not currently available for all potential contaminants of concern. Several contaminants are not indicated by epidemiological studies to be carcinogenic; consequently, these contaminants do not have slope factors. Furthermore, slope factors are not available for several potential contaminants of concern because their carcinogenicity has not been determined. These contaminants may contribute to carcinogenic effects from exposure to the soil, but their effect cannot be quantified. The unavailability of slope factors precludes a comprehensive screening assessment of the risk from exposure to site contaminants. The toxicity information available limits the screening of carcinogenic contaminants to the radionuclides, arsenic, beryllium, cadmium, and chromium, a definite limitation with regard to the assessinent of risk from exposure to soil at the site.

Noncarcinogenic effects are evaluated by comparing an exposure level over a 5-year period with an RfD derived for a chronic exposure. The RfDs available for the contaminants of concern in K-1407-C soil are given in Table 10. RfDs are representative of daily exposure levels that cause no deleterious effects during a lifetime. A chronic exposure duration is considered to be from 7 years to a lifetime. The use of the chronic RfDs assures that the screening is based on a conservative evaluation of adverse health effects. To evaluate the noncarcinogenic effects of exposure to soil contaminants, the dose is compared to the RfD. The noncarcinogen hazard quotient (dose/RfD) assumes that there is a level of exposure (i.e., 
Table 8. Slope factors for radionuclides detected in K-1407-C Retention Basin soil

\begin{tabular}{lccc}
\hline \multicolumn{1}{c}{ Element } & $\begin{array}{c}\text { Ingestion } \\
(\mathrm{pCi})^{-1}\end{array}$ & $\begin{array}{c}\text { Ground surface } \\
\left(\mathrm{pCl} / \mathrm{m}^{2} / \text { year }\right)^{-1}\end{array}$ & $\begin{array}{c}\text { Inhalation } \\
(\mathrm{pCl})^{-1}\end{array}$ \\
\hline Americium-241 & $3.10 \mathrm{E}-10$ & $1.60 \mathrm{E}-12$ & $4.00 \mathrm{E}-08$ \\
Cesium-137 & $2.80 \mathrm{E}-11$ & $0.00 \mathrm{E}+00$ & $1.90 \mathrm{E}-11$ \\
Cobalt-60 & $1.50 \mathrm{E}-11$ & $1.30 \mathrm{E}-10$ & $1.60 \mathrm{E}-10$ \\
Curium-244 & $2.00 \mathrm{E}-10$ & $5.80 \mathrm{E}-14$ & $2.70 \mathrm{E}-08$ \\
Europium-154 & $3.00 \mathrm{E}-12$ & $6.80 \mathrm{E}-11$ & $1.40 \mathrm{E}-10$ \\
Neptunium-237 & $2.70 \mathrm{E}-10$ & $1.80 \mathrm{E}-12$ & $3.60 \mathrm{E}-08$ \\
Plutonium-238 & $2.80 \mathrm{E}-10$ & $6.10 \mathrm{E}-14$ & $4.20 \mathrm{E}-08$ \\
Plutonium-239 & $3.10 \mathrm{E}-11$ & $2.60 \mathrm{E}-14$ & $4.10 \mathrm{E}-08$ \\
Potassium-40 & $1.10 \mathrm{E}-11$ & $7.80 \mathrm{E}-12$ & $7.60 \mathrm{E}-12$ \\
Technetium-99 & $1.30 \mathrm{E}-12$ & $3.40 \mathrm{E}-17$ & $8.30 \mathrm{E}-12$ \\
Uranium-234 & $1.40 \mathrm{E}-10$ & $5.70 \mathrm{E}-14$ & $2.70 \mathrm{E}-08$ \\
Uranium-235 & $1.30 \mathrm{E}-10$ & $9.60 \mathrm{E}-12$ & $2.50 \mathrm{E}-08$ \\
Uranium-238 & $1.30 \mathrm{E}-10$ & $4.60 \mathrm{E}-14$ & $2.40 \mathrm{E}-08$ \\
\hline
\end{tabular}

Source: Adapted from U.S. Environmental Protection Agency, Health Effects Assessment Summary Tables, OERR 9200,6-303 (90-3), U.S. Environmental Protection Agency, Washington, D. C., Juty 1990.

Table 9. Available slope factors for nonradioactive inetals detected in $\mathrm{K}-1407-\mathrm{C}$ Retention Basin soil

\begin{tabular}{lccc}
\hline \multicolumn{1}{c}{ Element } & $\begin{array}{c}\text { Ingestion } \\
(\mathrm{mg} / \mathrm{kg} / \text { day })^{-1}\end{array}$ & Ground surface & $\begin{array}{c}\text { Inhalation } \\
(\mathrm{mg} / \mathbf{k g} / \text { day })^{-1}\end{array}$ \\
\hline Arsenic & $\mathrm{ND}^{a}$ & $\mathrm{NA}^{b}$ & 50.0 \\
Beryllium & 4.3 & $\mathrm{NA}$ & 8.4 \\
Cadmium & $\mathrm{ND}$ & $\mathrm{NA}$ & 6.1 \\
\hline \multicolumn{1}{c}{${ }^{a} \mathrm{ND}=$ No daia available. } & & \\
${ }^{b} \mathrm{NA}=$ Not applicable. & \\
Source: Adapted from Integrated Risk Information System [data base], U.S. Environmental \\
Protection Agency, Environmental Criteria Assessment Office, Cincinnati, Ohio, December \\
1990.
\end{tabular}


Table 10. Available reference doses for K-1407-C Retention Basin soil contaminants

\begin{tabular}{lcc}
\hline Chemical & $\begin{array}{c}\text { Ingestion } \\
\text { reference dose } \\
\text { (mg/kg/day) }\end{array}$ & $\begin{array}{c}\text { Inhalation } \\
\text { reference dose } \\
\text { (mg/kg/day) }\end{array}$ \\
\hline Antimony & 0.0004 & $\mathrm{ND}$ \\
Arsenic & 0.0010 & $\mathrm{ND}$ \\
Barium & 0.0700 & 0.000625 \\
Beryllium & 0.0050 & $\mathrm{ND}$ \\
Boron & 0.0900 & $\mathrm{ND}$ \\
Cadmium & 0.0005 & $\mathrm{ND}$ \\
Manganese & 0.1000 & 0.001250 \\
Mercury & 0.0003 & 0.000375 \\
Nickel & 0.0200 & $\mathrm{ND}$ \\
Silver & 0.0030 & $\mathrm{ND}$ \\
Vanadium & 0.0070 & $\mathrm{ND}$ \\
Zinc & 0.2000 & $\mathrm{ND}$ \\
\hline
\end{tabular}

ND $=$ No data available.

the $\mathrm{RfD}$ ) below which it is unlikely for even sensitive populations to experience adverse health effects. If the exposure level (dose) exceeds this threshold (i.e., if dose/RfD exceeds $1)$, there may be concern for potential noncarcinogenic health effects.

RfDs are not available for some of the potential contaminants of concern. These contaminants may contribute to noncarcinogenic effects from exposure to the soil, but their effect cannot be quantified. Therefore, a comprehensive screening of the noncarcinogenic effects from exposure to soil at $\mathrm{K}-1407-\mathrm{C}$ is not possible.

\subsection{CONTAMINANT SCREENING}

The screening of $\mathrm{K}-1407-\mathrm{C}$ soil is a comparison of contaminant concentrations detected in soil to a guideline value, following the methodology outlined in the Data Analysis Approach Report for K-1407-B Holding Pond and K-1407-C Retention Basin, K/ER-23. ${ }^{7}$ The guideline value is derived from very conservative exposure scenarios (high intake rates) and chemicaland element-specific dose/response information.

The screening of the contaminants detected during the Phase 1 investigation was initiated to indicate the contaminants that may pose an imminent health hazard. Additionally, screening indicates the contaminants most likely to influence risk management decisions and cleanup goals. This prioritization of contaminants may be used to emphasize analytes in future soil samples that should be considered critical to the investigation of the site. It should be emphasized that screening is not used to eliminate any contaminants from consideration in future risk assessment. An evaluation of all contaminants detected in soil samples from the $\mathrm{K}-1407-\mathrm{C}$ Retention Basin will be included in the baseline risk assessment. Therefore, all 
contaminants detected at the site during preliminary phases of sampling must be included as analytes in subsequent phases of the investigation.

The screening of contamination at $\mathrm{K}-1407-\mathrm{C}$ is not intended to serve as a quantitative assessment of the potential adverse health effects incurred from exposure to soil at the site. The conservative exposure scenarios used in screening do not consider site-specific factors influencing the exposure to site contamination; consequently, the screening scenarios do not represent possible circumstances of exposure that may occur at the site. There are no activities currently taking place that involve the potential for exposure to soil contamination at $\mathrm{K}-1407-\mathrm{C}$.

The parameters applied to the screening of soil data from the K-1407-C Retention Basin are defined in the following discussion. A listing of the exposure pathways applied in the screening assessment is included, as well as the derivation of the contaminant concentrations in air for screening against inhalation guideline values. This is followed by a discussion of the duration of exposure and intake rates employed in the calculation of guideline values for the radioactive and the nonradioactive contaminants. Last, the guideline values are listed for radionuclides and nonradionuclides, and the screening results are presented.

\subsubsection{Exposure Pathways}

Screening is conducted for all exposure pathways for which exposure at the site is feasible in order to indicate the pathways that present the greatest potintial for the incidence of adverse health effects. Because the conditions of exposure and the slope factor and/or RfD vary with the nature of intake (ingestion, inhalation, dermal contact, and/or external exposure to radiation), the guideline value is different for each exposure pathway. The screening of radionuclides entails a comparison of contaminant concentrations against ingestion, inhalation, and external guidelines values. The screening of nonradioactive contaminants is conducted against ingestion and inhalation guideline values.

Screening against ingestion and external guidelines is straightforward; contaminant concentrations detected in each soil sample (Appendix B) are compared with the guideline values. However, because contaminant concentrations in air have not been measured, the concentrations applied in the inhalation screening must be calculated from soil concentrations. The following is an explanation of the derivation of air concentrations based on measured soil concentrations.

Inhalation exposure to soil contaminants is evaluated by considering the suspension of site soil by wind. The fugitive dust generated is estimated by the method described by Eckerman and Young. ${ }^{19}$ The contamination in the air generated by the wind is determined by applying an empirically derived resuspension factor for windborne contamination of $2 \times 10^{-7} / \mathrm{m}$ to the contaminant levels in surface soil. ${ }^{20}$ The resuspension factor is the ratio of the concentration in air $\left(\mathrm{m}^{3}\right)$ to the concentration on the surface $\left(\mathrm{m}^{2}\right)$.

For calculating the exposure concentrations in air due to dust, the contaminant levels in the soil must be converted from picocuries per gram for radionuclides or milligrams per kilogram for metals to picocuries per cubic meter or milligrams per cubic meter for use in this equation. The density of soil reported in the Blount County Soil Survey (series No. 7, 1953), $1.6 \times 10^{6} \mathrm{~g} / \mathrm{m}^{3}$, is applied to convert the representative surface soil concentrations. ${ }^{21}$ For 
example, the following calculation employs units of radioactive contamination to determine the amount of contaminant in a cubic meter of soil:

$$
1.6 \times 10^{6} \mathrm{~g} / \mathrm{m}^{3} \times \text { concentration }(\mathrm{pCi} / \mathrm{g} \text { soil })=\mathrm{pCi} \text { contaminant } / \mathrm{m}^{3} \text {. }
$$

It is assumed that only a thin veneer of soil actually releases dust due to wind; therefore, only the amount of contaminants in the surface layer should be used to determine concentrations in air. The concentration of the contaminant at the surface is represented by assuming the depth of the soil surface layer to be $1 \mathrm{~cm}$. Therefore, the contaminant "density" (the amount of contaminant per cubic meter) is multiplied by $0.01 \mathrm{~m}$ to estimate the surface soil contaminant level (milligrams per square meter):

$$
\mathrm{pCi} \text { contaminant } / \mathrm{m}^{3} \times 0.01 \mathrm{~m}=\text { concentration in surface layer of soil }\left(\mathrm{pCi} / \mathrm{m}^{2}\right) \text {. }
$$

The concentration of the contaminant in a square meter of the soil surface is converted to a concentration in air by the applicatinn of the resuspension factor. Resuspension factors are determined empirically and represent the amount of surface material (milligrams per square meter) that becomes airborne (milligrams per cubic meter) due to specific activities. The resuspension factor reported in Ref. 20 due to wind ranges from $3 \times 10^{-1}$ to $9 \times 10^{-11} / \mathrm{m}$. A value of $2 \times 10^{-7} / \mathrm{m}$ is applied in the inhalation screening of contaminants. With the quantity of surface material suspended due to wind and the estimated amount of contaminant per surface area of soil determined in the calculations above, the contaminant's concentration in air is determined:

$$
\left(2 \times 10^{-7} / \mathrm{m}\right) \times \text { surface concentration }\left(\mathrm{pCi} / \mathrm{m}^{2}\right)=\text { concentration in air }\left(\mathrm{pCi} / \mathrm{m}^{3}\right) \text {. }
$$

This concentration is compared to screening values based on contaminant inhalation toxicity.

\subsubsection{Radionuclide Screening}

Radionuclides are classified by EPA as human carcinogens based on epidemiological studies of ionizing-radiation-inducied cancers in humans. The evaluation of radioactive carcinogens considers exposure via ingestion, inhalation, and external exposure pathways. The external exposure pathway is a critical pathway for radiation exposure; however, for the screening of nonradioactive carcinogenicity, dermal exposure is ineffective relative to screening based on oral and inhalation exposure.

The calculation of guideline values follows the methodology outlined in the Data Analysis Approach Report for K-1407-B Holding Pond and K-1407-C Retention Basin, K/ER-23. ${ }^{7}$ For screening carcinogenic toxicity, the exposure model assumes a lifetime duration of exposure. The exposure model employs the body weight of a 70-kg adult, an ingestion rate of $0.001 \mathrm{~kg}$ of soil a day, and an inhalation rate of $20 \mathrm{~m}^{3} /$ day (Ref. 1). Guideline values used in the screening of radionuclide concentrations are listed in Table 11.

The results of the screening for carcinogenic toxicity of the radionuclides are displayed in Table 12. The results are presented as a ratio of samples in which concentrations equal to or greater than the guideline value were detected to the total number of samples analyzed for the contaminant. The ratios for each exposure pathway are presented by analyte and sample depth. 
The screening of radionuclide concentrations against ingestion guideline values indicates that the potential risk will be dominated by the effects of exposure to ${ }^{234} U$ and ${ }^{238} U$. The frequency of samples exceeding guideline values decreases with depth. However, there are still a considerable number of 18-in. samples in which concentrations exceed guidelines. Specifically, ${ }^{234} \mathrm{U}$ was detected at or above the ingestion guideline in 23 of 70 samples taken at the 18-in. depth.

Table 11. Guideline values for radionuclide screening

\begin{tabular}{|c|c|c|c|}
\hline Radionuclide & $\begin{array}{l}\text { Soil ingestion } \\
(\mathrm{pCi} / \mathrm{g})\end{array}$ & $\begin{array}{c}\text { External } \\
(\mathrm{pCi} / \mathrm{g})\end{array}$ & $\begin{array}{c}\text { Inhalation } \\
(\mathrm{pCi} / \mathrm{g})\end{array}$ \\
\hline Americium-241 & 11.90 & 0.63 & 0.00048 \\
\hline Cesium-137 & 131.58 & $\mathrm{NA}^{\mathrm{a}}$ & 1.04167 \\
\hline Cobalt-60 & 243.90 & 0.01 & 0.12346 \\
\hline Curium-244 & 18.52 & 16.95 & 0.00071 \\
\hline Europium-154 & 1234.57 & 0.01 & 0.13889 \\
\hline Neptunium-237 & 13.70 & 0.56 & 0.00056 \\
\hline Plutonium-238 & 13.16 & 16.95 & 0.00048 \\
\hline Plutonium-239 & 119.05 & 38.46 & 0.00038 \\
\hline Potassium-40 & 333.33 & 0.13 & 2.50000 \\
\hline Technetium-99 & 2857.14 & 29411.76 & 2.38095 \\
\hline Uranium-234 & 26.32 & 17.86 & 0.00071 \\
\hline Uranium-235 & 28.57 & 0.10 & 0.00077 \\
\hline Uranium-238 & 28.57 & 22.22 & 0.00083 \\
\hline
\end{tabular}

${ }^{\bullet}$ Not applicable.

Table 12 Frequency of radioactive soil samples croeeding carcinogenic toxicity guideline values

\begin{tabular}{lccc}
\hline \multirow{4}{*}{ Analyte } & $\begin{array}{c}\text { 6-in. } \\
\text { saniples }\end{array}$ & $\begin{array}{c}12 \text {-in. } \\
\text { samples }^{a}\end{array}$ & $\begin{array}{c}18 \text {-in. } \\
\text { samples }^{a}\end{array}$ \\
\hline \multicolumn{4}{c}{ Oral exposure } \\
Americium-241 & $5 / 78$ & $1 / 43$ & $0 / 40$ \\
Cesium-137 & $1 / 78$ & $0 / 61$ & $0 / 58$ \\
Neptunium-237 & $12 / 78$ & $1 / 43$ & $0 / 40$ \\
Plutonium-238 & $3 / 78$ & $0 / 43$ & $0 / 40$ \\
Plutonium-239 & $2 / 78$ & $0 / 43$ & $0 / 40$ \\
Technetium-99 & $4 / 78$ & $0 / 73$ & $0 / 70$ \\
Uranium-234 & $57 / 78$ & $37 / 74$ & $23 / 70$ \\
Uranium-235 & $7 / 78$ & $4 / 74$ & $1 / 70$ \\
Uranium-238 & $46 / 78$ & $27 / 74$ & $12 / 70$
\end{tabular}


Table 12 (continued)

\begin{tabular}{|c|c|c|c|}
\hline Analyte & $\begin{array}{c}\text { 6-in. } \\
\text { samples }\end{array}$ & $\begin{array}{l}\text { 12-in. } \\
\text { samples }\end{array}$ & $\begin{array}{l}\text { 18-in. } \\
\text { samples }\end{array}$ \\
\hline \multicolumn{4}{|c|}{ External exposure } \\
\hline $\begin{array}{l}\text { Americium-241 } \\
\text { Cobalt-60 } \\
\text { Europium-154 } \\
\text { Neptunium-237 } \\
\text { Plutonium-239 } \\
\text { Potassium-40 } \\
\text { Uranium-234 } \\
\text { Uranium-235 } \\
\text { Uranium-238 }\end{array}$ & $\begin{array}{c}38 / 78 \\
53 / 75 \\
1 / 1 \\
54 / 78 \\
8 / 78 \\
76 / 76 \\
61 / 78 \\
75 / 78 \\
48 / 78\end{array}$ & $\begin{array}{c}16 / 43 \\
1 / 1 \\
0 / 0 \\
20 / 43 \\
2 / 43 \\
61 / 61 \\
40 / 74 \\
70 / 74 \\
32 / 74\end{array}$ & $\begin{array}{c}7 / 40 \\
0 / 0 \\
0 / 0 \\
12 / 40 \\
1 / 40 \\
58 / 58 \\
31 / 70 \\
59 / 70 \\
15 / 70\end{array}$ \\
\hline \multicolumn{4}{|c|}{ Inhalation exposure } \\
\hline $\begin{array}{l}\text { Americium-241 } \\
\text { Neptunium-237 } \\
\text { Plutonium-238 } \\
\text { Plutonium-239 } \\
\text { Technetium-99 } \\
\text { Uranium-234 } \\
\text { Uranium-235 } \\
\text { Uranium-238 }\end{array}$ & $\begin{array}{l}53 / 78 \\
63 / 78 \\
30 / 78 \\
69 / 78 \\
11 / 78 \\
78 / 78 \\
73 / 78 \\
78 / 78\end{array}$ & $\begin{array}{c}28 / 43 \\
27 / 43 \\
11 / 43 \\
34 / 43 \\
5 / 73 \\
74 / 74 \\
58 / 74 \\
73 / 74\end{array}$ & $\begin{array}{c}22 / 40 \\
19 / 40 \\
5 / 40 \\
28 / 40 \\
4 / 70 \\
70 / 70 \\
53 / 70 \\
70 / 70\end{array}$ \\
\hline
\end{tabular}

aSamples $\geq$ guideline values/total samples analyzed.

In screening based on the external exposure, a majority of the 6-in. samples for all contaminants except ${ }^{239} \mathrm{Pu}$ were equal to or greater than the guideline value. The number of samples exceeding the guideline value decreases with sample depth except in the case of ${ }^{40} \mathrm{~K}$, which exceeds the guidelines in all samples. All analytes were detected at or above the guidelines in at least one 18-in. sample. The potential risk from external exposure to contamination in the 18-in. soil samples will be dominated by the effects incurred from the exposure to ${ }^{40} \mathrm{~K},{ }^{234} \mathrm{U}$, and ${ }^{235} \mathrm{U}$.

Inhalation screening results indicate that all analytes will contribute to the potential cancer risk from exposure to wind-generated dust. While the number of samples exceeding guideline values decreases with depth, a majority of the analytes are present at or above the guideline value in the 18 -in. samples.

The screening of radionuclides suggests that the extent of contamination in the K-1407-C Retention Basin soil has not been sufficiently delineated to support a comprehensive assessment of the risk from exposure to site soil. Soil samples were terminated at a depth of 18 in.; therefore, the risk incurred from exposure to soil below the 18-in. depth cannot be quantified. Based on the detection of radionuclide concentrations equal to or greater than the guideline values in 18-in. samples, it is presumed that concentrations greater than the guideline value may be present in soil below this depth. Consequently, radionuclide 
concentrations in the soil below the 18-in. depth may contribute to the risk incurred from exposure to site soil. Therefore, the screening of radionuclide contamination indicates the need for additional sampling to determine the extent and concentration of the radioactive isotopes below the 18-in. depth.

\subsubsection{Metal Screening}

In the screening of nonradioactive carcinogenicity, oral and inhalation exposures are considered. Contaminant concentrations are not screened against dermal exposure guideline values because the screening of nonradioactive carcinogenicity based on dermal exposure is considered ineffective relative to screening based on oral and inhalation exposure. In addition, dermal exposure at the site is not likely to occur.

For screening carcinogenic toxicity, the exposure model assumes a lifetime duration of exposure. The exposure model for carcinogens employs the body weight of a 70-kg adult, an ingestion rate of $0.0001 \mathrm{~kg}$ of soil per day, and an inhalation rate of $20 \mathrm{~m}^{3} /$ day (Ref. 1). The screening for systemic toxicity employs an exposure duration of 5 years. The exposure model for systemic toxicants employs a body weight of a 16-kg child, an ingestion rate of $0.0002 \mathrm{~kg}$ of soil a day, and an inhalation rate of $20 \mathrm{~m}^{3} /$ day (Ref. 1). Guideline values used in the screening of nonradioactive metal concentrations are listed in Table 13.

Table 13. Guideline values for nonradioactive metals

\begin{tabular}{ccc}
\hline Element & $\begin{array}{c}\text { Ingestion } \\
(\mathrm{mg} / \mathrm{kg})\end{array}$ & $\begin{array}{c}\text { Inhalation } \\
(\mathrm{mg} / \mathrm{kg})\end{array}$ \\
\hline
\end{tabular}

Carcinogenic guideline values

$\begin{array}{lcc}\text { Arsenic } & \mathrm{NA}^{a} & 0.0000007 \\ \text { Beryllium } & 1.62791 & 0.0000042 \\ \text { Cadmium } & \text { NA } & 0.0000057\end{array}$

Systemic toxicity guideline values

\begin{tabular}{lrl} 
Antimony & 32 & NA \\
Arsenic & 80 & NA \\
Barium & 5600 & 0.0005 \\
Beryllium & 400 & NA \\
Boron & 7200 & NA \\
Cadmium & 40 & NA \\
Manganese & 8000 & 0.0010 \\
Mercury & 24 & 0.0003 \\
Nickel & 1600 & NA \\
Silver & 240 & NA \\
Vanadium & 560 & NA \\
Zinc & 16000 & NA \\
\hline \multicolumn{2}{c}{${ }^{a}$ NA $=$ Not applicable. }
\end{tabular}


The results of the screening for the carcinogenicity and systemic toxicity of the nonradioactive contaminants are included in Table 14. The most significant result is the presence of the carcinogens arsenic, beryllium, and cadmium at levels at or above the inhalation guidelines in all samples. The results of the inhalation screening of the systemic toxicants barium, manganese, and mercury indicate that all samples contain concentrations at or above the guidelines. In addition, mercury is above the guideline value in a single sample at the 18-in. depth. Because the guidelines for metals are exceeded in 18-in. soil samples and because the soil below $18 \mathrm{in}$. has not been characterized, a thorough assessment of the health hazards based on the Phase 1 investigation of the K-1407-C Retention Basin is not possible.

Table 14. Frequency of nonradioactive soil analytes exceeding guideline values

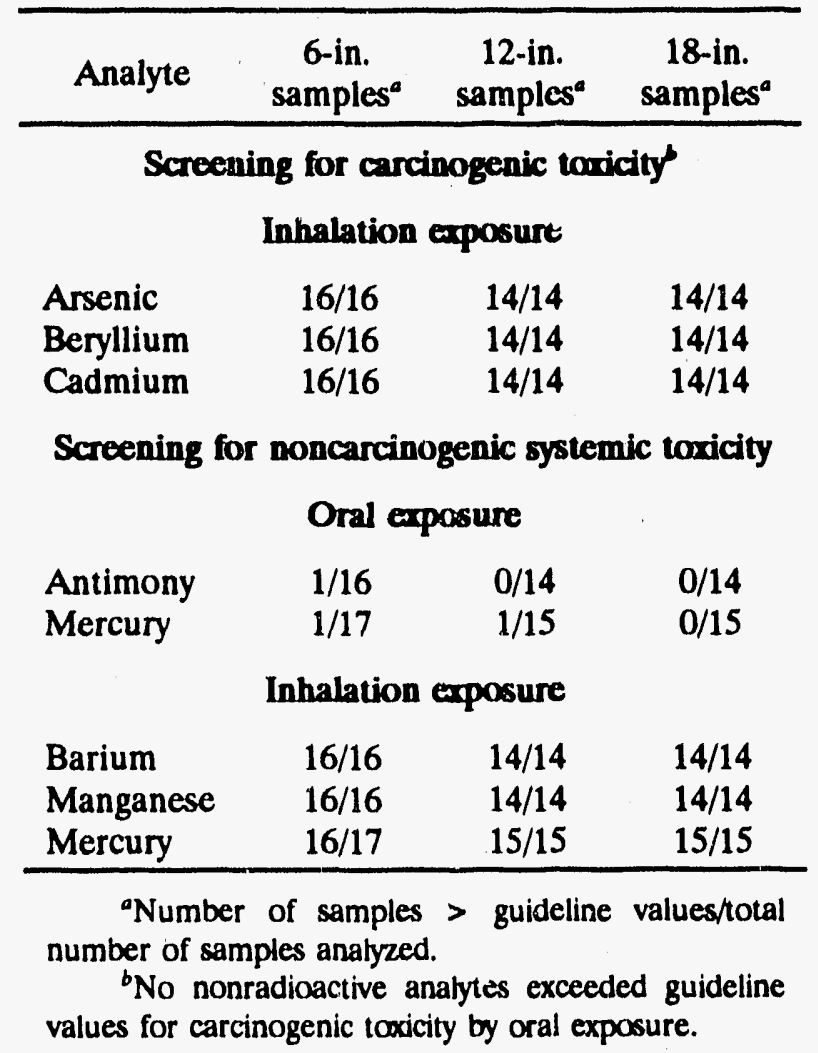

\subsection{DATA LIMITATIONS}

The lack of background samples and samples below $18 \mathrm{in}$. limits the ability of the investigation to comprehensively address the data needs of a Remedial Investigation Report/Baseline Risk Assessment. Additionally, the analytical data for radionuclides for the samples taken are incomplete. At the time this screening evaluation was undertaken, some of the 6- and 12-in. soil samples had not been analyzed for ${ }^{241} \mathrm{Am},{ }^{137} \mathrm{Cs},{ }^{60} \mathrm{Co},{ }^{237} \mathrm{~Np},{ }^{238} \mathrm{Pu}$, ${ }^{239} \mathrm{Pu}$, and $/$ or ${ }^{40} \mathrm{~K}$. 
Because no background samples are available, statistical differentiation between metal concentrations resulting from site activities and naturally occurring concentrations cannot be established. Therefore, because of the inability to discern between site-related and naturally occurring metal concentrations, all are considered as potentially related to the site.

Several limitations were found during the $\mathrm{QA} / \mathrm{QC}$ review of the data. Although there are no established holding times for radiochemical analyses, some holding times have approached or exceeded 1 year. Data were not available for each individual radiochemical analyte for all samples. In addition, there is some uncertainty about the accuracy of radionuclide data because there are no matrix spike data. The low level of confidence in the data resulting from the lack of matrix spike information will greatly increase the uncertainty of an assessment of risk determined from the exposure to radionuclides in the K-1407-C Retention Basin soil.

The health-based screening of contaminants detected in soil at the K-1407-C Retention Basin indicates that samples taken from the 12- to 18-in. interval contain contaminant concentrations exceeding guideline values. The results of the screening suggest that soil below 18 in. may contain contamination above guideline values and could feasibly contribute to risk from exposure to site soil. However, because soil sampling was terminated at a depth of 18 in., the extent of contamination below this depth cannot be determined. Therefore, a thorough assessment of risk from exposure to soil at the site cannot be conducted.

Dose/response information for many of the metals is not available, limiting the screening assessment for adverse health effects. Additionally, slope factors and RfDs are not available for all exposure pathways for all metals; health risks posed by exposure to contaminants without these values cannot be comprehensively quantified. A major limitation to the comprehensive quantification of risk from exposure to contamination at $\mathrm{K}-1407-\mathrm{C}$ is the lack of chemical-specific slope factors and RfDs for all exposure pathways and contaminants. Therefore, the total risk resulting from the exposure to contaminants at the site cannot be determined.

The evaluation of environmental pathways at the K-1407-C Retention Basin is restricted to the consideration of soil contamination. The K-1407-C environmental pathway evaluation is not complete until the human-health consequences of the potential transport of contamination via groundwater are considered. The evaluation of groundwater environmental and exposure pathways will be included in the Area 1 investigation. 


\section{STATISTICAL EVALUATION OF DATA}

This chapter discusses the stutistical evaluation of the analytical data produced from the latest soil sampling effort at the K-1407-C Retention Basin. Data are presented graphically and statistically analyzed. Section 6.1 is a statistical summary of the analytical data, and Sect. 6.2 describes the methodology and implications of two graphical studies.

\subsection{DATA SUMMARY}

The statistical data analysis began by exploring the available soil data for obvious errors, such as incorrect units, analytical procedures used, missing data, duplicated data, co-located samples with no corresponding regular soil sample, misspellings, etc. A complete list of these data observations was documented and given to the Remedial Action Program data base manager.

Approximately $21 \%$ of the available data were from biased samples. Biased samples are those taken where the field sampler measured high readings of radioactivity while scanning the surface of the soil. While these biased sample results are valid for use in probability kriging and contour plots, they were excluded in estimating the mean concentration of an analyte across the site or by depth. Including these samples could result in a positive bias in the estimation of the mean and variance. That is, including these biased samples would increase the mean and variance.

In order to estimate the mean and variance of the concentrations of each analyte across the site, the nondetected results had to be estimated. A nondetected result is a detection limit given by the laboratory with a " $<$ " qualifier. The sample was analyzed for the particular analyte, but the analyte was not detected at the detection limit. Therefore, the true quantity $x$ in the sample could be any value $0 \leq x<D$, where $D$ is the reported detection limit.

The distributions of the unbiased detected results of those analytes that had at least one nondetected result were examined. Histograms and plots of the data by analyte revealed that the lognormal distribution should be an adequate model to fit the detected results. All of these analytes exhibited a distribution heavily skewed to the right. A distribution is skewed to the right when there are many low concentrations and few very high concentrations. These few high concentrations cause the mean of the distribution to be greater than the median. The median of the distribution is that value for which half of the data are below and half are above. Although the shapes of the distributions were unique for each analyte, the versatile shape of the lognormal distribution should fit the data well. Details concerning the lognormal distribution and the procedure for estimating means and variances for the different populations of results are included in Appendix C.

Before the nondetected results could be estimated, one issue had to be resolved. A small sampling campaign was initiated immediately after the first sampling period to collect samples for mercury analysis. The sample locations were those that had samples analyzed for the 
metals analyses. Samples from one of the boreholes (13B) inadvertently were also submitted for the ICP metals analyses. This gave two sets of metals results for this borehole. Two other boreholes (09F and 07D) have two sets of mercury results. These data were then averaged to yield one result per analyte, sampling location, and depth.

Once the data were reduced to one result per analyte, sampling location, and sample depth, the remaining nondetected results were estimated using the lognormal distributions fit for each analyte. These estimates along with the detected results were then used in estimating the mean concentration of each analyte both across the site and by sample depth.

\subsubsection{Summary by Analyte}

Summary statistics on all of the soil data by analyte are given in Table 15 . The analytes are grouped into metals, mercury, and radiochemical analyses and are listed alphabetically within each type of analysis. Summary information includes the total number of results, the number of biased results, the number of detection limits, the smallest and largest detection limits, the smallest and largest detected results, the estimated mean of the unbiased results as described earlier, the associated units, and the analytical procedure used in the analysis. When one compares the largest detected results of each analyte to the health-based guideline values, it can be seen that the radionuclides ${ }^{241} \mathrm{Am},{ }^{137} \mathrm{Cs},{ }^{237} \mathrm{~Np},{ }^{238} \mathrm{Pu},{ }^{239} \mathrm{Pu},{ }^{99} \mathrm{Tc},{ }^{234} \mathrm{U},{ }^{235} \mathrm{U}$, and ${ }^{238} \mathrm{U}$ all have at least one sample result that exceeds its associated guideline value. In fact, ${ }^{234} U$ and ${ }^{238} U$ each have an estimated average concentration that exceeds the guideline value. Therefore, many uranium results must exceed this guideline value. While the average concentration for ${ }^{238} \mathrm{U}$ only slightly exceeded its guideline value of $28.5 \mathrm{pCi} / \mathrm{g}$, the average concentration for ${ }^{234} \mathrm{U}$ is almost three times its guideline value of $26.5 \mathrm{pCi} / \mathrm{g}$.

\subsubsection{Summary by Analyte and Sample Depth}

A similar summary of the data by analyte and sample depth is given in Table 16. As in Table 15, the analytes are grouped into metals, mercury, and radiochemical analyses and are listed alphabetically within each type of analysis. Then, within each analyte, the data are summarized by sample depth at the 6-, 12-, and 18-in. depths. The number of results, number of biased results, number of detection limits, smallest and largest detection limits, smallest and largest detected results, estimated mean of the unbiased results, and the associated units are given for each depth. As one compares the mean concentrations at each depth, the general trend is that the highest concentrations are at the 6-in. depth, the next highest at the 12-in. depth, and the lowest at the 18-in. depth. While the concentration decreases with depth, the 18-in. samples still contain contamination for some analytes. In fact, all nine of the radionuclides mentioned before as having exceeded guideline values $\left({ }^{241} \mathrm{Am},{ }^{137} \mathrm{Cs},{ }^{237} \mathrm{~Np}\right.$, ${ }^{238} \mathrm{Pu},{ }^{239} \mathrm{Pu},{ }^{99} \mathrm{Tc},{ }^{234} \mathrm{U},{ }^{235} \mathrm{U}$, and ${ }^{238} \mathrm{U}$ ) exceed their associated guideline values at the 6-in. depth. In addition, ${ }^{237} \mathrm{~Np}$ also exceeds its guideline value of $13.7 \mathrm{pCi} / \mathrm{g}$ at the 12 -in. depth, while ${ }^{234} \mathrm{U},{ }^{255} \mathrm{U}$, and ${ }^{238} \mathrm{U}$ exceed their guideline values at the 12 - and 18 -in. depths as well. For ${ }^{254} \mathrm{U}$ and ${ }^{25} \mathrm{U}$, the largest detected result at the 18 -in. level exceeds the guideline value by more than one order of magnitude.

\subsubsection{Significant Differences Between Sample Depths}

In order to determine whether the concentrations at the 6-, 12-, and 18-in. depths are statistically different, a Kruskal-Wallis Test was utilized. This test was chosen for several 
61

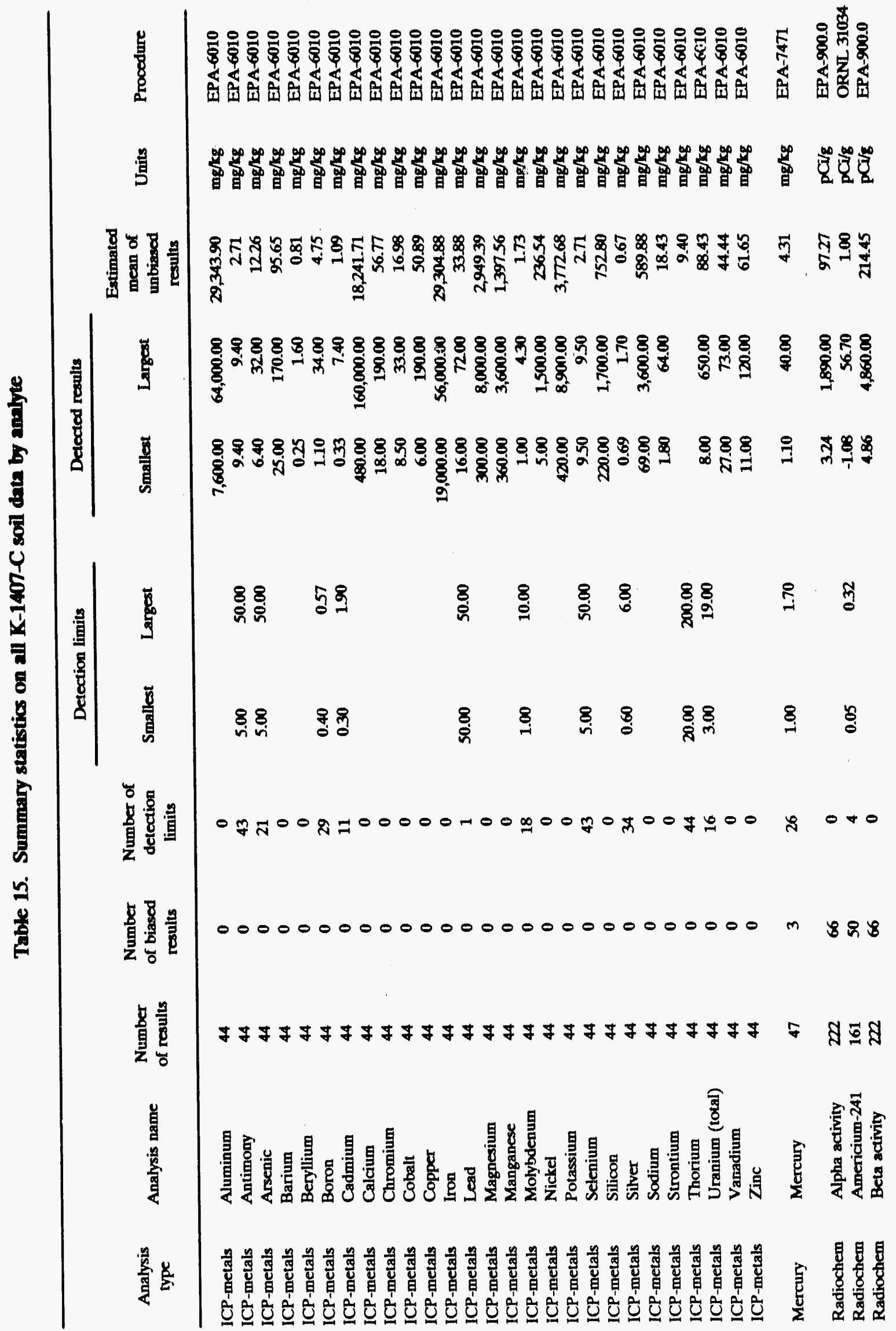




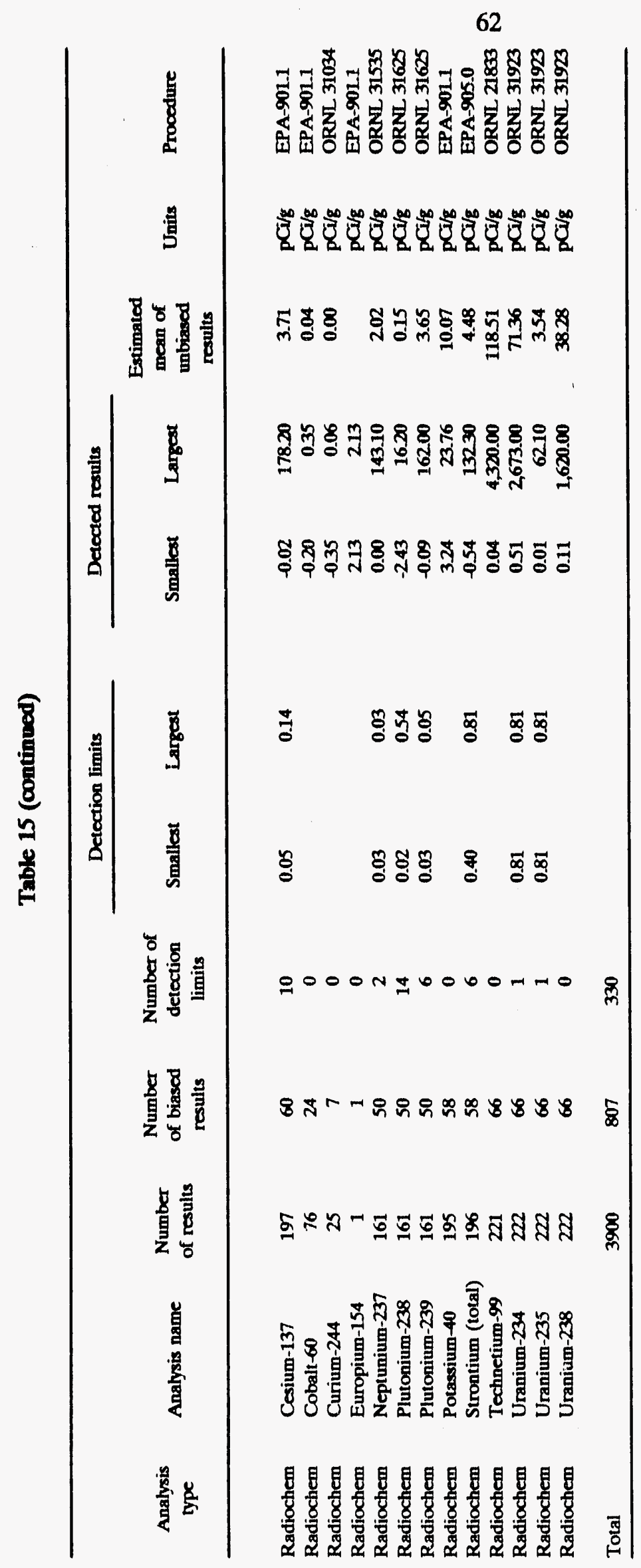


63

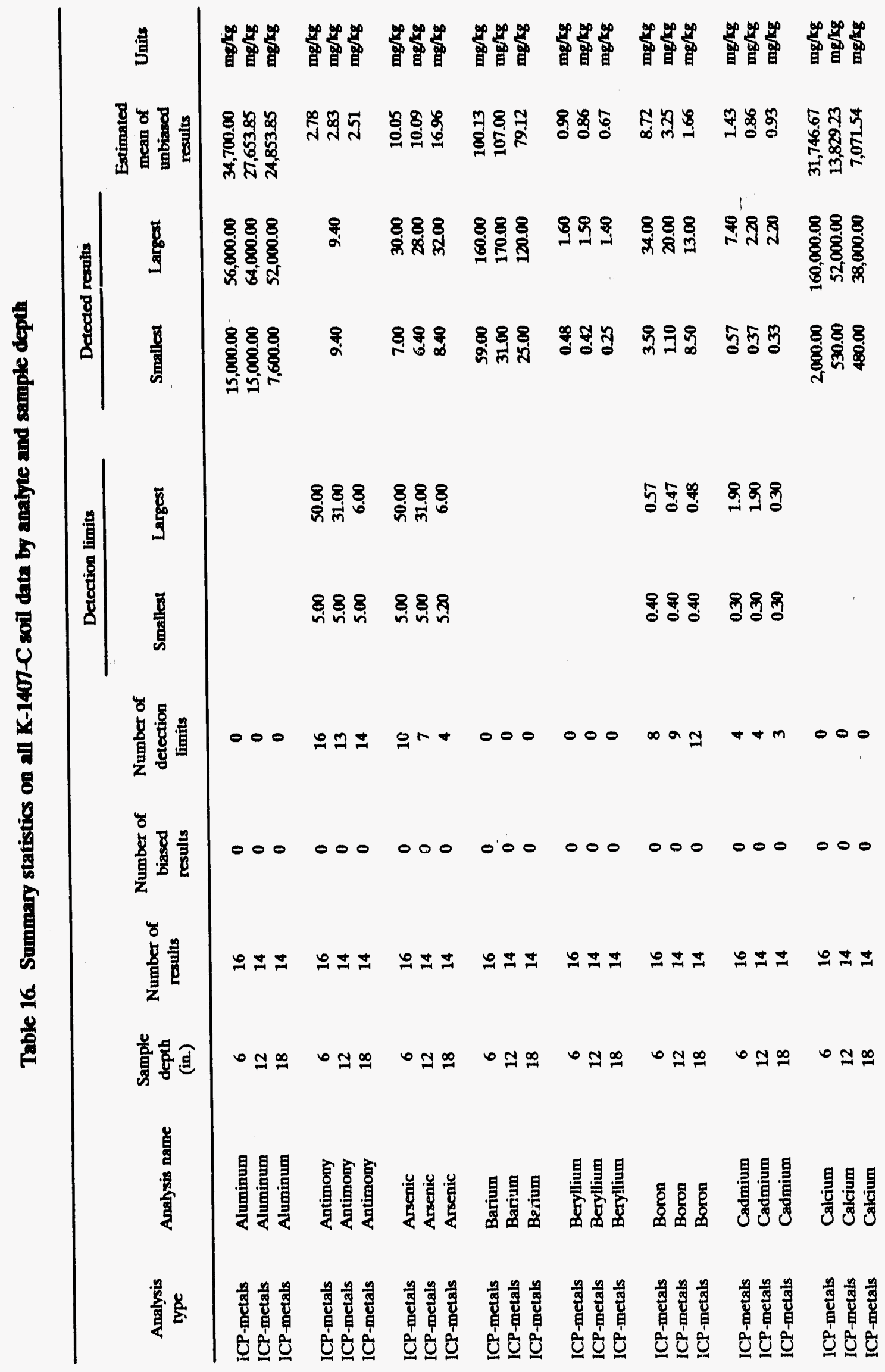




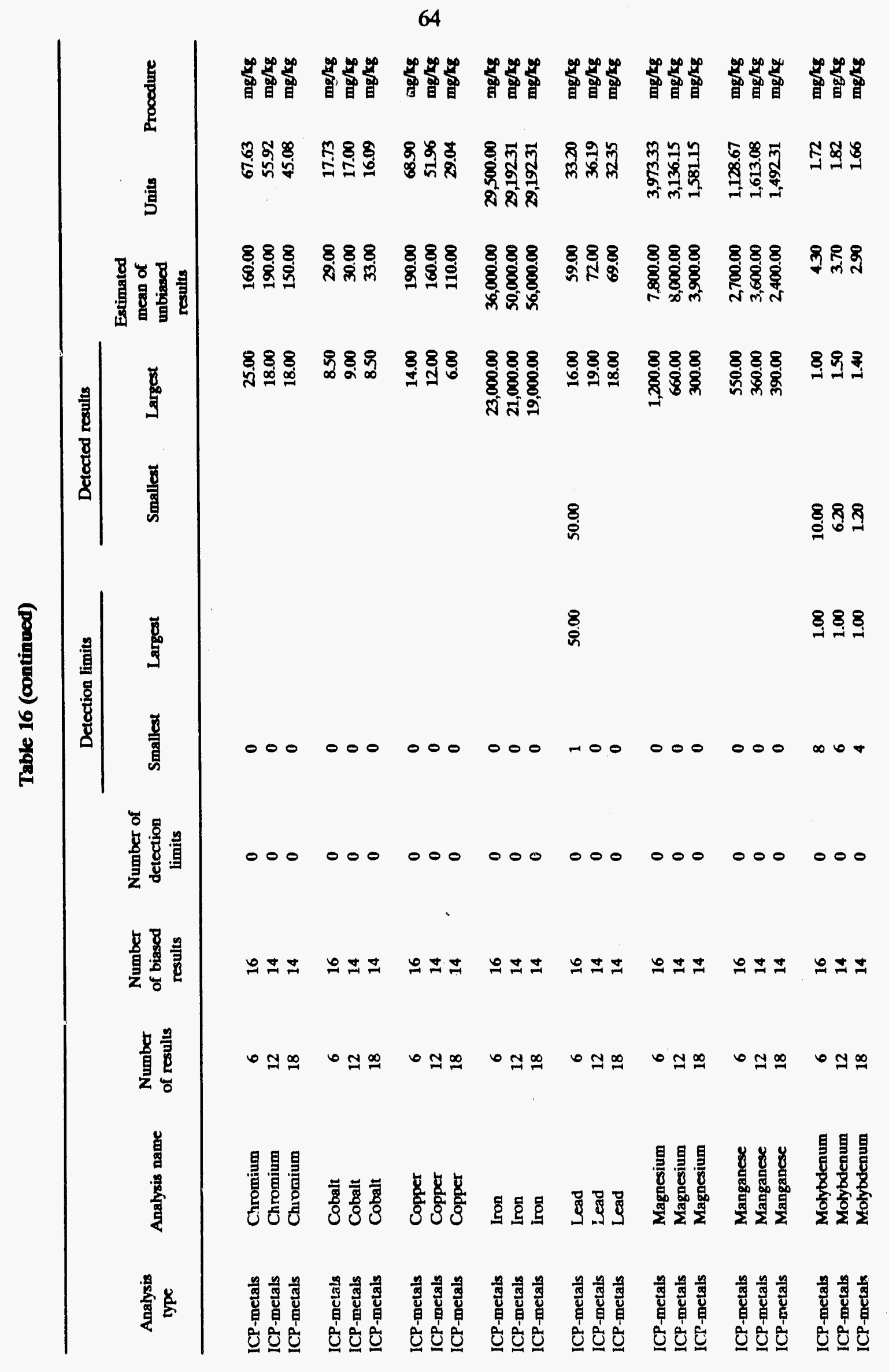




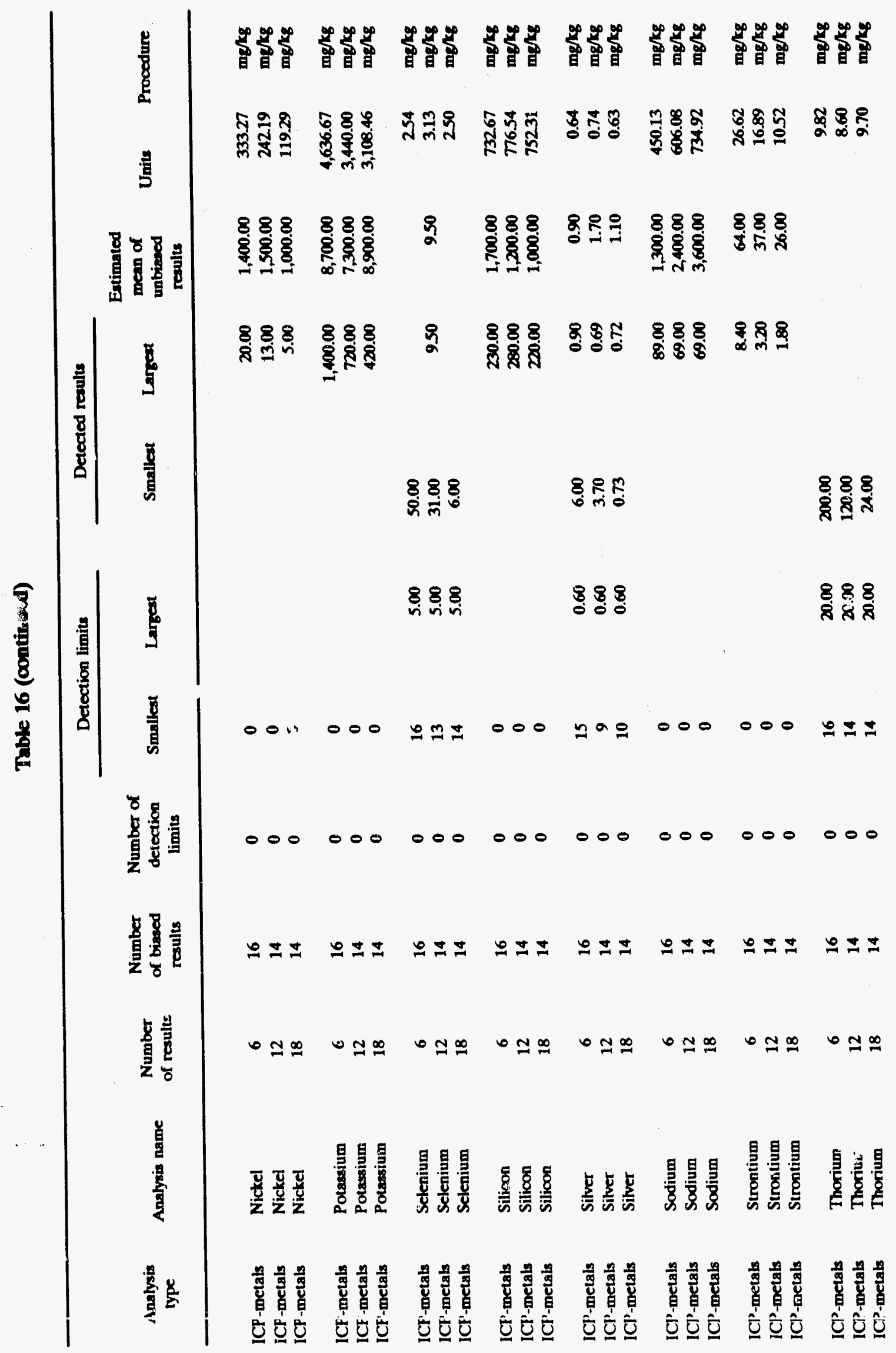




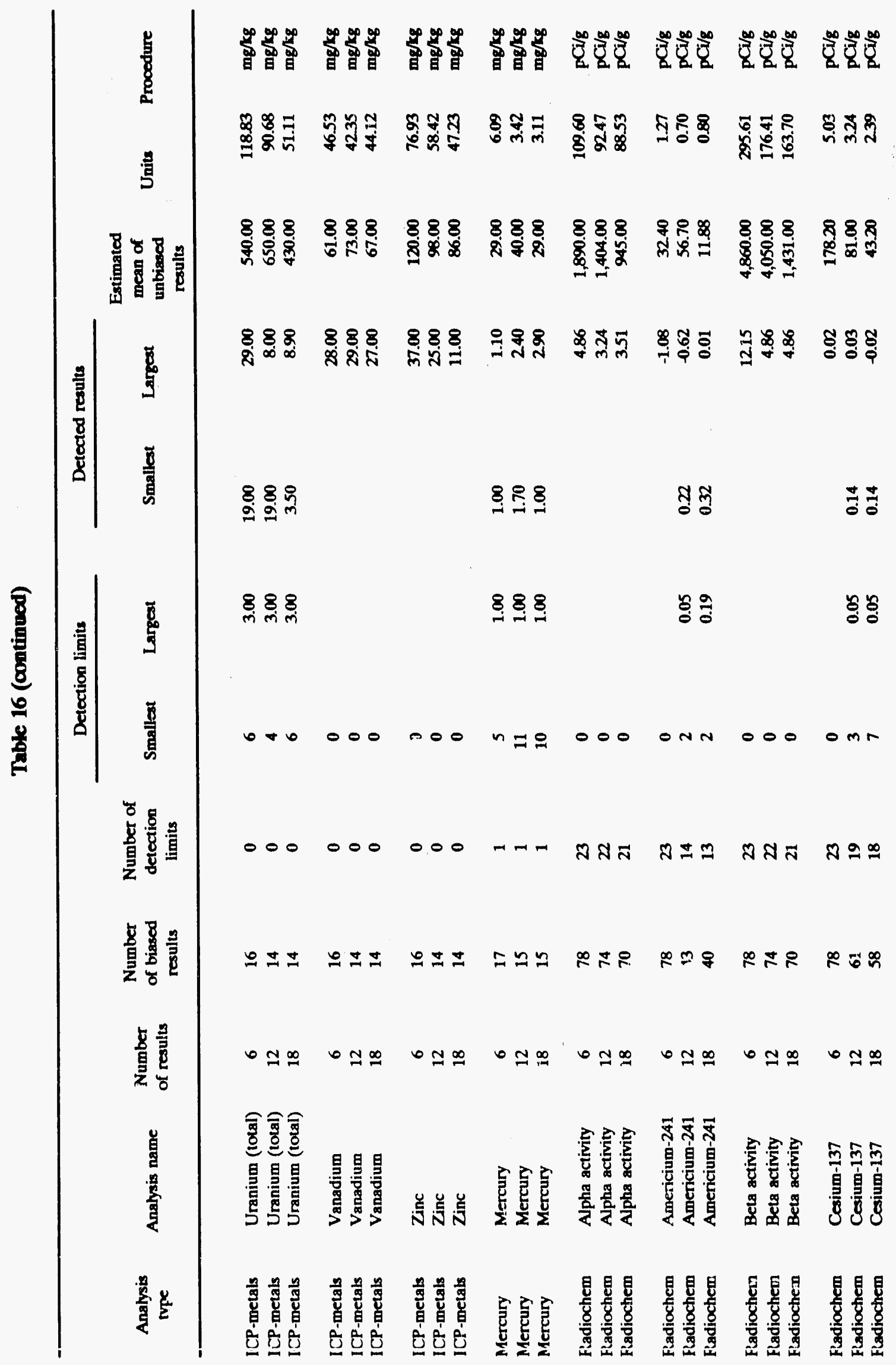




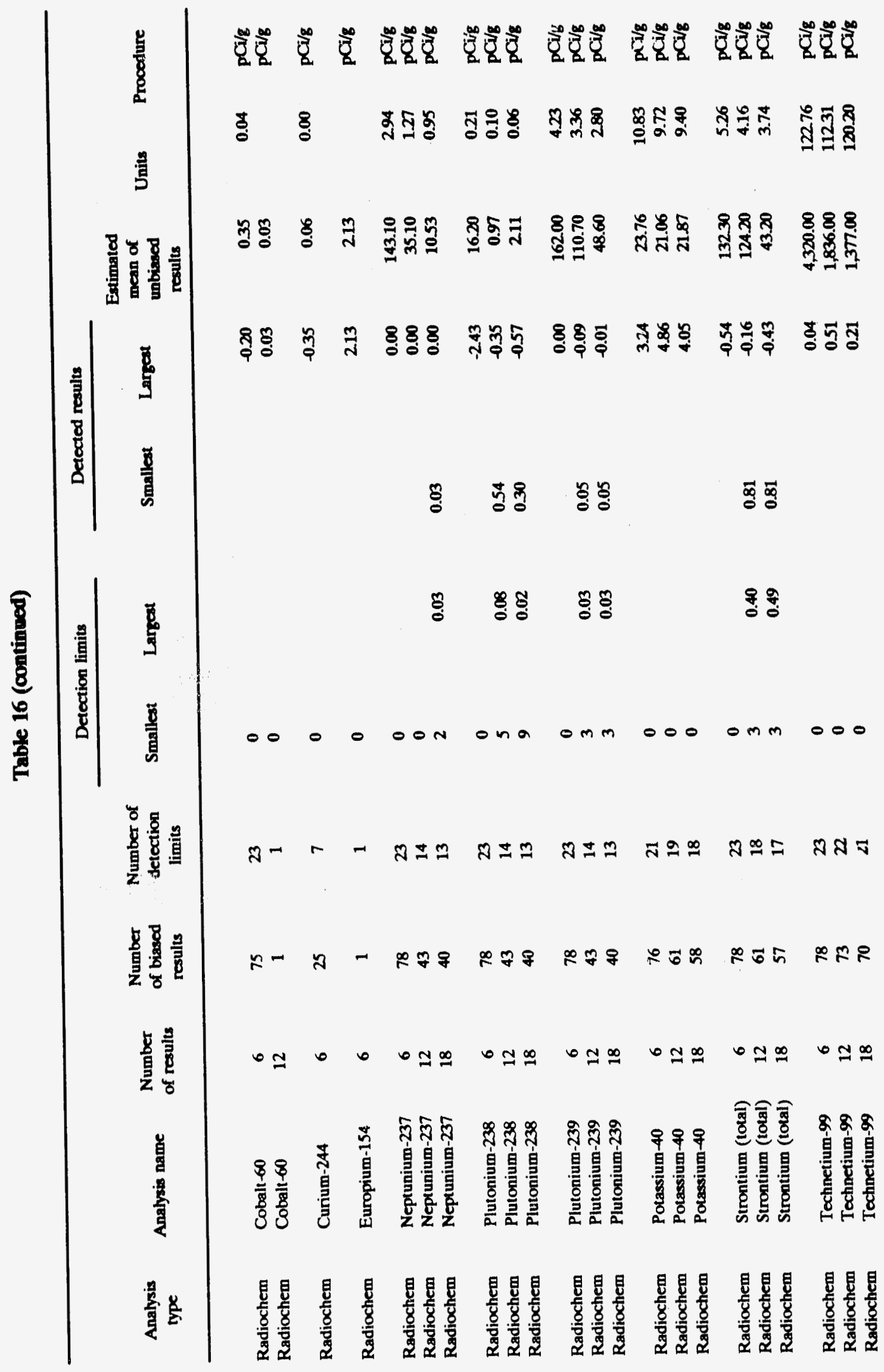




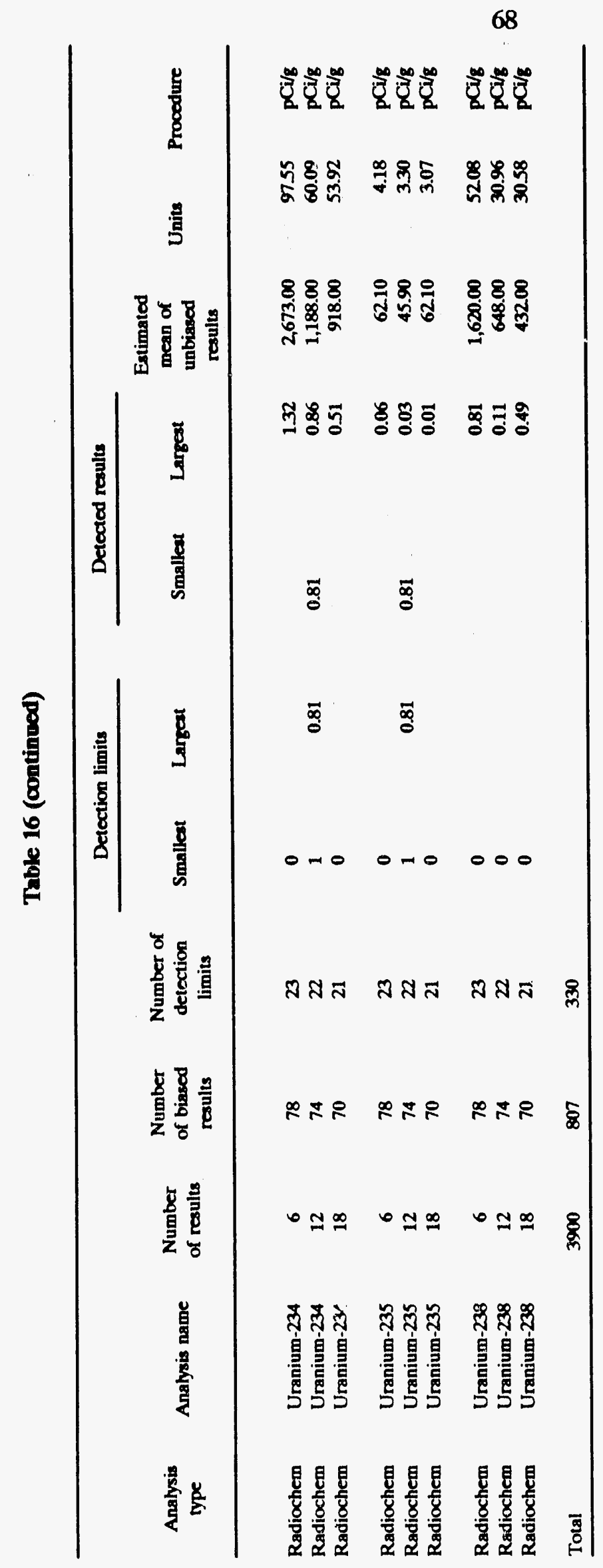


reasons. Because the data for each analyte are heavily skewed, not normally distributed, and have unequal variances, a standard analysis of variance could not be used. Instead, the nonparametric Kruskal-Wallis was more appropriate since it does not assume a particular underlying distribution when testing for equal means across several groups. Instead, it assumes that the shape of the distributions for each group is identical. This assumption is reasonable for the soil data since all analytes are heavily skewed to the right and resemble a lognormal shape.

Since Kruskal-Wallis is a nonparametric test, it ranks the data from lowest to highest and calculates a test statistic on the ranks instead of the actual results. This method was used to test the hypotheses:

$\mathrm{H}_{0}$ : The means at each sample depth are equal for a given analyte.

$\mathrm{H}_{1}$ : At least one mean is statistically different from the other two.

The results of the Kruskal-Wallis Test are given in Table 17. The analytes are grouped into metals, mercury, and radiochemical analyses and are listed alphabetically within each type of analysis. For each analyte the estimated mean concentrations at the 6-, 12-, and 18-in. depths are given, as are the units, the probability that the means at all depths are equal, and which depths have means that are statistically different at the 0.05 significance level. A probability exceeding 0.05 indicites that the mean concentrations at the three depths are not statistically different. A probability below 0.05 indicates that at least one of the three mean concentrations is statistically different from one of the other two. In this case, Dunn's distribution-free multiple comparison based on Kruskal-Wallis rank sums was utilized to compare the three pairs of means to determine which pairs of means are statistically different since all means are not equal. This multiple comparison procedure is valid for unequal sample sizes and is specific to Kruskal-Wallis rank sums. ${ }^{22}$ As Table 17 shows, all analytes with mean concentrations statistically differient at the three depths are also different between the 6- and 18-in. depths, where the 6-in. depth concentrations are always greater than the 18-in. depth concentrations. For ${ }^{137} \mathrm{Cs},{ }^{234} \mathrm{U},{ }^{235} \mathrm{U}$, and ${ }^{238} \mathrm{U}$, the 6-in. depth is also statistirnlly different from the 12-in. depth mean. This is further evidence that the top $6 \mathrm{in}$. of soil exhibits the greatest amount of contamination, and the concentration decreases with depth. However, the 18-in. depth still exhibits evidence of contamination. For example, the estimated mean concentration of ${ }^{231} \mathrm{U}$ at the 18-in. depth is more than twice ine health-based guideline value of $26.5 \mathrm{pCi} / \mathrm{g}$. Similarly, the estimated mean concentration of ${ }^{238} \mathrm{U}$ at the 18 -in. depth exceeds its guideline value of $28.5 \mathrm{pCi} / \mathrm{g}$. Since contamination still exists at the 18 -in. level, the depth of contamination has not been fully characterized. Therefore, deeper sampling will be necessary in order to determine the depth of contamination.

\subsection{DATA PRESENTATION}

The data from the K-1407-C sampling campaign are presented in two different graphical formats. First, concentrations of selected analytes are represented at each depth in a three-dimensional format. The data are also examined by way of two-dimensional contour plots that indicate the probability of exceeding a health-based guideline value at locations within the retention basin at a certain depth. 


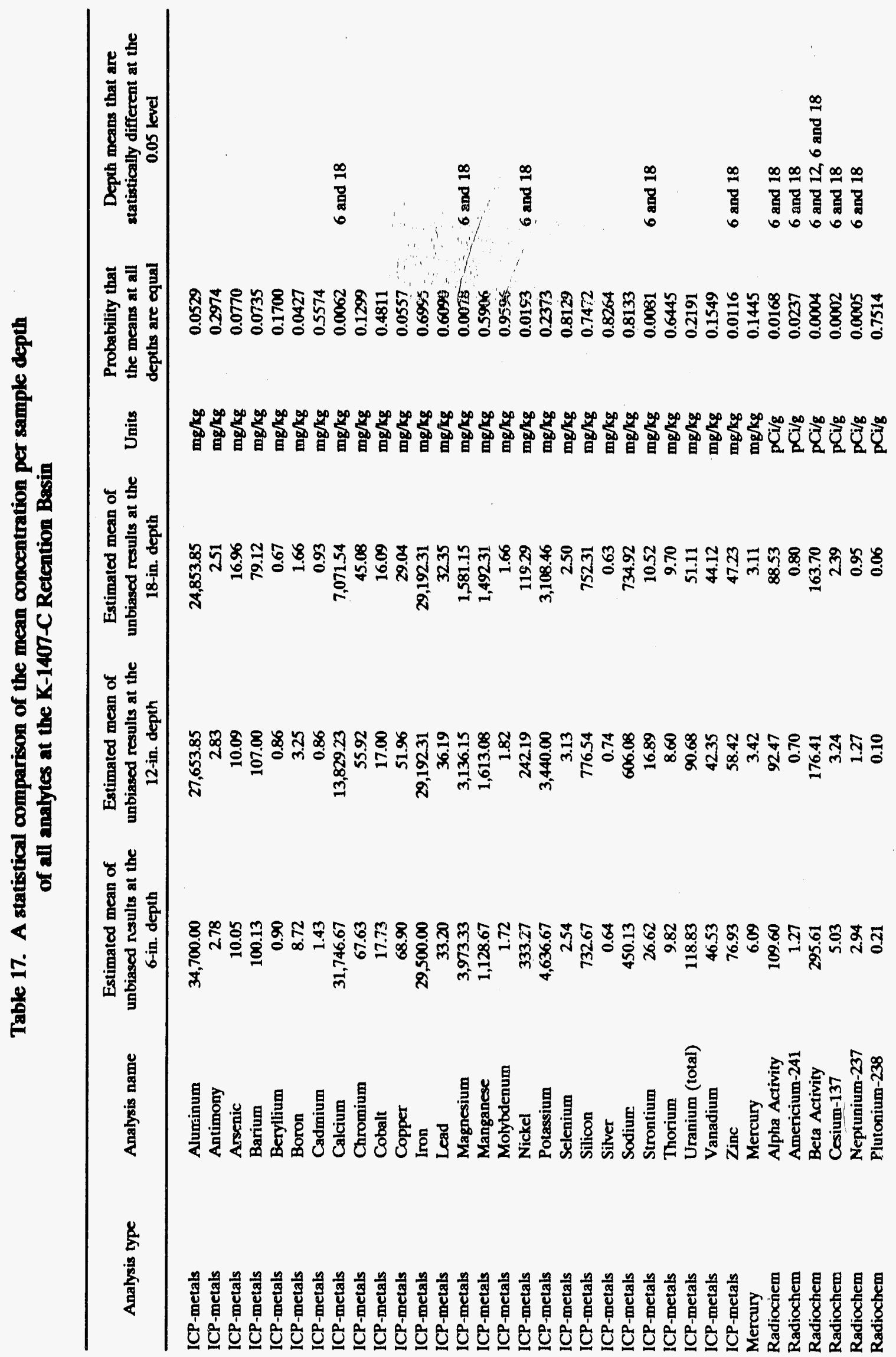




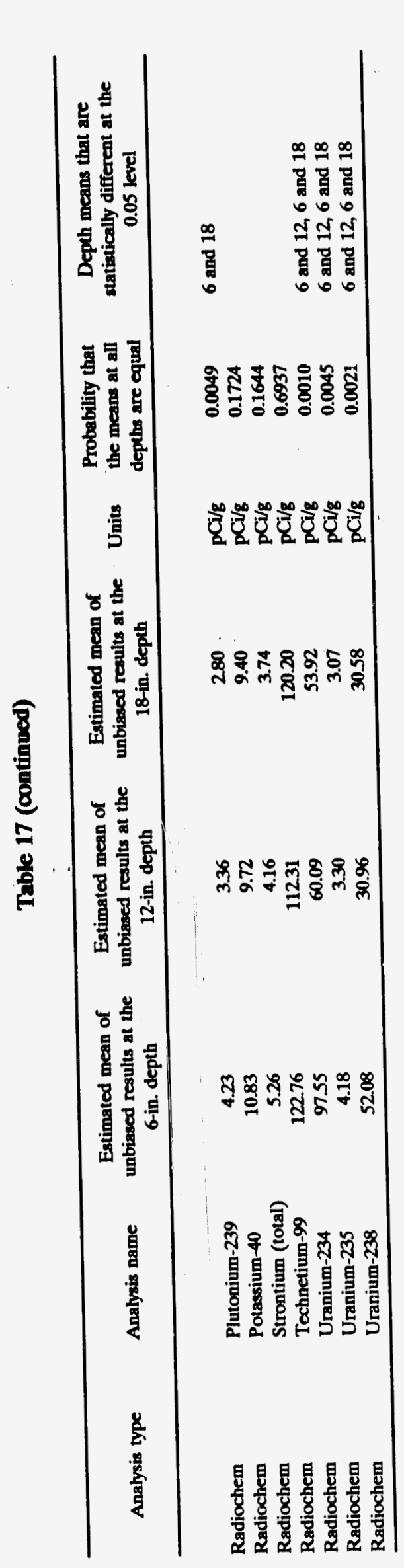




\subsubsection{Three-Dimensional Sample Concentration Plots}

\subsubsection{Construction of plots}

The concentrations of selected analytes have been plotted three-dimensionally to identify trends or patterns of analyte concentrations within a certain sampling depth. Each sample in the three-dimensional plots is represented by a separate needle. The height of the needle indicates the concentration of the analyte detected in the sample. Pyramid symbols represent concentrations below detection limits, and diamonds represent positive data. The value of the detection limit is used as the plotting value for analyses that indicated concentrations below detection limits. Negative results for radionuclides concentrations are set equal to zero for plotting purposes. Figure 25 illustrates the orientation of the three-dimensional plots on the base map that was presented earlier in this report. Figure 26 is a three-dimensional map of the sampling locations and the berm in the retention basin.

In Figs. 26 to 39 the dimensions of the retention basin are altered to improve the graphical presentation. Otherwise, the long length and narrow width of the retention basin would cause crowding of the needles, and perception of trends would be more difficult. The vertical scale of the plots, which indicates analyte concentration, is also altered for different depths of the same analyte. The largest value on the concentration axis is the highest concentration of that analyte for that depth. Allowing the scale to change over depths makes trends within a certain depth more evident. These plots are meant to indicate general areas of elevated concentrations and trends but do not easily lend themselves to identifying particular locations and concentrations.

\subsubsection{Findings}

The radionuclide plots indicate higher concentrations in the area of the berm, along the north side of the retention basin, and along the west end. This trend is evident at all sampling depths. The distribution of ${ }^{99} \mathrm{Tc},{ }^{234} \mathrm{U}$, and ${ }^{235} \mathrm{U}$ is presented in Figs. 27 to 35 . A similar distribution pattern is indicated by the plots of other radionuclides, which are included in Appendix D.

The metals data are less conclusive. For some analytes, there may be slightly higher concentrations in the east end of the retention basin at the 6-in. depth, as indicated by the plots for chromium, mercury, nickel and uranium at the 6-in. depth, Figs. 36 to 39 . However, most of the metal concentrations do not exhibit any definite pattern or trend. Increases in metal concentrations, unlike the radionuclides, are not indicated in the area of the berm. Additional metals plots can be found in Appendix D.

\subsubsection{Illustration of Contamination Probability Contours}

A drawback in the use of these three-dimensional figures that use only raw data is that they cannot be used for inference and therefore do not demonstrate the influence a high concentration might have on the surrounding area. Contour plots are one method of evaluating the effect that a high value may have on surrounding values. They provide an additional tool to help visualize the "surface" of chemical concentrations in the retention basin. 

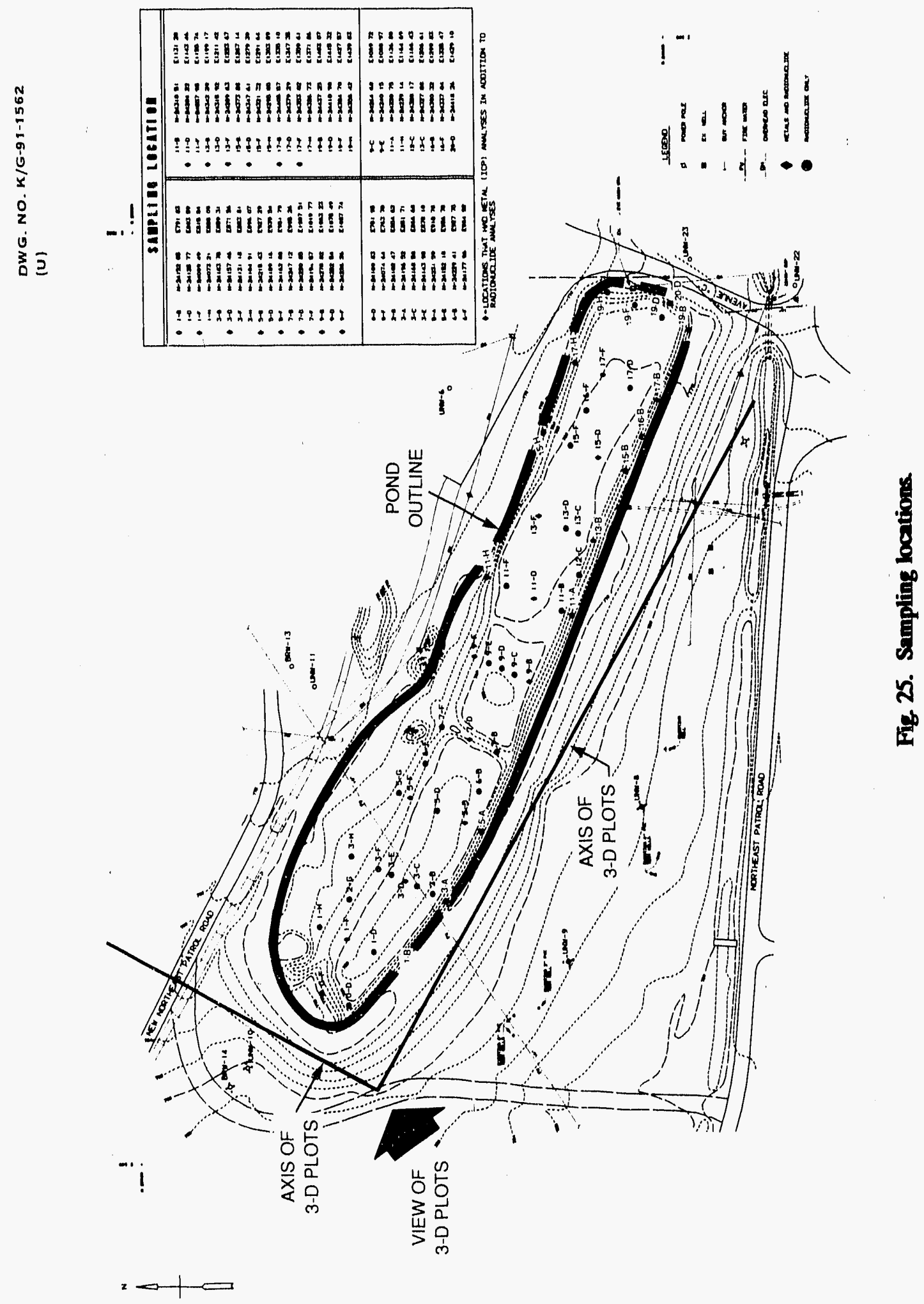


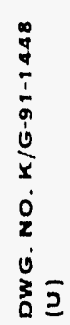

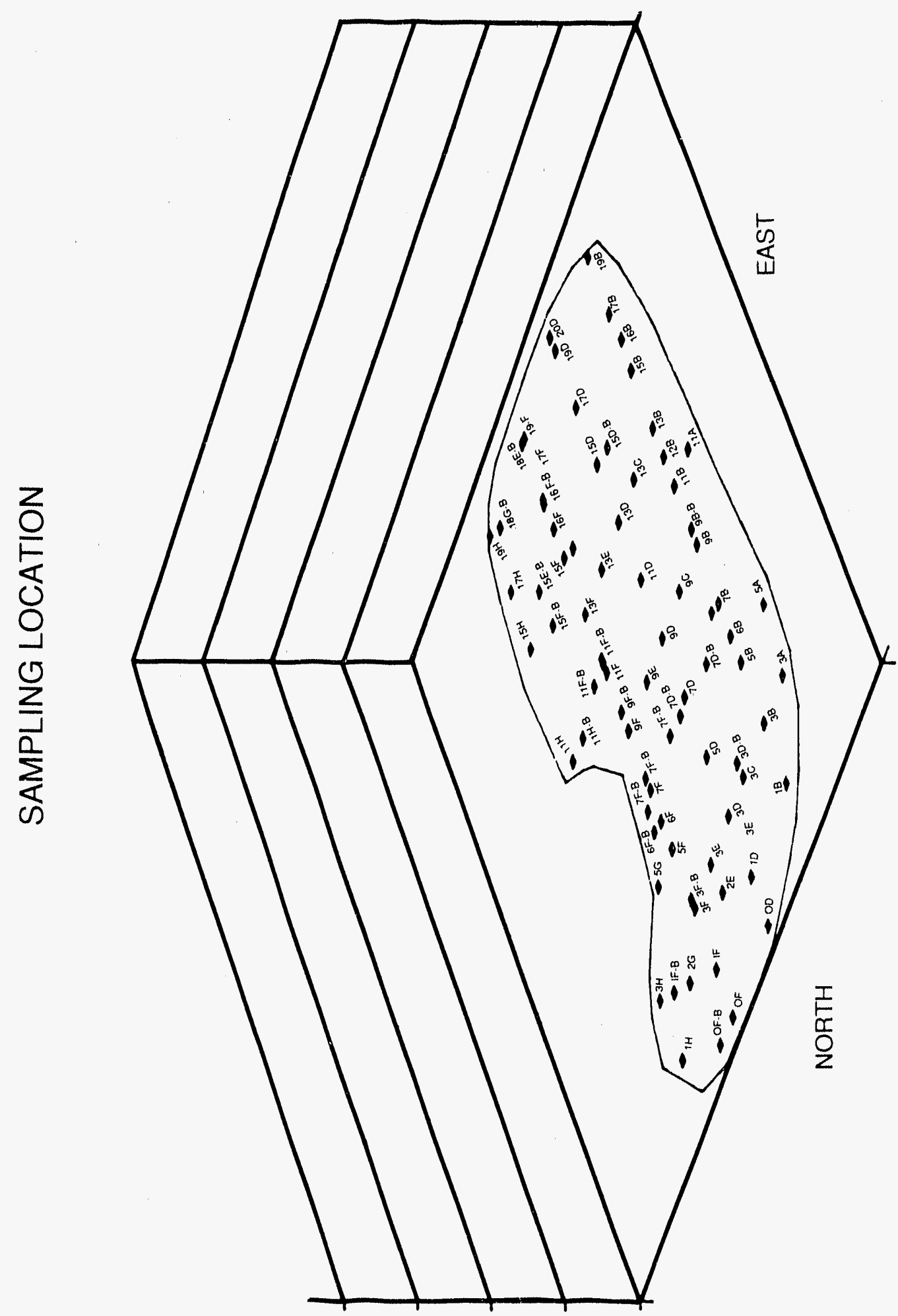

量 


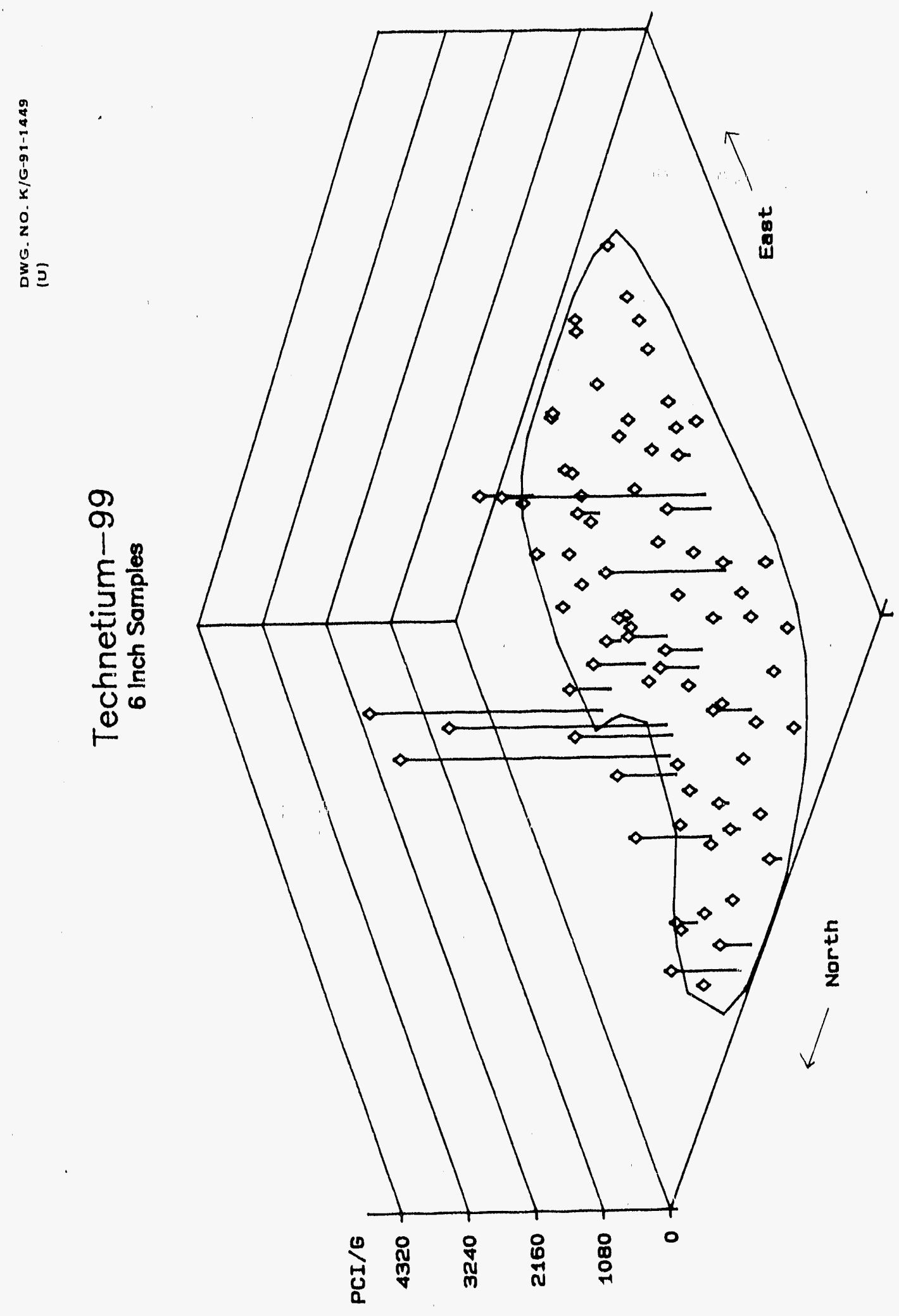

章

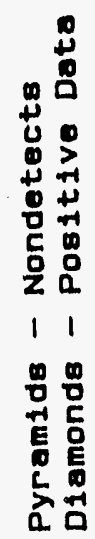



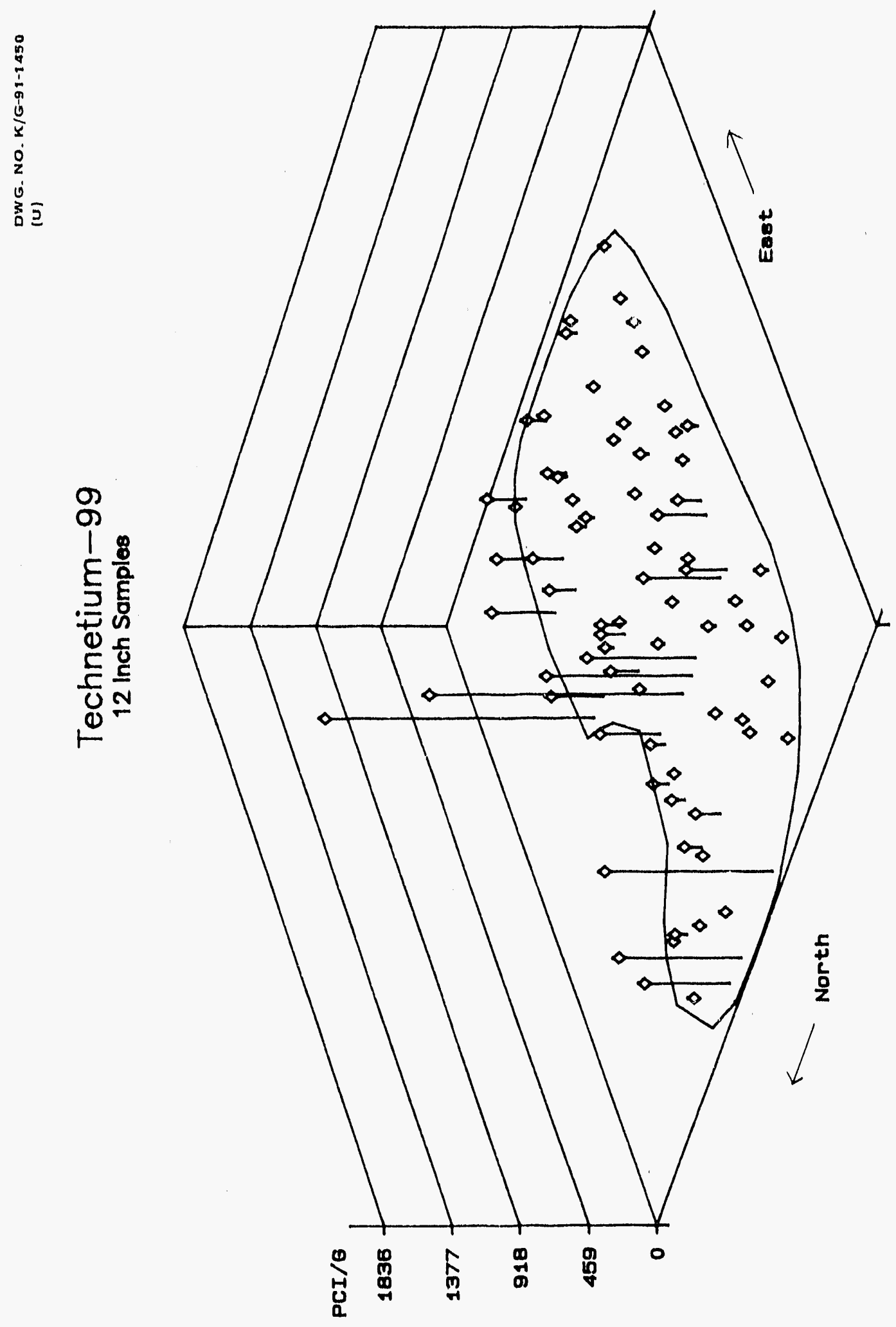

है

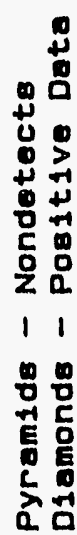




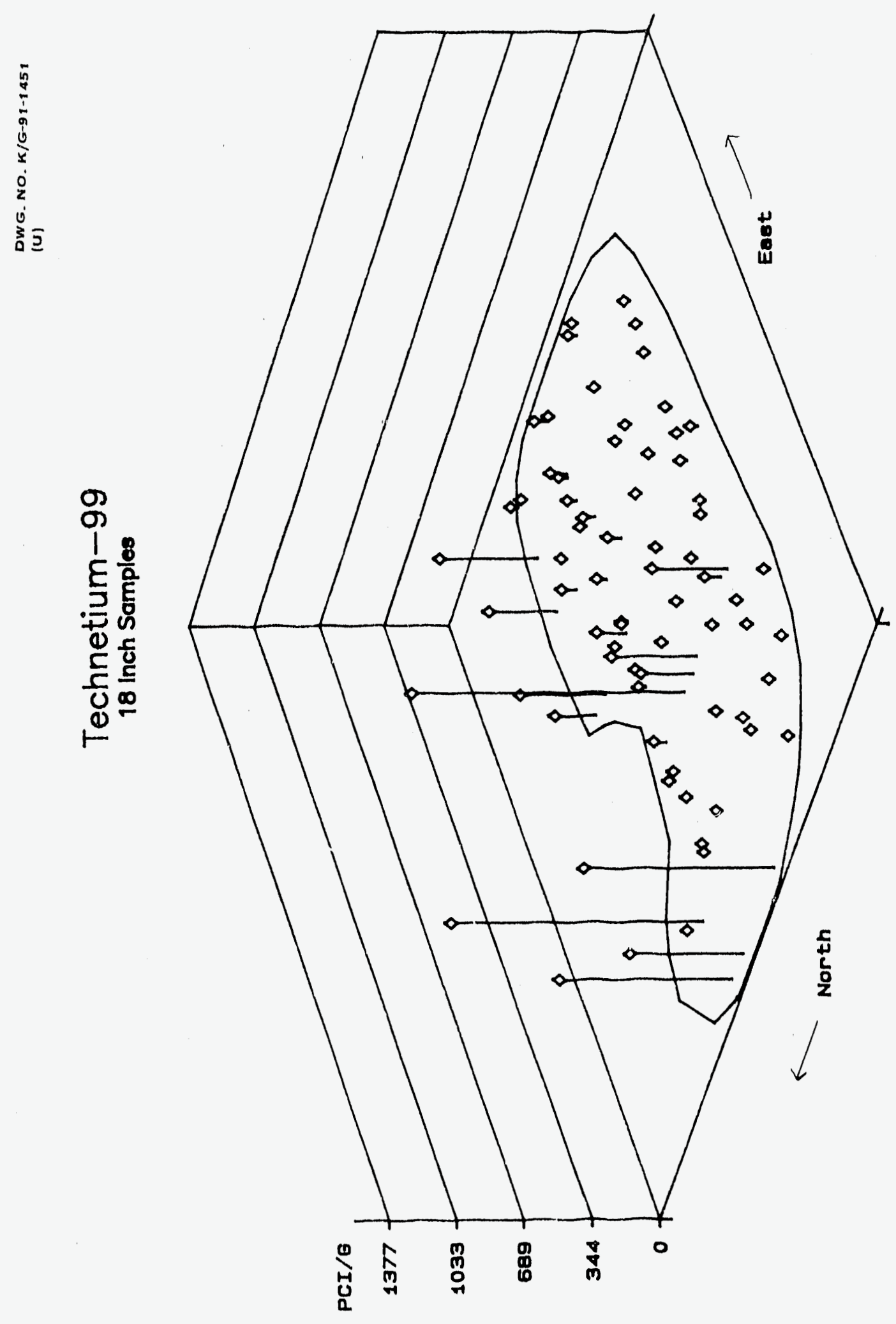

兽

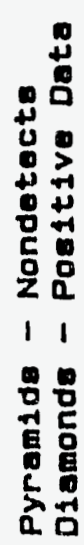




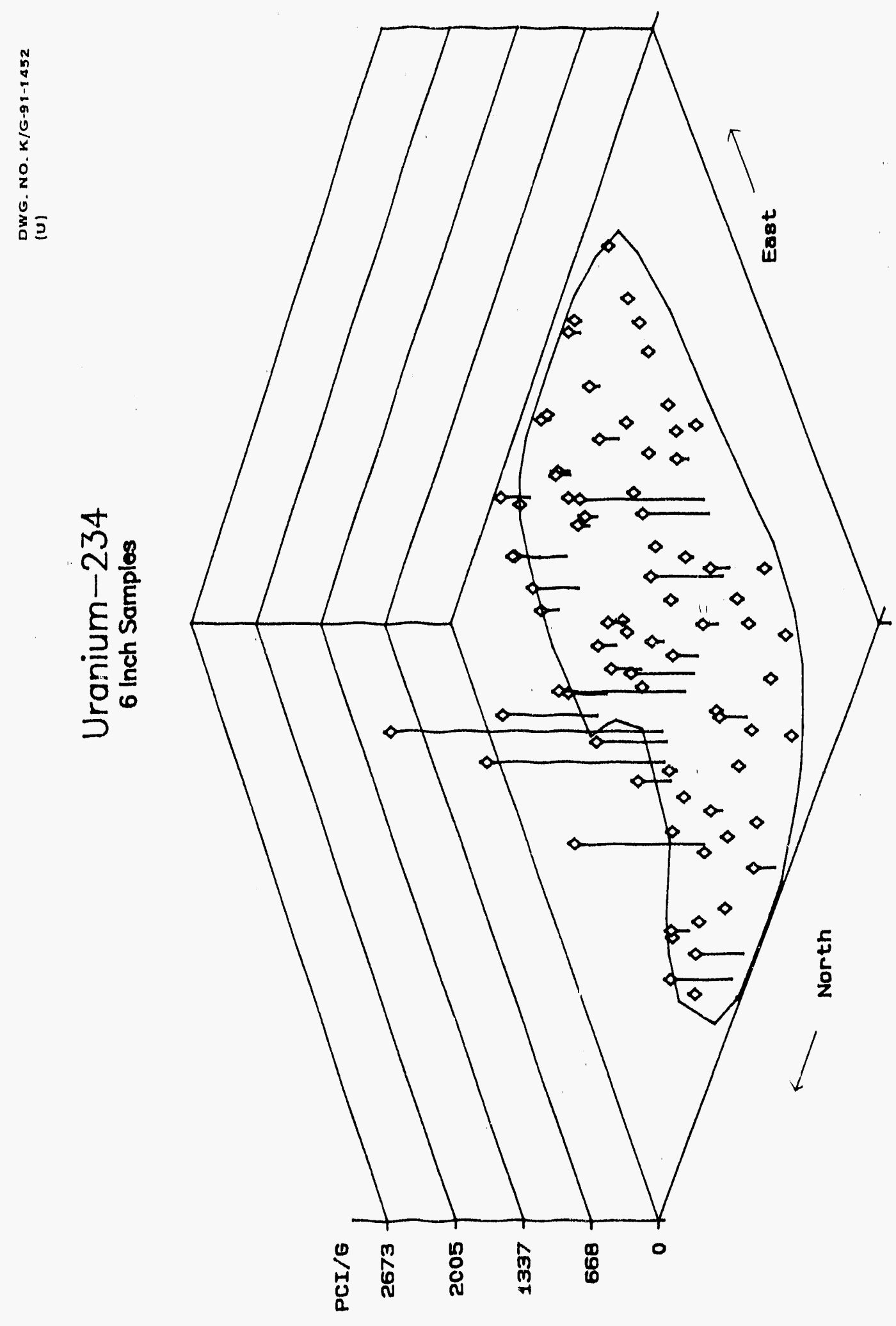

总

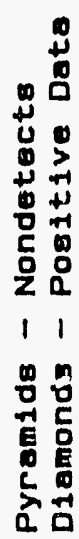



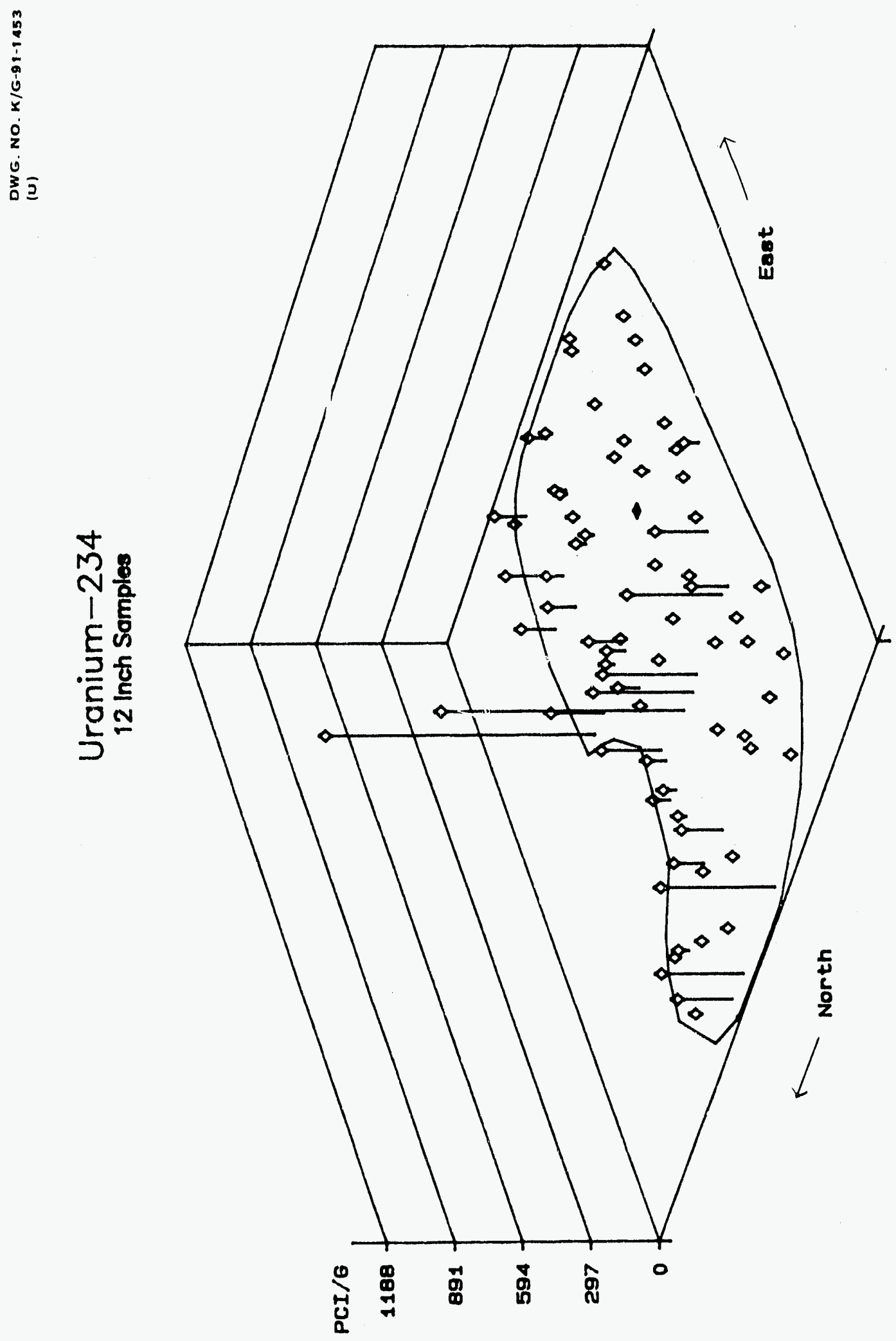

है

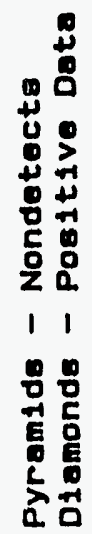




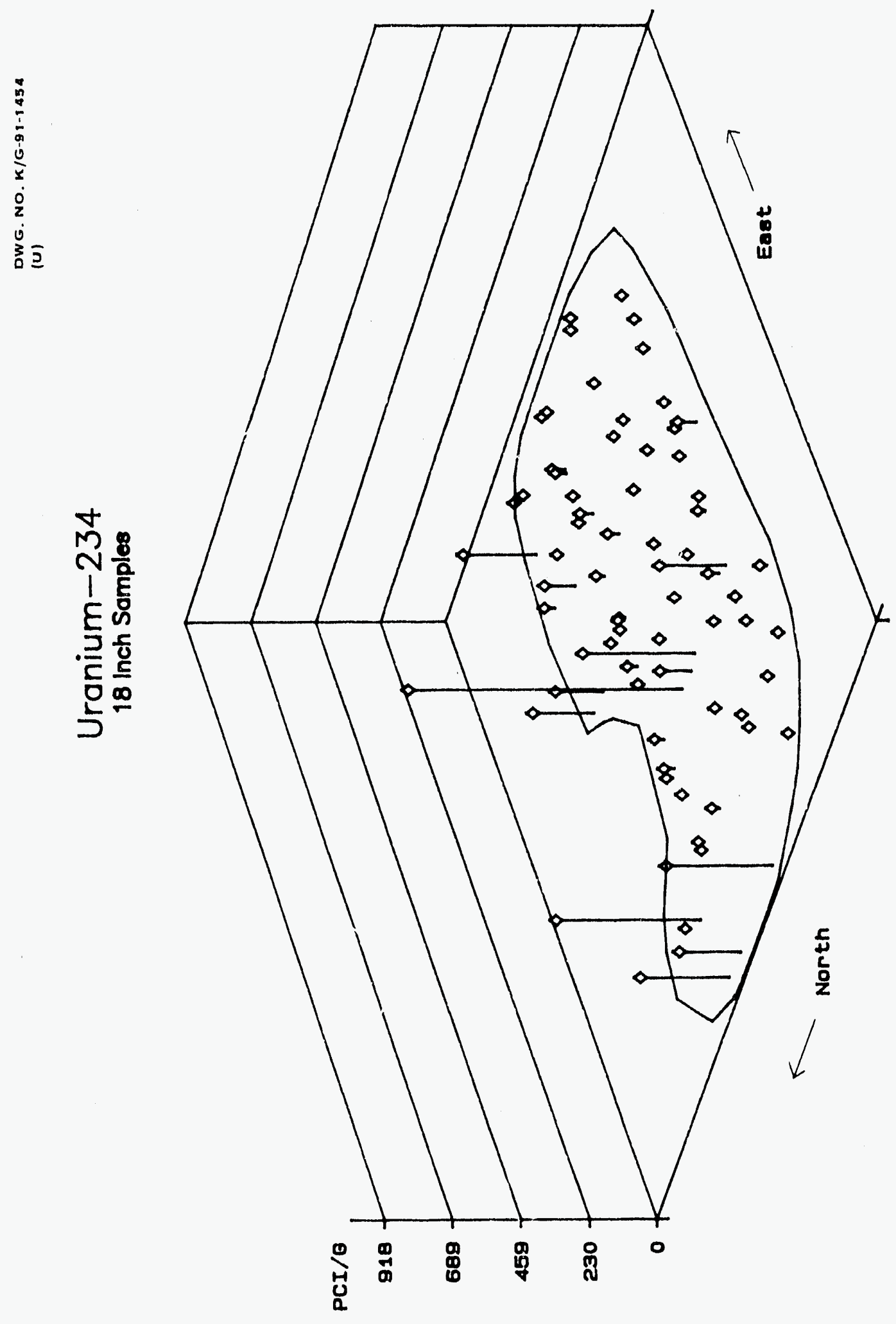

吽

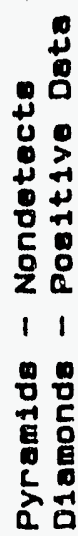




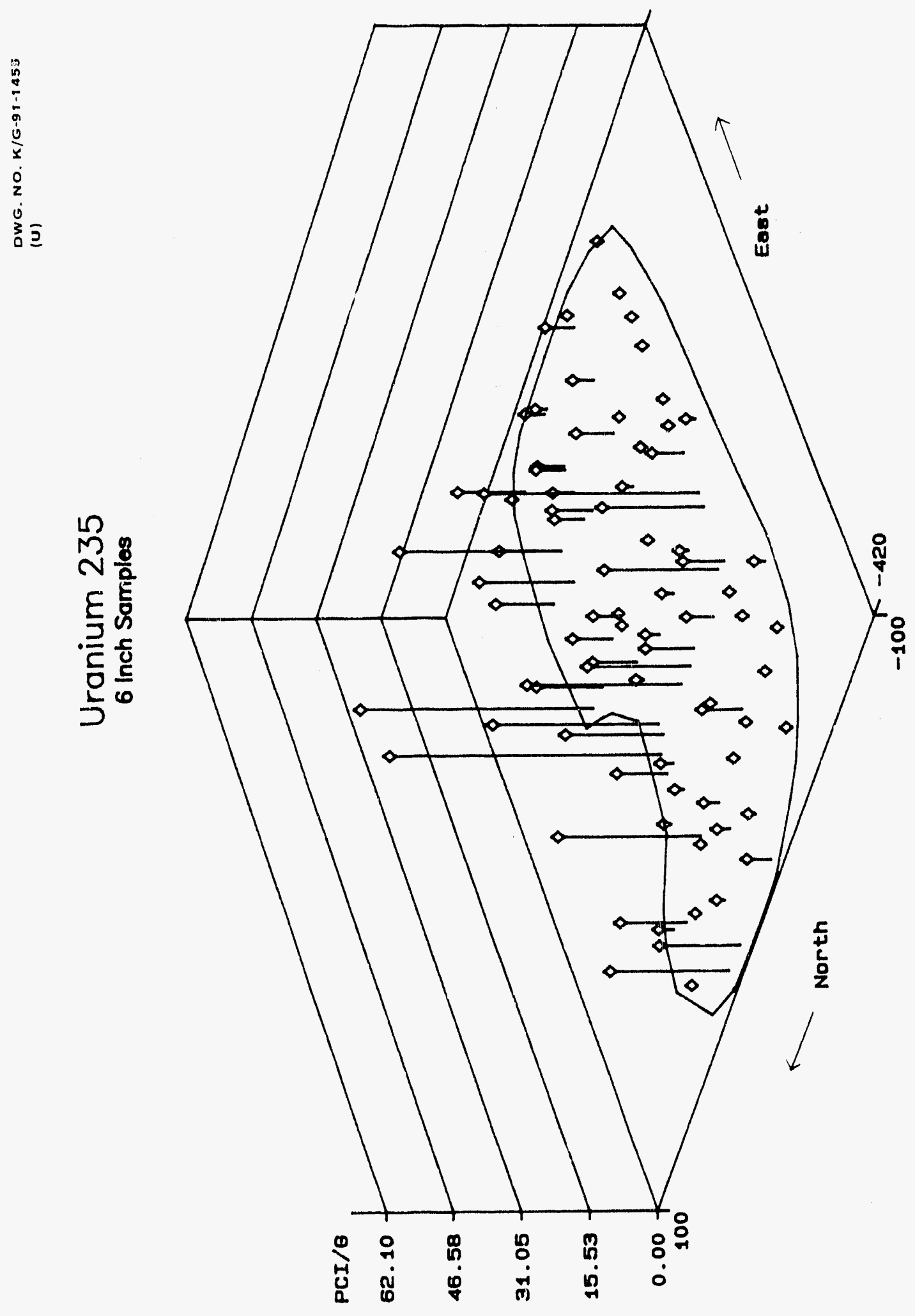

总

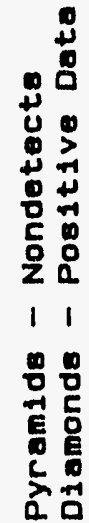




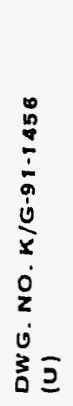

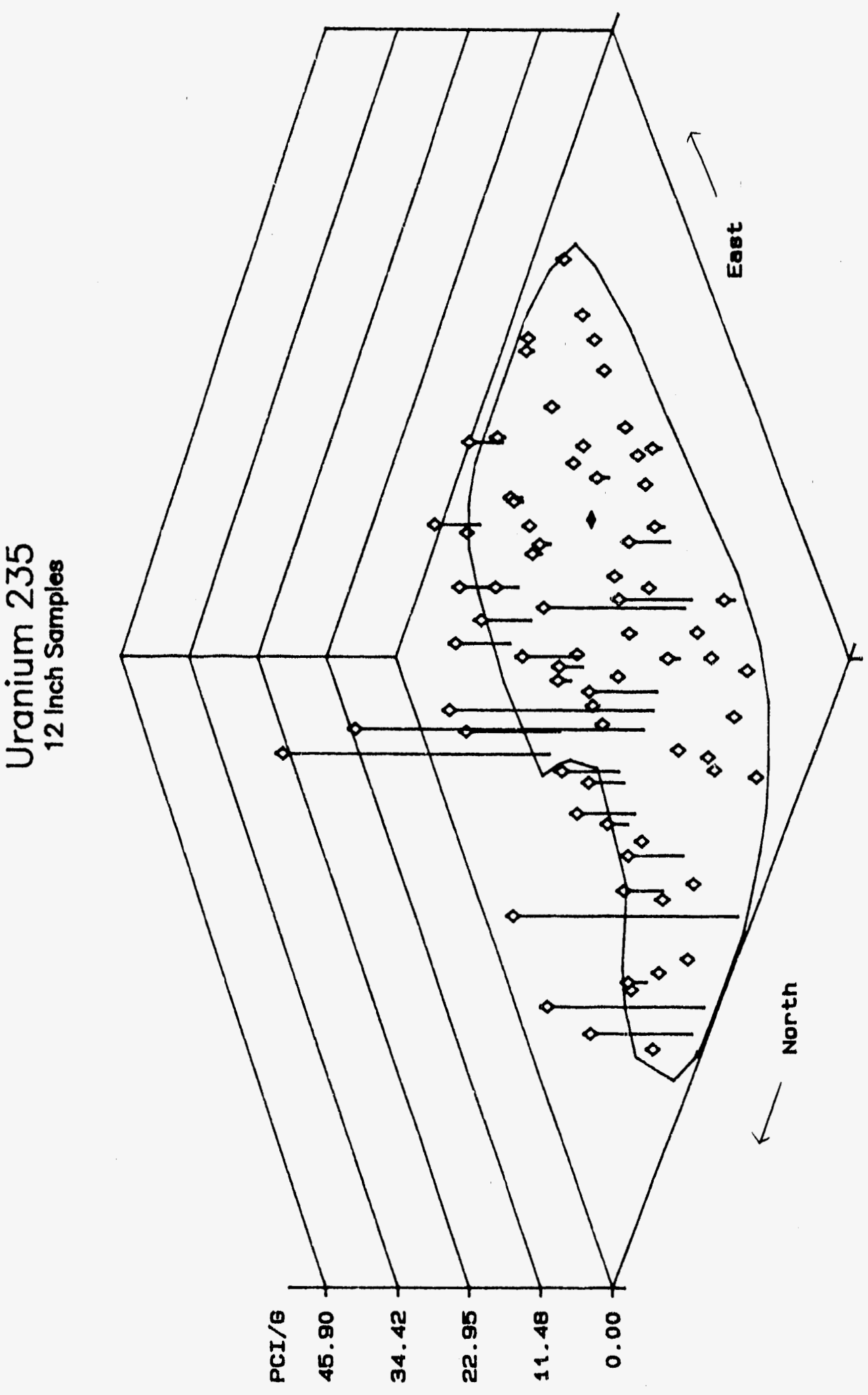

总

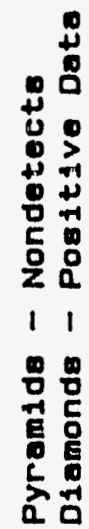




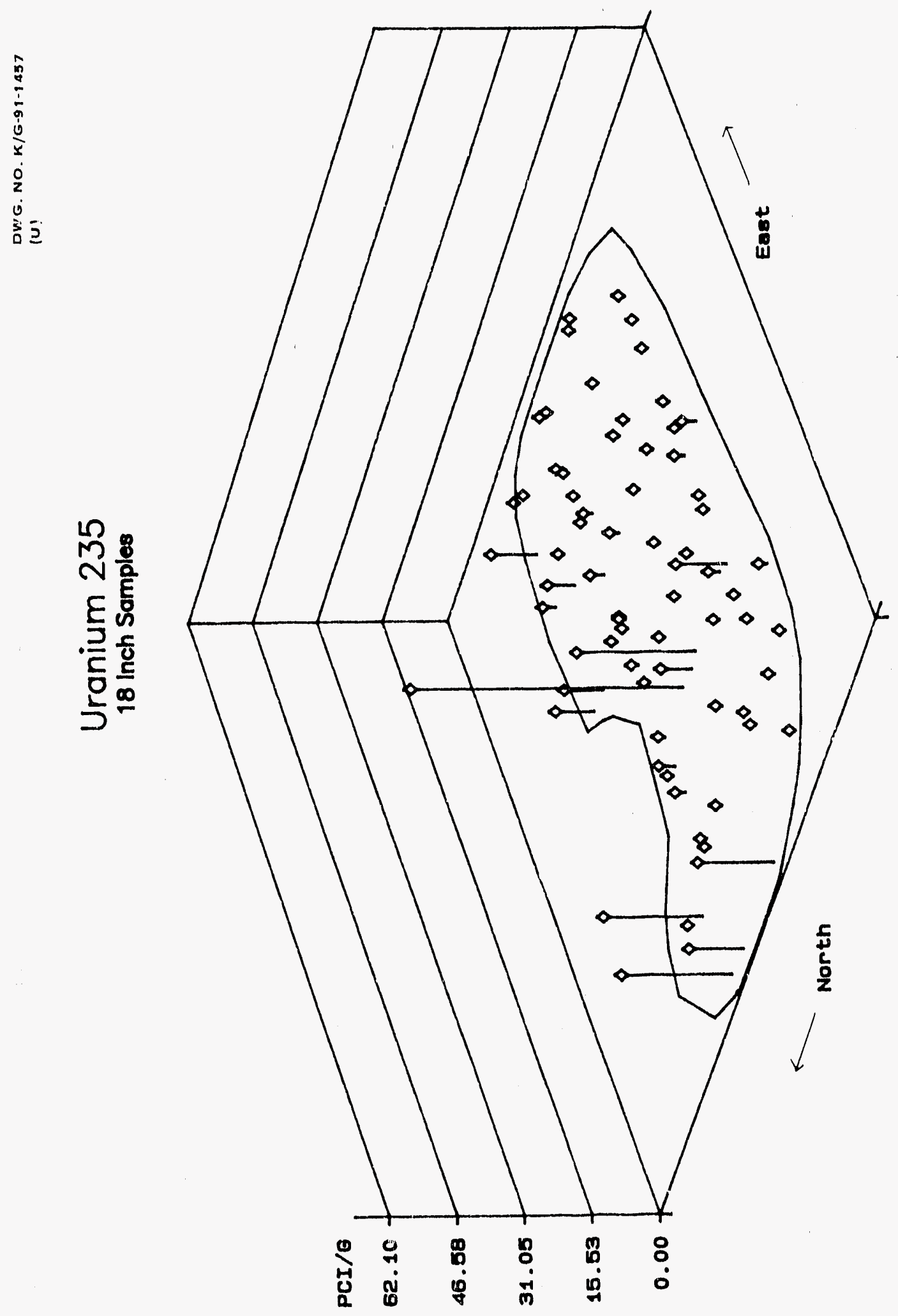

兽

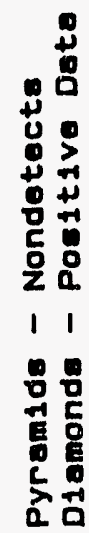




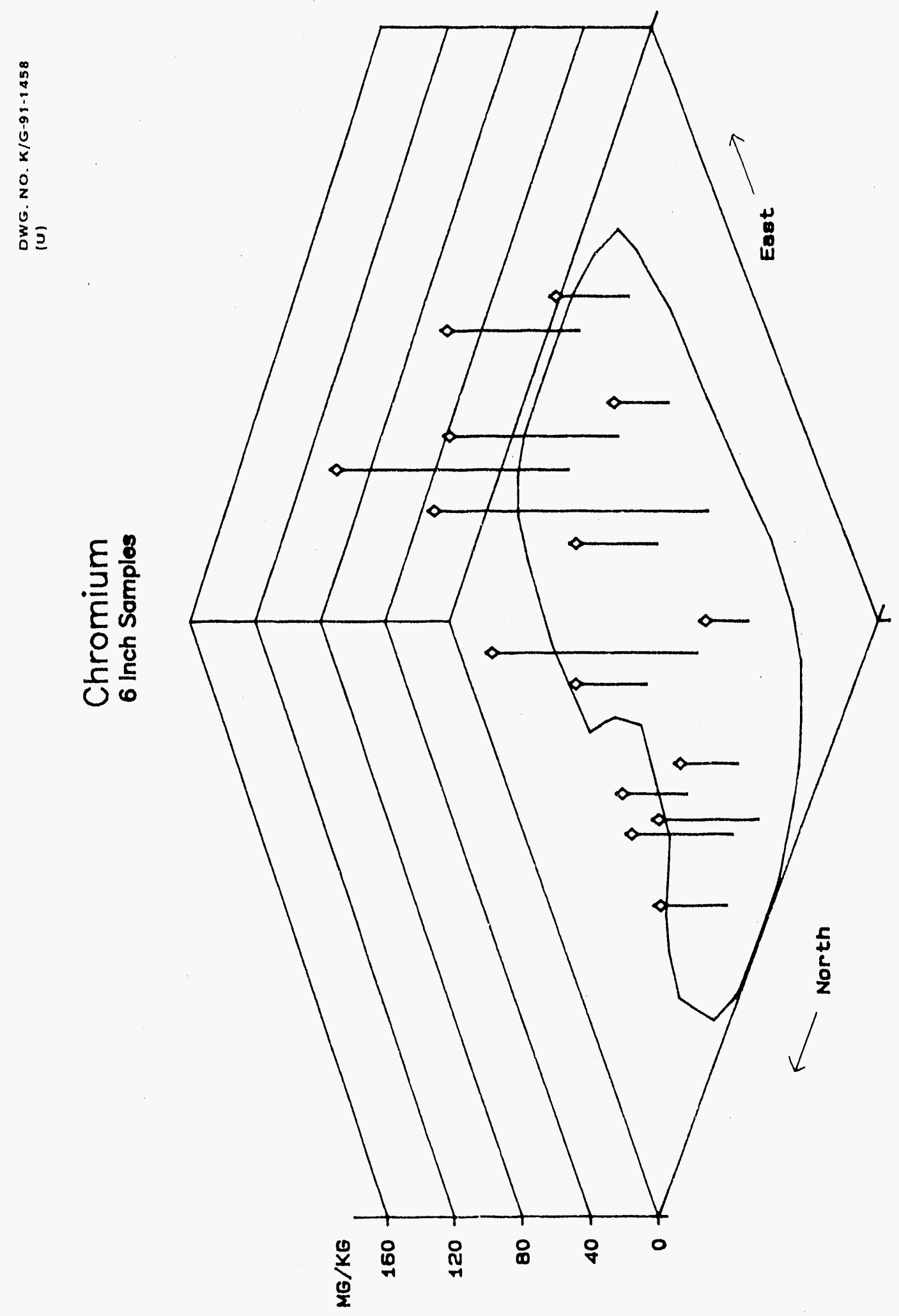

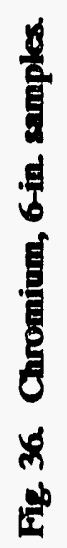

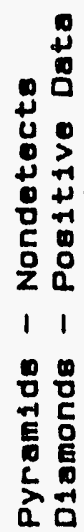



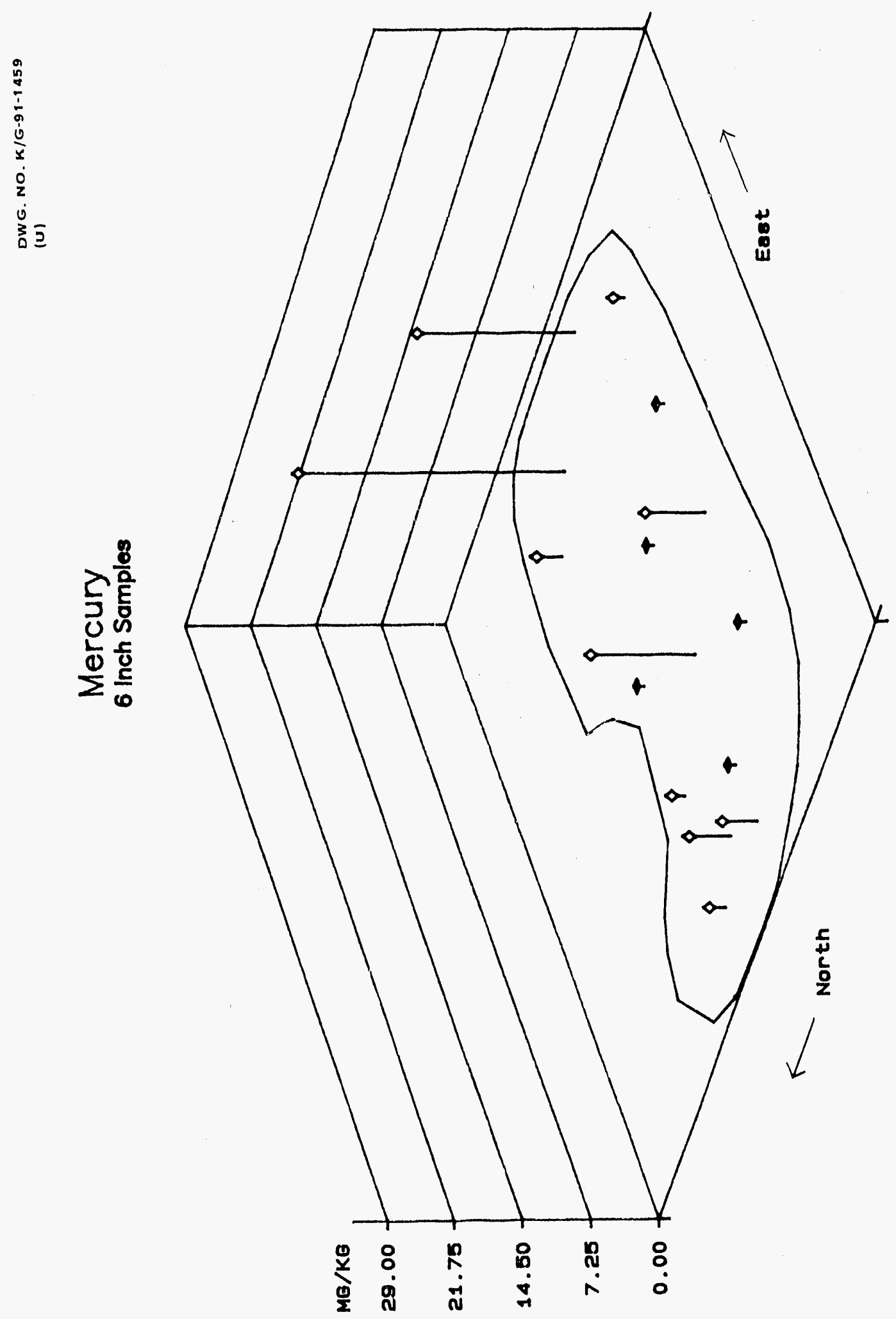

है

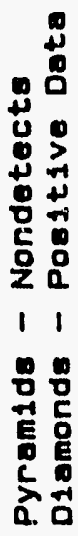




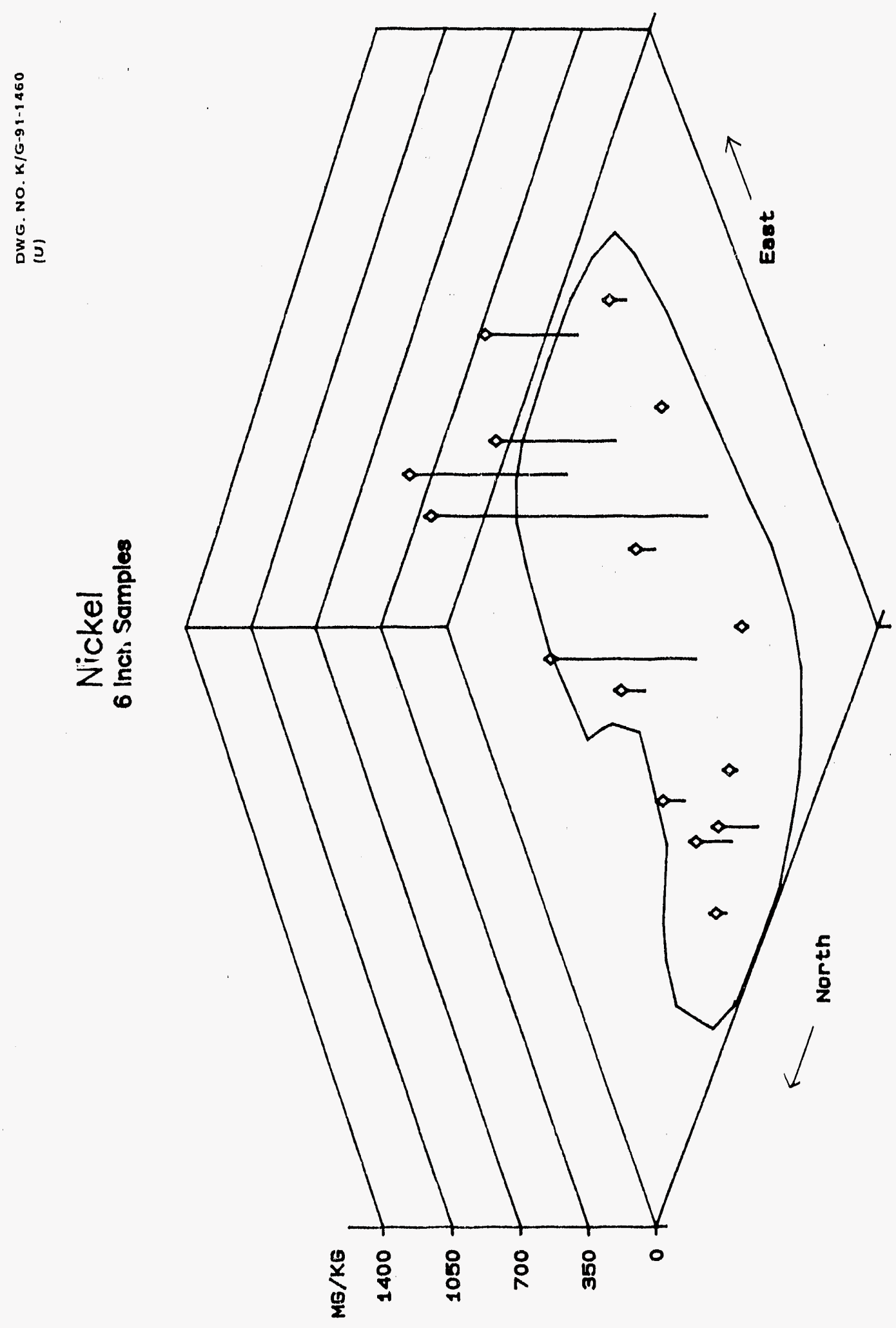

量

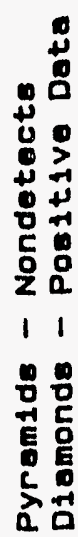




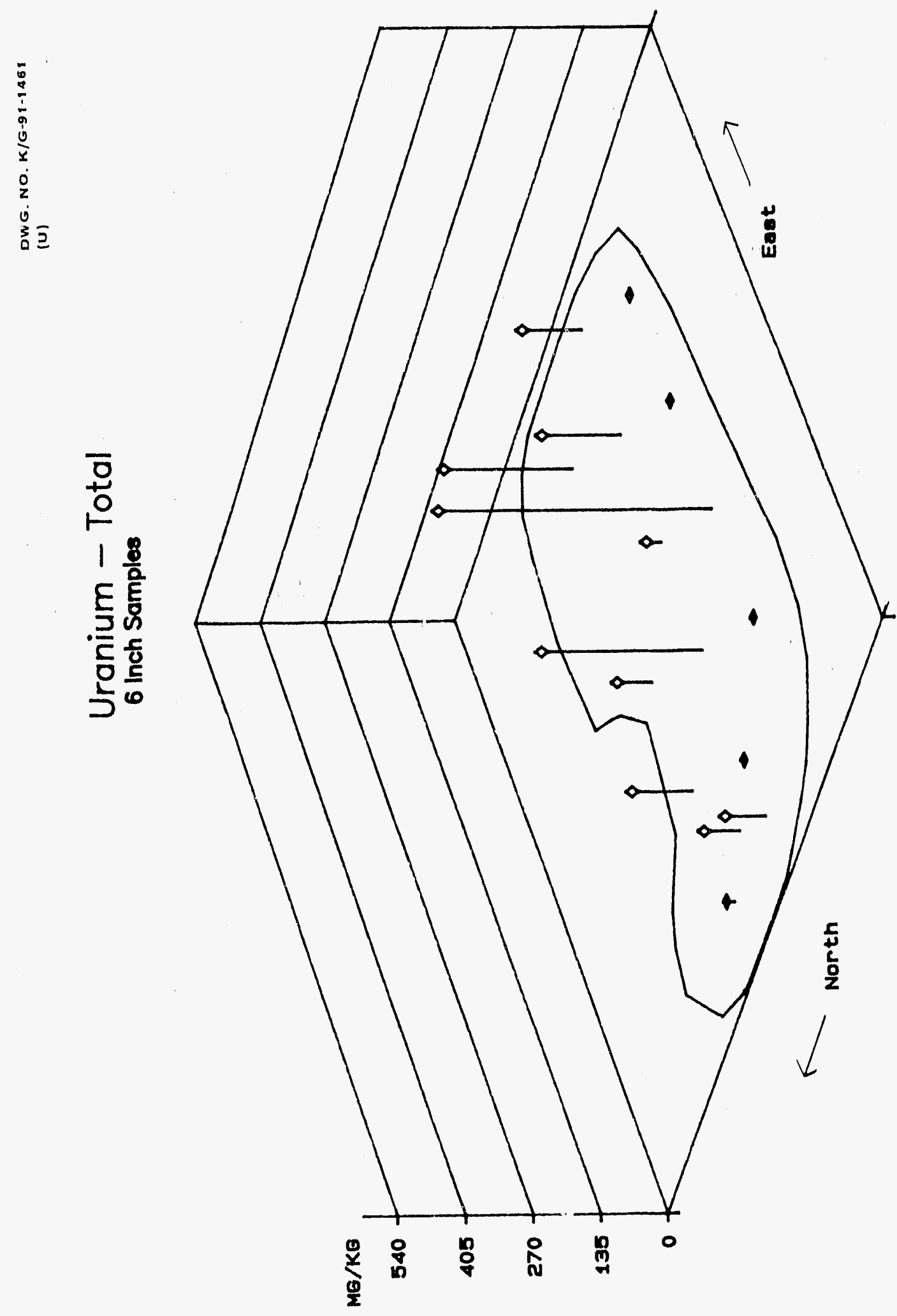

要

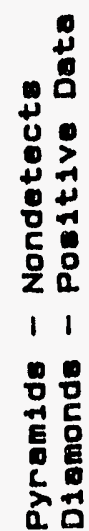




\subsubsection{Interpretation of contour plots}

Contour plots of the probability of exceeding a health-based guideline value for radionuclide concentrations were prepared for nine sets of data from the K-1407-C Retention Basin. Americium-241, ${ }^{237} \mathrm{~Np}$, and ${ }^{235} \mathrm{U}$ were considered at only the 6 -in. level, while ${ }^{234} \mathrm{U}$ and ${ }^{238} \mathrm{U}$ were appraised at 6,12 , and 18 in. There are insufficient data values greater than the health-based value in the remaining radiochemical data to contour probabilities with any degree of confidence. The contour lines in the figures do not represent estimated concentrations at a specific location, but rather probabilities of exceeding the threshold value. For instance, areas that coincide with the 0.50 line on the plot represent areas where the average concentration has a probability of 0.50 of being greater than the health-based guideline value for the particular analyte. The lines of equal probability on the plots are displayed in increments of 0.10 . The guideline values used in this study were obtained from Table 4, "Guideline values for radionuclides," in Data Analysis Approach Report for K-1407-B Holding Pond and K-1407-C Retention Basin (K/ER-23).

\subsection{Methodology}

The method used to prepare the probability contour plots is known as kriging. Kriging is a method of using weighted moving averages to estimate values for unsampled locations,

$$
z^{*}\left(x_{\mu}\right)=\sum \delta_{i} z\left(x_{1}\right) ; \quad 0<\delta_{i}<1
$$

within a certain area of interest. $z^{*}\left(x_{u}\right)$ is the kriging estimate at the unsampled location $x_{u}$, where $z\left(x_{i}\right)$ is the observed datum at the location $x_{i}$, and $\delta_{i}$ is the weight, between 0 and 1 , attached to that datum derived from the kriging process. The weights that are chosen depend on two things. One is the spatial relationship between the point for which an estimate is to be calculated and nearby points for which a data value is known. The other is the correlational structure in the data. This correlational structure must then be modeled. A typical type of structure might be that samples close together have data values that are similar and that samples further apari are more variable. This trend continues until the samples reach a certain distance apart, called the range of correlation, after which the variability between samples remains constant. The kriging process generates a regular grid of estimates that are used by a standard contouring software package to generate contour plots. The estimation grid that was laid out for K-1407-C has a grid spacing of $10 \mathrm{ft}$ by $20 \mathrm{ft}$.

The specific type of kriging that has been used with the K-1407-C Retention Basin data is called indicator kriging. For indicator kriging, the data values are transformed to indicator data ( 0 or 1$)$ depending on whether the particular datum is less than or equal to or is greater than some predefined guideline value. Ordinary kriging is then performed on these transformed data. The estimates that are obtained are not estimated concentrations at a specific location, but rather probabilities of exceeding the guideline value. The kriging calculations were done using the Geostatistical Environmental Assessment Software from EPA Environmental Monitoring Systems Laboratory in Las Vegas. This software is public domain personal computer software provided by EPA for use in environmental assessments. At the end of this chapter, references have been provided to give the interested reader a source of material describing the theory of kriging in general and of indicator kriging specifically. 


\subsection{Findings}

Probabilities for exceeding guideline values of more than 0.80 along the berm can be seen in Figs. 40 to 45 for ${ }^{234} U$ and ${ }^{238} U$ at 6,12 , and 18 in. Figure 40 exhibits probabilities of 1.00 for ${ }^{234} U$ on the berm at 6 in. Uranium-234 and ${ }^{238} U$ at 6,12 , and 18 in. (Figs. 40 to 45 ) have probabilities as high as 0.90 of exceeding the respective guideline values at the west end of the retention basin and on the north bank. As illustrated in Fig. 46, the probability that ${ }^{237} \mathrm{~Np}$ concentrations at $6 \mathrm{in}$. will exceed $13.7 \mathrm{pCi} / \mathrm{g}$ at the north end of the berm is greater than 0.70 and greater than 0.40 near the north bank at the east end of the retention basin. The probability of exceeding guideline levels for ${ }^{235} \mathrm{U}$ is not as great as some other radiological contaminants, but the largest probabilities do occur along the berm (Fig. 47). The plot for ${ }^{241} \mathrm{Am}$ (Fig. 48) does not exhibit a higher probability of exceeding guideline levels in the area of the berm. However, ${ }^{241} \mathrm{Am}$ concentrations are higher in the berm than elsewhere.

The plots indicate a high degree of correlation among the radionuclides. Generally, areas of higher concentrations are the north bank, west end, and the berm. All the contour plots exhibit higher probabilities of exceeding the health-based guideline values along the north side of the retention basin, and almost all show higher probabilities on the berm. These probability contour estimates of the $\mathrm{K}-1407-\mathrm{C}$ radiochemical data also demonstrate that the initial sampling campaign has failed to encompass completely the contamination left behind by the sludge removal process. Further sampling efforts are needed to extend the sampling region to the north and west as well as in depth.

\section{KRIGING REFERENCES}

M. M. Alli, E. A. Nowatzki, and D. E. Myers, "Probabilistic Analysis of Collapsing Soil by Indicator Kriging," Mathematical Geology, 22 (1), 15-38 (1990).

I. Clark, Practical Geostatistics, Applied Science Publishers, London, 1979.

B. M. Davis, "Indicator Kriging as Applied to an Alluvial Gold Deposit," in Geostatistics for Natural Resource Characterization, Part 1, Reidel, Dorecht, 1984, pp. 337-348.

E. H. Isaaks, "Risk Qualified Mappings for Hazardous Wastes, A Case Study in NonParametric Geostatistics," M.S. thesis, Branner Earth Sciences Library, Stanford University, Stanford, California, 1984.

A. G. Journel, "Non-Parametric Estimation of Spatial Distributions," Mathematical Geology, $15(3), 445-465$ (1983).

A. G. Journel, "The Place of Non-Parametric Geostatistics," in Geostatistics for Natural Resource Characterization, Part 1, Reidel, Dorecht, 1984, pp. 307-335.

A. G. Journel and C. J. Huijbregts, Mining Geostatistics, Academic Press, London, 1978.

I. C. Lemmer, "Estimating Local Recoverable Reserves Via Indicator Kriging," in Geostatistics for Natural Resource Characterization, Part 1, Reidel, Dorecht, 1984, pp. 349-364. 
J. A. Sullivan, "Non-Parametric Estimation of Spatial Distributions," Ph.D. dissertation, Branner Earth Sciences Library, Stanford University, Stanford, California, 1985.

A. R. Solow, "Mapping by Simple Indicator Kriging," Mathematical Geology, 18 (3), 335-352 (1986). 

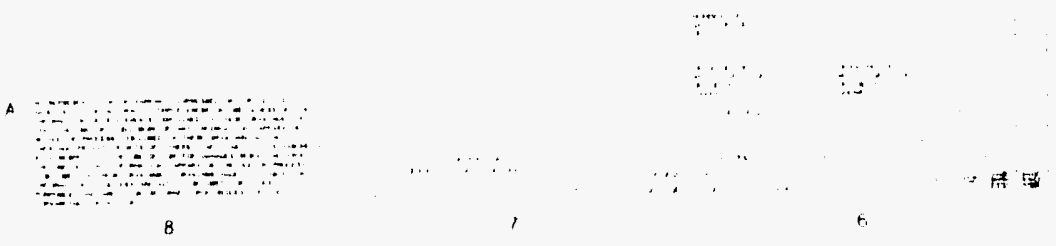

Fig. 41. Probability contour pket fo 


\footnotetext{
${ }^{234} \mathrm{U}, 6$ in. samples.
}

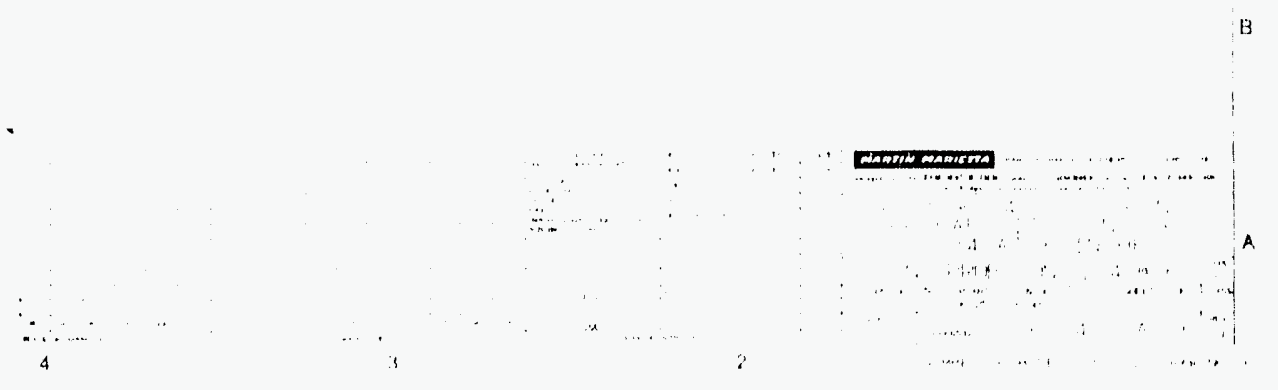

\author{
(1)
}

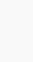


(3)

F.
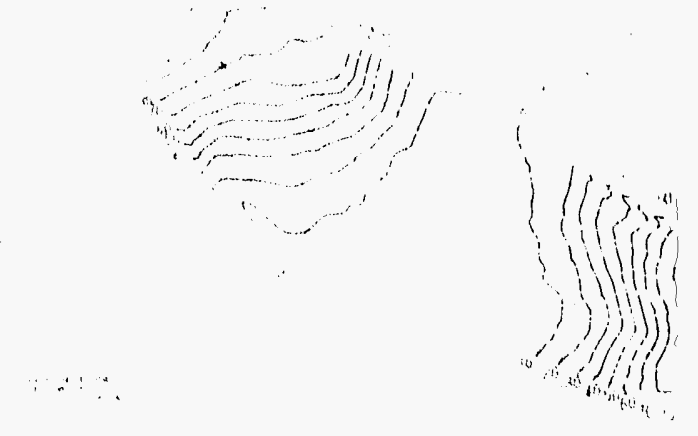

(.)

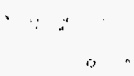

c.

B
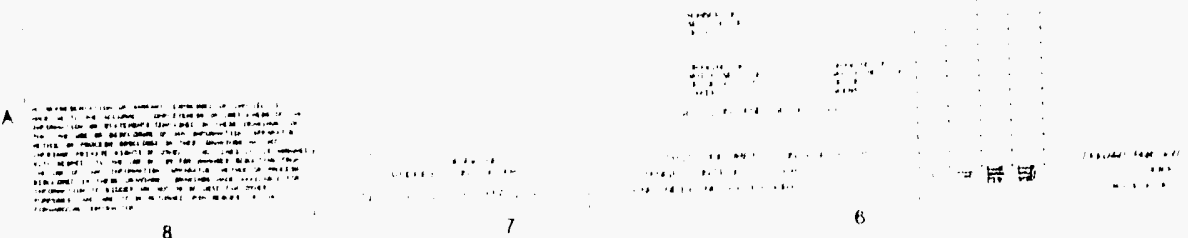

Fig. 41. Probabi 
92
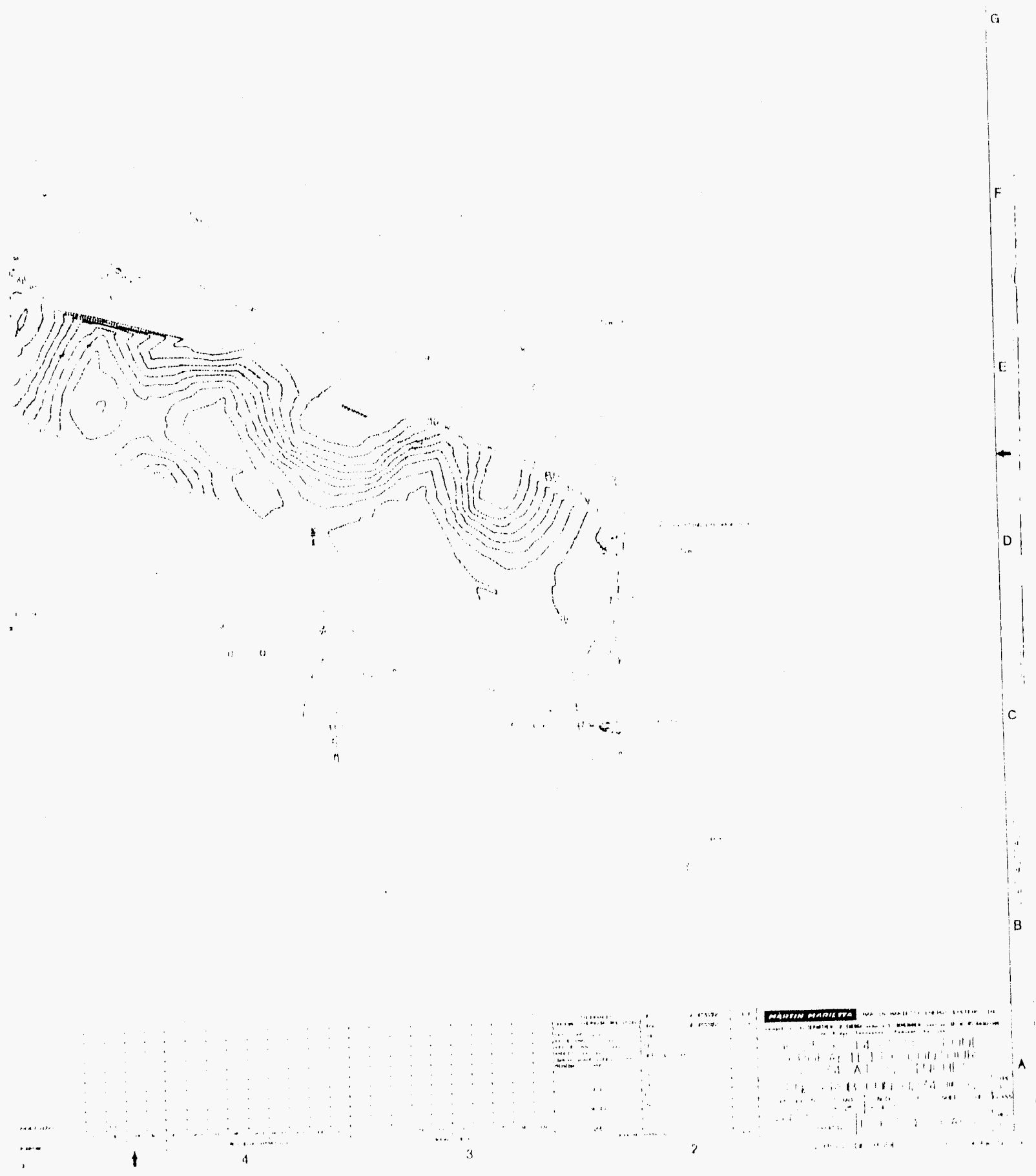

y contour plot for ${ }^{24}$ U, 12 in. samples. 
9.3

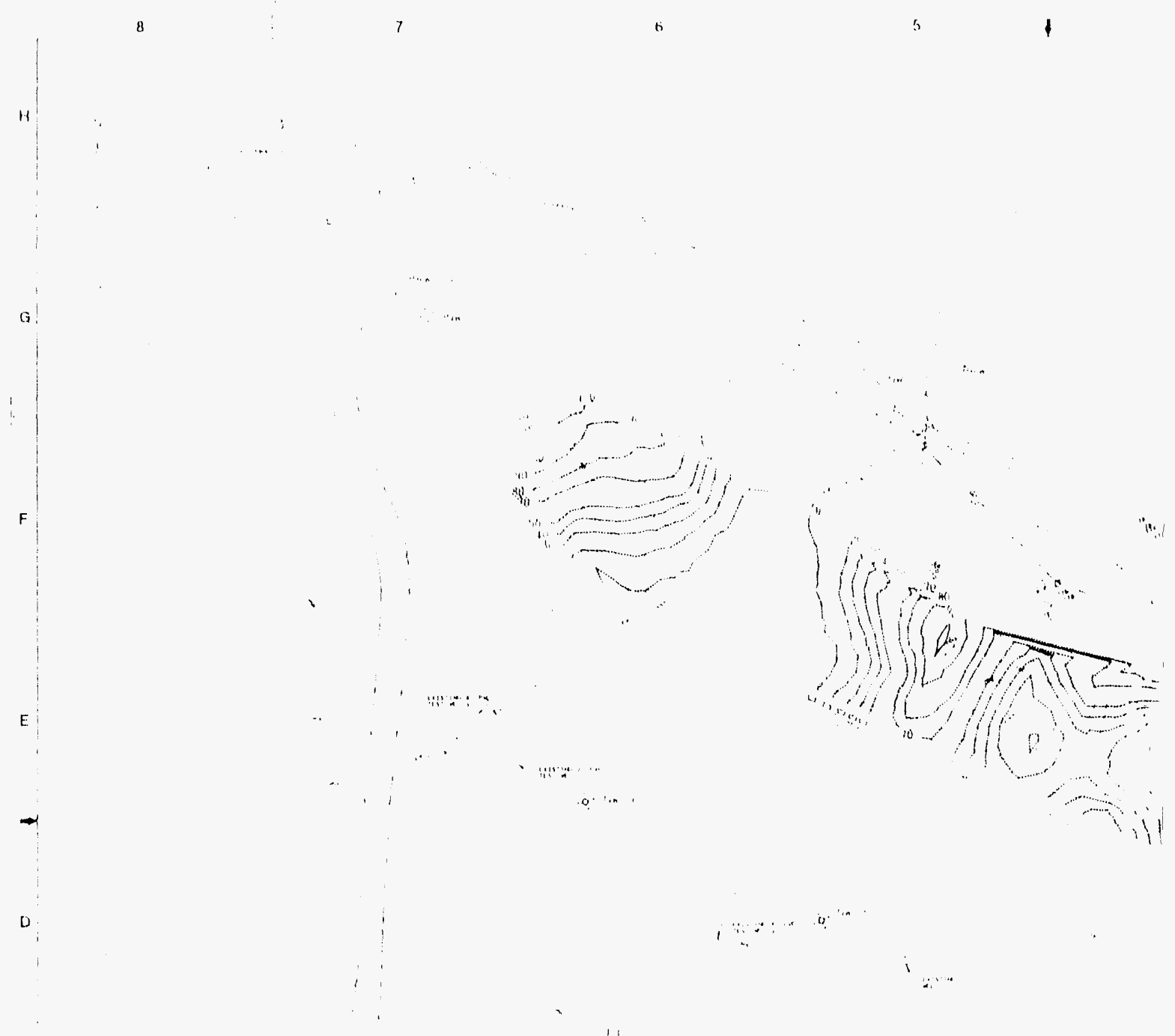

$c$
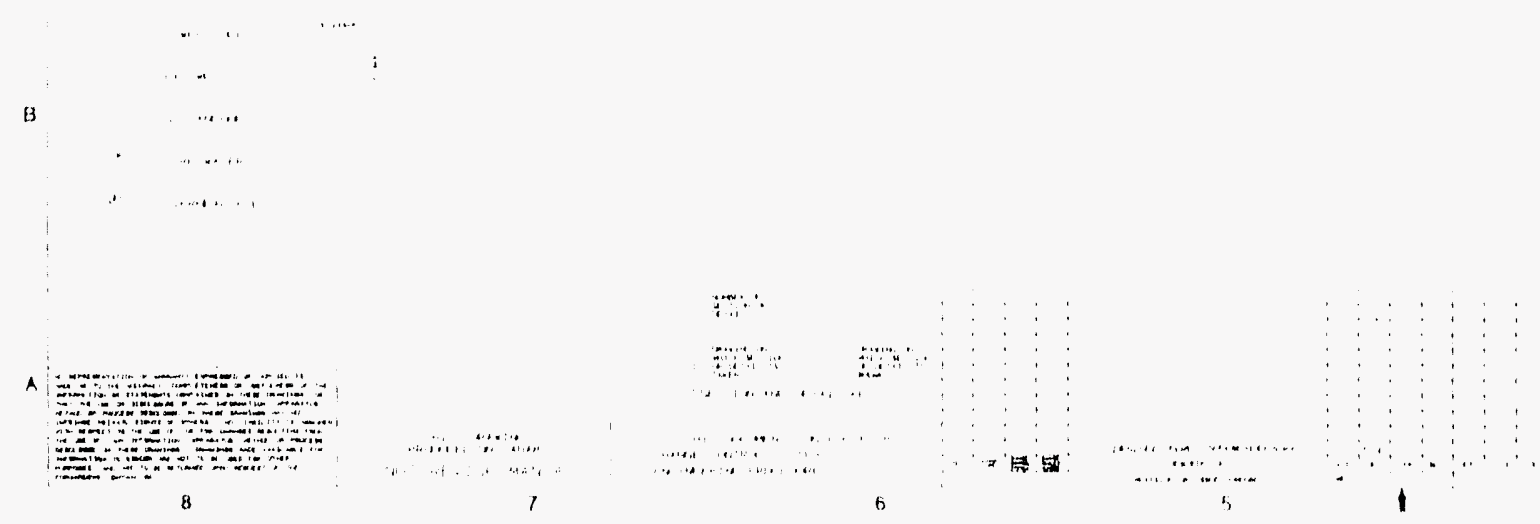

lig. 42. Probability contour ple 
4

3

2

.. $1 \ldots$

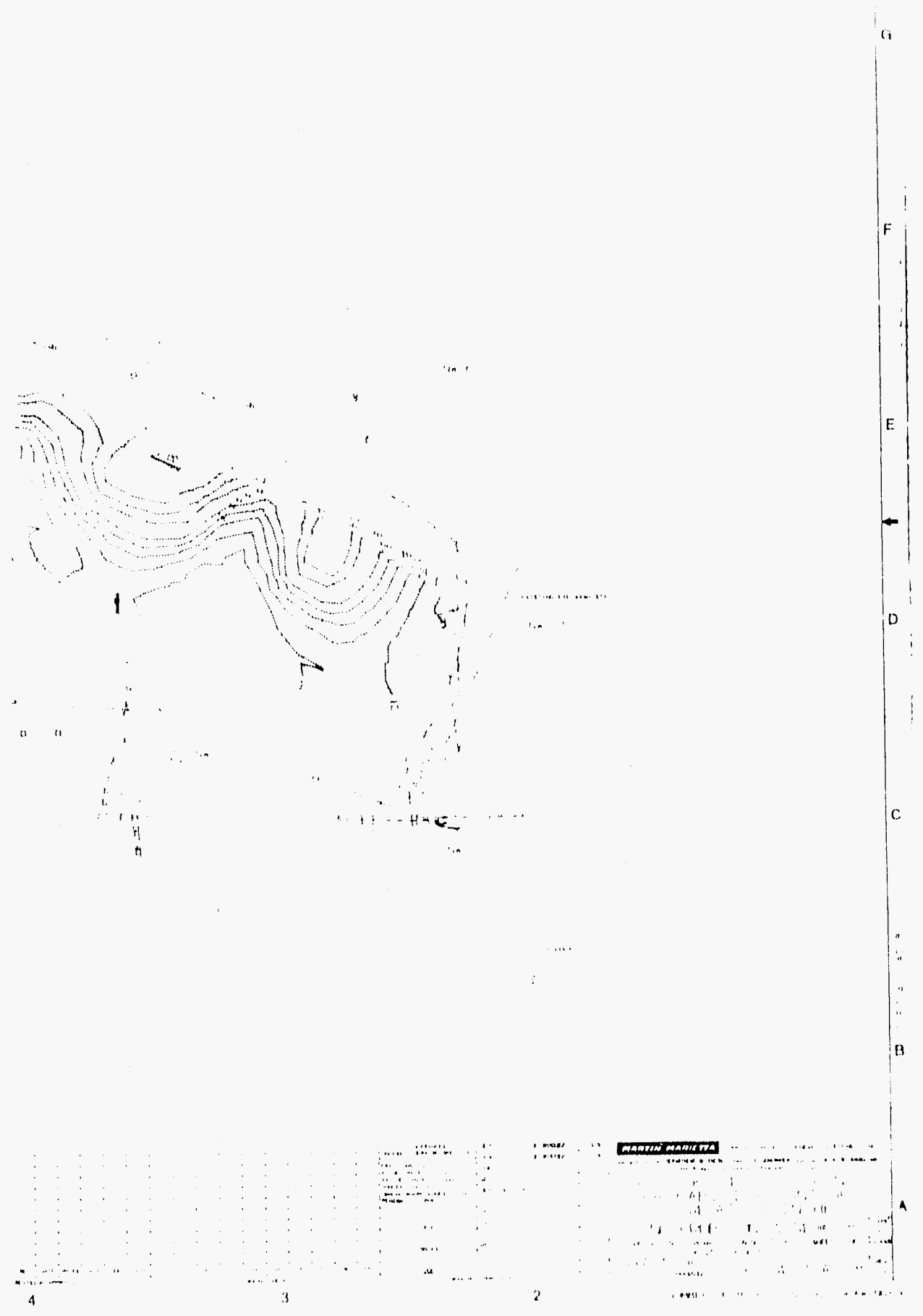

for ${ }^{24} U, 18$ in. samples. 


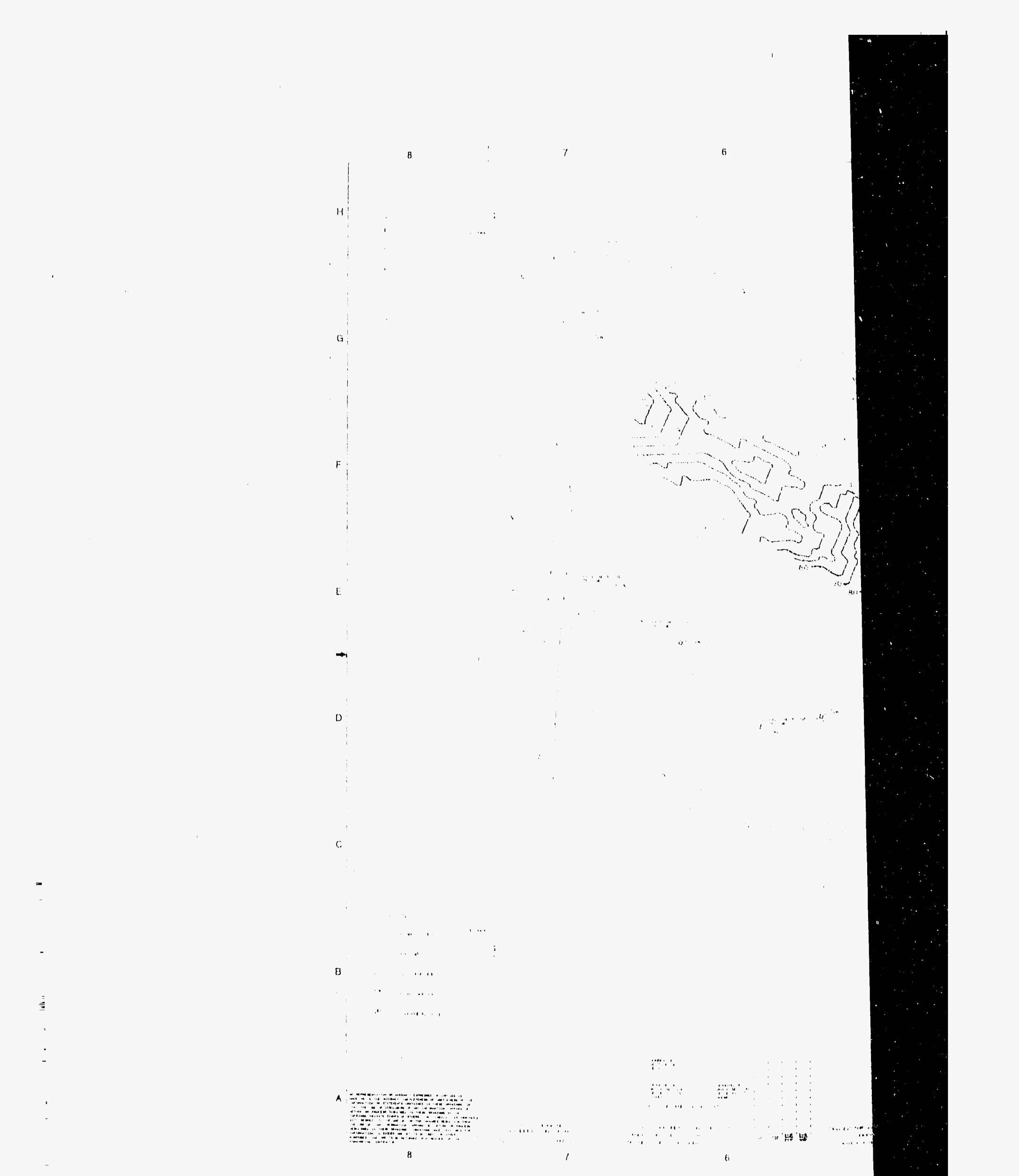



5

F

$E$

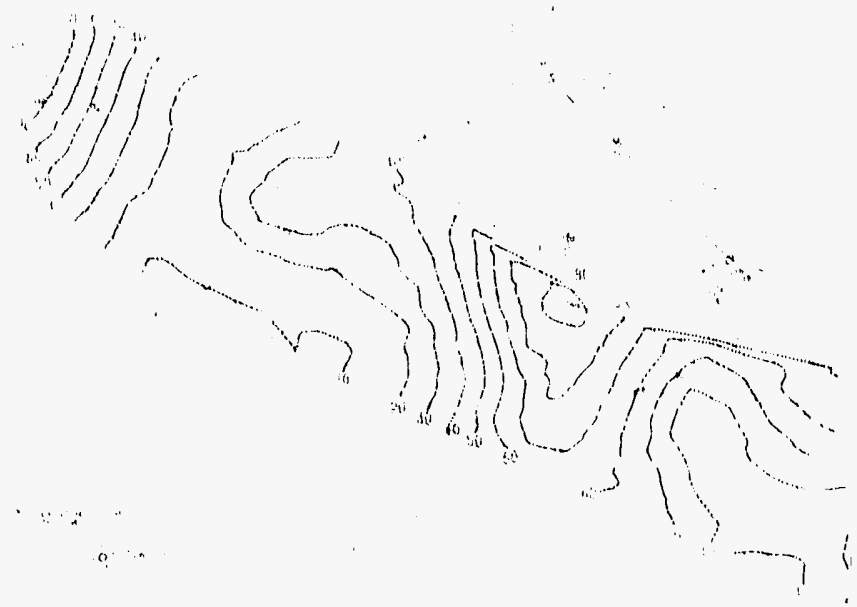

0

B

A $-1,4$

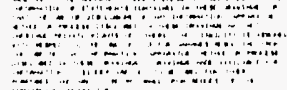

Bs

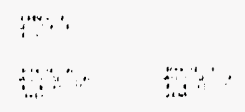

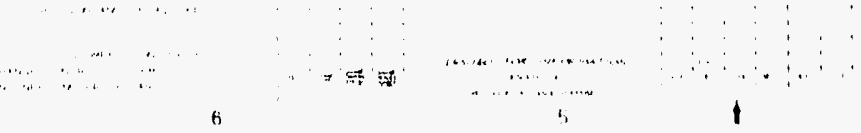

Fig. 44. Probability contour plot for 

11

a

F.

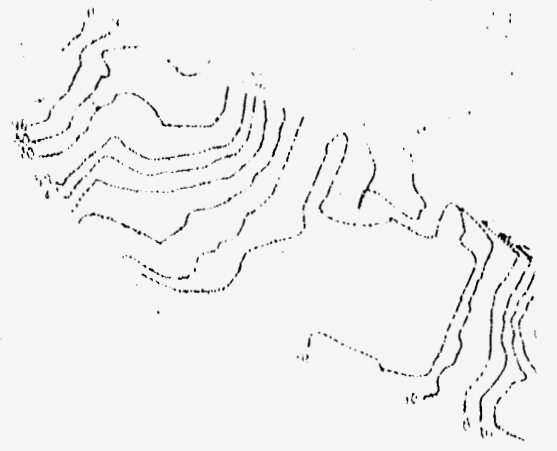

E

o

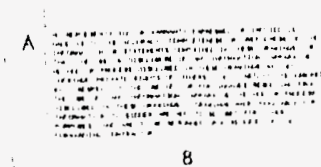

$$
\therefore
$$

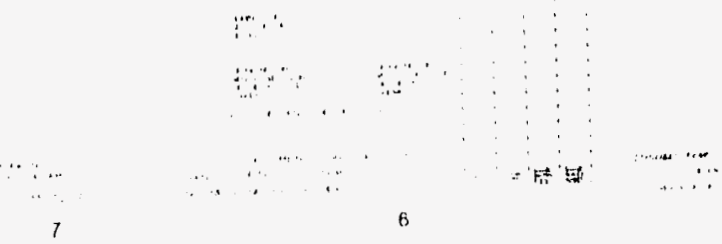

Fig. 45. Probat: 


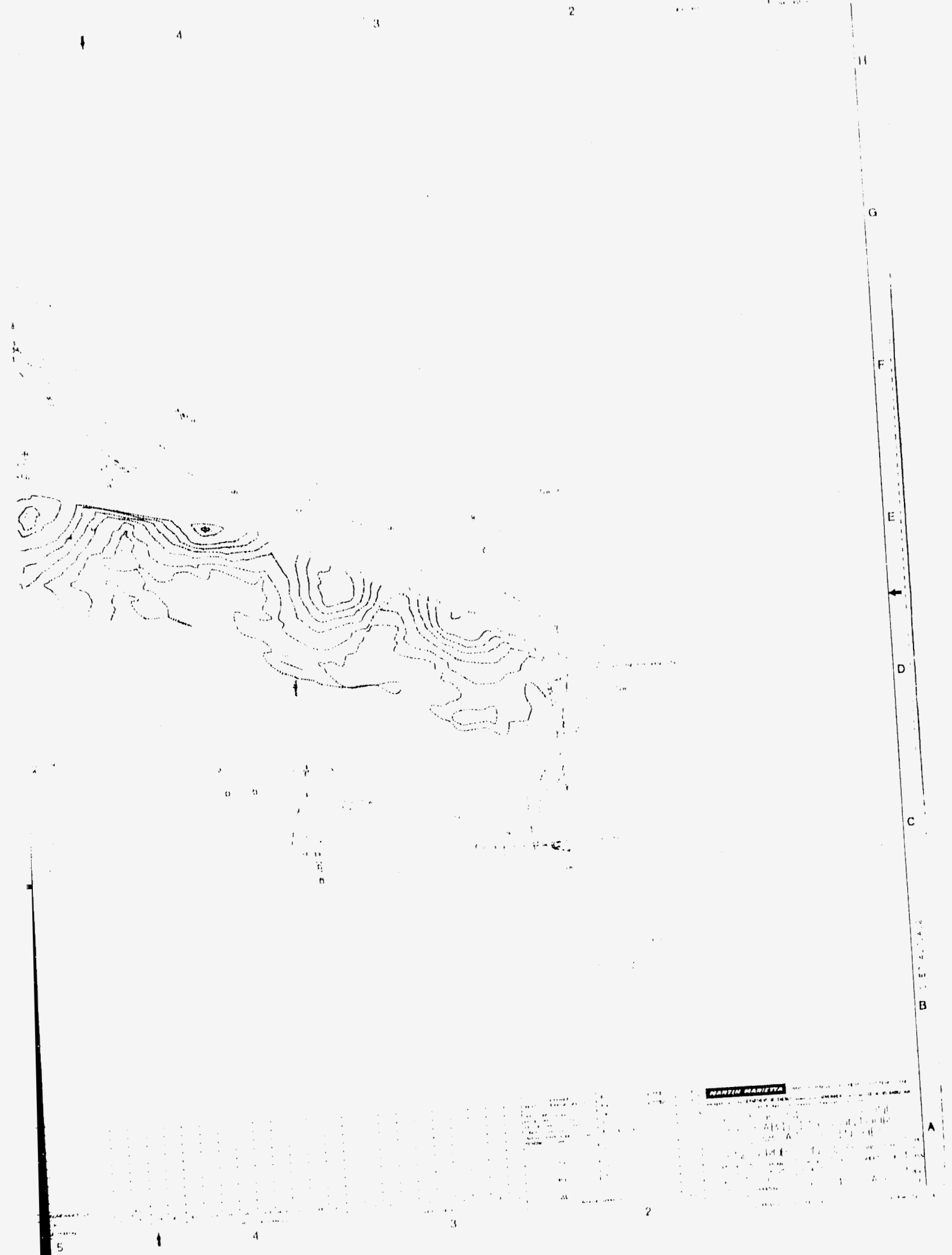

ity contour pket for ${ }^{248} \mathrm{U}, 18$-in. samples. 


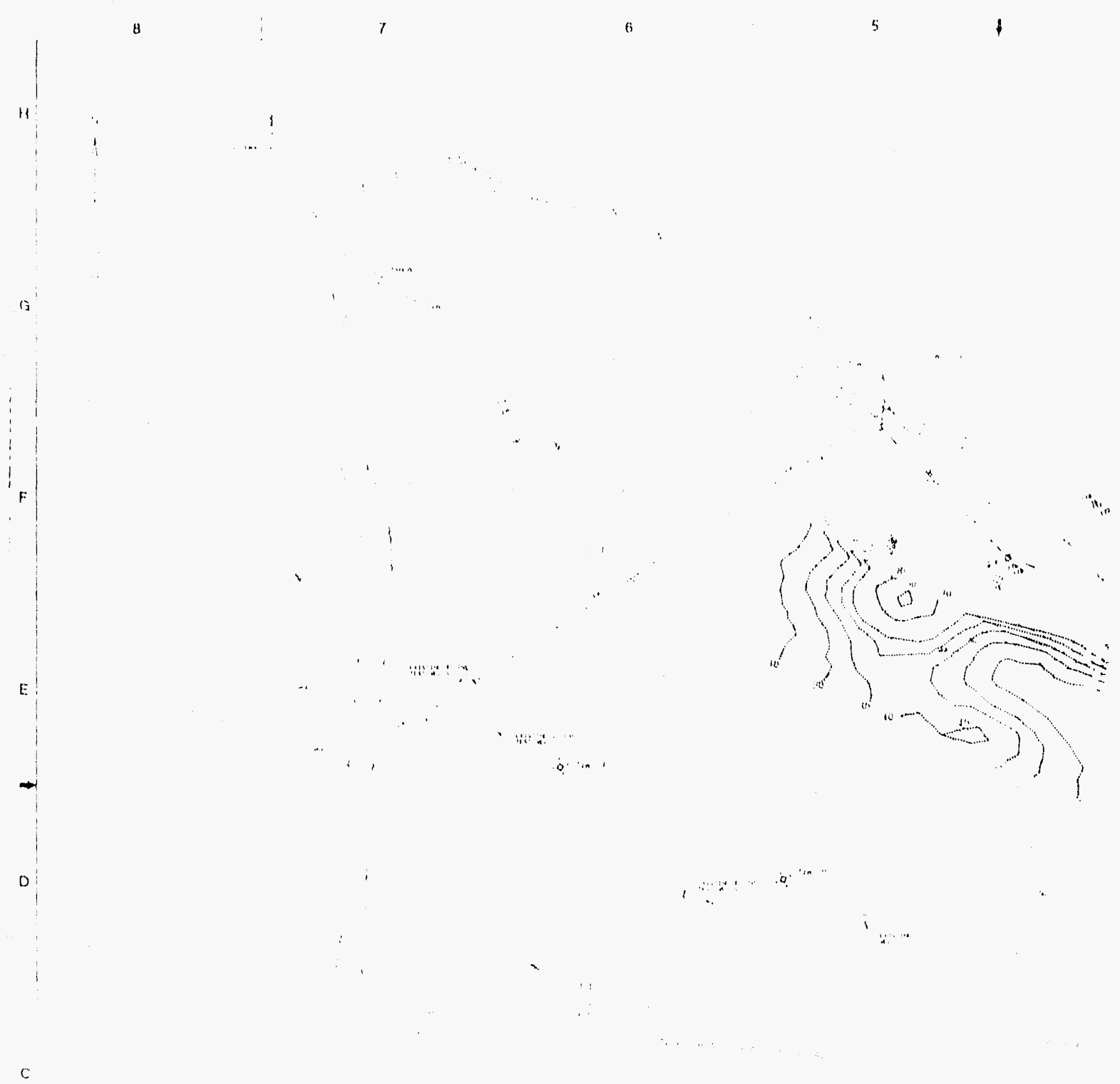

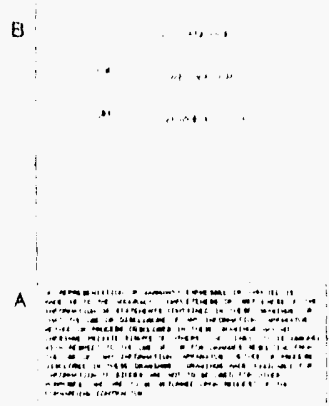

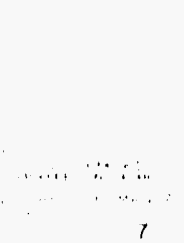

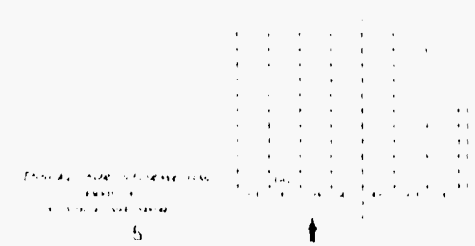

Iing. 46. Probability contour pk: 

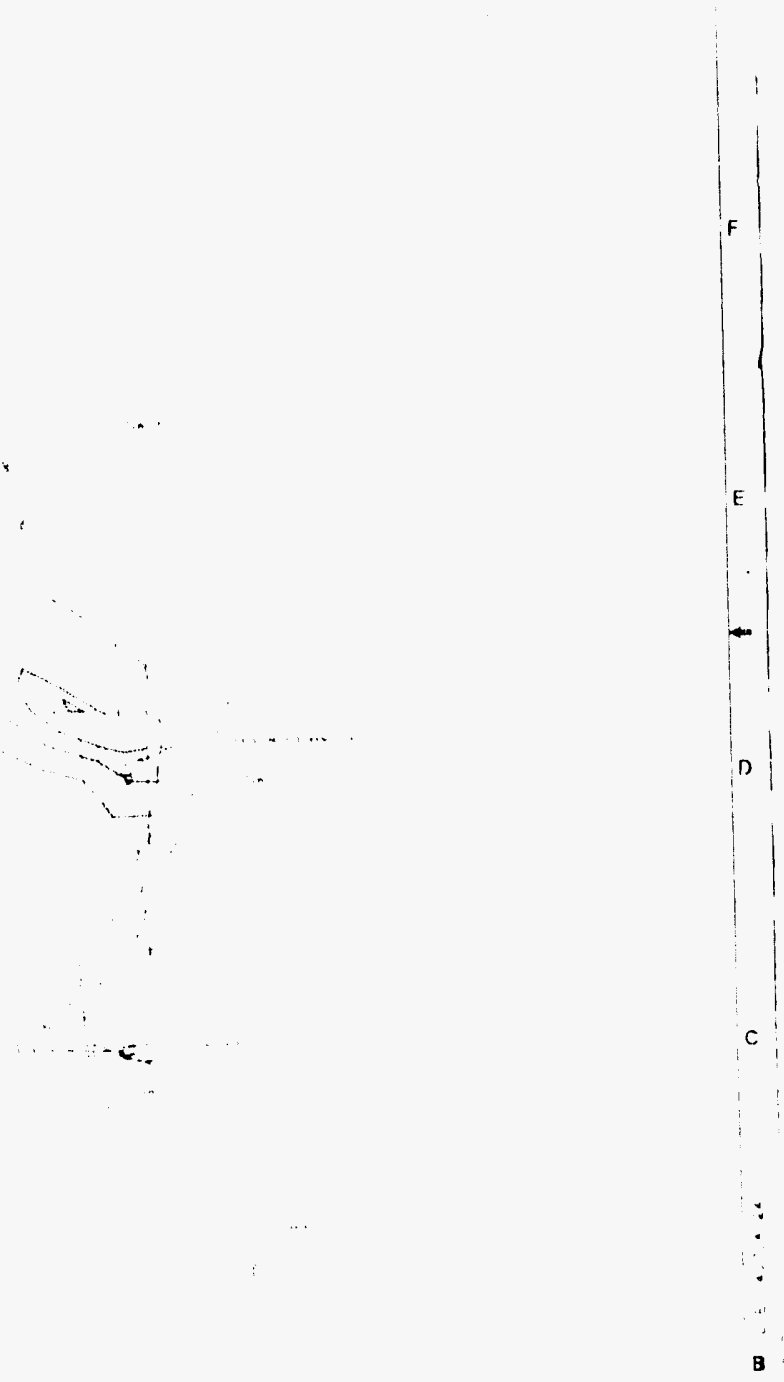

mantere masortan 

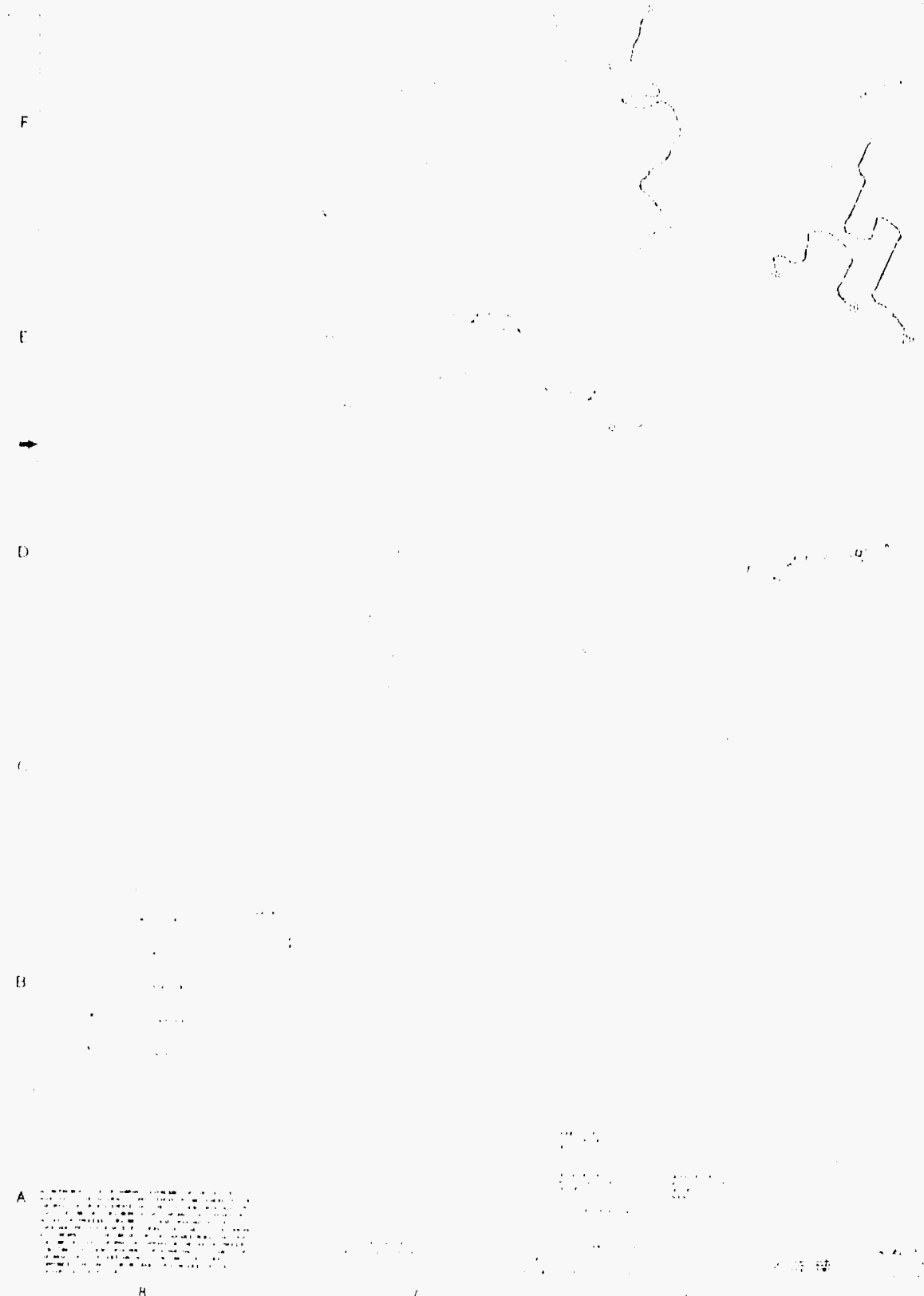


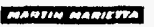




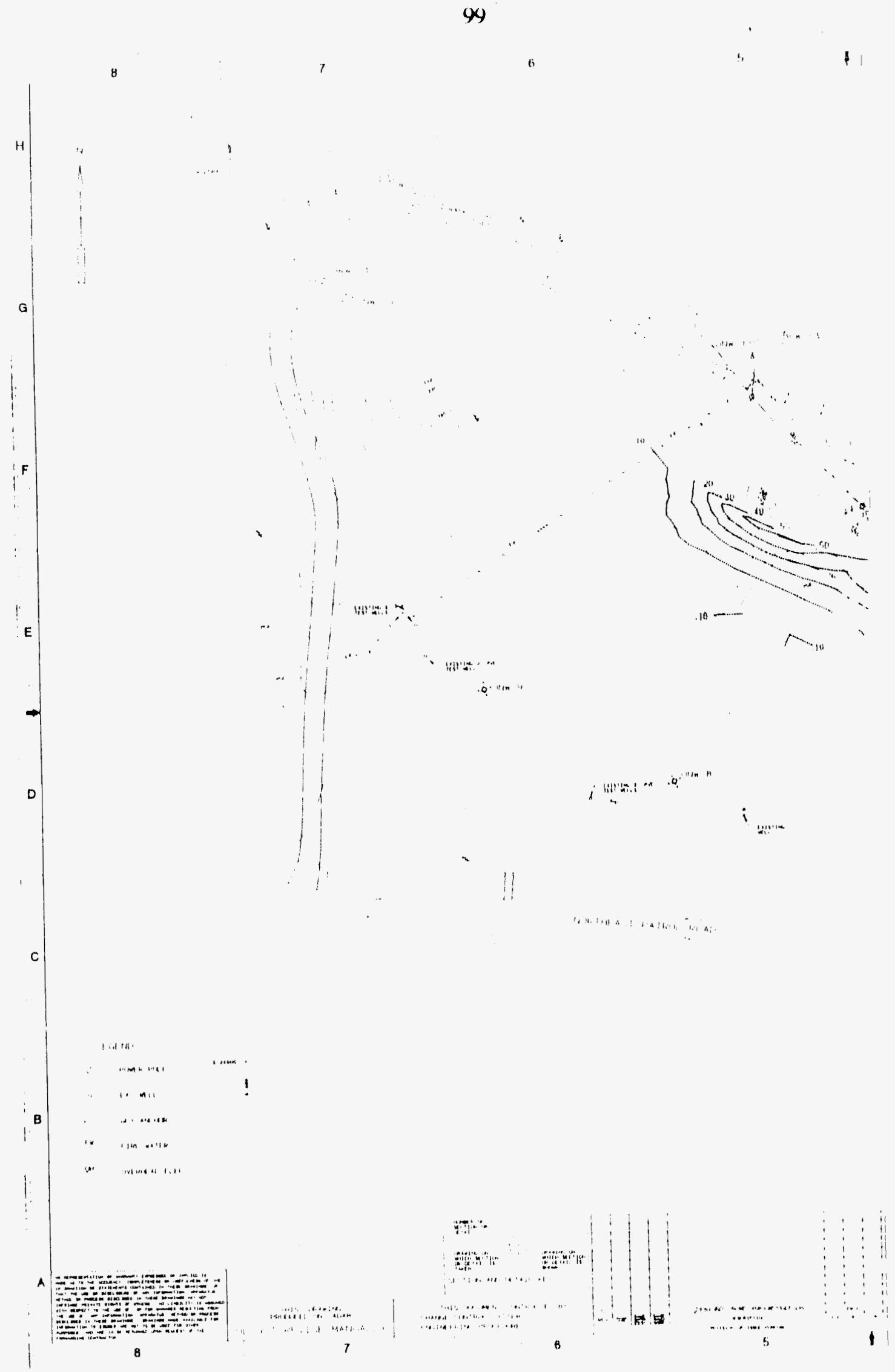

Fig. 4S. Probability conts 


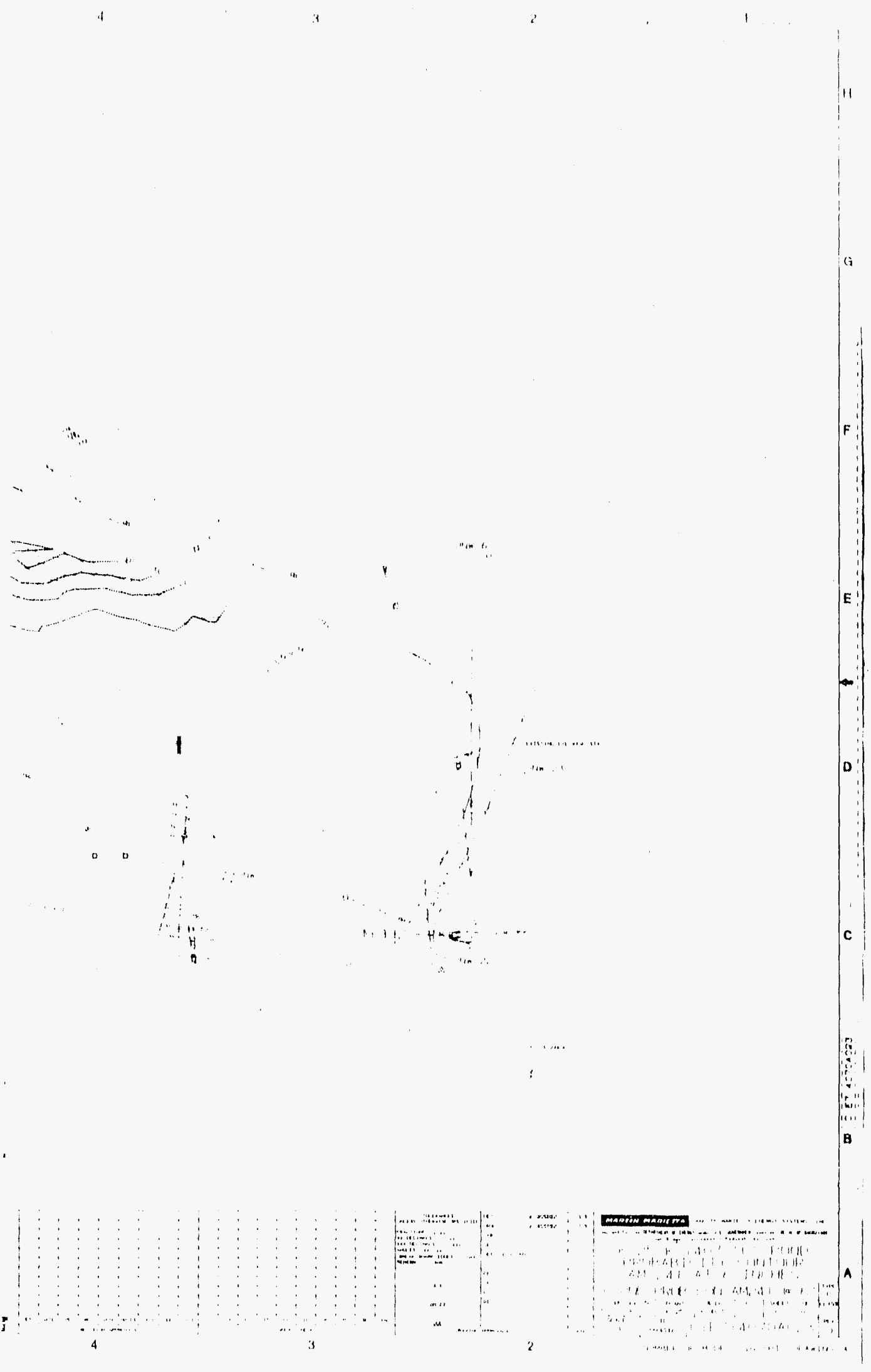

iur pkot for ${ }^{211} \mathrm{Am}, 6$-in. samples. 


\section{CONCLUSIONS AND RIICOMMLNDATIONS}

The investigation of the K-14017.C Retention Basin has not characterized the site well conogh wo support a Remedial Investigation Report/Baseline Risk Assessment. There are several data gaps in the investigation of the K 1407-C Retention Basin that must be alleviated belore characterization of the sitc is complete:

- Additional characterizalion of the hydrogeology of the area is needed in order to determine: the petential for contaminant transport via groundwater. Additionally, to quantify the migralion potential of contaminants via groundwater or surface water, soil parameters influencing tansport must be determined.

- Because samples were not taken below $18 \mathrm{in}$, the depth to which soil contamination extends is unknown.

- Because soil sampling was restricted to the retention basin, the lateral extent of contamination is uncertain. "The lateral extent of contamination is generally believed to be confined w the retention basin; however, sludge removal operations in the area of the northwest bank may have spread contaminants beyond the retention basin.

- Il is diflicult (o) differentiate between naturally oceurring background metal concentrations and metal concentrations related fo site operations because no background samples are available. The results of the Oak Ridge Reservation Hydrology and (ienkgy Study, which is currently being conducted, will include information on natural concentrations of metals in regional soils.

- The radionehemical analysis of soil samples is not complete. Several analyles have not been analyeed for in all samples.

- Equipment rinsate data were not available for metal and mercury samples; consequently, the possibility that samples were contaminated in the field due to incompletely cleaned cquipment camot be evaluated.

- Although there are no established holding fimes for radicxhemical analyses, some holding limes have approached or exceeded 1 year. In addition, since no radiochemical matrix spike data are atvitiable, there is no way to determine whether preparation procedures for the andyles are free from matrix interference effects.

- The health based screening of contaminants detected in soil al the K-1407.C. Retention Basin indicates that samples laken from the 12- to 18 in. interval contain contaminant concentrations exceeding guideline values. Becatuse soil sampling was terminated at a depth ol 18 in., the extent of contamination below this depth and the pertential adverse: heallh effects associated with exposure on soil betow is in. cannot be determined. 
Because of the deficiency of information regarding the physical and contaminant characterization at the site, a comprehensive evaluation of site contamination is not possible. Therefore, additional soil sampling is recommended to determine the lateral extent and depth of radioactive contamination. Additionally, the analysis of any soil samples should include rinsate and matrix spike data. These recommendations will be addressed in $t^{\prime}$. 2 Phase 2 sampling plan. 


\section{REFERENCES}

1. U.S. Environmental Protection Agency, RCRA Facility Investigation (RFI) Guidance, PB89-200299, May 1989.

2. Oak Ridge Gaseous Diffusion Plant, Closure Plan: K-1407-C Retention Basin, K/HS221, Martin Marietta Energy Systems, Inc., Oak Ridge, Tennessee, May 1988.

3. Environmental Restoration Division, K-25 Environmental Restoration Program, Closure Plan: K-1407-C Retention Basin, Revision 2, K/ER-27 and K/HS-221/R2, Martin Marietta Energy Systems, Inc., Oak Ridge, Tennessee, April 1990.

4. Ref. 3, p. 15.

5. Ref. 3, Appendix 5.

6. Environmental Restoration Division, K-25 Environmental Restoration Program, Site Characterization Summary, K-1407-C Retention Basin, K/ER-33, Martin Marietta Energy Systems, Inc., Oak Ridge, Tennessee, May 1990.

7. P. D. Miller, Data Analysis Approach Report for K-1407-B Holding Pond and K-1407-C Retention Basin, K/ER-23, Martin Marietta Energy Systems, Inc., Oak Ridge, Tennessee, September 1990.

8. Oak Ridge Gaseous Diffusion Plant, RCRA Facility Investigation Plan General Document, Oak Ridge Gaseous Diffusion Plant, Oak Ridge, Tennessee, K/HS-132, Revision 1, Martin Marietta Energy Systems, Inc., Oak Ridge, Tennessee, May 1989.

9. U.S. Department of Energy, Environmental Assessment of the Oak Ridge Gaseous Diffusion Plant Site, Oak Ridge, Tennessee, 1979.

10. T. W. Oakes et al., Environmental Surveillance of the U. S. Department of Energy Oak Ridge Reservation and Surrounding Environs During 1986, ES/ESH-1/V2, Martin Marietta Energy Systems, Oak Ridge, Tennessee, April 1987.

11. Environment, Safety, and Health, Oak Ridge National Laboratory, Environmental Surveillance of the Oak Ridge Reservation and Surrounding Environs During 1986, ORNL6271, Martin Marietta Energy Systems, Inc., Oak Ridge National Laboratory, Oak Ridge, Tennessee, 1986.

12. Ref. 8, p. 59 .

13. Ref. 8, p. 60 .

14. Ref. 8 , pp. $5-6$. 
15. Oak Ridge Gaseous Diffusion Plant, Oak Ridge Gaseous Diffusion Plant Remedial Action Program Data Management Plan, K/HS-232, Revision 1, Martin Marietta Energy Systems, Inc., Oak Ridge, Tennessee, December 1988.

16. U.S. Environmental Protection Agency, Risk Assessment Guidance for Superfund, Volume I: Human Health Evaluation Manual (Part A), EPA/540/1-89/002, U.S. Environmental Protection Agency, Washington, D.C., December 1989 (interim final).

17. U.S. Environmental Protection Agency, Health Effects Assessment Summary Tables, OERR 9200.6-303 (90-3), U.S. Environmental Protection Agency, Washington, D.C., July 1990.

18. Integrated Risk Information System [data base], U.S. Environmental Protection Agency, Environmental Criteria Assessment Office, Cincinnati, Ohio, December 1990.

19. K. E. Eckerman and M. W. Young, A Method for Calculating Residual Radioactivity Levels Following Decommissioning, NUREG-0707, U.S. Nuclear Regulatory Commission, Office of Standards Development, Washington, D.C., October 1980.

20. George A. Sehmel, "Deposition and Resuspension," in Atmospheric Science and Power Production, DOE/TIC-27601, edited by D. Randerson, Technical Information Center, Office of Scientific and Technical Information, U.S. Department of Energy, 1984.

21. Blount County, Tennessee, Soil Survey, Series 1953, No. 7, U.S. Department of Agriculture, 1959.

22. M. Hollander and D. A. Wolfe, Nonparametric Statistical Methods, John Wiley and Sons, New York, 1973, p. 125. 
Appendix A

GAMMA EXPOSURE RATES AND BETA-GAMMA DOSE RATES 


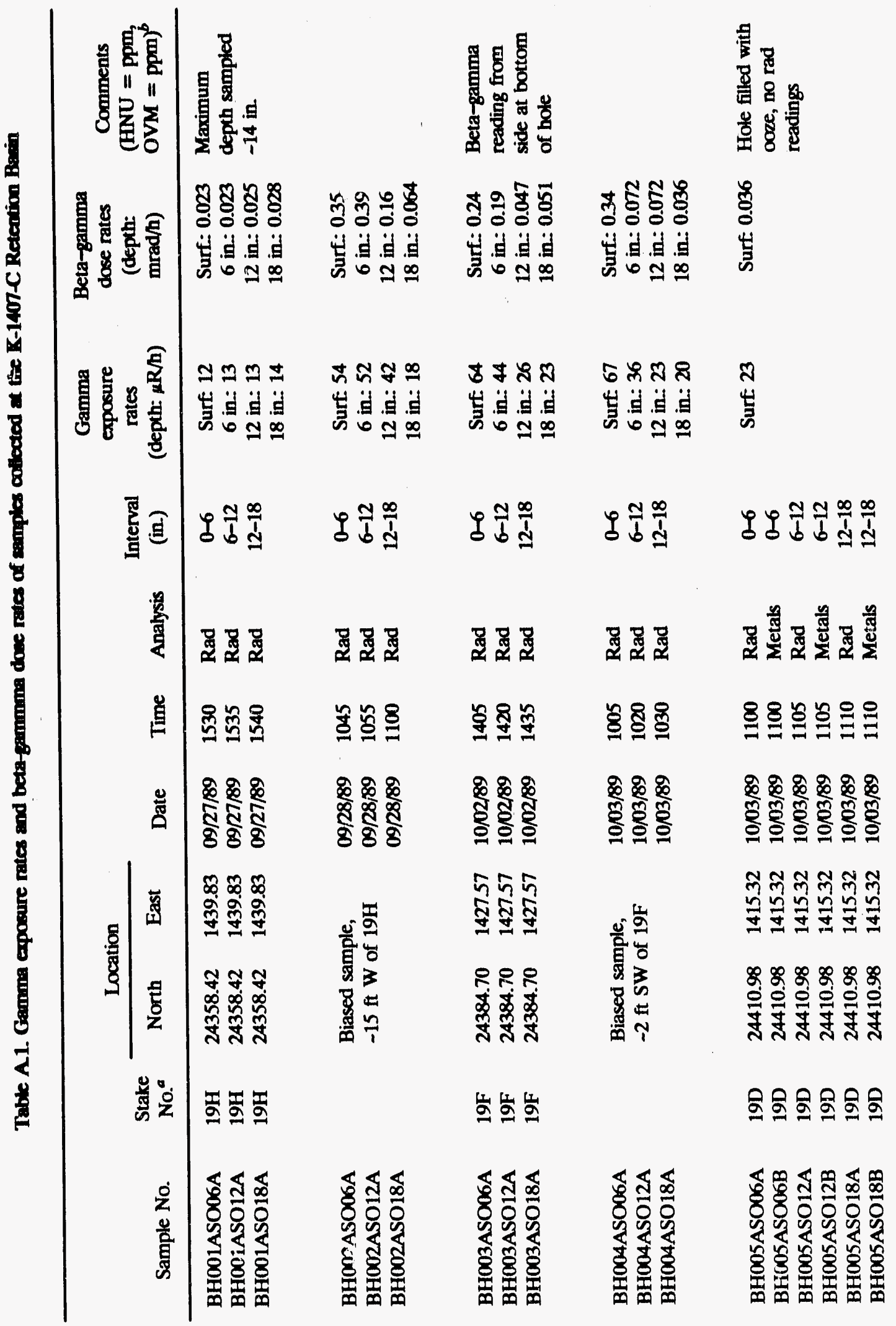




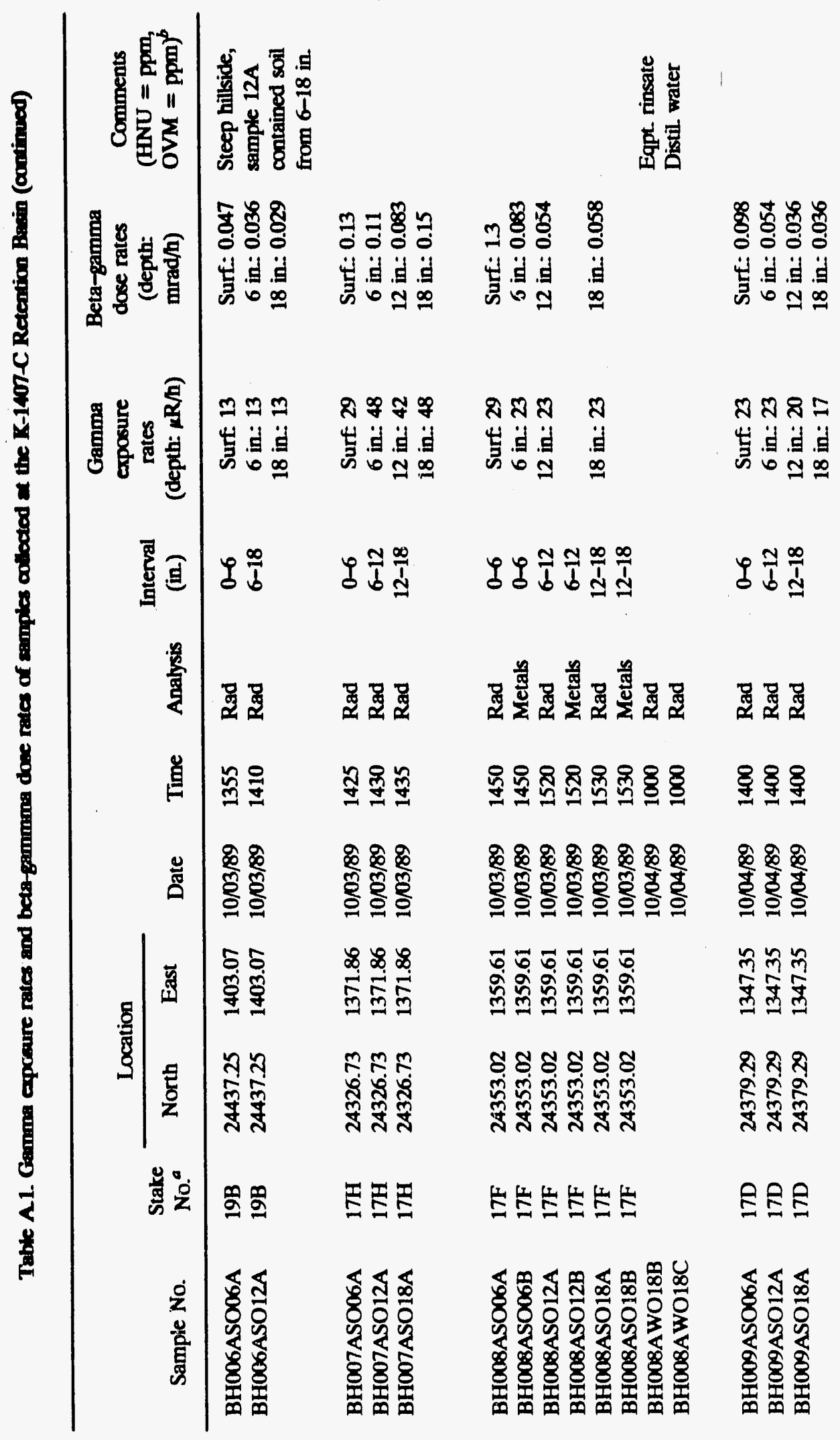




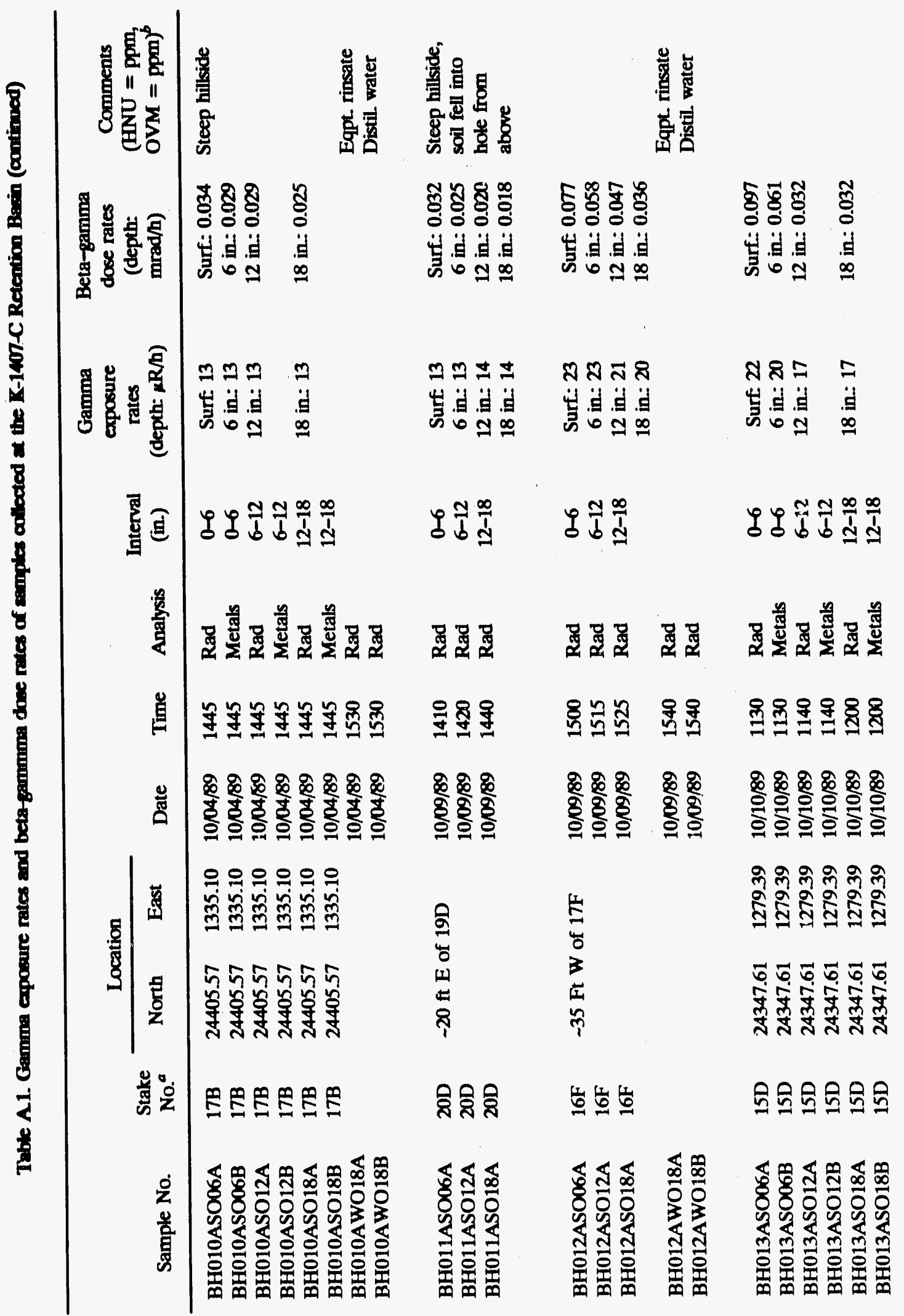




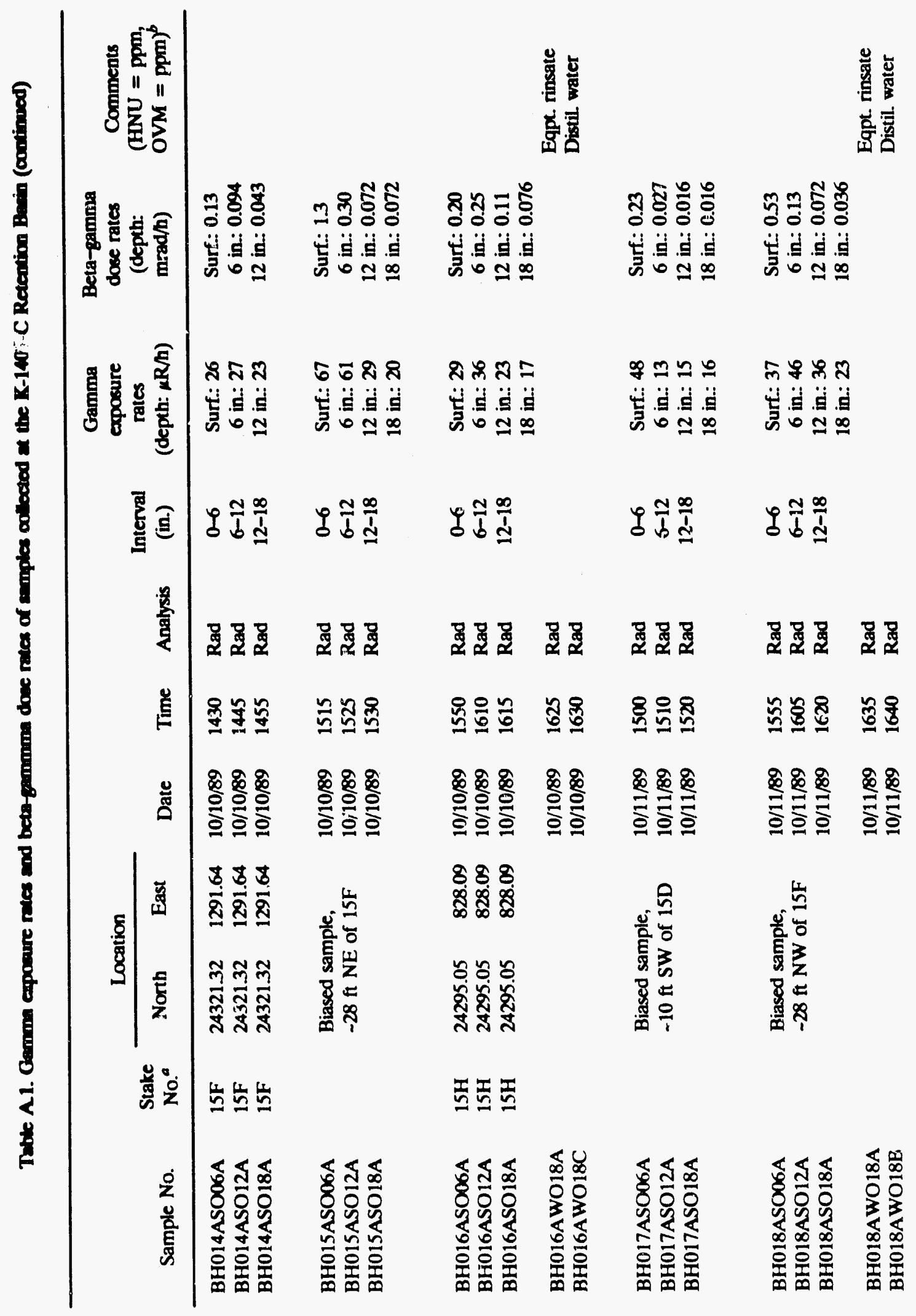




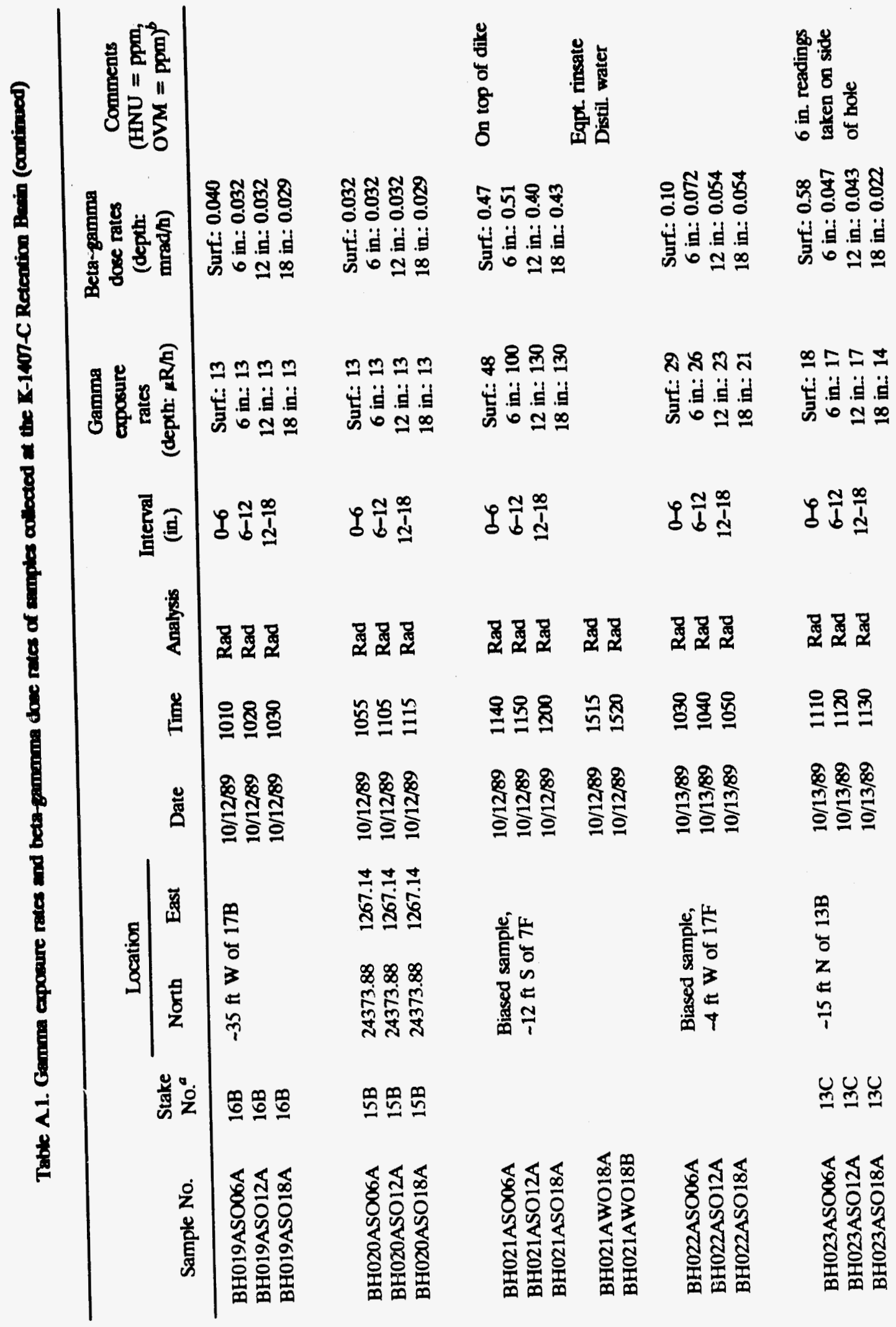




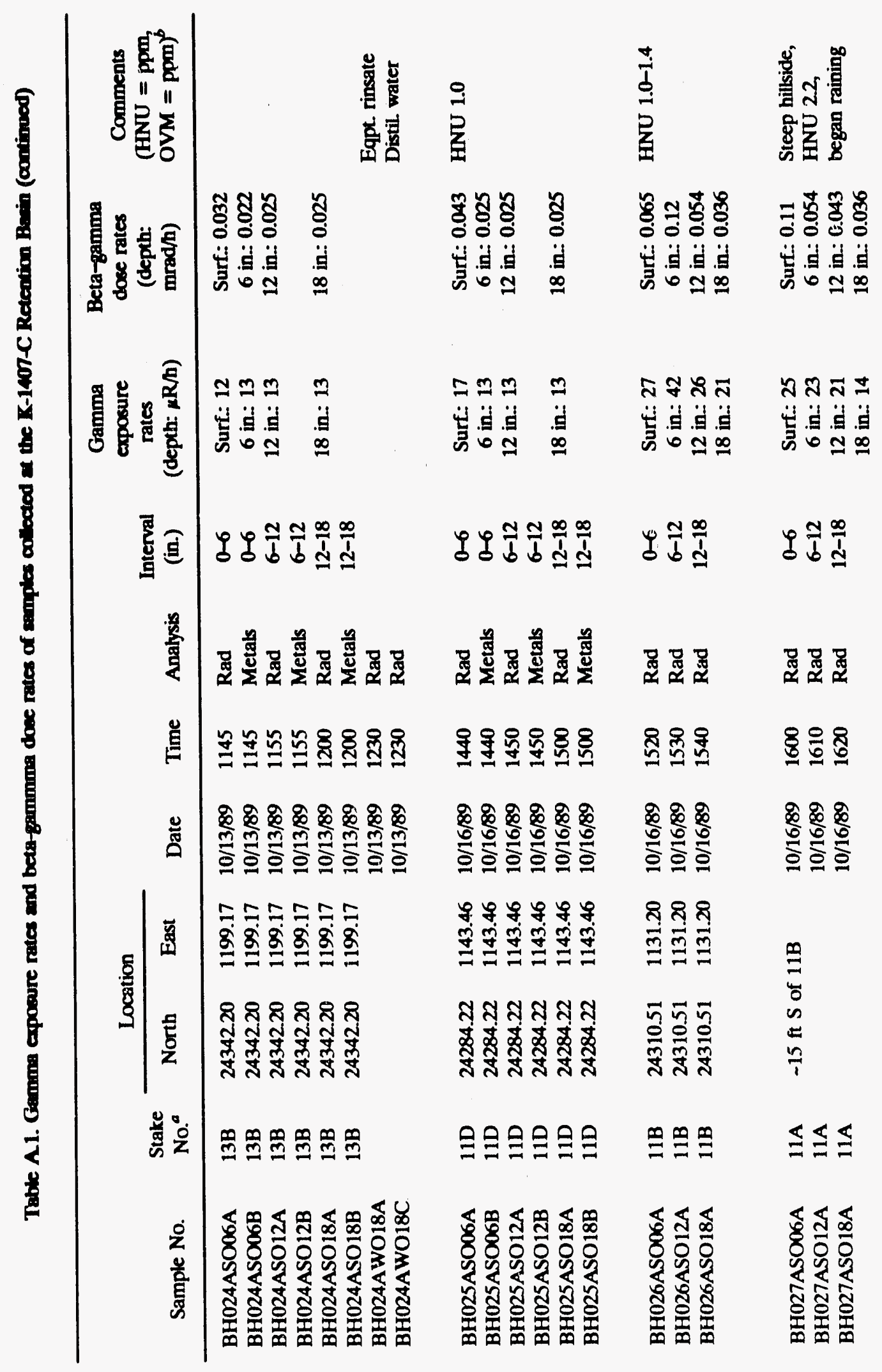




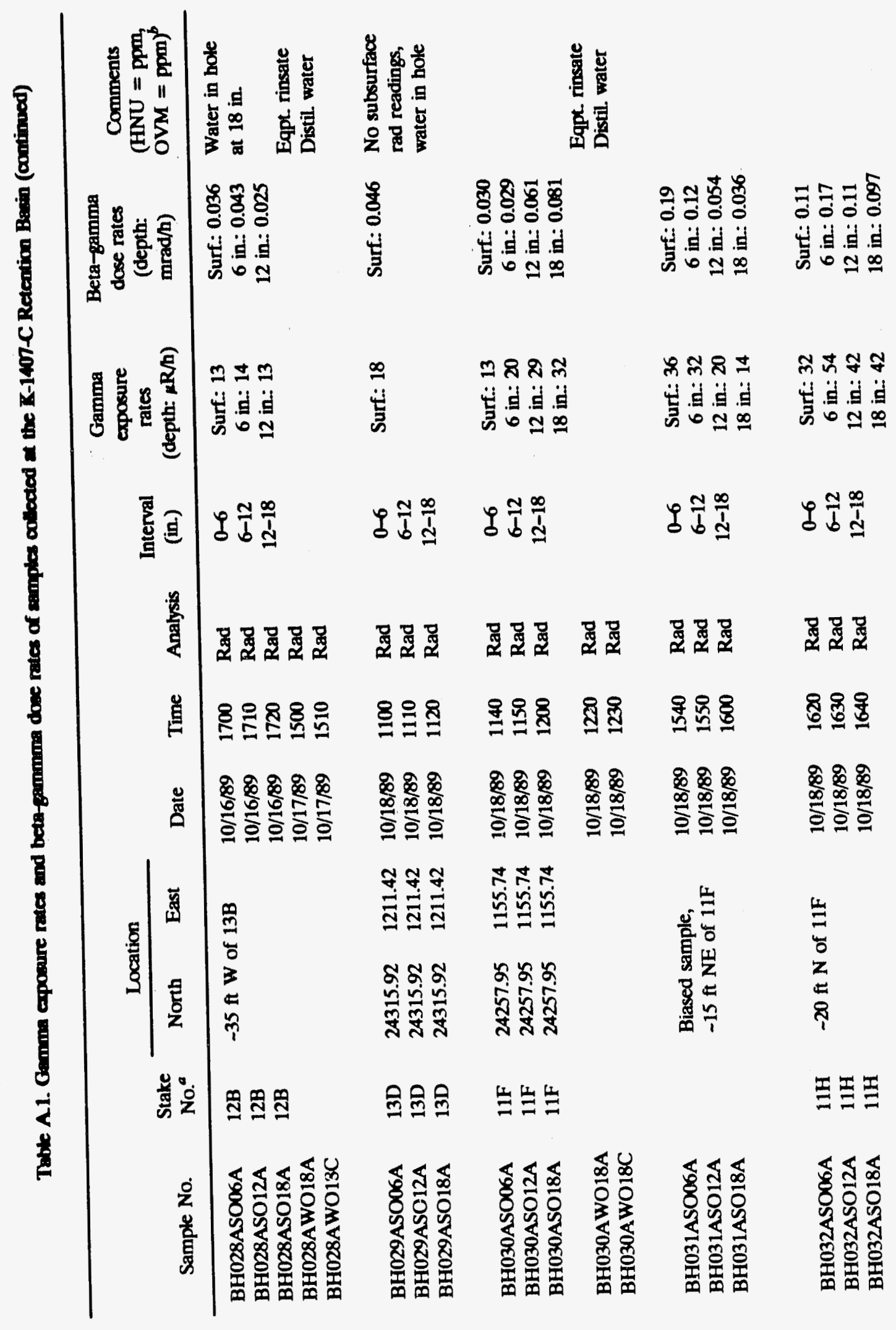




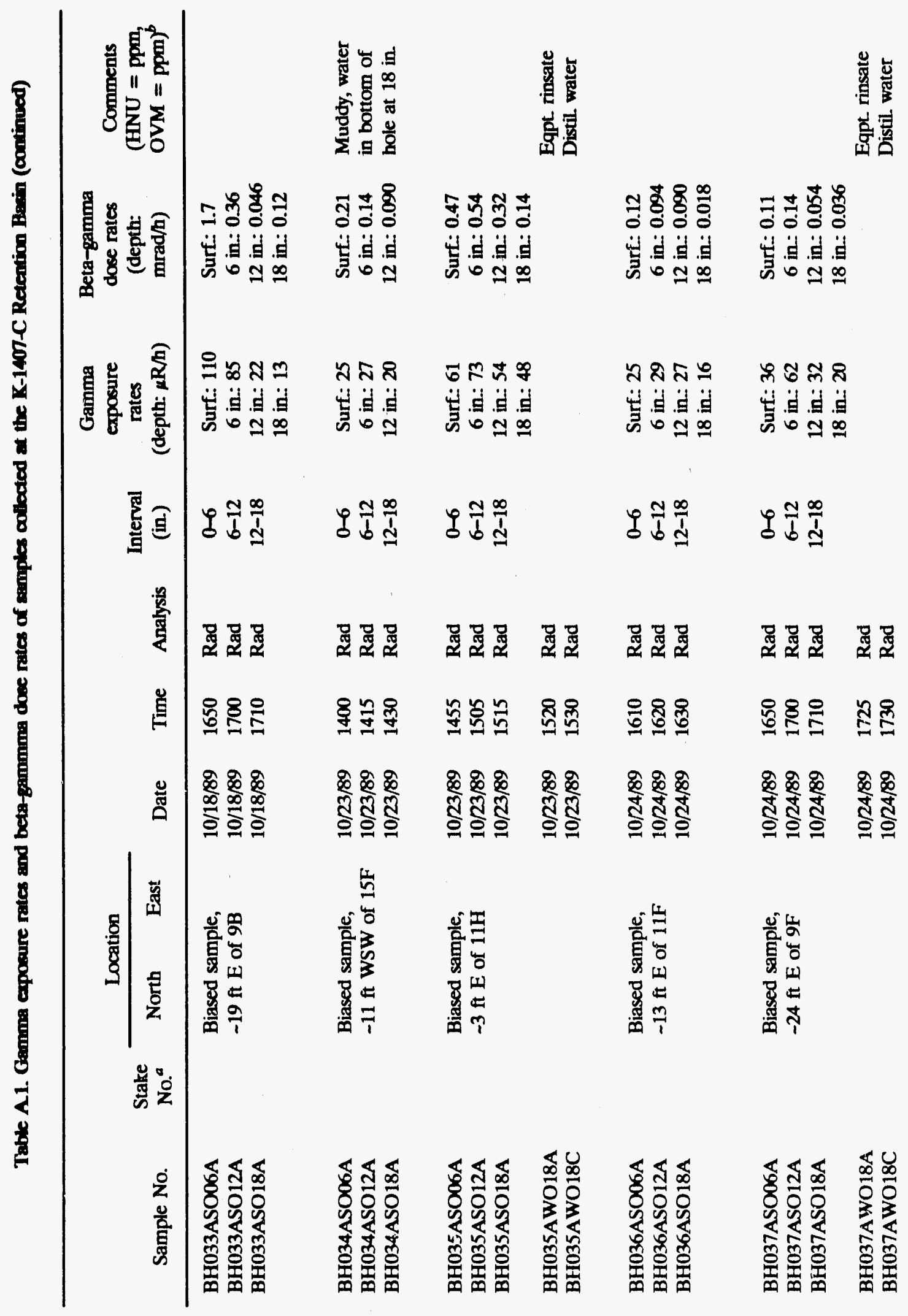




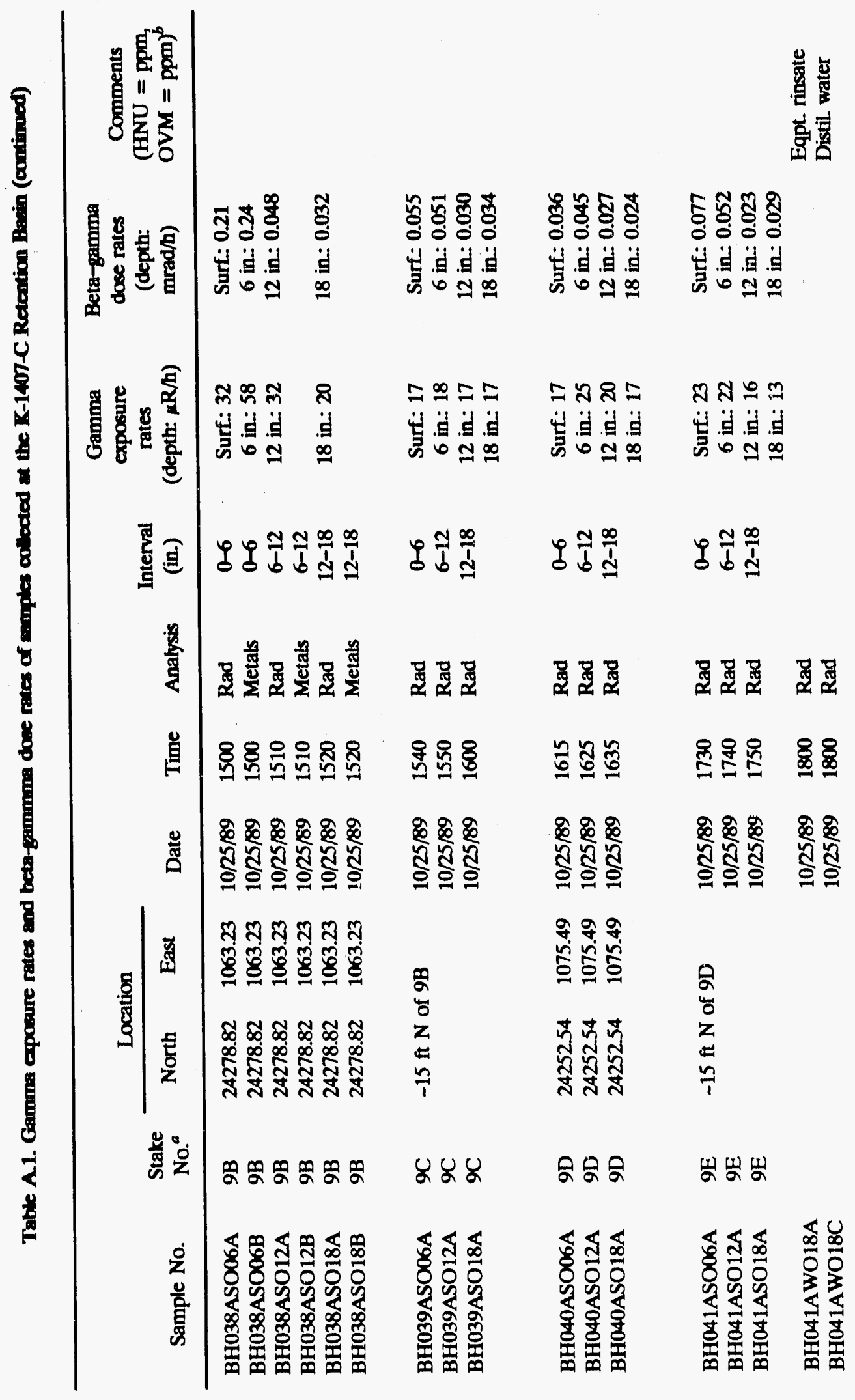




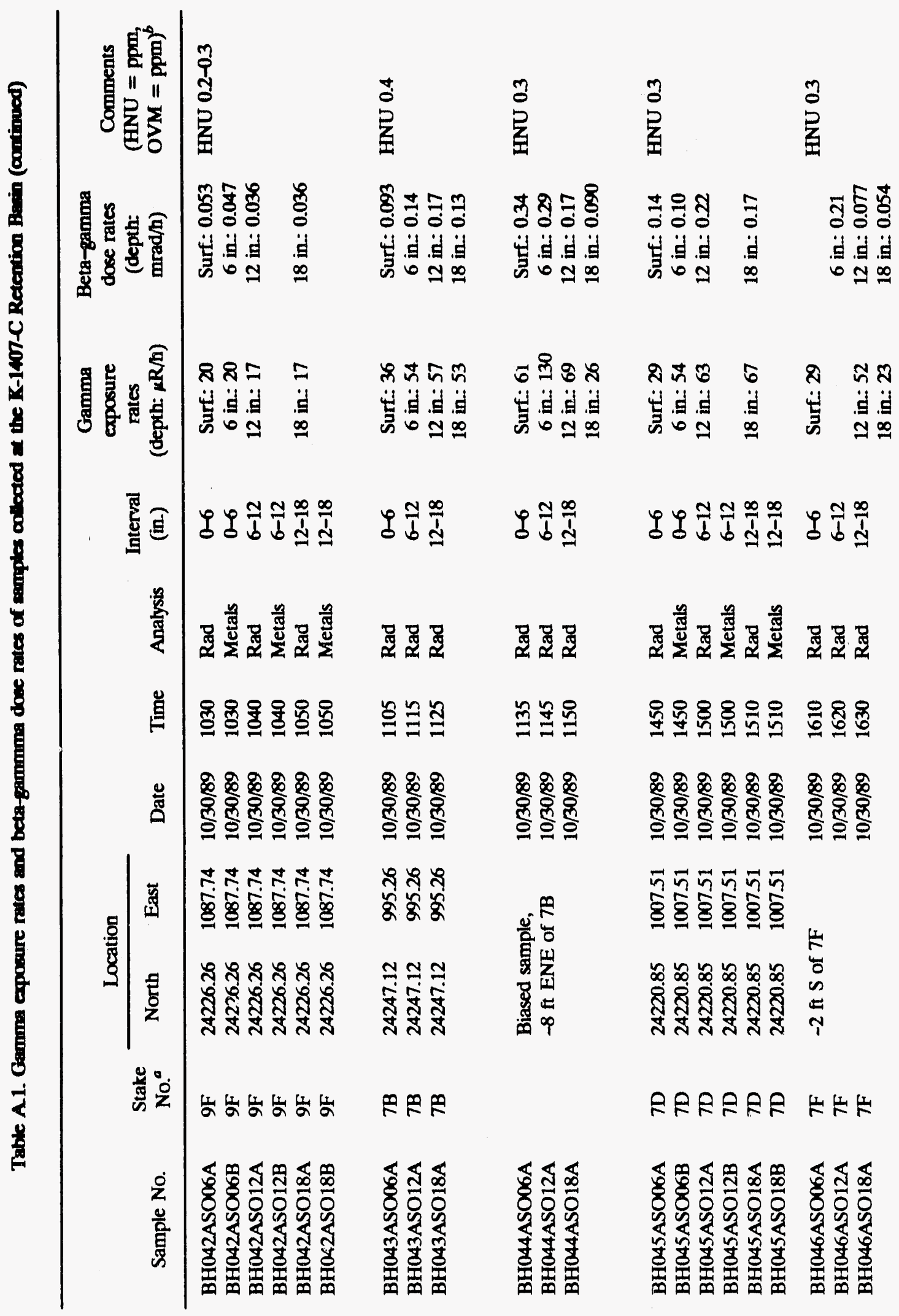




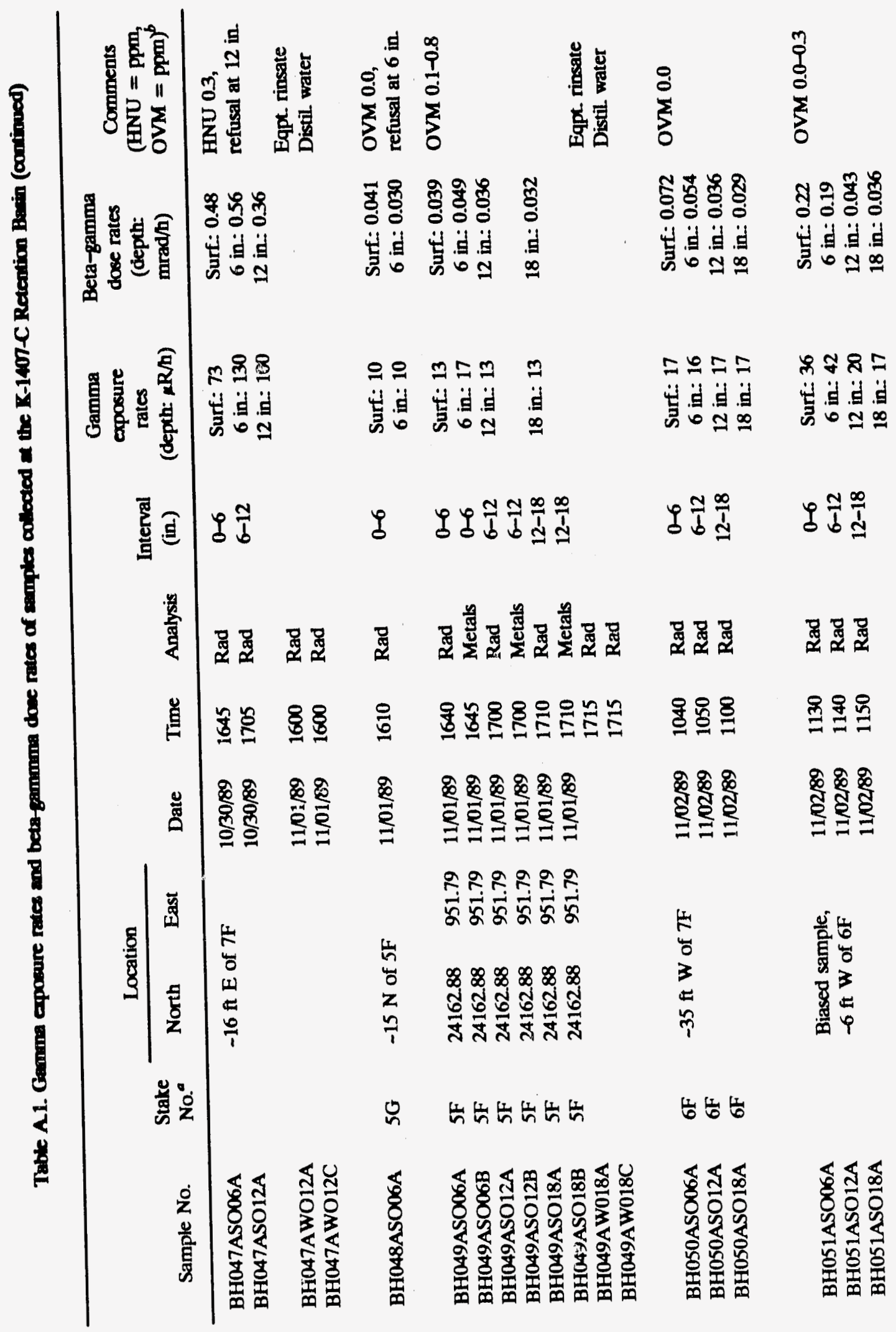




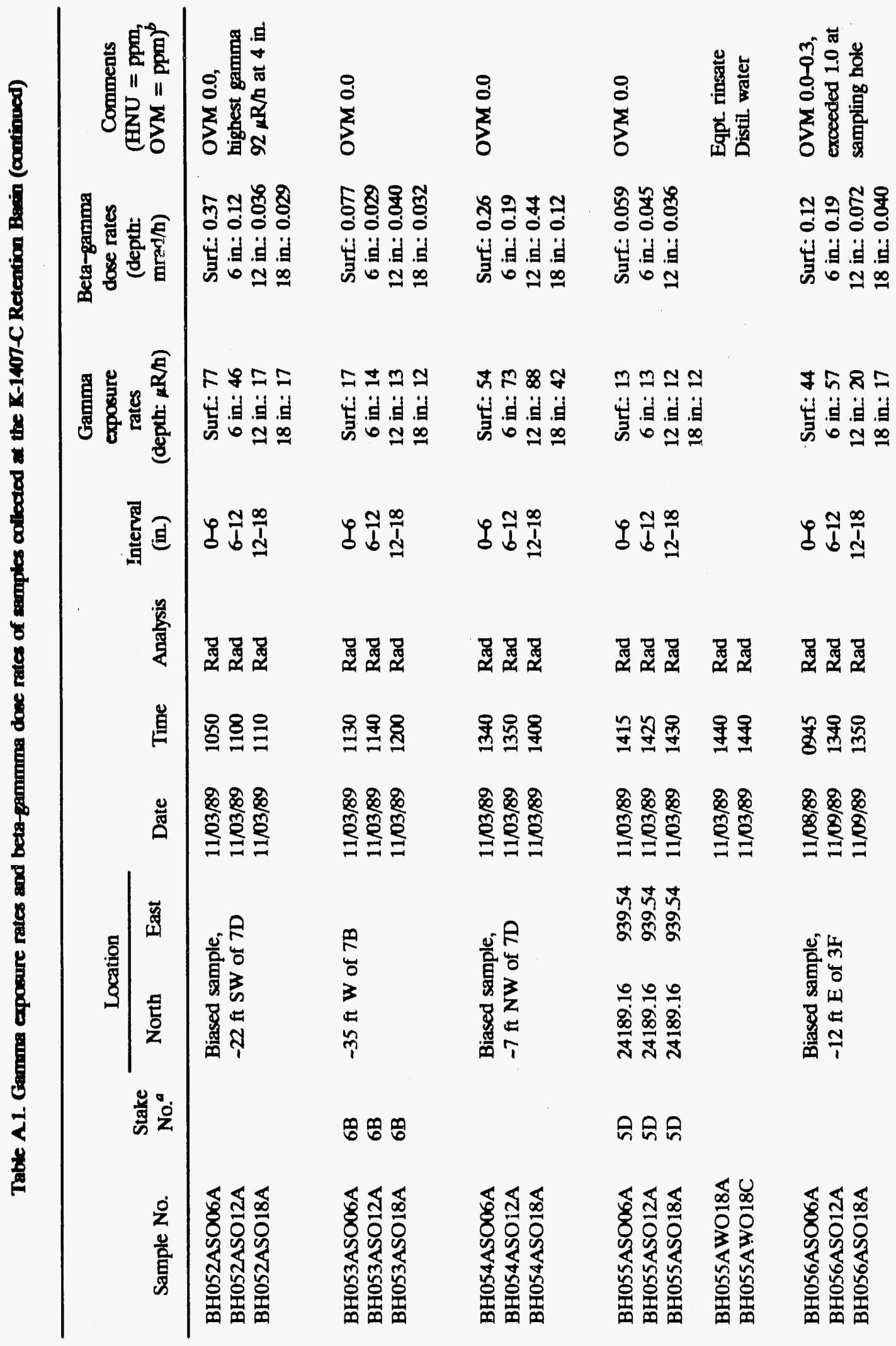




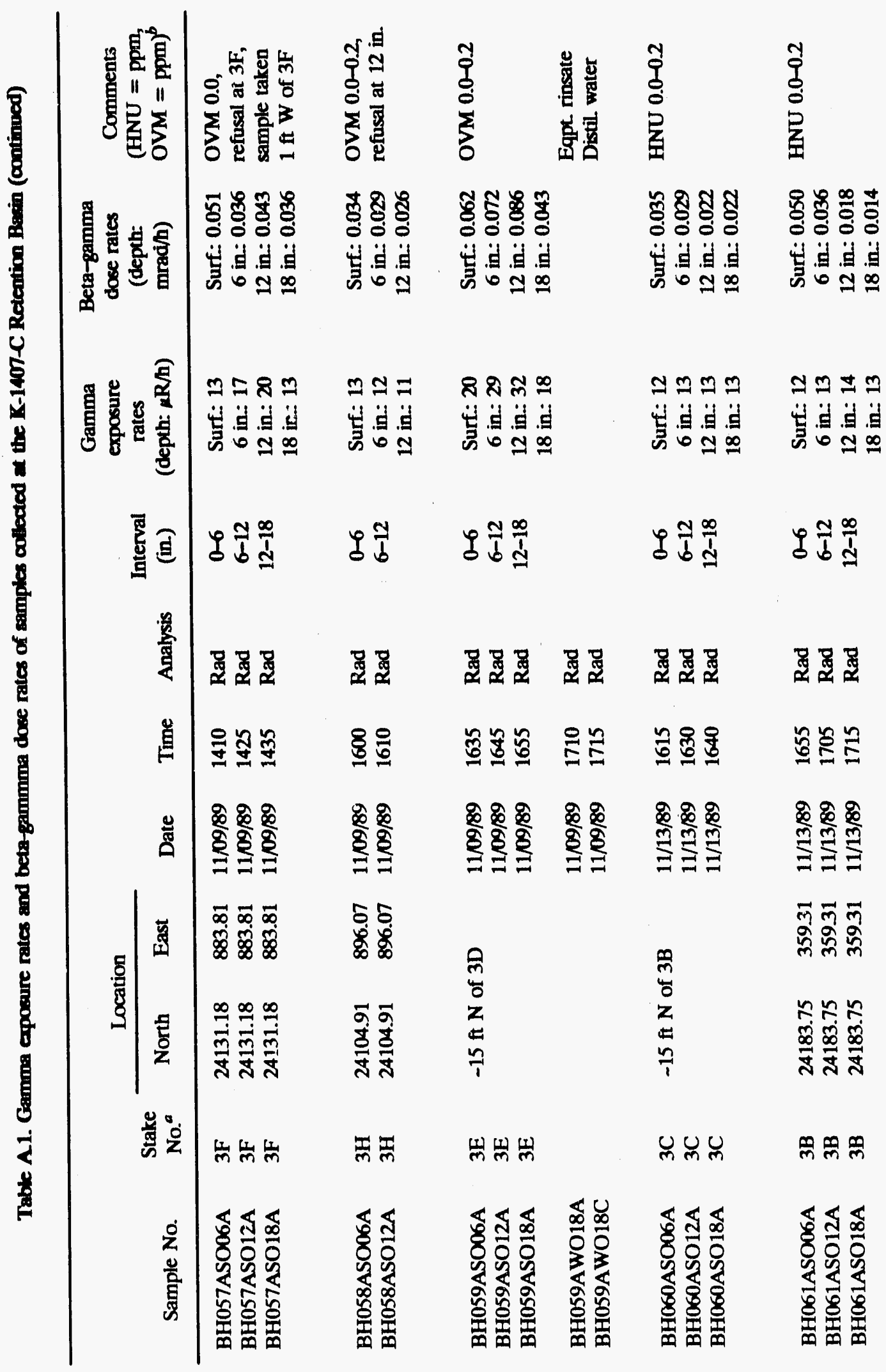




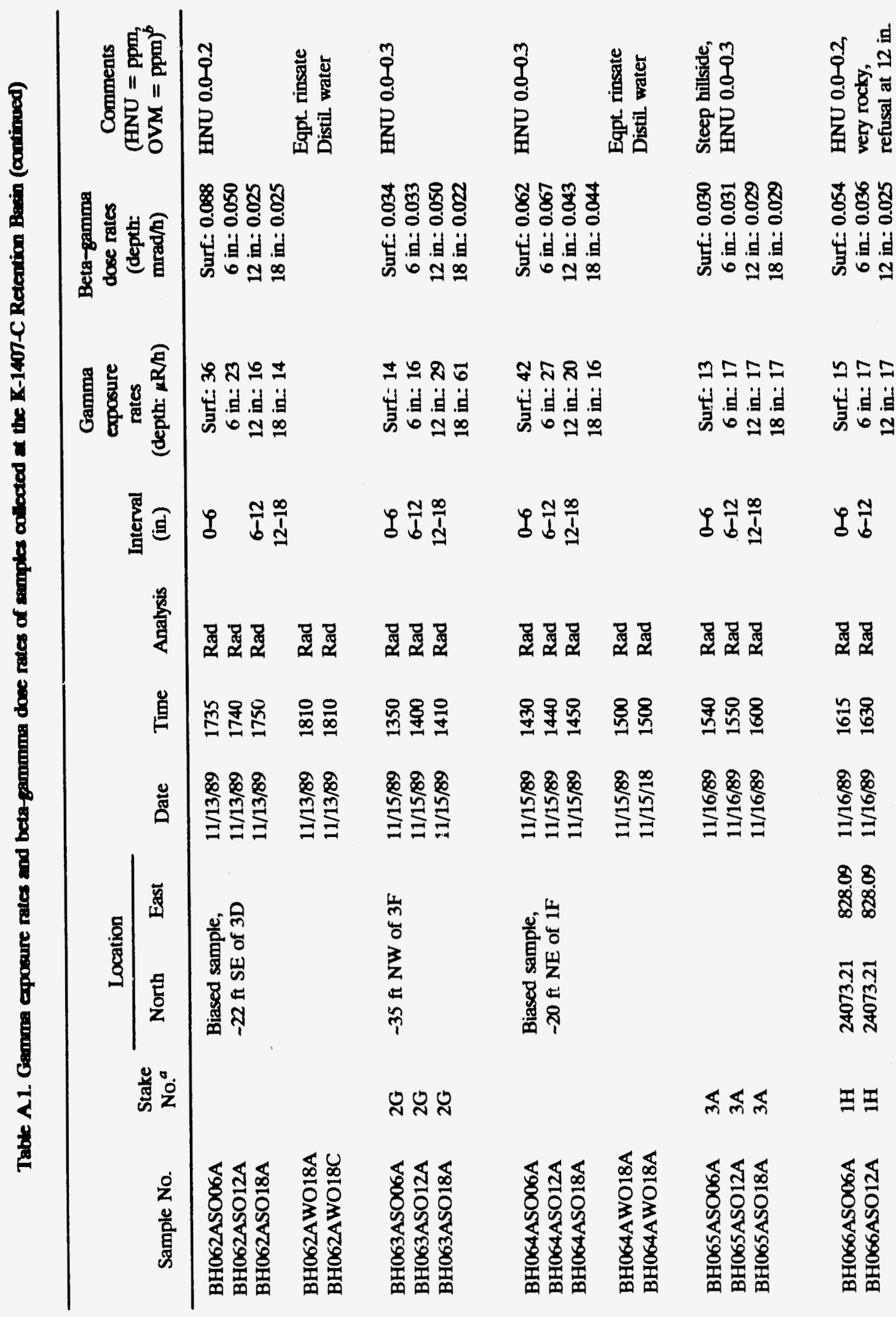




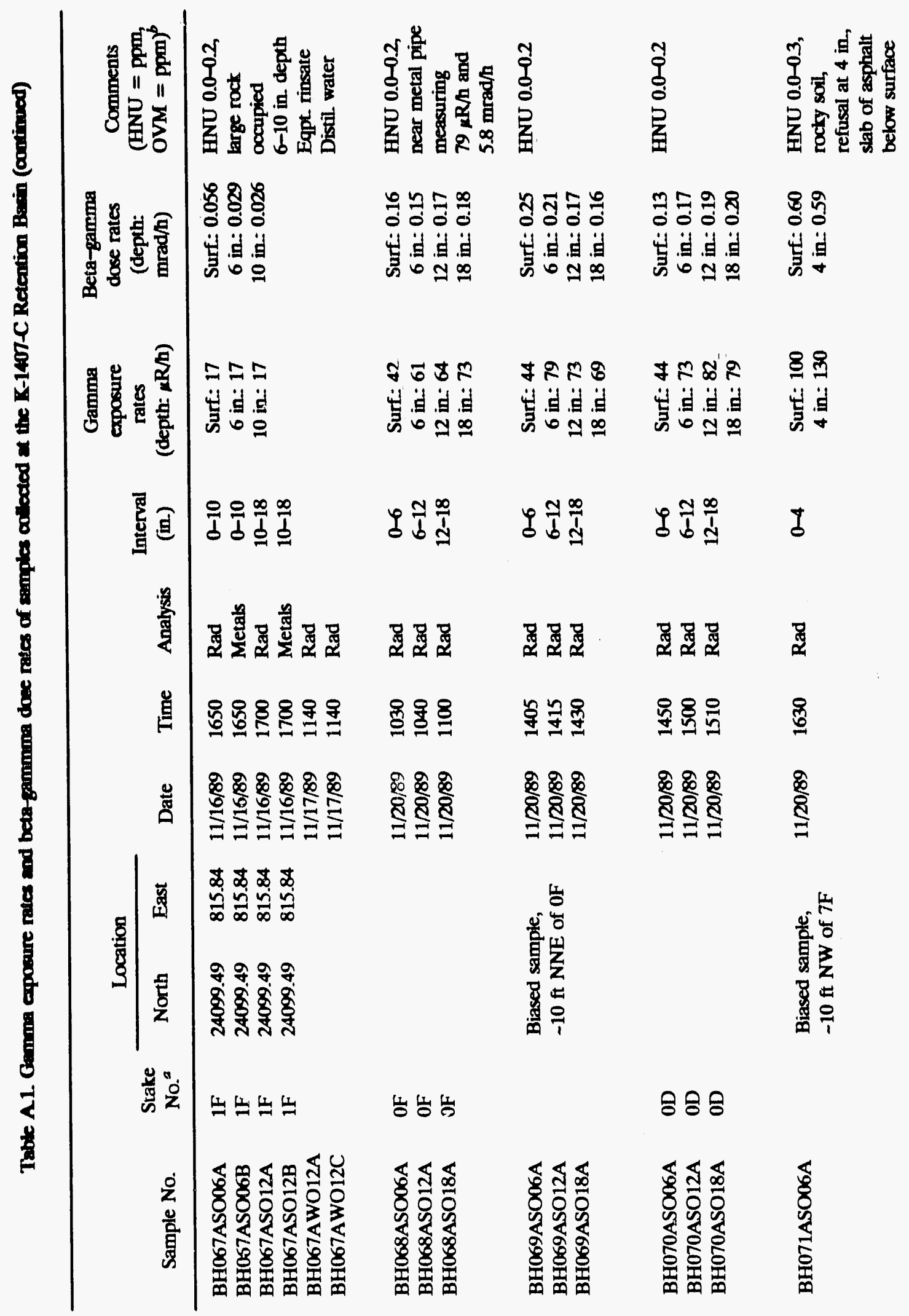




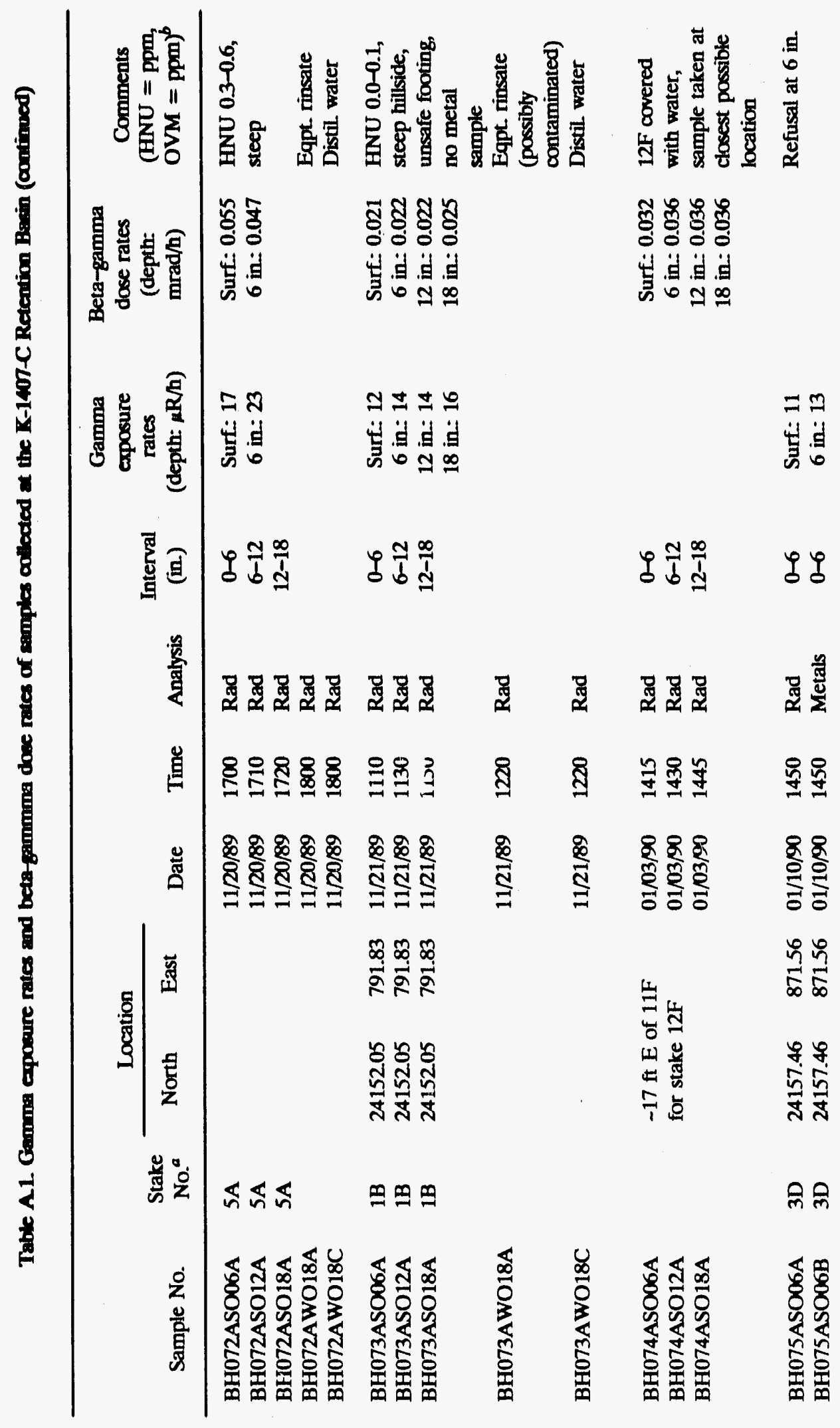




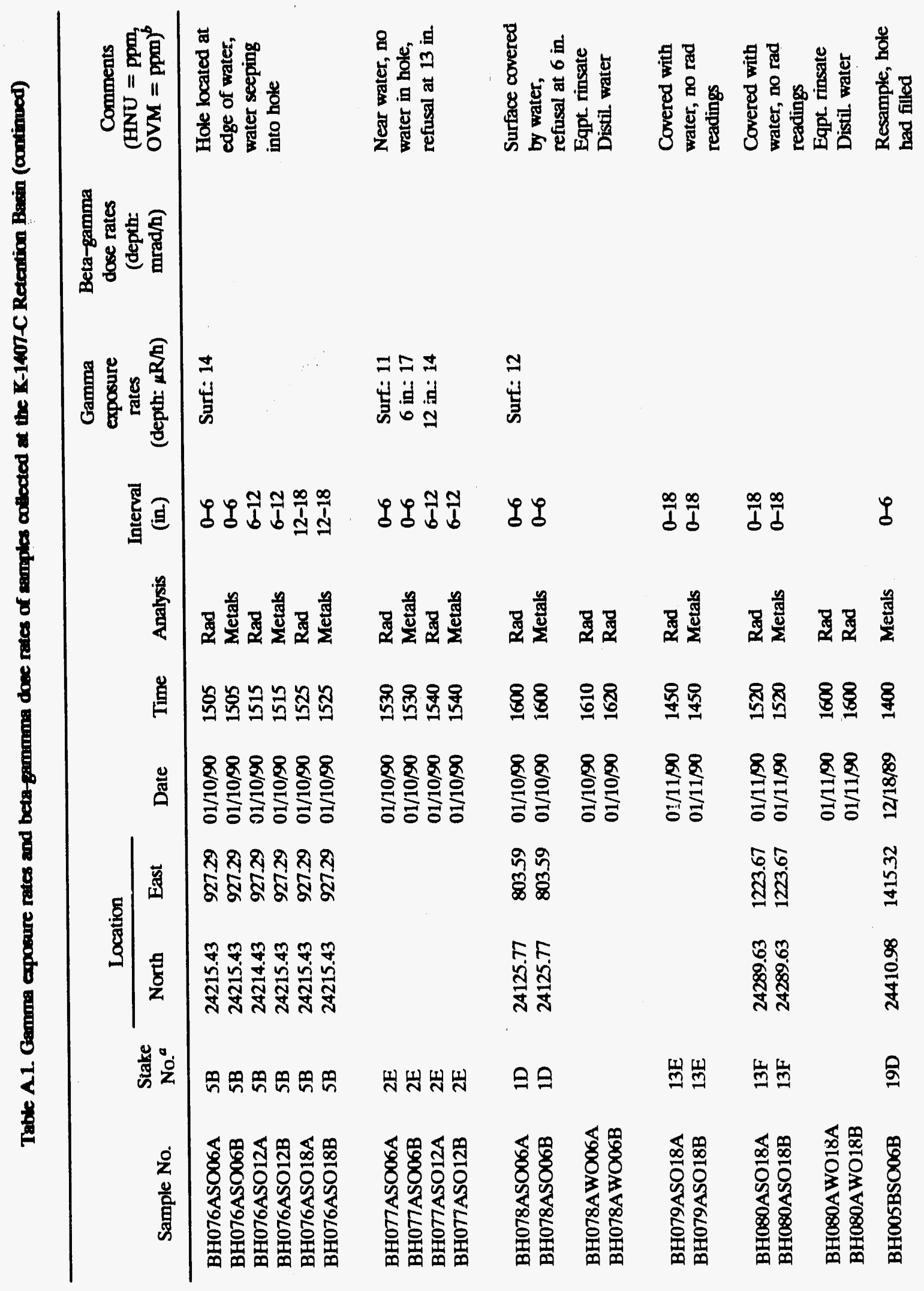




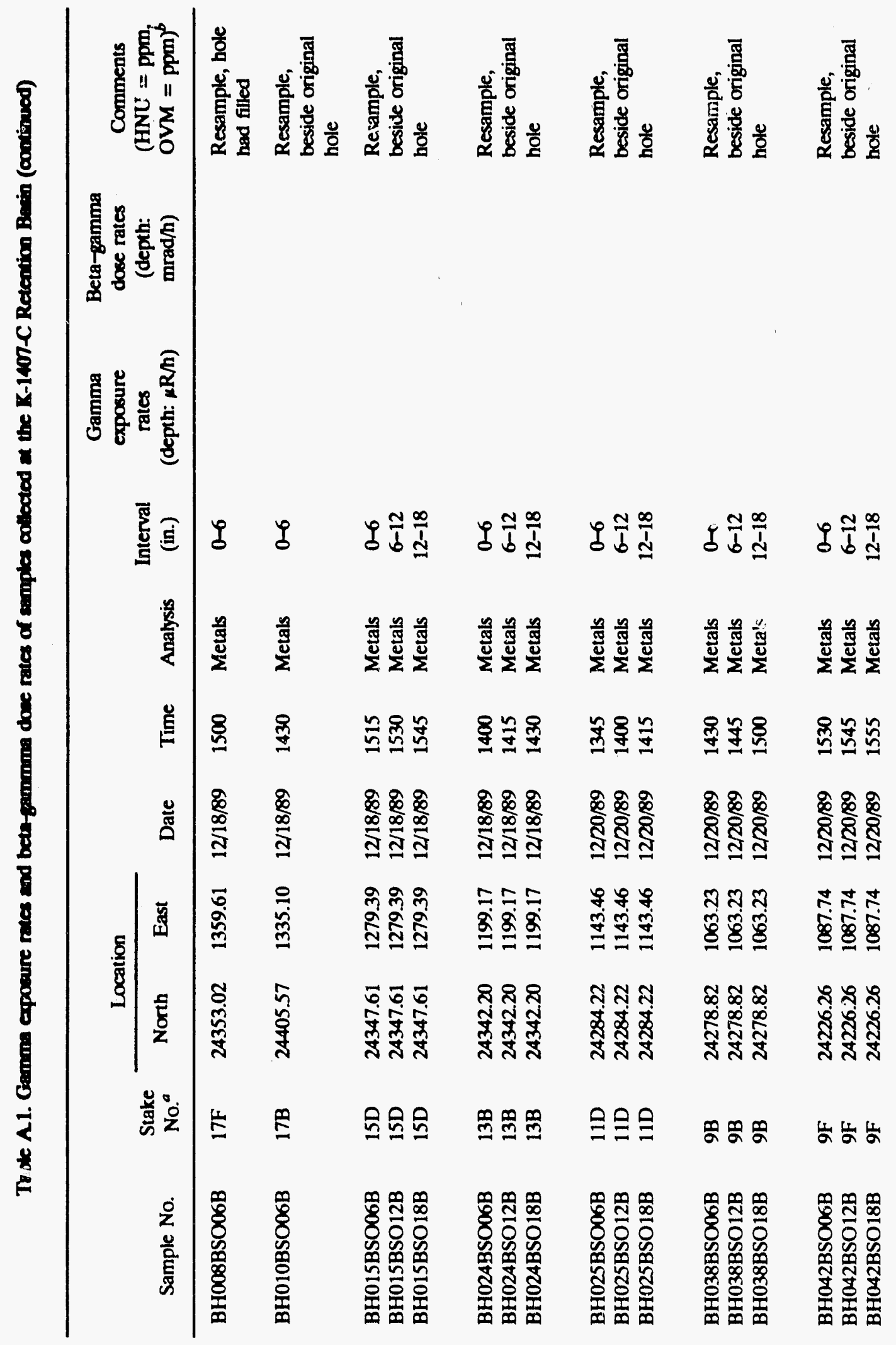




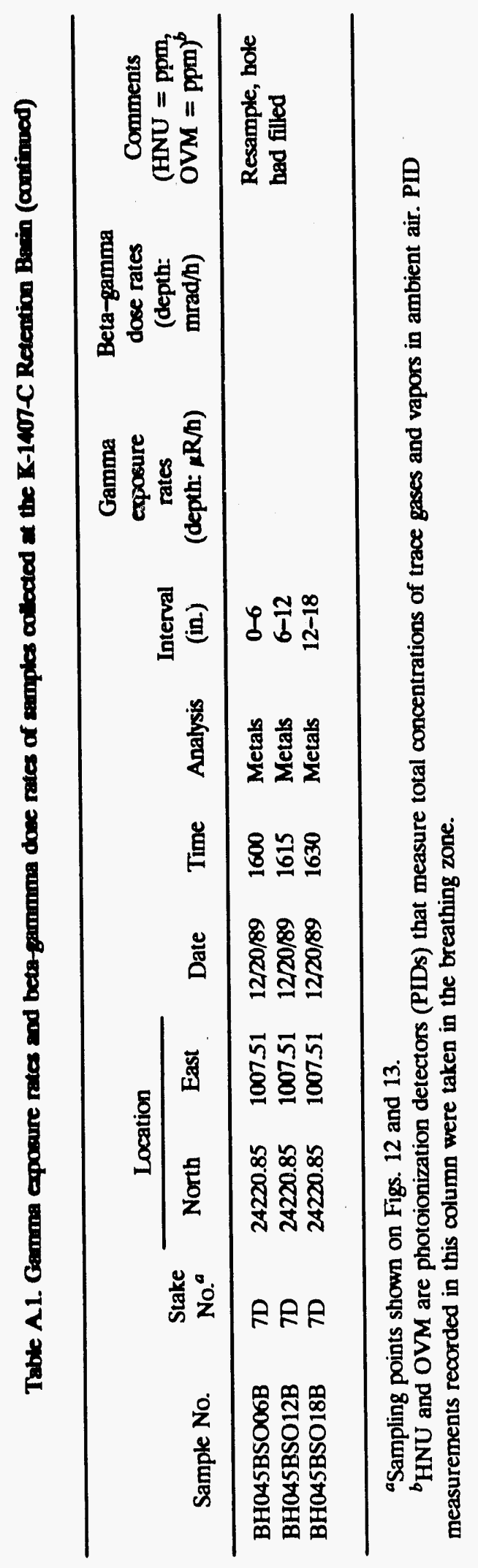


Appendix B

ANALYTICAL DATA 
Table B.1. K-1407-C Retention Basin sediment sample analysiselemental analysis

\begin{tabular}{|c|c|c|c|c|c|}
\hline Date & Hole & Location & $\begin{array}{c}\text { 6-in. } \\
(\mathrm{mg} / \mathrm{kg})\end{array}$ & $\begin{array}{l}\text { 12-in. } \\
(\mathrm{mg} / \mathrm{kg})\end{array}$ & $\begin{array}{c}\text { 18-in. } \\
(\mathrm{mg} / \mathrm{kg})\end{array}$ \\
\hline
\end{tabular}

\begin{tabular}{|c|c|c|c|c|c|}
\hline \multicolumn{6}{|c|}{ Aluminum } \\
\hline $01 / 11 / 90$ & BH078 & 01D & 35000 & - & - \\
\hline $11 / 16 / 89$ & BH067 & $01 \mathrm{~F}$ & 39000 & 21000 & - \\
\hline $01 / 11 / 90$ & BH077 & $02 \mathrm{E}$ & 36000 & 30000 & - \\
\hline $01 / 11 / 90$ & BH075 & 03D & 26000 & - & - \\
\hline $01 / 11 / 90$ & BH076 & 05B & 25000 & 21000 & 18000 \\
\hline $11 / 07 / 89$ & BH049 & $05 \mathrm{~F}$ & 15000 & 15000 & 19000 \\
\hline $10 / 30 / 89$ & BH045 & 07D & 32000 & 36000 & 36000 \\
\hline $10 / 26 / 89$ & BH038 & 09B & 45000 & 31000 & 18000 \\
\hline $10 / 30 / 89$ & BH042 & 09F & 30000 & 24000 & 21000 \\
\hline $10 / 18 / 89$ & BH025 & $11 D$ & 26000 & 16000 & 7600 \\
\hline $10 / 13 / 89$ & BHO24 & $13 \mathrm{~B}$ & 16000 & 19000 & 16000 \\
\hline $12 / 20 / 89$ & BHO24 & 13B & 27000 & 26000 & 33000 \\
\hline $01 / 12 / 90$ & BH079 & $13 E$ & - & - & 32000 \\
\hline $01 / 12 / 90$ & BH080 & $13 \mathrm{~F}$ & - & - & 52000 \\
\hline $10 / 11 / 89$ & BH013 & $15 \mathrm{D}$ & 54000 & 19000 & 12000 \\
\hline $10 / 04 / 89$ & BH010 & 17B & 30000 & 25000 & 23000 \\
\hline $10 / 04 / 89$ & BH008 & $17 \mathrm{~F}$ & 56000 & 64000 & 29000 \\
\hline $10 / 04 / 89$ & BH005 & $19 D$ & 50000 & 35000 & 31000 \\
\hline \multicolumn{6}{|c|}{ Antimony } \\
\hline $01 / 11 / 90$ & BH078 & 01D & $<7.1$ & - & - \\
\hline $11 / 16 / 89$ & BH067 & $01 \mathrm{~F}$ & $<32$ & $<31$ & - \\
\hline $01 / 11 / 90$ & BH077 & $02 \mathrm{E}$ & $<6.1$ & $<5.5$ & - \\
\hline $01 / 11 / 90$ & BH075 & 03D & $<6.1$ & - & - \\
\hline $01 / 11 / 90$ & BH076 & 05B & $<6$ & $<5.9$ & $<5.4$ \\
\hline $11 / 07 / 89$ & BH049 & $05 \mathrm{~F}$ & $<5$ & $<5$ & $<5$ \\
\hline $10 / 30 / 89$ & BH045 & 07D & $<5$ & $<5$ & $<5$ \\
\hline $10 / 26 / 89$ & BH038 & 09B & $<50$ & $<5$ & $<5$ \\
\hline $10 / 30 / 89$ & BH042 & $09 \mathrm{~F}$ & $<5$ & $<5$ & $<5$ \\
\hline $10 / 18 / 89$ & BH025 & 11D & $<5$ & $<5$ & $<5$ \\
\hline $10 / 13 / 89$ & BH024 & $13 B$ & $<5$ & $<5$ & $<5$ \\
\hline $12 / 20 / 89$ & BH024 & $13 B$ & $<5.7$ & $<5.2$ & $<5.8$ \\
\hline $01 / 12 / 90$ & ВН079 & $13 E$ & - & - & $<6$ \\
\hline $01 / 12 / 90$ & BH080 & $13 \mathrm{~F}$ & - & - & $<5.2$ \\
\hline $10 / 11 / 89$ & BH013 & 15D & $<5$ & $<5$ & $<5$ \\
\hline $10 / 04 / 89$ & BH010 & 17B & $<5$ & $<5$ & $<5$ \\
\hline $10 / 04 / 89$ & BH008 & $17 \mathrm{~F}$ & $<5$ & 9.4 & $<5$ \\
\hline $10 / 04 / 89$ & BH005 & 19D & $<5$ & $<5$ & $<5$ \\
\hline
\end{tabular}


130

Table B.1. K-1407-C Retention Basin sediment sample analysiselemental analysis (continued)

\begin{tabular}{|c|c|c|c|c|c|}
\hline Date & Hole & Location & $\begin{array}{c}\text { 6-in. } \\
(\mathrm{mg} / \mathrm{kg})\end{array}$ & $\begin{array}{l}\text { 12-in. } \\
(\mathrm{mg} / \mathrm{kg})\end{array}$ & $\begin{array}{c}18 \text {-in. } \\
(\mathrm{mg} / \mathrm{kg})\end{array}$ \\
\hline
\end{tabular}

Arsenic

\begin{tabular}{|c|c|c|c|c|c|}
\hline $01 / 11 / 90$ & BH078 & 01D & 13 & - & - \\
\hline $11 / 16 / 89$ & BH067 & $01 \mathrm{~F}$ & $<32$ & $<31$ & - \\
\hline $01 / 11 / 90$ & BH077 & $02 \mathrm{E}$ & $<6.1$ & 7.7 & - \\
\hline $01 / 11 / 90$ & BH075 & 03D & $<6.1$ & - & - \\
\hline $01 / 11 / 90$ & BH076 & 05B & $<6$ & $<5.9$ & $<5$. \\
\hline $11 / 07 / 89$ & BH049 & $05 \mathrm{~F}$ & 29 & 28 & 24 \\
\hline $10 / 30 / 89$ & BH045 & 07D & $<5$ & 20 & 8. \\
\hline $10 / 26 / 89$ & BH038 & 09B & $<50$ & 6.4 & 17 \\
\hline 10/30/89 & BH042 & $09 \mathrm{~F}$ & 30 & $<5$ & 23 \\
\hline $10 / 18 / 89$ & BH025 & 11D & 12 & $<5$ & 24 \\
\hline $10 / 13 / 89$ & BH024 & 13B & $<5$ & $<5$ & 14 \\
\hline $12 / 20 / 89$ & BH024 & 13B & $<5.7$ & $<5.2$ & $<5.8$ \\
\hline $01 / 12 / 90$ & BH079 & $13 \mathrm{E}$ & - & - & $<6$ \\
\hline $01 / 12 / 90$ & BH080 & $13 \mathrm{~F}$ & - & - & $<5.2$ \\
\hline $10 / 11 / 89$ & BH013 & 15D & 7 & $<5$ & 26 \\
\hline $10 / 04 / 89$ & BH010 & 17B & 8.1 & 14 & 20 \\
\hline $10 / 04 / 89$ & BH008 & $17 \mathrm{~F}$ & $<5$ & 14 & 24 \\
\hline $10 / 04 / 89$ & BH005 & 19D & $<5$ & 7.7 & 32 \\
\hline
\end{tabular}

Barium

\begin{tabular}{|c|c|c|c|c|c|}
\hline $01 / 11 / 90$ & BH078 & 01D & 120 & - & - \\
\hline $11 / 16 / 89$ & BH067 & $01 \mathrm{~F}$ & 59 & 110 & - \\
\hline $01 / 11 / 90$ & BH077 & $02 \mathrm{E}$ & 110 & 170 & - \\
\hline $01 / 11 / 90$ & BH075 & 03D & 120 & - & - \\
\hline $01 / 11 / 90$ & BH976 & 05B & 77 & 72 & 65 \\
\hline $11 / 07 / 89$ & BH049 & $05 \mathrm{~F}$ & 100 & 130 & 94 \\
\hline $10 / 30 / 89$ & BH045 & 07D & 110 & 130 & 120 \\
\hline $10 / 26 / 89$ & BH038 & 09B & 94 & 140 & 85 \\
\hline $10 / 30 / 89$ & BH042 & $09 \mathrm{~F}$ & 110 & 84 & 72 \\
\hline $10 / 18 / 89$ & BH025 & 11D & 76 & 68 & 45 \\
\hline $10 / 13 / 89$ & BH024 & 13B & 140 & 130 & 83 \\
\hline $12 / 20 / 89$ & BH024 & 13B & 160 & 150 & 100 \\
\hline $01 / 12 / 90$ & BH079 & $13 \mathrm{E}$ & - & - & 72 \\
\hline $01 / 12 / 90$ & BH080 & $13 \mathrm{~F}$ & - & - & 110 \\
\hline $10 / 11 / 89$ & BH013 & 15D & 80 & 31 & 25 \\
\hline $10 / 04 / 89$ & BH010 & $17 \mathrm{~B}$ & 66 & 120 & 110 \\
\hline $10 / 04 / 89$ & BH008 & $17 \mathrm{~F}$ & 110 & 96 & 39 \\
\hline $10 / 04 / 89$ & BH005 & 19D & 120 & 100 & 100 \\
\hline
\end{tabular}


Table B.1. K-1407-C Retention Basin sediment sample analysiselemental analysis (continued)

\begin{tabular}{|c|c|c|c|c|c|}
\hline Date & Hole & Location & $\begin{array}{c}\text { 6-in. } \\
(\mathrm{mg} / \mathrm{kg})\end{array}$ & $\begin{array}{c}\text { 12-in. } \\
\text { (mg/kg) }\end{array}$ & $\begin{array}{c}\text { 18-in. } \\
(\mathrm{mg} / \mathrm{kg})\end{array}$ \\
\hline
\end{tabular}

Beryllium

$\begin{array}{llllll}01 / 11 / 90 & \text { BH078 } & \text { 01D } & 1.3 & - & - \\ 11 / 16 / 89 & \text { BH067 } & \text { 01F } & 0.78 & 1.3 & - \\ 01 / 11 / 90 & \text { BH077 } & \text { 02E } & 1.2 & 1.3 & - \\ 01 / 11 / 90 & \text { BH075 } & \text { 03D } & 1.6 & - & - \\ 01 / 11 / 90 & \text { BH076 } & \text { 05B } & 0.48 & 0.42 & 0.31 \\ 11 / 07 / 89 & \text { BH049 } & \text { 05F } & 0.92 & 0.64 & 0.71 \\ 10 / 30 / 89 & \text { BH045 } & \text { 07D } & 0.65 & 0.77 & 0.88 \\ 10 / 26 / 89 & \text { BH038 } & \text { 09B } & 0.61 & 0.95 & 0.57 \\ 10 / 30 / 89 & \text { BH042 } & \text { 09F } & 0.8 & 0.51 & 0.39 \\ 10 / 18 / 89 & \text { BH025 } & 11 D & 0.5 & 0.42 & 0.25 \\ 10 / 13 / 89 & \text { BH024 } & 13 \mathrm{~B} & 0.71 & 0.88 & 0.47 \\ 12 / 20 / 89 & \text { BH024 } & 13 \mathrm{~B} & 0.9 & 1 & 0.58 \\ 01 / 12 / 90 & \text { BH079 } & 13 \mathrm{E} & - & - & 0.6 \\ 01 / 12 / 90 & \text { BH080 } & 13 \mathrm{~F} & - & - & 1.4 \\ 10 / 11 / 89 & \text { BH013 } & 15 \mathrm{D} & 0.93 & 0.49 & 0.49 \\ 10 / 04 / 89 & \text { BH010 } & 17 \mathrm{~B} & 0.58 & 0.94 & 0.74 \\ 10 / 04 / 89 & \text { BH008 } & \text { 17F } & 1.2 & 1.5 & 0.99 \\ 10 / 04 / 89 & \text { BH005 } & 19 \mathrm{D} & 1.1 & 1 & 0.85\end{array}$

Boron

$\begin{array}{lccccc}01 / 11 / 90 & \text { BH078 } & \text { 01D } & <0.57 & - & - \\ 11 / 16 / 89 & \text { BH067 } & \text { 01F } & 5.8 & 4.2 & - \\ 01 / 11 / 90 & \text { BH077 } & \text { 02E } & <0.49 & <0.44 & - \\ 01 / 11 / 90 & \text { BH075 } & \text { 03D } & <0.49 & - & - \\ 01 / 11 / 90 & \text { BH076 } & \text { 05B } & <0.48 & <0.47 & <0.43 \\ 11 / 07 / 89 & \text { BH049 } & \text { 05F } & 3.5 & 7.6 & <0.4 \\ 10 / 30 / 89 & \text { BH045 } & \text { 07D } & 12 & 20 & 13 \\ 10 / 26 / 89 & \text { BH038 } & \text { 09B } & 33 & 1.1 & <0.4 \\ 10 / 30 / 89 & \text { BH042 } & \text { 09F } & 9.7 & <0.4 & <0.4 \\ 10 / 18 / 89 & \text { BH025 } & 11 \mathrm{D} & <0.4 & <0.4 & <0.4 \\ 10 / 13 / 89 & \text { BH024 } & 13 \mathrm{~B} & <0.4 & <0.4 & <0.4 \\ 12 / 20 / 89 & \text { BH024 } & 13 \mathrm{~B} & <0.46 & <0.42 & 8.5 \\ 01 / 12 / 90 & \text { BH079 } & 13 \mathrm{E} & - & - & <0.48 \\ 01 / 12 / 90 & \text { BH080 } & 13 \mathrm{~F} & - & - & <0.42 \\ 10 / 11 / 89 & \text { BH013 } & 15 \mathrm{D} & 14 & <0.4 & <0.4 \\ 10 / 04 / 89 & \text { BH010 } & 17 \mathrm{~B} & <0.4 & <0.4 & <0.4 \\ 10 / 04 / 89 & \text { BH008 } & 17 \mathrm{~F} & 34 & 6.6 & <0.4 \\ 10 / 04 / 89 & \text { BH005 } & 19 \mathrm{D} & 16 & <0.4 & <0.4\end{array}$


Table B.1. K-1407-C Retention Basin sediment sample analysiselemental analysis (continued)

\begin{tabular}{|c|c|c|c|c|c|}
\hline Date & Hole & Location & $\begin{array}{c}\text { 6-in. } \\
(\mathrm{mg} / \mathrm{kg})\end{array}$ & $\begin{array}{c}\text { 12-in. } \\
\text { (mg/kg) }\end{array}$ & $\begin{array}{l}\text { 18-in. } \\
(\mathrm{mg} / \mathrm{kg})\end{array}$ \\
\hline
\end{tabular}

Cadmium

\begin{tabular}{|c|c|c|c|c|c|}
\hline $01 / 11 / 90$ & BH078 & 01D & 1.2 & - & - \\
\hline $11 / 16 / 89$ & BH067 & $01 \mathrm{~F}$ & $<1.9$ & $<1.9$ & - \\
\hline $01 / 11 / 90$ & BH077 & $02 \mathrm{E}$ & 1.9 & 1.7 & - \\
\hline $01 / 11 / 90$ & BH075 & 03D & 1.5 & - & - \\
\hline $01 / 11 / 90$ & BH076 & 05B & 0.81 & 0.74 & 0.9 \\
\hline $11,07 / 89$ & BH049 & $05 \mathrm{~F}$ & $<0.3$ & $<0.3$ & $<0.3$ \\
\hline $10 / 30 / 89$ & BH045 & 07D & $<0.3$ & 0.43 & 0.8 \\
\hline $10 / 26 / 89$ & BH038 & 09B & 7.4 & 0.5 & 0.4 \\
\hline $10 / 30 / 89$ & BH042 & $09 \mathrm{~F}$ & $<0.3$ & $<0.3$ & $<0.3$ \\
\hline $10 / 18 / 89$ & BH025 & $11 \mathrm{D}$ & 1 & 0.37 & 0.3 \\
\hline 10/13/89 & BH024 & 13B & 0.57 & 0.38 & 0.3 \\
\hline $12 / 20 / 89$ & BH024 & $13 \mathrm{~B}$ & 1.2 & 0.64 & 0.9 \\
\hline $01 / 12 / 90$ & BH079 & $13 \mathrm{E}$ & - & - & 1.2 \\
\hline $01 / 12 / 90$ & BH080 & $13 \mathrm{~F}$ & - & - & 2.2 \\
\hline $10 / 11 / 89$ & BH013 & 15D & 1.8 & $<0.3$ & $<0.3$ \\
\hline 10/04/89 & BH010 & $17 \mathrm{~B}$ & 0.58 & 1.2 & 1.1 \\
\hline 10/04/89 & BH008 & $17 \mathrm{~F}$ & 1.7 & 2.2 & 2 \\
\hline $10 / 04 / 89$ & BHOO5 & 19D & 1.3 & 1.8 & 1.8 \\
\hline \multicolumn{6}{|c|}{ Calcium } \\
\hline $01 / 11 / 90$ & BH078 & 01D & 24000 & - & - \\
\hline $11 / 16 / 89$ & BH067 & $01 \mathrm{~F}$ & 37000 & 13000 & - \\
\hline $01 / 11 / 90$ & BH077 & $02 \mathrm{E}$ & 28000 & 26000 & - \\
\hline $01 / 11 / 90$ & BH075 & 03D & 11000 & - & - \\
\hline $01 / 11 / 90$ & BH076 & 05B & 2000 & 1200 & 670 \\
\hline $11 / 07 / 89$ & BH049 & $05 \mathrm{~F}$ & 15000 & 15000 & 2900 \\
\hline $10 / 30 / 89$ & BH045 & 07D & 25000 & 52000 & 38000 \\
\hline $10 / 26 / 89$ & BH038 & 09B & 160000 & 19000 & 5100 \\
\hline $10 / 30 / 89$ & BH042 & $09 \mathrm{~F}$ & 9400 & 2600 & 2600 \\
\hline $10 / 18 / 89$ & BH025 & 11D & 6900 & 3000 & 480 \\
\hline $10 / 13 / 89$ & BH024 & 13B & 10000 & 3100 & 1500 \\
\hline $12 / 20 / 89$ & BHO24 & 13B & 5800 & 3600 & 1100 \\
\hline $01 / 12 / 90$ & BH079 & $13 \mathrm{E}$ & - & - & 15000 \\
\hline $01 / 12 / 90$ & BH080 & $13 \mathrm{~F}$ & - & - & 11000 \\
\hline $10 / 11 / 89$ & BH013 & $15 \mathrm{D}$ & 35000 & 530 & 480 \\
\hline $10 / 04 / 89$ & BH010 & 17B & 11000 & 5100 & 5200 \\
\hline $10 / 04 / 89$ & ВH008 & $17 \mathrm{~F}$ & 65000 & 29000 & 3000 \\
\hline $10 / 04 / 89$ & BH005 & 19D & 39000 & 10000 & 6200 \\
\hline
\end{tabular}


Table B.1. K-1407-C Retention Basin sodiment sample analysiselemental analysis (continued)

\begin{tabular}{|c|c|c|c|c|c|}
\hline Date & Hole & Location & $\begin{array}{c}\text { 6-in. } \\
(\mathrm{mg} / \mathrm{kg})\end{array}$ & $\begin{array}{l}\text { 12-in. } \\
(\mathrm{mg} / \mathrm{kg})\end{array}$ & $\begin{array}{l}\text { 18-in. } \\
(\mathrm{mg} / \mathrm{kg})\end{array}$ \\
\hline
\end{tabular}

\section{Chromium}

$\begin{array}{lrrrrr}01 / 11 / 90 & \text { BH078 } & \text { 01D } & 58 & - & - \\ 11 / 16 / 89 & \text { BH067 } & \text { 01F } & 39 & 31 & - \\ 01 / 11 / 90 & \text { BH077 } & \text { 02E } & 59 & 78 & - \\ 01 / 11 / 90 & \text { BH075 } & \text { 03D } & 34 & - & - \\ 01 / 11 / 90 & \text { BH076 } & \text { 05B } & 25 & 18 & 18 \\ 11 / 07 / 89 & \text { BH049 } & 05 \mathrm{~F} & 38 & 26 & 25 \\ 10 / 30 / 89 & \text { BH045 } & 07 \mathrm{D} & 120 & 190 & 150 \\ 10 / 26 / 89 & \text { BH038 } & \text { 09B } & 160 & 76 & 25 \\ 10 / 30 / 89 & \text { BH042 } & 09 \mathrm{~F} & 42 & 28 & 21 \\ 10 / 18 / 89 & \text { BH025 } & 11 \mathrm{D} & 48 & 31 & 21 \\ 10 / 13 / 89 & \text { BH024 } & 13 \mathrm{~B} & 27 & 27 & 22 \\ 12 / 20 / 89 & \text { BH024 } & 13 \mathrm{~B} & 32 & 31 & 30 \\ 01 / 12 / 90 & \text { BH079 } & 13 \mathrm{E} & - & - & 74 \\ 01 / 12 / 90 & \text { BH080 } & 13 \mathrm{~F} & - & - & 59 \\ 10 / 11 / 89 & \text { BH013 } & 15 \mathrm{D} & 100 & 47 & 46 \\ 10 / 04 / 89 & \text { BH010 } & 17 \mathrm{~B} & 43 & 26 & 31 \\ 10 / 04 / 89 & \text { BH008 } & 17 \mathrm{~F} & 140 & 97 & 46 \\ 10 / 04 / 89 & \text { BH005 } & 19 \mathrm{D} & 79 & 50 & 44\end{array}$

Cobalt

$01 / 11 / 90$
$11 / 16 / 89$
$01 / 11 / 90$
$01 / 11 / 90$
$01 / 11 / 90$
$11 / 07 / 89$
$10 / 30 / 89$
$10 / 26 / 89$
$10 / 30 / 89$
$10 / 18 / 89$
$10 / 13 / 89$
$12 / 20 / 89$
$01 / 12 / 90$
$01 / 12 / 90$
$10 / 11 / 89$
$10 / 04 / 89$
$10 / 04 / 89$
$10 / 04 / 89$

BH078
BH067
BH077
BH075
BH076
BH049
BH045
BH038
BH042
BH025
BH024
BH024
BH079
BH080
BH013
BH010
BH008
BH005

01D

$01 \mathrm{~F}$

02E

03D

05B

05F

07D

09B

09F

11D

13B

13B

13E

13F

15D

17B

$17 \mathrm{~F}$

19D

19
29
18
18
8.5
14
22
21
19
22
15
16
-
-
16
11
18
15

\begin{tabular}{r}
$\overline{16}$ \\
24 \\
$\overline{11}$ \\
12 \\
30 \\
19 \\
16 \\
19 \\
17 \\
19 \\
- \\
\hline 9 \\
15 \\
21 \\
11
\end{tabular}

-
$\overline{-}$
$\overline{11}$
15
24
16
16
8.5
15
15
18
33
19
15
8.7
10


Table B.1. K-1407-C Retention Bosin sediment sample analysiselemental analysis (continued)

\begin{tabular}{|c|c|c|c|c|c|}
\hline Date & Hole & Location & $\begin{array}{c}\text { 6-in. } \\
(\mathrm{mg} / \mathrm{kg})\end{array}$ & $\begin{array}{c}\text { 12-in. } \\
(\mathrm{mg} / \mathrm{kg})\end{array}$ & $\begin{array}{l}\text { 18-in. } \\
(\mathrm{mg} / \mathrm{kg})\end{array}$ \\
\hline
\end{tabular}

\begin{tabular}{|c|c|c|c|c|c|}
\hline \multicolumn{6}{|c|}{ Copper } \\
\hline $01 / 11 / 90$ & BH078 & $01 \mathrm{D}$ & 43 & - & - \\
\hline $11 / 16 / 89$ & BH067 & $01 \mathrm{~F}$ & 33 & 24 & - \\
\hline $01 / 11 / 90$ & BH077 & $02 \mathrm{E}$ & 44 & 57 & - \\
\hline $01 / 11 / 90$ & BH075 & 03D & 28 & - & - \\
\hline $01 / 11 / 90$ & BH076 & $05 \mathrm{~B}$ & 14 & 12 & 11 \\
\hline $11 / 07 / 89$ & ВH049 & $05 \mathrm{~F}$ & 56 & 110 & 22 \\
\hline $10 / 30 / 89$ & BH045 & 07D & 81 & 160 & 110 \\
\hline 10/26/89 & BH038 & 09B & 190 & 58 & 13 \\
\hline 10/30/89 & BH042 & $09 \mathrm{~F}$ & 25 & 13 & 13 \\
\hline 10/18/89 & BH025 & $11 D$ & 24 & 14 & 6 \\
\hline $10 / 13 / 89$ & BH024 & $13 B$ & 17 & 13 & 27 \\
\hline $12 / 20 / 89$ & BH024 & $13 B$ & 16 & 12 & 14 \\
\hline $01 / 12 / 90$ & BH079 & $13 \mathrm{E}$ & - & - & 31 \\
\hline $01 / 12 / 90$ & BH080 & $13 \mathrm{~F}$ & - & - & 39 \\
\hline $10 / 11 / 89$ & BH013 & 15D & 130 & 19 & 15 \\
\hline $10 / 04 / 89$ & BH010 & $17 \mathrm{~B}$ & 29 & 18 & 17 \\
\hline $10 / 04 / 89$ & ВH008 & $17 \mathrm{~F}$ & 180 & 130 & 41 \\
\hline $10 / 04 / 89$ & BH005 & $19 \mathrm{D}$ & 140 & 48 & 39 \\
\hline \multicolumn{6}{|c|}{ Iron } \\
\hline $01 / 11 / 90$ & BH078 & 01D & 30000 & - & - \\
\hline $11 / 16 / 89$ & ВH067 & $01 \mathrm{~F}$ & 34000 & 34000 & - \\
\hline $01 / 11 / 90$ & BH077 & $02 E$ & 32000 & 33000 & - \\
\hline $01 / 11 / 90$ & BH075 & 03D & 31000 & - & - \\
\hline $01 / 11 / 90$ & BH076 & 05B & 25000 & 22000 & 20000 \\
\hline $11 / 07 / 89$ & BH049 & $05 \mathrm{~F}$ & 25000 & 24000 & 23000 \\
\hline $10 / 30 / 89$ & BH045 & 07D & 25000 & 26000 & 27000 \\
\hline $10 / 26 / 89$ & BH038 & 09B & 30000 & 21000 & 20000 \\
\hline $10 / 30 / 89$ & $\mathrm{BH} 042$ & $09 \mathrm{~F}$ & 25000 & 27000 & 26000 \\
\hline $10 / 18 / 89$ & BH025 & 11D & 29000 & 25000 & 19000 \\
\hline $10 / 13 / 89$ & BH024 & $13 B$ & 23000 & 24000 & 25000 \\
\hline $12 / 20 / 89$ & BH024 & 13B & 26000 & 23000 & 28000 \\
\hline $01 / 12 / 90$ & BH079 & $13 \mathrm{E}$ & - & - & 27000 \\
\hline $01 / 12 / 90$ & BH080 & $13 \mathrm{~F}$ & - & - & 40000 \\
\hline $10 / 11 / 89$ & BH013 & $15 \mathrm{D}$ & 36000 & 34000 & 35000 \\
\hline $10 / 04 / 89$ & BH010 & $17 \mathrm{~B}$ & 31000 & 25000 & 27000 \\
\hline $10 / 04 / 89$ & ВH008 & $17 \mathrm{~F}$ & 34000 & 50000 & 56000 \\
\hline $10 / 04 / 89$ & BH005 & 19D & 31000 & 35000 & 33000 \\
\hline
\end{tabular}


Table B.1. K-1407-C Retention Basin sediment sample analysiselemental analysis (continued)

\begin{tabular}{|c|c|c|c|c|c|}
\hline Date & Hole & Location & $\begin{array}{c}\text { 6-in. } \\
(\mathrm{mg} / \mathrm{kg})\end{array}$ & $\begin{array}{c}\text { 12-in. } \\
(\mathrm{mg} / \mathrm{kg})\end{array}$ & $\begin{array}{c}\text { 18-in. } \\
(\mathrm{mg} / \mathrm{kg})\end{array}$ \\
\hline
\end{tabular}

Lead

$01 / 11 / 90$
$11 / 16 / 89$
$01 / 11 / 90$
$01 / 11 / 90$
$01 / 11 / 90$
$11 / 07 / 89$
$10 / 30 / 89$
$10 / 26 / 89$
$10 / 30 / 89$
$10 / 18 / 89$
$10 / 13 / 89$
$12 / 20 / 89$
$01 / 12 / 90$
$01 / 12 / 90$
$10 / 11 / 89$
$10 / 04 / 89$
$10 / 04 / 89$
$10 / 04 / 89$

$01 / 11 / 90$

$11 / 16 / 89$

$01 / 11 / 90$

$01 / 11 / 90$

$01 / 11 / 90$

$11 / 07 / 89$

$10 / 30 / 89$

$10 / 26 / 89$

$10 / 30 / 89$

$10 / 18 / 89$

$10 / 13 / 89$

$12 / 20 / 89$

$01 / 12 / 90$

$01 / 12 / 90$

$10 / 11 / 89$

$10 / 04 / 89$

$10 / 04 / 89$

$10 / 04 / 89$

\begin{abstract}
BH078
BH067

BH077

BH075

BH076

BH049

BH045

BH()38

BH042

BH025

BH024

BH024

BH079

BH080

BH013

BH010

BH008

BH005
\end{abstract}

BH078

BH067

BH077

BH075

BH076

BH049

BH045

BH038

BH042

BH025

BH024

BH024

BH079

BH080

BH013

BH010

BH008

BH005

$01 \mathrm{D}$
$01 \mathrm{~F}$
$02 \mathrm{E}$
$03 \mathrm{D}$
$05 \mathrm{~B}$
$05 \mathrm{~F}$
$07 \mathrm{D}$
$09 \mathrm{~B}$
$09 \mathrm{~F}$
$11 \mathrm{D}$
$13 \mathrm{~B}$
$13 \mathrm{~B}$
$13 \mathrm{E}$
$13 \mathrm{~F}$
$15 \mathrm{D}$
$17 \mathrm{~B}$
$17 \mathrm{~F}$
$19 \mathrm{D}$

01D

O2E

03D

05B

07D

09B

09F

11D

13B

13B

$13 \mathrm{E}$

15D

17B

19D

\section{Magnesium}

26
59

28

16

18

34

31

$<50$

27

36

37

42

$-$

$\overline{46}$

46

31

45

31

$\begin{array}{lr}\text { 01D } & 6200 \\ \text { 01F } & 4600 \\ \text { 02E } & 7000 \\ \text { 03D } & 7800 \\ \text { 05B } & 1800 \\ \text { 05F } & 3600 \\ \text { 07D } & 2100 \\ \text { 09B } & 3500 \\ \text { 09F } & 1500 \\ 11 \mathrm{D} & 1200 \\ 13 \mathrm{~B} & 5700 \\ 13 \mathrm{~B} & 2900 \\ 13 \mathrm{E} & - \\ 13 \mathrm{~F} & - \\ 15 \mathrm{D} & 3500 \\ 17 \mathrm{~B} & 1300 \\ 17 \mathrm{~F} & 6300 \\ 19 \mathrm{D} & 4900\end{array}$

$\begin{array}{rr}8000 & - \\ 7200 & - \\ - & - \\ 1500 & \overline{-} \\ 6300 & 1000 \\ 2800 & 1300 \\ 1600 & 3100 \\ 850 & 750 \\ 660 & 720 \\ 1500 & 300 \\ 2000 & 810 \\ - & 1600 \\ - & 1800 \\ 810 & 3200 \\ 1500 & 380 \\ 3600 & 1800 \\ 4200 & 1100 \\ 4200 & 3900\end{array}$


Table B.1. K-1407-C Retention Basin sediment sample analysiselemental analysis (continued)

\begin{tabular}{|c|c|c|c|c|c|}
\hline Date & Hole & Location & $\begin{array}{c}\text { 6-in. } \\
(\mathrm{mg} / \mathrm{kg})\end{array}$ & $\begin{array}{c}\text { 12-in. } \\
(\mathrm{mg} / \mathrm{kg})\end{array}$ & $\begin{array}{c}\text { 18-in. } \\
(\mathrm{mg} / \mathrm{kg})\end{array}$ \\
\hline
\end{tabular}

\begin{tabular}{|c|c|c|c|c|c|}
\hline \multicolumn{6}{|c|}{ Manganese } \\
\hline $01 / 11 / 90$ & ВH078 & 01D & 870 & - & - \\
\hline $11 / 16 / 89$ & BH067. & $01 \mathrm{~F}$ & 550 & 460 & - \\
\hline $01 / 11 / 90$ & BH077 & $02 \mathrm{E}$ & 750 & 1700 & - \\
\hline $01 / 11 / 90$ & BH075 & 03D & 560 & - & - \\
\hline $01 / 11 / 90$ & BH076 & 05B & 830 & 1500 & 2200 \\
\hline $11 / 07 / 89$ & BH049 & $05 \mathrm{~F}$ & 730 & 1200 & 2400 \\
\hline $10 / 30 / 89$ & BH045 & 07D & 2000 & 2200 & 2000 \\
\hline $10 / 26 / 89$ & BH038 & 09B & 1100 & 2900 & 2300 \\
\hline $10 / 30 / 89$ & BH042 & $09 \mathrm{~F}$ & 2200 & 2000 & 2200 \\
\hline $10 / 18 / 89$ & BH025 & 11D & 2000 & 1600 & 550 \\
\hline $10 / 13 / 89$ & BH024 & 13B & 2100 & 3000 & 1700 \\
\hline 12/20/89 & BH024 & 13B & 2700 & 3600 & 1900 \\
\hline $01 / 12 / 90$ & BH079 & $13 \mathrm{E}$ & - & - & 1300 \\
\hline $01 / 12 / 90$ & BH080 & $13 \mathrm{~F}$ & - & - & 1300 \\
\hline $10 / 11 / 89$ & BH013 & $15 \mathrm{D}$ & 650 & 360 & 510 \\
\hline $10 / 04 / 89$ & BH010 & $17 \mathrm{~B}$ & 1100 & 2700 & 2000 \\
\hline $10 / 04 / 89$ & BH008 & $17 \mathrm{~F}$ & 640 & 650 & 450 \\
\hline $10 / 04 / 89$ & BHOOS & 19D & 550 & 400 & 390 \\
\hline \multicolumn{6}{|c|}{ Mercury } \\
\hline $01 / 11 / 90$ & BH078 & 01D & 3.6 & - & - \\
\hline $11 / 16 / 89$ & BH067 & $01 \mathrm{~F}$ & 1.8 & $<1$ & - \\
\hline $01 / 11 / 90$ & BH077 & $02 \mathrm{E}$ & 4.5 & $<1$ & - \\
\hline $01 / 11 / 90$ & BH075 & 03D & $<1$ & - & - \\
\hline $01 / 11 / 90$ & BH076 & 05B & $<1$ & $<1$ & $<1$ \\
\hline $11 / 07 / 89$ & BH049 & $05 \mathrm{~F}$ & 1.4 & $<1$ & $<1$ \\
\hline $10 / 30 / 89$ & BH045 & 07D & 22 & 40 & 29 \\
\hline $12 / 20 / 89$ & BH045 & 07D & 11 & 16 & 8.6 \\
\hline $12 / 20 / 89$ & BH038 & 09B & 6.3 & $<1$ & $<1$ \\
\hline $10 / 30 / 89$ & BH042 & $09 \mathrm{~F}$ & 2.2 & $<1$ & $<1$ \\
\hline $12 / 20 / 89$ & BH042 & $09 \mathrm{~F}$ & $<1$ & $<1$ & $<1$ \\
\hline $12 / 20 / 89$ & $\mathrm{BH} 025$ & 11D & $<1$ & $<1$ & $<1$ \\
\hline $12 / 20 / 89$ & BH024 & 13B & $<1$ & $<1$ & $<1$ \\
\hline $01 / 12 / 90$ & BH079 & $13 \mathrm{E}$ & - & - & 7 \\
\hline $01 / 12 / 90$ & BH080 & $13 \mathrm{~F}$ & - & - & 2.9 \\
\hline $12 / 20 / 89$ & BH015 & 15F-B & 2.7 & $<1$ & $<1$ \\
\hline $10 / 04 / 89$ & BH010 & 17B & - & $<1.7$ & $<1$ \\
\hline $12 / 20 / 89$ & BH010 & 17B & 1.1 & - & - \\
\hline $10 / 04 / 89$ & BH008 & $17 \mathrm{~F}$ & - & 2.4 & $<1$ \\
\hline $12 / 20 / 89$ & BH008 & $17 \mathrm{~F}$ & 29 & - & - \\
\hline $10 / 04 / 89$ & BH005 & 19D & - & 4.7 & 4.1 \\
\hline $12 / 20 / 89$ & BH005 & 19D & 17 & - & - \\
\hline
\end{tabular}


Table B.1. K-1407-C Retention Basin sediment sample analysiselemental analysis (continued)

\begin{tabular}{|c|c|c|c|c|c|}
\hline Date & Hole & Location & $\begin{array}{c}\text { 6-in. } \\
(\mathrm{mg} / \mathrm{kg})\end{array}$ & $\begin{array}{c}12-\mathrm{in} . \\
(\mathrm{mg} / \mathrm{kg})\end{array}$ & $\begin{array}{c}18-\ln . \\
(\mathrm{mg} / \mathrm{kg})\end{array}$ \\
\hline \multicolumn{6}{|c|}{ Molybdenum } \\
\hline $01 / 11 / 90$ & BH078 & 01D & $<1.4$ & - & - \\
\hline $11 / 16 / 89$ & BH067 & $01 \mathrm{~F}$ & $<6.4$ & $<6.2$ & - \\
\hline $01 / 11 / 90$ & BH077 & $02 \mathrm{E}$ & $<1.2$ & $<1.1$ & - \\
\hline $01 / 11 / 90$ & BH075 & 03D & $<1.2$ & - & - \\
\hline $01 / 11 / 90$ & BH076 & 05B & $<1.2$ & $<1.2$ & $<1.1$ \\
\hline $11 / 07 / 89$ & BH049 & $05 \mathrm{~F}$ & 1.4 & $<1$ & 1.7 \\
\hline $10 / 30 / 89$ & BH045 & 07D & 4.3 & 1.8 & 1.5 \\
\hline $10 / 26 / 89$ & BH038 & 09B & $<10$ & 3.4 & 2.9 \\
\hline $10 / 30 / 89$ & BH042 & 09F & 1.3 & 1.5 & 1.5 \\
\hline $10 / 18 / 89$ & BH025 & 11D & 1 & 2.9 & 1.4 \\
\hline $10 / 13 / 89$ & BH024 & 13B & 1.1 & 1.7 & 2.1 \\
\hline $12 / 20 / 89$ & BH024 & 13B & $<1.1$ & $<1$ & $<1.2$ \\
\hline $01 / 12 / 90$ & ВH079 & $13 \mathrm{E}$ & - & - & $<1.2$ \\
\hline $01 / 12 / 90$ & ВHO80 & $13 \mathrm{~F}$ & - & - & $<1$ \\
\hline $10 / 11 / 89$ & BH013 & $15 D$ & 2 & $<1$ & 2.4 \\
\hline $10 / 04 / 89$ & BH010 & $17 \mathrm{~B}$ & 2.4 & 1.9 & 1.4 \\
\hline $10 / 04 / 89$ & BH008 & $17 \mathrm{~F}$ & 3.3 & 3.7 & 2.5 \\
\hline 10/04/89 & BHOO5 & $19 D$ & $<1$ & 1.6 & 1.8 \\
\hline
\end{tabular}

Nickel

$\begin{array}{lrrrrr}01 / 11 / 90 & \text { BH078 } & \text { O1D } & 200 & - & - \\ 11 / 16 / 89 & \text { BH067 } & \text { O1F } & 52 & 44 & - \\ 01 / 11 / 90 & \text { BH077 } & \text { O2E } & 180 & 330 & - \\ 01 / 11 / 90 & \text { BH075 } & \text { 03D } & 39 & - & - \\ 01 / 11 / 90 & \text { BH076 } & \text { O5B } & 31 & 20 & 12 \\ 11 / 07 / 89 & \text { BH049 } & 05 \mathrm{~F} & 110 & 36 & 19 \\ 10 / 30 / 89 & \text { BH045 } & \text { O7D } & 740 & 1500 & 1000 \\ 10 / 26 / 89 & \text { BH038 } & \text { O9B } & 1400 & 500 & 53 \\ 10 / 30 / 89 & \text { BH042 } & \text { 09F } & 120 & 24 & 20 \\ 10 / 18 / 89 & \text { BH025 } & 11 \mathrm{D} & 100 & 42 & 5 \\ 10 / 13 / 89 & \text { BH024 } & 13 \mathrm{~B} & 24 & 13 & 9.5 \\ 12 / 20 / 89 & \text { BH024 } & 13 \mathrm{~B} & 20 & 16 & 18 \\ 01 / 12 / 90 & \text { BH079 } & 13 \mathrm{E} & - & - & 160 \\ 01 / 12 / 90 & \text { BH080 } & 13 \mathrm{~F} & - & - & 100 \\ 10 / 11 / 89 & \text { BH013 } & 15 \mathrm{D} & 620 & 16 & 14 \\ 10 / 04 / 89 & \text { BH010 } & 17 \mathrm{~B} & 85 & 22 & 19 \\ 10 / 04 / 89 & \text { BH008 } & 17 \mathrm{~F} & 820 & 490 & 51 \\ 10 / 04 / 89 & \text { BH005 } & 19 \mathrm{D} & 480 & 110 & 84\end{array}$


Tuble B.1. K-1407-C Retention Basin sediment sample analysiselemental analysis (continued)

\begin{tabular}{|c|c|c|c|c|c|}
\hline Date & Hole & Location & $\underset{(\mathrm{mg} / \mathrm{kg})}{6-\mathrm{ln} .}$ & $\begin{array}{c}\text { 12-in. } \\
(\mathrm{mg} / \mathrm{kg})\end{array}$ & $\begin{array}{l}\text { 18-in. } \\
(\mathrm{mg} / \mathrm{kg})\end{array}$ \\
\hline
\end{tabular}

Potassium

$\begin{array}{rrrrrr}01 / 11 / 90 & \text { BH078 } & \text { 01D } & 7200 & - & - \\ 11 / 16 / 89 & \text { BH067 } & \text { 01F } & 5000 & 3700 & - \\ 01 / 11 / 90 & \text { BH077 } & \text { 02E } & 5700 & 7000 & - \\ 01 / 11 / 90 & \text { BH075 } & \text { 03D } & 4900 & - & - \\ 01 / 11 / 90 & \text { BH076 } & 05 \mathrm{~B} & 1700 & 1300 & 960 \\ 11 / 07 / 89 & \text { BH049 } & 05 \mathrm{~F} & 3000 & 2800 & 2200 \\ 10 / 30 / 89 & \text { BH045 } & \text { 07D } & 2700 & 3800 & 4400 \\ 10 / 26 / 89 & \text { BH038 } & \text { 09B } & 5800 & 2200 & 860 \\ 10 / 30 / 89 & \text { BH042 } & \text { 09F } & 3300 & 3500 & 3500 \\ 10 / 18 / 89 & \text { BH025 } & 11 \mathrm{D} & 1400 & 720 & 420 \\ 10 / 13 / 89 & \text { BH024 } & 13 \mathrm{~B} & 3200 & 2400 & 3100 \\ 12 / 20 / 89 & \text { BH024 } & 13 \mathrm{~B} & 2700 & 2600 & 4400 \\ 01 / 12 / 90 & \text { BH079 } & 13 \mathrm{E} & - & - & 3600 \\ 01 / 12 / 90 & \text { BH080 } & 13 \mathrm{~F} & - & - & 8900 \\ 10 / 11 / 89 & \text { BH013 } & 15 \mathrm{D} & 6300 & 1600 & 820 \\ 10 / 04 / 89 & \text { BH010 } & 17 \mathrm{~B} & 2300 & 2400 & 2800 \\ 10 / 04 / 89 & \text { BH008 } & 17 \mathrm{~F} & 8700 & 7300 & 4000 \\ 10 / 04 / 89 & \text { BH005 } & 19 \mathrm{D} & 8600 & 5900 & 4200\end{array}$

Selenium

$\begin{array}{llllll}01 / 11 / 90 & \text { BH078 } & 01 \mathrm{D} & <7.1 & - & - \\ 11 / 16 / 89 & \text { BH067 } & 01 \mathrm{~F} & <32 & <31 & - \\ 01 / 11 / 90 & \text { BH077 } & 02 \mathrm{E} & <6.1 & <5.5 & - \\ 01 / 11 / 90 & \text { BH075 } & 03 \mathrm{D} & <6.1 & - & - \\ 01 / 11 / 90 & \text { BH076 } & 05 \mathrm{~B} & <6 & <5.9 & <5.4 \\ 11 / 07 / 89 & \text { BH049 } & 05 \mathrm{~F} & <5 & <5 & <5 \\ 10 / 30 / 89 & \text { BH045 } & 07 \mathrm{D} & <5 & <5 & <5 \\ 10 / 26 / 89 & \text { BH038 } & \text { 09B } & <50 & <5 & <5 \\ 10 / 30 / 89 & \text { BH042 } & \text { 09F } & <5 & <5 & <5 \\ 10 / 18 / 89 & \text { BH025 } & 11 \mathrm{D} & <5 & <5 & <5 \\ 10 / 13 / 89 & \text { BH024 } & 13 \mathrm{~B} & <5 & <5 & <5 \\ 12 / 20 / 89 & \text { BH024 } & 13 \mathrm{~B} & <5.7 & <5.2 & <5.8 \\ 01 / 12 / 90 & \text { BH079 } & 13 \mathrm{E} & - & - & <6 \\ 01 / 12 / 90 & \text { BH080 } & 13 \mathrm{~F} & - & - & <5.2 \\ 10 / 11 / 89 & \text { BH013 } & 15 \mathrm{D} & <5 & <5 & <5 \\ 10 / 04 / 89 & \text { BH010 } & 17 \mathrm{~B} & <5 & <5 & <5 \\ 10 / 04 / 89 & \text { BH008 } & 17 \mathrm{~F} & <5 & <.5 & <5 \\ 10 / 04 / 89 & \text { BH005 } & 19 \mathrm{D} & <5 & <5 & <5\end{array}$


Table B.1. K-1407-C Retention Basin sodiment sample analysiselemental analysis (continued)

\begin{tabular}{|c|c|c|c|c|c|}
\hline Date & Hole & Location & $\underset{(\mathrm{mg} / \mathrm{kg})}{\text { 6-in. }}$ & $\begin{array}{c}\text { 12-in. } \\
(\mathrm{mg} / \mathrm{kg})\end{array}$ & $\begin{array}{c}\text { 18-in. } \\
(\mathrm{mg} / \mathrm{kg})\end{array}$ \\
\hline
\end{tabular}

Silicon

$\begin{array}{rrrrrr}01 / 11 / 90 & \text { BH078 } & \text { 01D } & 410 & - & - \\ 11 / 16 / 89 & \text { BH067 } & 01 \mathrm{~F} & 410 & 390 & - \\ 01 / 11 / 90 & \text { BH077 } & \text { 02E } & 400 & 310 & - \\ 01 / 11 / 90 & \text { BH075 } & 03 \mathrm{D} & 280 & - & - \\ 01 / 11 / 90 & \text { BH076 } & 05 \mathrm{~B} & 230 & 280 & 220 \\ 11 / 07 / 89 & \text { BH049 } & 05 \mathrm{~F} & 850 & 860 & 930 \\ 10 / 30 / 89 & \text { BH045 } & 07 \mathrm{D} & 1000 & 1200 & 1000 \\ 10 / 26 / 89 & \text { BH038 } & \text { 09B } & 1700 & 950 & 940 \\ 10 / 30 / 89 & \text { BH042 } & \text { 09F } & 770 & 870 & 870 \\ 10 / 18 / 89 & \text { BH025 } & 11 \mathrm{D} & 560 & 570 & 600 \\ 10 / 13 / 89 & \text { BH024 } & 13 \mathrm{~B} & 590 & 920 & 940 \\ 12 / 20 / 89 & \text { BH024 } & 13 \mathrm{~B} & 570 & 630 & 520 \\ 01 / 12 / 90 & \text { BH079 } & 13 \mathrm{E} & - & - & 480 \\ 01 / 12 / 90 & \text { BH080 } & 13 \mathrm{~F} & - & - & 370 \\ 10 / 11 / 89 & \text { BH013 } & 15 \mathrm{D} & 690 & 1000 & 950 \\ 10 / 04 / 89 & \text { BH010 } & 17 \mathrm{~B} & 810 & 910 & 810 \\ 10 / 04 / 89 & \text { BH008 } & 17 \mathrm{~F} & 1100 & 980 & 990 \\ 10 / 04 / 89 & \text { BH005 } & 19 \mathrm{D} & 1200 & 1000 & 890\end{array}$

Silver

$\begin{array}{llllcc}01 / 11 / 90 & \text { BH078 } & \text { O1D } & <0.85 & - & - \\ 11 / 16 / 89 & \text { BH067 } & \text { O1F } & <3.9 & <3.7 & - \\ 01 / 11 / 90 & \text { BH077 } & \text { O2E } & <0.74 & 1.1 & - \\ 01 / 11 / 90 & \text { BH075 } & \text { 03D } & <0.73 & - & - \\ 01 / 11 / 90 & \text { BH076 } & \text { 05B } & <0.72 & <0.71 & <0.64 \\ 11 / 07 / 89 & \text { BH049 } & \text { 05F } & <0.6 & <0.6 & <0.6 \\ 10 / 30 / 89 & \text { BH045 } & \text { 07D } & <0.6 & 1.7 & 1.1 \\ 10 / 26 / 89 & \text { BH038 } & \text { 09B } & <6 & 0.69 & <0.6 \\ 10 / 30 / 89 & \text { BH042 } & \text { O9F } & <0.6 & <0.6 & <0.6 \\ 10 / 18 / 89 & \text { BH025 } & 11 D & <0.6 & <0.6 & <0.6 \\ 10 / 13 / 89 & \text { BH024 } & 13 \mathrm{~B} & <0.6 & <0.6 & <0.6 \\ 12 / 20 / 89 & \text { BH024 } & 13 \mathrm{~B} & <0.69 & <0.62 & <0.7 \\ 01 / 12 / 90 & \text { BH079 } & 13 \mathrm{E} & - & - & <0.73 \\ 01 / 12 / 90 & \text { BH080 } & 13 \mathrm{~F} & - & - & 0.72 \\ 10 / 11 / 89 & \text { BH013 } & 15 \mathrm{D} & <0.6 & <0.6 & <0.6 \\ 10 / 04 / 89 & \text { BH010 } & 17 \mathrm{~B} & <0.6 & <0.6 & <0.6 \\ 10 / 04 / 89 & \text { BH008 } & 17 \mathrm{~F} & 0.9 & 0.88 & 0.78 \\ 10 / 04 / 89 & \text { BH005 } & 19 D & <0.6 & 0.72 & 0.74\end{array}$


Table B.1. K-1407-C Retention Basin sediment sample analysiselemental analysis (continued)

\begin{tabular}{|c|c|c|c|c|c|}
\hline Date & Hole & Location & $\begin{array}{c}\text { 6-in. } \\
(\mathrm{mg} / \mathrm{kg})\end{array}$ & $\begin{array}{c}12 \text {-in. } \\
(\mathrm{mg} / \mathrm{kg})\end{array}$ & $\begin{array}{l}\text { 18-in. } \\
(\mathrm{mg} / \mathrm{kg})\end{array}$ \\
\hline
\end{tabular}

\begin{tabular}{|c|c|c|c|c|c|}
\hline \multicolumn{6}{|c|}{ Sodium } \\
\hline $01 / 11 / 90$ & BH078 & 01D & 330 & - & - \\
\hline $11 / 16 / 89$ & BH067 & $01 \mathrm{~F}$ & 380 & 450 & - \\
\hline $01 / 11 / 90$ & BH077 & $02 \mathrm{E}$ & 300 & 330 & - \\
\hline $01 / 11 / 90$ & BH075 & 03D & 250 & - & - \\
\hline $01 / 11 / 90$ & BH076 & 05B & 310 & 380 & 230 \\
\hline $11 / 07 / 89$ & BH049 & $05 \mathrm{~F}$ & 110 & 260 & 300 \\
\hline $10 / 30 / 89$ & BH045 & 07D & 180 & 330 & 280 \\
\hline $10 / 26 / 89$ & BH038 & O9B & 850 & 280 & 430 \\
\hline $10 / 30 / 89$ & BH042 & $09 \mathrm{~F}$ & 320 & 290 & 280 \\
\hline $10 / 18 / 89$ & BHO25 & 11D & 470 & 450 & 390 \\
\hline $10 / 13 / 63$ & BH024 & $13 B$ & 96 & 140 & 190 \\
\hline $12 / 20 / 89$ & BH024 & 13B & 130 & 180 & 340 \\
\hline $01 / 12 / 90$ & BH079 & $13 \mathrm{E}$ & - & - & 700 \\
\hline $01 / 12 / 90$ & ВH080 & $13 \mathrm{~F}$ & - & - & 960 \\
\hline $10 / 11 / 89$ & BH013 & 15D & 1300 & 1700 & 1300 \\
\hline $10 / 04 / 89$ & BHO10 & 17B & 89 & 69 & 69 \\
\hline $10 / 04 / 89$ & BH008 & $17 F$ & 1200 & 2400 & 3600 \\
\hline $10 / 04 / 89$ & BH005 & $19 \mathrm{D}$ & 550 & 780 & 750 \\
\hline \multicolumn{6}{|c|}{ Strontium } \\
\hline $01 / 11 / 90$ & BH078 & $01 D$ & 27 & - & - \\
\hline $11 / 16 / 89$ & BH067 & $01 \mathrm{~F}$ & 42 & 18 & - \\
\hline $01 / 11 / 90$ & BH077 & $02 \mathrm{E}$ & 29 & 31 & - \\
\hline $01 / 11 / 90$ & BH075 & 03D & 18 & - & - \\
\hline $01 / 11 / 90$ & BH076 & OSB & 8.9 & 7.1 & 4.5 \\
\hline $11 / 07 / 89$ & BH049 & $05 \mathrm{~F}$ & 25 & 24 & 9.4 \\
\hline $10 / 30 / 89$ & BH045 & 07D & 20 & 33 & 26 \\
\hline $10 / 26 / 89$ & BH038 & $09 \mathrm{~B}$ & 64 & 18 & 9.5 \\
\hline $10 / 30 / 89$ & BH042 & $09 \mathrm{~F}$ & 12 & 6.5 & 6 \\
\hline $10 / 18 / 89$ & ВH025 & $11 D$ & 9.6 & 5.6 & 2.5 \\
\hline $10 / 13 / 89$ & BHO24 & $13 B$ & 8.4 & 6.9 & 4.7 \\
\hline $12 / 20 / 89$ & BH024 & $13 B$ & 9.2 & 9.5 & 8.8 \\
\hline $01 / 12 / 90$ & BH079 & $13 E$ & - & - & 23 \\
\hline $01 / 12 / 90$ & BH080 & $13 \mathrm{~F}$ & - & - & 17 \\
\hline $10 / 11 / 89$ & BH013 & $15 D$ & 25 & 3.2 & 1.8 \\
\hline $10 / 04 / 89$ & BH010 & 17B & 13 & 10 & 10 \\
\hline 10/04/89 & BH008 & $17 \mathrm{~F}$ & 56 & 37 & 7.3 \\
\hline $10 / 04 / 89$ & BHOOS & 19D & 41 & 18 & 13 \\
\hline
\end{tabular}


Table B.1. K-1407-C Retention Basin sediment sample analysiselemental analysis (continued)

\begin{tabular}{|c|c|c|c|c|c|}
\hline Date & Hole & Location & $\begin{array}{c}\text { 6-in. } \\
(\mathrm{mg} / \mathrm{kg})\end{array}$ & $\begin{array}{c}12 \text {-in. } \\
(\mathrm{mg} / \mathrm{kg})\end{array}$ & $\begin{array}{c}\text { 18-in. } \\
(\mathrm{mg} / \mathrm{kg})\end{array}$ \\
\hline \multicolumn{6}{|c|}{ Thorium } \\
\hline $01 / 11 / 90$ & BH078 & 01D & $<28$ & - & - \\
\hline $11 / 16 / 89$ & BH067 & $01 F$ & $<130$ & $<120$ & - \\
\hline $01 / 11 / 90$ & BH077 & $02 \mathrm{E}$ & $<25$ & $<22$ & - \\
\hline $01 / 11 / 90$ & BH075 & CBD & $<24$ & - & - \\
\hline $01 / 11 / 90$ & BH076 & 05Б & $<24$ & $<24$ & $<21$ \\
\hline $11 / 07 / 89$ & BH049 & $05 \mathrm{~F}$ & $<20$ & $<20$ & $<20$ \\
\hline $10 / 30 / 89$ & BH045 & 07D & $<20$ & $<20$ & $<20$ \\
\hline $10 / 26 / 89$ & BH038 & 09B & $<200$ & $<20$ & $<20$ \\
\hline $10 / 30 / 89$ & BH042 & 09F & $<20$ & $<20$ & $<20$ \\
\hline $10 / 18 / 89$ & BH025 & 11D & $<20$ & $<20$ & $<20$ \\
\hline $10 / 13 / 89$ & BH024 & $13 B$ & $<20$ & $<20$ & $<20$ \\
\hline $12 / 20 / 89$ & BH024 & 13B & $<23$ & $<21$ & $<23$ \\
\hline $01 / 12 / 90$ & BH079 & $13 \mathrm{E}$ & - & - & $<24$ \\
\hline $01 / 12 / 90$ & BH080 & $13 \mathrm{~F}$ & - & - & $<21$ \\
\hline $10 / 11 / 89$ & BH013 & $15 \mathrm{D}$ & $<20$ & $<20$ & $<20$ \\
\hline $10 / 04 / 89$ & BH010 & 17B & $<20$ & $<20$ & $<20$ \\
\hline $10 / 04 / 89$ & BH008 & $17 \mathrm{~F}$ & $<20$ & $<20$ & $<20$ \\
\hline $10 / 04 / 89$ & BHOOS & 19D & $<20$ & $<20$ & $<20$ \\
\hline \multicolumn{6}{|c|}{ Uranium - Total } \\
\hline $01 / 11 / 90$ & BH078 & $01 \mathrm{D}$ & 78 & - & - \\
\hline $11 / 16 / 89$ & BH067 & $01 \mathrm{~F}$ & $<19$ & $<19$ & - \\
\hline $01 / 11 / 90$ & BH077 & $02 \mathrm{E}$ & 69 & 89 & - \\
\hline $01 / 11 / 90$ & BH075 & 03D & $<3.6$ & - & - \\
\hline $01 / 11 / 90$ & BH076 & 05B & $<3.6$ & $<3.5$ & $<3.2$ \\
\hline $11 / 07 / 89$ & BH049 & $05 \mathrm{~F}$ & 120 & 45 & $<3$ \\
\hline $10 / 30 / 89$ & BH045 & 07D & 320 & 650 & 430 \\
\hline $10 / 26 / 89$ & ВH038 & 09B & 540 & 180 & 27 \\
\hline $10 / 30 / 89$ & BH042 & $09 \mathrm{~F}$ & 69 & 25 & 8.9 \\
\hline $10 / 18 / 89$ & BH025 & 11D & 29 & 11 & $<3$ \\
\hline $10 / 13 / 89$ & BHO24 & $13 B$ & $<3$ & 8 & $<3$ \\
\hline $12 / 20 / 89$ & $\mathrm{BH} 024$ & $13 B$ & $<3.4$ & $<3.1$ & $<3.5$ \\
\hline $01 / 12 / 90$ & BH079 & $13 \mathrm{E}$ & - & - & 36 \\
\hline $01 / 12 / 90$ & ВH080 & $13 \mathrm{~F}$ & - & - & 38 \\
\hline $10 / 11 / 89$ & $\mathrm{BH} 013$ & $15 \mathrm{D}$ & 160 & $<3$ & $<3$ \\
\hline $10 / 04 / 89$ & BH010 & $17 \mathrm{~B}$ & $<3$ & 15 & 9.3 \\
\hline $10 / 04 / 89$ & BH008 & $17 F$ & 260 & 120 & 91 \\
\hline $10 / 04 / 89$ & BH005 & 19D & 120 & 21 & 14 \\
\hline
\end{tabular}


Table B.1. K-1407-C Retention Basin sediment sample analyaiselemental analysis (continued)

\begin{tabular}{|c|c|c|c|c|c|}
\hline Date & Hole & Location & $\begin{array}{c}\text { 6-in. } \\
(\mathrm{mg} / \mathrm{kg})\end{array}$ & $\begin{array}{c}\text { 12-in. } \\
(\mathrm{mg} / \mathrm{kg})\end{array}$ & $\begin{array}{c}\text { 18-in. } \\
\text { (mg/kg) }\end{array}$ \\
\hline
\end{tabular}

Vanadium

$01 / 11 / 90$
$11 / 16 / 89$
$01 / 11 / 90$
$01 / 11 / 90$
$01 / 11 / 90$
$11 / 07 / 89$
$10 / 30 / 89$
$10 / 26 / 89$
$10 / 30 / 89$
$10 / 18 / 89$
$10 / 13 / 89$
$12 / 20 / 89$
$01 / 12 / 90$
$01 / 12 / 90$
$10 / 11 / 89$
$10 / 04 / 89$
$10 / 04 / 89$
$10 / 04 / 89$

$01 / 11 / 90$

$11 / 16 / 89$

$01 / 11 / 90$

$01 / 11 / 90$

$01 / 11 / 90$

$11 / 07 / 89$

$10 / 30 / 89$

$10 / 26 / 89$

$10 / 30 / 89$

$10 / 18 / 89$

$10 / 13 / 89$

$12 / 20 / 89$

$01 / 12 / 90$

$01 / 12 / 90$

$10 / 11 / 89$

$10 / 04 / 89$

$10 / 04 / 89$

10/04/89

$\begin{array}{ll}\text { BH078 } & \text { 01D } \\ \text { BH067 } & \text { 01F } \\ \text { BH077 } & \text { 02E } \\ \text { BH075 } & \text { 03D } \\ \text { BH076 } & \text { 05B } \\ \text { BH049 } & \text { 05F } \\ \text { BH045 } & \text { 07D } \\ \text { BH038 } & \text { U9B } \\ \text { BH042 } & \text { 09F } \\ \text { BH025 } & 11 D \\ \text { BH024 } & 13 \text { B } \\ \text { BH024 } & 13 B \\ \text { BH079 } & 13 E \\ \text { BH080 } & 13 F \\ \text { BH013 } & 15 D \\ \text { BH010 } & 17 B \\ \text { BH008 } & 17 F \\ \text { BH005 } & 19 D\end{array}$

01D
$01 \mathrm{~F}$

O2E

03D

05B

05F

07D

UYB

09F

11D

13B

13E

$13 \mathrm{~F}$

15D

17B

19D

42
53
46
34
46
28
47
47
48
47
34
44
-
-
54
54
61
52

$\overline{29}$
39
-
39
36
48
39
47
38
38
41
-
-
44
40
73
39

-
$\overline{-}$
$\overline{35}$
40
47
33
43
27
37
48
53
61
45
41
67
39

Zinc

BH078

BH067

BH077

BH075

BH076

BH049

BH045

BH038

BH042

$\mathrm{BH}^{25}$

BH024

BH024

BH079

BH080

BH013

BH010

BH008

BH005

$\begin{array}{lr}\text { 01D } & 77 \\ 01 \mathrm{~F} & 120 \\ 02 \mathrm{E} & 91 \\ 03 \mathrm{D} & 70 \\ 05 \mathrm{~B} & 52 \\ 05 \mathrm{~F} & 63 \\ 07 \mathrm{D} & 72 \\ \text { 09B } & 120 \\ 09 \mathrm{~F} & 58 \\ 11 \mathrm{D} & 48 \\ 13 \mathrm{~B} & 37 \\ 13 \mathrm{~B} & 51 \\ 13 \mathrm{E} & - \\ 13 \mathrm{~F} & - \\ 15 \mathrm{D} & 110 \\ 17 \mathrm{~B} & 48 \\ \text { 17F } & 100 \\ 19 \mathrm{D} & 81\end{array}$

$\begin{array}{ll}\overline{80} & - \\ 74 & - \\ \overline{48} & - \\ 67 & 40 \\ 94 & 33 \\ 62 & 86 \\ 40 & 32 \\ 28 & 35 \\ 34 & 11 \\ 47 & 27 \\ - & 61 \\ - & 64 \\ 25 & 86 \\ 41 & 27 \\ 98 & 38 \\ 62 & 63 \\ & 55\end{array}$


Table B.2. K-1407-C Retention Basin sediment sample analysisradionuclide analysis

\begin{tabular}{|c|c|c|c|c|c|}
\hline Date & Hole & Location & $\begin{array}{c}\text { 6-in. } \\
(\mathrm{pCi} / \mathrm{g})\end{array}$ & $\begin{array}{l}12 \text {-in. } \\
(\mathrm{pCi} / \mathrm{g})\end{array}$ & $\begin{array}{l}\text { 18-in. } \\
(\mathrm{pCi} / \mathrm{g})\end{array}$ \\
\hline \multicolumn{6}{|c|}{ Americium-2A1 } \\
\hline $11 / 20 / 89$ & BH070 & OOD & 3.2 & - & - \\
\hline $11 / 20 / 89$ & BH068 & $00 \mathrm{~F}$ & 8.1 & - & - \\
\hline $11 / 20 / 89$ & BH069 & $00 \mathrm{~F}-\mathrm{B}$ & 9.2 & - & - \\
\hline $11 / 21 / 89$ & BH073 & $01 \mathrm{~B}$ & 0.076 & - & - \\
\hline $01 / 10 / 90$ & BH078 & 01D & 0.23 & - & - \\
\hline $11 / 16 / 89$ & BH067 & $01 \mathrm{~F}$ & 0.068 & - & - \\
\hline $11 / 15 / 89$ & BH064 & 01F-B & 3.8 & - & - \\
\hline $11 / 16 / 89$ & BH066 & $01 \mathrm{H}$ & 0.16 & - & - \\
\hline $01 / 10 / 90$ & BH077 & $02 \mathrm{E}$ & 0.43 & - & - \\
\hline $11 / 15 / 89$ & BH063 & $02 G$ & 0.35 & - & - \\
\hline $11 / 16 / 89$ & BH065 & $03 A$ & 0.024 & - & - \\
\hline $11 / 13 / 89$ & BH061 & 03B & 0.084 & 0.049 & 0.043 \\
\hline $11 / 13 / 89$ & BH060 & $03 \mathrm{C}$ & 0.068 & 0.032 & 0.054 \\
\hline $01 / 10 / 90$ & BH075 & 03D & 0.027 & - & - \\
\hline $11 / 13 / 89$ & BH062 & 03D-B & -0.5 & - & - \\
\hline $11 / 09 / 89$ & BH059 & 03E & 1.8 & 1.9 & 0.27 \\
\hline $11 / 09 / 89$ & BH057 & $03 F$ & 0.15 & 0.22 & 0.022 \\
\hline $11 / 09 / 89$ & BH056 & 03F-B & 5.1 & 1.4 & 0.41 \\
\hline $11 / 09 / 89$ & BH058 & $03 \mathrm{H}$ & 0.59 & 0.084 & - \\
\hline $11 / 20 / 89$ & BH072 & $05 \mathrm{~A}$ & 0.11 & - & - \\
\hline $01 / 10 / 90$ & BH076 & 05B & 0.065 & - & - \\
\hline $11 / 03 / 89$ & BH055 & 05D & 0.081 & 0.038 & 0.024 \\
\hline $11 / 01 / 89$ & BHO49 & $05 \mathrm{~F}$ & 1.3 & 0.19 & 0.062 \\
\hline $11 / 01 / 89$ & BH048 & $05 G$ & 0.81 & - & - \\
\hline $11 / 03 / 89$ & BH053 & O6B & 0.1 & 0.089 & 0.17 \\
\hline $11 / 02 / 89$ & BH050 & $06 \mathrm{~F}$ & 1.5 & 0.046 & 0.26 \\
\hline $11 / 02 / 89$ & BH051 & O6F-B & 16 & 1.1 & 0.12 \\
\hline $10 / 30 / 89$ & BH043 & 07B & 1.1 & 2.6 & 12 \\
\hline $10 / 30 / 89$ & BHO44 & 07B-B & 10 & 8.9 & 0.46 \\
\hline $10 / 30 / 89$ & BH045 & 07D & 3.2 & 6.8 & 4.3 \\
\hline $11 / 03 / 89$ & BH052 & 07D-B & 2.2 & 0.3 & 0.11 \\
\hline $11 / 03 / 89$ & BH054 & 07D-B & 1.1 & 5.7 & 0.95 \\
\hline $10 / 30 / 89$ & BH046 & $07 \mathrm{~F}$ & 8.1 & 0.43 & 0.16 \\
\hline $10 / 12 / 89$ & BH021 & 07F-B & 5.7 & 2 & 7 \\
\hline $10 / 30 / 89$ & BH047 & 07F-B & 16 & 2.2 & - \\
\hline $11 / 20 / 89$ & BH071 & 07F-B & 32 & - & - \\
\hline $10 / 25 / 89$ & BH038 & O9B & 3.8 & 4 & 0.11 \\
\hline $10 / 18 / 89$ & BH033 & 09B-B & -0.03 & - & - \\
\hline $10 / 25 / 89$ & BH039 & $09 \mathrm{C}$ & 1.9 & 0.15 & 0.054 \\
\hline $10 / 25 / 89$ & BHO40 & O9D & 3.2 & 0.32 & $<0.19$ \\
\hline $10 / 25 / 89$ & $\mathrm{BH} 041$ & $09 \mathrm{E}$ & -0.05 & 0.35 & 0.16 \\
\hline $10 / 30 / 89$ & BHO42 & $09 \mathrm{~F}$ & 0.49 & 0.076 & 0.35 \\
\hline $10 / 24 / 89$ & BH037 & 09F-B & 13 & 3.2 & 0.14 \\
\hline $10 / 16 / 89$ & BH027 & $11 \mathrm{~A}$ & 0.38 & - & - \\
\hline
\end{tabular}


Table B.2. K-1407-C Retention Basin sediment sample analysisradionuclide analysis (continued)

\begin{tabular}{|c|c|c|c|c|c|}
\hline Date & Hole & Location & $\begin{array}{l}\text { 6-in. } \\
(\mathrm{pCi} / \mathrm{g})\end{array}$ & $\begin{array}{l}\text { 12-in. } \\
(\mathrm{pCi} / \mathrm{g})\end{array}$ & $\begin{array}{l}\text { 18-in. } \\
(\mathrm{pCi} / \mathrm{g})\end{array}$ \\
\hline
\end{tabular}

Americium-241 (continued)

\begin{tabular}{|c|c|c|c|c|c|}
\hline $10 / 16 / 89$ & BH026 & 11B & 6.8 & - & - \\
\hline $10 / 16 / 89$ & BH025 & 11D & 0.2 & - & - \\
\hline $10 / 18 / 89$ & BH030 & $11 \mathrm{~F}$ & 0.068 & - & - \\
\hline $10 / 18 / 89$ & BH031 & 11F-B & 1.9 & - & - \\
\hline $10 / 24 / 89$ & BH036 & $11 \mathrm{~F}-\mathrm{B}$ & 4 & 1.9 & 0.16 \\
\hline 10/18/89 & BH032 & $11 \mathrm{H}$ & 0.07 & - & - \\
\hline $10 / 23 / 89$ & BH035 & $11 \mathrm{H}-\mathrm{B}$ & 23 & 57 & 1.6 \\
\hline $10 / 16 / 89$ & BH028 & $12 B$ & 0.3 & - & - \\
\hline $01 / 03 / 90$ & BH074 & $12 \mathrm{~F}$ & 0.054 & -0.6 & 0.07 \\
\hline $10 / 13 / 89$ & BH024 & 13B & -0.005 & - & - \\
\hline $10 / 13 / 89$ & BH023 & $13 \mathrm{C}$ & 0.22 & 0.3 & $<0.32$ \\
\hline $10 / 18 / 89$ & BH029 & 13D & 0.35 & - & - \\
\hline $10 / 12 / 89$ & BHO20 & $15 B$ & 0.019 & 0.078 & 0.0089 \\
\hline 10/10/89 & BH013 & 15D & 1.1 & - & - \\
\hline $10 / 11 / 89$ & BH017 & 15D-B & 0.12 & - & - \\
\hline 10/10/89 & BH014 & $15 \mathrm{~F}$ & 8.6 & - & - \\
\hline 10/10/89 & BH015 & 15F-B & 0.59 & - & - \\
\hline 10/11/89 & BH018 & $15 F-B$ & 3.5 & - & - \\
\hline 10/23/89 & BH034 & $15 \mathrm{~F}-\mathrm{B}$ & -1 & 0.84 & 1 \\
\hline $10 / 10 / 89$ & BH016 & $15 \mathrm{H}$ & 3 & - & - \\
\hline $10 / 12 / 89$ & BH019 & 16B & 0.016 & 0.054 & 0.073 \\
\hline 10/13/89 & BH022 & $16 \mathrm{E}-\mathrm{B}$ & 1.4 & 0.26 & 0.15 \\
\hline $10 / 09 / 89$ & BH012 & $16 \mathrm{~F}$ & 1.1 & - & - \\
\hline $10 / 04 / 89$ & BH010 & 17B & 0.12 & $<0.054$ & 0.016 \\
\hline 10/04/89 & BH009 & 17D & 0.92 & $<0.22$ & 0.0086 \\
\hline $10 / 03 / 89$ & BH008 & $17 \mathrm{~F}$ & 1.5 & 0.57 & 0.059 \\
\hline 10/03/89 & ВH007 & $17 \mathrm{H}$ & 2.5 & 0.26 & 2.7 \\
\hline 10/03/89 & BH004 & 18E-B & 0.57 & 0.062 & 0.059 \\
\hline 09/28/89 & BHOO2 & 18G-B & 4 & 4 & 0.59 \\
\hline 10/03/89 & BH006 & 19B & 0.18 & 0.059 & - \\
\hline 10/03/89 & BH005 & 19D & 0.81 & 0.2 & 0.22 \\
\hline $10 / 02 / 89$ & BH003 & $19 \mathrm{~F}$ & 0.25 & 1.2 & 0.23 \\
\hline $09 / 27 / 89$ & BHOO1 & $19 \mathrm{H}$ & 0.073 & 0.1 & 0.07 \\
\hline $10 / 09 / 89$ & BH011 & $20 \mathrm{D}$ & 0.062 & - & - \\
\hline \multicolumn{6}{|c|}{ Cesium-137 } \\
\hline $11 / 20 / 89$ & BH070 & OOD & 5.7 & - & - \\
\hline $11 / 20 / 89$ & BH068 & OOF & 16 & - & - \\
\hline $11 / 20 / 89$ & BH069 & OOF-B & 27 & - & - \\
\hline $11 / 21 / 89$ & BH073 & 01B & 0.12 & - & - \\
\hline $01 / 10 / 90$ & BH078 & 01D & 1.4 & - & - \\
\hline $11 / 16 / 89$ & BH067 & $01 \mathrm{~F}$ & 0.65 & - & - \\
\hline
\end{tabular}


Table B.2. K-1407-C Retention Basin sediment sample analysisradionuclide analysis (continued)

\begin{tabular}{|c|c|c|c|c|c|}
\hline Date & Hole & Location & $\begin{array}{c}\text { 6-in. } \\
(\mathrm{pCi} / \mathrm{g})\end{array}$ & $\begin{array}{l}\text { 12-in. } \\
\text { (pCi/g) }\end{array}$ & $\begin{array}{l}\text { 18-in. } \\
(\mathrm{pCi} / \mathrm{g})\end{array}$ \\
\hline \multicolumn{6}{|c|}{ Cesium-137 (continued) } \\
\hline $11 / 15 / 89$ & BH!064 & 01F-B & 4.6 & - & - \\
\hline $11 / 16 / 89$ & BH066 & $01 \mathrm{H}$ & 0.68 & - & - \\
\hline $01 / 10 / 90$ & BH077 & $02 \mathrm{E}$ & 3 & - & - \\
\hline $11 / 15 / 89$ & BH063 & $02 G$ & 1.9 & - & - \\
\hline $11 / 16 / 89$ & BH065 & 03A & 0.38 & - & - \\
\hline $11 / 13 / 89$ & BH061 & 03B & 0.054 & $<0.054$ & $<0.054$ \\
\hline $11 / 13 / 89$ & BH060 & $03 \mathrm{C}$ & 0.024 & $<0.081$ & $<0.081$ \\
\hline $01 / 10 / 90$ & BH075 & 03D & 0.21 & - & - \\
\hline $11 / 13 / 89$ & BH062 & 03D-B & 27 & - & - \\
\hline $11 / 09 / 89$ & BH059 & 03E & 4 & 9.4 & 1.6 \\
\hline $11 / 09 / 89$ & BH057 & 03F & 0.84 & 1.1 & 0.19 \\
\hline $11 / 09 / 89$ & BH056 & 03F-B & 26 & 4.9 & 0.41 \\
\hline $11 / 09 / 89$ & BH058 & $03 \mathrm{H}$ & 1.7 & 0.23 & - \\
\hline $11 / 20 / 89$ & BH072 & 05A & 2.3 & - & - \\
\hline $01 / 10 / 90$ & BH076 & 05B & 0.49 & - & - \\
\hline $11 / 03 / 89$ & BH055 & 05D & 0.76 & 0.11 & $<0.054$ \\
\hline $11 / 01 / 89$ & BH049 & $05 \mathrm{~F}$ & 0.65 & 0.22 & 0.12 \\
\hline $11 / 01 / 89$ & BH048 & $05 G$ & 0.19 & - & - \\
\hline $11 / 03 / 89$ & BH053 & O6B & 1.5 & 0.54 & 0.32 \\
\hline $11 / 02 / 89$ & BH050 & $06 \mathrm{~F}$ & 0.86 & 0.14 & 0.11 \\
\hline $11 / 02 / 89$ & BH051 & 06F-B & 12 & 2.4 & 0.11 \\
\hline $10 / 30 / 89$ & BH043 & 07B & 15 & 9.4 & 13 \\
\hline $10 / 30 / 89$ & BH044 & 07B-B & 54 & 38 & 3.5 \\
\hline $10 / 30 / 89$ & BH045 & 07D & 23 & 30 & 22 \\
\hline $11 / 03 / 89$ & BH052. & 07D-B & 18 & 1 & 0.21 \\
\hline $11 / 03 / 89$ & BH054 & 07D-B & 43 & 38 & 15 \\
\hline $10 / 30 / 89$ & BH046 & $07 \mathrm{~F}$ & 32 & 3.5 & 1.3 \\
\hline $10 / 12 / 89$ & BH021 & 07F-B & 49 & 59 & 43 \\
\hline $10 / 30 / 89$ & BH047 & 07F-B & 57 & 14 & - \\
\hline $11 / 20 / 89$ & BH071 & 07F-B & 110 & - & - \\
\hline $10 / 25 / 89$ & BH038 & $09 \mathrm{~B}$ & 23 & 14 & 14 \\
\hline $10 / 18 / 89$ & BH033 & 09B-B & 180 & 4.9 & 0.22 \\
\hline $10 / 25 / 89$ & BH039 & $09 \mathrm{C}$ & 3 & 0.59 & 0.13 \\
\hline $10 / 25 / 89$ & BHOSO & 09D & 3.8 & 1 & 0.051 \\
\hline $10 / 25 / 89$ & BH041 & 09E & 5.9 & 0.68 & 0.07 \\
\hline 10/30/89 & BH042 & $09 \mathrm{~F}$ & 2 & 0.46 & 0.95 \\
\hline $10 / 24 / 89$ & BH037 & 09F-B & 15 & 5.4 & 13 \\
\hline $10 / 16 / 89$ & BH027 & $11 \mathrm{~A}$ & 1.6 & 2.5 & 1.1 \\
\hline $10 / 16 / 89$ & BH026 & $11 \mathrm{~B}$ & 5.1 & 0.7 & 1.2 \\
\hline $10 / 16 / 89$ & BHO25 & $11 D$ & 1.2 & 0.17 & 0.043 \\
\hline $10 / 18 / 89$ & BH030 & $11 \mathrm{~F}$ & 0.13 & 4.6 & 6.2 \\
\hline $10 / 18 / 89$ & BH031 & 11F-B & 12 & 1.9 & 0.086 \\
\hline $10 / 24 / 89$ & BH036 & $11 F-B$ & 9.4 & 8.9 & 0.51 \\
\hline
\end{tabular}


Table B.2 K-1407-C Retention Basin sediment sample analysisradionuclide analysis (continued)

\begin{tabular}{|c|c|c|c|c|c|}
\hline Date & Hole & Location & $\underset{(\mathrm{pCi} / \mathrm{g})}{\text { 6-in. }}$ & $\begin{array}{l}\text { 12-in. } \\
\text { (pCi/g) }\end{array}$ & $\begin{array}{c}\text { 18-in. } \\
(\mathrm{pCi} / \mathrm{g})\end{array}$ \\
\hline
\end{tabular}

\section{Cesium-137 (continued)}

$\begin{array}{llllcc}10 / 18 / 89 & \text { BH032 } & 11 \mathrm{H} & 25 & 15 & 7.3 \\ 10 / 23 / 89 & \text { BH035 } & 11 \mathrm{H}-\mathrm{B} & 97 & 81 & 13 \\ 10 / 16 / 89 & \text { BH028 } & 12 \mathrm{~B} & 1.8 & 0.03 & <0.14 \\ 01 / 03 / 90 & \text { BH074 } & 12 \mathrm{~F} & 0.38 & 0.081 & -0.003 \\ 10 / 13 / 89 & \text { BH024 } & 13 \mathrm{~B} & 0.059 & 0.068 & 0.089 \\ 10 / 13 / 89 & \text { BH023 } & 13 \mathrm{C} & 1.6 & 2.2 & <0.11 \\ 10 / 18 / 89 & \text { BHO29 } & 13 \mathrm{D} & 2.7 & 0.092 & 0.03 \\ 10 / 12 / 89 & \text { BH020 } & 15 \mathrm{~B} & 0.076 & 0.12 & <0.14 \\ 10 / 10 / 89 & \text { BH013 } & 15 \mathrm{D} & 5.4 & 0.21 & 0.092 \\ 10 / 11 / 89 & \text { BH017 } & 15 \mathrm{D}-\mathrm{B} & 0.76 & 0.19 & 0.041 \\ 10 / 10 / 89 & \text { BH014 } & 15 \mathrm{~F} & 8.6 & 0.54 & 0.12 \\ 10 / 10 / 89 & \text { BH015 } & 15 \mathrm{~F}-\mathrm{B} & 84 & 5.7 & 1.8 \\ 10 / 11 / 89 & \text { BH018 } & 15 \mathrm{~F}-\mathrm{B} & 26 & 6.2 & 3.8 \\ 10 / 23 / 89 & \text { BH034 } & 15 \mathrm{~F}-\mathrm{B} & 16 & 1.5 & 1.4 \\ 10 / 10 / 89 & \text { BH016 } & 15 \mathrm{H} & 8.9 & 8.4 & 3 \\ 10 / 12 / 89 & \text { BH019 } & 16 \mathrm{~B} & 0.22 & 0.059 & 0.035 \\ 10 / 13 / 89 & \text { BH022 } & 16 \mathrm{E}-\mathrm{B} & 11 & 0.76 & 0.095 \\ 10 / 09 / 89 & \text { BH012 } & 16 \mathrm{~F} & 8.9 & 0.19 & 0.086 \\ 10 / 04 / 89 & \text { BH010 } & 17 \mathrm{~B} & 0.81 & <0.14 & <.11 \\ 10 / 04 / 89 & \text { BH009 } & 17 \mathrm{D} & 12 & 0.43 & 0.24 \\ 10 / 03 / 89 & \text { BH008 } & 17 \mathrm{~F} & 11 & 2.2 & 0.43 \\ 10 / 03 / 89 & \text { BH007 } & 17 \mathrm{H} & 19 & 10 & 17 \\ 10 / 03 / 89 & \text { BH004 } & 18 \mathrm{E}-\mathrm{B} & 8.6 & 3.5 & 0.62 \\ 09 / 28 / 89 & \text { BH002 } & 18 \mathrm{G}-\mathrm{B} & 76 & 19 & 0.89 \\ 10 / 03 / 89 & \text { BH006 } & 19 \mathrm{~B} & 0.38 & 0.23 & - \\ 10 / 03 / 89 & \text { BH005 } & 19 \mathrm{D} & 7.6 & 1.4 & 1.2 \\ 10 / 02 / 89 & \text { BH003 } & 19 \mathrm{~F} & 2.3 & 15 & 3 \\ 09 / 27 / 89 & \text { BH001 } & 19 \mathrm{H} & 0.21 & 0.084 & 0.076 \\ 10 / 09 / 89 & \text { BH011 } & 20 \mathrm{D} & 0.35 & 0.13 & -0.02\end{array}$

Cobalt-60

$11 / 20 / 89$
$11 / 20 / 89$
$11 / 20 / 89$
$11 / 21 / 89$
$11 / 16 / 89$
$11 / 15 / 89$
$11 / 16 / 89$
$11 / 15 / 89$
$11 / 16 / 89$
$11 / 13 / 89$
$11 / 13 / 89$

BH070

BH068

BH069

BH073

BH067

BH064

BH066

BH063

BH065

BH061

BH060

O0D
$00 \mathrm{~F}$
$00 \mathrm{~F}-\mathrm{B}$
$01 \mathrm{~B}$
$01 \mathrm{~F}$
$01 \mathrm{~F}-\mathrm{B}$
$01 \mathrm{H}$
$02 \mathrm{G}$
$03 \mathrm{~A}$
$03 \mathrm{~B}$
$03 \mathrm{C}$

-0.01
-0.005
0.022
-0.04
0.03
0.078
0.035
0.057
0.022
-0.03
0.022

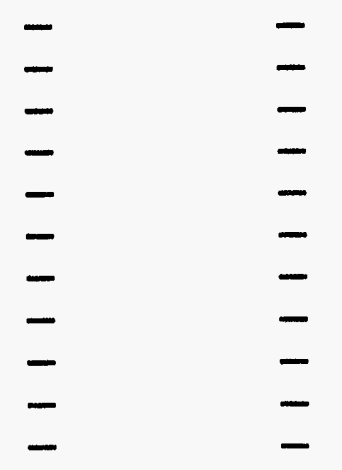


Table B.2 K-1407-C Retention Basin sedinent sample analysisradionuclide analysis (continued)

\begin{tabular}{|c|c|c|c|c|c|}
\hline Date & Hole & Location & $\underset{(\mathrm{pCi} / \mathrm{g})}{\text { 6-in. }}$ & $\begin{array}{l}\text { 12-in. } \\
(\mathrm{pCL} / \mathrm{g})\end{array}$ & $\begin{array}{l}\text { 18-in. } \\
(\mathrm{pCi} / \mathrm{g})\end{array}$ \\
\hline
\end{tabular}

\section{Cobalt-60 (continued)}

\begin{tabular}{|c|c|c|c|c|c|}
\hline $01 / 10 / 90$ & BH075 & 03D & 0.089 & - & - \\
\hline $11 / 13 / 89$ & BH062 & 03D-B & 0.022 & - & - \\
\hline $11 / 09 / 89$ & BH059 & 03E & 0.022 & - & - \\
\hline $11 / 09 / 89$ & BH057 & $03 \mathrm{~F}$ & 0.0054 & - & - \\
\hline $11 / 09 / 89$ & BH056 & 03F-B & 0.032 & - & - \\
\hline $11 / 09 / 89$ & BH058 & $03 \mathrm{H}$ & -0.008 & - & - \\
\hline $11 / 20 / 89$ & BH072 & 05A & 0.062 & - & - \\
\hline $11 / 03 / 89$ & BH055 & 05D & -0.008 & - & - \\
\hline $11 / 01 / 89$ & BH049 & $05 \mathrm{~F}$ & -0.03 & - & - \\
\hline $11 / 01 / 89$ & BH048 & $05 \mathrm{G}$ & -0.02 & - & - \\
\hline $11 / 03 / 89$ & BH053 & O6B & -0.01 & - & - \\
\hline $11 / 02 / 89$ & BH050 & 06F & 0.022 & - & - \\
\hline $11 / 02 / 89$ & BH051 & 06F-B & 0.014 & - & - \\
\hline 10/30/89 & BH043 & 07B & 0.092 & - & - \\
\hline $10 / 30 / 89$ & BH044 & 07B-B & 0.078 & - & - \\
\hline $10 / 30 / 89$ & BH045 & 07D & 0.0081 & - & - \\
\hline $11 / 03 / 89$ & BH052 & 07D-B & 0.0027 & - & - \\
\hline 11/03/89 & BH054 & 07D-B & 0.11 & - & - \\
\hline 10/30/89 & BH046 & $07 \mathrm{~F}$ & 0.089 & - & - \\
\hline $10 / 12 / 89$ & BH021 & 07F-B & -0.2 & - & - \\
\hline $10 / 30 / 89$ & BH047 & 07F.B & 0.0081 & - & - \\
\hline $11 / 20 / 89$ & BH071 & 07F-B & 0.12 & - & - \\
\hline $10 / 25 / 89$ & BH038 & 09B & 0.073 & - & - \\
\hline $10 / 18 / 89$ & BH033 & 09B-B & 0.068 & - & - \\
\hline $10 / 25 / 89$ & BH039 & $09 \mathrm{C}$ & 0.032 & - & - \\
\hline $10 / 25 / 89$ & BH040 & 09D & 0.049 & - & - \\
\hline $10 / 25 / 89$ & BH041 & $09 \mathrm{E}$ & 0.022 & - & - \\
\hline $10 / 30 / 89$ & BH042 & 09F & -0.003 & - & - \\
\hline $10 / 24 / 89$ & BH037 & 09F-B & 0.065 & - & - \\
\hline $10 / 16 / 89$ & BH027 & $11 \mathrm{~A}$ & -0.03 & - & - \\
\hline $10 / 16 / 89$ & BH026 & $11 \mathrm{~B}$ & 0.041 & - & - \\
\hline $10 / 16 / 89$ & BH025 & $11 D$ & 0.016 & - & - \\
\hline $10 / 18 / 89$ & BH030 & $11 \mathrm{~F}$ & 0.041 & - & - \\
\hline $10 / 18 / 89$ & BH031 & 11F-B & 0.03 & - & - \\
\hline $10 / 24 / 89$ & BH036 & 11F-B & 0.027 & 0.032 & - \\
\hline $10 / 18 / 89$ & BH032 & $11 \mathrm{H}$ & -0.04 & - & - \\
\hline $10 / 23 / 89$ & BH035 & $11 \mathrm{H}-\mathrm{B}$ & 0.14 & - & - \\
\hline $10 / 16 / 89$ & BH028 & 12B & 0.057 & - & - \\
\hline $01 / 03 / 90$ & BH074 & $12 \mathrm{~F}$ & 0.35 & - & - \\
\hline $10 / 13 / 89$ & BH024 & 13B & 0.043 & - & - \\
\hline $10 / 13 / 89$ & BH023 & $13 \mathrm{C}$ & -0.03 & - & - \\
\hline $10 / 18 / 89$ & BH029 & 13D & 0.046 & - & - \\
\hline $10 / 12 / 89$ & BH020 & $15 B$ & 0.092 & - & - \\
\hline
\end{tabular}


Table B.2. K-1407-C Retention Basin sediment sample analysisradionuclide analysis (continued)

\begin{tabular}{|c|c|c|c|c|c|}
\hline Date & Hole & Location & $\underset{(\mathrm{pCi} / \mathrm{g})}{\text { 6-in. }}$ & $\begin{array}{c}\text { 12-in. } \\
(\mathrm{pCi} / \mathrm{g})\end{array}$ & $\begin{array}{l}\text { 18-in. } \\
(\mathrm{pCi} / \mathrm{g})\end{array}$ \\
\hline
\end{tabular}

Cobalt-60 (continued)

$\begin{array}{llllll}10 / 10 / 89 & \text { BH013 } & \text { 15D } & 0.089 & - & - \\ 10 / 11 / 89 & \text { BH017 } & \text { 15D-B } & -0.05 & - & - \\ 10 / 10 / 89 & \text { BH014 } & 15 \mathrm{~F} & 0.011 & - & - \\ 10 / 10 / 89 & \text { BH015 } & 15 \mathrm{~F}-\mathrm{B} & 0.011 & - & - \\ 10 / 11 / 89 & \text { BH018 } & 15 \mathrm{~F}-\mathrm{B} & -0.03 & - & - \\ 10 / 23 / 89 & \text { BH034 } & 15 \mathrm{~F}-\mathrm{B} & 0.032 & - & - \\ 10 / 10 / 89 & \text { BH016 } & 15 \mathrm{H} & 0.07 & - & - \\ 10 / 12 / 89 & \text { BH019 } & 16 \mathrm{~B} & 0.027 & - & - \\ 10 / 13 / 89 & \text { BH022 } & 16 \mathrm{E}-\mathrm{B} & 0.054 & - & - \\ 10 / 09 / 89 & \text { BH012 } & 16 \mathrm{~F} & -0.02 & - & - \\ 10 / 04 / 89 & \text { BH010 } & 17 \mathrm{~B} & 0.019 & - & - \\ 10 / 04 / 89 & \text { BH009 } & 17 \mathrm{D} & 0.032 & - & - \\ 10 / 03 / 89 & \text { BH008 } & 17 \mathrm{~F} & 0.065 & - & - \\ 10 / 03 / 89 & \text { BH007 } & 17 \mathrm{H} & 0.03 & - & - \\ 10 / 03 / 89 & \text { BH004 } & 18 \mathrm{E}-\mathrm{B} & 0.016 & - & - \\ 09 / 28 / 89 & \text { BH002 } & 18 \mathrm{G}-\mathrm{B} & -0.003 & - & - \\ 10 / 03 / 89 & \text { BH006 } & 19 \mathrm{~B} & -0.005 & - & - \\ 10 / 03 / 89 & \text { BH005 } & 19 \mathrm{D} & 0.03 & - & - \\ 10 / 02 / 89 & \text { BH003 } & 19 \mathrm{~F} & 0.081 & - & - \\ 09 / 27 / 89 & \text { BH001 } & 19 \mathrm{H} & -0.04 & - & - \\ 10 / 09 / 89 & \text { BH011 } & 20 \mathrm{D} & 0.016 & - & -\end{array}$

\section{Curium-244}

$\begin{array}{llllll}10 / 12 / 89 & \text { BH021 } & \text { 07F-B } & -0.01 & - & - \\ 01 / 03 / 90 & \text { BH074 } & 12 \mathrm{~F} & -0.001 & - & - \\ 10 / 13 / 89 & \text { BH024 } & 13 \mathrm{~B} & -0.02 & - & - \\ 10 / 13 / 89 & \text { BH023 } & 13 \mathrm{C} & -0.01 & - & - \\ 10 / 12 / 89 & \text { BH020 } & 15 \mathrm{~B} & -0.04 & - & - \\ 10 / 10 / 89 & \text { BH013 } & 15 \mathrm{D} & -0.009 & - & - \\ 10 / 11 / 89 & \text { BH017 } & 15 \mathrm{D}-\mathrm{B} & -0.01 & - & - \\ 10 / 10 / 89 & \text { BH014 } & 15 \mathrm{~F} & 0.059 & - & - \\ 10 / 10 / 89 & \text { BH015 } & 15 \mathrm{~F}-\mathrm{B} & -0.04 & - & - \\ 10 / 11 / 89 & \text { BH018 } & 15 \mathrm{~F}-\mathrm{B} & -0.08 & - & - \\ 10 / 10 / 89 & \text { BH016 } & 15 \mathrm{H} & 0.0027 & - & - \\ 10 / 12 / 89 & \text { BH019 } & 16 \mathrm{~B} & -0.03 & - & - \\ 10 / 13 / 89 & \text { BH022 } & 16 \mathrm{E}-\mathrm{B} & -0.04 & - & - \\ 10 / 09 / 89 & \text { BH012 } & 16 \mathrm{~F} & -0.04 & - & - \\ 10 / 04 / 89 & \text { BH010 } & 17 \mathrm{~B} & -0.003 & - & - \\ 10 / 04 / 89 & \text { BH009 } & 17 \mathrm{D} & -0.02 & - & - \\ 10 / 03 / 89 & \text { BH008 } & 17 \mathrm{~F} & -0.04 & - & - \\ 10 / 03 / 89 & \text { BH007 } & 17 \mathrm{H} & -0.04 & - & - \\ 10 / 03 / 89 & \text { BH004 } & 18 \mathrm{E}-\mathrm{B} & 0.0081 & - & -\end{array}$


Table B.2. K-1407-C Retention Basin sediment sample analysisradionuclide analysis (continued)

\begin{tabular}{|c|c|c|c|c|c|}
\hline Date & Hole & Location & $\begin{array}{c}\text { 6-in. } \\
(\mathrm{pCi} / \mathrm{g})\end{array}$ & $\begin{array}{l}12-\ln . \\
(\mathrm{pCi} / \mathrm{g})\end{array}$ & $\begin{array}{c}18 \text {-in. } \\
(\mathrm{pCl} / \mathrm{g})\end{array}$ \\
\hline \multicolumn{6}{|c|}{ Curium-244 (continued) } \\
\hline 09/28/89 & BHOO2 & 18G-B & -0.4 & - & - \\
\hline $10 / 03 / 89$ & BH006 & 19B & -0.03 & - & - \\
\hline $10 / 03 / 89$ & BH005 & 19D & 0.024 & - & - \\
\hline $10 / 02 / 89$ & BH003 & $19 \mathrm{~F}$ & -0.2 & - & - \\
\hline 09/27/89 & BH001 & $19 \mathrm{H}$ & -0.005 & - & - \\
\hline $10 / 09 / 89$ & BH011 & $20 \mathrm{D}$ & -0.03 & - & - \\
\hline \multicolumn{6}{|c|}{ Europium-154 } \\
\hline 10/18/89 & BH033 & 09B-B & 2.1 & - & - \\
\hline \multicolumn{6}{|c|}{ Gross alpha } \\
\hline $11 / 20 / 89$ & BH070 & $00 \mathrm{D}$ & 230 & 680 & 570 \\
\hline $11 / 20 / 89$ & BH068 & $00 \mathrm{~F}$ & 510 & 540 & 410 \\
\hline $11 / 20 / 89$ & BH069 & OOF-B & 760 & 410 & 540 \\
\hline $11 / 21 / 89$ & BH073 & $01 \mathrm{~B}$ & 11 & 12 & 9.2 \\
\hline $01 / 10 / 90$ & BH078 & 01D & 35 & - & - \\
\hline $11 / 16 / 89$ & BH067 & $01 \mathrm{~F}$ & 35 & 14 & - \\
\hline $11 / 15 / 89$ & BH064 & 01F-B & 220 & 84 & 19 \\
\hline $11 / 16 / 89$ & BH066 & $01 \mathrm{H}$ & 22 & 12 & - \\
\hline $01 / 10 / 90$ & ВH077 & $02 \mathrm{E}$ & 73 & 37 & - \\
\hline $11 / 15 / 89$ & BH063 & $02 G$ & 54 & 13 & 650 \\
\hline $11 / 16 / 89$ & BH065 & 03A & 25 & 27 & 23 \\
\hline $11 / 13 / 89$ & BH061 & 03B & 14 & 8.4 & 8.9 \\
\hline $11 / 13 / 89$ & BH060 & 03C & 12 & 11 & 8.1 \\
\hline $01 / 10 / 90$ & BH075 & 03D & 4.9 & - & - \\
\hline $11 / 13 / 89$ & BH062 & 03D-B & 380 & 10 & 23 \\
\hline $11 / 09 / 89$ & BH059 & 03E & 110 & 260 & 49 \\
\hline $11 / 09 / 89$ & BH057 & $03 \mathrm{~F}$ & 41 & 32 & 17 \\
\hline $11 / 09 / 89$ & BH056 & 03F-B & 1100 & 230 & 18 \\
\hline $11 / 09 / 89$ & BH058 & $03 \mathrm{H}$ & 59 & 13 & - \\
\hline $11 / 20 / 89$ & BH072 & $05 \mathrm{~A}$ & 68 & 62 & 43 \\
\hline $01 / 10 / 90$ & BH076 & 05B & 20 & 8.1 & 7.8 \\
\hline $11 / 03 / 89$ & BH055 & 05D & 19 & 5.1 & 3.8 \\
\hline $11 / 01 / 89$ & BH049 & $05 F$ & 65 & 54 & 27 \\
\hline $11 / 01 / 89$ & ВH048 & $05 G$ & 19 & - & - \\
\hline $11 / 03 / 89$ & BH053 & O6B & 54 & 22 & 14 \\
\hline $11 / 02 / 89$ & BH0S0 & $06 \mathrm{~F}$ & 100 & 89 & 59 \\
\hline $11 / 02 / 89$ & BH051 & 06F-B & 320 & 110 & 11 \\
\hline $10 / 30 / 89$ & BH043 & 07B & 270 & 210 & 410 \\
\hline $10 / 30 / 89$ & BHO44 & 07B-B & 810 & 570 & 78 \\
\hline $10 / 30 / 89$ & BH045 & 07D & 300 & 540 & 490 \\
\hline
\end{tabular}


Table B.2. K-1407-C Retention Besin rediment sample anatysisradionuclide analysis (continued)

\begin{tabular}{|c|c|c|c|c|c|}
\hline Date & Hole & Location & $\underset{(\mathrm{pCi} / \mathrm{g})}{\text { 6-in. }}$ & $\begin{array}{l}\text { 12-in. } \\
(\mathrm{pCi} / \mathrm{g})\end{array}$ & $\begin{array}{c}\text { 18-in. } \\
(\mathrm{pCl} / \mathrm{g})\end{array}$ \\
\hline
\end{tabular}

\section{Gross alpha (continued)}

\begin{tabular}{|c|c|c|c|c|c|}
\hline $11 / 03 / 89$ & BH052 & 07D-B & 240 & 17 & 11 \\
\hline $11 / 03 / 89$ & BH054 & 07D-B & 810 & 680 & 170 \\
\hline $10 / 30 / 89$ & BH046 & $07 \mathrm{~F}$ & 890 & 140 & 68 \\
\hline $10 / 12 / 89$ & BHO21 & 07F-B & 1100 & 1400 & 950 \\
\hline $10 / 30 / 89$ & BH047 & 07F-B & 1900 & 380 & - \\
\hline $11 / 20 / 89$ & BH071 & 07F-B & 1900 & - & - \\
\hline $10 / 25 / 89$ & BH038 & 09B & 540 & 350 & 54 \\
\hline $10 / 18 / 89$ & BH033 & 09B-B & 1900 & 86 & 14 \\
\hline $10 / 25 / 89$ & BH039 & $09 \mathrm{C}$ & 100 & 18 & 13 \\
\hline $10 / 25 / 89$ & BH040 & 09D & 92 & 25 & 4.3 \\
\hline $10 / 25 / 89$ & BH041 & 09E & 92 & 17 & 7 \\
\hline $10 / 30 / 89$ & BH042 & 09F & 70 & 30 & 27 \\
\hline $10 / 24 / 89$ & BH037 & 09F-B & 1000 & 150 & 49 \\
\hline $10 / 16 / 89$ & BH027 & $11 \mathrm{~A}$ & 65 & 65 & 41 \\
\hline $10 / 16 / 89$ & BH026 & $11 \mathrm{~B}$ & 170 & 25 & 35 \\
\hline $10 / 16 / 89$ & BH025 & 11D & 41 & 15 & 5.4 \\
\hline $10 / 18 / 89$ & BH030 & $11 \mathrm{~F}$ & 14 & 140 & 170 \\
\hline $10 / 18 / 89$ & BH031 & 11F-B & 190 & 25 & 18 \\
\hline 10/24/89 & BH036 & 11F-B & 250 & 210 & 17 \\
\hline 10/18/89 & BH032 & $11 \mathrm{H}$ & 380 & 350 & 300 \\
\hline $10 / 23 / 89$ & BH035 & $11 \mathrm{H}-\mathrm{B}$ & 350 & 1400 & 270 \\
\hline $10 / 16 / 89$ & BH028 & $12 \mathrm{~B}$ & 54 & 3.2 & 10 \\
\hline $01 / 03 / 90$ & BH074 & $12 \mathrm{~F}$ & 8.6 & 7.8 & 5.1 \\
\hline $10 / 13 / 89$ & BH024 & $13 B$ & 5.4 & 18 & 3.5 \\
\hline $10 / 13 / 89$ & BH023 & $13 \mathrm{C}$ & 32 & 54 & 5.9 \\
\hline $10 / 18 / 89$ & BH029 & 13D & 54 & 14 & 6.8 \\
\hline $01 / 11 / 90$ & BH079 & $13 \mathrm{E}$ & - & - & 57 \\
\hline $01 / 11 / 90$ & BH080 & $13 \mathrm{~F}$ & - & - & 43 \\
\hline $10 / 12 / 89$ & BH020 & 15B & 14 & 15 & 11 \\
\hline $10 / 10 / 89$ & BH013 & 15D & 65 & 14 & 11 \\
\hline $10 / 11 / 89$ & BH017 & 15D-B & 49 & 10 & 11 \\
\hline $10 / 10 / 89$ & BH014 & $15 \mathrm{~F}$ & 180 & 59 & 43 \\
\hline 10/10/89 & BH015 & 15F-B & 1100 & 100 & 38 \\
\hline $10 / 11 / 89$ & BH018 & $15 \mathrm{~F}-\mathrm{B}$ & 410 & 130 & 120 \\
\hline $10 / 23 / 89$ & BH034 & 15F-B & 220 & 57 & 76 \\
\hline $10 / 10 / 89$ & BH016 & $15 \mathrm{H}$ & 200 & 220 & 95 \\
\hline $10 / 12 / 89$ & BH019 & $16 \mathrm{~B}$ & 13 & 19 & 16 \\
\hline 10/13/89 & BH022 & $16 \mathrm{E}-\mathrm{B}$ & 170 & 38 & 46 \\
\hline 10/09/89 & BH012 & $16 \mathrm{~F}$ & 95 & 25 & 14 \\
\hline $10 / 04 / 89$ & BH010 & 17B & 22 & 19 & 13 \\
\hline $10 / 04 / 89$ & BH009 & 17D & 110 & 19 & 22 \\
\hline $10 / 03 / 89$ & BH008 & $17 \mathrm{~F}$ & 130 & 76 & 59 \\
\hline $10 / 03 / 89$ & BH007 & $17 \mathrm{H}$ & 210 & 190 & 320 \\
\hline
\end{tabular}


Table B.2 K-1407-C Retention Basin sediment sample analysisradionuclide analysis (continued)

\begin{tabular}{|c|c|c|c|c|c|}
\hline Date & Hole & Location & $\underset{(\mathrm{pCi} / \mathrm{g})}{6-\mathrm{in}}$ & $\begin{array}{l}\text { 12-in. } \\
\text { (pCi/g) }\end{array}$ & $\begin{array}{l}\text { 18-in. } \\
(\mathrm{pCl} / \mathrm{g})\end{array}$ \\
\hline
\end{tabular}

\section{Gross alpha (continued)}

$10 / 03 / 89$
$09 / 28 / 89$
$10 / 03 / 89$
$10 / 03 / 89$
$10 / 02 / 89$
$09 / 27 / 89$
$10 / 09 / 89$

$11 / 20 / 89$
$11 / 20 / 89$
$11 / 20 / 89$
$11 / 21 / 89$
$01 / 10 / 90$
$11 / 16 / 89$
$11 / 15 / 89$
$11 / 16 / 89$
$01 / 10 / 90$
$11 / 15 / 89$
$11 / 16 / 89$
$11 / 13 / 89$
$11 / 13 / 89$
$01 / 10 / 90$
$11 / 13 / 89$
$11 / 09 / 89$
$11 / 09 / 89$
$11 / 09 / 89$
$11 / 09 / 89$
$11 / 20 / 89$
$01 / 10 / 90$
$11 / 03 / 89$
$11 / 01 / 89$
$11 / 01 / 89$
$11 / 03 / 89$
$11 / 02 / 89$
$11 / 02 / 89$
$10 / 30 / 89$
$10 / 30 / 89$
$10 / 30 / 89$
$11 / 03 / 89$
$11 / 03 / 89$
$10 / 30 / 89$

BHOO4
BHOO2
BHOO6
BHO05
BHO03
BH001
BH011

$18 \mathrm{E}-\mathrm{B}$
$18 \mathrm{G}-\mathrm{B}$
$19 \mathrm{~B}$
$19 \mathrm{D}$
$19 \mathrm{~F}$
$19 \mathrm{H}$
$20 \mathrm{D}$

78
16
17
97
100
17
9.2

\section{Gross beta}

BH070
BH068
BH069
BH073
BH078
BH067
BH064
BH066
BH077
BH063
BH065
BH061
BH060
BH075
BH062
BH059
BH057
BH056
BH058
BH072
BH076
BH055
BH049
BH048
BH053
BH050
BH051
BH043
BH044
BH045
BH052
BH054
BH046

$\begin{array}{lr}\text { 00D } & 490 \\ \text { 00F } & 890 \\ \text { 00F-B } & 1700 \\ \text { 01B } & 15 \\ \text { 01D } & 120 \\ \text { 01F } & 62 \\ \text { 01F-B } & 430 \\ \text { 01H } & 51 \\ \text { 02E } & 220 \\ \text { 02G } & 160 \\ \text { 03A } & 81 \\ \text { 03B } & 17 \\ \text { 03C } & 65 \\ \text { 03D } & 17 \\ \text { 03D-B } & 810 \\ \text { 03E } & 210 \\ \text { 03F } & 110 \\ \text { 03F-B } & 1900 \\ \text { 03H } & 110 \\ \text { 05A } & 220 \\ \text { 05B } & 51 \\ \text { 05D } & 57 \\ \text { 05F } & 110 \\ \text { 05G } & 17 \\ \text { 06B } & 97 \\ \text { 06F } & 130 \\ \text { 06F-B } & 970 \\ \text { 07B } & 570 \\ \text { 07B-B } & 3000 \\ \text { 07D } & 970 \\ \text { 07D-B } & 590 \\ \text { 07D-B } & 1900 \\ \text { 07F } & 2400\end{array}$

$\begin{array}{rc}32 & 19 \\ 260 & 30 \\ 21 & - \\ 30 & 41 \\ 150 & 35 \\ 18 & 16 \\ 12 & 6.2\end{array}$


Table B.2 K-1407-C Retention Basin sediment sample analyaisradionuclide analysis (continued)

\begin{tabular}{|c|c|c|c|c|c|}
\hline Date & Hole & Location & $\underset{(\mathrm{pCi} / \mathrm{g})}{\text { 6-in. }}$ & $\begin{array}{l}\text { 12-in. } \\
(\mathrm{pCi} / \mathrm{g})\end{array}$ & $\begin{array}{l}\text { 18-in. } \\
(\mathrm{pCi} / \mathrm{g})\end{array}$ \\
\hline
\end{tabular}

Gross beta (continued)

\begin{tabular}{|c|c|c|c|c|c|}
\hline $10 / 12 / 89$ & BH021 & 07F-B & 2300 & 2500 & 1400 \\
\hline $10 / 30 / 89$ & BH047 & 07F-B & 4600 & 780 & - \\
\hline $11 / 20 / 89$ & BH071 & 07F-B & 4600 & - & - \\
\hline $10 / 25 / 89$ & BH038 & 09B & 1300 & 360 & 92 \\
\hline $10 / 18 / 89$ & BH033 & 09B-B & 4900 & 190 & 21 \\
\hline $10 / 25 / 89$ & BH039 & $09 \mathrm{C}$ & 220 & 38 & 25 \\
\hline $10 / 25 / 89$ & BH040 & 09D & 220 & 5.9 & 9.4 \\
\hline $10 / 25 / 89$ & BH041 & $09 \mathrm{E}$ & 430 & 65 & 16 \\
\hline 10/30/89 & BH042 & $09 \mathrm{~F}$ & 180 & 49 & 68 \\
\hline $10 / 24 / 89$ & BH037 & 09F-B & 1800 & 460 & 92 \\
\hline $10 / 16 / 89$ & BH027 & $11 \mathrm{~A}$ & 170 & 180 & 100 \\
\hline $10 / 16 / 89$ & BH026 & $11 \mathrm{~B}$ & 350 & 59 & 95 \\
\hline $10 / 16 / 89$ & BH025 & 11D & 89 & 32 & 10 \\
\hline $10 / 18 / 89$ & BH030 & $11 \mathrm{~F}$ & 12 & 320 & 380 \\
\hline $10 / 18 / 89$ & BH031 & $11 F-B$ & 490 & 54 & 26 \\
\hline $10 / 24 / 89$ & BH036 & $11 F-B$ & 760 & 430 & 41 \\
\hline $10 / 18 / 8$ & BH032 & $11 \mathrm{H}$ & 700 & 540 & 430 \\
\hline $10 / 23 / 89$ & BH035 & $11 \mathrm{H}-\mathrm{B}$ & 920 & 4100 & 620 \\
\hline $10 / 16 / 89$ & BH028 & $12 \mathrm{~B}$ & 100 & 15 & 11 \\
\hline $01 / 03 / 90$ & BH074 & $12 \mathrm{~F}$ & 21 & 14 & 19 \\
\hline $10 / 13 / 89$ & BH024 & 13B & 30 & 19 & 16 \\
\hline $10 / 13 / 89$ & BH023 & $13 \mathrm{C}$ & 78 & 110 & 9.2 \\
\hline $10 / 18 / 89$ & BH029 & 13D & 110 & 4.9 & 16 \\
\hline $01 / 11 / 90$ & BH079 & $13 \mathrm{E}$ & - & - & 120 \\
\hline $01 / 11 / 90$ & BH080 & $13 F$ & - & - & 110 \\
\hline $10 / 12 / 89$ & BH020 & 15B & 46 & 21 & 30 \\
\hline $10 / 10 / 89$ & BH013 & 15D & 220 & 38 & 20 \\
\hline $10 / 11 / 89$ & BH017 & 15D-B & 59 & 18 & 11 \\
\hline $10 / 10 / 89$ & BH014 & $15 \mathrm{~F}$ & 540 & 150 & 78 \\
\hline $10 / 10 / 89$ & BH015 & 15F-B & 3500 & 250 & 110 \\
\hline $10 / 11 / 89$ & BH018 & 15F-B & 1200 & 430 & 260 \\
\hline $10 / 23 / 89$ & BH034 & 15F-B & 430 & 140 & 190 \\
\hline $10 / 10 / 89$ & BH016 & $15 \mathrm{H}$ & 760 & 570 & 590 \\
\hline $10 / 12 / 89$ & BH019 & $16 \mathrm{~B}$ & 62 & 59 & 22 \\
\hline $10 / 13 / 89$ & BH022 & 16E-B & 510 & 95 & 86 \\
\hline 10/09/89 & BH012 & $16 \mathrm{~F}$ & 350 & 65 & 35 \\
\hline $10 / 04 / 89$ & BH010 & 17B & 68 & 57 & 35 \\
\hline $10 / 04 / 89$ & BH009 & $17 \mathrm{D}$ & 380 & 38 & 23 \\
\hline $10 / 03 / 89$ & BH008 & $17 \mathrm{~F}$ & 540 & 160 & 92 \\
\hline $10 / 03 / 89$ & BH007 & $17 \mathrm{H}$ & 840 & 350 & 620 \\
\hline $10 / 03 / 89$ & BH004 & 18E-B & 270 & 70 & 30 \\
\hline 09/28/89 & BH0O2 & 18G-B & 1200 & 680 & 54 \\
\hline $10 / 03 / 89$ & BH006 & $19 B$ & 57 & 41 & - \\
\hline
\end{tabular}


Table B.2. K-1407-C Retention Besin sediment sample analysisradionuclide analysis (continued)

\begin{tabular}{|c|c|c|c|c|c|}
\hline Date & Hole & Location & $\begin{array}{c}6-\mathrm{in} . \\
(\mathrm{pCi} / \mathrm{g})\end{array}$ & $\begin{array}{c}\text { 12-in. } \\
(\mathrm{pCi} / \mathrm{g})\end{array}$ & $\begin{array}{c}\text { 18-in. } \\
(\mathrm{pCi} / \mathrm{g})\end{array}$ \\
\hline \multicolumn{6}{|c|}{ Gross beta (continued) } \\
\hline $10 / 03 / 89$ & BH005 & 19D & 460 & 100 & 68 \\
\hline $10 / 02 / 89$ & BH003 & $19 \mathrm{~F}$ & 230 & 320 & 84 \\
\hline $09 / 27 / 89$ & BH0O1 & $19 \mathrm{H}$ & 430 & 12 & 15 \\
\hline $10 / 09 / 89$ & BH011 & 20D & 30 & 25 & 13 \\
\hline \multicolumn{6}{|c|}{ Neptunium-237 } \\
\hline $11 / 20 / 89$ & BH070 & COD & 1 & - & - \\
\hline $11 / 20 / 89$ & BH068 & $00 \mathrm{~F}$ & 3.5 & - & - \\
\hline $11 / 20 / 89$ & BH069 & OOF-B & 5.9 & - & - \\
\hline $11 / 21 / 89$ & BH073 & $01 B$ & 0.0046 & - & - \\
\hline $01 / 10 / 90$ & BH078 & 01D & 0.81 & - & - \\
\hline $11 / 16 / 89$ & BH067 & $01 \mathrm{~F}$ & 0.14 & - & - \\
\hline $11 / 15 / 89$ & SHO64 & 01F-B & 0.81 & - & - \\
\hline $11 / 16 / 89$ & BH066 & $01 \mathrm{H}$ & 0.065 & - & - \\
\hline $01 / 10 / 90$ & BH077 & $02 \mathrm{E}$ & 0.95 & - & - \\
\hline $11 / 15 / 89$ & BH063 & $02 G$ & 0.46 & - & - \\
\hline $11 / 16 / 89$ & BH065 & $0 \tilde{A} \mathrm{~A}$ & ก.032 & - & - \\
\hline $11 / 13 / 89$ & BH061 & 03B & 0.0051 & 0.0095 & 0.022 \\
\hline $11 / 13 / 89$ & BH060 & 03C & 0.023 & 0.01 & $<0.027$ \\
\hline $01 / 10 / 90$ & BH075 & 03D & 0.86 & - & - \\
\hline $11 / 13 / 89$ & BH062 & 03D-B & 6.8 & - & - \\
\hline $11 / 09 / 89$ & BH059 & 03E & 1.1 & 4.9 & 0.65 \\
\hline $11 / 09 / 89$ & BH057 & $03 F$ & 0.23 & 0.35 & 0.065 \\
\hline $11 / 09 / 89$ & BH056 & 03F-B & 11 & 0.086 & 2.5 \\
\hline $11 / 09 / 89$ & BH058 & $03 \mathrm{H}$ & 0.54 & 0.13 & - \\
\hline $11 / 20 / 89$ & BH072 & $05 \mathrm{~A}$ & 0.11 & - & - \\
\hline $01 / 10 / 90$ & BH076 & 05B & 1.6 & - & - \\
\hline $11 / 03 / 89$ & BH055 & 05D & 0.17 & 0.057 & 0.017 \\
\hline $11 / 01 / 89$ & BHO49 & $05 \mathrm{~F}$ & 0.27 & 0.068 & 0.051 \\
\hline $11 / 01 / 89$ & BHO48 & $05 \mathrm{G}$ & 0.043 & - & - \\
\hline $11 / 03 / 89$ & BH053 & O6B & 0.49 & 0.14 & 0.049 \\
\hline $11 / 02 / 89$ & BH050 & $06 \mathrm{~F}$ & 0.51 & 0.024 & 0.011 \\
\hline $11 / 02 / 89$ & BH051 & O6F-B & 9.7 & 0.62 & 0.065 \\
\hline $10 / 30 / 89$ & BHO43 & 07B & 4.3 & 5.4 & 4.6 \\
\hline 10/30/89 & BHO44 & 07B-B & 35 & 12 & 0.46 \\
\hline $10 / 30 / 89$ & BH045 & 07D & 10 & 7.8 & 9.4 \\
\hline $11 / 03 / 89$ & BH052 & 07D-B & 7.6 & 0.51 & 0.051 \\
\hline $11 / 03 / 89$ & BH054 & 07D-B & 18 & 12 & 1.8 \\
\hline $10 / 30 / 89$ & BH046 & $07 \mathrm{~F}$ & 30 & 1.1 & 0.65 \\
\hline $10 / 12 / 89$ & BH021 & 07F-B & 30 & 2.2 & 11 \\
\hline $10 / 30 / 89$ & BH047 & 07F-B & 59 & 3 & - \\
\hline $11 / 20 / 89$ & BH071 & 07F-B & 41 & - & - \\
\hline
\end{tabular}


Table B.2. K-1407-C Retention Bosin sodisnent sample analycis-radionuclide analysis (continued)

\begin{tabular}{|c|c|c|c|c|c|}
\hline Date & Hole & Location & $\underset{(\mathrm{pCi} / \mathrm{g})}{\text { 6-in. }}$ & $\begin{array}{l}\text { 12-in. } \\
(\mathrm{pCi} / \mathrm{g})\end{array}$ & $\begin{array}{l}\text { 18-in. } \\
(\mathrm{pCi} / \mathrm{g})\end{array}$ \\
\hline \multicolumn{6}{|c|}{ Neptunium-237 (continued) } \\
\hline $10 / 25 / 89$ & BH038 & $09 \mathrm{~B}$ & 8.9 & 4.6 & 0.25 \\
\hline $10 / 18 / 89$ & BH033 & 09B-B & 140 & - & - \\
\hline $10 / 25 / 89$ & BH039 & $09 \mathrm{C}$ & 1.7 & 0.25 & 0.068 \\
\hline $10 / 25 / 89$ & BH040 & 09D & 1.5 & 0.3 & 0.0057 \\
\hline $10 / 25 / 89$ & BH041 & 09E & 3.8 & 0.3 & 0.041 \\
\hline $10 / 30 / 89$ & BHO42 & $09 \mathrm{~F}$ & 2.5 & 0.12 & 0.3 \\
\hline $10 / 24 / 89$ & BH037 & 09F-B & 7.3 & 2.2 & 0.26 \\
\hline $10 / 16 / 89$ & BH027 & $11 \mathrm{~A}$ & 0.92 & - & - \\
\hline $10 / 16 / 89$ & BH026 & $11 B$ & 2.2 & - & - \\
\hline $10 / 16 / 89$ & BH025 & 11D & 0.86 & - & - \\
\hline $10 / 18 / 89$ & BH030 & $11 \mathrm{~F}$ & 0.13 & - & - \\
\hline $10 / 18 / 89$ & BH031 & 11F-B & 7.8 & - & - \\
\hline $10 / 24 / 89$ & BH036 & $11 \mathrm{~F}-\mathrm{B}$ & 6.2 & 3.2 & 0.19 \\
\hline $10 / 18 / 89$ & BH032 & $11 \mathrm{H}$ & 20 & - & - \\
\hline $10 / 3 / 89$ & BH035 & $11 \mathrm{H}-\mathrm{B}$ & 46 & 35 & 1.9 \\
\hline $10 / 16 / 89$ & BH028 & $12 \mathrm{~B}$ & 1.2 & - & - \\
\hline $01 / 03 / 90$ & BH074 & $12 \mathrm{~F}$ & 0.011 & 0.54 & 0.014 \\
\hline $10 / 13 / 89$ & 'H024 & $13 B$ & 0.043 & - & - \\
\hline $10 / 13 / 89$ & BH023 & $13 \mathrm{C}$ & 1.4 & 0.57 & 0.03 \\
\hline $10 / 18 / 89$ & BH029 & 13D & 2 & - & - \\
\hline $10 / 12 / 89$ & BH020 & $15 B$ & 0.046 & 0.0035 & 0.014 \\
\hline $10 / 10,89$ & BH013 & 15D & 3.8 & - & - \\
\hline $10 / 11 / 89$ & BH017 & 15D-B & 0.86 & - & - \\
\hline $10 / 10 / 89$ & BH014 & $15 \mathrm{~F}$ & 7.3 & - & - \\
\hline $10 / 10 / 89$ & BH015 & $15 F-B$ & 32 & - & - \\
\hline $10 / 11 / 89$ & BH018 & $15 F-B$ & 14 & - & - \\
\hline $10 / 23 / 89$ & BH034 & $15 \mathrm{~F}-\mathrm{B}$ & 8.1 & 0.51 & 0.62 \\
\hline $10 / 10 / 89$ & BH016 & $15 \mathrm{H}$ & 9.4 & - & - \\
\hline $10 / 12 / 89$ & BH019 & $16 \mathrm{~B}$ & 0.12 & 0.041 & 0.0024 \\
\hline $10 / 13 / 89$ & ВH022 & $16 \mathrm{E}-\mathrm{B}$ & 8.1 & 0.17 & 0.092 \\
\hline $10 / 09 / 89$ & BH012 & $16 \mathrm{~F}$ & 4.9 & - & - \\
\hline $10 / 04 / 89$ & BH010 & $17 \mathrm{~B}$ & 0.38 & 0.038 & $<0.027$ \\
\hline $10 / 04 / 89$ & ВH009 & $17 \mathrm{D}$ & 5.1 & 0.07 & 0.07 \\
\hline $10 / 03 / 89$ & BH008 & $17 \mathrm{~F}$ & 7.8 & 1.2 & 0.13 \\
\hline $10 / 03 / 89$ & BH007 & $17 \mathrm{H}$ & 12 & 4 & 7.6 \\
\hline $10 / 03 / 89$ & BHOO4 & $18 \mathrm{E}-\mathrm{B}$ & 2.4 & 0.65 & 0.35 \\
\hline 09/28/89 & $\mathrm{BH} 002$ & 18G-B & 27 & 8.4 & 0.6 \\
\hline $10 / 03 / 89$ & BHOO6 & $19 \mathrm{~B}$ & 0.18 & 0.11 & - \\
\hline $10 / 03 / 89$ & BH005 & $19 D$ & 5.1 & 0.65 & 0.41 \\
\hline $10 / 02 / 89$ & BH003 & $19 \mathrm{~F}$ & 0.81 & 4 & 1.2 \\
\hline 09/27/89 & $\mathrm{BHCO1}$ & $19 \mathrm{H}$ & 0.24 & 0.015 & 0.011 \\
\hline $10 / 89$ & BH011 & $20 \mathrm{D}$ & 0.16 & - & - \\
\hline
\end{tabular}


Table B.2 K-1407-C Retention Basin sodiment sample anatyaisradionuclide analysis (continued)

\begin{tabular}{|c|c|c|c|c|c|}
\hline Date & Hole & Location & $\underset{(\mathrm{pCi} / \mathrm{g})}{\text { 6-in. }}$ & $\begin{array}{l}\text { 12-in. } \\
(\mathrm{pCi} / \mathrm{g})\end{array}$ & $\begin{array}{l}\text { 18-in. } \\
(\mathrm{pCi} / \mathrm{g})\end{array}$ \\
\hline
\end{tabular}

Plutonium-238

\begin{tabular}{|c|c|c|c|c|c|}
\hline $11 / 20 / 89$ & BH070 & OOD & 0.054 & - & - \\
\hline $11 / 20 / 89$ & BHO68 & $00 \mathrm{~F}$ & 0.49 & - & - \\
\hline $11 / 20 / 89$ & BH069 & $O O F-B$ & 0.62 & - & - \\
\hline $11 / 21 / 89$ & BH073 & 01B & 0.0027 & - & - \\
\hline $01 / 10 / 90$ & BH078 & 01D & 0.014 & - & - \\
\hline $11 / 16 / 89$ & BH067 & $01 \mathrm{~F}$ & 0.03 & - & - \\
\hline $11 / 15 / 89$ & BH064 & 01F-B & 0.3 & - & - \\
\hline $11 / 16 / 89$ & BH066 & $01 \mathrm{H}$ & 0.0027 & - & - \\
\hline 01/10/90 & BH077 & $02 \mathrm{E}$ & 0.019 & - & - \\
\hline $11 / 15 / 89$ & BH063 & $02 G$ & 0.043 & - & - \\
\hline $11 / 16 / 89$ & BH065 & 03A & 0.015 & - & - \\
\hline $11 / 13 / 89$ & BH061 & 03B & -0.02 & 0.0054 & $<0.054$ \\
\hline $11 / 13 / 89$ & BH060 & $03 \mathrm{C}$ & 0.0054 & 0.016 & $<0.054$ \\
\hline 01/10/90 & BH075 & 03D & 0.0019 & - & - \\
\hline $11 / 13 / 89$ & BH062 & 03D-B & 0.19 & - & - \\
\hline $11 / 09 / 89$ & BH059 & 03E & 0.16 & $<0.54$ & 0.089 \\
\hline $11 / 09 / 89$ & BH057 & $03 \mathrm{~F}$ & -0.005 & $<0.27$ & 0.035 \\
\hline $11 / 09 / 89$ & BH056 & 03F-B & -1 & $<0.54$ & 0.12 \\
\hline $11 / 09 / 89$ & BH058 & $03 \mathrm{H}$ & -0.01 & 0.03 & - \\
\hline $11 / 20 / 89$ & BHI $/ 2$ & $05 \mathrm{~A}$ & 0.03 & - & - \\
\hline $01 / 10 / 90$ & $\mathrm{BH}, 76$ & 05B & 0.0081 & - & - \\
\hline $11 / 03 / 89$ & BH055 & 05D & 0.018 & -0.005 & 0.007 \\
\hline $11 / 01 / 89$ & BH049 & $05 \mathrm{~F}$ & 1.1 & -0.02 & -0.008 \\
\hline $11 / 01 / 89$ & BH048 & $05 \mathrm{G}$ & 0.3 & - & - \\
\hline $11 / 03 / 89$ & BH053 & O6B & 0.1 & -0.009 & -0.04 \\
\hline $11 / 02 / 89$ & BH050 & $06 \mathrm{~F}$ & 2.7 & -0.08 & -0.03 \\
\hline $11 / 02 / 89$ & BH051 & 06F-B & 16 & 0.022 & -0.03 \\
\hline $10 / 30 / 89$ & BH043 & 07B & 0.19 & -0.2 & -0.2 \\
\hline $10 / 30 / 89$ & BH044 & 07B-B & 0.86 & 0.97 & $<0.054$ \\
\hline $10 / 30 / 89$ & $\mathrm{BH} 045$ & 07D & 0.3 & $<0.54$ & 0.41 \\
\hline $11 / 03 / 89$ & BH052 & 07D-B & 0.27 & 0.054 & -0.02 \\
\hline $11 / 03 / 89$ & BH054 & 07D-B & 0.84 & 0.054 & -0.6 \\
\hline 10/30/89 & BH046 & $07 \mathrm{~F}$ & 0.92 & 0.068 & $<0.054$ \\
\hline $10 / 12 / 89$ & BH021 & 07F-B & -0.8 & 0.41 & 2.1 \\
\hline $10 / 30 / 89$ & BH047 & 07F-B & 1.5 & 0.38 & - \\
\hline $11 / 20 / 89$ & BH071 & 07F-B & 0.81 & - & - \\
\hline $10 / 25 / 89$ & BH038 & 09B & 0.092 & 0.51 & $<0.054$ \\
\hline 10/18/89 & BH033 & 09B-B & 1.9 & - & - \\
\hline $10 / 25 / 89$ & BH039 & $09 \mathrm{C}$ & 0.07 & 0.013 & 0.0038 \\
\hline $10 / 25 / 89$ & BHO40 & 09D & 0.027 & 0.018 & $<0.019$ \\
\hline $10 / 25 / 89$ & BH041 & $09 \mathrm{E}$ & 3.5 & 0.046 & 0.0041 \\
\hline $10 / 30 / 89$ & $\mathrm{BH} 042$ & $09 \mathrm{~F}$ & 0.11 & 0.032 & 0.014 \\
\hline $10 / 24 / 89$ & BH037 & 09F-B & 14 & -0.05 & 0.076 \\
\hline
\end{tabular}


Table B.2. K-1407-C Retention Basin sediment sample analysisradionuclide analysis (continued)

\begin{tabular}{|c|c|c|c|c|c|}
\hline Date & Hole & Location & $\begin{array}{l}\text { 6-in. } \\
(\mathrm{pCi} / \mathrm{g})\end{array}$ & $\begin{array}{l}\text { 12-in. } \\
\text { (pCi/g) }\end{array}$ & $\begin{array}{l}\text { 18-in. } \\
(\mathrm{pCi} / \mathrm{g})\end{array}$ \\
\hline
\end{tabular}

Plutonium-238 (continued)

\begin{tabular}{|c|c|c|c|c|c|}
\hline $10 / 16 / 89$ & BH027 & $11 \mathrm{~A}$ & 0.022 & - & - \\
\hline $10 / 16 / 89$ & BH026 & $11 \mathrm{~B}$ & 0.027 & - & - \\
\hline $10 / 16 / 89$ & BH025 & 11D & 0.03 & - & - \\
\hline $10 / 18 / 89$ & BH030 & $11 \mathrm{~F}$ & -0.01 & - & - \\
\hline $10 / 18 / 89$ & BH031 & $11 F-B$ & 0.18 & - & - \\
\hline $10 / 24 / 89$ & BH036 & 11F-B & 1.6 & 0.068 & 0.0024 \\
\hline $10 / 18 / 89$ & BH032 & $11 \mathrm{H}$ & 0.46 & - & - \\
\hline 10/23/89 & BH035 & $11 \mathrm{H}-\mathrm{B}$ & 14 & 0.35 & 0.51 \\
\hline 10/16/89 & BH028 & 12B & 0.022 & - & - \\
\hline $01 / 03 / 90$ & BH074 & $12 \mathrm{~F}$ & 0.013 & -0.01 & 0.032 \\
\hline 10/13/89 & BH024 & 13B & -0.01 & - & - \\
\hline $10 / 13 / 89$ & BH023 & $13 \mathrm{C}$ & 0.0081 & 0.086 & $<0.027$ \\
\hline 10/18/89 & BH029 & 13D & 0.0054 & - & - \\
\hline $10 / 12 / 89$ & BH02O & $15 B$ & -0.003 & 0.011 & 0.0011 \\
\hline $10 / 10 / 89$ & BH013 & 15D & 0.057 & - & - \\
\hline $10 / 11 / 89$ & PH017 & 15D-B & 0.016 & - & - \\
\hline $10 / 10 / 89$ & $83 H 1014$ & $15 \mathrm{~F}$ & 0.11 & - & - \\
\hline $10 / 10 / 89$ & BH015 & $15 F-B$ & 0.7 & - & - \\
\hline $10 / 11 / 89$ & BH018 & $15 F-B$ & -2 & - & - \\
\hline $10 / 23 / 89$ & BH034 & $15 F-B$ & 7.6 & 0.092 & 0.032 \\
\hline $10 / 10 / 89$ & BH016 & $15 \mathrm{H}$ & 0.14 & - & - \\
\hline $10 / 12 / 89$ & BH019 & $16 \mathrm{~B}$ & 0.0092 & 0.022 & 0.0065 \\
\hline $10 / 13 / 89$ & BH022 & $16 E-B$ & 0.59 & 0.017 & 0.035 \\
\hline 10/09/89 & BH012 & $16 \mathrm{~F}$ & 0.054 & - & $\cdots$ \\
\hline $10 / 04 / 89$ & BH010 & 17B & -0.04 & 0.024 & 0.022 \\
\hline 10/04/89 & ВH009 & 17D & 0.041 & $<0.081$ & 0.154 \\
\hline $10 / 03 / 89$ & BH008 & $17 \mathrm{~F}$ & 0.18 & 0.038 & 0.3 \\
\hline $10 / 03 / 89$ & ВH007 & $17 \mathrm{H}$ & 0.18 & 0.22 & $<0.3$ \\
\hline $10 / 03 / 89$ & BH004 & 18E-B & -0.06 & 0.041 & 0.032 \\
\hline 09/28/89 & BHOO2 & $18 \mathrm{G}-\mathrm{B}$ & 0.54 & -0.4 & 0.049 \\
\hline $10 / 03 / 89$ & BH006 & 19B & -0.04 & 0.089 & - \\
\hline $10 / 03 / 89$ & BH005 & 19D & 0.054 & 0.03 & $<0.054$ \\
\hline $10 / 02 / 89$ & BHOO3 & $19 \mathrm{~F}$ & 0.03 & 0.22 & 0.041 \\
\hline 09/27/89 & BH001 & $19 \mathrm{H}$ & -0.005 & -0.04 & -0.02 \\
\hline $10 / 09 / 89$ & BH011 & 20D & 0.0027 & - & - \\
\hline
\end{tabular}

Plutonium-239

$\begin{array}{lllcll}11 / 20 / 89 & \text { BH070 } & \text { OOD } & 3.5 & - & - \\ 11 / 20 / 89 & \text { BH068 } & \text { OOF } & 8.6 & - & - \\ 11 / 20 / 89 & \text { BH069 } & \text { 0OF-B } & 30 & - & - \\ 11 / 21 / 89 & \text { BH073 } & 01 \mathrm{~B} & 0.03 & - & - \\ 01 / 10 / 90 & \text { BH078 } & 01 D & 2 & - & -\end{array}$


Table B.2 K-1407-C Retention Basin sedircent sample analysisradionuclide analysis (continued)

\begin{tabular}{|c|c|c|c|c|c|}
\hline Date & Hole & Location & $\underset{(\mathrm{pCi} / \mathrm{g})}{\text { 6-in. }}$ & $\begin{array}{l}\text { 12-in. } \\
(\mathrm{pCi} / \mathrm{g})\end{array}$ & $\begin{array}{c}\text { 18-in. } \\
(\mathrm{pCi} / \mathrm{g})\end{array}$ \\
\hline \multicolumn{6}{|c|}{ Plutonium-239 (continued) } \\
\hline $11 / 16 / 89$ & BH067 & $01 \mathrm{~F}$ & 0.84 & - & - \\
\hline $11 / 15 / 89$ & BH064 & 01F-B & 7 & - & - \\
\hline $11 / 16 / 89$ & 8H066 & $01 \mathrm{H}$ & 0.21 & - & - \\
\hline $01 / 10 / 90$ & BH077 & $02 \mathrm{E}$ & 3.5 & - & - \\
\hline $11 / 15 / 89$ & BH063 & $02 \mathrm{G}$ & 2.3 & - & - \\
\hline $11 / 16 / 89$ & BH065 & 03A & 0.032 & - & - \\
\hline $11 / 13 / 89$ & BH061 & 03B & 0.059 & $<0.027$ & $<0.027$ \\
\hline $11 / 13 / 89$ & BH060 & 035 & 0.084 & 0.019 & $<0.054$ \\
\hline $01 / 10 / 90$ & BH075 & 03D & 0.095 & - & - \\
\hline $11 / 13 / 89$ & BH062 & 03D-B & 18 & - & - \\
\hline $11 / 09 / 89$ & BH059 & 03E & 3.2 & 11 & 1.6 \\
\hline $11 / 09 / 89$ & BH057 & $03 \mathrm{~F}$ & 0.97 & 1.1 & 0.22 \\
\hline $11 / 09 / 89$ & BH056 & 03F-B & 43 & 6.2 & 0.46 \\
\hline $11 / 09 / 89$ & BH058 & $03 \mathrm{H}$ & 2.2 & 0.17 & - \\
\hline $11 / 20 / 89$ & BH072 & $05 \mathrm{~A}$ & 0.92 & - & - \\
\hline $01 / 10 / 90$ & BH076 & 05B & 0.46 & - & - \\
\hline $11 / 03 / 89$ & BH055 & 05D & 0.49 & 0.062 & 0.0049 \\
\hline $11 / 01 / 89$ & BH049 & $05 \mathrm{~F}$ & 0.92 & 0.3 & 0.13 \\
\hline $11 / 01 / 89$ & BH048 & $05 \mathrm{G}$ & 0.21 & - & - \\
\hline $11 / 03 / 89$ & BH053 & 06B & 1.6 & 0.38 & 0.23 \\
\hline $11 / 02 / 89$ & BH050 & $06 \mathrm{~F}$ & 0.7 & -0.05 & 0.21 \\
\hline $11 / 02 / 89$ & BH051 & 06F-B & 24 & 3.5 & 0.17 \\
\hline $10 / 30 / 89$ & BH043 & 07B & 13 & 9.2 & 17 \\
\hline $10 / 30 / 89$ & BH044 & 07B-B & 59 & 43 & 1.7 \\
\hline $10 / 30 / 89$ & BH045 & 07D & 20 & 30 & 27 \\
\hline $11 / 03 / 89$ & BH0.52 & 07D-B & 20 & 1.4 & 0.089 \\
\hline $11 / 03 / 89$ & BH054 & 07D-B & 43 & 35 & 6.5 \\
\hline $10 / 30 / 89$ & BH046 & 07F & 54 & 4.9 & 2.5 \\
\hline $10 / 12 / 89$ & BH021 & 07F-B & 27 & 8.9 & 49 \\
\hline $10 / 30 / 89$ & BH047 & 07F-B & 92 & 15 & - \\
\hline $11 / 20 / 89$ & BH071 & 07F-B & 130 & - & - \\
\hline $10 / 25 / 89$ & BH038 & 09B & 2.6 & 17 & 0.81 \\
\hline $10 / 18 / 89$ & BH033 & 09B-B & 160 & - & - \\
\hline $10 / 25 / 89$ & BH039 & $09 \mathrm{C}$ & 8.6 & 0.7 & 0.24 \\
\hline $10 / 25 / 89$ & ВH040 & 09D & 11 & 1.1 & 0.007 \\
\hline $10 / 25 / 89$ & BH041 & $09 \mathrm{E}$ & 7 & 0.84 & 0.025 \\
\hline $10 / 30 / 89$ & BH042 & $09 \mathrm{~F}$ & 1.4 & 0.57 & 0.92 \\
\hline $10 / 24 / 89$ & BH037 & 09F-B & 14 & 6.5 & 0.89 \\
\hline $10 / 16 / 89$ & BH027 & $11 \mathrm{~A}$ & 1.8 & - & - \\
\hline $10 / 16 / 89$ & BH026 & $11 B$ & 4.3 & - & - \\
\hline $10 / 16 / 89$ & BH025 & $11 \mathrm{D}$ & 1.3 & - & - \\
\hline $10 / 18 / 89$ & ВH030 & $11 \mathrm{~F}$ & 0.13 & - & - \\
\hline $10 / 18 / 89$ & BH031 & $11 \mathrm{~F}-\mathrm{B}$ & 14 & - & - \\
\hline
\end{tabular}


Table B.2 K-1407-C Retention Basin sediment sample analysisradionuclide analysis (continued)

\begin{tabular}{|c|c|c|c|c|c|}
\hline Date & Hole & Location & $\begin{array}{c}\text { 6-in. } \\
(\mathrm{pCi} / \mathrm{g})\end{array}$ & $\begin{array}{l}12 \text {-in. } \\
\text { (pCi/g) }\end{array}$ & $\begin{array}{c}\text { 18-in. } \\
(\mathrm{pCi} / \mathrm{g})\end{array}$ \\
\hline \multicolumn{6}{|c|}{ Plutonium-239 (continued) } \\
\hline $10 / 24 / 89$ & BH036 & $11 \mathrm{~F}-\mathrm{B}$ & 9.7 & 7.8 & 0.57 \\
\hline $10 / 18 / 89$ & BH032 & $11 \mathrm{H}$ & 26 & - & - \\
\hline $10 / 23 / 89$ & BH035 & $11 \mathrm{H}-\mathrm{B}$ & 78 & 110 & 12 \\
\hline $10 / 16 / 89$ & BH028 & $12 \mathrm{~B}$ & 1.7 & - & - \\
\hline $01 / 03 / 90$ & BH074 & $12 \mathrm{~F}$ & 0.054 & -0.002 & 0.049 \\
\hline $10 / 13 / 89$ & BH024 & 13B & 0.0027 & - & - \\
\hline $10 / 13 / 89$ & BH023 & $13 \mathrm{C}$ & 1.2 & 2.5 & 0.13 \\
\hline $10 / 18 / 89$ & BH029 & $13 D$ & 2.1 & - & - \\
\hline $10 / 12 / 89$ & BHO20 & $15 B$ & 0.062 & $<0.027$ & 0.043 \\
\hline $10 / 10 / 89$ & BH013 & 15D & 3.5 & - & - \\
\hline $10 / 11 / 89$ & BH017 & 15D-B & 0.65 & - & - \\
\hline $10 / 10 / 89$ & BH014 & $15 \mathrm{~F}$ & 4 & - & - \\
\hline $10 / 10 / 89$ & BH015 & $15 F-B$ & 35 & - & - \\
\hline $10 / 11 / 89$ & BH018 & $15 \mathrm{~F}-\mathrm{B}$ & 17 & - & - \\
\hline $10 / 23 / 89$ & BH034 & $15 \mathrm{~F}-\mathrm{B}$ & 18 & 2.1 & 2.3 \\
\hline $10 / 10 / 89$ & BH016 & $15 \mathrm{H}$ & 6.8 & - & - \\
\hline $10 / 12 / 89$ & BH019. & $16 B$ & 0.12 & 0.059 & 0.013 \\
\hline $10 / 13 / 89$ & BH022 & $16 \mathrm{E}-\mathrm{B}$ & 10 & 0.73 & 0.38 \\
\hline $10 / 09 / 89$ & BH012 & $16 \mathrm{~F}$ & 3.8 & - & - \\
\hline $10 / 04 / 89$ & BH010 & $17 \mathrm{~B}$ & 0.59 & $<0.054$ & $<0.027$ \\
\hline $10 / 04 / 89$ & BH0O9 & 17D & 3.5 & 0.15 & 0.035 \\
\hline $10 / 03 / 89$ & BH008 & $17 \mathrm{~F}$ & 6.5 & 2.7 & 0.35 \\
\hline $10 / 03 / 89$ & ВH007 & $17 \mathrm{H}$ & 9.4 & 6.2 & 21 \\
\hline $10 / 03 / 89$ & BHOO4 & $18 \mathrm{E}-\mathrm{B}$ & 1.8 & 0.7 & 0.41 \\
\hline 09/28/89 & BH0O2 & 18G-B & 26 & 10 & 0.65 \\
\hline $10 / 03 / 89$ & BH006 & 19B & 0.17 & 0.15 & - \\
\hline $10 / 03 / 89$ & BH005 & 19D & 3.5 & 0.86 & 0.57 \\
\hline $10 / 02 / 89$ & BHOO3 & $19 \mathrm{~F}$ & 0.57 & 7.3 & 2.1 \\
\hline 09/27/89 & BH001 & $19 \mathrm{H}$ & 0.2 & -0.09 & -0.006 \\
\hline $10 / 09 / 89$ & BH011 & $20 D$ & 0.3 & - & - \\
\hline \multicolumn{6}{|c|}{ Potassium-40 } \\
\hline $11 / 20 / 89$ & BH070 & OOD & 6.2 & - & - \\
\hline $11 / 20 / 89$ & BH068 & $00 \mathrm{~F}$ & 9.4 & - & - \\
\hline $11 / 20 / 89$ & BH069 & OOF-B & 8.1 & - & - \\
\hline $11 / 21 / 89$ & BH073 & 01 : & 9.7 & - & - \\
\hline $01 / 10 / 90$ & BH078 & $01 D$ & 22 & - & - \\
\hline $11 / 16 / 89$ & BH067 & $01 \mathrm{~F}$ & 18 & - & - \\
\hline $11 / 15 / 89$ & BH064 & 01F-B & 24 & - & - \\
\hline $11 / 16 / 89$ & BH066 & $01 \mathrm{H}$ & 22 & - & - \\
\hline $01 / 10 / 90$ & BH077 & $02 E$ & 15 & - & - \\
\hline $11 / 15 / 89$ & BH063 & $02 \mathrm{G}$ & 8.4 & - & - \\
\hline
\end{tabular}


Table B.2 K-1407-C Retention Basin sediment sample analysisradionuclide analysis (continued)

\begin{tabular}{|c|c|c|c|c|c|}
\hline Date & Hole & Location & $\begin{array}{c}\text { 6-in. } \\
(\mathrm{pCi} / \mathrm{g})\end{array}$ & $\begin{array}{l}12 \text {-in. } \\
(\mathrm{pCl} / \mathrm{g})\end{array}$ & $\begin{array}{l}\text { 18-in. } \\
(\mathrm{pCi} / \mathrm{g})\end{array}$ \\
\hline \multicolumn{6}{|c|}{ Potassium-40 (continued) } \\
\hline $11 / 16 / 89$ & Ructos & $03 \mathrm{~A}$ & 9.4 & - & - \\
\hline $11 / 13 / 89$ & BHU61 & $0,3 B$ & 6.8 & 8.6 & 5.7 \\
\hline $11 / 13 / 89$ & BH060 & 03C & 21 & 21 & 13 \\
\hline $01 / 10 / 90$ & BH075 & 03D & 18 & - & - \\
\hline $11 / 13 / 89$ & BH062 & 03D-B & 11 & - & - \\
\hline $11 / 09 / 89$ & BH059 & 03E & 16 & 12 & 8.1 \\
\hline $11 / 09 / 89$ & BH05"7 & 03F & 11 & 8.6 & 6.8 \\
\hline $11 / 09 / 89$ & BH056 & 03F $-B$ & 11 & 5.9 & 6.8 \\
\hline $11 / 09 / 89$ & BH058 & $03 \mathrm{H}$ & 8.1 & 10 & - \\
\hline $11 / 20 / 89$ & BH072 & 05A & 6.5 & - & - \\
\hline $01 / 10 / 90$ & BH076 & 05B & 8.1 & - & - \\
\hline $11 / 03 / 89$ & BH055 & 05D & 5.7 & 5.1 & 6.2 \\
\hline $11 / 01 / 89$ & BH049 & $05 \mathrm{~F}$ & 18 & 10 & 8.6 \\
\hline $11 / 01 / 89$ & BH048 & $05 G$ & 8.4 & - & - \\
\hline $11 / 03 / 89$ & BH053 & $06 \mathrm{~B}$ & 6.8 & 6.8 & 6.5 \\
\hline $11 / 02 / 89$ & BH050 & $06 \mathrm{~F}$ & 9.4 & 9.7 & 9.7 \\
\hline $11 / 02 / 89$ & BH051 & 06F-B & 9.2 & 13 & 8.6 \\
\hline $10 / 30 / 89$ & BH043 & 07B & 11 & 11 & 13 \\
\hline $10 / 30 / 89$ & $\mathrm{BH} 044$ & 07B-B & 7.3 & 7 & 5.7 \\
\hline $10 / 30 / 89$ & BH045 & 07D & 9.2 & 6.2 & 9.2 \\
\hline $11 / 03 / 89$ & BH052 & 07D-B & 8.4 & 8.1 & 6.8 \\
\hline $11 / 03 / 89$ & BH054 & 07D-B & 9.7 & 13 & 8.6 \\
\hline $10 / 30 / 89$ & BH046 & $07 \mathrm{~F}$ & 6.2 & 7 & 7 \\
\hline $10 / 12 / 89$ & BHO21 & 07F-B & 8.1 & 6.8 & 7 \\
\hline $10 / 30 / 89$ & BH047 & 07F-B & 4.3 & 5.9 & - \\
\hline $11 / 20 / 89$ & BH071 & 07F-B & 9.2 & - & - \\
\hline $10 / 25 / 89$ & BH038 & 09B & 4.6 & 5.9 & 5.9 \\
\hline $10 / 18 / 89$ & BH033 & O9B-B & 5.7 & 7.6 & 5.9 \\
\hline $10 / 25 / 89$ & ВH039 & $09 \mathrm{C}$ & 8.4 & 9.2 & 9.2 \\
\hline $10 / 25 / 89$ & BHO40 & 09D & 6.2 & 7 & 5.9 \\
\hline $10 / 25 / 89$ & BH041 & $09 \mathrm{E}$ & 6.2 & 5.7 & 4.9 \\
\hline $10 / 30 / 89$ & $\mathrm{BH} 042$ & $09 \mathrm{~F}$ & 7.3 & 8.9 & 9.2 \\
\hline $10 / 24 / 89$ & BH037 & 09F-B & - & 7.3 & 6.2 \\
\hline $10 / 16 / 89$ & BH027 & $11 \mathrm{~A}$ & 10 & 6.8 & 4.6 \\
\hline $10 / 16 / 89$ & BH026 & $11 \mathrm{~B}$ & 7 & 7 & 7.8 \\
\hline $10 / 16 / 89$ & BH025 & 11D & 5.7 & 4.9 & 4 \\
\hline $10 / 18 / 89$ & $\mathrm{BH} 030$ & $11 \mathrm{~F}$ & 5.4 & 6.5 & 6.2 \\
\hline $10 / 18 / 89$ & BH031 & $11 \mathrm{~F}-\mathrm{B}$ & 8.1 & 7.8 & 8.6 \\
\hline $10 / 24 / 89$ & BH036 & $11 \mathrm{~F}-\mathrm{B}$ & - & 8.6 & 7.8 \\
\hline $10 / 18 / 89$ & BHO32 & $11 \mathrm{H}$ & 5.9 & 6.2 & 5.9 \\
\hline $10 / 23 / 89$ & BH035 & $11 \mathrm{H}-\mathrm{B}$ & 3.2 & 5.4 & 6.2 \\
\hline $10 / 16 / 89$ & BH028 & $12 \mathrm{~B}$ & 6.2 & 5.7 & 7.3 \\
\hline $01 / 03 / 90$ & BH074 & $12 \mathrm{~F}$ & 8.9 & 8.4 & 8.4 \\
\hline
\end{tabular}


Table B.2. K-1407-C Retention Basin sediment sample analysisradionuclide analysis (continued)

\begin{tabular}{|c|c|c|c|c|c|}
\hline Date & Hole & Location & $\begin{array}{l}\text { 6-in. } \\
(\mathrm{pCi} / \mathrm{g})\end{array}$ & $\begin{array}{l}\text { 12-in. } \\
(\mathrm{pCi} / \mathrm{g})\end{array}$ & $\underset{(\mathrm{pCi} / \mathrm{g})}{18 \text {-in. }}$ \\
\hline
\end{tabular}

Potassium-40 (continued)

$\begin{array}{lllccc}10 / 13 / 89 & \text { BHO24 } & 13 \mathrm{~B} & 12 & 7.6 & 6.8 \\ 10 / 13 / 89 & \text { BH023 } & 13 \mathrm{C} & 10 & 7.6 & 5.7 \\ 10 / 18 / 89 & \text { BH029 } & 13 \mathrm{D} & 7.8 & 6.2 & 8.1 \\ 10 / 12 / 89 & \text { BH020 } & 15 \mathrm{~B} & 10 & 8.6 & 8.4 \\ 10 / 10 / 89 & \text { BH013 } & 15 \mathrm{D} & 13 & 12 & 7 \\ 10 / 11 / 89 & \text { BH017 } & 15 \mathrm{D}-\mathrm{B} & 11 & 14 & 16 \\ 10 / 10 / 89 & \text { BH014 } & 15 \mathrm{~F} & 11 & 12 & 10 \\ 10 / 10 / 89 & \text { BH015 } & 15 \mathrm{~F}-\mathrm{B} & 9.7 & 13 & 11 \\ 10 / 11 / 89 & \text { BH018 } & 15 \mathrm{~F}-\mathrm{B} & 4.3 & 12 & 14 \\ 10 / 23 / 89 & \text { BH034 } & 15 \mathrm{~F}-\mathrm{B} & 12 & 9.2 & 10 \\ 10 / 10 / 89 & \text { BH016 } & 15 \mathrm{H} & 11 & 12 & 13 \\ 10 / 12 / 89 & \text { BH019 } & 16 \mathrm{~B} & 10 & 8.1 & 7.6 \\ 10 / 13 / 89 & \text { BH022 } & 16 \mathrm{E}-\mathrm{B} & 14 & 14 & 14 \\ 10 / 09 / 89 & \text { BH012 } & 16 \mathrm{~F} & 14 & 6.8 & 9.7 \\ 10 / 04 / 89 & \text { BH010 } & 17 \mathrm{~B} & 7.8 & 8.1 & 8.4 \\ 10 / 04 / 89 & \text { BH009 } & 17 \mathrm{D} & 13 & 15 & 17 \\ 10 / 03 / 89 & \text { BH008 } & 17 \mathrm{~F} & 14 & 17 & 18 \\ 10 / 03 / 89 & \text { BH007 } & 17 \mathrm{H} & 12 & 11 & 11 \\ 10 / 03 / 89 & \text { BH004 } & 18 \mathrm{E}-\mathrm{B} & 22 & 19 & 14 \\ 09 / 28 / 89 & \text { BH002 } & 18 \mathrm{G}-\mathrm{B} & 16 & 18 & 17 \\ 10 / 03 / 89 & \text { BH006 } & 19 \mathrm{~B} & 14 & 8.4 & -19 \\ 10 / 03 / 89 & \text { BH005 } & 19 \mathrm{D} & 13 & 19 & 22 \\ 10 / 12 / 89 & \text { BH003 } & 19 \mathrm{~F} & 20 & 21 & 11 \\ 09 / 27 / 89 & \text { BH001 } & 19 \mathrm{H} & 8.6 & 10 & 21 \\ 10 / 09 / 89 & \text { BH011 } & 20 \mathrm{D} & 21 & 20 & \end{array}$

\section{Technetium-99}

$\begin{array}{lllrcc}11 / 20 / 89 & \text { BH070 } & \text { OOD } & 180 & 1100 & 950 \\ 11 / 20 / 89 & \text { BH068 } & \text { OOF } & 490 & 810 & 570 \\ 11 / 20 / 89 & \text { BH069 } & \text { 00F-B } & 1100 & 570 & 860 \\ 11 / 21 / 89 & \text { BH073 } & \text { 01B } & 23 & 4.6 & 8.4 \\ 01 / 10 / 90 & \text { BH078 } & 01 \mathrm{D} & 76 & - & - \\ 11 / 16 / 89 & \text { BH067 } & 01 \mathrm{~F} & 41 & 2.1 & - \\ 11 / 15 / 89 & \text { BH064 } & 01 \mathrm{~F}-\mathrm{B} & 320 & 81 & 12 \\ 11 / 16 / 89 & \text { BH066 } & 01 \mathrm{H} & 26 & 2.4 & - \\ \| 1 / 10 / 90 & \text { BH077 } & 02 \mathrm{E} & 150 & - & - \\ \| 1 / 15 / 89 & \text { BH063 } & 02 \mathrm{G} & 100 & 8.1 & 1300 \\ \| 1 / 16 / 89 & \text { BH065 } & \text { 03A } & 43 & 18 & 21 \\ \| 1 / 13 / 89 & \text { BH061 } & \text { 03B } & 7 & 0.51 & 1.4 \\ \| 1 / 13 / 89 & \text { BH060 } & \text { 03C } & 2.7 & 0.62 & 0.21 \\ 01 / 10 / 90 & \text { BH075 } & \text { 03D } & 5.7 & - & - \\ \| 1 / 13 / 89 & \text { BH062 } & \text { 03D-B } & 590 & 12 & 13\end{array}$


Table B.2. K-1407-C Retention Basin sediment sample analysisradionuclide analysis (continued)

\begin{tabular}{|c|c|c|c|c|c|}
\hline Date & Hole & Location & $\begin{array}{c}\text { 6-in. } \\
(\mathrm{pC} i / \mathrm{g})\end{array}$ & $\begin{array}{c}\text { 12-in. } \\
(\mathrm{pCi} / \mathrm{g})\end{array}$ & $\begin{array}{c}18 \text {-in. } \\
(\mathrm{pCi} / \mathrm{g})\end{array}$ \\
\hline \multicolumn{6}{|c|}{ Technetium-99 (continued) } \\
\hline $11 / 09 / 89$ & BH059 & 03E & 150 & 160 & 27 \\
\hline $11 / 09 / 89$ & BH057 & $03 \mathrm{~F}$ & 49 & 16 & 14 \\
\hline $11 / 09 / 89$ & BH056 & 03F-B & 1200 & 120 & 7.3 \\
\hline $11 / 09 / 89$ & BH058 & $03 \mathrm{H}$ & 49 & 4.6 & - \\
\hline $11 / 20 / 89$ & BH072 & 05A & 100 & 49 & 21 \\
\hline $01 / 10 / 90$ & BH076 & 05B & 23 & 3.2 & 6.5 \\
\hline $11 / 03 / 8 ?$ & BH055 & 05D & 10 & 4.6 & 4.3 \\
\hline $11 / 01 / 89$ & BH049 & $05 \mathrm{~F}$ & 49 & 89 & 2.5 \\
\hline $11 / 01 / 89$ & BH048 & $05 \mathrm{G}$ & 7.3 & - & - \\
\hline $11 / 03 / 89$ & BH053 & $06 \mathrm{~B}$ & 17 & 16 & 11 \\
\hline $11 / 02 / 89$ & BH050 & $06 \mathrm{~F}$ & 73 & 3.2 & 16 \\
\hline $11 / 02 / 89$ & BH051 & 06F-B & 950 & 100 & 5.9 \\
\hline $10 / 30 / 89$ & BH043 & 07B & 130 & 270 & 380 \\
\hline $10 / 30 / 89$ & BHO44 & 07B-B & 1900 & 510 & 81 \\
\hline $10 / 30 / 89$ & BH045 & 07D & 570 & 730 & 430 \\
\hline $11 / 03 / 89$ & BH052 & 07D-B & 120 & 49 & 19 \\
\hline $11 / 03 / 89$ & BH054 & 07D-B & 590 & 970 & 260 \\
\hline $10 / 30 / 89$ & BH046 & $07 \mathrm{~F}$ & 1600 & 97 & 62 \\
\hline $10 / 12 / 89$ & BH021 & 07F-B & 11 & 1700 & 1400 \\
\hline $10 / 30 / 89$ & BH047 & 07F-B & 3500 & 410 & - \\
\hline $11 / 20 / 89$ & BH071 & 07F-B & 4300 & - & - \\
\hline $10 / 25 / 89$ & BH038 & 09B & 680 & 320 & 30 \\
\hline $10 / 18 / 89$ & BH033 & 09B-B & 3200 & 160 & 8.9 \\
\hline $10 / 25 / 89$ & BH039 & $09 \mathrm{C}$ & 24 & 15 & 2.4 \\
\hline $10 / 25 / 89$ & BHO40 & 09D & 35 & 21 & 1.4 \\
\hline $10 / 25 / 89$ & BH041 & $09 \mathrm{E}$ & 620 & 20 & 2.5 \\
\hline $10 / 30 / 89$ & BHO42 & $09 \mathrm{~F}$ & 35 & 35 & 38 \\
\hline $10 / 24 / 89$ & BH037 & 09F-B & 840 & 190 & 23 \\
\hline $10 / 16 / 89$ & BH027 & $11 \mathrm{~A}$ & 70 & 68 & 41 \\
\hline $10 / 16 / 89$ & BH026 & $11 \mathrm{~B}$ & 170 & 21 & 32 \\
\hline $10 / 16 / 89$ & BH025 & $11 D$ & 24 & 2.5 & 1.8 \\
\hline $10 / 18 / 89$ & BH030 & $11 \mathrm{~F}$ & 4 & 160 & 150 \\
\hline $10 / 18 / 89$ & BH031 & $11 F-B$ & 220 & 57 & 1.9 \\
\hline $10 / 24 / 89$ & BH036 & 11F-B & 140 & 140 & 7.8 \\
\hline $10 / 18 / 89$ & BH032 & $11 \mathrm{H}$ & 680 & 350 & 430 \\
\hline $10 / 23 / 89$ & BH035 & $11 \mathrm{H}-\mathrm{B}$ & 3800 & 1800 & 210 \\
\hline $10 / 16 / 89$ & BH028 & $12 \mathrm{~B}$ & 43 & 1.7 & 0.65 \\
\hline $01 / 03 / 90$ & BH074 & $12 \mathrm{~F}$ & 5.7 & 3.5 & 1.8 \\
\hline $10 / 13 / 89$ & BH024 & $13 B$ & 0.084 & 5.9 & 4.9 \\
\hline $10 / 13 / 89$ & BH023 & $13 C$ & 0.49 & 57 & 3.5 \\
\hline $10 / 18 / 89$ & ВH029 & $13 D$ & 76 & 2.4 & 2.1 \\
\hline $01 / 11 / 90$ & BH079 & $13 E$ & - & - & 70 \\
\hline $01 / 11 / 90$ & BH080 & $13 \mathrm{~F}$ & - & - & 49 \\
\hline
\end{tabular}


Table B.2. K-1407-C Retention Basin sediment sample analysisradionuclide analysis (continued)

\begin{tabular}{|c|c|c|c|c|c|}
\hline Date & Hole & Location & $\begin{array}{c}\text { 6-in. } \\
(\mathrm{pCl} / \mathrm{g})\end{array}$ & $\begin{array}{l}\text { 12-in. } \\
(\mathrm{pCi} / \mathrm{g})\end{array}$ & $\begin{array}{l}\text { 18-in. } \\
\text { (pCi/g) }\end{array}$ \\
\hline
\end{tabular}

Technetium-99 (continued)

$\begin{array}{llllrc}10 / 12 / 89 & \text { BH020 } & 15 \mathrm{~B} & 0.089 & 2.3 & 11 \\ 10 / 10 / 89 & \text { BH013 } & 15 \mathrm{D} & 0.7 & 10 & 7 \\ 10 / 11 / 89 & \text { BH017 } & 15 \mathrm{D}-\mathrm{B} & 0.51 & 4 & 2.1 \\ 10 / 10 / 89 & \text { BH014 } & 15 \mathrm{~F} & 5.7 & 62 & 32 \\ 10 / 10 / 89 & \text { BH015 } & 15 \mathrm{~F}-\mathrm{B} & 5.9 & 200 & 16 \\ 10 / 11 / 89 & \text { BH018 } & 15 \mathrm{~F}-\mathrm{B} & 3 & 180 & 78 \\ 10 / 23 / 89 & \text { BH034 } & 15 \mathrm{~F}-\mathrm{B} & 350 & 54 & 59 \\ 10 / 10 / 89 & \text { BH016 } & 15 \mathrm{H} & 0.65 & 430 & 350 \\ 10 / 12 / 89 & \text { BH019 } & 16 \mathrm{~B} & 0.43 & 22 & 8.9 \\ 10 / 13 / 89 & \text { BH022 } & 16 \mathrm{E}-\mathrm{B} & 1.8 & 59 & 49 \\ 10 / 09 / 89 & \text { BH012 } & 16 \mathrm{~F} & 2.2 & 21 & 49 \\ 10 / 04 / 89 & \text { BH010 } & 17 \mathrm{~B} & 14 & 35 & 13 \\ 10 / 04 / 89 & \text { BH009 } & 17 \mathrm{D} & 38 & 15 & 13 \\ 10 / 03 / 89 & \text { BHI008 } & 17 \mathrm{~F} & 110 & 120 & 86 \\ 10 / 03 / 89 & \text { BH007 } & 17 \mathrm{H} & 110 & 270 & 510 \\ 10 / 03 / 89 & \text { BH004 } & 18 \mathrm{E}-\mathrm{B} & 19 & 30 & 8.1 \\ 09 / 28 / 89 & \text { BH002 } & 18 \mathrm{G}-\mathrm{B} & 860 & 260 & 32 \\ 10 / 03 / 89 & \text { BH006 } & 19 \mathrm{~B} & 3.2 & 12 & - \\ 10 / 03 / 89 & \text { BH005 } & 19 \mathrm{D} & 65 & 70 & 46 \\ 10 / 02 / 89 & \text { BH003 } & 19 \mathrm{~F} & 10 & 130 & 68 \\ 09 / 27 / 89 & \text { BH001 } & 19 \mathrm{H} & 5.1 & 4.6 & 41 \\ 10 / 09 / 89 & \text { BH011 } & \text { 20D } & 0.043 & 7 & 1.1\end{array}$

\section{Total strontium}

$\begin{array}{lllccc}11 / 20 / 89 & \text { BH070 } & \text { OOD } & 10 & 20 & 19 \\ 11 / 20 / 89 & \text { BH068 } & \text { OOF } & 16 & 15 & 13 \\ 11 / 20 / 89 & \text { BH069 } & \text { 00F-B } & 22 & 10 & 15 \\ 11 / 21 / 89 & \text { BH073 } & \text { 01B } & 0.49 & <0.41 & <0.49 \\ 01 / 10 / 90 & \text { BH078 } & \text { 01D } & 2.4 & - & - \\ 11 / 16 / 89 & \text { BH067 } & \text { 01F } & 1.6 & 0.78 & - \\ 11 / 15 / 89 & \text { BH064 } & \text { O1F-B } & 3.8 & 0.73 & 0.51 \\ 11 / 16 / 89 & \text { BH066 } & \text { 01H } & 0.3 & 0.65 & - \\ 01 / 10 / 90 & \text { BH077 } & \text { 02E } & 2.6 & 0.76 & - \\ 11 / 15 / 89 & \text { BH063 } & \text { 02G } & 2 & 0.41 & 9.4 \\ 11 / 16 / 89 & \text { BH065 } & \text { 03A } & 0.43 & <0.49 & 0.51 \\ 11 / 13 / 89 & \text { BH061 } & \text { 03B } & 0.59 & 1.3 & 2.5 \\ 11 / 13 / 89 & \text { BH060 } & \text { 03C } & 0.54 & 3 & 0.81 \\ 01 / 10 / 90 & \text { BH075 } & \text { 03D } & 0.97 & - & 0.62 \\ 11 / 13 / 89 & \text { BH062 } & \text { 03D-B } & 17 & 0.65 & 5.4 \\ 11 / 09 / 89 & \text { BH059 } & \text { 03E } & 3.8 & 9.2 & 0.49 \\ 11 / 09 / 89 & \text { BH057 } & \text { 03F } & 0.81 & 0.95 & 1.4 \\ 11 / 09 / 89 & \text { BH056 } & \text { 03F-B } & 21 & 4.3 & \end{array}$


163

Table B.2. K-1407-C Retention Basin sediment sample analysisradionuclide analysis (continued)

\begin{tabular}{|c|c|c|c|c|c|}
\hline Date & Hole & Location & $\begin{array}{c}\text { 6-in. } \\
(\mathrm{pCi} / \mathrm{g})\end{array}$ & $\begin{array}{l}\text { 12-in. } \\
(\mathrm{pCi} / \mathrm{g})\end{array}$ & $\begin{array}{c}18-i n . \\
(\mathrm{pCi} / \mathrm{g})\end{array}$ \\
\hline \multicolumn{6}{|c|}{ Total strontium (continued) } \\
\hline $11 / 09 / 89$ & BH058 & $03 \mathrm{H}$ & 1.6 & 0.81 & - \\
\hline $11 / 20 / 89$ & BH072 & 05A & 5.7 & 0.97 & 1.2 \\
\hline $01 / 10 / 90$ & BH076 & 05B & 2.6 & $<0.81$ & $<0.81$ \\
\hline $11 / 03 / 89$ & BH055 & 05D & 1.7 & 0.89 & 0.43 \\
\hline $11 / 01 / 89$ & BH049 & $05 \mathrm{~F}$ & 1.9 & 2.1 & 0.19 \\
\hline $11 / 01 / 89$ & BH048 & 05G & 0.19 & - & - \\
\hline $11 / 03 / 89$ & BH053 & O6B & 2.7 & 0.89 & 1.1 \\
\hline $11 / 02 / 89$ & BH050 & O6F & 1.7 & 1.2 & 0.86 \\
\hline $11 / 02 / 89$ & BH051 & O6F-B & 11 & 3.2 & 1.6 \\
\hline $10 / 30 / 89$ & BH043 & 07B & 11 & 11 & 12 \\
\hline $10 / 30 / 89$ & BH044 & 07B-B & 46 & 35 & 7.3 \\
\hline $10 / 30 / 89$ & BH045 & 07D & 21 & 30 & 27 \\
\hline $11 / 03 / 89$ & BH052 & 07D-B & 54 & 14 & 5.1 \\
\hline $11 / 03 / 89$ & BH054 & 07D-B & 35 & 30 & 8.6 \\
\hline $10 / 30 / 89$ & BH046 & 07F & 46 & 8.6 & 2.2 \\
\hline $10 / 12 / 89$ & BH021 & 07F-B & 30 & 7.6 & 43 \\
\hline $10 / 30 / 89$ & BH047 & 07F-B & 46 & 13 & - \\
\hline $11 / 20 / 89$ & BH071 & 07F-B & 130 & - & - \\
\hline $10 / 25 / 89$ & BH038 & 09B & 18 & 12 & 1.6 \\
\hline $10 / 18 / 89$ & BH033 & 09B-B & 130 & - & - \\
\hline $10 / 25 / 89$ & BH039 & $09 \mathrm{C}$ & 3.2 & 0.3 & 0.14 \\
\hline $10 / 25 / 89$ & BH040 & 09D & 3.2 & 0.81 & 0.35 \\
\hline $10 / 25 / 89$ & BH041 & 09E & 4.9 & -0.1 & -0.2 \\
\hline $10 / 30 / 89$ & BH042 & 09F & 2.4 & 3.2 & 3.2 \\
\hline $10 / 24 / 89$ & BH037 & 09F-B & 11 & 5.7 & 3 \\
\hline $10 / 16 / 89$ & BH027 & $11 \mathrm{~A}$ & 3 & - & - \\
\hline $10 / 16 / 89$ & BH026 & $11 \mathrm{~B}$ & 7.6 & - & - \\
\hline $10 / 16 / 89$ & BH025 & 11D & 1.2 & - & - \\
\hline $10 / 18 / 89$ & BH030 & $11 \mathrm{~F}$ & 0.38 & - & - \\
\hline $10 / 18 / 89$ & BH031 & $11 \mathrm{~F}-\mathrm{B}$ & 12 & - & - \\
\hline $10 / 24 / 89$ & BH036 & $11 \mathrm{~F}-\mathrm{B}$ & 7.8 & 6.8 & 1.7 \\
\hline $10 / 18 / 89$ & BH032 & $11 \mathrm{H}$ & 25 & - & - \\
\hline 10/23/89 & ВH035 & $11 \mathrm{H}-\mathrm{B}$ & 62 & 120 & 19 \\
\hline $10 / 16 / 89$ & BH028 & $12 \mathrm{~B}$ & 1.8 & - & - \\
\hline $01 / 03 / 90$ & BH074 & $12 \mathrm{~F}$ & 1.6 & -0.1 & -0.3 \\
\hline $10 / 13 / 89$ & BH024 & 13B & -0.4 & - & - \\
\hline $10 / 13 / 89$ & BH023 & $13 C$ & 1.4 & 1.7 & 0.14 \\
\hline $10 / 18 / 89$ & BH029 & 13D & 4.6 & - & - \\
\hline $01 / 11 / 90$ & BH079 & $13 \mathrm{E}$ & - & - & 3.8 \\
\hline $01 / 11 / 90$ & BHOSO & $13 \mathrm{~F}$ & - & - & 4.3 \\
\hline $10 / 12 / 89$ & BH020 & $15 B$ & 0.89 & 0.81 & 0.73 \\
\hline $10 / 10 / 89$ & BH013 & $15 \mathrm{D}$ & 1.8 & 1.1 & 1.2 \\
\hline $10 / 11 / 89$ & BH017 & 15D-B & 1.2 & - & - \\
\hline
\end{tabular}


Table B.2. K-1407-C Retention Basin sediment sample analysisradionuclide analysis (continued)

\begin{tabular}{|c|c|c|c|c|c|}
\hline Date & Hole & Location & $\underset{(\mathrm{pCl} / \mathrm{g})}{\text { 6-in. }}$ & $\begin{array}{l}\text { 12-in. } \\
\text { (pCi/g) }\end{array}$ & $\begin{array}{l}\text { 18-in. } \\
(\mathrm{pCi} / \mathrm{g})\end{array}$ \\
\hline
\end{tabular}

Total strontium (continued)

$\begin{array}{lllllc}10 / 10 / 89 & \text { BH014 } & 15 \mathrm{~F} & 11 & 4 & 5.9 \\ 10 / 10 / 89 & \text { BH015 } & 15 \mathrm{~F}-\mathrm{B} & 30 & 6.2 & 5.9 \\ 10 / 11 / 89 & \text { BH018 } & 15 \mathrm{~F}-\mathrm{B} & 24 & - & - \\ 10 / 23 / 89 & \text { BH034 } & 15 \mathrm{~F}-\mathrm{B} & 13 & 4 & 3.5 \\ 10 / 10 / 89 & \text { BH016 } & 15 \mathrm{H} & 5.9 & - & - \\ 10 / 12 / 89 & \text { BH019 } & 16 \mathrm{~B} & 3 & 0.38 & 1.1 \\ 10 / 13 / 89 & \text { BH022 } & 16 \mathrm{E}-\mathrm{B} & 9.7 & 5.1 & 3.2 \\ 10 / 09 / 89 & \text { BH012 } & 16 \mathrm{~F} & 4.9 & 5.4 & 4.6 \\ 10 / 04 / 89 & \text { BH010 } & 17 \mathrm{~B} & 6.8 & 0.054 & 0.3 \\ 10 / 04 / 89 & \text { BH009 } & 17 \mathrm{D} & -0.5 & 2.1 & 0.24 \\ 10 / 03 / 89 & \text { BH008 } & 17 \mathrm{~F} & 6.5 & 5.9 & 1.5 \\ 10 / 03 / 89 & \text { BH007 } & 17 \mathrm{H} & 14 & 9.7 & 12 \\ 10 / 03 / 89 & \text { BH004 } & 18 \mathrm{E}-\mathrm{B} & 20 & 4.9 & 1.4 \\ 09 / 28 / 89 & \text { BH002 } & 18 \mathrm{G}-\mathrm{B} & 19 & 16 & 4.6 \\ 10 / 03 / 89 & \text { BH006 } & 19 \mathrm{~B} & -0.5 & 0.81 & - \\ 10 / 03 / 89 & \text { BH005 } & 19 \mathrm{D} & 7.8 & 10 & 4 \\ 10 / 02 / 89 & \text { BH003 } & 19 \mathrm{~F} & 11 & 11 & 7.8 \\ 09 / 27 / 89 & \text { BH001 } & 19 \mathrm{H} & 0.054 & 0.054 & -0.4 \\ 10 / 09 / 89 & \text { BH011 } & 20 \mathrm{D} & -0.2 & -0.2 & 0.38\end{array}$

Uranium-234

\begin{tabular}{|c|c|c|c|c|c|}
\hline $11 / 20 / 89$ & BH070 & OOD & 210 & 490 & 350 \\
\hline $11 / 20 / 89$ & 1068 & $00 \mathrm{~F}$ & 460 & 350 & 210 \\
\hline $11 / 20 / 89$ & BH069 & OOF-B & 590 & 230 & 300 \\
\hline $11 / 21 / 89$ & BH073 & 01B & 2.5 & 1 & 1.6 \\
\hline $01 / 10 / 90$ & BH078 & 01D & 30 & - & - \\
\hline $11 / 16 / 89$ & BH067 & $01 F$ & 27 & 1.4 & - \\
\hline $11 / 15 / 89$ & BH064 & 01F-B & 180 & 46 & 5.7 \\
\hline $11 / 16 / 89$ & BH066 & $01 \mathrm{H}$ & 15 & 5.1 & - \\
\hline $01 / 10 / 90$ & BH077 & $02 \mathrm{E}$ & 59 & 3.5 & - \\
\hline $11 / 15 / 89$ & BH063 & $02 \mathrm{G}$ & 41 & 6.5 & 490 \\
\hline $11 / 16 / 89$ & BH065 & $03 \mathrm{~A}$ & 22 & 12 & 21 \\
\hline $11 / 13 / 89$ & BH061 & 03B & 2.5 & 0.89 & 0.51 \\
\hline $11 / 13 / 89$ & BH060 & $03 \mathrm{C}$ & 5.4 & 0.86 & 0.78 \\
\hline $01 / 10 / 90$ & BH075 & 03D & 2.6 & - & - \\
\hline $11 / 13 / 89$ & BH062 & 03D-B & 260 & 3.8 & 6.2 \\
\hline $11 / 09 / 89$ & BH059 & 03E & 110 & 180 & 26 \\
\hline $11 / 09 / 89$ & BH057 & $03 \mathrm{~F}$ & 30 & 19 & 11 \\
\hline $11 / 09 / 89$ & BH056 & 03F-B & 1300 & 130 & 10 \\
\hline $11 / 09 / 89$ & BH058 & $03 \mathrm{H}$ & 38 & 6.8 & - \\
\hline $11 / 20 / 89$ & BH072 & $05 \mathrm{~A}$ & 57 & 32 & 23 \\
\hline $01 / 10 / 90$ & BH076 & 05B & 9.4 & 2.2 & 1.3 \\
\hline
\end{tabular}


Table B.2. K-1407-C Retention Basin sediment sample analysisradionuclide analysis (continued)

\begin{tabular}{|c|c|c|c|c|c|}
\hline Date & Hole & Location & $\underset{(\mathrm{pCl} / \mathrm{g})}{\text { 6-in. }}$ & $\begin{array}{c}\text { 12-in. } \\
(\mathrm{pCl} / \mathrm{g})\end{array}$ & $\underset{(\mathrm{pCl} / \mathrm{g})}{18-\mathrm{in}}$ \\
\hline
\end{tabular}

Uranium-234 (continuod)

\begin{tabular}{|c|c|c|c|c|c|}
\hline $11 / 03 / 89$ & BH055 & 05D & 18 & 1.6 & 1.4 \\
\hline $11 / 01 / 89$ & BH049 & $05 \mathrm{~F}$ & 30 & 38 & 9.2 \\
\hline $11 / 01 / 89$ & BH048 & $05 \mathrm{G}$ & 21 & - & - \\
\hline $11 / 03 / 89$ & BH053 & O6B & 32 & 11 & 6.2 \\
\hline $11 / 02 / 89$ & BH050 & $06 \mathrm{~F}$ & 76 & 57 & 35 \\
\hline $11 / 02 / 89$ & BH051 & 06F-B & 320 & 73 & 5.7 \\
\hline $10 / 30 / 89$ & ВН043 & 07B & 180 & 160 & 220 \\
\hline 10/30/89 & BH044 & 07B-B & 700 & 410 & 38 \\
\hline $10 / 30 / 89$ & BH045 & 07D & 240 & 410 & 380 \\
\hline $11 / 03 / 89$ & BH052 & 07D-B & 150 & 7.6 & 2.5 \\
\hline $11 / 03 / 89$ & BH054 & 07D-B & 620 & 430 & 110 \\
\hline $10 / 30 / 89$ & BH046 & $07 \mathrm{~F}$ & 700 & 84 & 32 \\
\hline $10 / 12 / 89$ & BH021 & 07F-B & 1200 & 1100 & 920 \\
\hline $10 / 30 / 89$ & BH047 & 07F-B & 2700 & 260 & - \\
\hline $11 / 20 / 89$ & BH071 & 07F-B & 1800 & - & - \\
\hline $10 / 25 / 89$ & BH038 & 09B & 650 & 220 & 25 \\
\hline $10 / 18 / 89$ & BH033 & 09B-B & 1200 & 27 & 4.3 \\
\hline $10 / 25 / 89$ & BH039 & $09 \mathrm{C}$ & 73 & 10 & 8.9 \\
\hline $10 / 25 / 89$ & BH040 & 09D & 68 & 14 & 1.5 \\
\hline $10 / 25 / 89$ & BH041 & $09 \mathrm{E}$ & 110 & 14 & 3 \\
\hline 10/30/89 & BH042 & 09F & 51 & 24 & 20 \\
\hline $10 / 24 / 89$ & BH037 & 09F-B & 300 & 92 & 35 \\
\hline $10 / 16 / 89$ & BH027 & $11 \mathrm{~A}$ & 43 & 62 & 65 \\
\hline $10 / 16 / 89$ & BH026 & 11B & $\$ 10$ & 14 & 19 \\
\hline $10 / 16 / 89$ & BH025 & 11D & 23 & 2.7 & 1.5 \\
\hline $10 / 18 / 89$ & BH030 & $11 \mathrm{~F}$ & 3.5 & 81 & 14 \\
\hline $10 / 18 / 89$ & BH031 & 11F-B & 190 & 38 & 7.6 \\
\hline $10 / 24 / 89$ & BH036 & $11 \mathrm{~F}-\mathrm{B}$ & 160 & 150 & 9.4 \\
\hline $10 / 18 / 89$ & BH032. & $11 \mathrm{H}$ & 380 & 230 & 160 \\
\hline $10 / 23 / 89$ & BH035 & $11 \mathrm{H}-\mathrm{B}$ & 950 & 1200 & 210 \\
\hline $10 / 16 / 89$ & BH028 & $12 B$ & 25 & 1.1 & 1.2 \\
\hline $01 / 03 / 90$ & BH074 & $12 \mathrm{~F}$ & 1.3 & 0.86 & 1.4 \\
\hline $10 / 13 / 89$ & BH024 & 13B & 2.3 & 5.9 & 2.7 \\
\hline $10 / 13 / 89$ & BH023 & $13 \mathrm{C}$ & 27 & 32 & 1.2 \\
\hline $10 / 18 / 89$ & BH029 & 13D & 43 & $<0.81$ & 1.4 \\
\hline $01 / 11 / 90$ & BH079 & $13 \mathrm{E}$ & - & - & 41 \\
\hline $01 / 11 / 90$ & BH080 & $13 \mathrm{~F}$ & - & - & 30 \\
\hline $10 / 12 / 89$ & BH020 & 15B & 5.1 & 4.6 & 4.6 \\
\hline $10 / 10 / 89$ & BH013 & $15 \mathrm{D}$ & 190 & 3.8 & 3 \\
\hline $10 / 11 / 89$ & BH017 & 15D-B & 13 & 2 & 1 \\
\hline $10 / 10 / 89$ & BH014 & $15 \mathrm{~F}$ & 110 & 43 & 22 \\
\hline $10 / 10 / 89$ & BH015 & 15F-B & 540 & 73 & 19 \\
\hline $10 / 11 / 89$ & BH018 & 15F-B & 460 & 120 & 110 \\
\hline
\end{tabular}


Table B.2. K-1407-C Retention Basin sediment sample analysisradionuclide analysis (continued)

\begin{tabular}{|c|c|c|c|c|c|}
\hline Date & Hole & Location & $\underset{(\mathrm{pCi} / \mathrm{g})}{\text { 6-in. }}$ & $\begin{array}{c}12-\mathrm{in} . \\
(\mathrm{pCl} / \mathrm{g})\end{array}$ & $\begin{array}{l}\text { 18-in. } \\
(\mathrm{pCi} / \mathrm{g})\end{array}$ \\
\hline
\end{tabular}

Uranium-234 (continued)

$\begin{array}{lllccc}10 / 23 / 89 & \text { BH034 } & 15 F-B & 120 & 38 & 46 \\ 10 / 10 / 89 & \text { BH016 } & 15 \mathrm{H} & 170 & 150 & 38 \\ 10 / 12 / 89 & \text { BH019 } & 16 \mathrm{~B} & 9.4 & 7.3 & 5.1 \\ 10 / 13 / 89 & \text { BH022 } & 16 \mathrm{E}-\mathrm{B} & 150 & 30 & 38 \\ 10 / 09 / 89 & \text { BH012 } & 16 \mathrm{~F} & 110 & 13 & 8.6 \\ 10 / 04 / 89 & \text { BH010 } & 17 \mathrm{~B} & 12 & 8.6 & 10 \\ 10 / 04 / 89 & \text { BH009 } & 17 \mathrm{D} & 100 & 3 & 3.8 \\ 10 / 03 / 89 & \text { BH008 } & 17 \mathrm{~F} & 120 & 49 & 46 \\ 10 / 03 / 89 & \text { BH007 } & 17 \mathrm{H} & 260 & 140 & 250 \\ 10 / 03 / 89 & \text { BH004 } & 18 \mathrm{E}-\mathrm{B} & 54 & 14 & 4.6 \\ 09 / 28 / 89 & \text { BH002 } & 18 \mathrm{G}-\mathrm{B} & 300 & 140 & 8.6 \\ 10 / 03 / 89 & \text { BH006 } & 19 \mathrm{~B} & 16 & 6.8 & - \\ 10 / 03 / 89 & \text { BH005 } & 19 \mathrm{D} & 120 & 20 & 18 \\ 10 / 02 / 89 & \text { BH003 } & 19 \mathrm{~F} & 92 & 81 & 16 \\ 09 / 27 / 89 & \text { BH001 } & 19 \mathrm{H} & 9.4 & 8.9 & 7.8 \\ 10 / 09 / 89 & \text { BH011 } & 20 \mathrm{D} & 9.2 & 6.5 & 1.1\end{array}$

Uranium-235

$\begin{array}{llllll}11 / 20 / 89 & \text { BH070 } & \text { OOD } & 5.4 & 35 & 17 \\ 11 / 20 / 89 & \text { BH068 } & \text { OOF } & 18 & 25 & 12 \\ 11 / 20 / 89 & \text { BH069 } & \text { 00F-B } & 27 & 16 & 25 \\ 11 / 21 / 89 & \text { BH073 } & \text { 01B } & 0.1 & 0.065 & 0.086 \\ 01 / 10 / 90 & \text { BH078 } & \text { 01D } & 1.7 & - & - \\ 11 / 16 / 89 & \text { BH067 } & \text { 01F } & 1.9 & 0.12 & - \\ 11 / 15 / 89 & \text { BH064 } & \text { 01F-B } & 15 & 3 & 0.23 \\ 11 / 16 / 89 & \text { BH066 } & \text { 01H } & 0.59 & 0.21 & - \\ 01 / 10 / 90 & \text { BH077 } & \text { 02E } & 3 & 0.22 & - \\ 11 / 15 / 89 & \text { BH063 } & \text { 02G } & 1.2 & 0.41 & 22 \\ 11 / 16 / 89 & \text { BH065 } & \text { 03A } & 1.1 & 0.86 & 1.2 \\ 11 / 13 / 89 & \text { BH061 } & \text { 03B } & 0.21 & 0.041 & 0.03 \\ 11 / 13 / 89 & \text { BH060 } & \text { 03C } & 0.38 & 0.032 & 0.611 \\ 01 / 10 / 90 & \text { BH075 } & \text { 03D } & 0.23 & - & - \\ 11 / 13 / 89 & \text { BH062 } & \text { 03D-B } & 9.2 & 0.16 & 0.21 \\ 11 / 09 / 89 & \text { BH059 } & \text { 03E } & 3.5 & 8.6 & 1.3 \\ 11 / 09 / 89 & \text { BH057 } & \text { 03F } & 0.84 & 0.62 & 0.43 \\ 11 / 09 / 89 & \text { BH056 } & \text { 03F-B } & 32 & 6.2 & 0.57 \\ 11 / 09 / 89 & \text { BH058 } & \text { 03H } & 3.5 & 0.35 & - \\ 11 / 20 / 89 & \text { BH072 } & \text { 05A } & 2.4 & 1.6 & 1.9 \\ 01 / 10 / 90 & \text { BH076 } & \text { 05B } & 0.54 & 0.23 & 0.1 \\ 11 / 03 / 89 & \text { BH055 } & \text { 05D } & 0.92 & 0.14 & 0.13 \\ 11 / 01 / 89 & \text { BH049 } & \text { 05F } & 2.1 & 0.54 & 2.4 \\ 11 / 01 / 89 & \text { BH048 } & \text { 05G } & 1.8 & - & -\end{array}$


Table B.2. K-1407-C Retention Basin sediment sample analysisradionuclide anatysis (continued)

\begin{tabular}{|c|c|c|c|c|c|}
\hline Date & Hole & Location & $\begin{array}{c}\text { 6-in. } \\
(\mathrm{pCi} / \mathrm{g})\end{array}$ & $\begin{array}{c}12-\mathrm{in} . \\
(\mathrm{pCi} / \mathrm{g})\end{array}$ & $\begin{array}{c}18 \text {-in. } \\
(\mathrm{pCl} / \mathrm{g})\end{array}$ \\
\hline \multicolumn{6}{|c|}{ Uranium-235 (continued) } \\
\hline $11 / 03 / 89$ & BH053 & 06B & 1.3 & 0.95 & 0.84 \\
\hline $11 / 02 / 89$ & BH0SO & $06 \mathrm{~F}$ & 3 & 9.2 & 3.8 \\
\hline $11 / 02 / 89$ & BH0S1 & 06F-B & 12 & 3.2 & 0.41 \\
\hline $10 / 30 / 89$ & BH043 & 07B & 9.4 & 11 & 11 \\
\hline $10 / 30 / 89$ & BHO44 & 07B-B & 26 & 22 & 2.5 \\
\hline $10 / 30 / 89$ & BHO45 & 07D & 11 & 11 & 27 \\
\hline $11 / 03 / 89$ & BH052 & 07D-B & 6.2 & 1.7 & 0.41 \\
\hline $11 / 03 / 89$ & BH054 & 07D-B & 23 & 32 & 7 \\
\hline $10 / 30 / 89$ & BH046 & $07 \mathrm{~F}$ & 22 & 5.7 & 1.6 \\
\hline $10 / 12 / 89$ & BH021 & 07F-B & 35 & 46 & 62 \\
\hline $10 / 30 / 89$ & BH047 & 07F-B & 38 & 9.2 & - \\
\hline $11 / 20 / 89$ & BH071 & 07F-B & 62 & - & - \\
\hline $10 / 25 / 89$ & BH038 & 09B & 23 & 6.5 & 0.46 \\
\hline $10 / 18 / 89$ & BH033 & 09B-B & 49 & 1.5 & 0.27 \\
\hline $10 / 25 / 89$ & BH039 & $09 \mathrm{C}$ & 2.1 & 0.59 & 0.76 \\
\hline $10 / 25 / 89$ & $\mathrm{BH} 040$ & 09D & 2.7 & 1.1 & 0.17 \\
\hline $10 / 25 / 89$ & BH041 & $09 \mathrm{E}^{\prime}$ & 3.2 & 0.43 & 0.38 \\
\hline $10 / 30 / 89$ & $\mathrm{BH} 042$ & $09 \mathrm{~F}$ & 1.6 & 0.12 & 0.078 \\
\hline $10 / 24 / 89$ & BH037 & 09F-B & 10 & 0.68 & 1.6 \\
\hline $10 / 16 / 89$ & BH027 & $11 \mathrm{~A}$ & 2.1 & 1.4 & 3.2 \\
\hline $10 / 16 / 89$ & BH026 & $11 \mathrm{~B}$ & 7.3 & 0.49 & 2.3 \\
\hline $10 / 16 / 89$ & BH025 & 11D & 1.3 & 0.11 & 0.041 \\
\hline $10 / 18 / 89$ & BH030 & $11 F^{\prime}$ & 0.3 & 3.8 & 0.62 \\
\hline $10 / 18 / 89$ & BH031 & $11 F-B$ & 9.2 & 2.1 & 0.49 \\
\hline $10 / 24 / 89$ & BH036 & $11 F \cdot B$ & 6.2 & 9.2 & 0.49 \\
\hline $10 / 18 / 89$ & BH032 & $11 \mathrm{H}$ & 15 & 15 & 9.2 \\
\hline $10 / 23 / 89$ & BH035 & $11 \mathrm{H}-\mathrm{B}$ & 54 & 43 & 9.2 \\
\hline $10 / 16 / 89$ & BH028 & $12 \mathrm{~B}$ & 1.2 & 0.059 & 0.032 \\
\hline $01 / 03 / 90$ & BH074 & $12 \mathrm{~F}$ & 0.062 & 0.18 & 0.16 \\
\hline $10 / 13 / 89$ & BH024 & 13B & 0.073 & 0.38 & 0.19 \\
\hline $10 / 13 / 89$ & $\mathrm{BH} 023$ & $13 \mathrm{C}$ & 1.4 & 1.9 & 0.032 \\
\hline $10 / 18 / 89$ & BH029 & 13D & 2.5 & $<0.81$ & 0.086 \\
\hline $01 / 11 / 90$ & BH079 & $13 \mathrm{E}$ & - & - & 2.2 \\
\hline $01 / 11 / 90$ & BH080 & $13 \mathrm{~F}$ & - & - & 3.2 \\
\hline $10 / 12 / 89$ & $\mathrm{BH} 020$ & $15 B$ & 0.25 & 0.41 & 0.38 \\
\hline $10 / 10 / 89$ & BH013 & $15 \mathrm{D}$ & 8.6 & 0.15 & 0.13 \\
\hline $10 / 11 / 89$ & BH017 & 15D-B & 0.78 & 0.14 & 0.025 \\
\hline $10 / 10 / 89$ & BH014 & $15 \mathrm{~F}$ & 6.8 & 1.5 & 0.97 \\
\hline $10 / 10 / 89$ & BH015 & $15 F-B$ & 38 & 3.8 & 1.1 \\
\hline $10 / 11 / 89$ & BH018 & 15F-B & 22 & 8.1 & 6.5 \\
\hline $10 / 23 / 89$ & BH034 & $15 F-B$ & 9.2 & 1.7 & 2.2 \\
\hline $10 / 10 / 89$ & BH016 & $15 \mathrm{H}$ & 14 & 8.9 & 3 \\
\hline $10 / 12 / 89$ & BH019 & $16 \mathrm{~B}$ & 0.57 & 0.54 & 0.65 \\
\hline
\end{tabular}


Table B.2 K-1407-C Retention Basin sediment sample analysisradionuclide analysis (continued)

\begin{tabular}{|c|c|c|c|c|c|}
\hline Date & Hole & Location & $\underset{(\mathrm{pCi} / \mathrm{g})}{\text { 6-in. }}$ & $\begin{array}{l}\text { 12-in. } \\
(\mathrm{pCi} / \mathrm{g})\end{array}$ & $\begin{array}{l}\text { 18-in. } \\
(\mathrm{pCi} / \mathrm{g})\end{array}$ \\
\hline
\end{tabular}

Uranium-235 (continued)

$10 / 13 / 89$
$10 / 09 / 89$
$10 / 04 / 89$
$10 / 04 / 89$
$10 / 03 / 89$
$10 / 03 / 89$
$10 / 03 / 89$
$09 / 28 / 89$
$10 / 03 / 89$
$10 / 03 / 89$
$10 / 02 / 89$
$09 / 27 / 89$
$10 / 09 / 89$

$11 / 20 / 89$

$11 / 20 / 89$

$11 / 20 / 89$

$11 / 21 / 89$

$01 / 10 / 90$

$11 / 16 / 89$

$11 / 15 / 89$

$11 / 16 / 89$

$01 / 10 / 90$

$11 / 15 / 89$

$11 / 16 / 89$

$11 / 13 / 89$

$11 / 13 / 89$

$01 / 10 / 90$

$11 / 13 / 89$

$11 / 09 / 89$

$11 / 09 / 89$

$11 / 09 / 89$

$11 / 09 / 89$

$11 / 20 / 89$

$01 / 10 / 90$

$11 / 03 / 89$

$11 / 01 / 89$

$11 / 01 / 89$

$11 / 03 / 89$

$11 / 02 / 89$

$11 / 02 / 89$

$\begin{array}{ll}\text { BH022 } & 16 \mathrm{E}-\mathrm{B} \\ \text { BH012 } & 16 \mathrm{~F} \\ \text { BH010 } & 17 \mathrm{~B} \\ \text { BH009 } & 17 \mathrm{D} \\ \text { BH009 } & 17 \mathrm{~F} \\ \text { BHO07 } & 17 \mathrm{H} \\ \text { BH004 } & 18 \mathrm{E}-\mathrm{B} \\ \text { BH002 } & 18 \mathrm{G}-\mathrm{B} \\ \text { BH006 } & 19 \mathrm{~B} \\ \text { BH005 } & 19 \mathrm{D} \\ \text { BH003 } & 19 \mathrm{~F} \\ \text { BH001 } & 19 \mathrm{H} \\ \text { BH011 } & 20 \mathrm{D}\end{array}$

6.8

4.9

0.81

4.9

6.2

8.4

2.7

16

1.5

6.8

4.6

0.76

0.54

1.5
0.41
0.65
0.3
1.9
5.1
1.2
7.6
0.32
1.3
5.4
0.51
0.11

0.73

0.41

1.2

0.35

2.2

11

0.41

0.68

1.5

1.5

0.73

0.046

\section{Uranium-238}

$\begin{array}{llccc}\text { BH070 } & \text { OOD } & 78 & 210 & 190 \\ \text { BH068 } & \text { OOF } & 210 & 170 & 100 \\ \text { BH069 } & \text { O0F-B } & 300 & 120 & 160 \\ \text { BH073 } & \text { 01B } & 1.5 & 0.59 & 0.81 \\ \text { BH078 } & \text { 01D } & 17 & - & - \\ \text { BH067 } & \text { 01F } & 15 & 0.81 & - \\ \text { BH064 } & \text { 01F-B } & 110 & 27 & 3 \\ \text { BH066 } & \text { 01H } & 6.5 & 2.2 & - \\ \text { BH077 } & \text { 02E } & 35 & 2.3 & - \\ \text { BH063 } & \text { 02G } & 22 & 3.2 & 300 \\ \text { BH065 } & \text { 03A } & 7.6 & 4.3 & 6.2 \\ \text { BH061 } & \text { 03B } & 1.4 & 0.59 & 0.49 \\ \text { BH060 } & \text { 03C } & 2.2 & 0.68 & 0.51 \\ \text { BH075 } & \text { 03D } & 1.6 & - & - \\ \text { BH062 } & \text { 03D-B } & 130 & 1.9 & 3.2 \\ \text { BH059 } & \text { 03E } & 43 & 92 & 15 \\ \text { BH057 } & \text { 03F } & 16 & 8.9 & 3.5 \\ \text { BH056 } & \text { 03F-B } & 410 & 76 & 5.7 \\ \text { BH058 } & \text { 03H } & 19 & 3.5 & - \\ \text { BH072 } & \text { 05A } & 59 & 27 & 18 \\ \text { BH076 } & \text { 05B } & 4.9 & 1.1 & 0.95 \\ \text { BH055 } & \text { 05D } & 12 & 1 & 0.84 \\ \text { BH049 } & \text { 05F } & 17 & 23 & 5.7 \\ \text { BH048 } & \text { 05G } & 7.6 & - & - \\ \text { BH053 } & \text { 06B } & 15 & 6.2 & 3.5 \\ \text { BH050 } & \text { 06F } & 41 & 32 & 18 \\ \text { BH051 } & \text { 06F-B } & 190 & 43 & 3.2\end{array}$


Table B.2. K-1407-C Retention Bosin sediment sample analysisradionuclide analysis (continued)

\begin{tabular}{|c|c|c|c|c|c|}
\hline Date & Hole & Location & $\underset{(\mathrm{pCi} / \mathrm{g})}{\text { 6-in. }}$ & $\begin{array}{l}\text { 12-in. } \\
(\mathrm{pCi} / \mathrm{g})\end{array}$ & $\begin{array}{l}\text { 18-in. } \\
(\mathrm{pCi} / \mathrm{g})\end{array}$ \\
\hline
\end{tabular}

\section{Uranium-238 (continued)}

\begin{tabular}{|c|c|c|c|c|c|}
\hline $10 / 30 / 89$ & BHO43 & 07B & 120 & 89 & 150 \\
\hline $10 / 30 / 89$ & BH044 & 07B-B & 380 & 240 & 20 \\
\hline $10 / 30 / 89$ & BH045 & 07D & 140 & 210 & 220 \\
\hline 11/03/89 & BH052 & 07D-B & 92 & 4.9 & 1.6 \\
\hline 11/03/89 & BH054 & 07D-B & 520 & 230 & 51 \\
\hline 10/30/89 & BH046 & $07 \mathrm{~F}$ & 350 & 43 & 17 \\
\hline $10 / 12 / 89$ & BH021 & 07F-B & 490 & 430 & 430 \\
\hline 10/30/89 & BH047 & 07F-B & 1600 & 150 & - \\
\hline $11 / 20 / 89$ & BH071 & 07F-B & 950 & - & - \\
\hline $10 / 25 / 89$ & BH038 & 09B & 350 & 130 & 16 \\
\hline $10 / 18 / 89$ & BH033 & 09B-B & 730 & 16 & 2.5 \\
\hline $10 / 25 / 89$ & BH039 & $09 \mathrm{C}$ & 43 & 5.7 & 4.9 \\
\hline $10 / 25 / 89$ & BH040 & O9D & 41 & 7.6 & 1.1 \\
\hline $10 / 25 / 89$ & BH041 & 09E & 65 & 7.3 & 1.6 \\
\hline $10 / 30 / 89$ & BH042 & $09 \mathrm{~F}$ & 27 & 13 & 12 \\
\hline $10 / 24 / 89$ & BH037 & O9F-B & 150 & 51 & 21 \\
\hline $10 / 16 / 89$ & BH027 & $11 \mathrm{~A}$ & 21 & 35 & 21 \\
\hline $10 / 16 / 89$ & BH026 & $11 \mathrm{~B}$ & 73 & 8.4 & 13 \\
\hline $10 / 16 / 89$ & BH025 & 11D & 12 & 1.5 & 0.95 \\
\hline $10 / 18 / 89$ & BH030 & $11 \mathrm{~F}$ & 1.9 & 43 & 7 \\
\hline $10 / 18 / 89$ & BH031 & $11 \mathrm{~F}-\mathrm{B}$ & 100 & 21 & 3.5 \\
\hline $10 / 24 / 89$ & BH036 & 11F-B & 97 & 76 & 4.9 \\
\hline $10 / 18 / 89$ & BH032 & $11 \mathrm{H}$ & 210 & 100 & 84 \\
\hline $10 / 23 / 89$ & BH035 & $11 \mathrm{H}-\mathrm{B}$ & 590 & 650 & 130 \\
\hline $10 / 16 / 89$ & BH028 & $12 B$ & 15 & 0.81 & 0.84 \\
\hline $01 / 03 / 90$ & BH074 & $12 \mathrm{~F}$ & 0.81 & 0.54 & 0.76 \\
\hline $10 / 13 / 89$ & BH024 & 13B & 1.6 & 3.8 & 1.6 \\
\hline $10 / 13 / 89$ & BH023 & $13 C$ & 14 & 16 & 0.86 \\
\hline $10 / 18 / 89$ & BH029 & 13D & 23 & 0.11 & 0.78 \\
\hline $01 / 11 / 90$ & BH079 & $13 E$ & - & - & 22 \\
\hline $01 / 11 / 90$ & BHOSO & $13 F$ & - & - & 20 \\
\hline $10 / 12 / 89$ & BH020 & 15B & 3 & 3.2 & 3.5 \\
\hline $10 / 10 / 89$ & BH013 & 15D & 110 & 2.3 & 1.7 \\
\hline $10 / 11 / 89$ & BH017 & 15D-B & 6.2 & 1.1 & 0.62 \\
\hline $10 / 10 / 89$ & BH014 & $15 \mathrm{~F}$ & 59 & 24 & 14 \\
\hline $10 / 10 / 89$ & BH015 & $15 F-B$ & 300 & 32 & 11 \\
\hline $10 / 11 / 89$ & BH018 & $15 \mathrm{~F}-\mathrm{B}$ & 230 & 68 & 41 \\
\hline $10 / 23 / 89$ & BH034 & $15 \mathrm{~F}-\mathrm{B}$ & 54 & 22 & 24 \\
\hline $10 / 10 / 39$ & BH016 & $15 \mathrm{H}$ & 110 & 95 & 25 \\
\hline $10 / 12 / 89$ & BH019 & $16 B$ & 5.4 & 4.6 & 3.8 \\
\hline $10 / 13 / 89$ & BH022 & $16 E-B$ & 78 & 14 & 21 \\
\hline $10 / 09 / 89$ & BH012 & $16 \mathrm{~F}$ & 59 & 7.8 & 5.1 \\
\hline $10 / 04 / 89$ & BH010 & 17B & 5.9 & 4.6 & 5.4 \\
\hline
\end{tabular}


Table B.2. K-1407-C Retention Bosin sediment sample analysisradionuclide analysis (continued)

\begin{tabular}{|c|c|c|c|c|c|}
\hline Date & Hole & Location & $\begin{array}{c}\text { 6-in. } \\
(\mathrm{pCi} / \mathrm{g})\end{array}$ & $\begin{array}{l}12 \text {-in. } \\
(\mathrm{pCi} / \mathrm{g})\end{array}$ & $\begin{array}{c}\text { 18-in. } \\
(\mathrm{pCi} / \mathrm{g})\end{array}$ \\
\hline \multicolumn{6}{|c|}{ Uranium-238 (continued) } \\
\hline $10 / 04 / 89$ & BH0O9 & 17D & 54 & 1.8 & 1.8 \\
\hline $10 / 03 / 89$ & BH008 & $17 \mathrm{~F}$ & 59 & 25 & 23 \\
\hline $10,03 / 89$ & BH007 & $17 \mathrm{H}$ & 130 & 68 & 140 \\
\hline $10 / 03 / 89$ & BH004 & $18 \mathrm{E} \cdot \mathrm{B}$ & 38 & 10 & 2.7 \\
\hline $09 / 28,99$ & BHOO2 & 18G-B & 150 & 73 & 5.1 \\
\hline $10 / 03 / 89$ & BH006 & $19 \mathrm{~B}$ & 9.2 & 3.2 & - \\
\hline $10 / 03 / 89$ & BH005 & 19D & 62 & 11 & 8.6 \\
\hline $10 / 02 / 89$ & BH003 & $19 \mathrm{~F}$ & 54 & 49 & 9.7 \\
\hline $09 / 27 / 89$ & BH001 & $19 \mathrm{H}$ & 3 & 3 & 2 \\
\hline $10 / 09 / 89$ & BH011 & 20D & 4.9 & 3.2 & 0.57 \\
\hline
\end{tabular}


Table B.3. K-1407-C Retention Basin sediment sample analysisfield blants and equipment rinsates

\begin{tabular}{|c|c|c|c|c|}
\hline Date & Hole & Location & $\begin{array}{c}\text { Blank } \\
(\mathrm{pCi} / \mathrm{L})\end{array}$ & $\begin{array}{l}\text { Rinsate } \\
(\mathrm{pCi} / L)\end{array}$ \\
\hline
\end{tabular}

\begin{tabular}{|c|c|c|c|c|}
\hline \multicolumn{5}{|c|}{ Americium-241 } \\
\hline $10 / 12 / 89$ & BH021 & 07F-B & 0.19 & 0.16 \\
\hline $10 / 13 / 89$ & BH024 & 13B & -0.09 & 0.014 \\
\hline $10 / 11 / 89$ & BH018 & $15 \mathrm{~F}-\mathrm{B}$ & -0.04 & -0.07 \\
\hline $10 / 04 / 89$ & BH010 & 17B & - & 0.51 \\
\hline $10 / 03 / 89$ & BH008 & $17 \mathrm{~F}$ & - & 0.081 \\
\hline \multicolumn{5}{|c|}{ Cesium-137 } \\
\hline $11 / 21 / 89$ & BH073 & $01 B$ & -6 & 1.1 \\
\hline $01 / 10 / 90$ & BH078 & 01D & -0.001 & 0.00027 \\
\hline $11 / 16 / 89$ & BH067 & $01 \mathrm{~F}$ & 1.4 & 0.54 \\
\hline $11 / 15 / 89$ & BH064 & 01F-B & 2.7 & 1.9 \\
\hline $11 / 13 / 89$ & BH062 & 03D-B & 2.2 & 0.81 \\
\hline $11 / 09 / 89$ & BH059 & 03E & 0.81 & 5.7 \\
\hline $11 / 20 / 89$ & BH072 & $05 \mathrm{~A}$ & -1 & 0.27 \\
\hline $11 / 03 / 89$ & BH055 & 05D & 0.00054 & 0.00081 \\
\hline $11 / 01 / 89$ & BH049 & $05 F$ & -0.0005 & 0.00027 \\
\hline $10 / 12 / 89$ & BH021 & 07F-B & -0.0005 & 0.003 \\
\hline $10 / 30 / 89$ & BH047 & 07F-B & -0.002 & -0.0008 \\
\hline $10 / 25 / 89$ & BH041 & $09 \mathrm{E}$ & 0.81 & 4 \\
\hline $10 / 24 / 89$ & BH037 & 09F-B & 4.6 & -4 \\
\hline $10 / 18 / 89$ & BH030 & $11 \mathrm{~F}$ & -5 & 2.4 \\
\hline $10 / 23 / 89$ & BH035 & $11 \mathrm{H}-\mathrm{B}$ & -2 & -5 \\
\hline $10 / 16 / 89$ & BH028 & $12 \mathrm{~B}$ & 0.27 & 1.1 \\
\hline $10 / 13 / 89$ & BH024 & $13 B$ & -0.0008 & 0.0022 \\
\hline $01 / 11 / 90$ & BH080 & $13 \mathrm{~F}$ & 0.00054 & -0.001 \\
\hline $10 / 11 / 89$ & BH018 & $15 F-B$ & -0.0003 & 3.8 \\
\hline $10 / 04 / 89$ & BH010 & 17B & - & 2.4 \\
\hline $10 / 03 / 89$ & BH008 & $17 \mathrm{~F}$ & - & 1.4 \\
\hline
\end{tabular}

\section{Cobalt -60}

$11 / 21 / 89$

$01 / 10 / 90$

$11 / 16 / 89$

$11 / 15 / 89$

$11 / 13 / 89$

$11 / 09 / 89$

$11 / 20 / 89$

$11 / 03 / 89$

$11 / 01 / 89$

$10 / 12 / 89$

$10 / 30 / 89$

$10 / 25 / 89$
BH073

BH078

BH067

BH064

BH062

BH059

BH072

BH055

BH04a

BHO21

BH047

BH041

01B
$01 D$
$01 F$
$01 F-B$
$03 D-B$
$03 E$
$05 A$
$05 D$
$05 F$
$07 F-B$
$07 F-B$
$09 E$

$-3$

2.7

0.0046

4.3

0.0046

0.54

0.54

0.81

0.81

$-9$

$-0.0005$

$-0.001$

$-0.0008$

$-0.004$

$-0.3$

9.7

0.81

3

5.4

$-0.0003$

0.0046

$-0.002$

0.0032

1.4 
Table B.3. K-1407-C Retention Bosin sediment sample analysisfield blanks and equipment rinsates (continued)

\begin{tabular}{|c|c|c|c|c|}
\hline Date & Hole & Location & $\begin{array}{c}\text { Blank } \\
(\mathrm{pCi} / \mathrm{L})\end{array}$ & $\begin{array}{l}\text { Rinsate } \\
(\mathrm{pCi} / \mathrm{L})\end{array}$ \\
\hline \multicolumn{5}{|c|}{ Cobalt-60 (continued) } \\
\hline $10 / 24 / 89$ & BH037 & 09F-B & -4 & 4.3 \\
\hline $10 / 18 / 89$ & BH030 & $11 \mathrm{~F}$ & 4 & 3.8 \\
\hline $10 / 23 / 89$ & BH035 & $11 \mathrm{H}-\mathrm{B}$ & .7 & 1.4 \\
\hline $10 / 16 / 89$ & BH028 & $12 B$ & 6.5 & 6.2 \\
\hline $10 / 13 / 89$ & BH024 & 13B & 0.0014 & -0.007 \\
\hline $01 / 11 / 90$ & BH080 & $13 \mathrm{~F}$ & 0.0049 & 0.0038 \\
\hline $10 / 11 / 89$ & BH018 & $15 \mathrm{~F}-\mathrm{B}$ & 0.00054 & -3 \\
\hline $10 / 04 / 89$ & BH010 & $17 \mathrm{~B}$ & - & 0.54 \\
\hline $10 / 03 / 89$ & BH008 & $17 \mathrm{~F}$ & - & -3 \\
\hline \multicolumn{5}{|c|}{ Curium-244 } \\
\hline $10 / 12 / 89$ & BH021 & 07F-B & -0.2 & -0.2 \\
\hline $10 / 13 / 89$ & BH024 & 13B & -0.2 & -0.3 \\
\hline $10 / 11 / 89$ & BH018 & $15 F-B$ & -0.2 & -0.2 \\
\hline $10 / 04 / 89$ & BH010 & $17 \mathrm{~B}$ & - & -0.1 \\
\hline $10 / 03 / 89$ & BH0O8 & $17 \mathrm{~F}$ & - & -0.2 \\
\hline \multicolumn{5}{|c|}{ Gross alphn } \\
\hline $11 / 21 / 89$ & BH073 & 01B & 0.54 & 11 \\
\hline $01 / 10 / 90$ & BH078 & $01 \mathrm{D}$ & 0.0015 & 0.0016 \\
\hline $11 / 16 / 89$ & BH067 & $01 \mathrm{~F}$ & -1 & -8 \\
\hline $11 / 15 / 89$ & BH064 & 01F-B & 4 & -2 \\
\hline $11 / 13 / 89$ & BH062 & 03D-B & -4 & -6 \\
\hline $11 / 09 / 89$ & BH059 & 03E & -3 & -6 \\
\hline $11 / 20 / 89$ & BH072 & $05 \mathrm{~A}$ & 6.5 & 0.54 \\
\hline $11 / 03 / 89$ & BH055 & 05D & -0.007 & 0.0065 \\
\hline $11 / 01 / 89$ & BH049 & $05 \mathrm{~F}$ & 0.0081 & 0.0046 \\
\hline $10 / 12 / 89$ & BH021 & 07F-B & 2.3 & 1.6 \\
\hline $10 / 30 / 89$ & BH047 & 07F-B & 0.0095 & 0.0057 \\
\hline $10 / 25 / 89$ & BH041 & $09 \mathrm{E}$ & 2.4 & 14 \\
\hline $10 / 24 / 89$ & BH037 & 09F-B & -1 & 0.81 \\
\hline $10 / 18 / 89$ & BH030 & $11 \mathrm{~F}$ & -3 & -4 \\
\hline $10 / 23 / 89$ & BH035 & $11 \mathrm{H}-\mathrm{B}$ & 4.9 & 0.81 \\
\hline $10 / 16 / 89$ & BH028 & $12 B$ & -3 & -20000 \\
\hline $10 / 13 / 89$ & BH024 & 13B & 0.89 & 0.95 \\
\hline $01 / 11 / 90$ & ВH080 & $13 \mathrm{~F}$ & 0.0027 & 0.001 \\
\hline $10 / 11 / 89$ & BH018 & $15 F-B$ & -0.4 & 2.2 \\
\hline $10 / 04 / 89$ & BH010 & $17 \mathrm{~B}$ & - & 1.6 \\
\hline $10 / 03 / 89$ & BH008 & $17 \mathrm{~F}$ & - & 0 \\
\hline
\end{tabular}


Table B.3. K-1407-C Retention Basin sediment sample analysisfield blanks and equipment rinsates (continued)

\begin{tabular}{|c|c|c|c|c|}
\hline Date & Hole & Location & $\begin{array}{c}\text { Blank } \\
(\mathrm{pCi} / \mathrm{L})\end{array}$ & $\begin{array}{l}\text { Rinsate } \\
(\mathrm{pCi} / \mathrm{L})\end{array}$ \\
\hline
\end{tabular}

\section{Gross beta}

$11 / 21 / 89$

$01 / 10 / 90$

$11 / 16 / 89$

$11 / 15 / 89$

$11 / 13 / 89$

$11 / 09 / 89$

$11 / 20 / 89$

$11 / 03 / 89$

$11 / 01 / 89$

$10 / 12 / 89$

$10 / 30 / 89$

$10 / 25 / 89$

$10 / 24 / 89$

$10 / 18 / 89$

$10 / 23 / 89$

$10 / 16 / 89$

$10 / 13 / 89$

$01 / 11 / 90$

$10 / 11 / 89$

$10 / 04 / 89$

$10 / 03 / 89$

$10 / 12 / 89$

$10 / 13 / 89$

$10 / 11 / 89$

$10 / 04 / 89$

$10 / 03 / 89$

$10 / 12 / 89$

$10 / 13 / 89$

$10 / 11 / 89$

10/04/89

10/03/89

$10 / 12 / 89$

$10 / 13 / 89$

$10 / 11 / 89$
BH073

BH078

BH067

BH064

BH062

BH059

BH072

BH055

BH049

BH021

BH047

BH041

BH037

BH030

BH035

BH028

BH024

BH080

BH018

BH010

BH008

BH021

BH024

BH018

BH010

BH008

BH021

BH024

BH018

BH010

BH008

BH021

BH024

BH018
01B

01D

01F

01F-B

03D-B

03E

05A

05D

05F

07F-B

07F-B

09E

09F-B

$11 \mathrm{~F}$

11H-B

$12 \mathrm{~B}$

13B

$13 \mathrm{~F}$

15F-B

17B

$17 \mathrm{~F}$

Neptunium-237

$07 F-B$
$13 B$
$15 F-B$
$17 B$
$17 F$

Plutonium-238

$07 F-B$
$13 B$
$15 F-B$
$17 B$
$17 F$

Plutonium-239$$
<2.7
$$

$<2.7$

$<2.7$

-

-

$\begin{array}{ll}-0.08 & 0.0027 \\ -0.05 & 0.019 \\ -0.06 & -0.1 \\ - & 0.081 \\ - & -0.05\end{array}$

8.1 0.0035 2.7

$-10$

11

43

$-3$

$-0.0005$

0.022

0.81

0.0081

$-30$

35

14

$-20$

$-20$

5.4

0.0089

3

2.4

17
$-0.1$

0.1

$-0.01$ 
Table B.3. K-1407-C Retention Basin sediment sample analysisfield blanks and equipment rinsates (continued)

\begin{tabular}{|c|c|c|c|c|}
\hline Date & Hole & Location & $\begin{array}{c}\text { Blank } \\
(\mathrm{pCi} / \mathrm{L})\end{array}$ & $\begin{array}{l}\text { Rinsate } \\
(\mathrm{pCi} / \mathrm{L})\end{array}$ \\
\hline \multicolumn{5}{|c|}{ Plutonium-239 (continued) } \\
\hline $10 / 04 / 89$ & BH010 & 17B & - & -0.09 \\
\hline $10 / 03 / 89$ & BH0O8 & $17 \mathrm{~F}$ & - & -0.3 \\
\hline \multicolumn{5}{|c|}{ Technetium-99 } \\
\hline $10 / 12 / 89$ & BH021 & O7F-B & 1.9 & -0.5 \\
\hline 10/13/89 & BH024 & 13B & 7 & 6.8 \\
\hline $10 / 11 / 89$ & BH018 & 15F-B & -2 & 30 \\
\hline $10 / 04 / 89$ & BH010 & $17 \mathrm{~B}$ & - & 0 \\
\hline $10 / 03 / 89$ & BH008 & $17 \mathrm{~F}$ & - & 10 \\
\hline \multicolumn{5}{|c|}{ Uranium-234 } \\
\hline $10 / 12 / 89$ & BH021 & 07F-B & 0.22 & 0.46 \\
\hline 10/13/89 & BH024 & $13 B$ & 0.62 & 0.25 \\
\hline $10 / 11 / 89$ & BH018 & 15F-B & 0.12 & 0.51 \\
\hline $10 / 04 / 89$ & BH010 & 17B & - & 1.5 \\
\hline $10 / 03 / 89$ & BH008 & $17 F$ & - & 0.62 \\
\hline \multicolumn{5}{|c|}{ Uranium-235 } \\
\hline $10 / 12 / 89$ & BH021 & 07F-B & 0.035 & 0.086 \\
\hline $10 / 13 / 89$ & BH024 & $13 B$ & 0.23 & 0.097 \\
\hline $10 / 11 / 89$ & BH018 & 15F-B & 0.12 & 0.16 \\
\hline $10 / 04 / 89$ & BH010 & 17B & - & 0.076 \\
\hline $10 / 03 / 89$ & BH008 & $17 \mathrm{~F}$ & - & 0.076 \\
\hline \multicolumn{5}{|c|}{ Uranium-238 } \\
\hline $10 / 12 / 89$ & BH021 & 07F-B & 0.14 & 0.11 \\
\hline $10 / 13 / 89$ & BH024 & $13 \mathrm{~B}$ & 0.32 & 0.11 \\
\hline $10 / 11 / 89$ & BH018 & 15F-B & 0.097 & 0.51 \\
\hline $10 / 04 / 89$ & BH010 & 17B & - & 1.7 \\
\hline $10 / 03 / 89$ & BH008 & $17 \mathrm{~F}$ & - & 0.25 \\
\hline
\end{tabular}


Appendix C

CALCULATIONS EMPLOYED IN THE STATISTICAL EVALUATION OF DATA 
The lognormal distribution has two parameters. The location parameter, $\mu_{N}$, controls where the center of the distribution is located. The shape parameter, $\sigma_{N}$, controls the overall shape of the distribution. For example, when $\sigma_{N}=0.25$, the shape resembles the normal distribution with only a slight positive skew. However, for a $\sigma_{N}=3$, the shape resembles a heavily skewed exponential distribution.

The concentration $X$ of an analyte is distributed lognormal if $Y=\log X$ is normally distributed with mean $\mu_{N}$ and variance $\sigma^{2}{ }_{N}$, where "log" is the natural logarithm $\left(\log _{e}\right)$. It is known that the mean $\mu_{L}$, variance $\sigma^{2}{ }_{L}$, and cumulative distribution function $F(x)$ of a lognormal distribution are given by

$$
\begin{gathered}
\mu_{L}=e^{\mu_{N}+\frac{\sigma_{N}^{2}}{2}}, \\
\sigma_{L}^{2}=\mu_{L}^{2}\left(e^{\sigma_{N}^{2}}-1\right), \\
F(x)=\Phi\left[\frac{\log (x)-\mu_{N}}{\sigma_{N}}\right],
\end{gathered}
$$

where $e \approx 2.718282$ and

$$
\Phi(u)=\int_{-\infty}^{u} \frac{1}{\sqrt{2 \pi}} e^{-\frac{t^{2}}{2}} d t
$$

$\Phi(u)$ is the cumulative standard normal distribution function with mean 0 and variance 1 . In practice, one uses tabled values found in any elementary statistics textbook when evaluating $\Phi(u)$.

In order to find the value $x$ such that $\operatorname{Pr}\{X \leq x\}=p$ for $0<p<1$, the inverse cumulative distribution function $\mathrm{F}^{-1}$ can be derived as follows.

$$
p=F(x)=\Phi\left[\frac{\log (x)-\mu_{N}}{\sigma_{N}}\right]
$$

implies that $x=F^{-1}(p)$, and therefore

$$
\Phi^{-1}(p)=\frac{\log (x)-\mu_{N}}{\sigma_{N}}
$$


and

$$
x=F^{-1}(p)=e^{\theta_{N} \theta^{-1}(p)+\mu_{N}}
$$

One approach to modeling the soils data using the lognormal distribution is to "pin down" the theoretical distribution to two percentiles of the sample data. A percentile $P_{x}$ of a distribution is that value for which $x \%$ of the data fall at or below $P_{x}$. For example, $P_{0.50}$ is the median of the distribution for which $50 \%$ of the data fall at or below $P_{0.50}$ and $50 \%$ are above it. If one desires the theoretical distribution to match the sample data at two specific percentiles $P_{a}$ and $P_{b}$, the following equations are derived for $a$ and $b$, where $a * b, 0<a<1$ and $0<b<1$ :

$$
F\left(P_{a}\right)=\Phi\left[\frac{\log \left(P_{a}\right)-\mu_{N}}{\sigma_{N}}\right]=a
$$

and

$$
F\left(P_{b}\right)=\Phi\left[\frac{\log \left(P_{b}\right)-\mu_{N}}{\sigma_{N}}\right]=b
$$

which implies that

$$
\frac{\log \left(P_{a}\right)-\mu_{N}}{\sigma_{W}}=z_{a}
$$

and

$$
\frac{\log \left(P_{b}\right)-\mu_{N}}{\sigma_{N}}=z_{b},
$$

where $z_{u}=\Phi^{-1}(u)$ is the standard normal critical value for witich $\operatorname{Pr}\left(Z \leq z_{u}\right)=u$.

Therefore, the two equations to solve for $\mu_{N}$ and $\sigma_{N}$ are

$$
\begin{aligned}
& \log \left(P_{a}\right)=\mu_{N}+z_{a} \sigma_{N} \\
& \log \left(P_{b}\right)=\mu_{N}+z_{b} \sigma_{N}
\end{aligned}
$$

The solution to this system of equations is then

$$
\mu_{N}=\frac{z_{b} \log \left(P_{a}\right)-z_{a} \log \left(P_{b}\right)}{z_{b}-z_{a}}
$$


and

$$
\sigma_{N}=\frac{\log \left(P_{b}\right)-\log \left(P_{a}\right)}{z_{b}-z_{a}}
$$

Hence, these equations ensure that the theoretical distribution will equal the sample detected results at the two chosen percentiles $P_{a}$ and $P_{b}$.

Before determining the parameters of the lognormal distribution which would best fit the detected soils data for each analyte, all negative results were set to zero. Practically, this was necessary since there are no negative concentrations of an analyte in the soil. Also from a mathematical perspective, one cannot take the logarithnis of negative or zero values. Hence, the percentiles chosen for the parameters of the distributions must have a positive concentration.

A Chi-square Goodness of Fit Test was utilized to determine how well a model fit the detected soils data. This test is widely used to test the adequacy of models and is found in many statistics textbooks. The test statistic $T$ compares the observed frequencies of results from the data to what is expected under the hypothesized theoretical distribution. The test statistic becomes large when the differences between observed frequencies and expected frequencies are large. A large test statistic leads one to conclude that the model does not adequately fit the data.

The number of disjoint intervals $k$ used to categorize the data were determined by the equation

$$
k=\sqrt{n}-1
$$

where $\boldsymbol{n}$ is the number of unbiased detected results for an analyte. A rule of thumb for the chi-square test is that the expected frequencies in each interval should be at least 5 . This equation for $k$ was found to best satisfy this criterion. The endpoints of each of the $k$ intervals used to categorize the data were derived so that each interval represented approximately an equal amount of area under the theoretical distribution. The right endpoint $R_{i}$ for each interval was calculated by

$$
R_{i}=F^{-1}\left(\frac{i}{k}\right)
$$

for $i=1,2, \ldots, k-1$ where $R_{k}=\infty$.

The test statistic $T$ was compared to a chi-square critical value $\chi_{k-3}^{2}$ with $k-3$ degrees of freedom (df) at the 0.05 significance level. If $k \leq 3$, the chi-square critical value $\chi_{1}^{2}$ with 1 degree of freedom, the 0.05 significance level was used. The formula for determining the degrees of freedom in a chi-square test is

$$
\mathrm{df}=k-1-\text { the number of estimated parameters. }
$$


Here the parameters $\mu_{N}$ and $\sigma_{N}$ are estimated from the data as the location and shape parameters, respectively, of the theoretical lognormal distribution. Hence, $k-1-2$ degrees of freedom were used for the chi-square test when $k>3$.

Several pairs of percentiles $P_{a}$ and $P_{b}$ were tried for modeling the soils data, using the chi-square test as the criterion. It became evident that the 25 th and 75 th percentiles provided the best fit to the metals and mercury data. The $p$ values associated with the test statistic were above the assumed 0.05 significance level for the test. However, for the radiochemical analytes, the 10th and 75 th percentiles were found to fit the data better. One reason for this may be that the radiochemical results were more highly skewed than the metals and mercury data. Hence, the parameters of the theoretical distritution needed to be chosen closer to the many low concentrations near the 10 th percentile.

However, the detected ${ }^{238} \mathrm{Pu}$ results posed a particular problem. The first nonzero percentile of these results was the 22nd percentile. Of the 99 detected results, 22 were negative or zero. No percentile parameters were found to adequately fit these data to a lognormal distribution. Other attempts using the coefficient of variation (standard deviation divided by the mean) were equally futile. However, the largest of the 12 nondetected values was $0.54 \mathrm{pCi} / \mathrm{g}$, which is far below the guideline value of $13.2 \mathrm{pCi} / \mathrm{g}$. Hence, since no model was found to adequately fit the ${ }^{238} \mathrm{Pu}$ detected results, the detection limit was used. The estimated mean is an overestimate by using the detection limits, but since the nondetected values are nearly zero, there is no appreciable loss in accuracy.

Another problem with modeling the detected metals data arose when antimony, selenium, and thorium were found to have at most one detected result. In order to glean some information about the distribution of these analytes, the nondetected results had to be used. Since the true concentration $X$ of an analyte could have any value $0 \leq X \leq D$, where $D$ is the detection limit, and many results were tied at a few detection limits, for the purpose of estimating the distribution, these detection limits were replaced by values spread equally from zero to the detection limit, depending on the number of results tied at a particular detection limit. The formula used for distributing values of a detection limit is

$$
x_{i}=D\left(\frac{j}{n_{i}+1}\right),
$$

where

$$
\begin{aligned}
n_{i} & =\text { number of results tied at detection limit } i \\
i & =1,2, \ldots, d \\
d & =\text { number of distinct detection limits for an analyte, } \\
j & =1,2, \ldots, n_{i}
\end{aligned}
$$

For example, if there is only one " $<5$ " nondetected result for an analyte, the replaced value $x_{i j}$ for estimating the distribution is 2.5 . If there are two " $<6$ " results, then the replaced values are 2 and 4 . Hence, using all unbiased results for antimony, selenium, and thorium, since there were an insufficient number of detected results to estimate the distribution of each, gave distributions resembling those of the other metals. Using the 25th and 75th 
percentiles on these three analytes as were utilized on the other metals gave an adequate fit from the lognormal distribution.

After adequately fitting all analytes except ${ }^{238} \mathrm{Pu}$ to a lognorinal distribution, the nondetected values could be estimated. These estimates will be used along with the detected results to provide an unbiased estimate of the mean concentration per analyte across the site and by depth. The general formula for estimating the concentration $x_{i j}$ fromi the detection limit $D$ is

$$
x_{y}=F^{-1}\left[F(D)\left(\frac{j}{n_{i}+1}\right)\right]
$$

or

$$
x_{i j}=e^{\sigma_{N} \Delta^{-1}\left\{\cdot\left[\frac{\log (D)-\mu_{N}}{\sigma_{N}}\right]\left(\frac{1}{N_{i}+1}\right)\right\}+\mu_{N}} .
$$

The idea of the above equation is first to find the area $A$ such that $A=\operatorname{Pr}\{X \leq D\}$ from the lognormal distribution fit to the detected values. This area is then partitioned into $n_{i}+1$ equal parts. Then the inverse function $\mathrm{F}^{-1}$ calculates the estimated concentration $x_{i j}$ from the area under the curve. 
Appendix D

\section{DIMENSIONAL CONCENTRATION PLOTS}




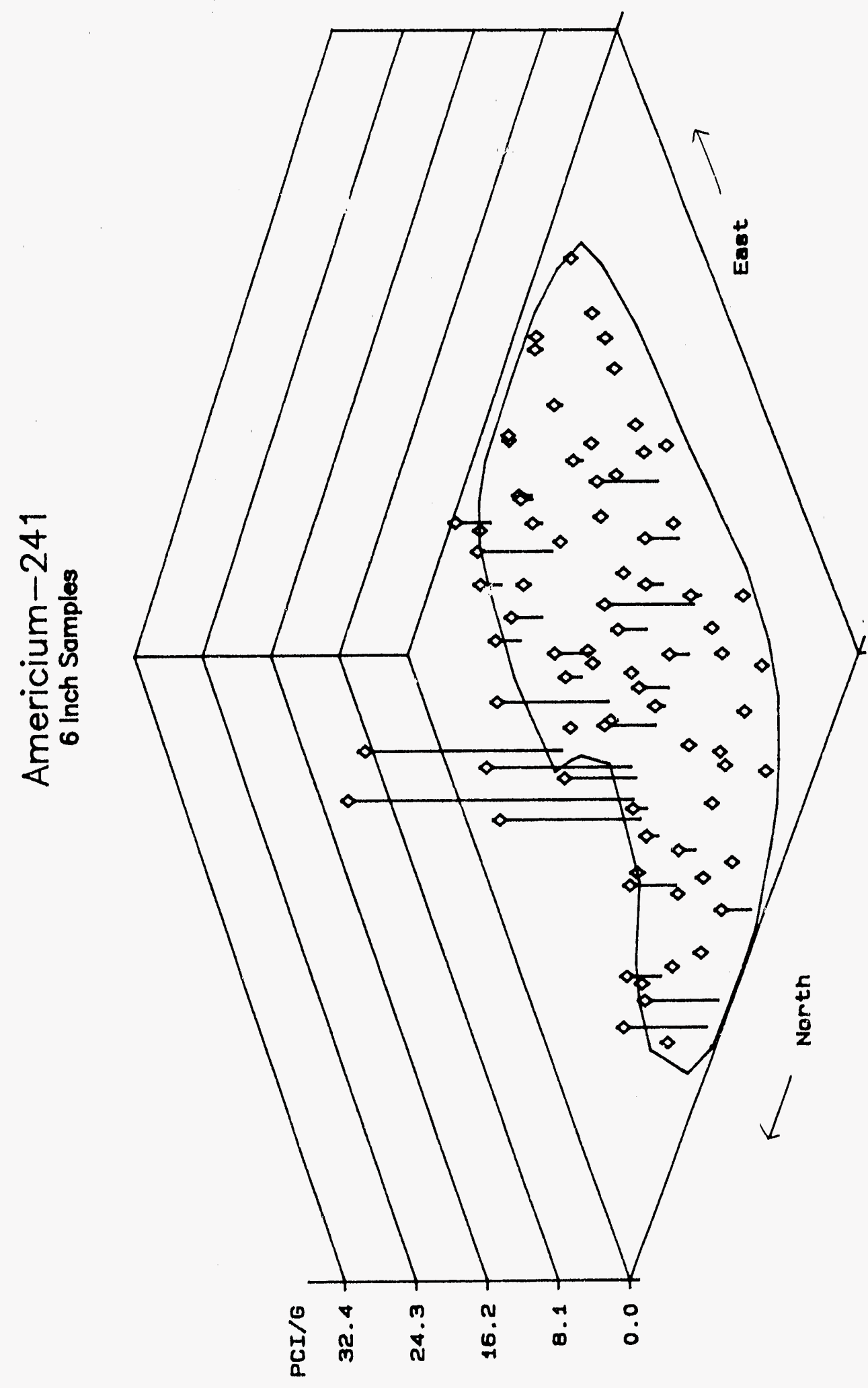

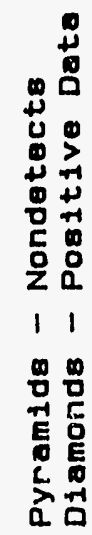




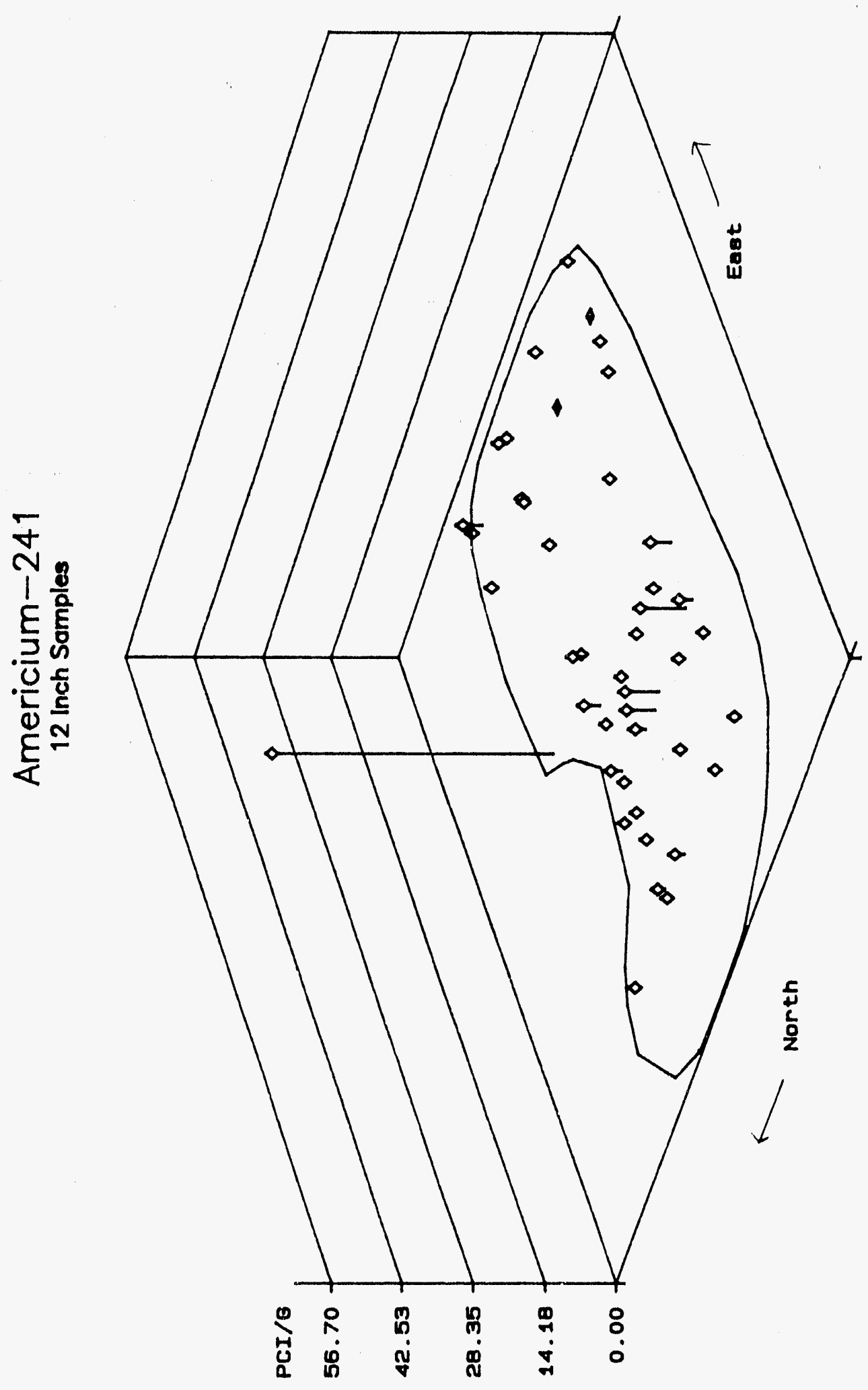

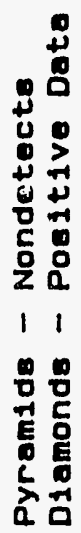




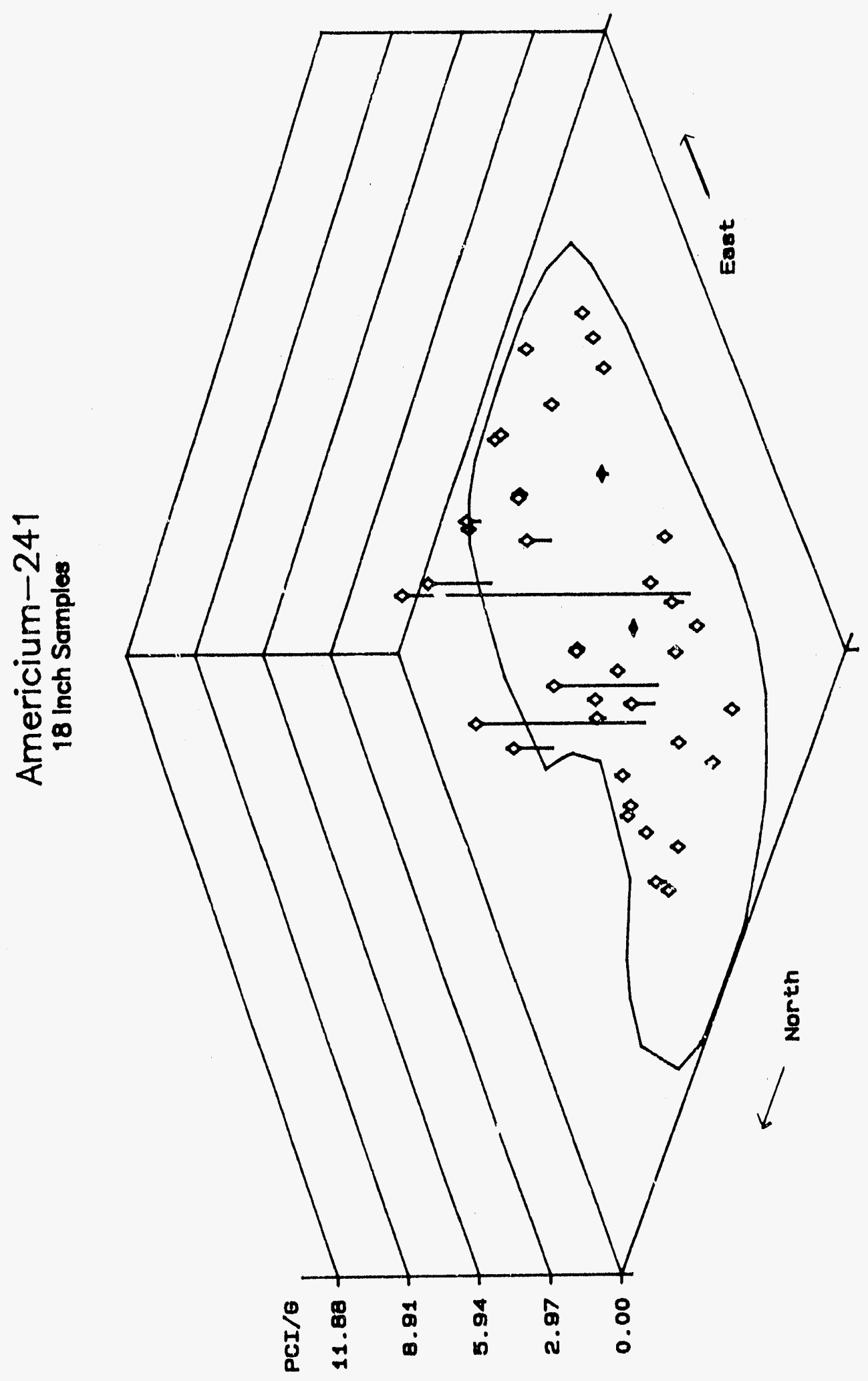

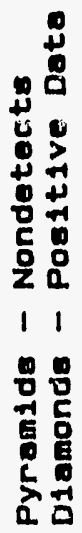




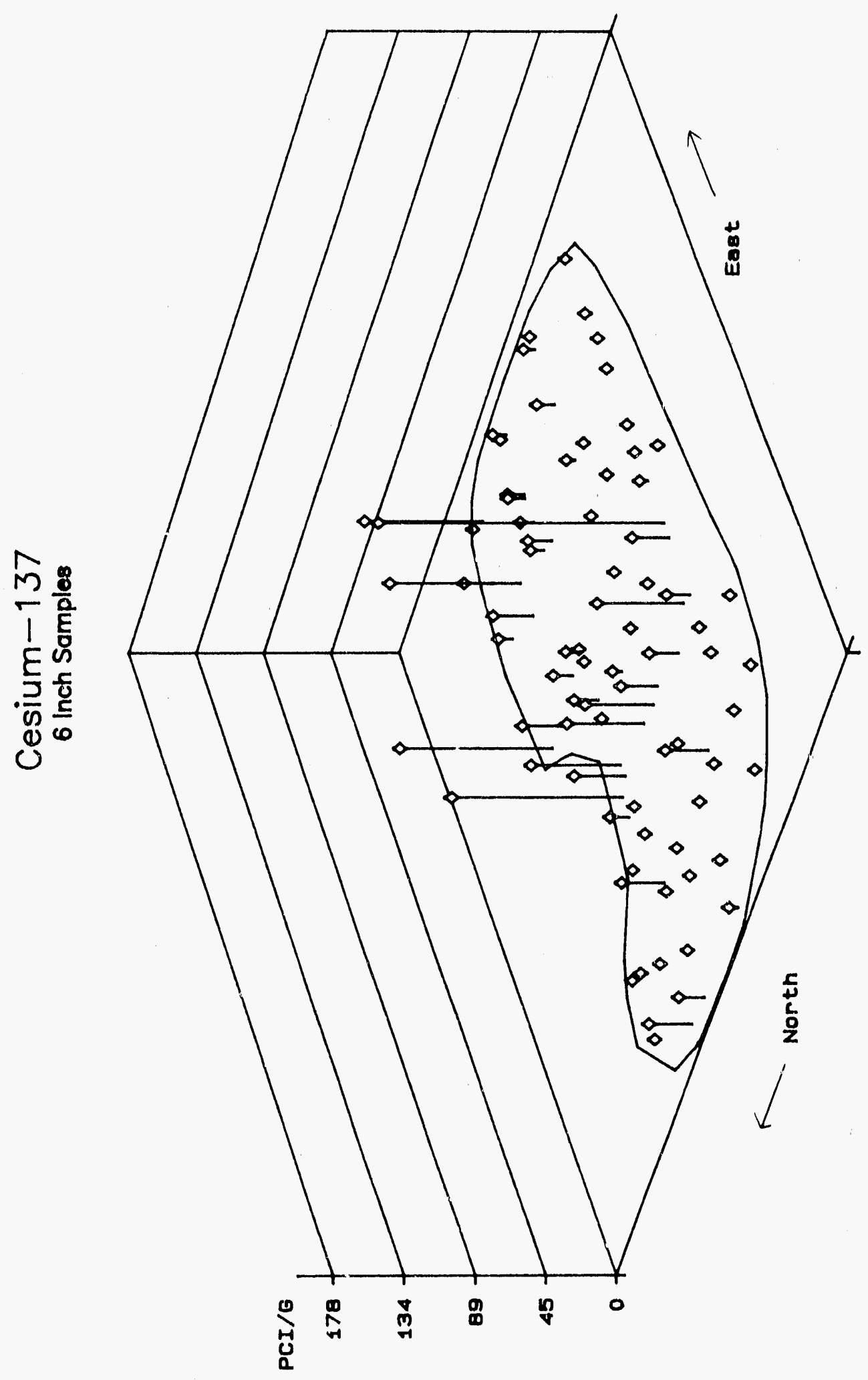

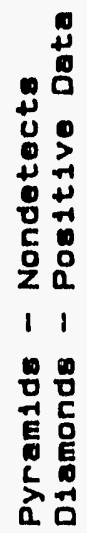




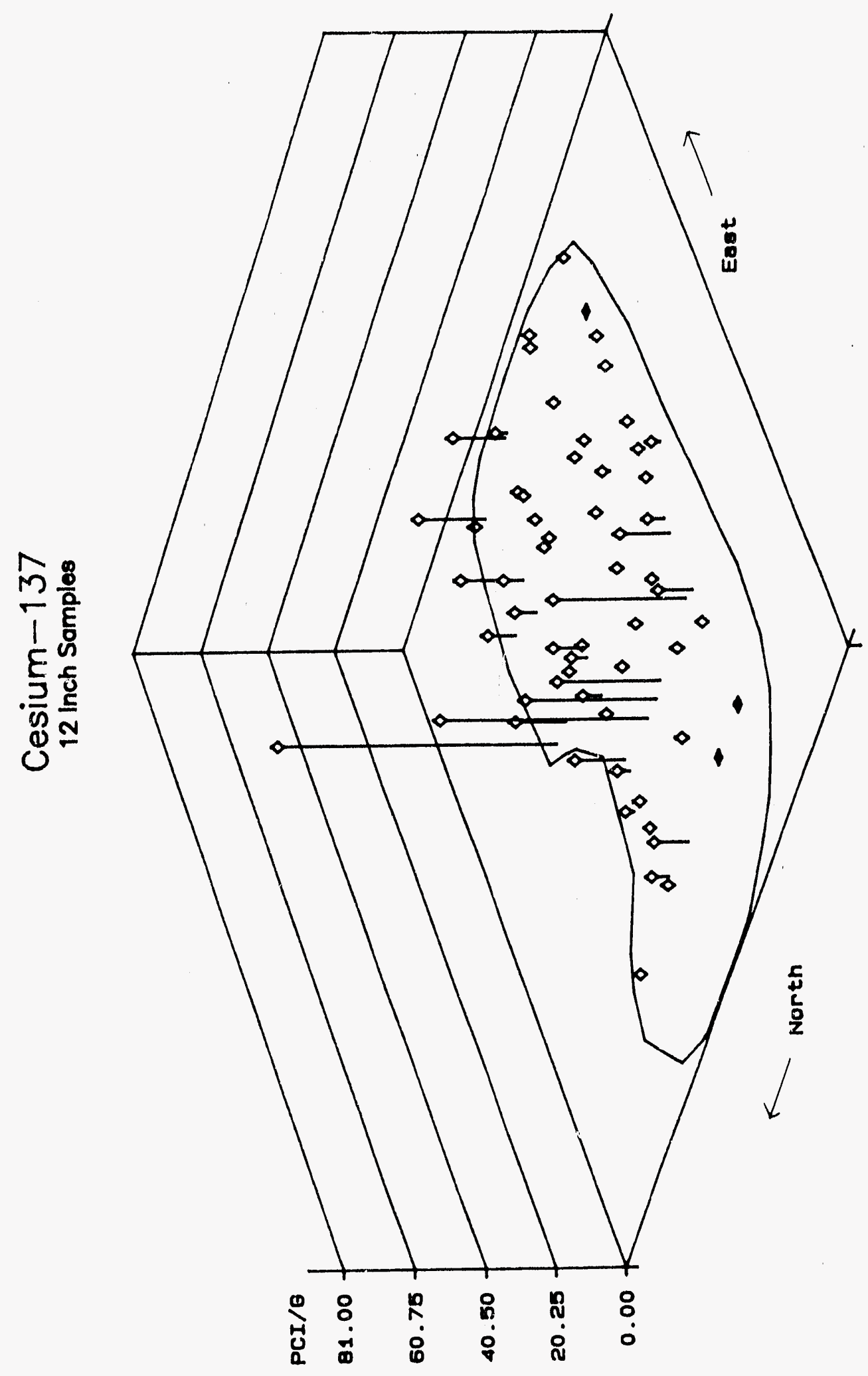

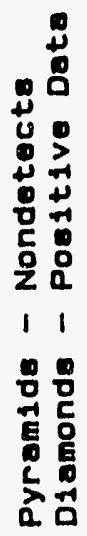




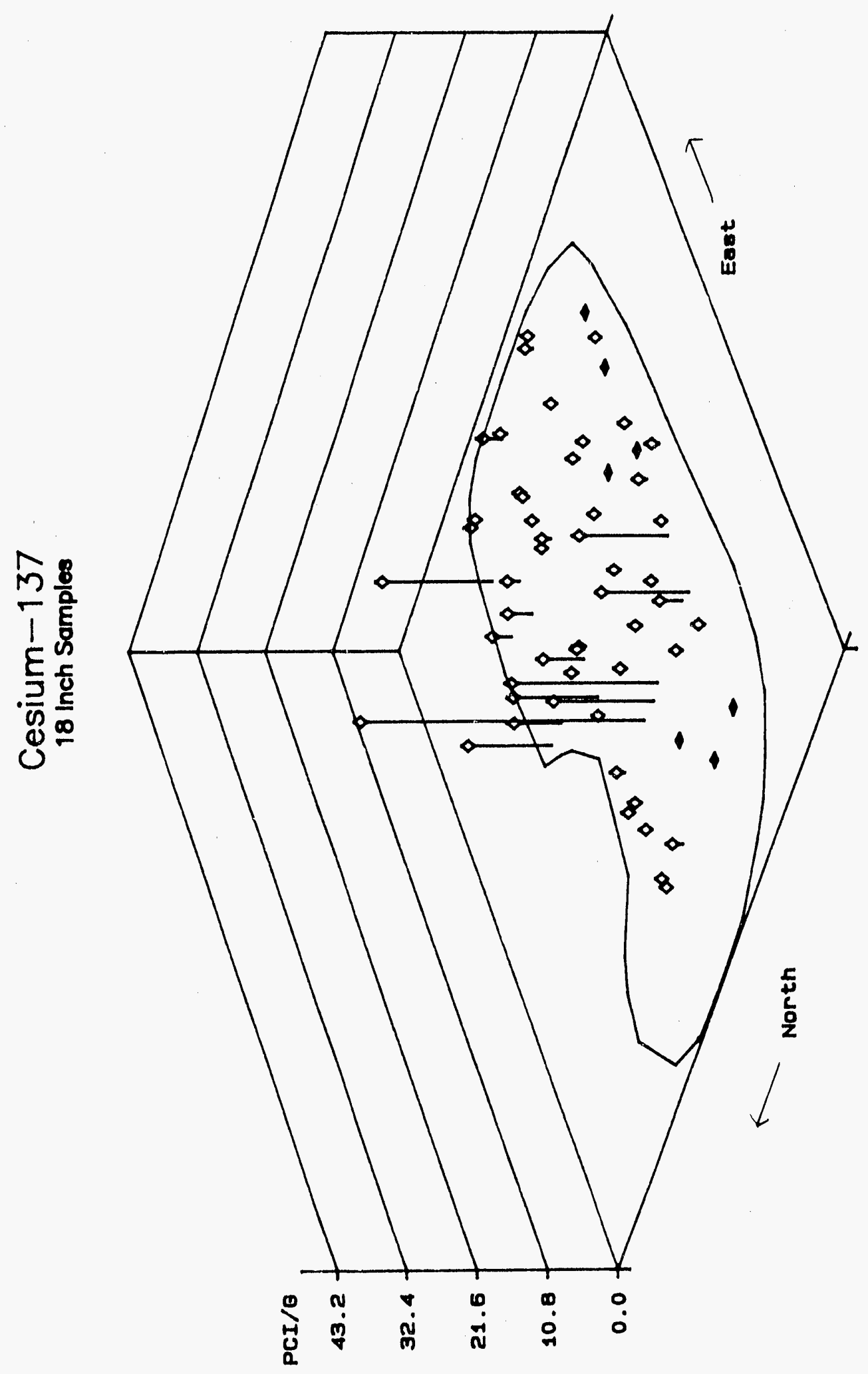

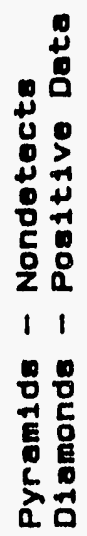




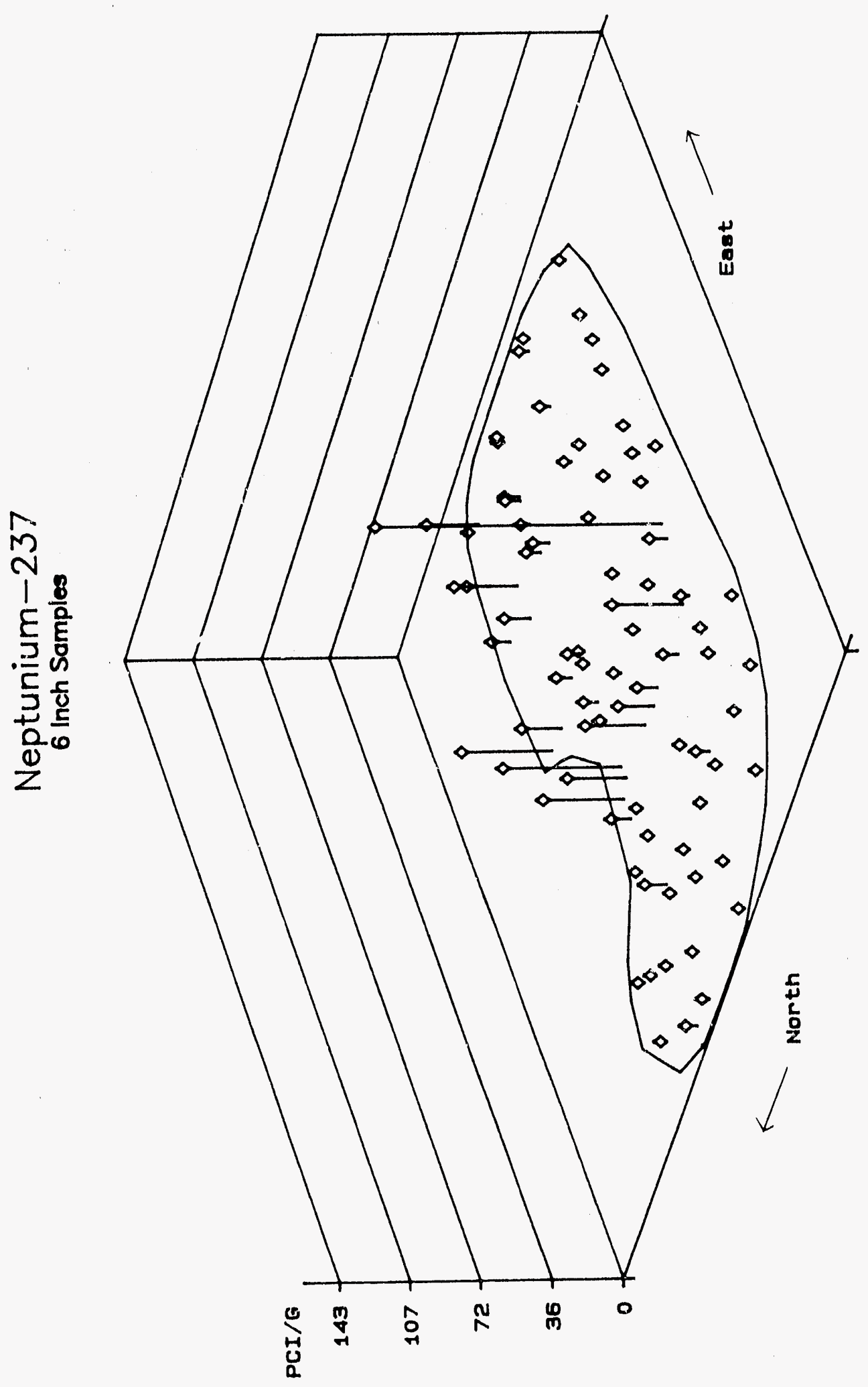

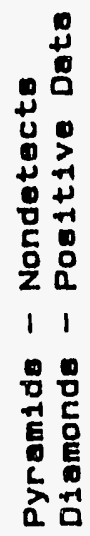




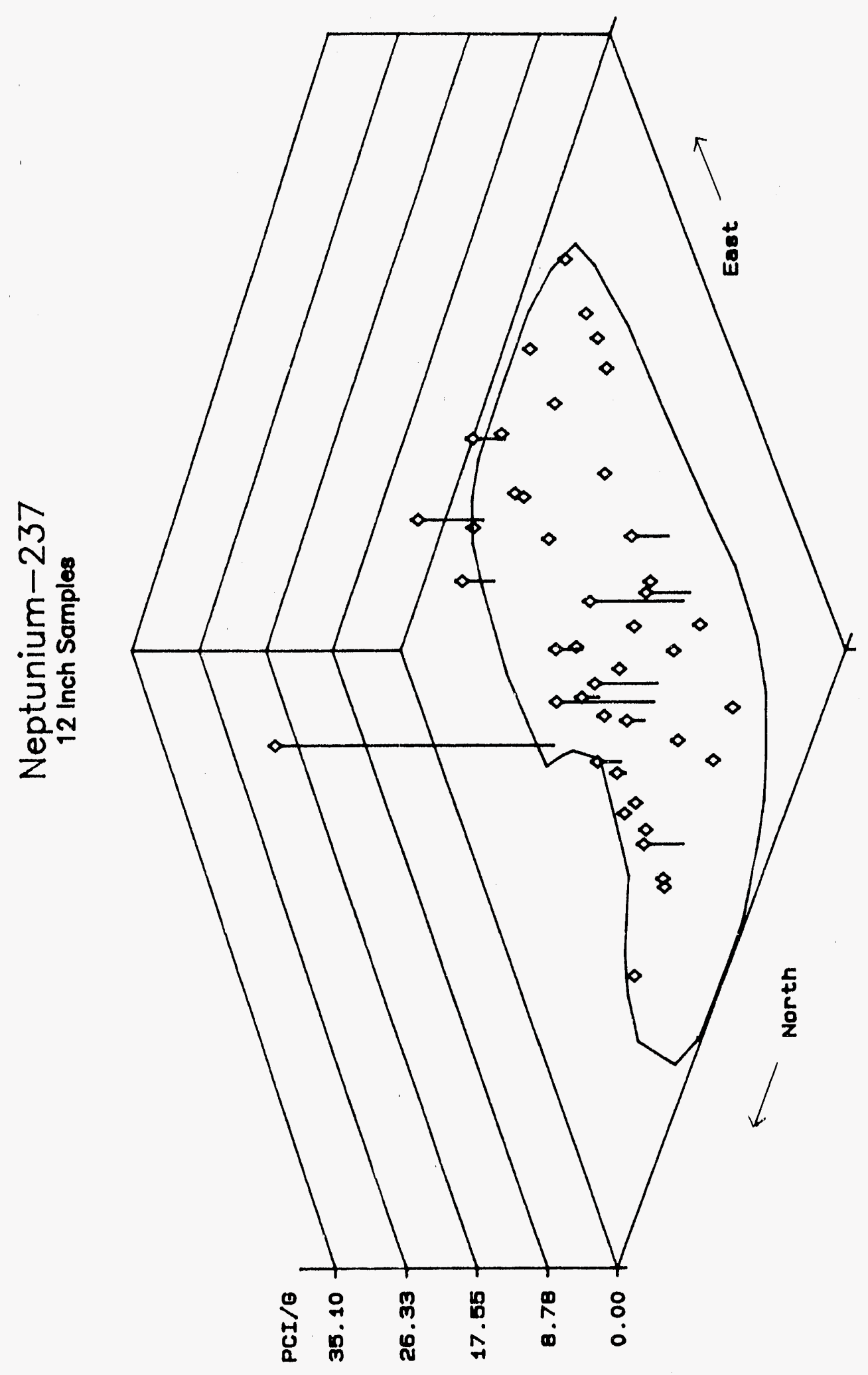

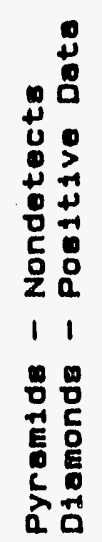




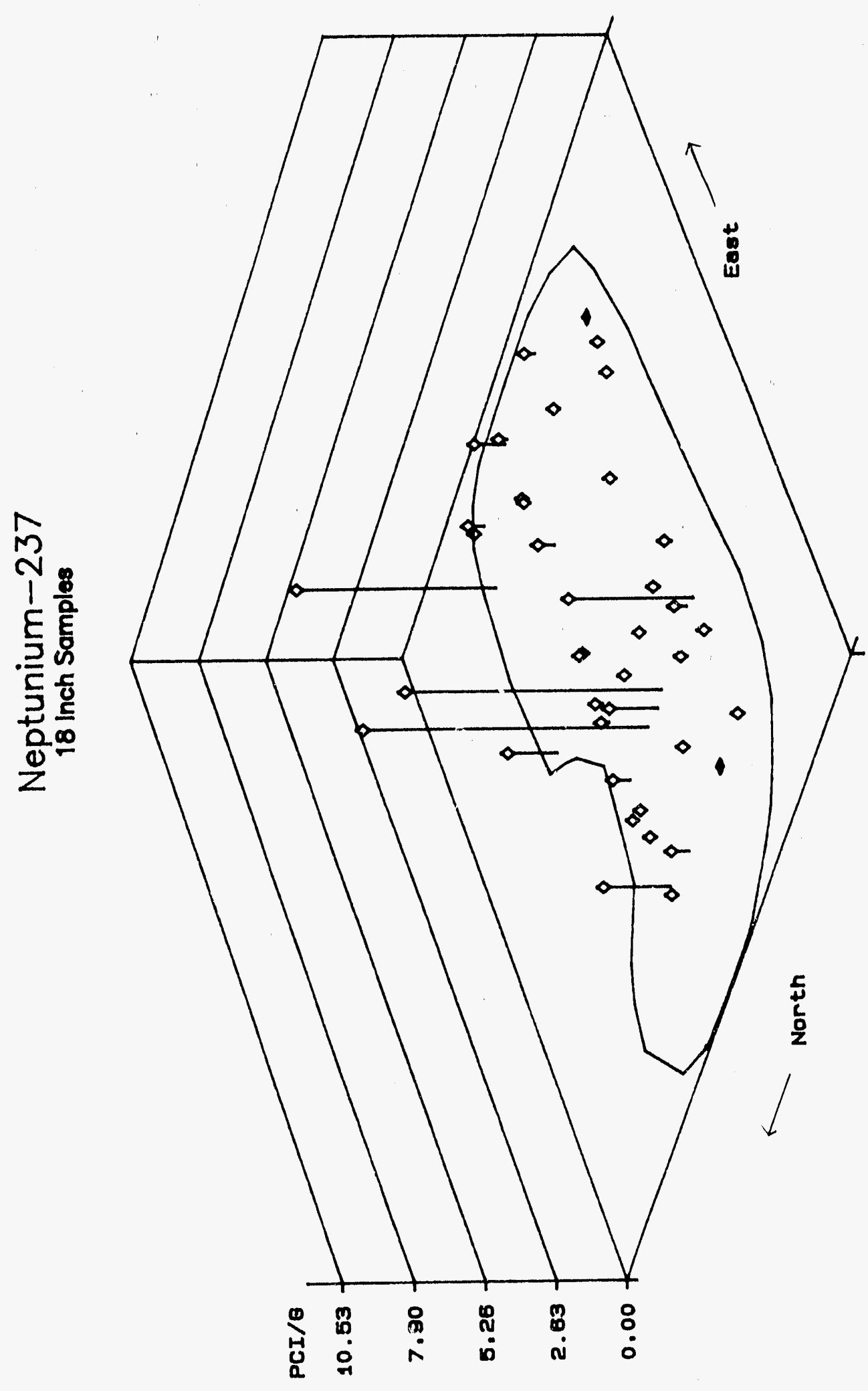

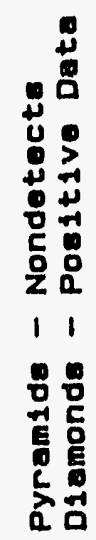




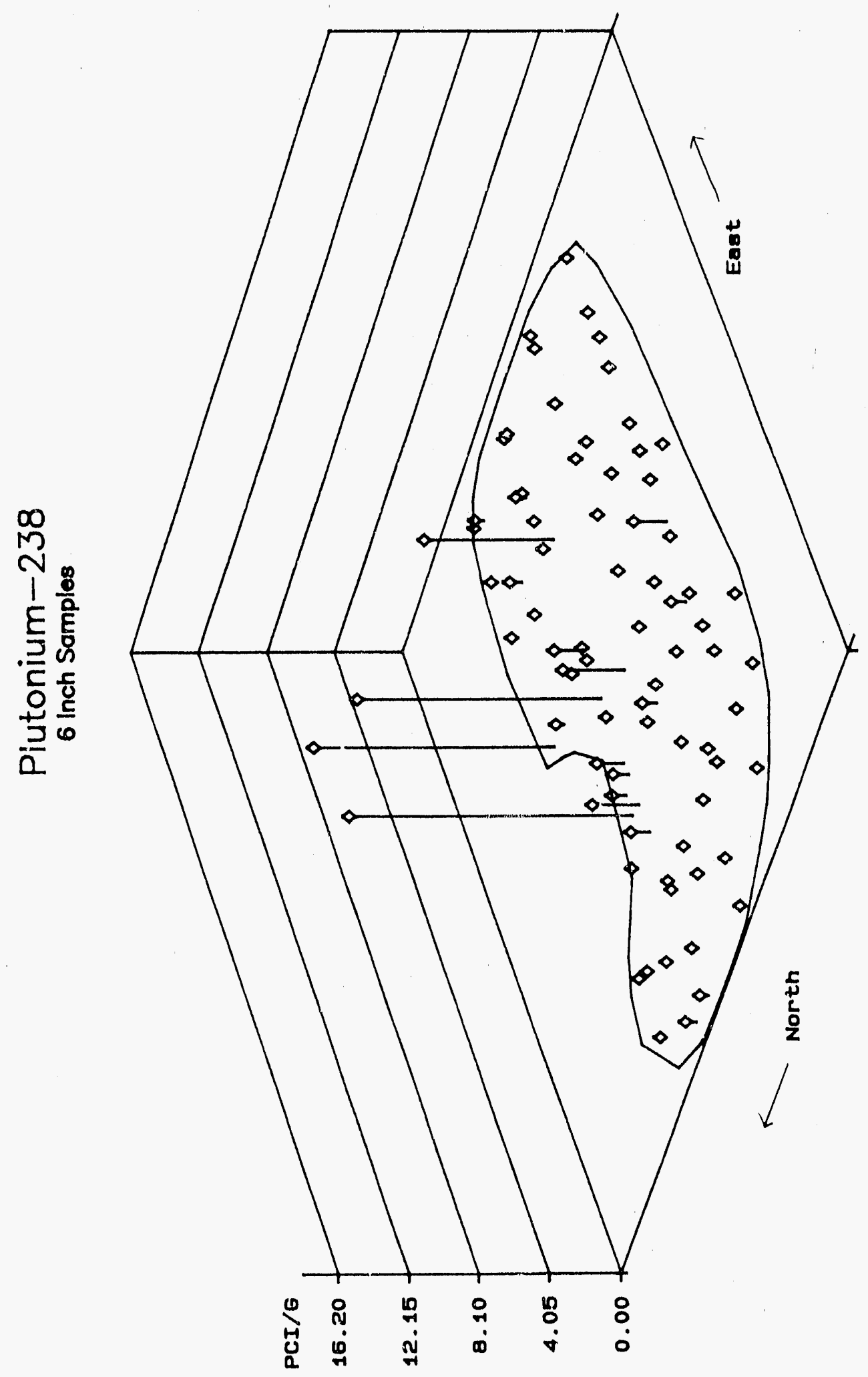

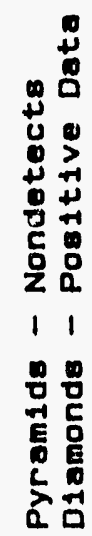




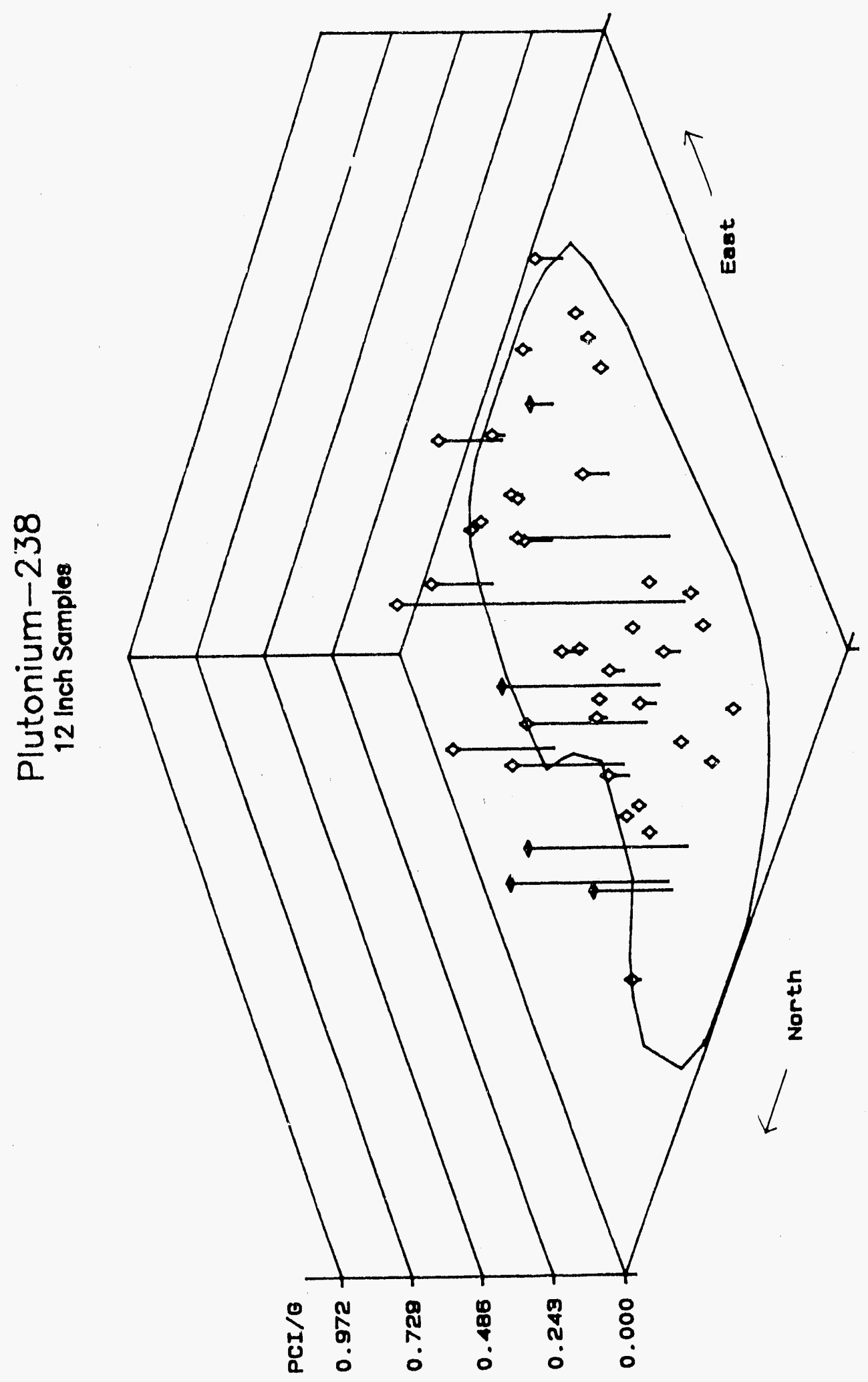

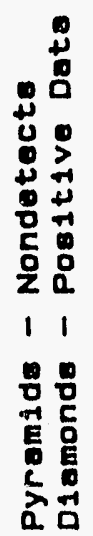




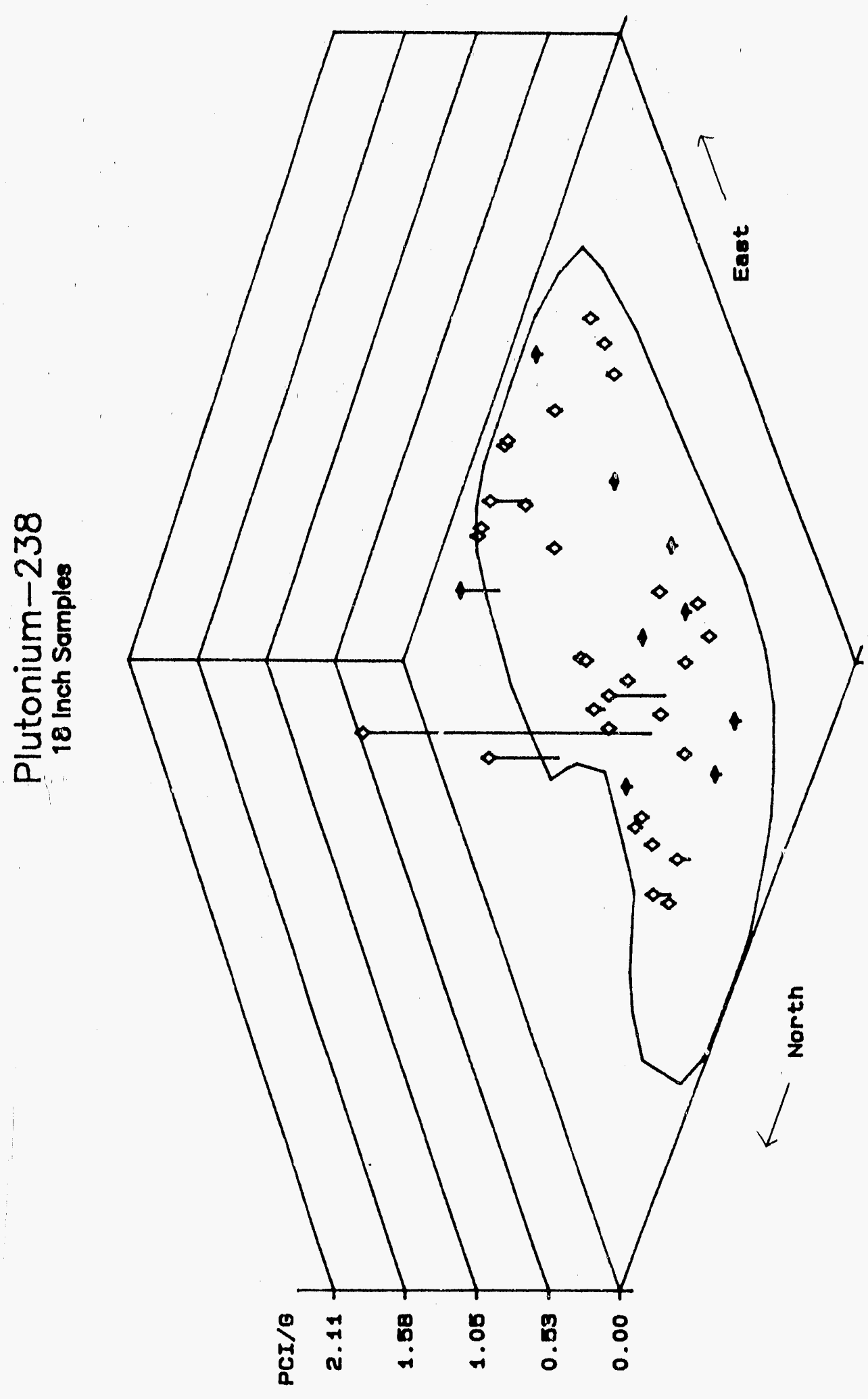

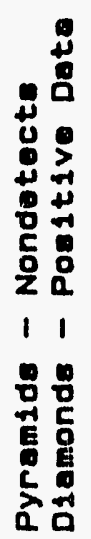




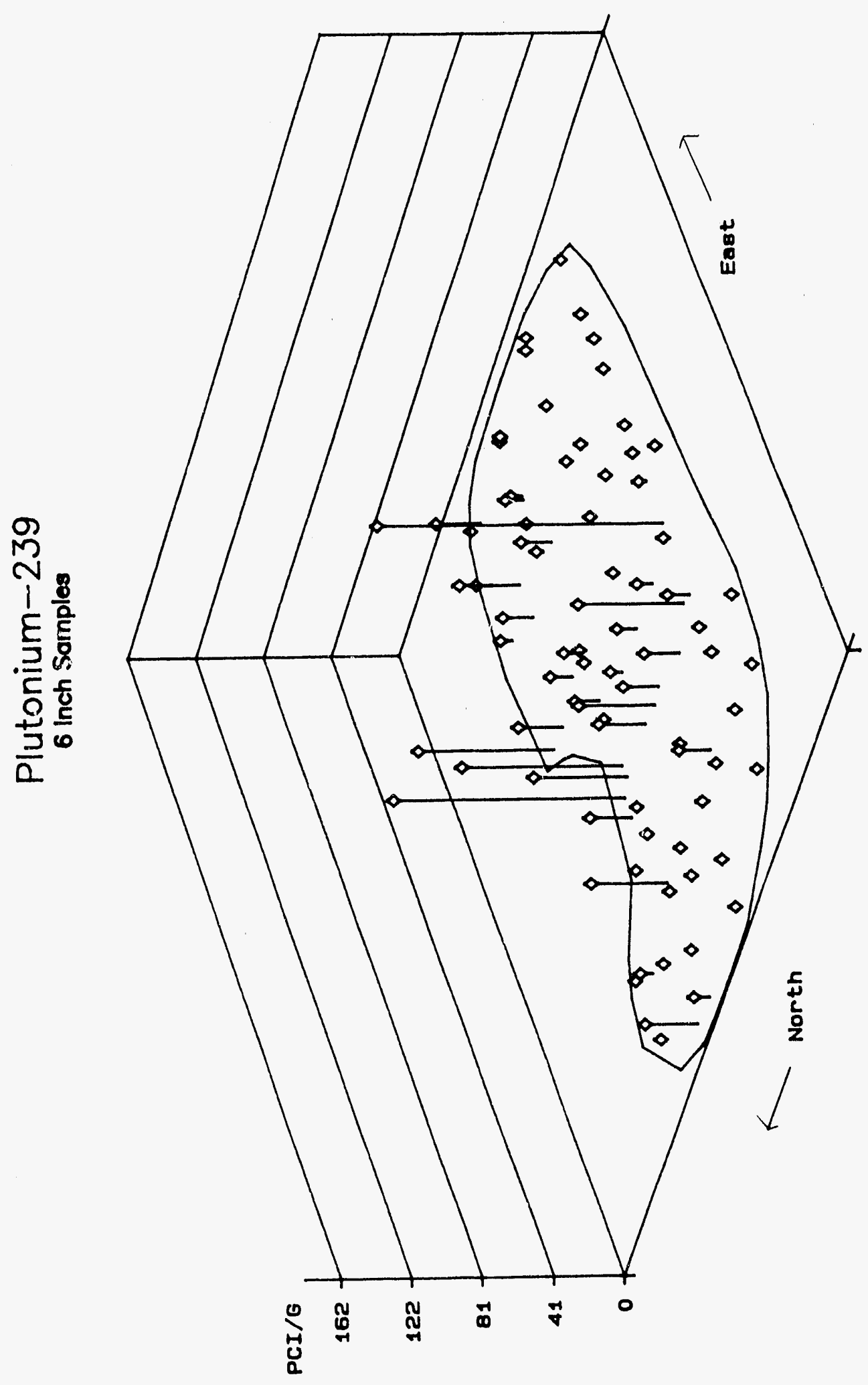

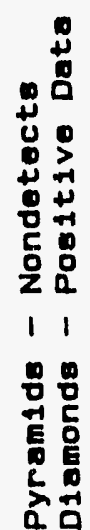




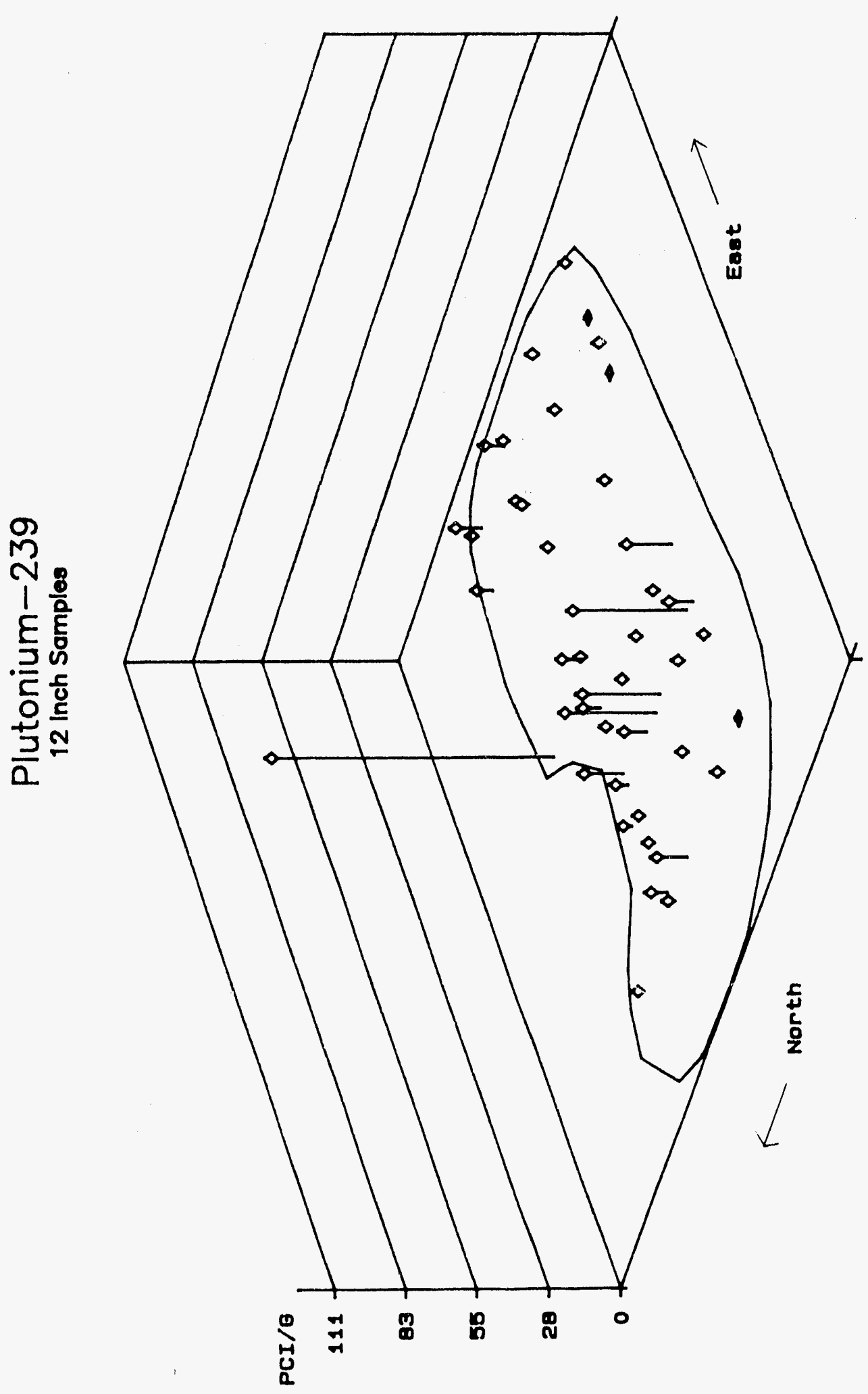

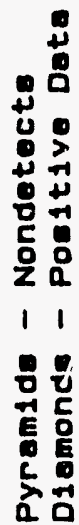




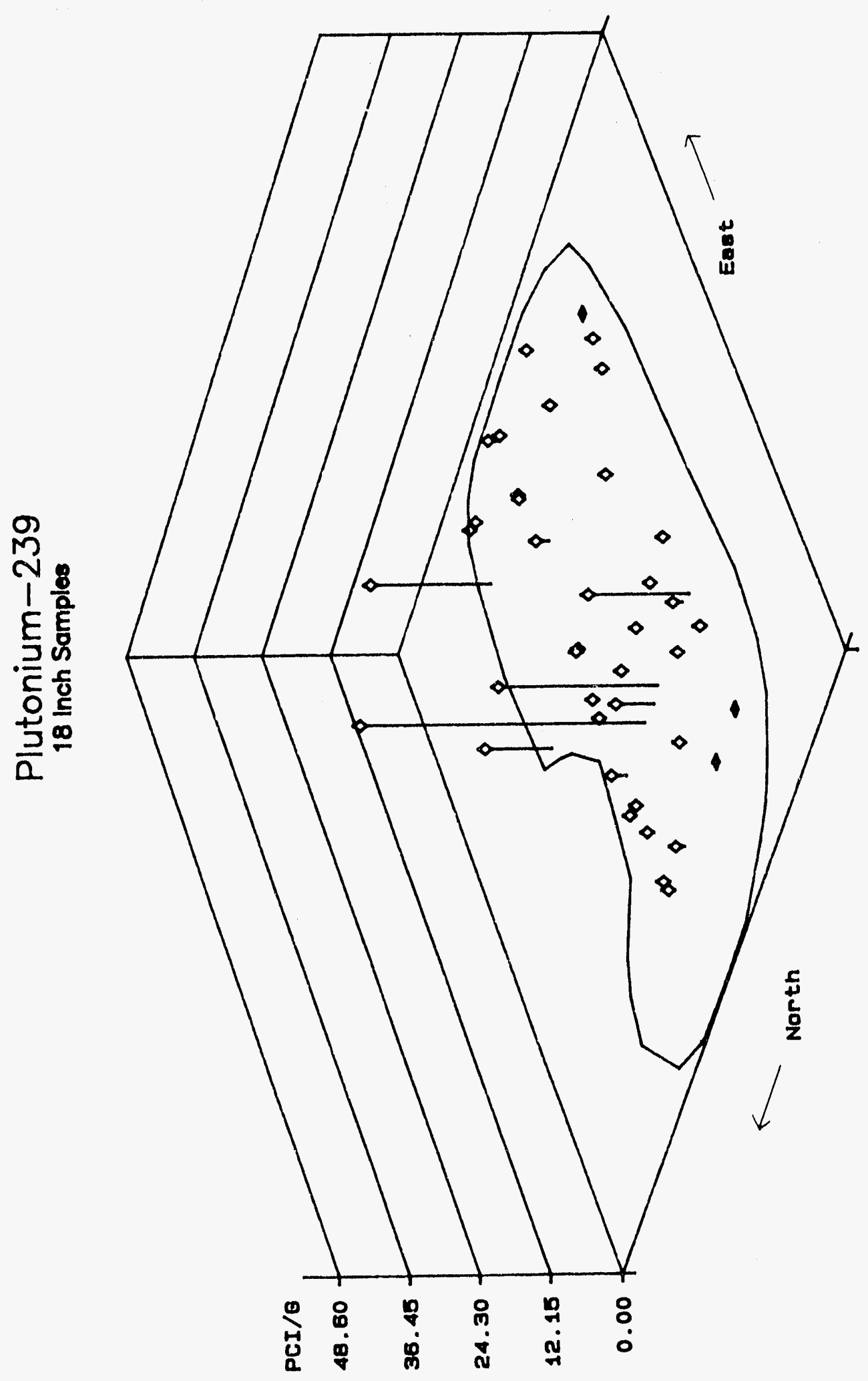

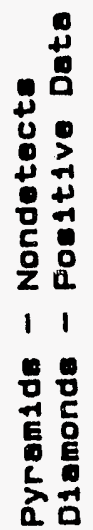




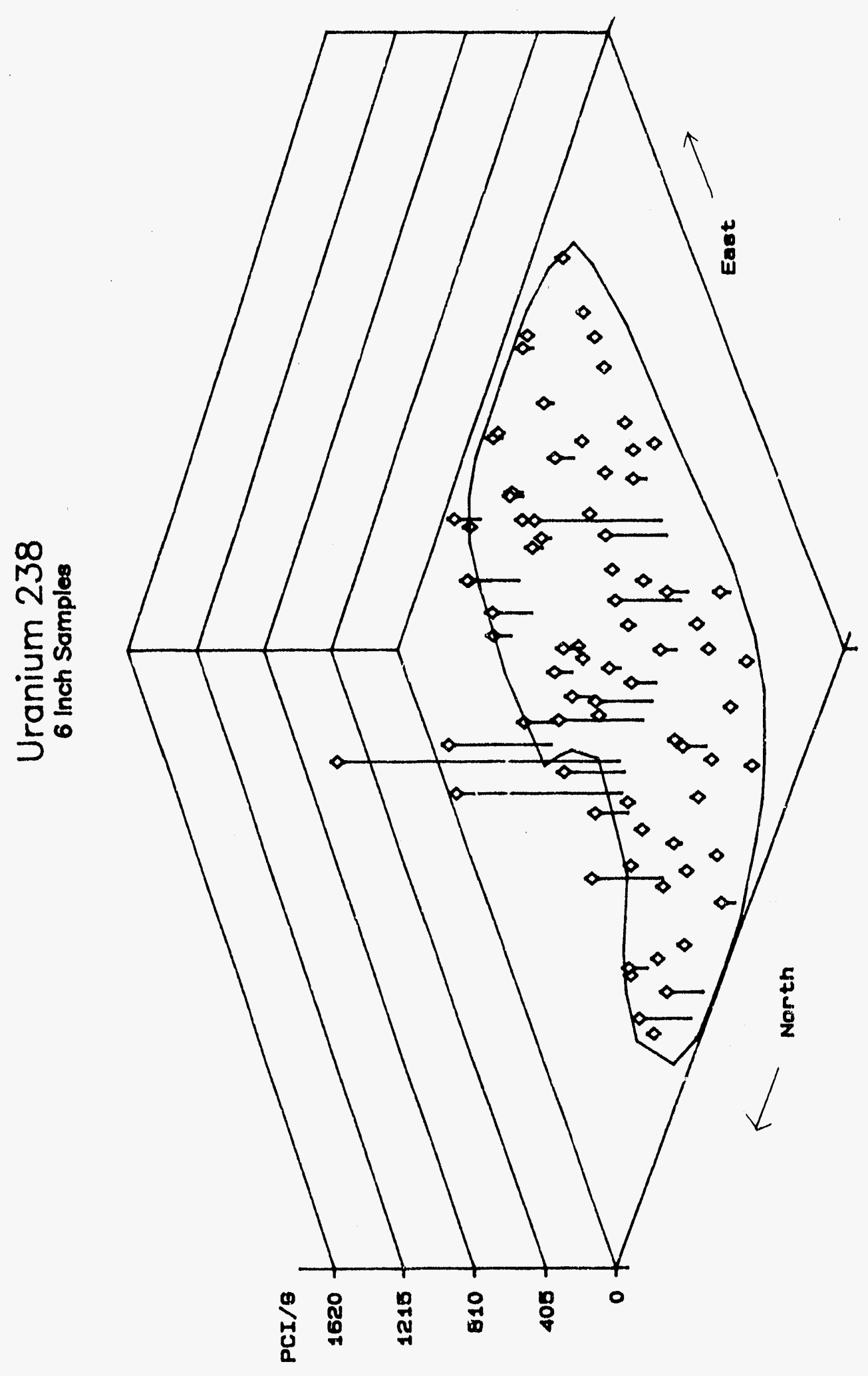

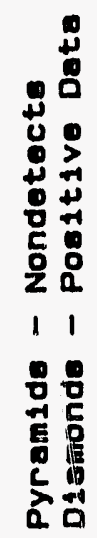




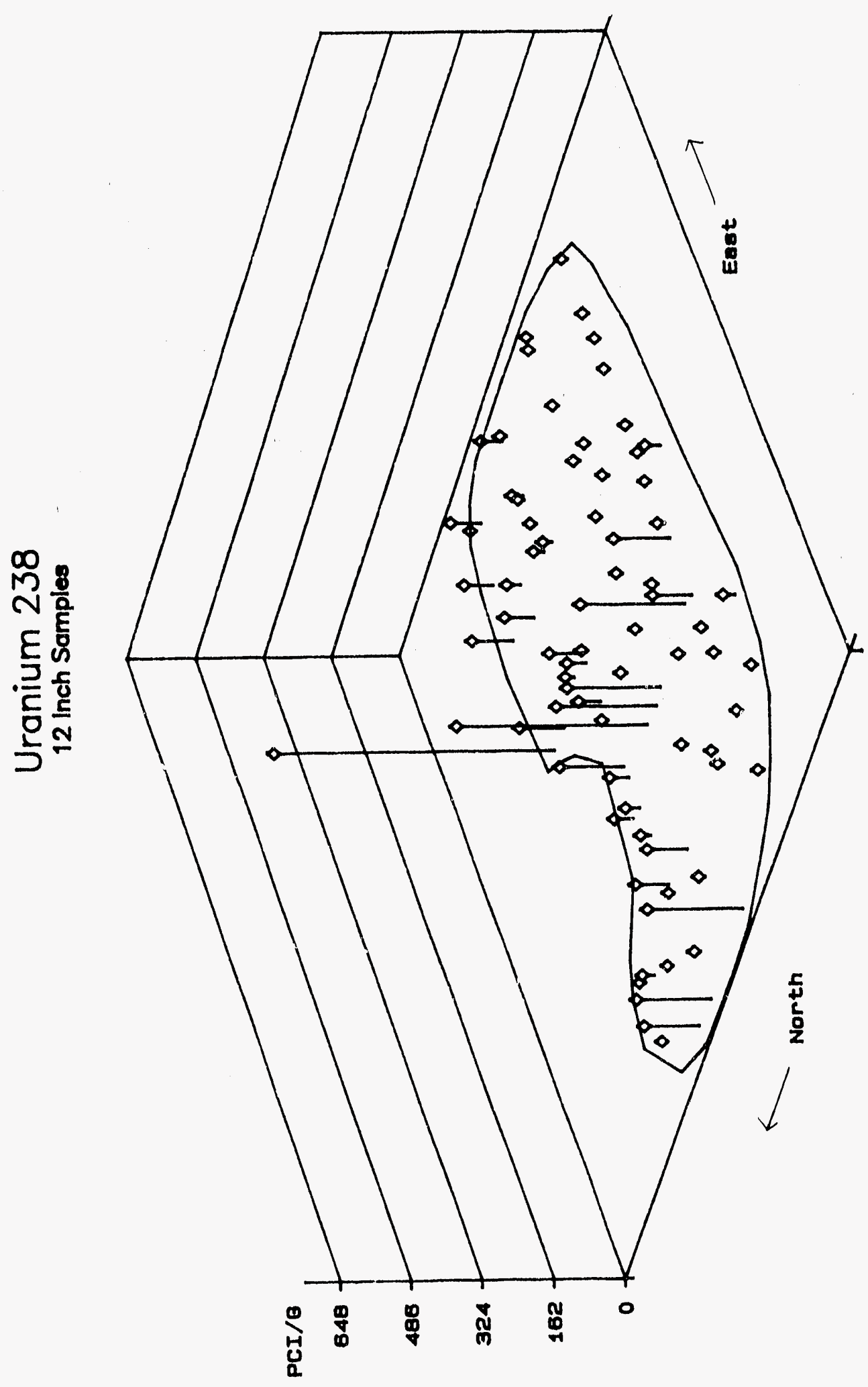

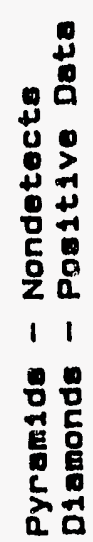




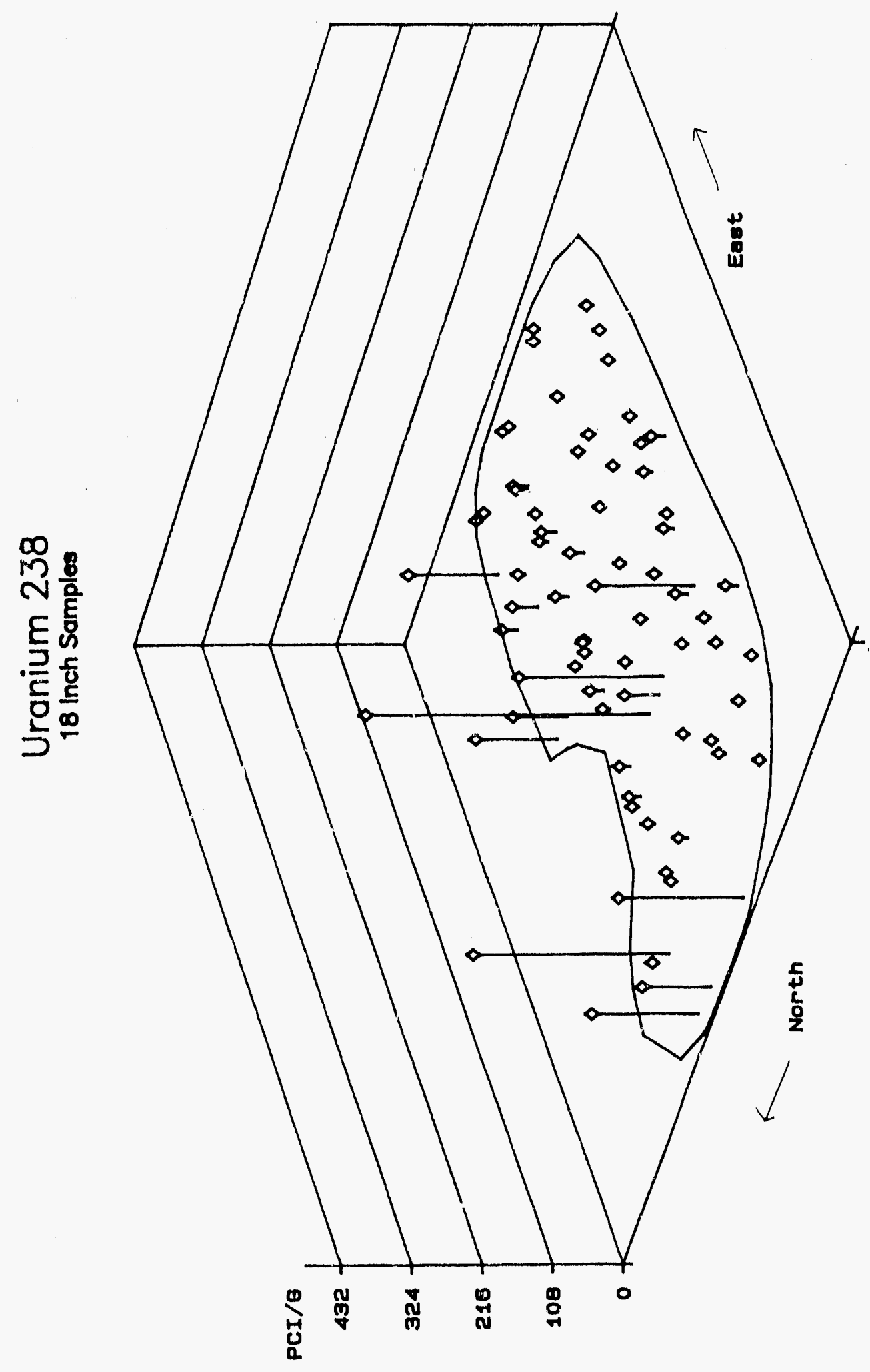

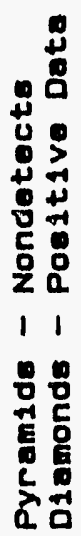




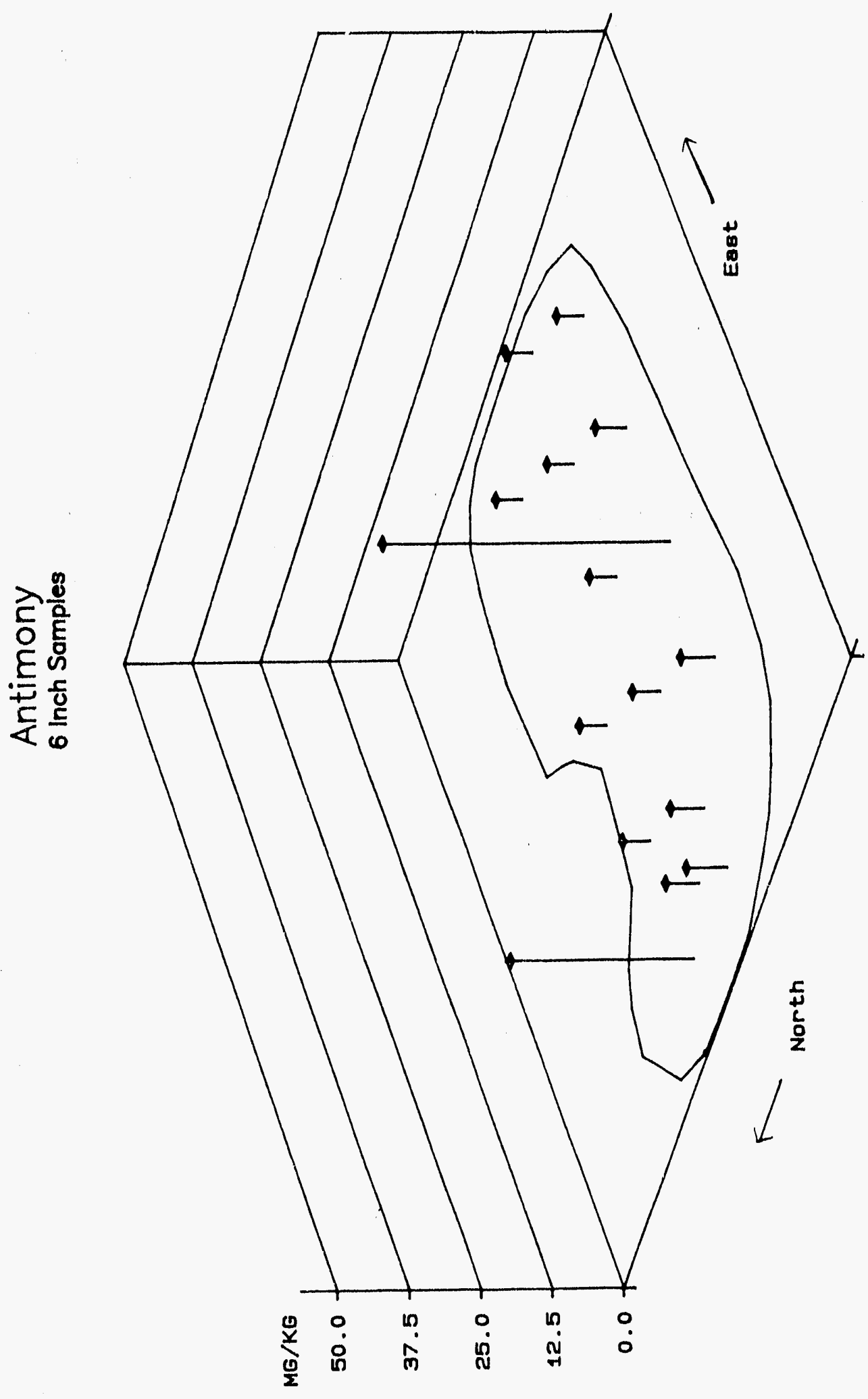

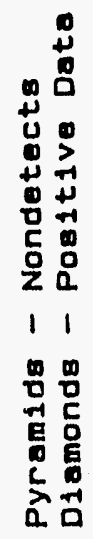




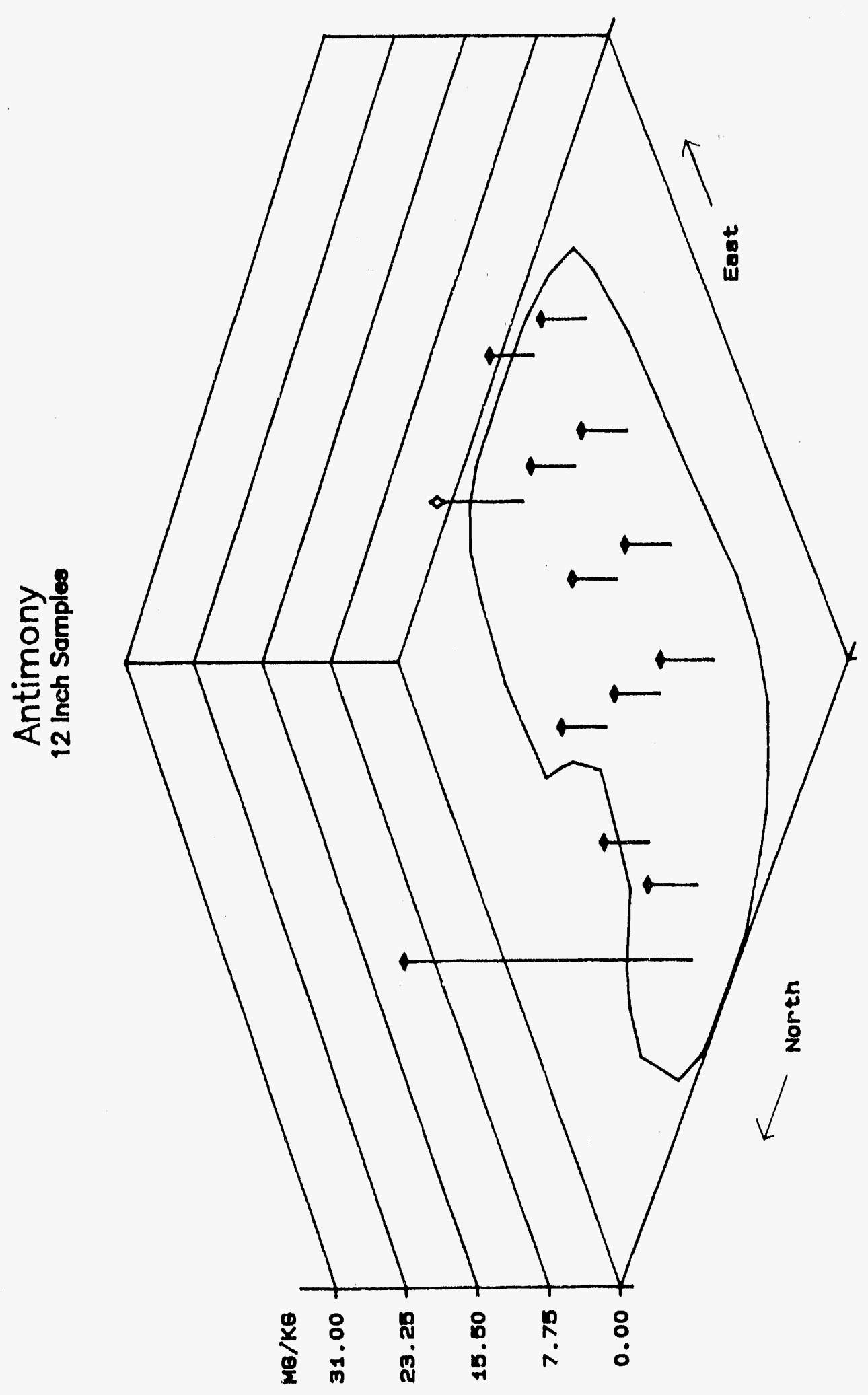

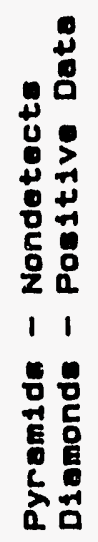




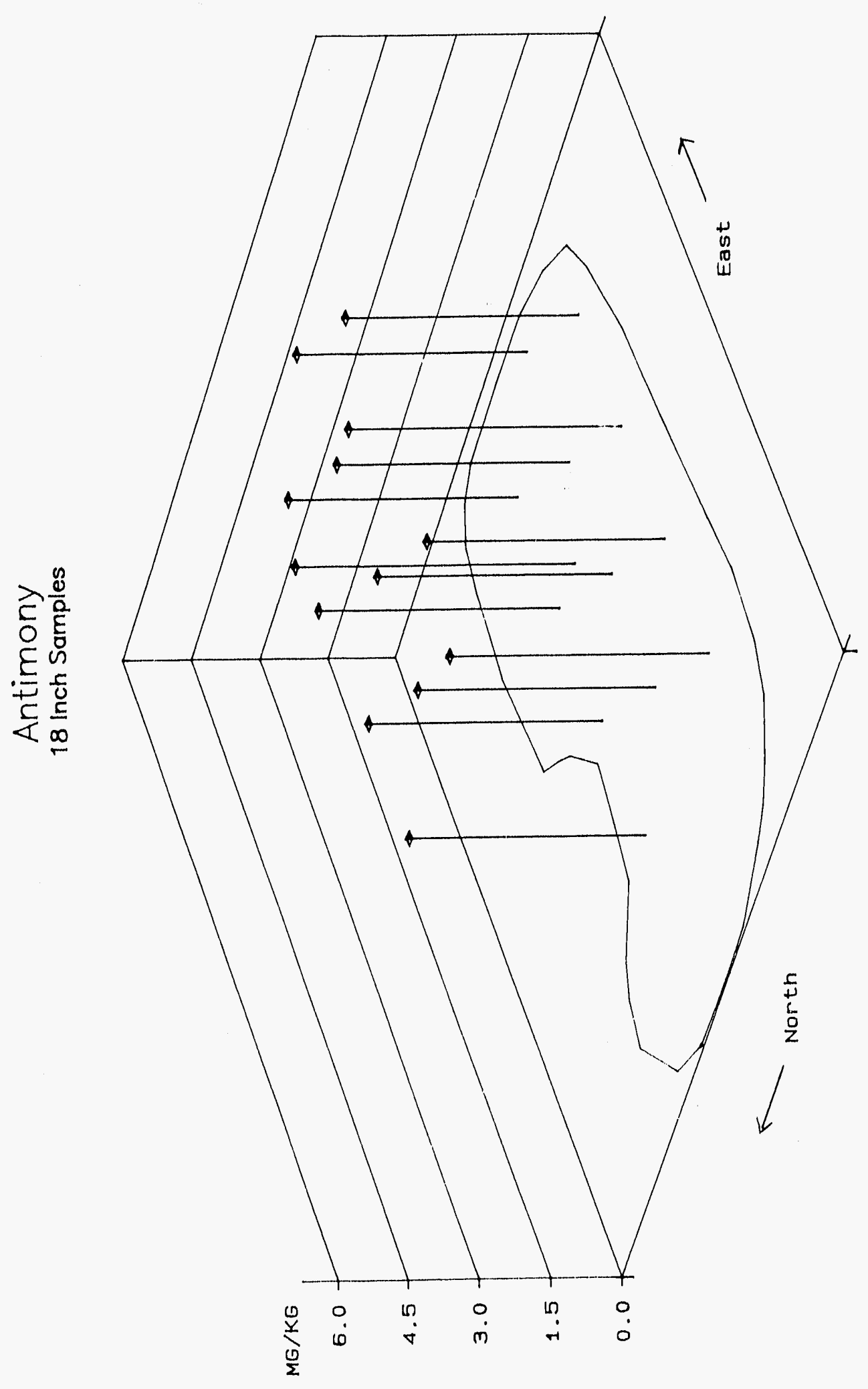

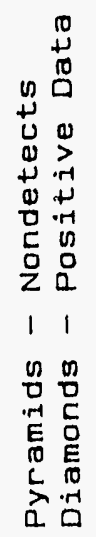




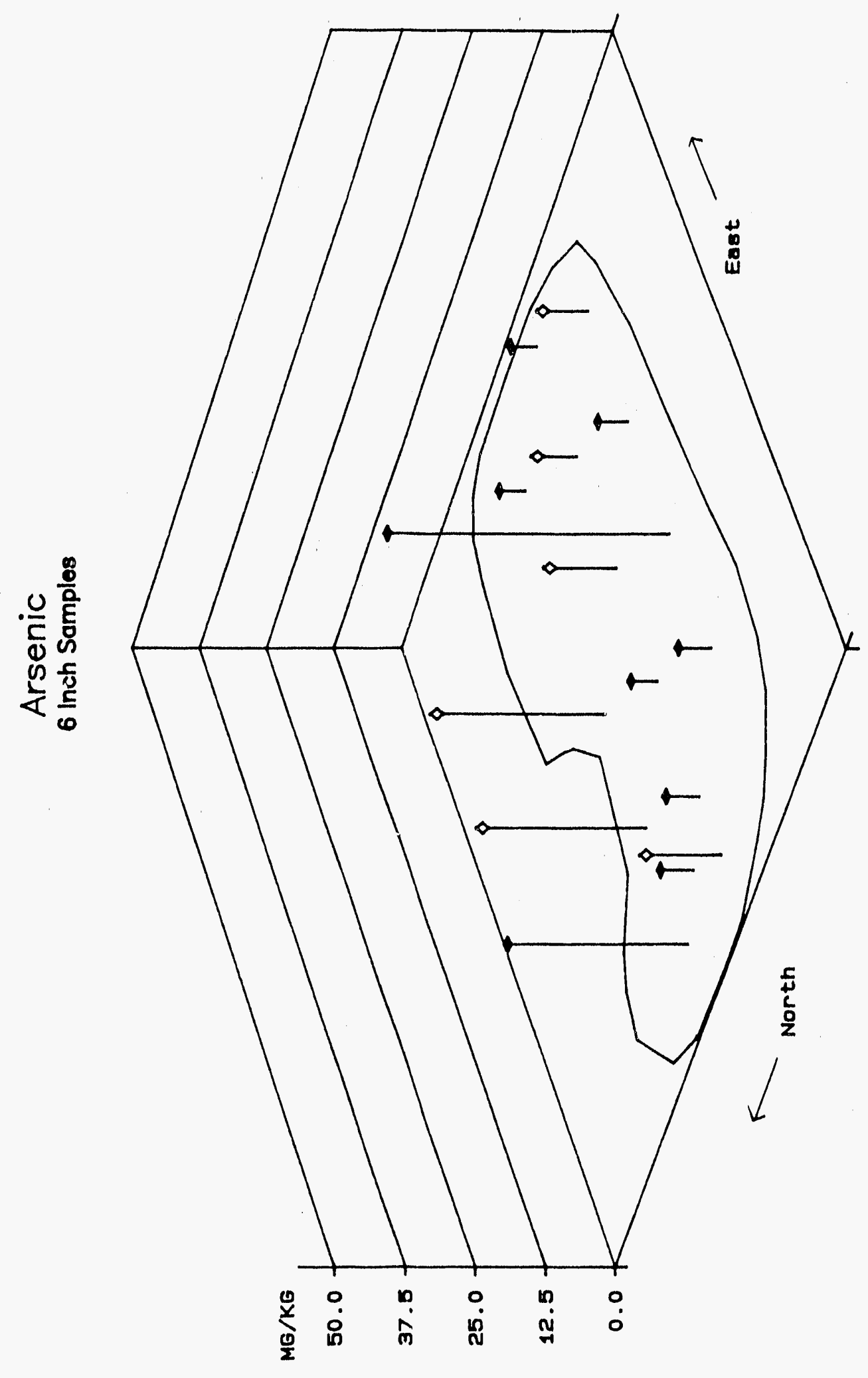

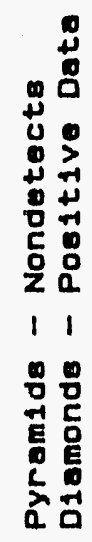




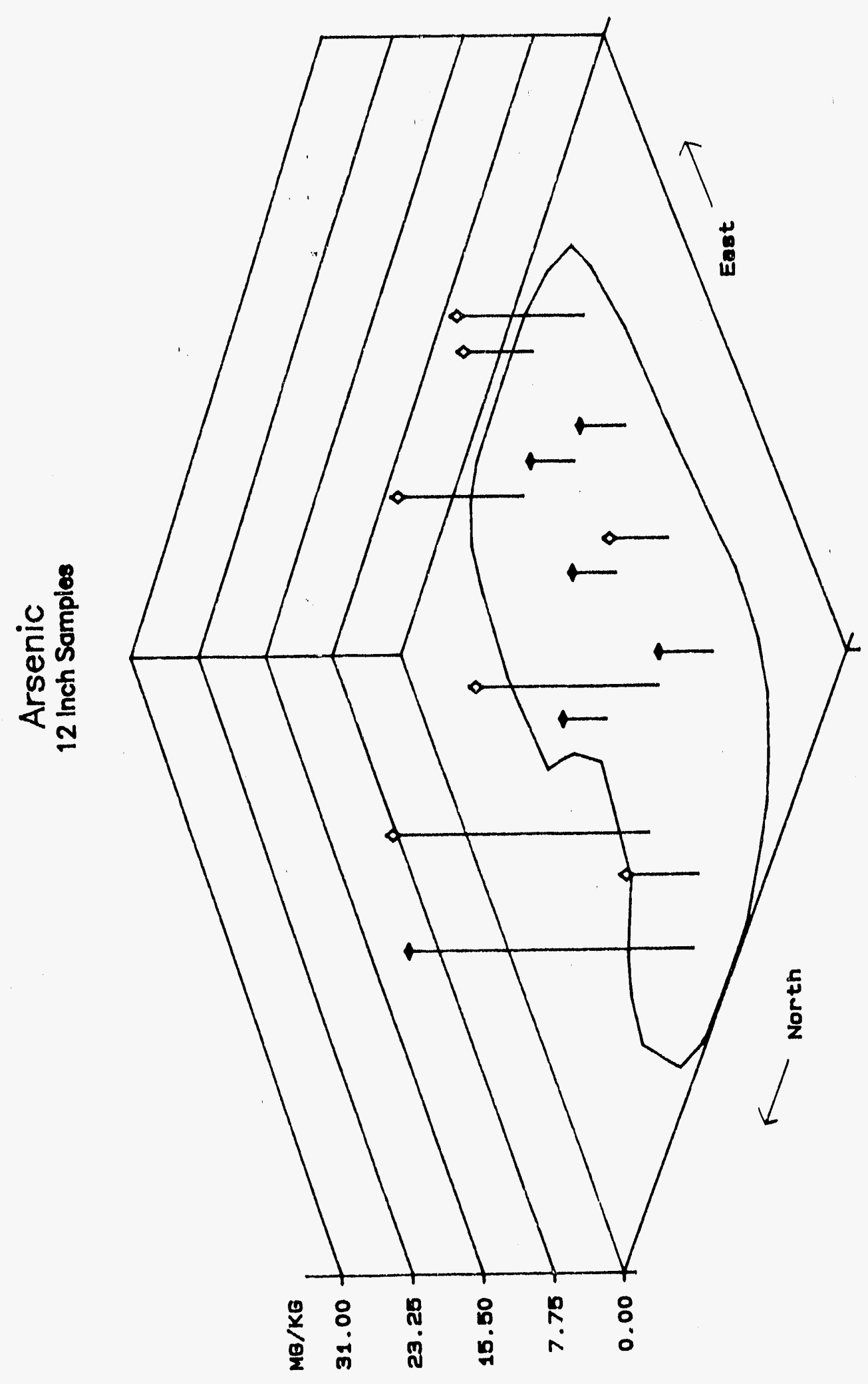

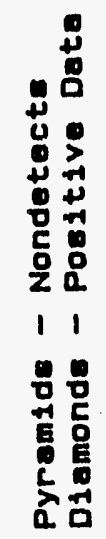




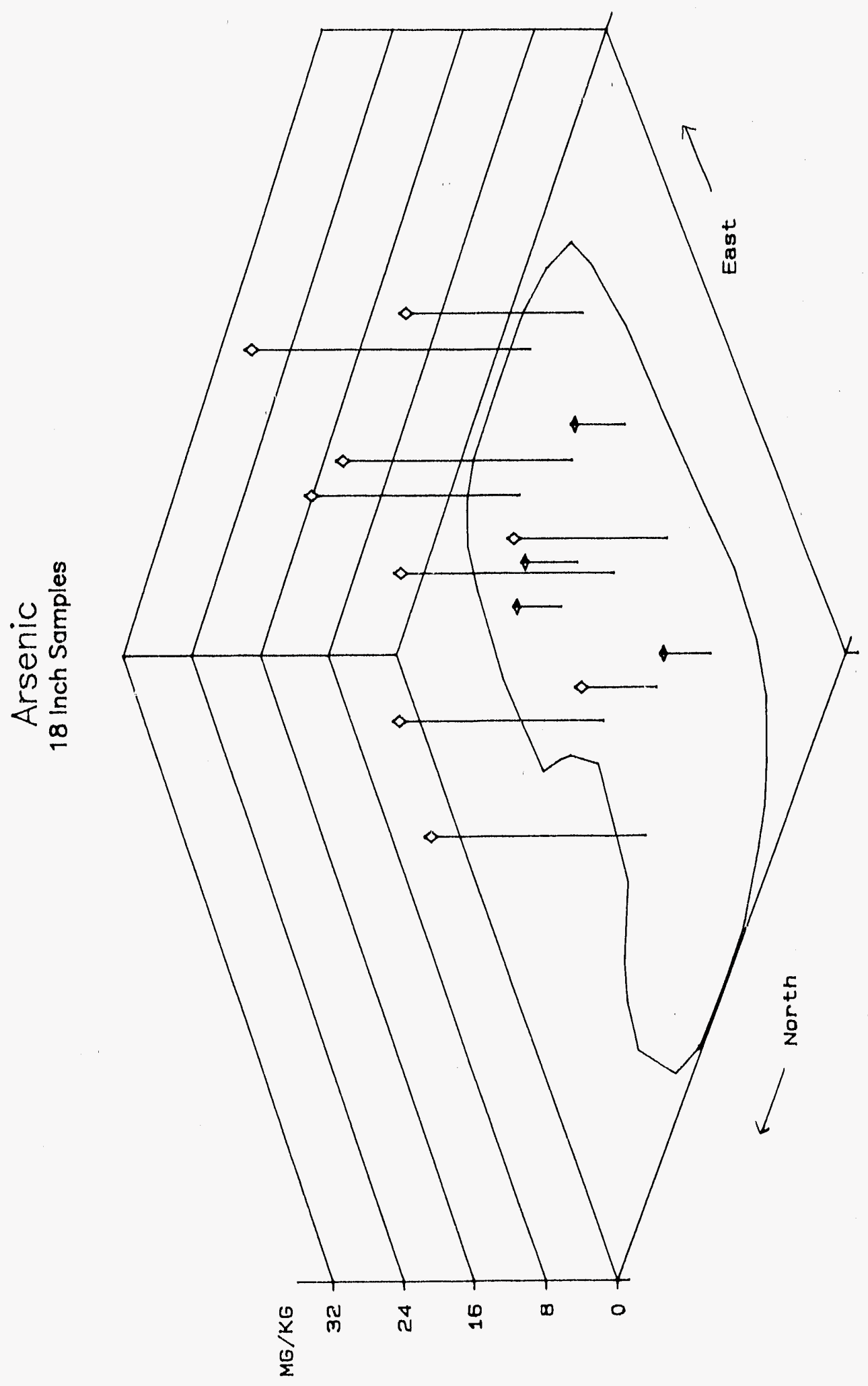

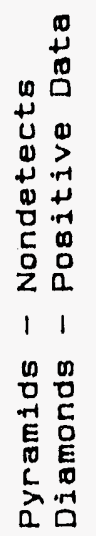




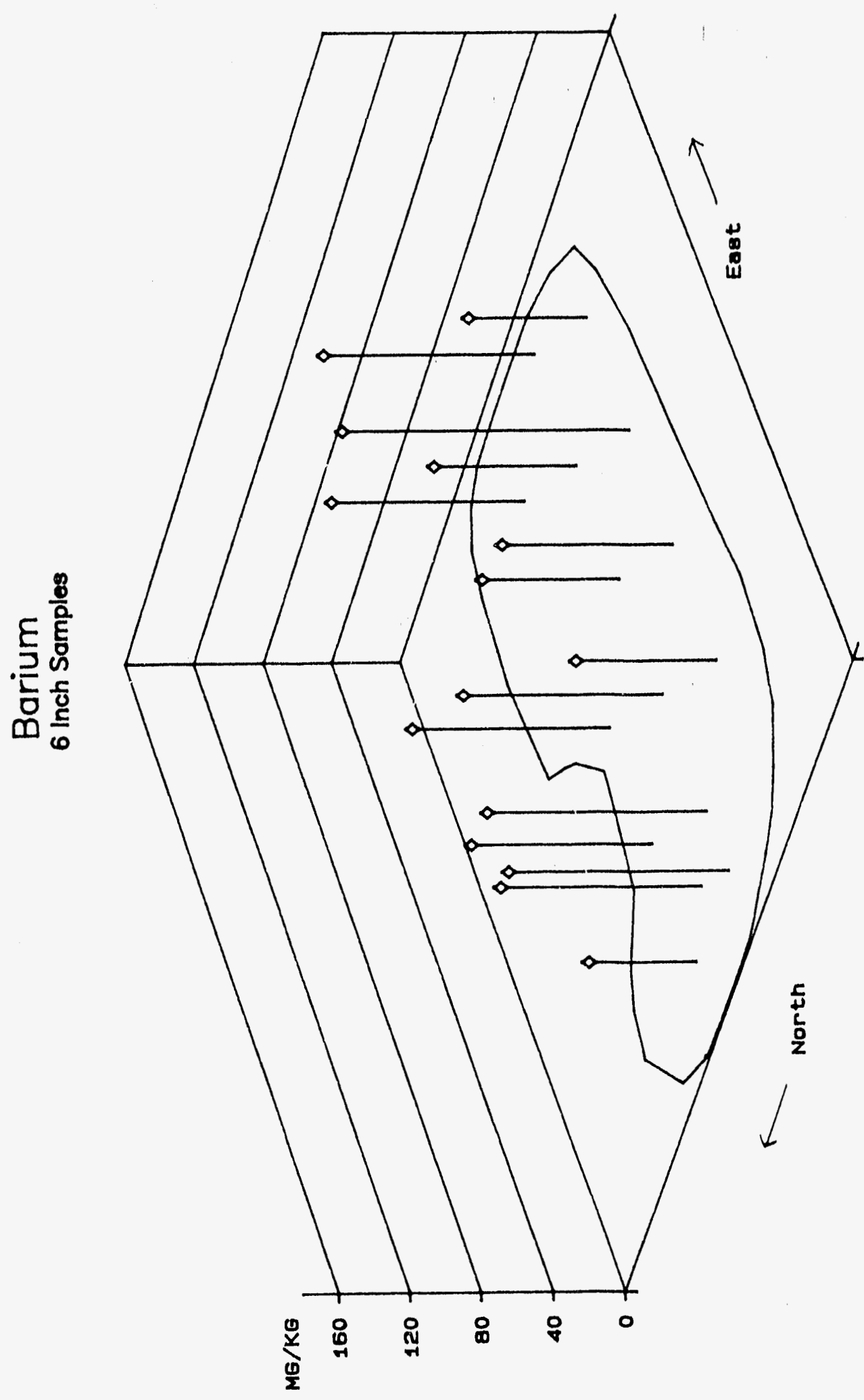

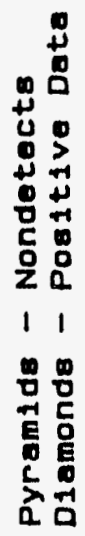




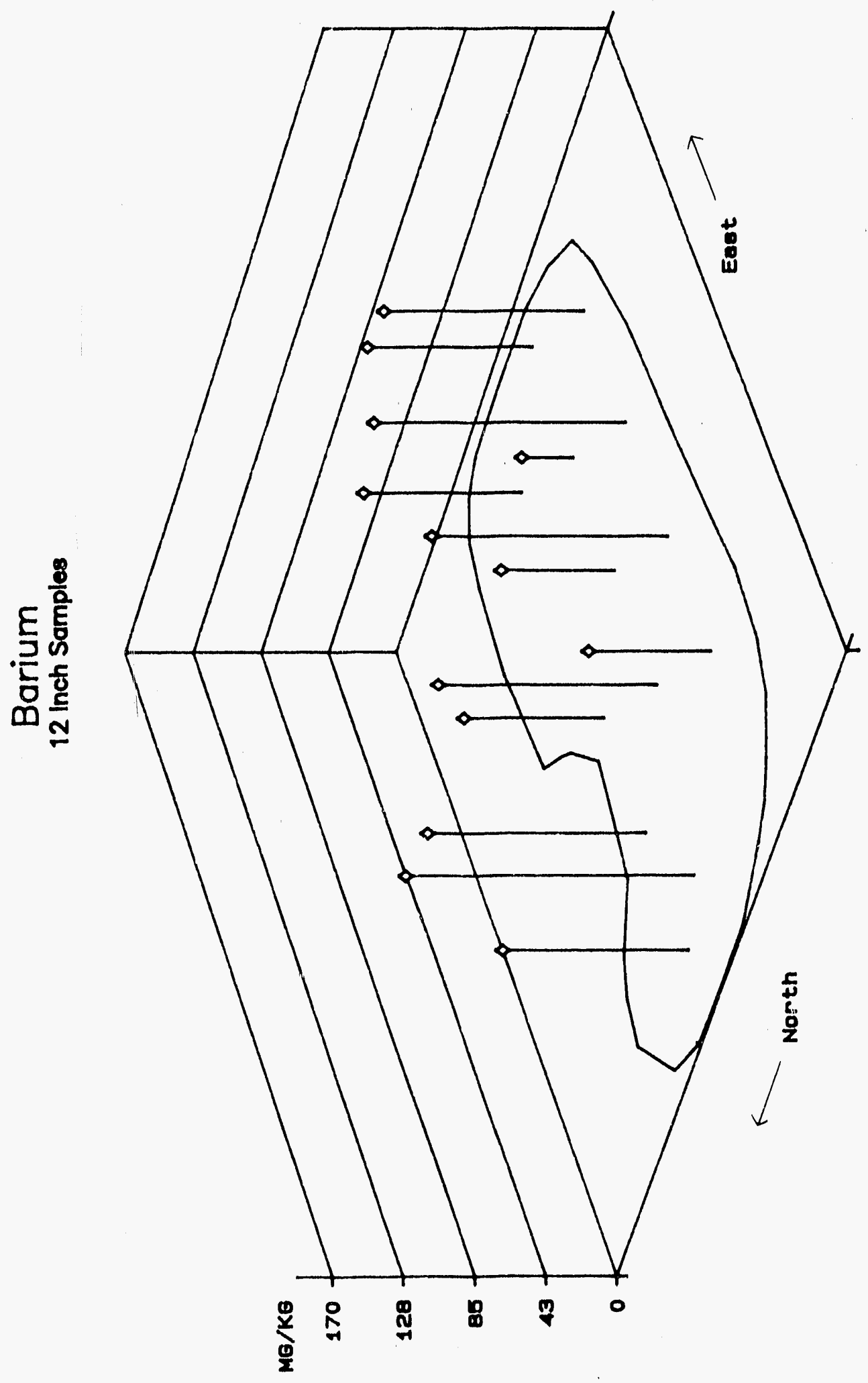

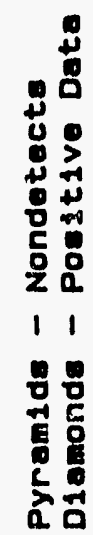




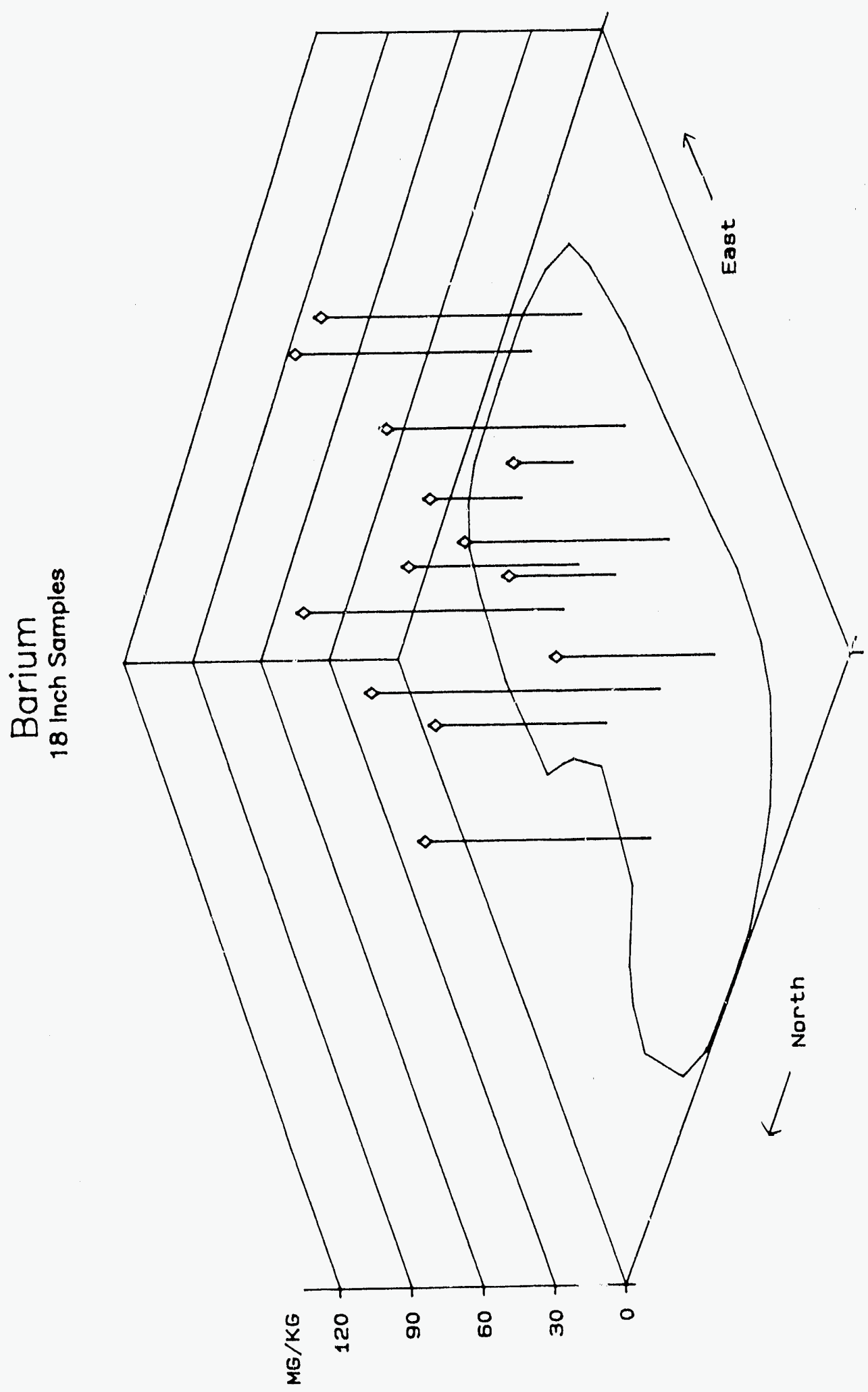

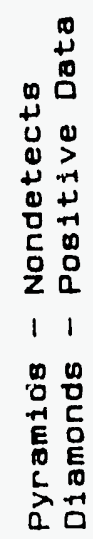




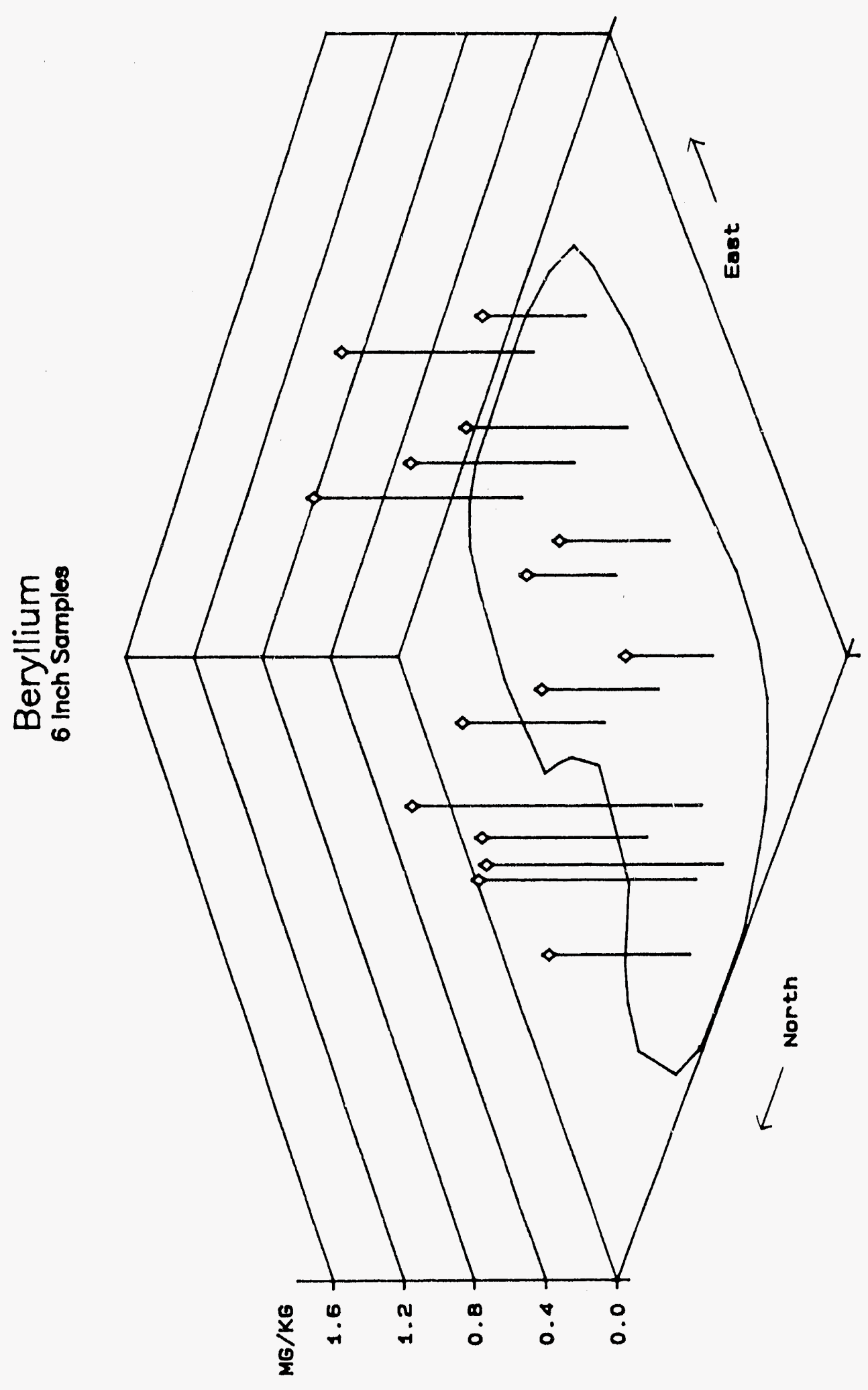

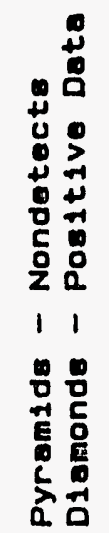




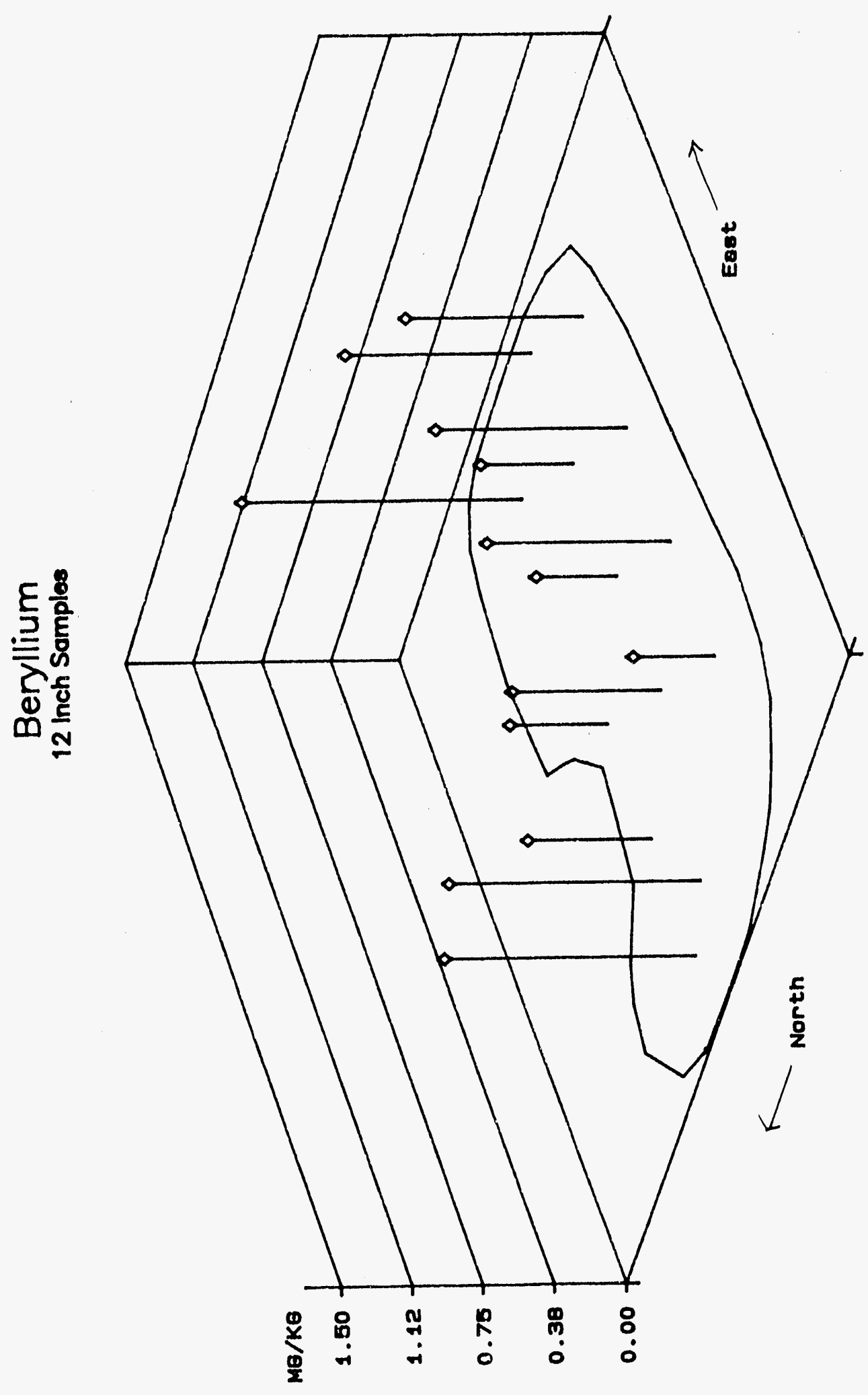

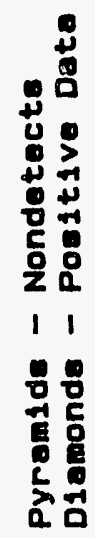




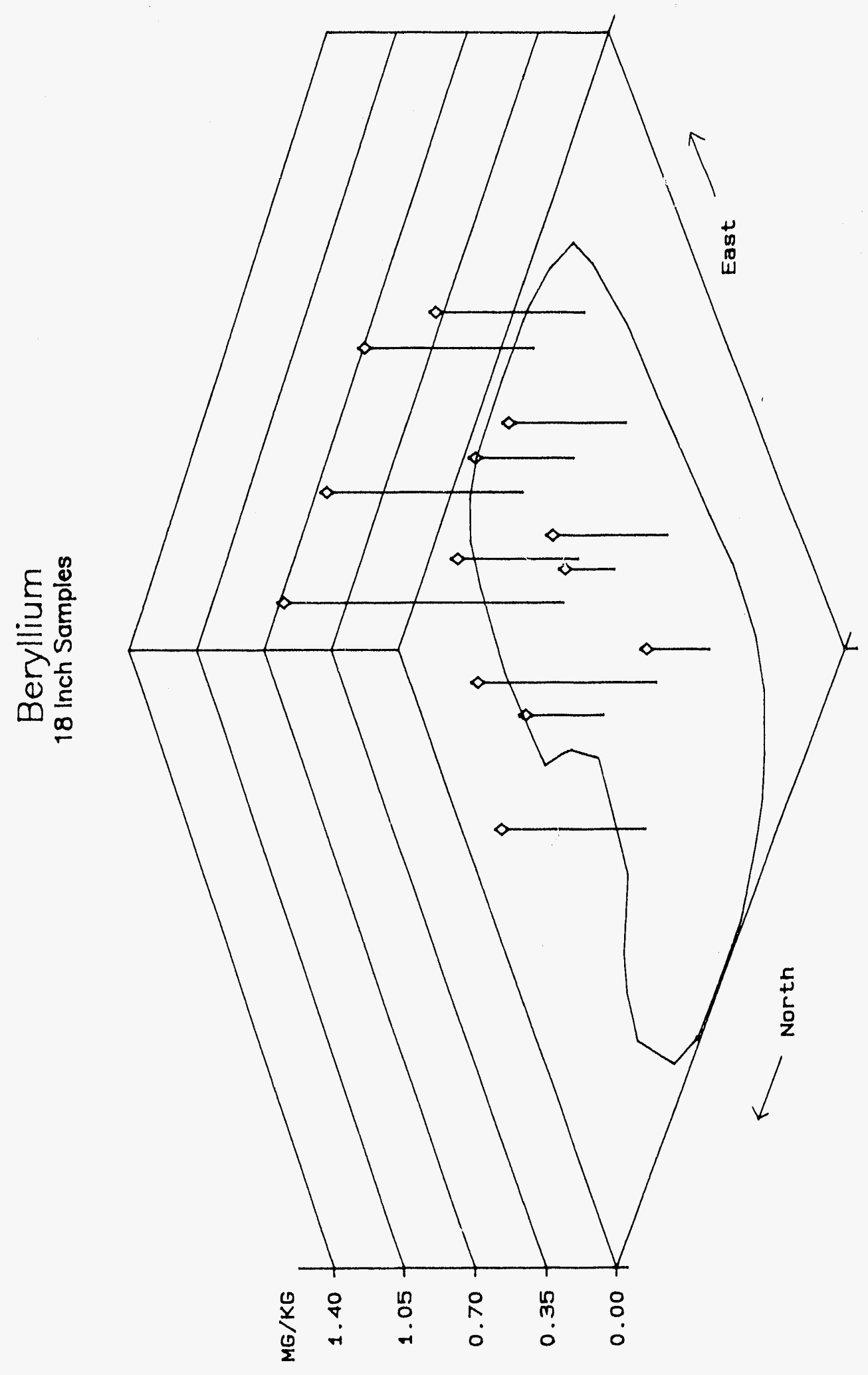

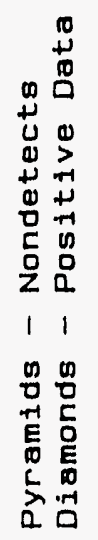




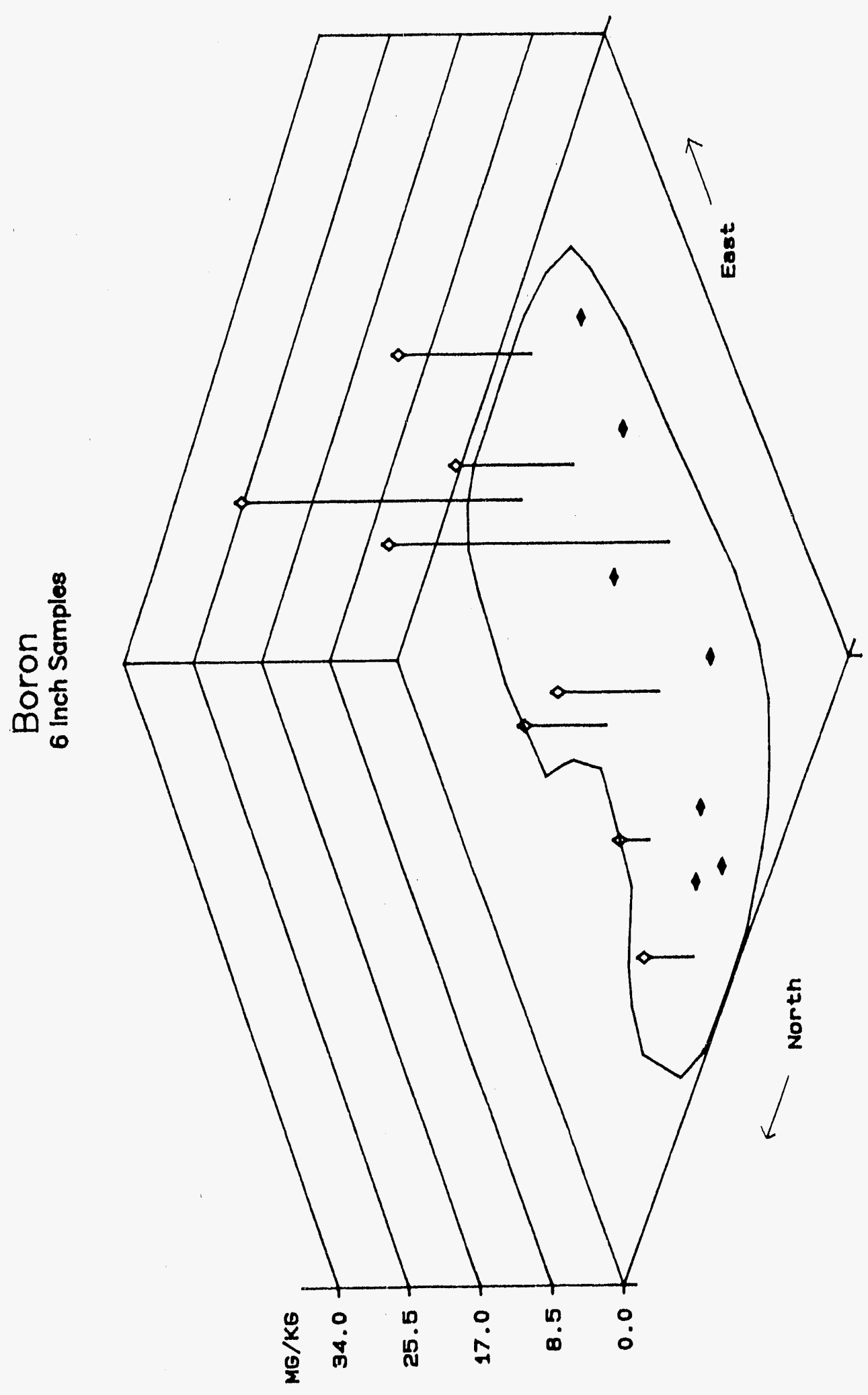

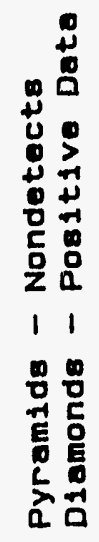




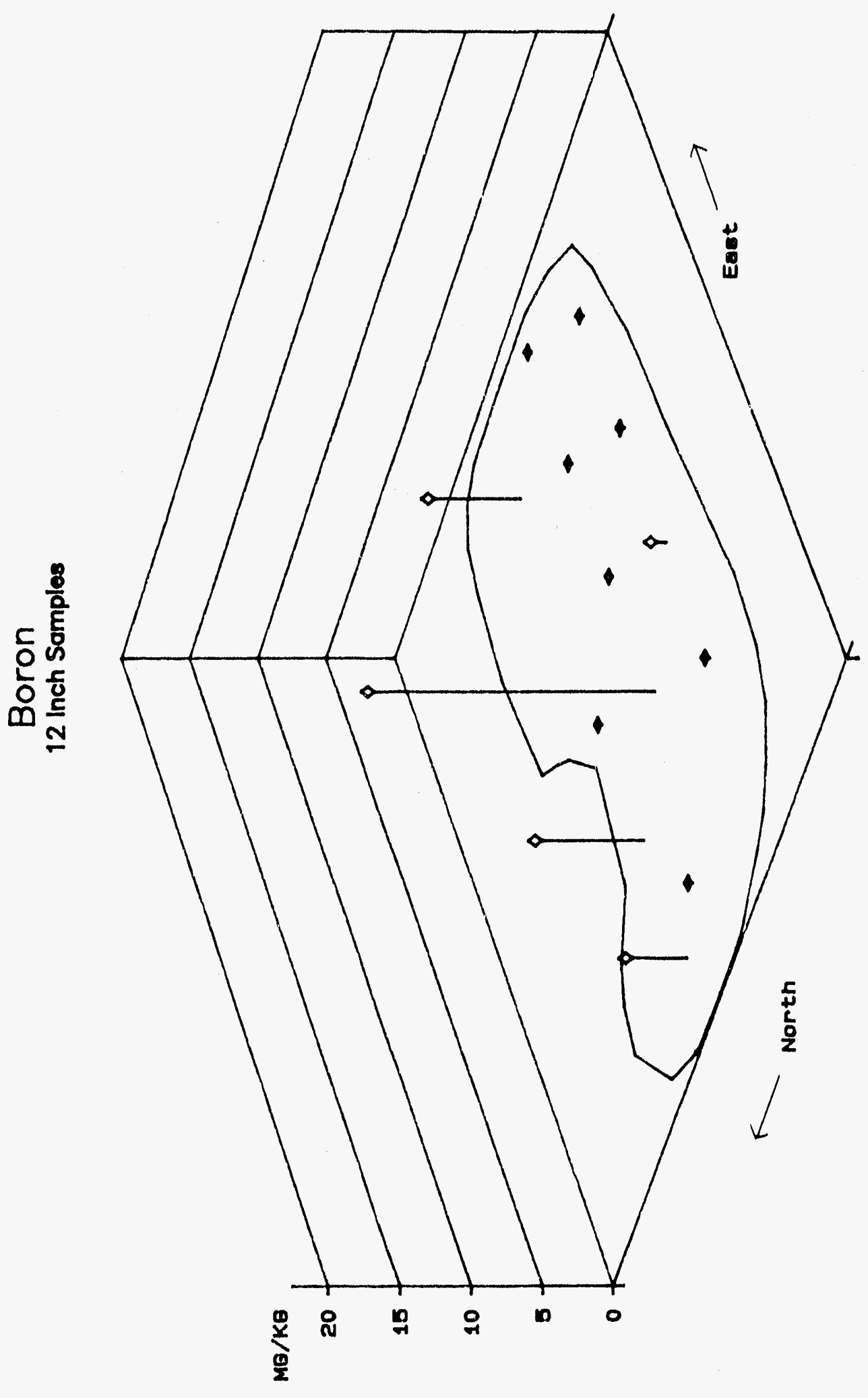

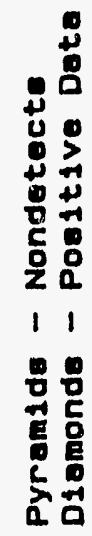




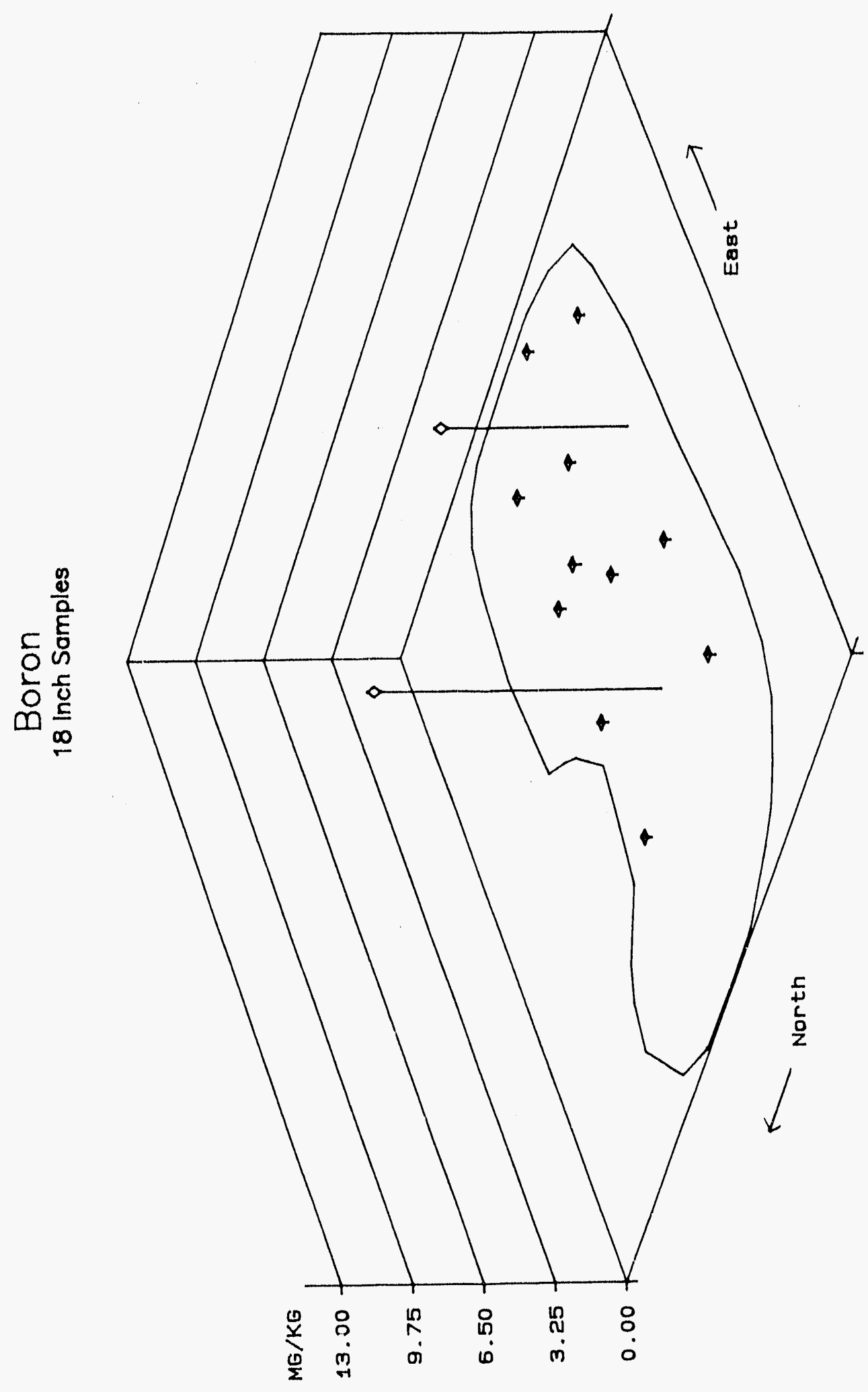

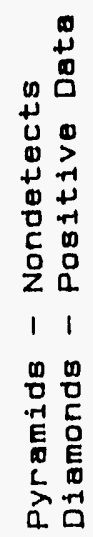




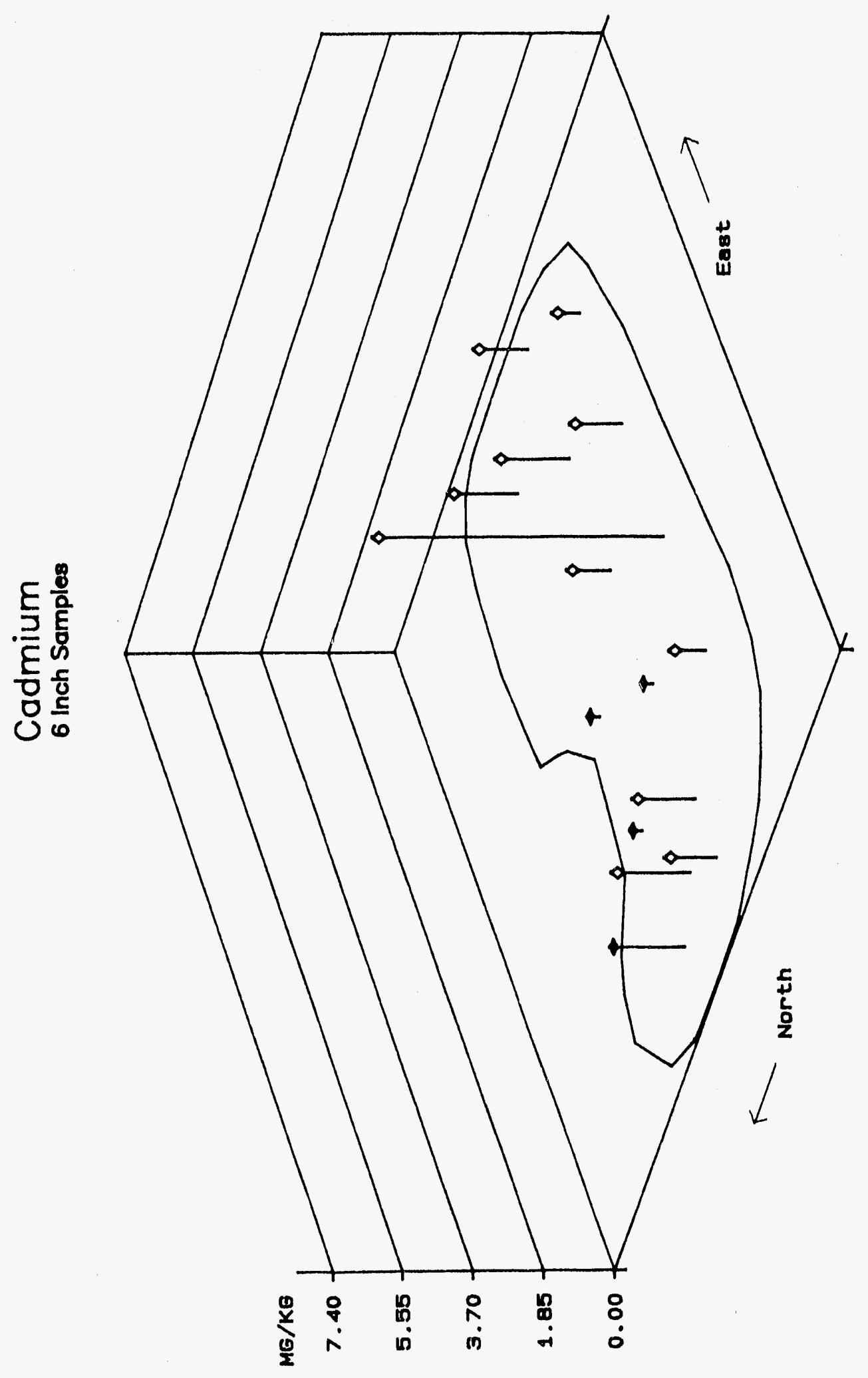

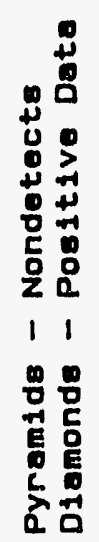




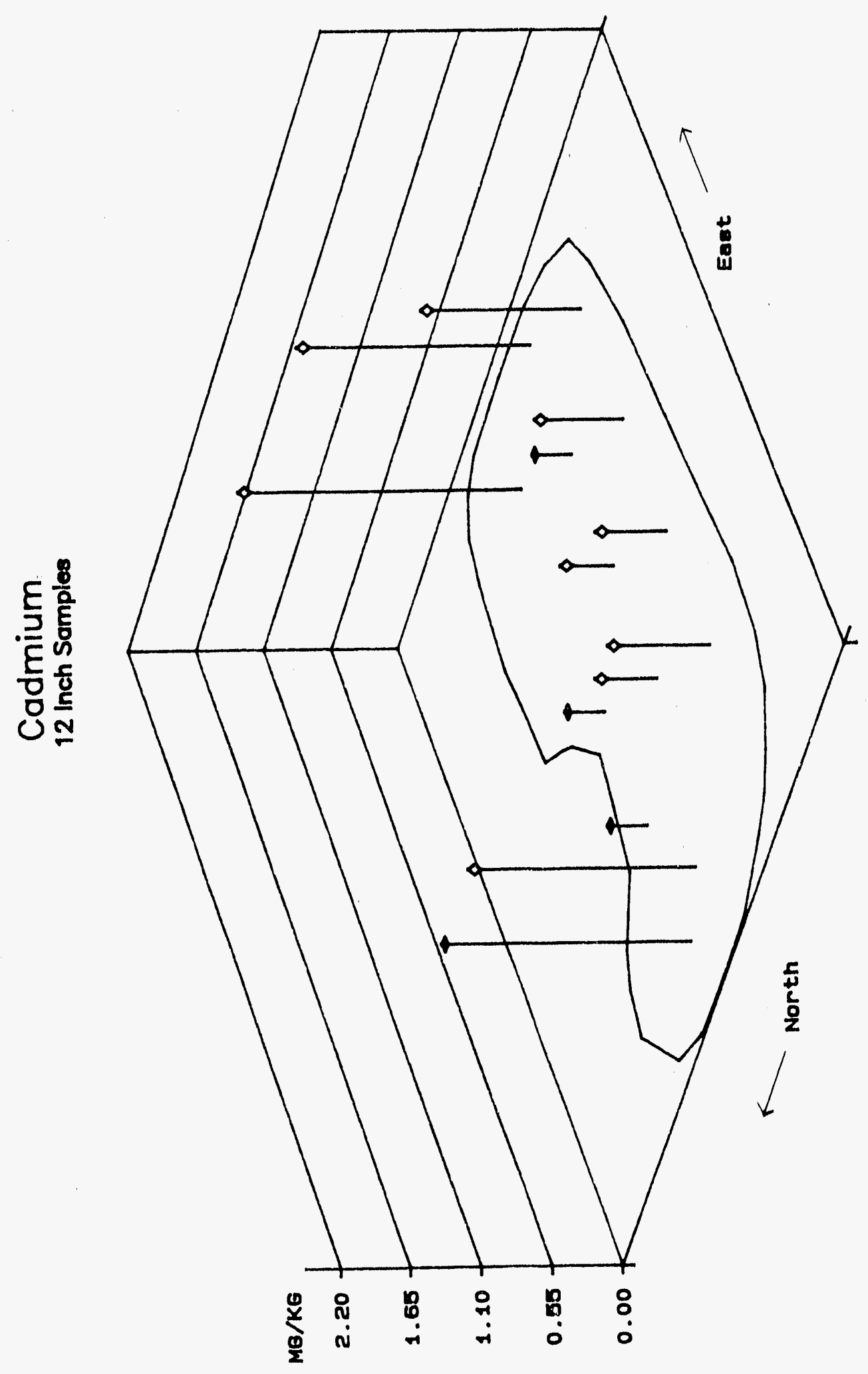

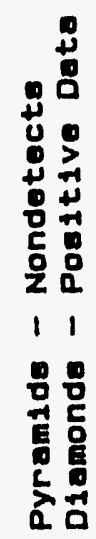




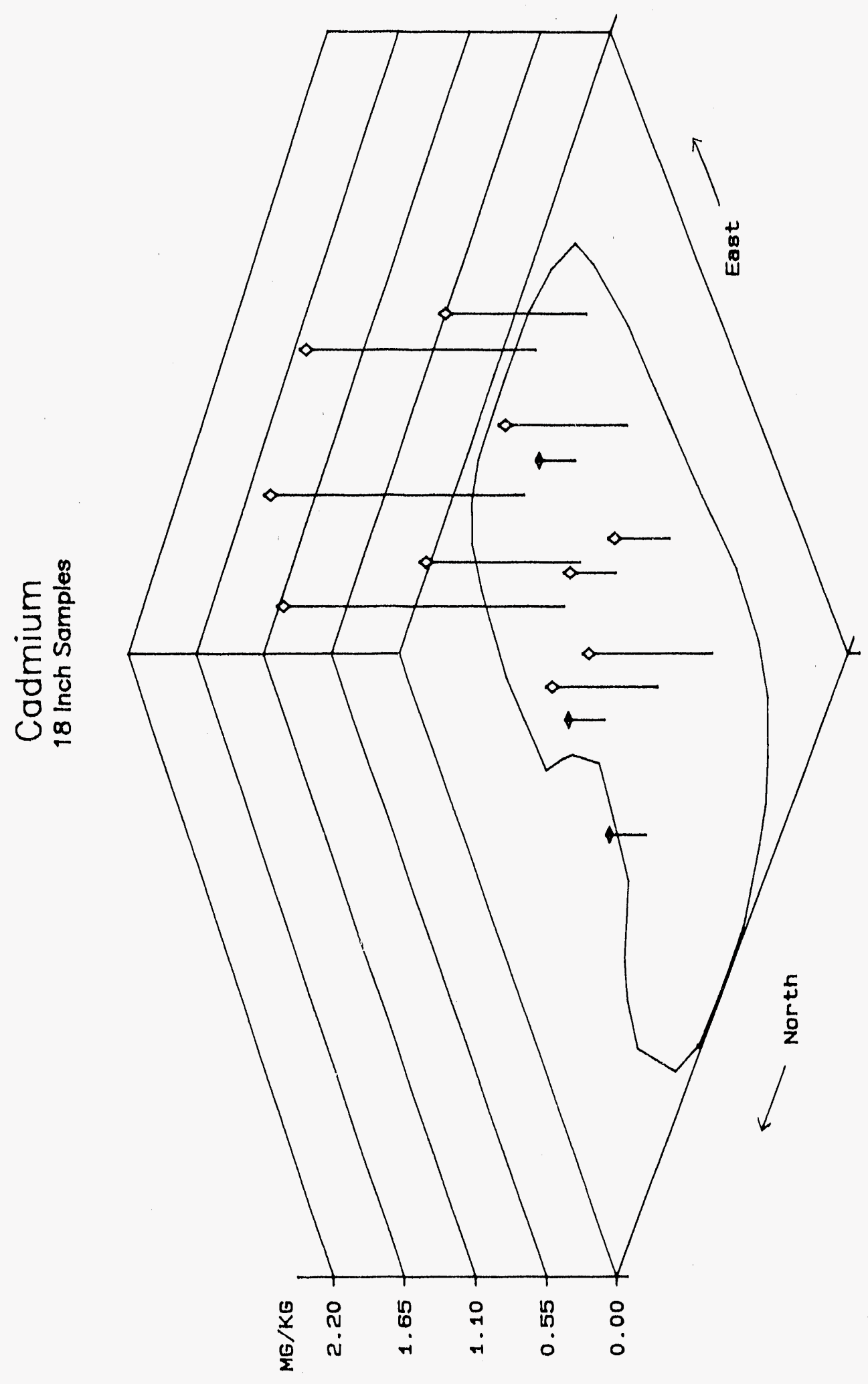

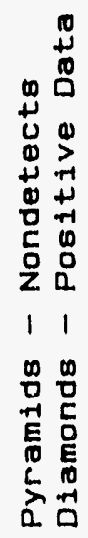




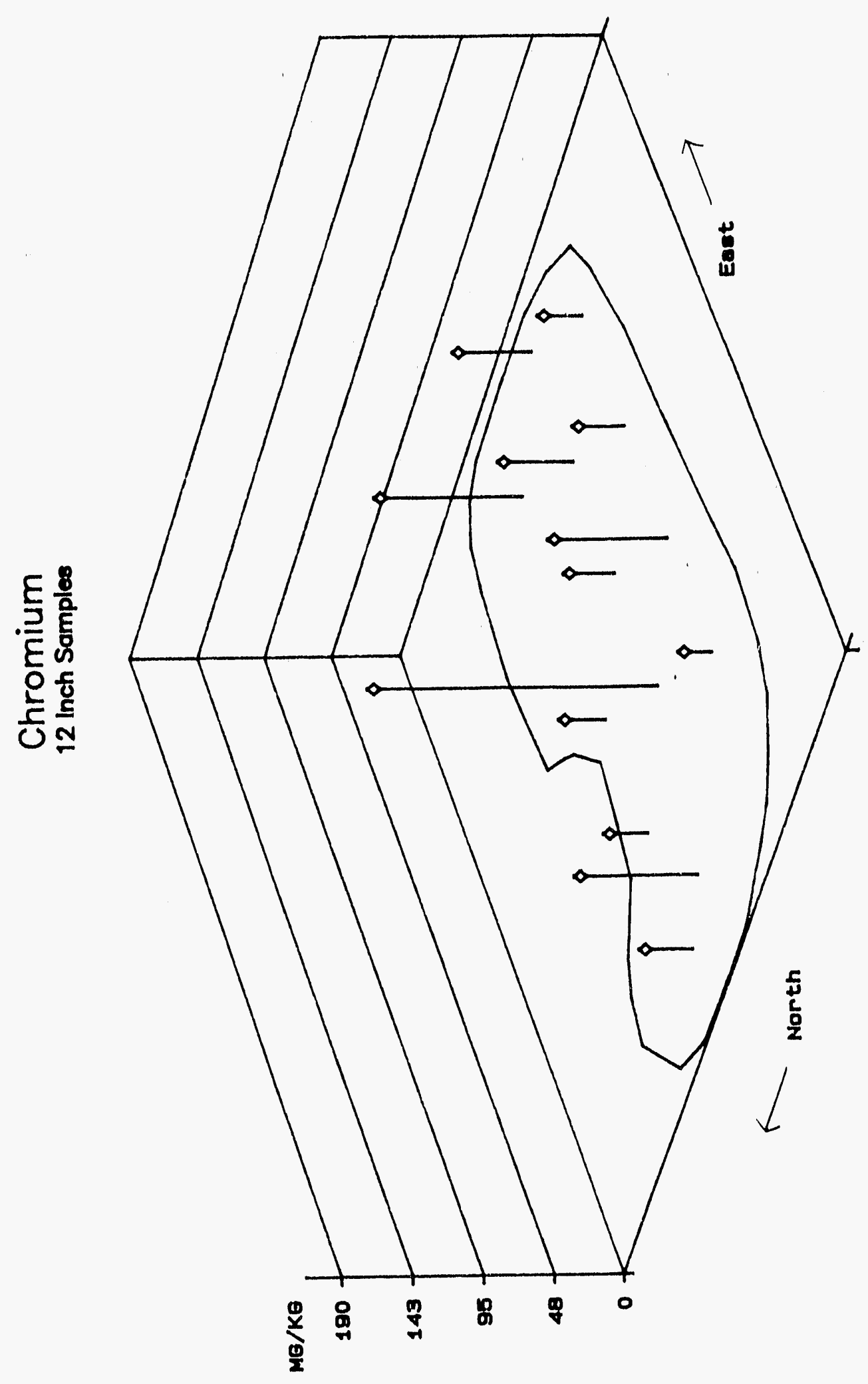

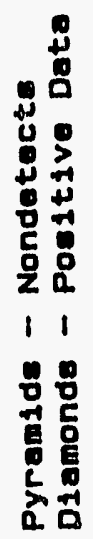


222
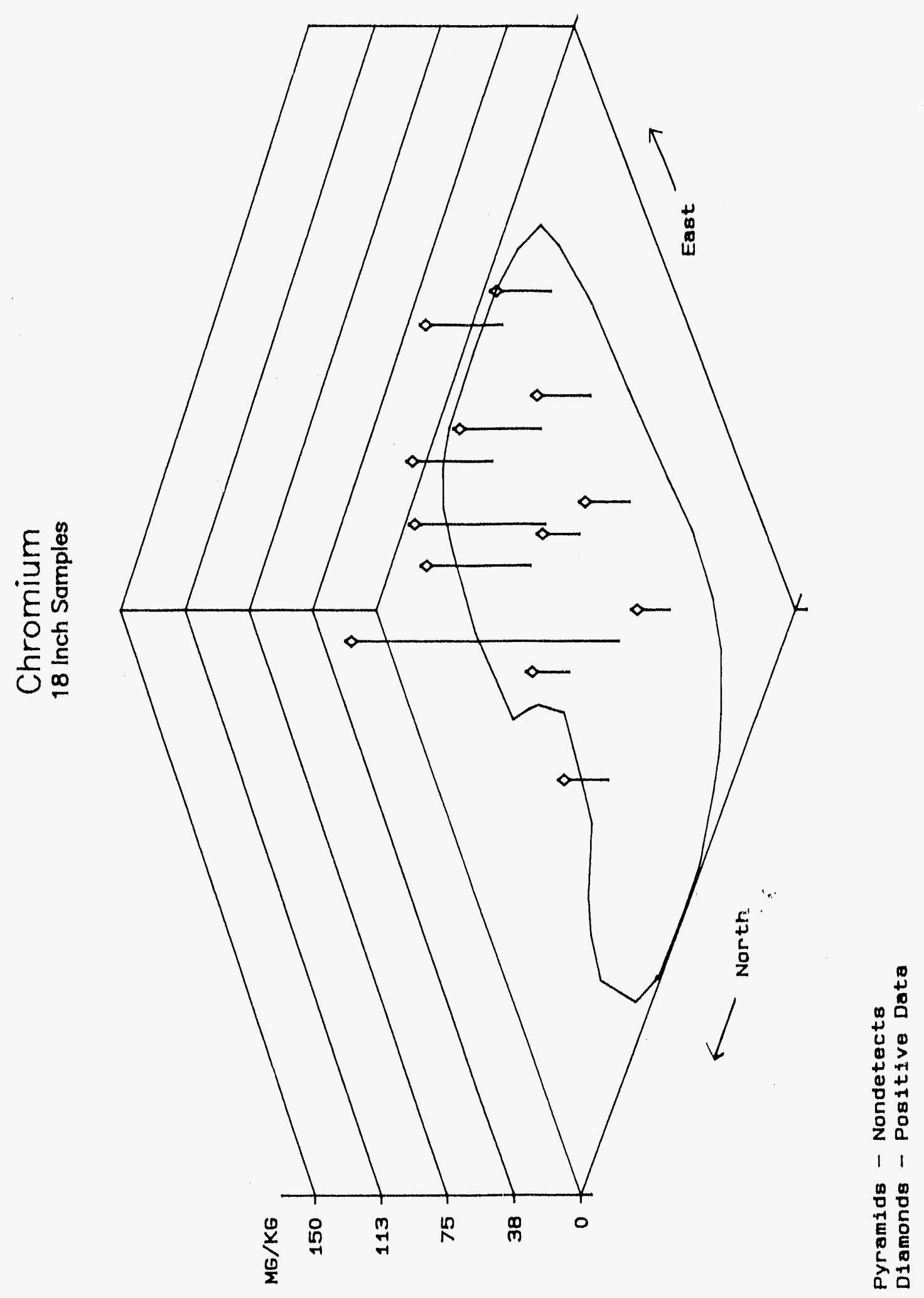


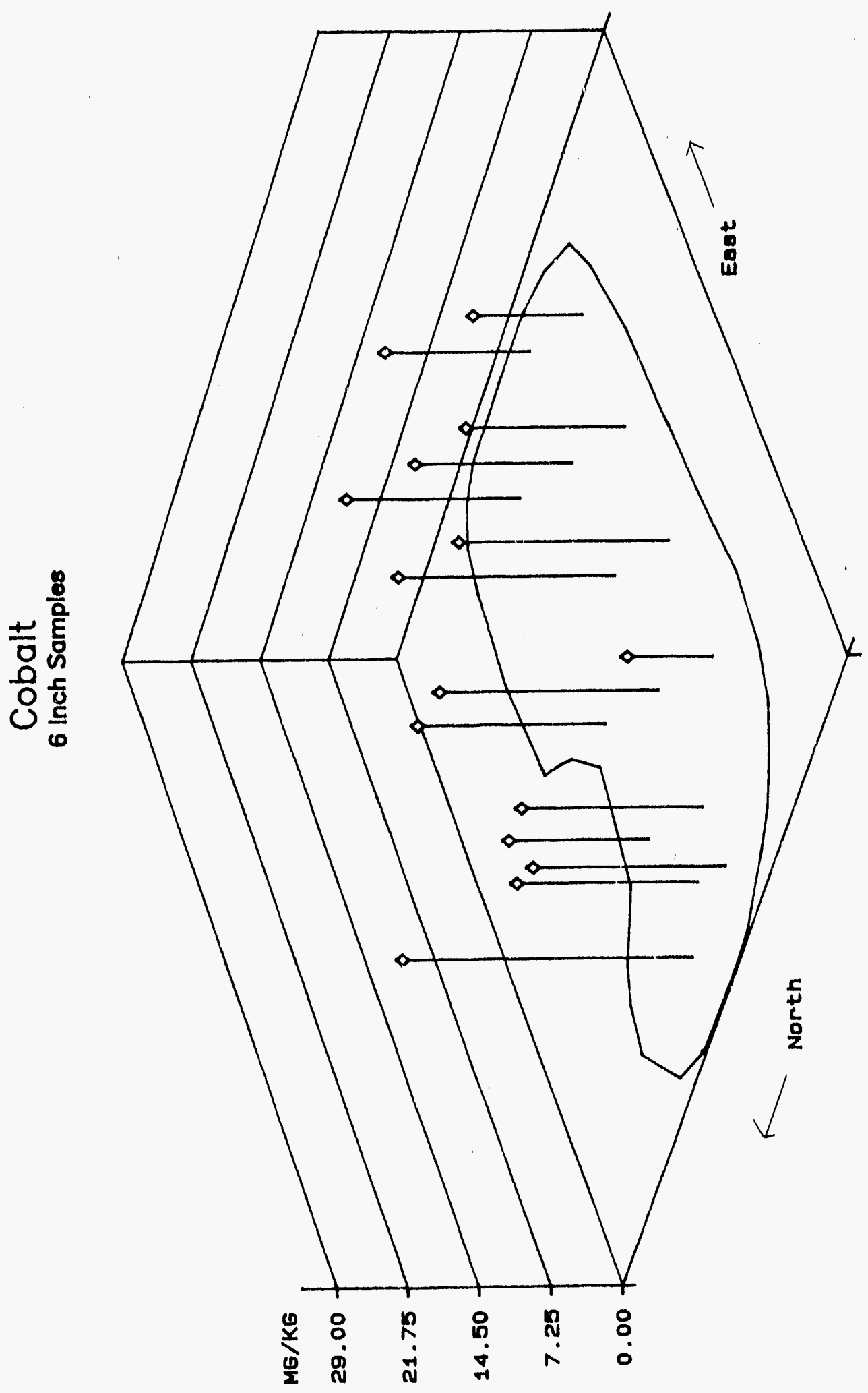

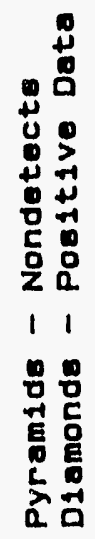




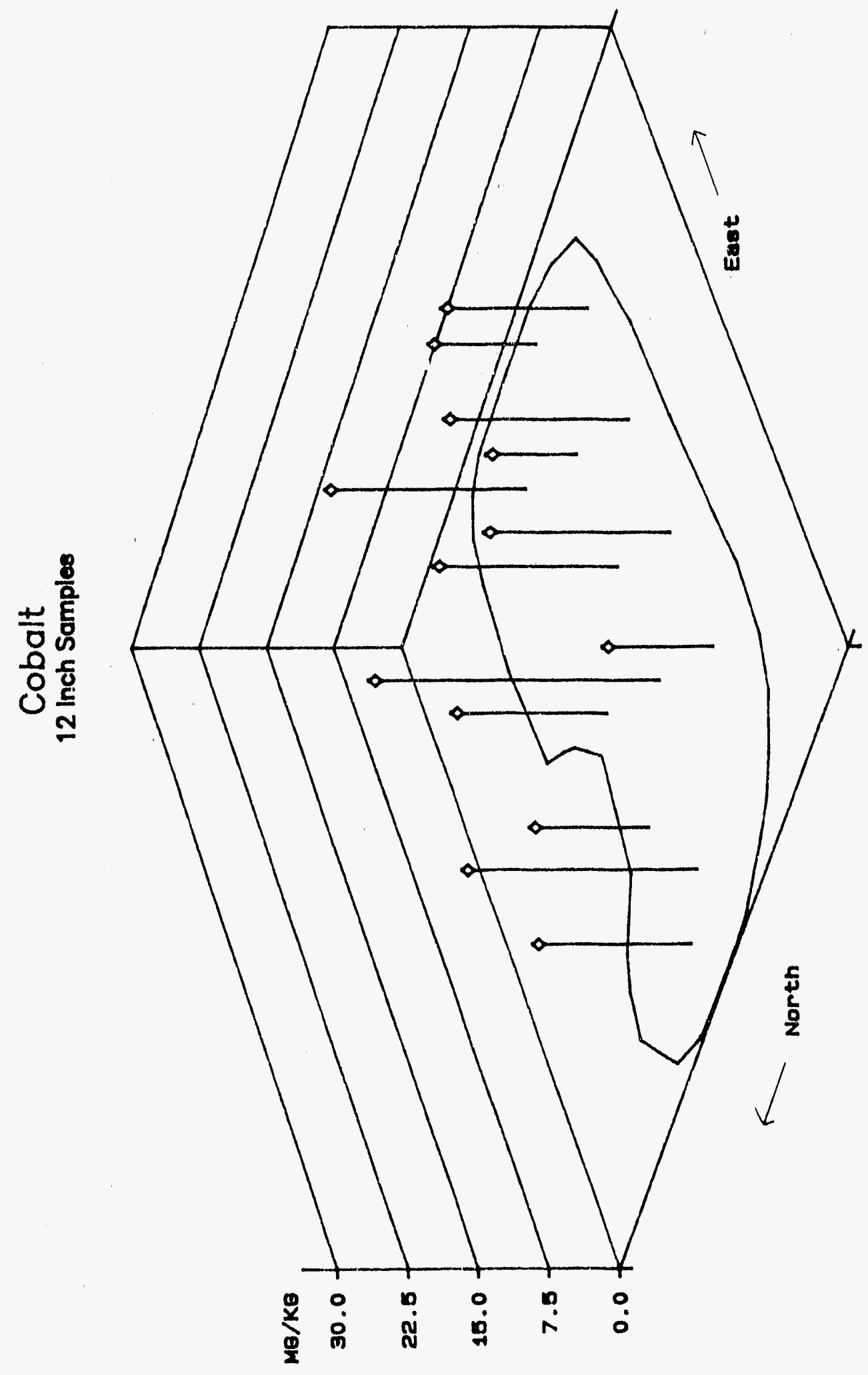

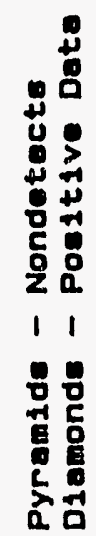




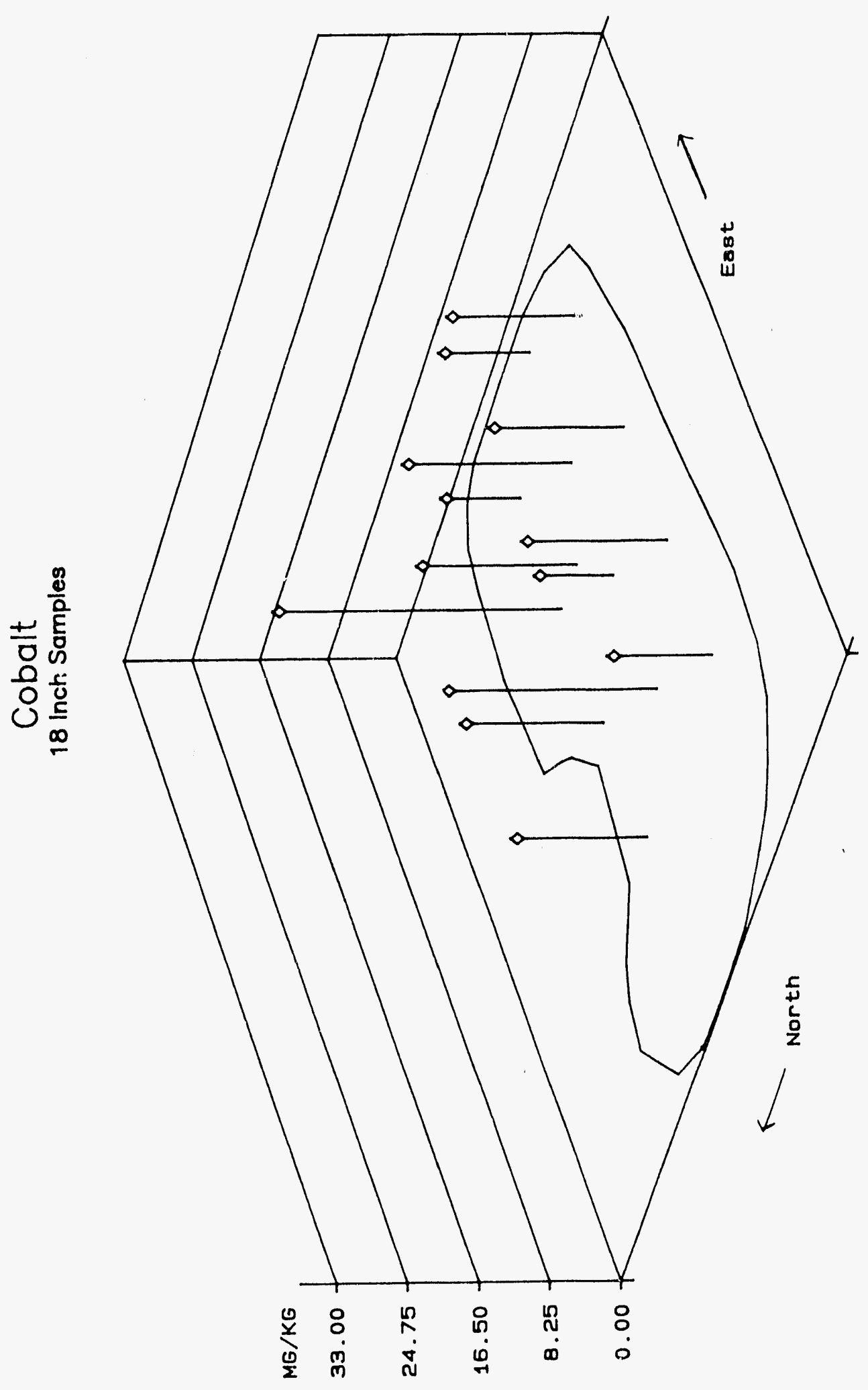

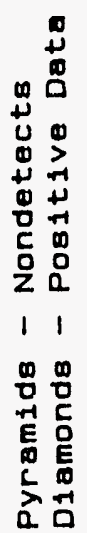




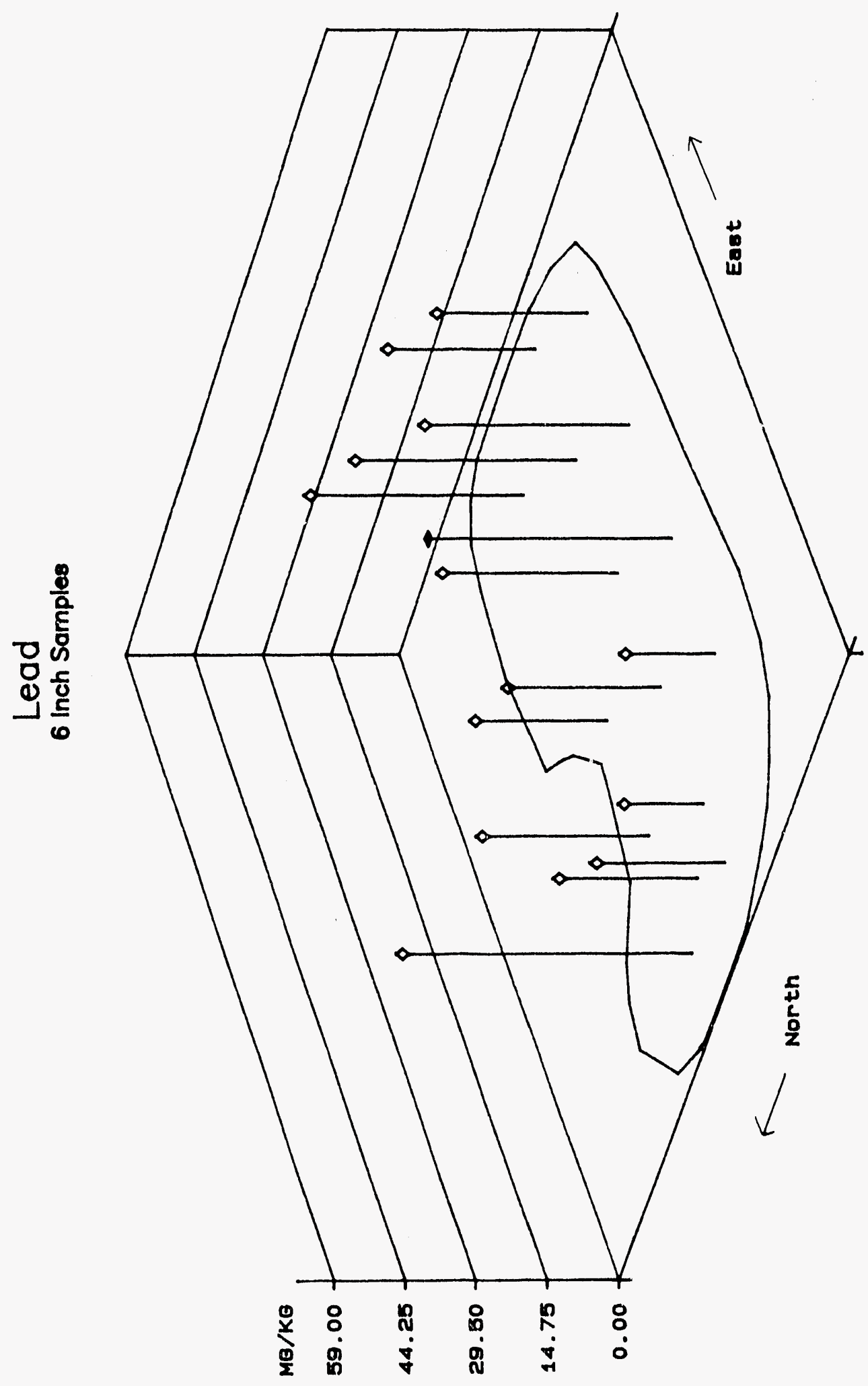

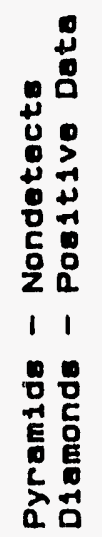




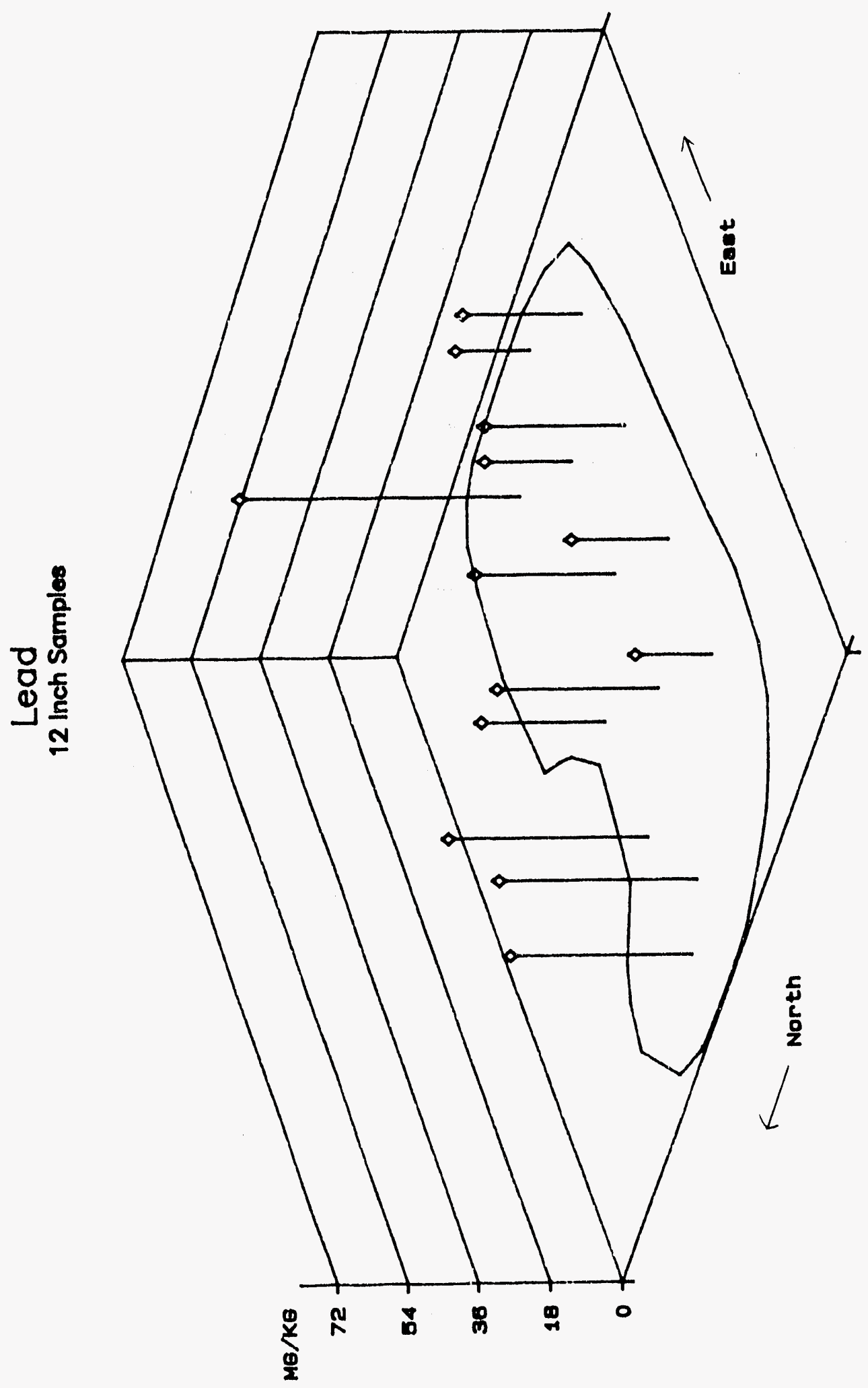

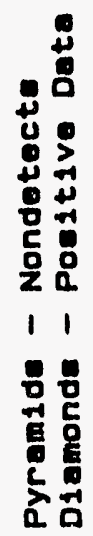




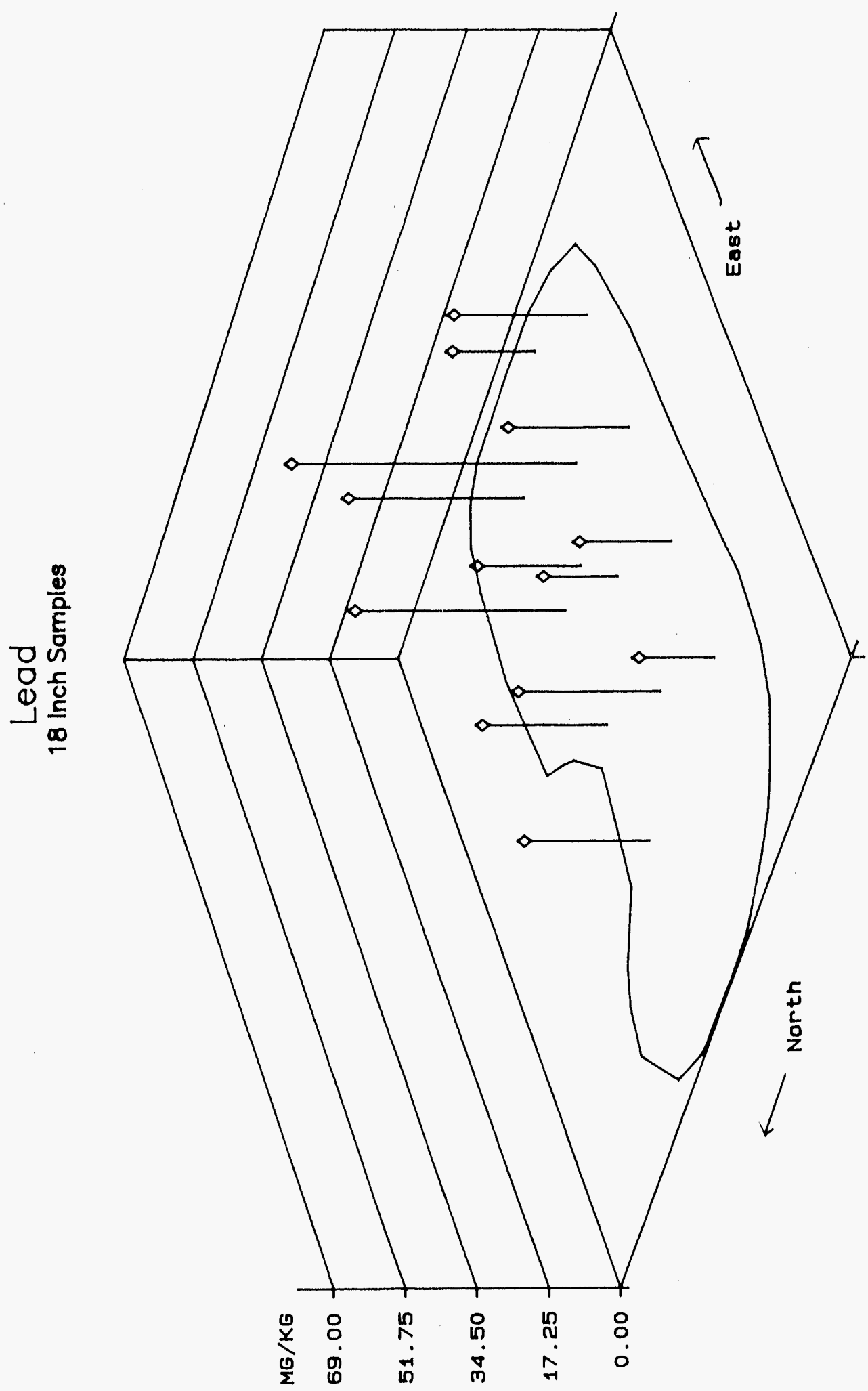

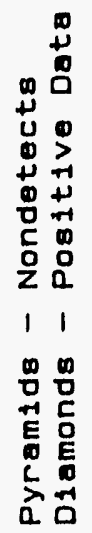




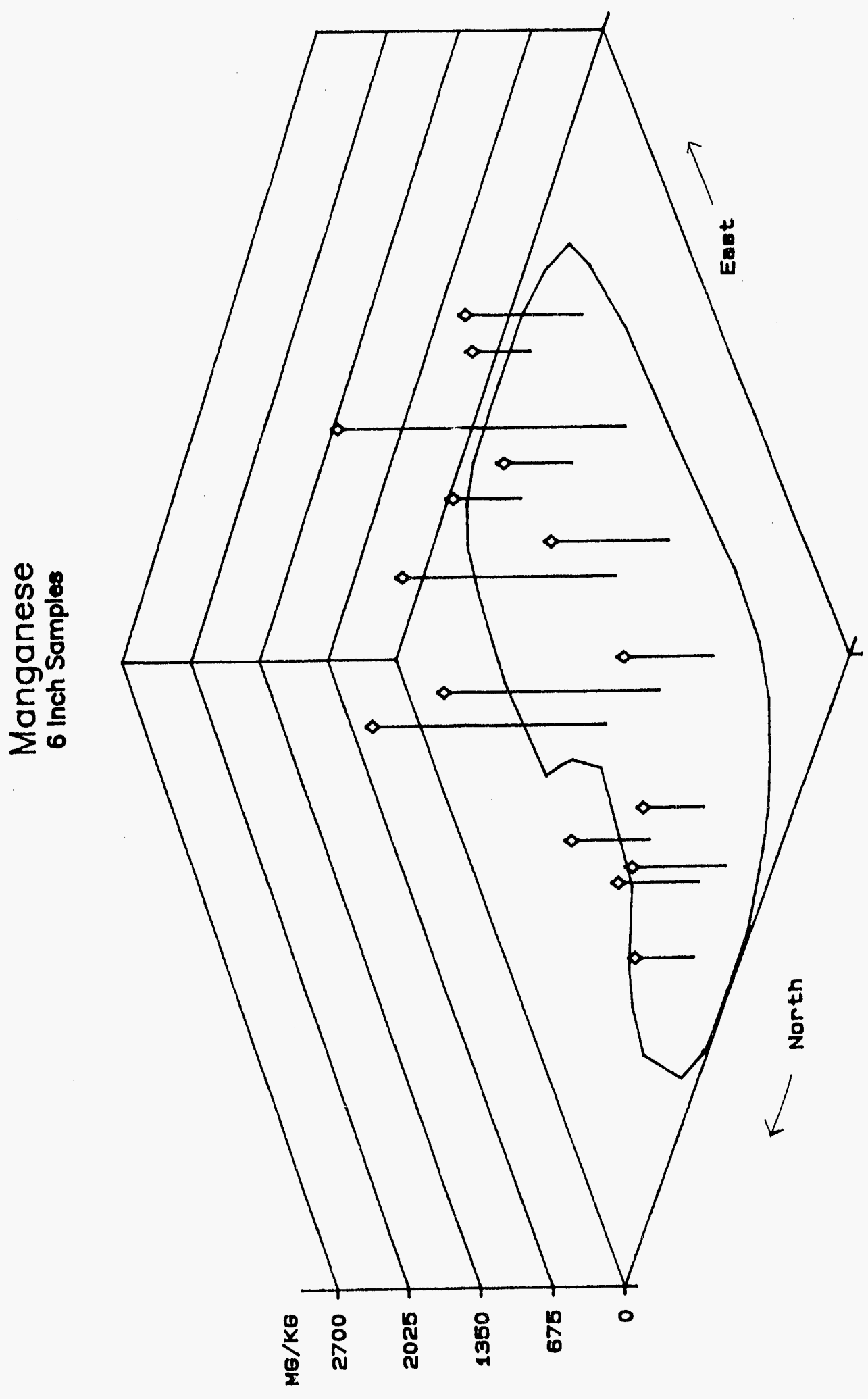

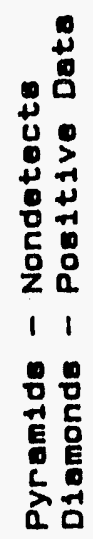




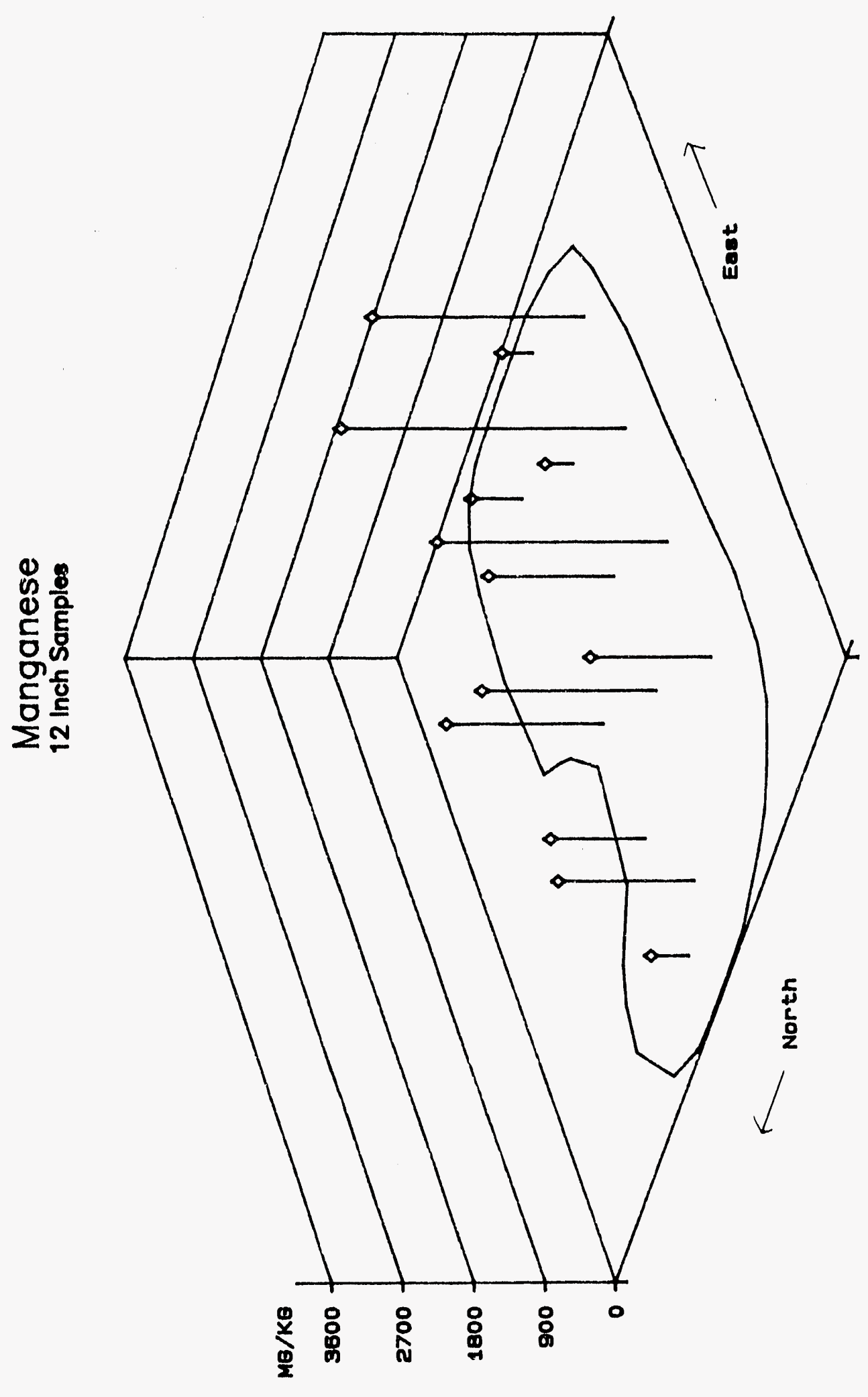

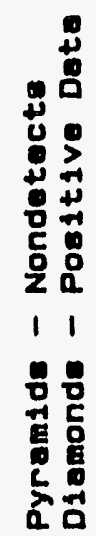




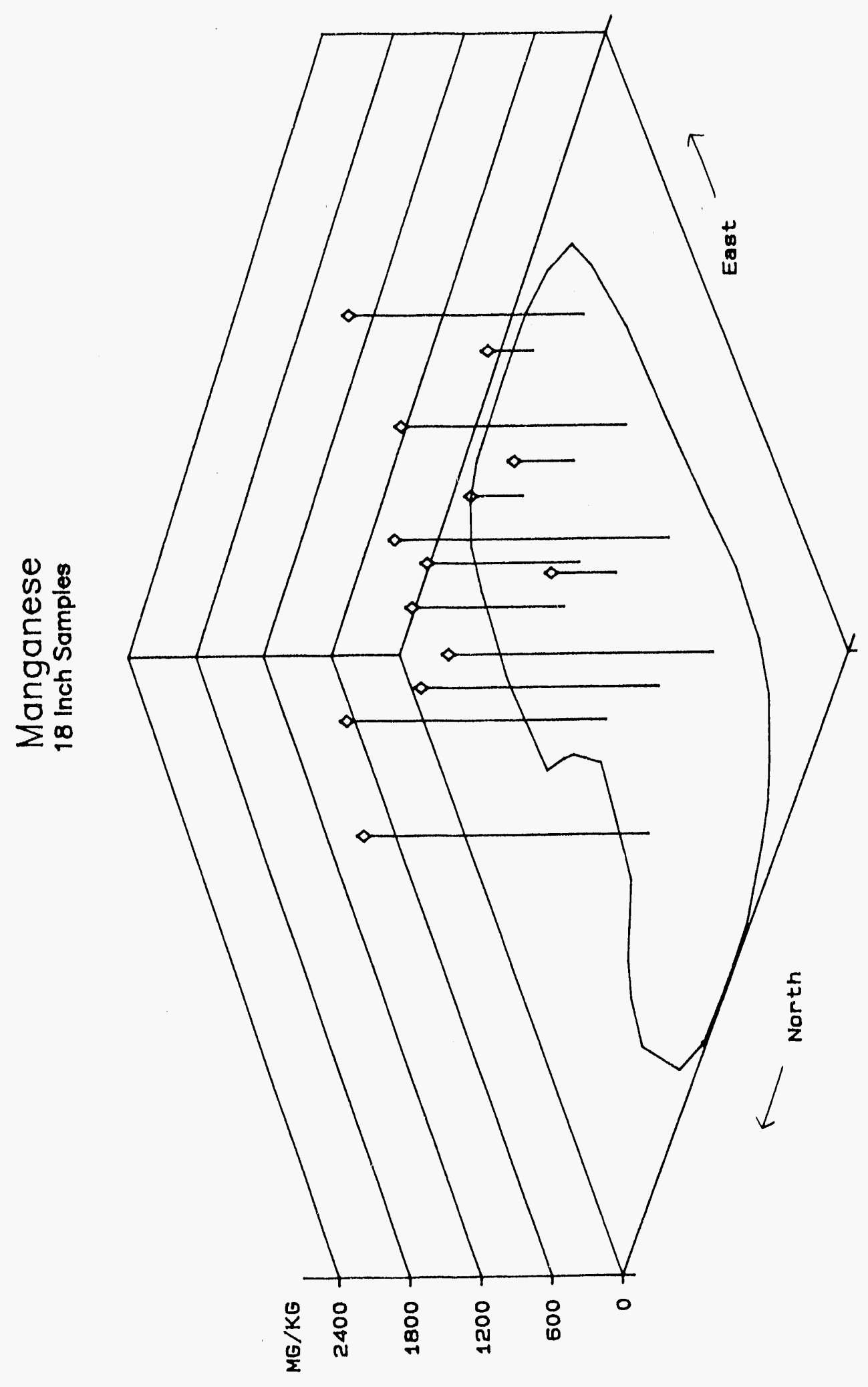

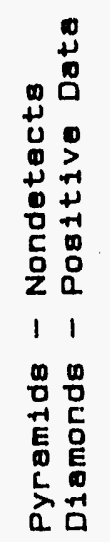




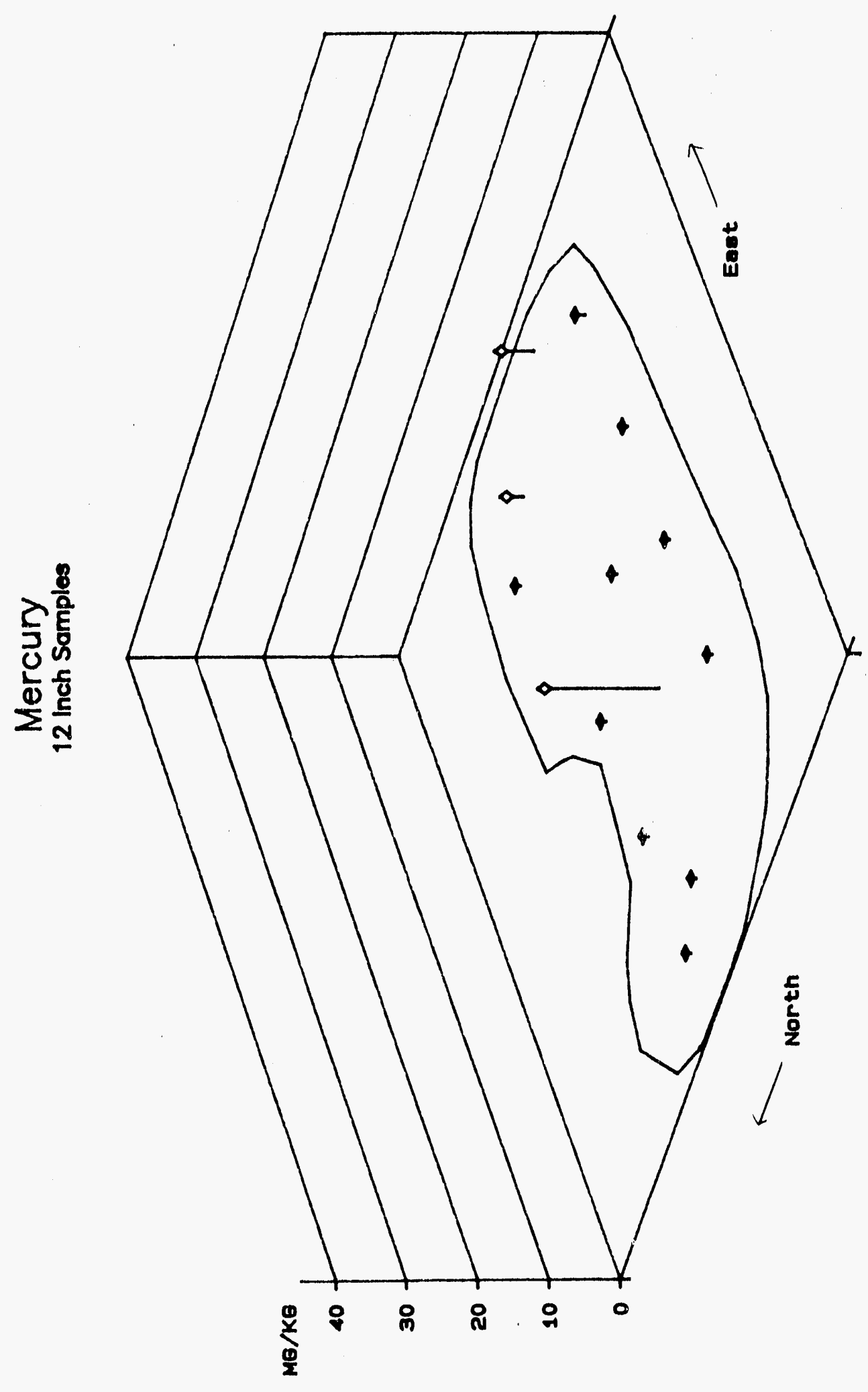

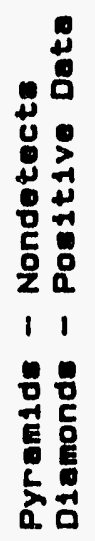




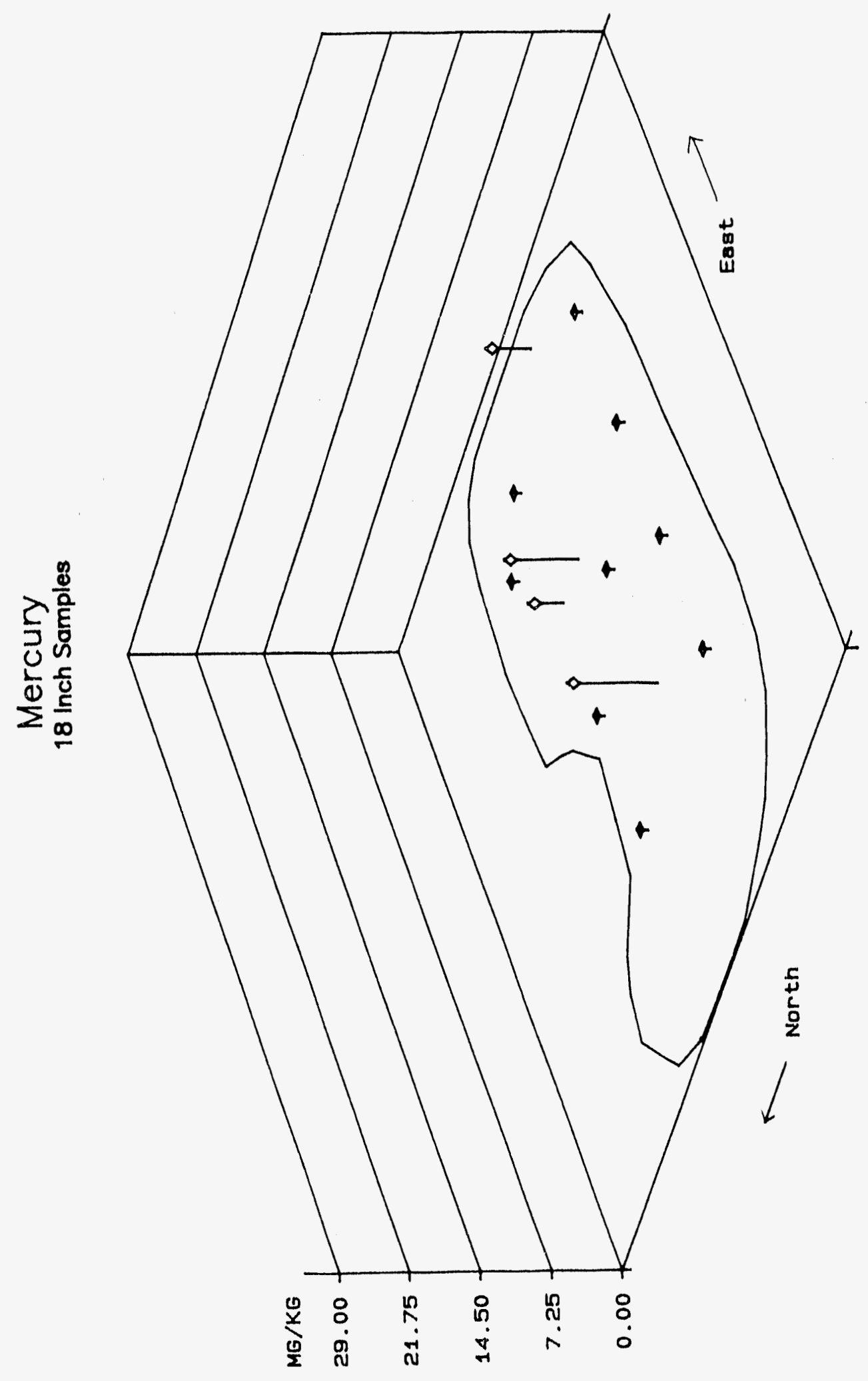

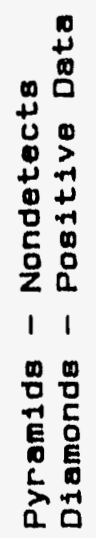




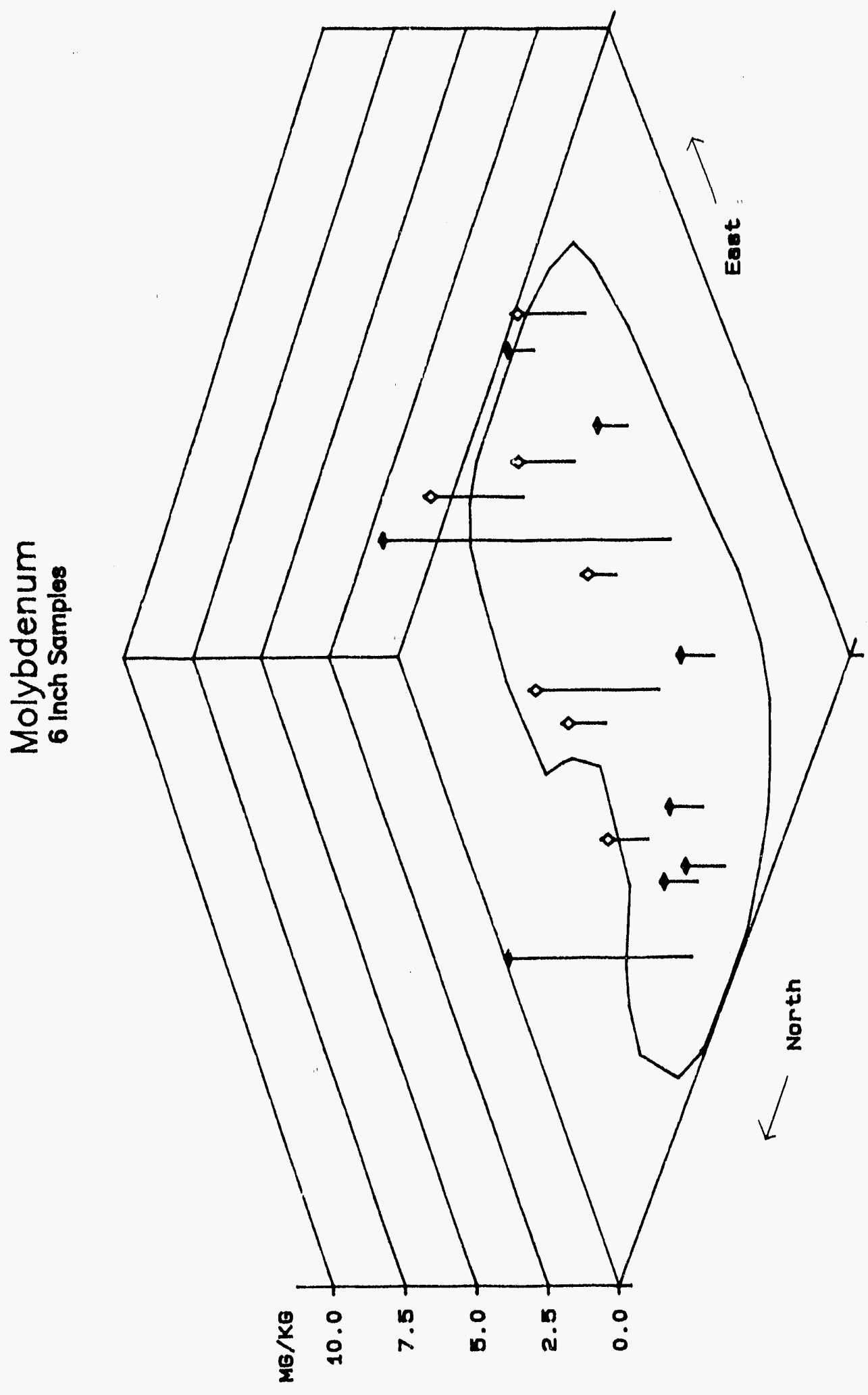

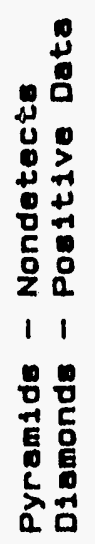




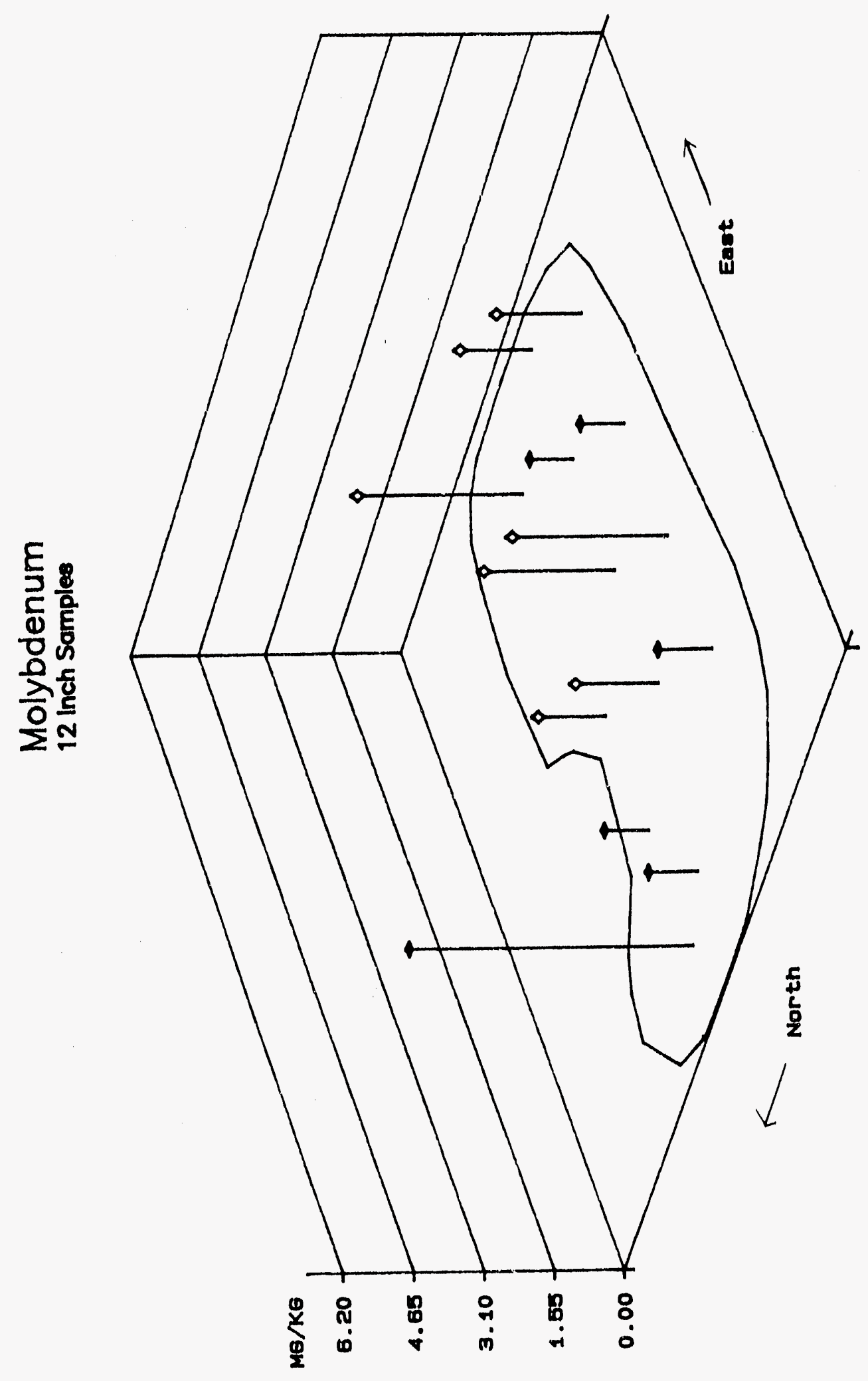

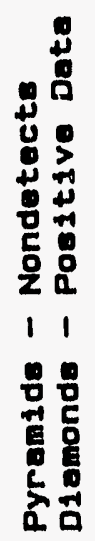




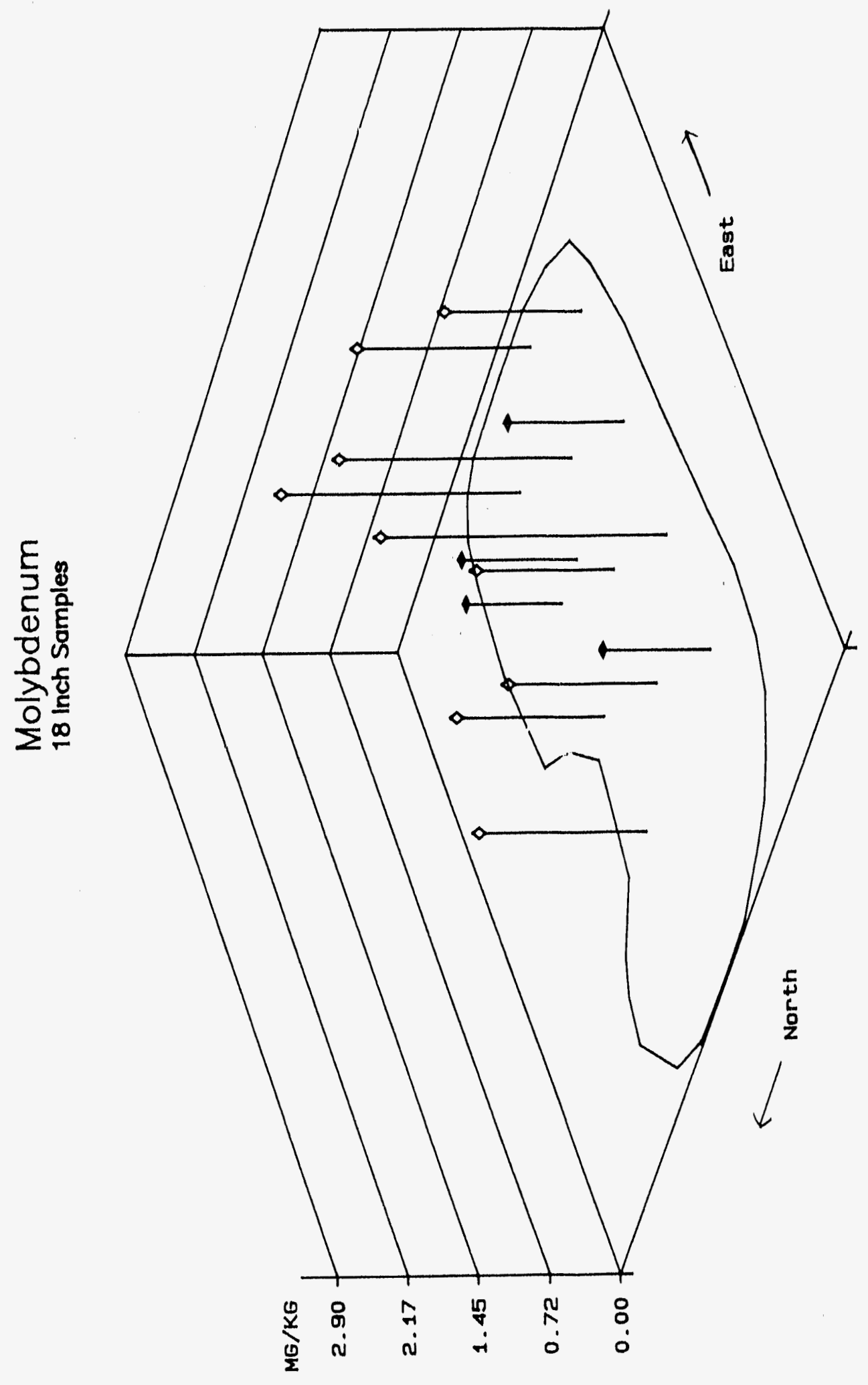

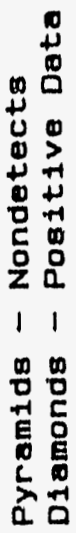




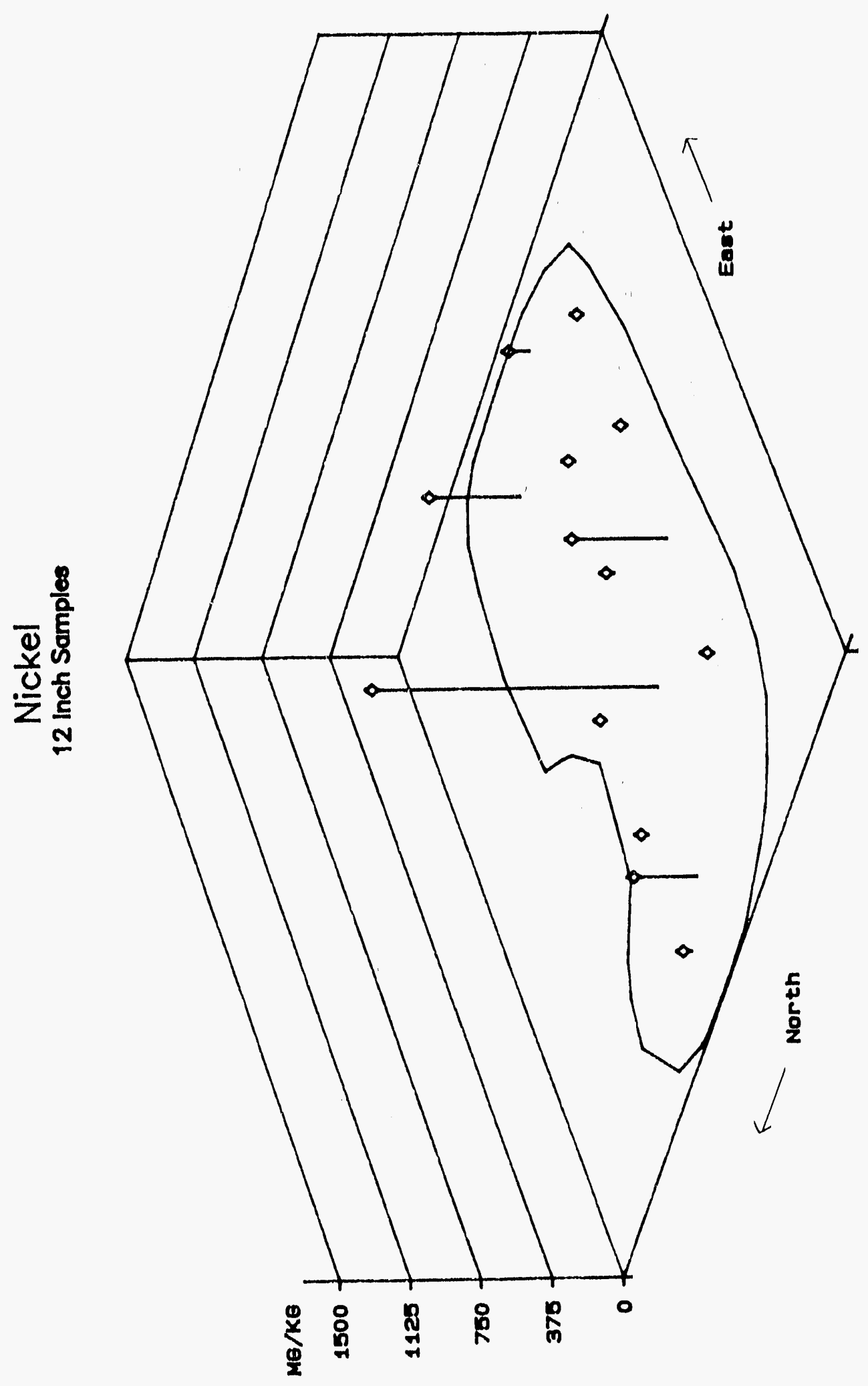

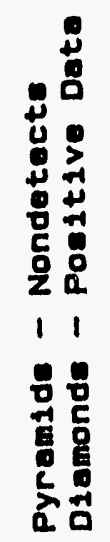




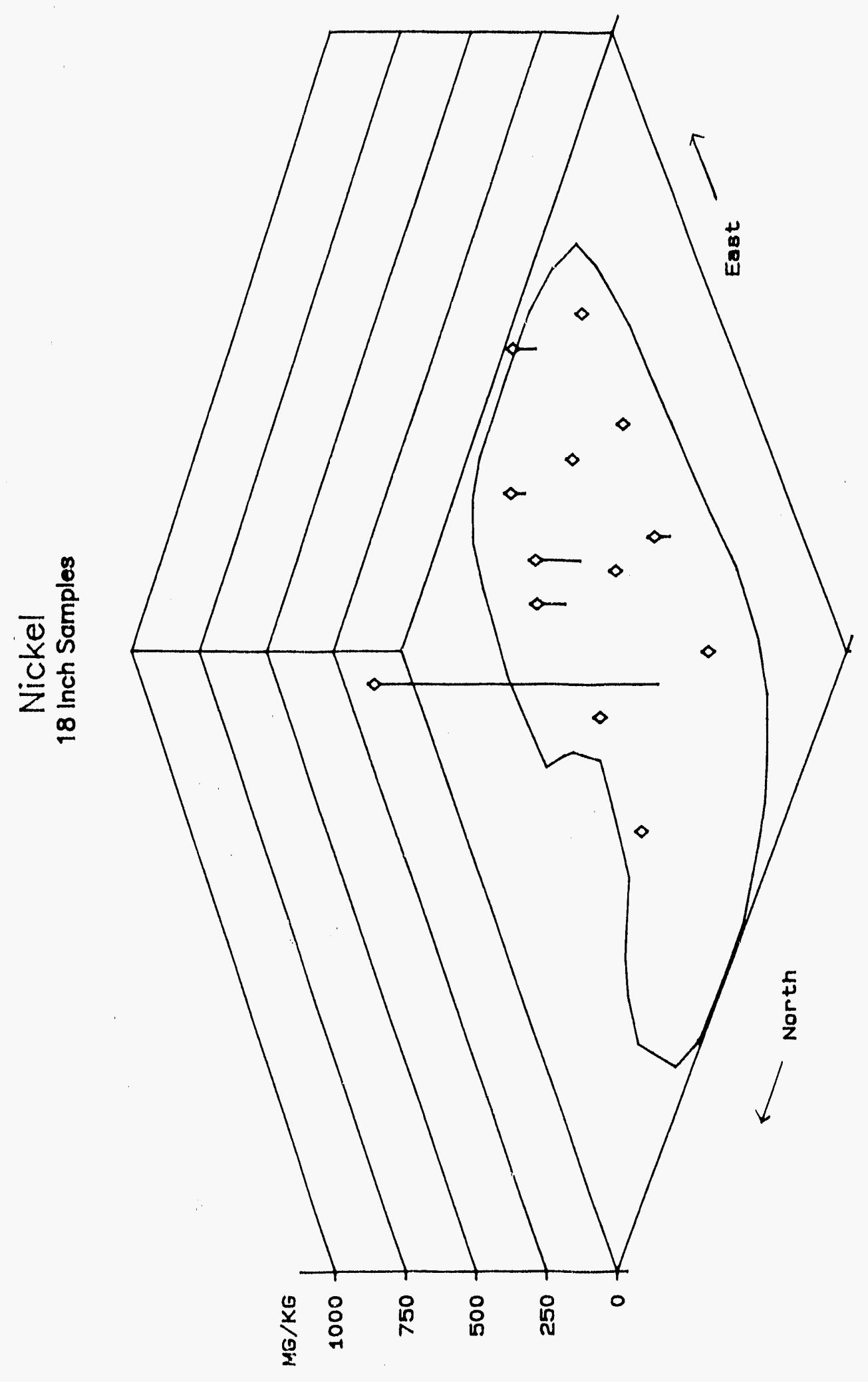

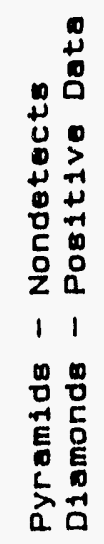




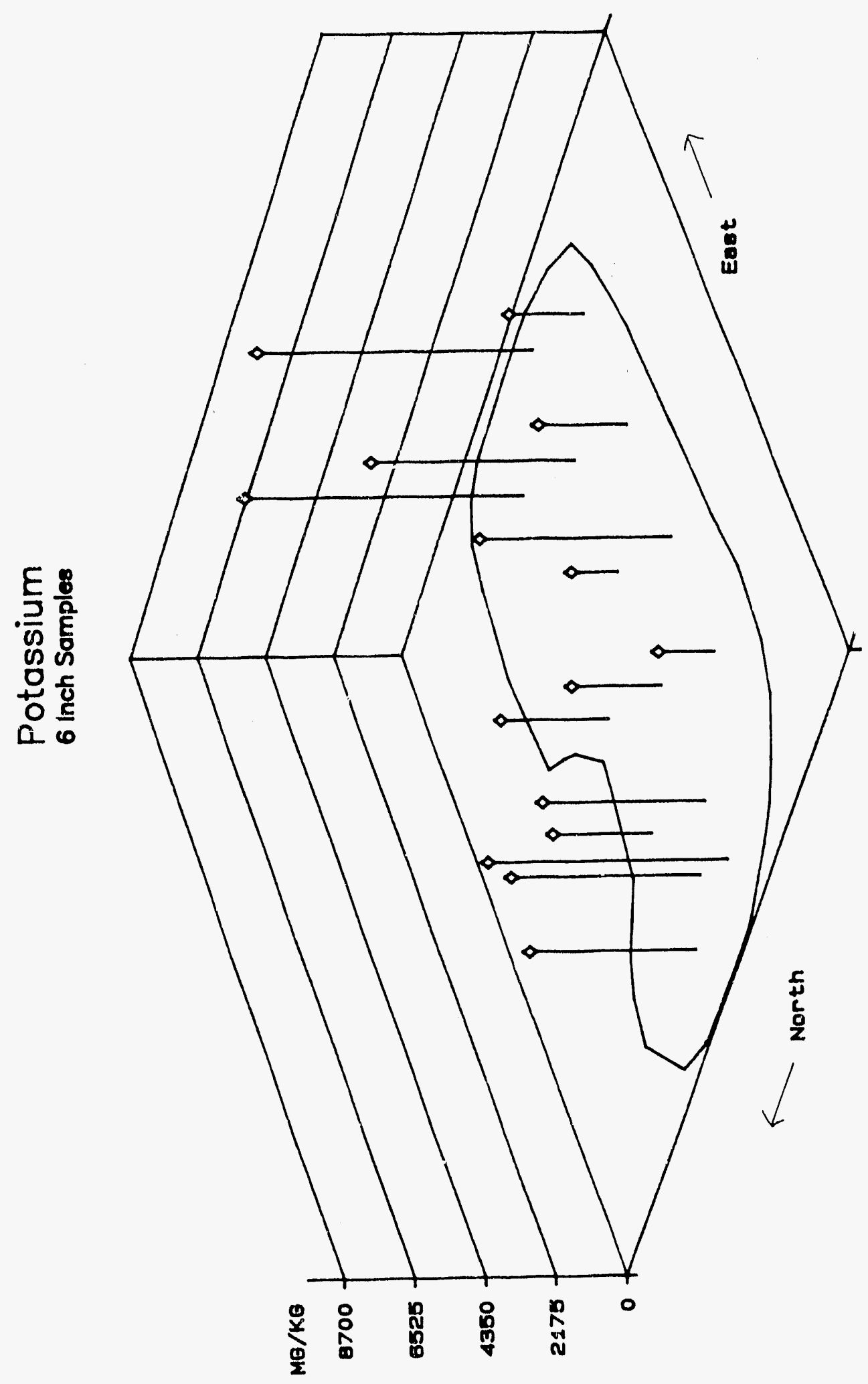

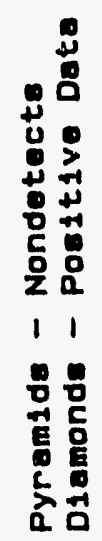




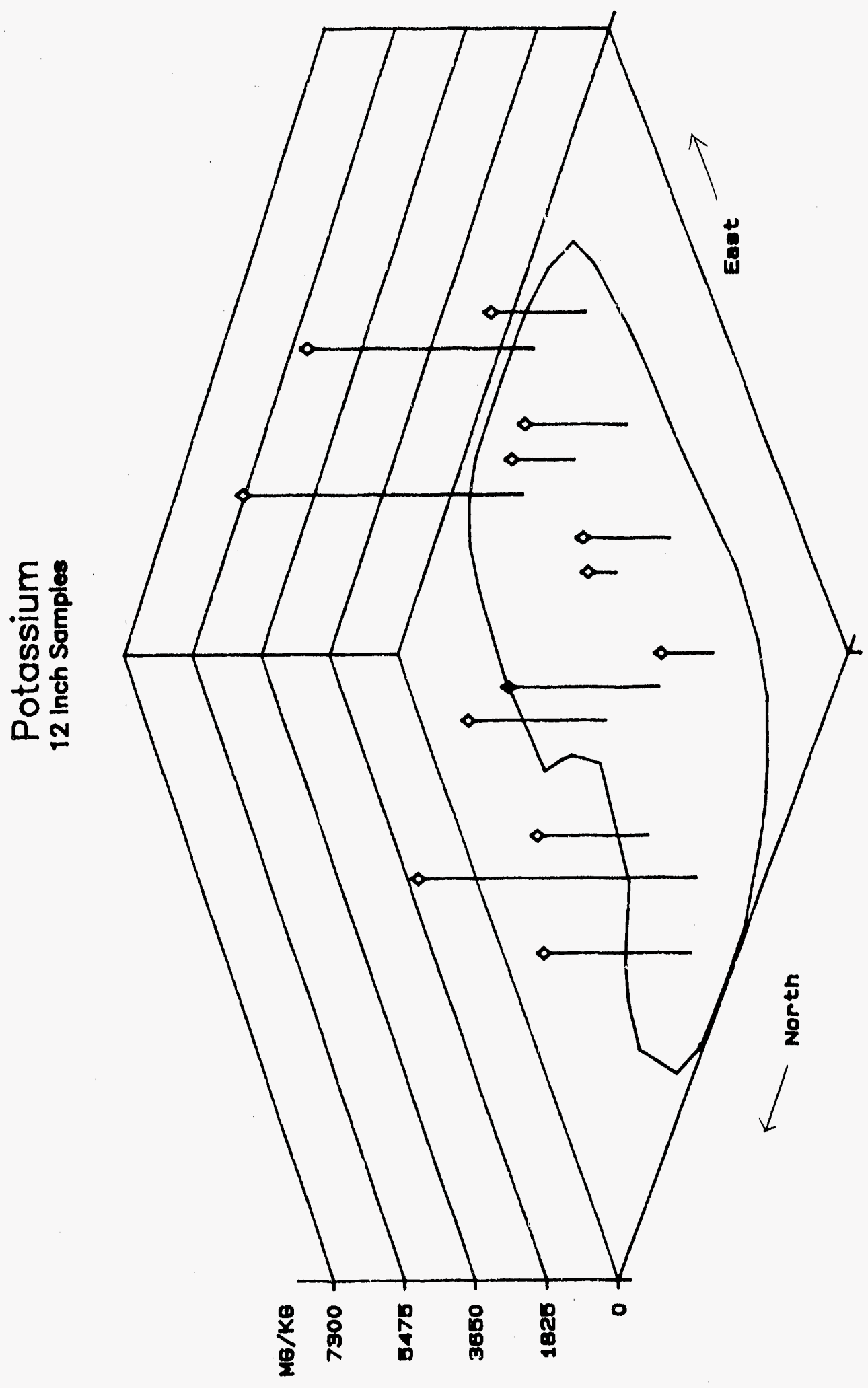

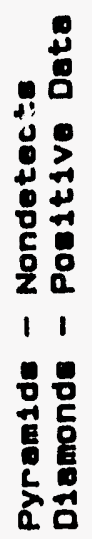




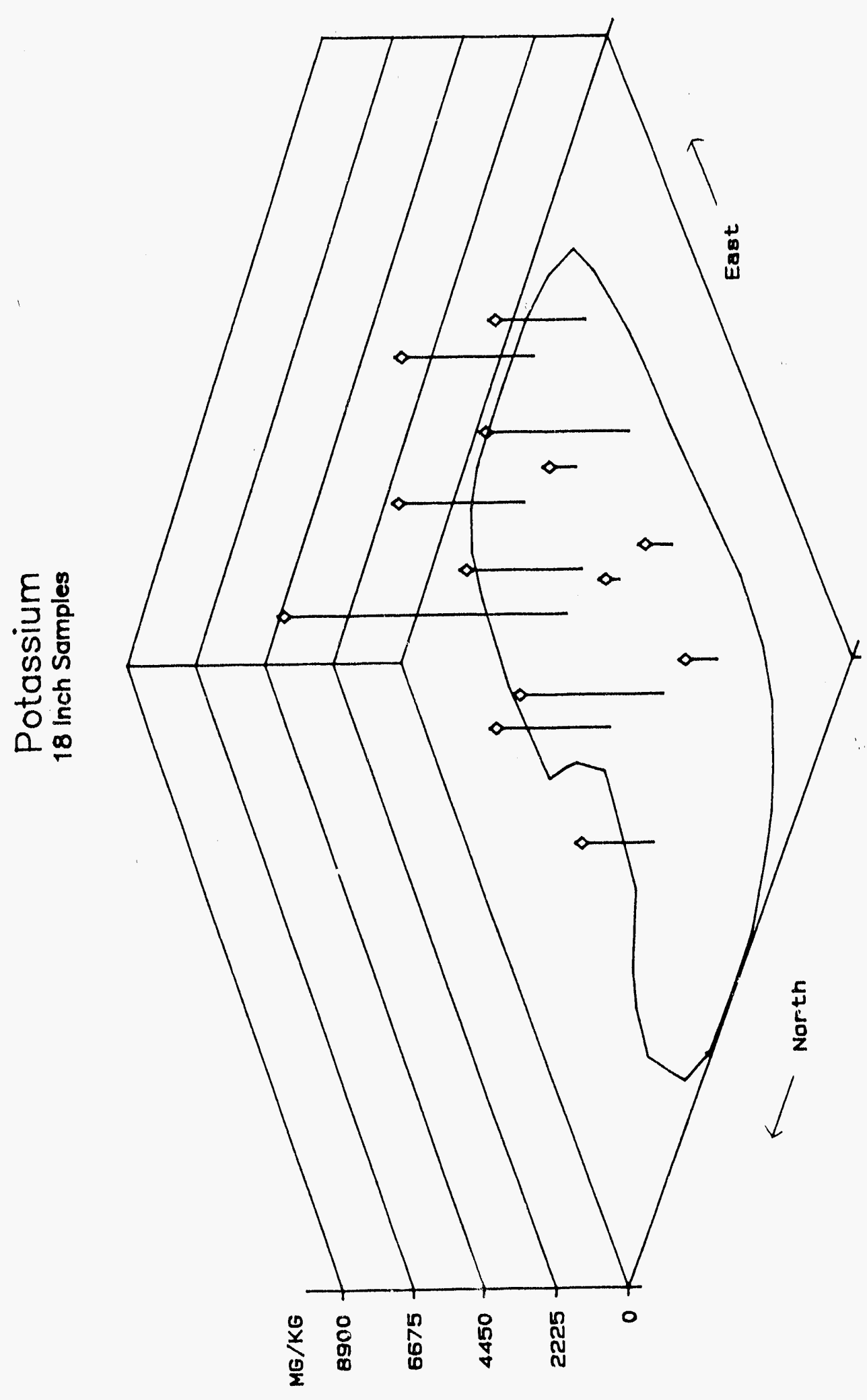

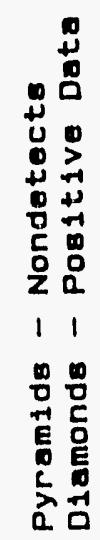




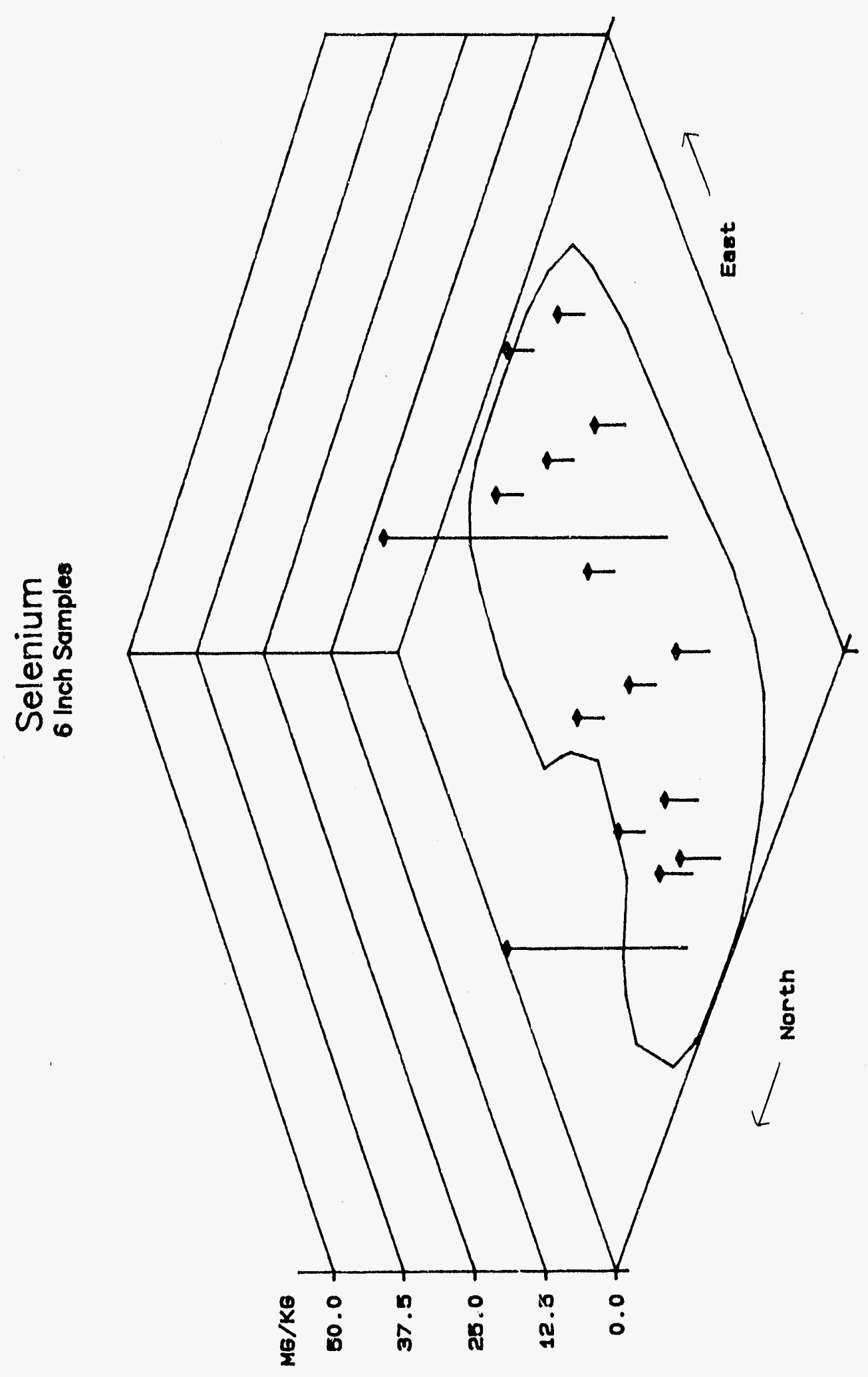

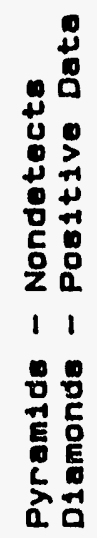




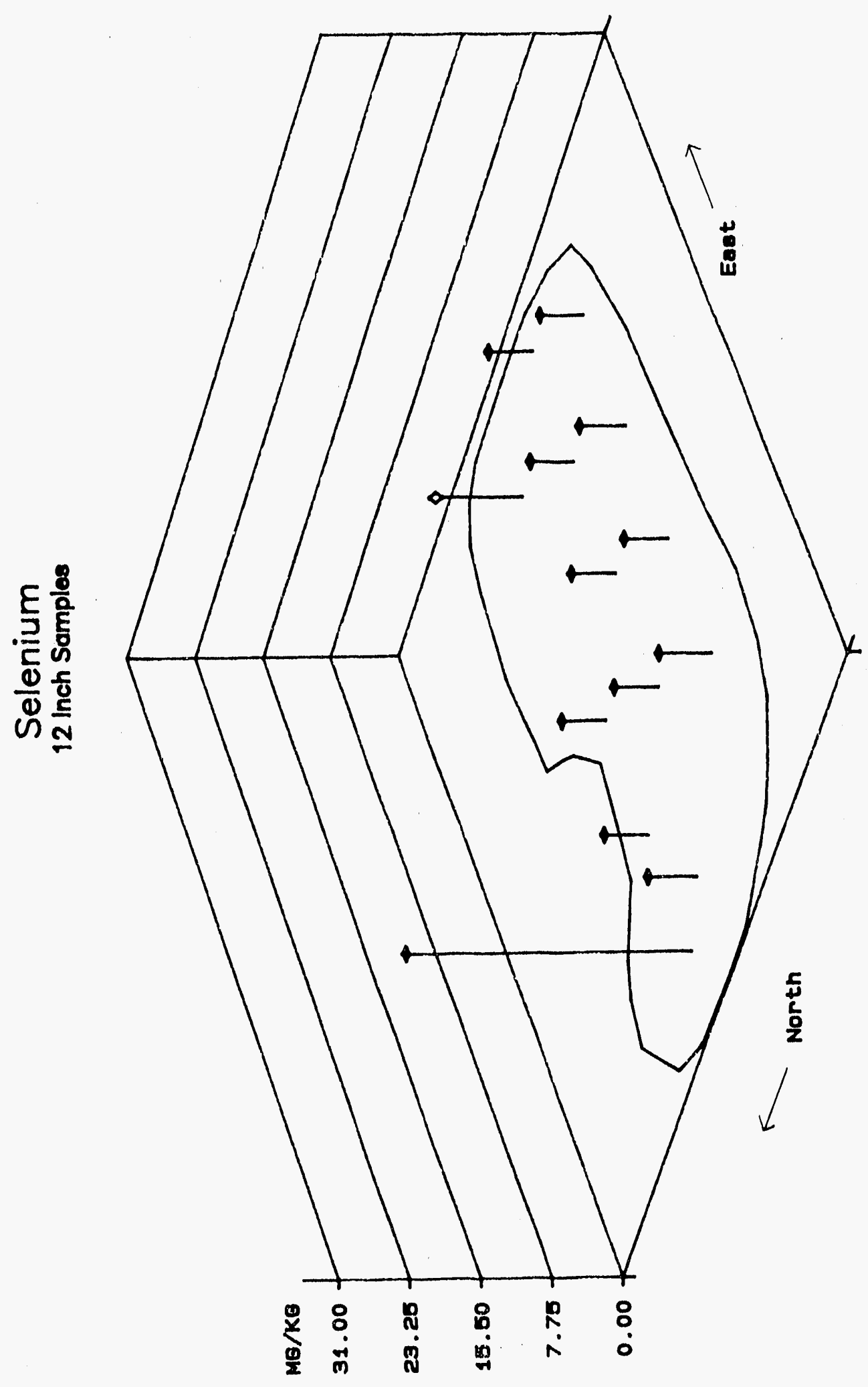

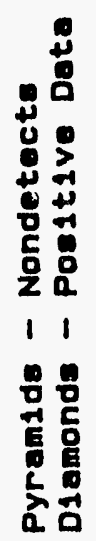




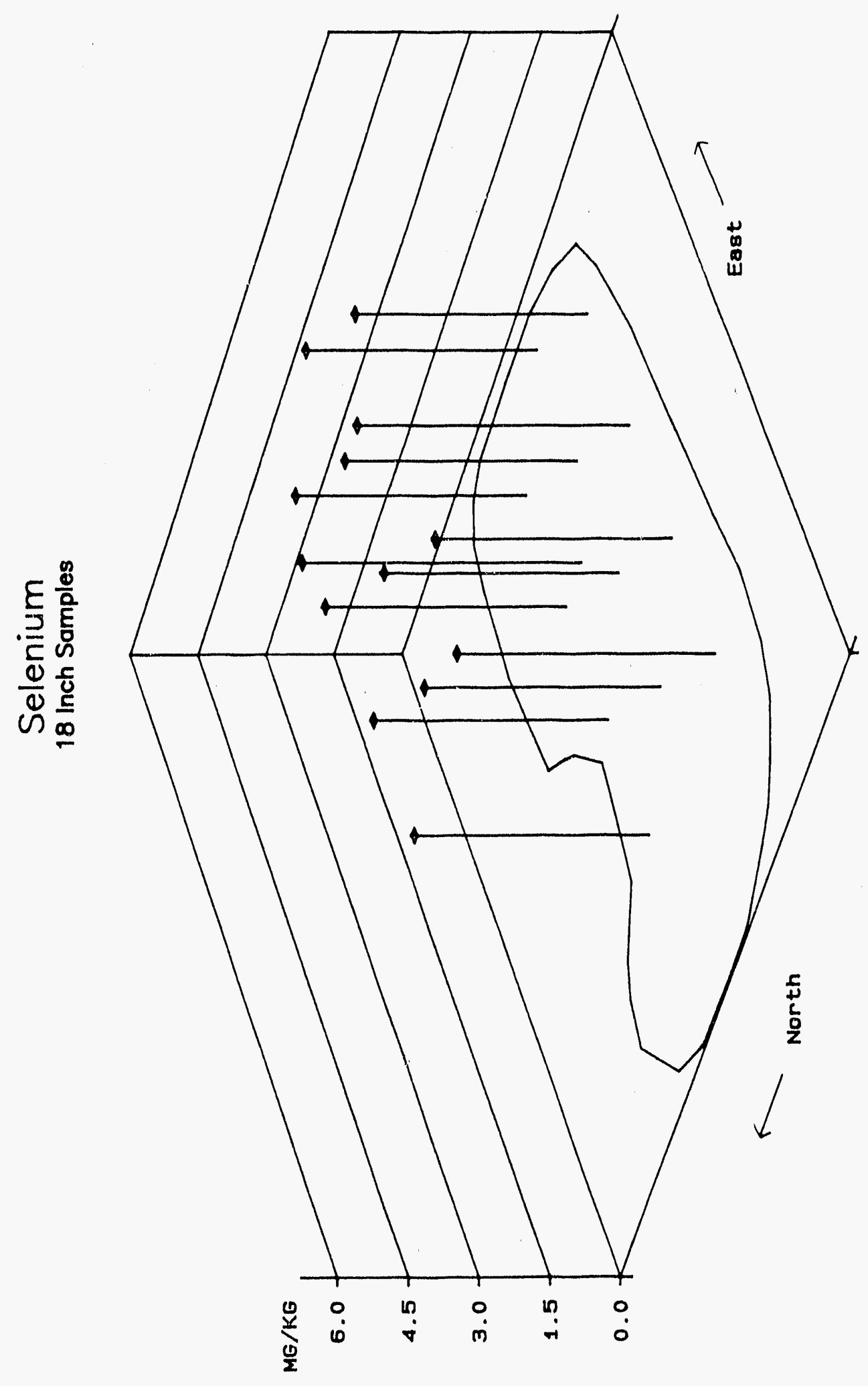

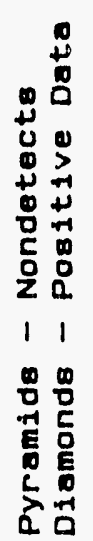




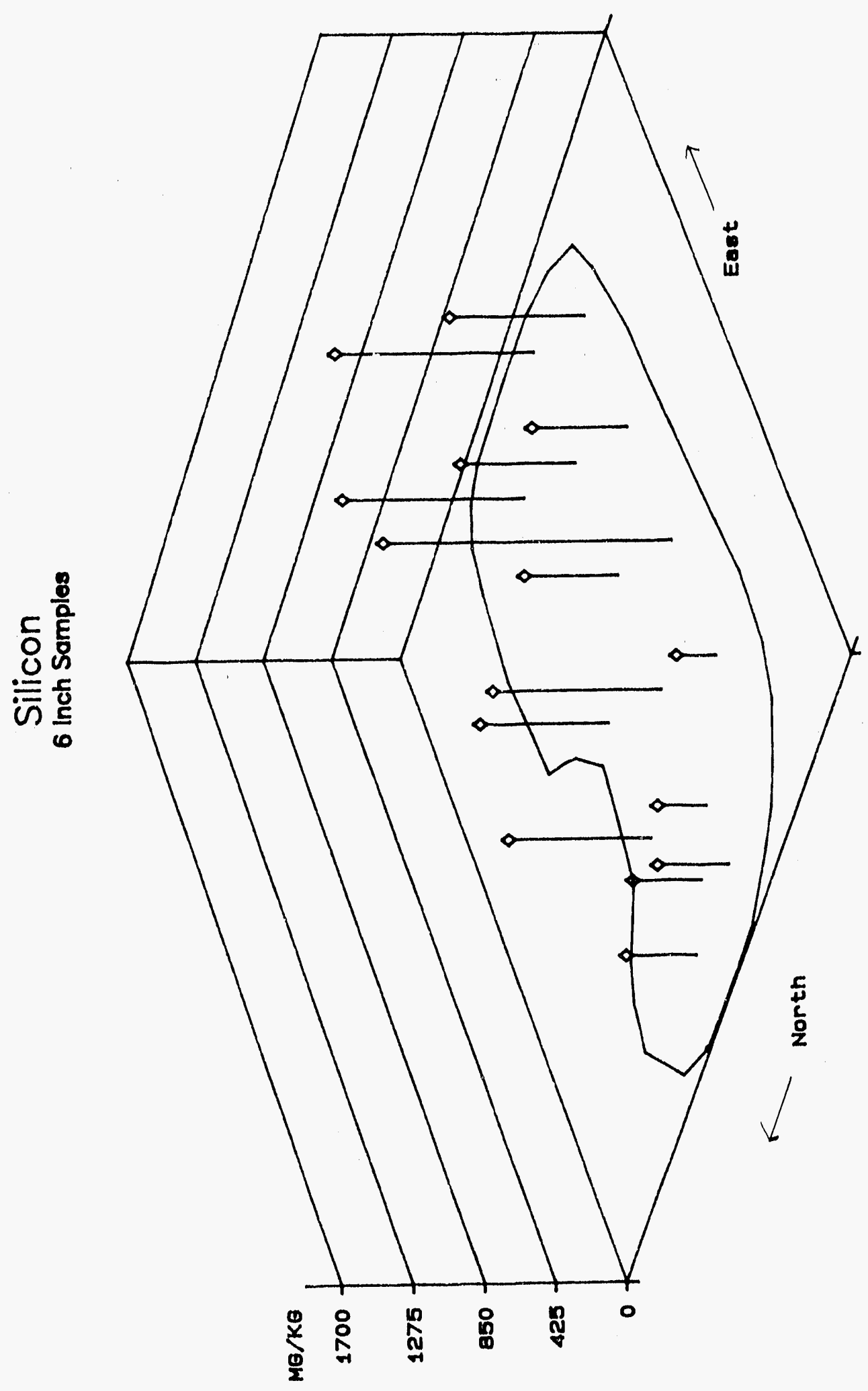

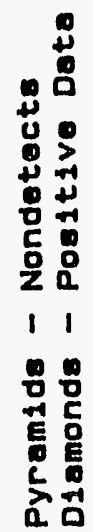




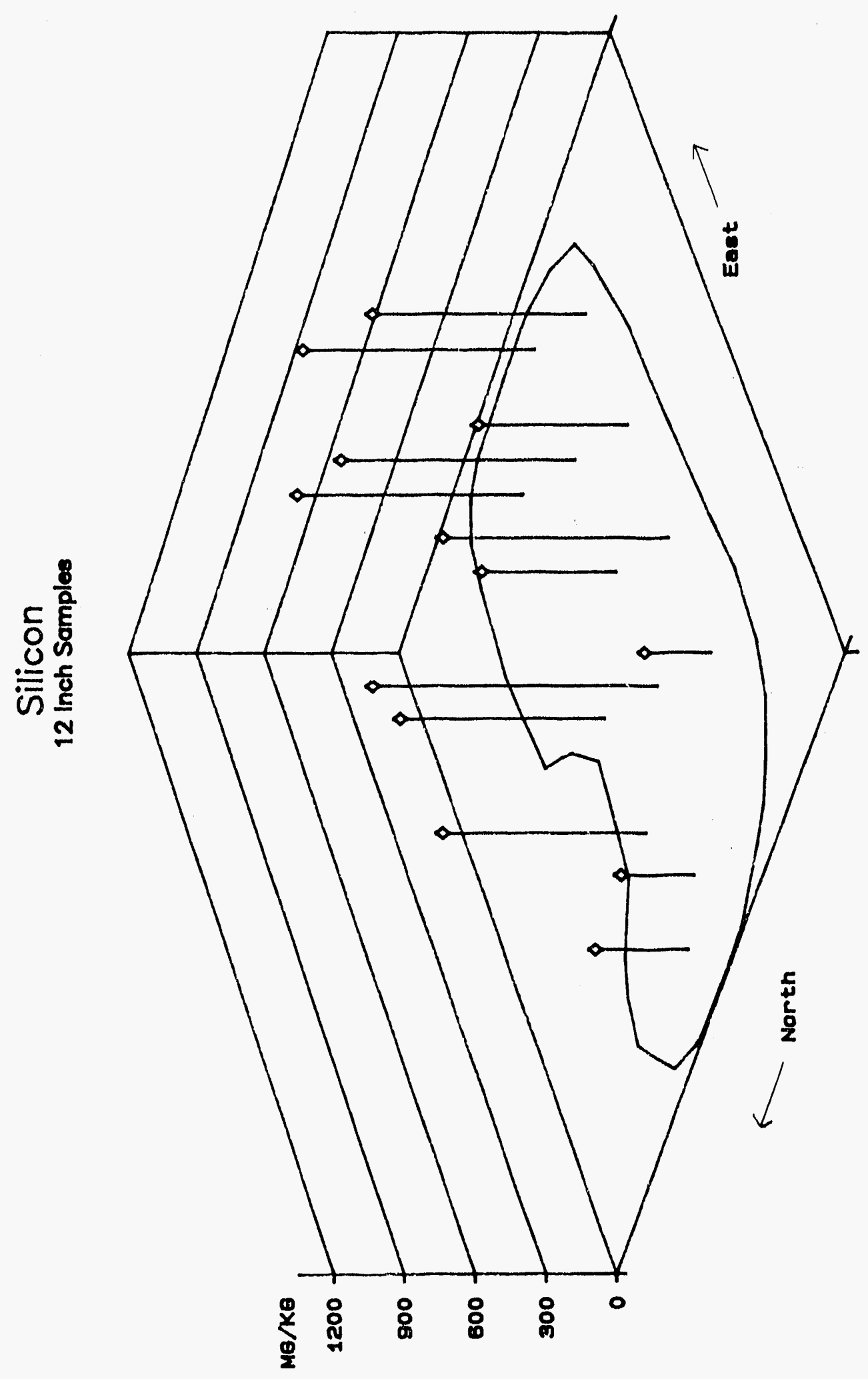

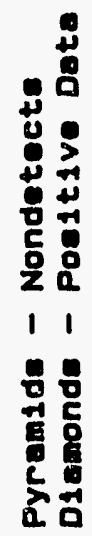




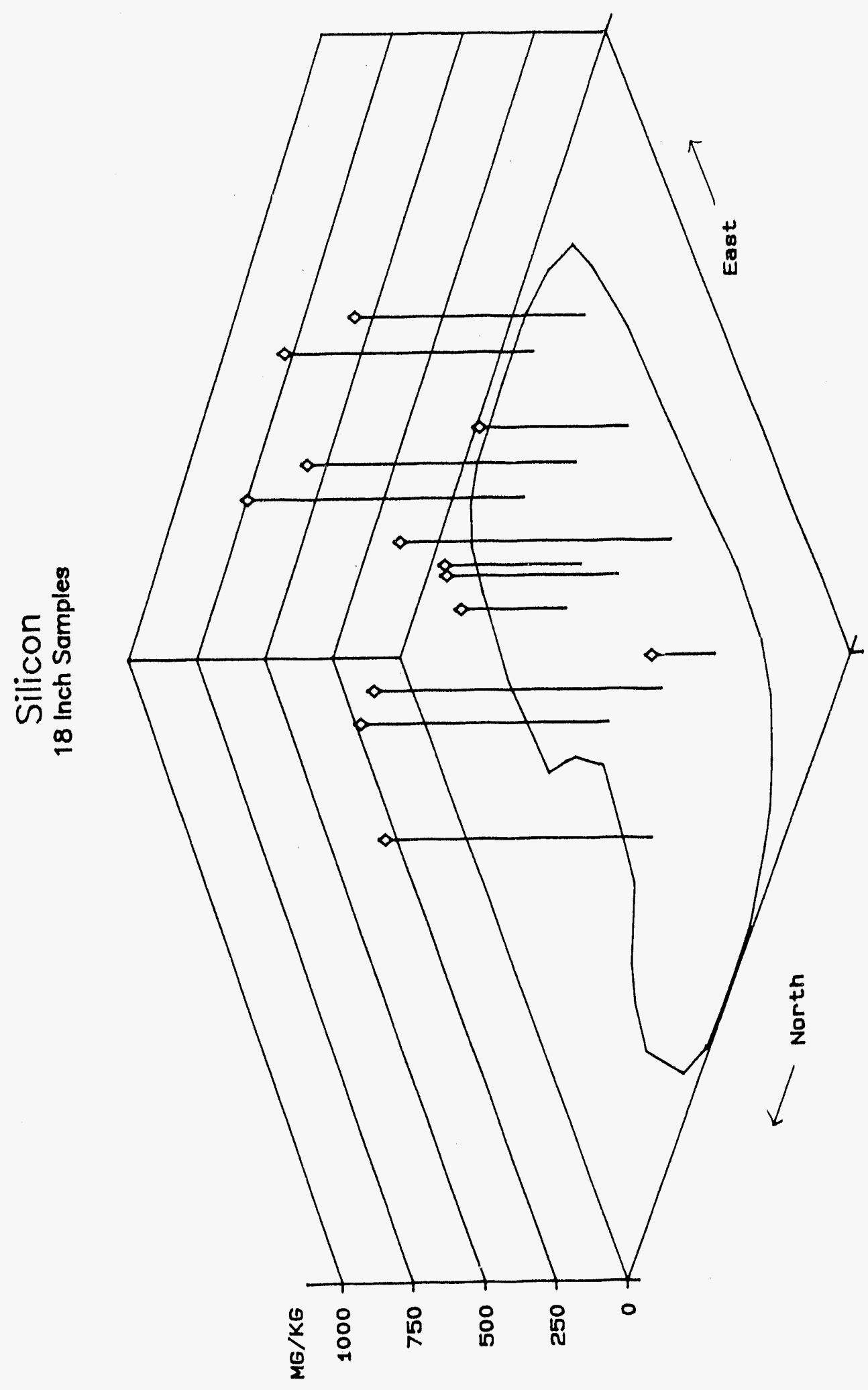

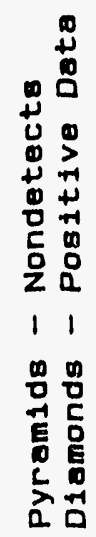




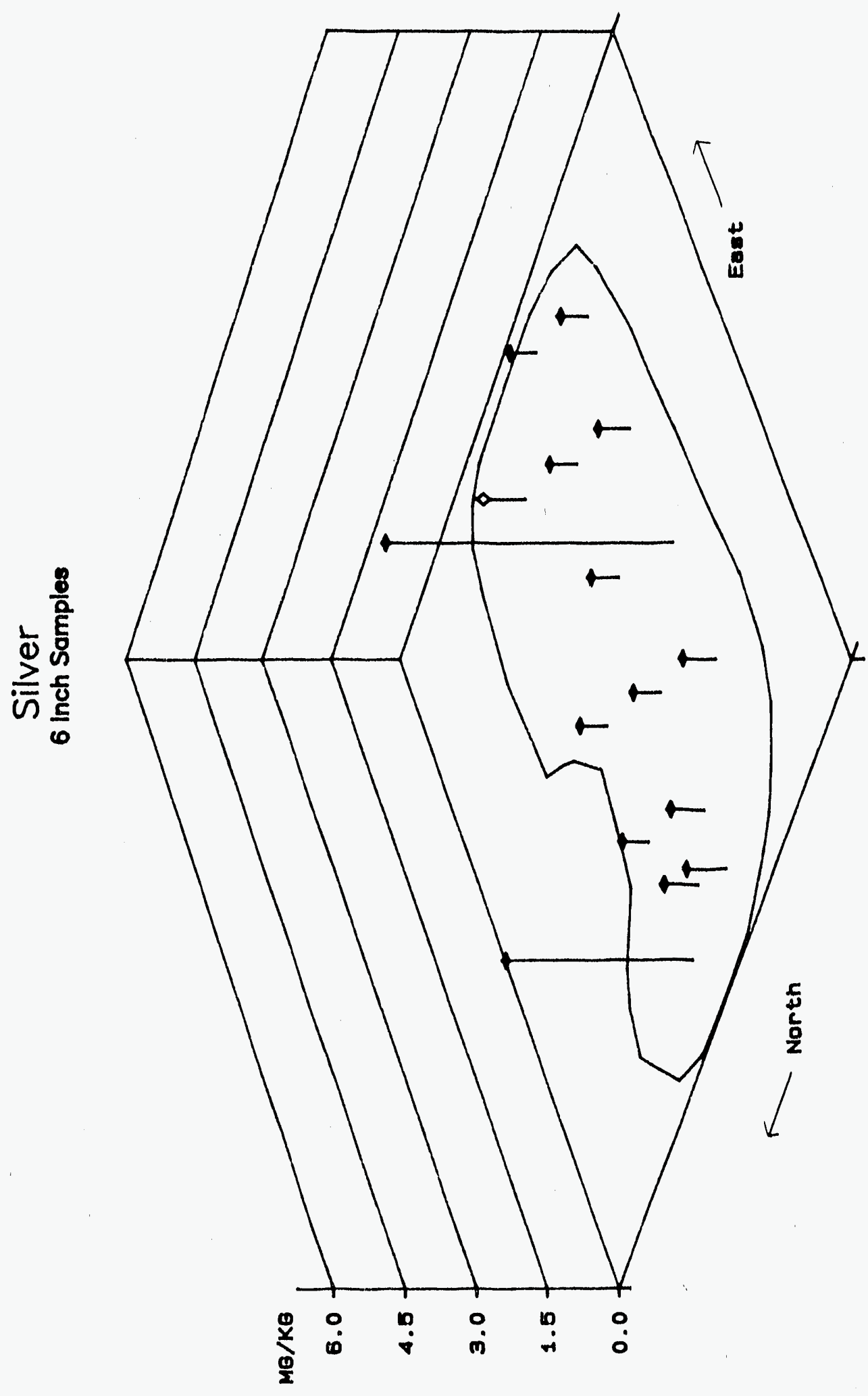

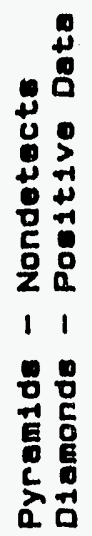




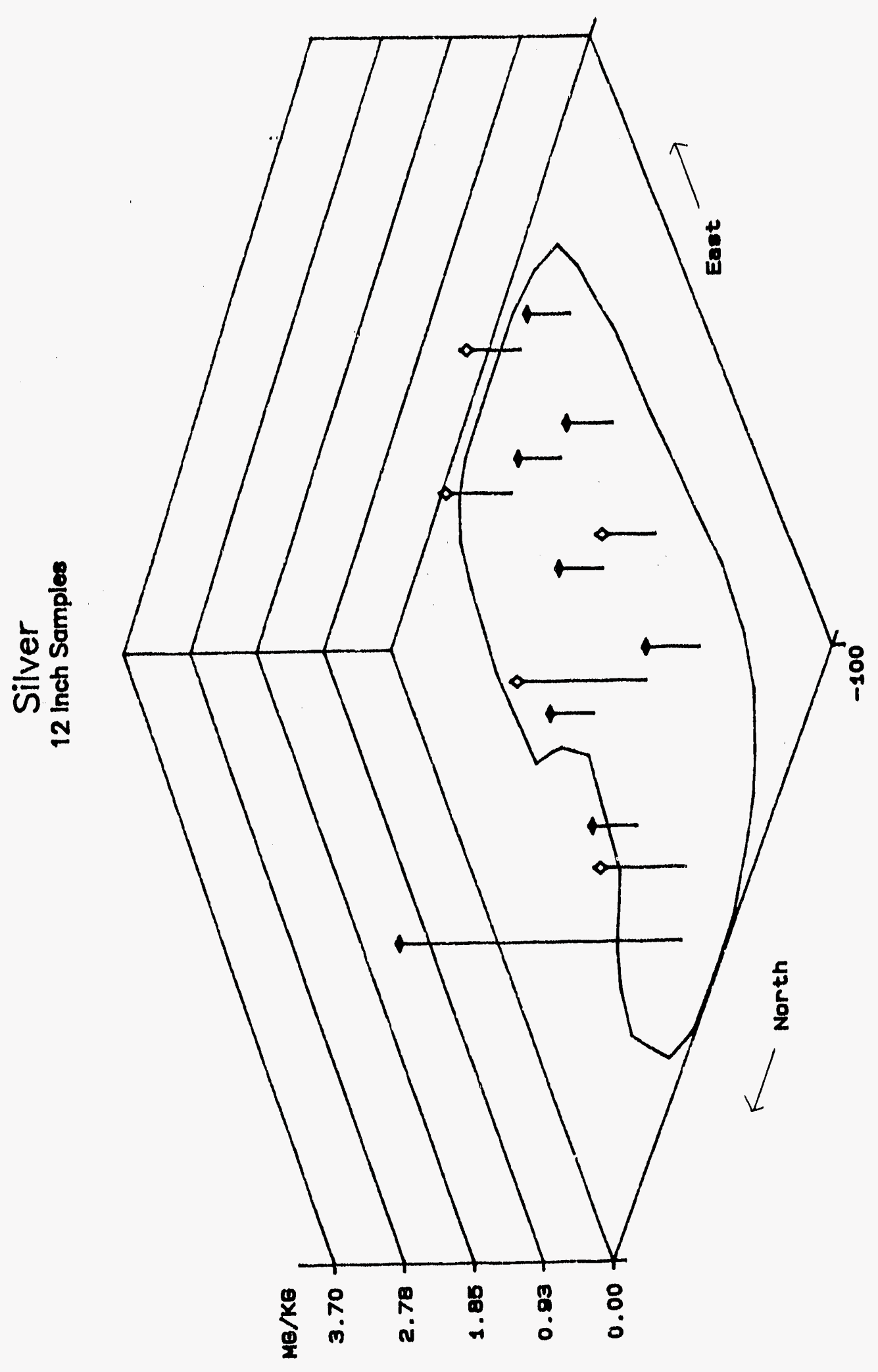

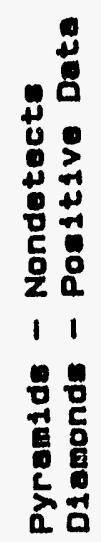




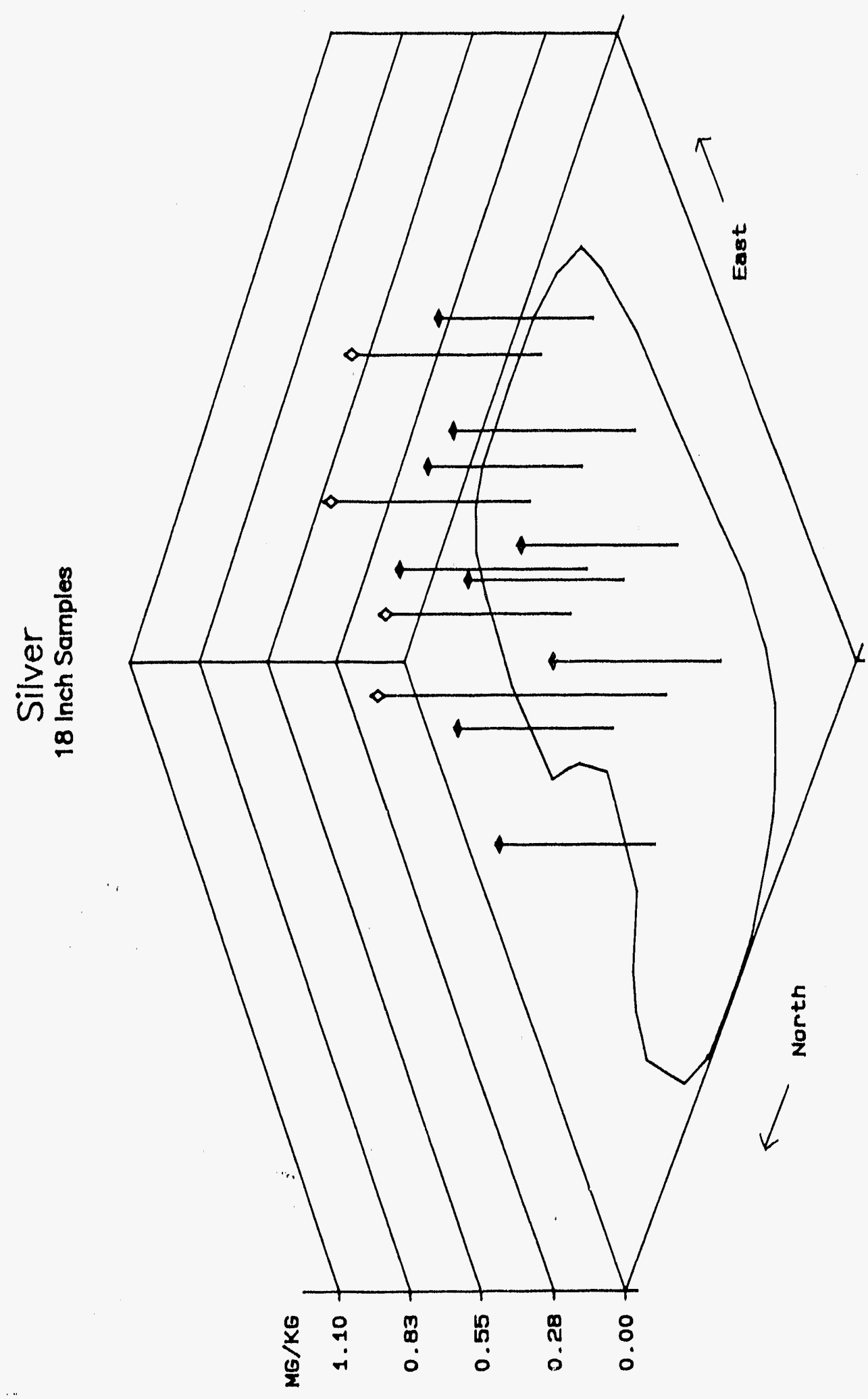

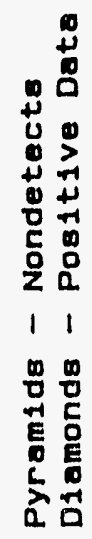




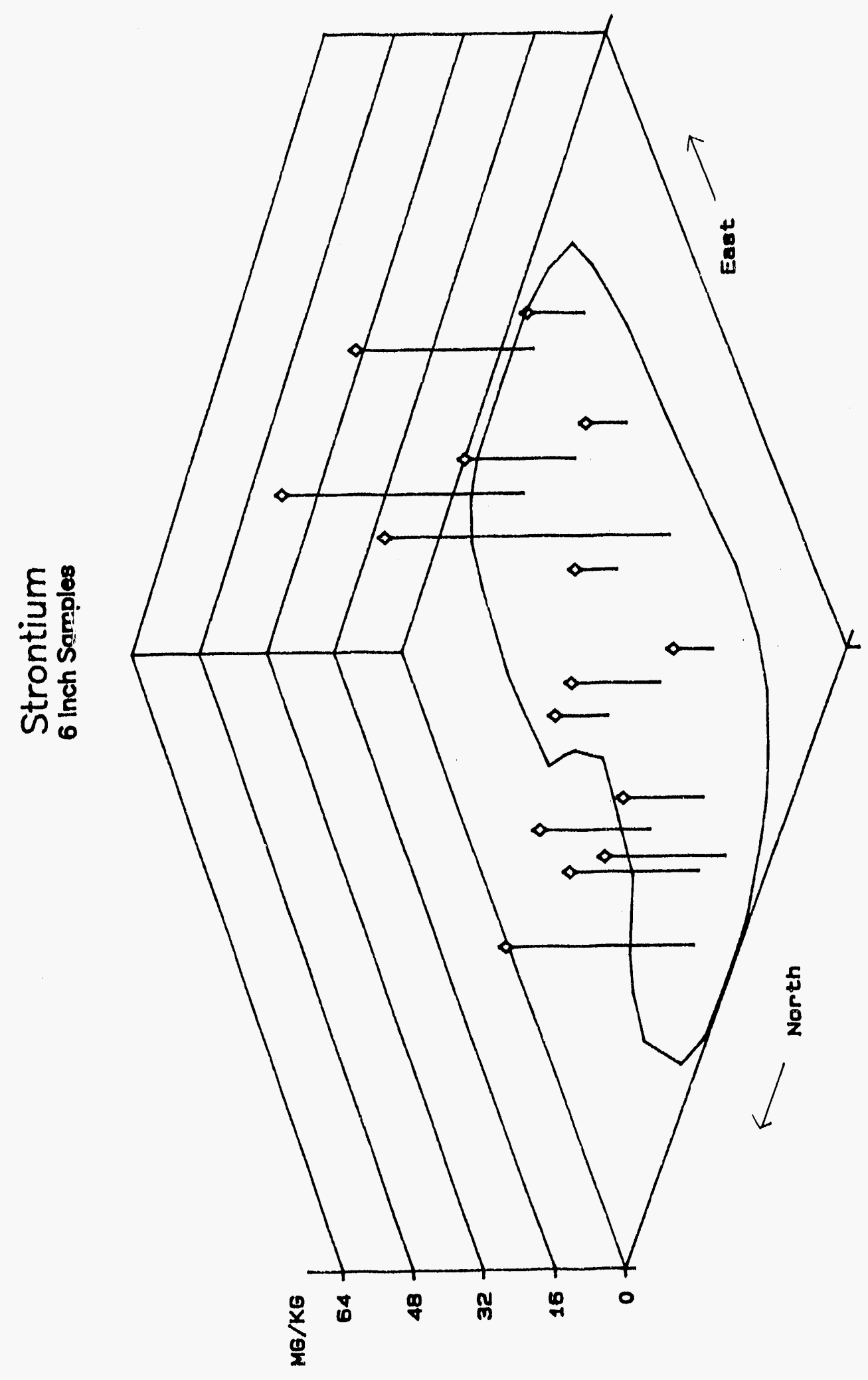

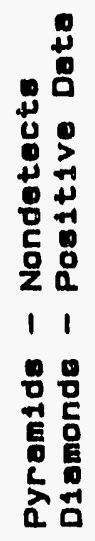




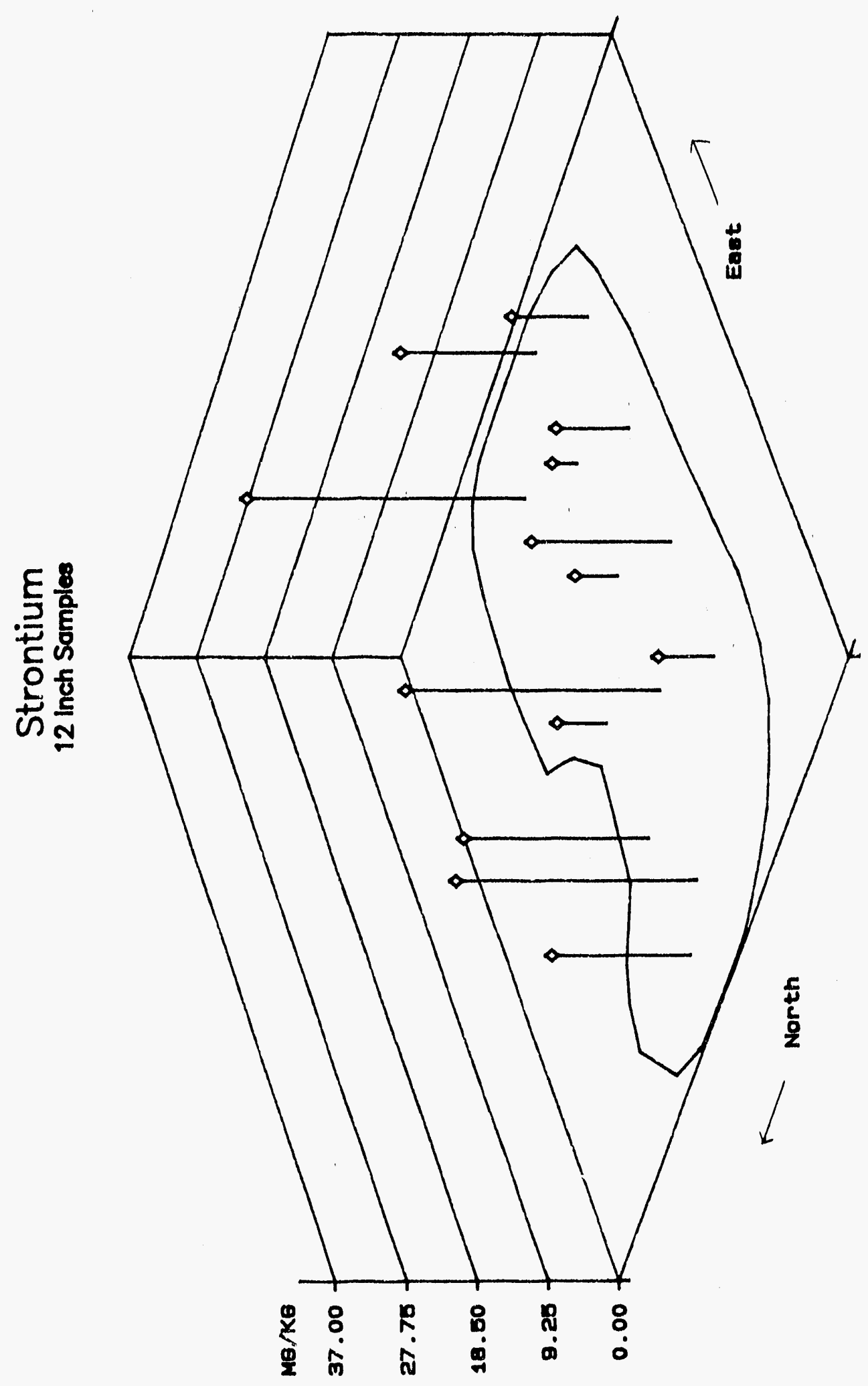

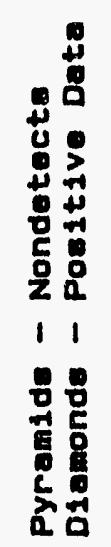




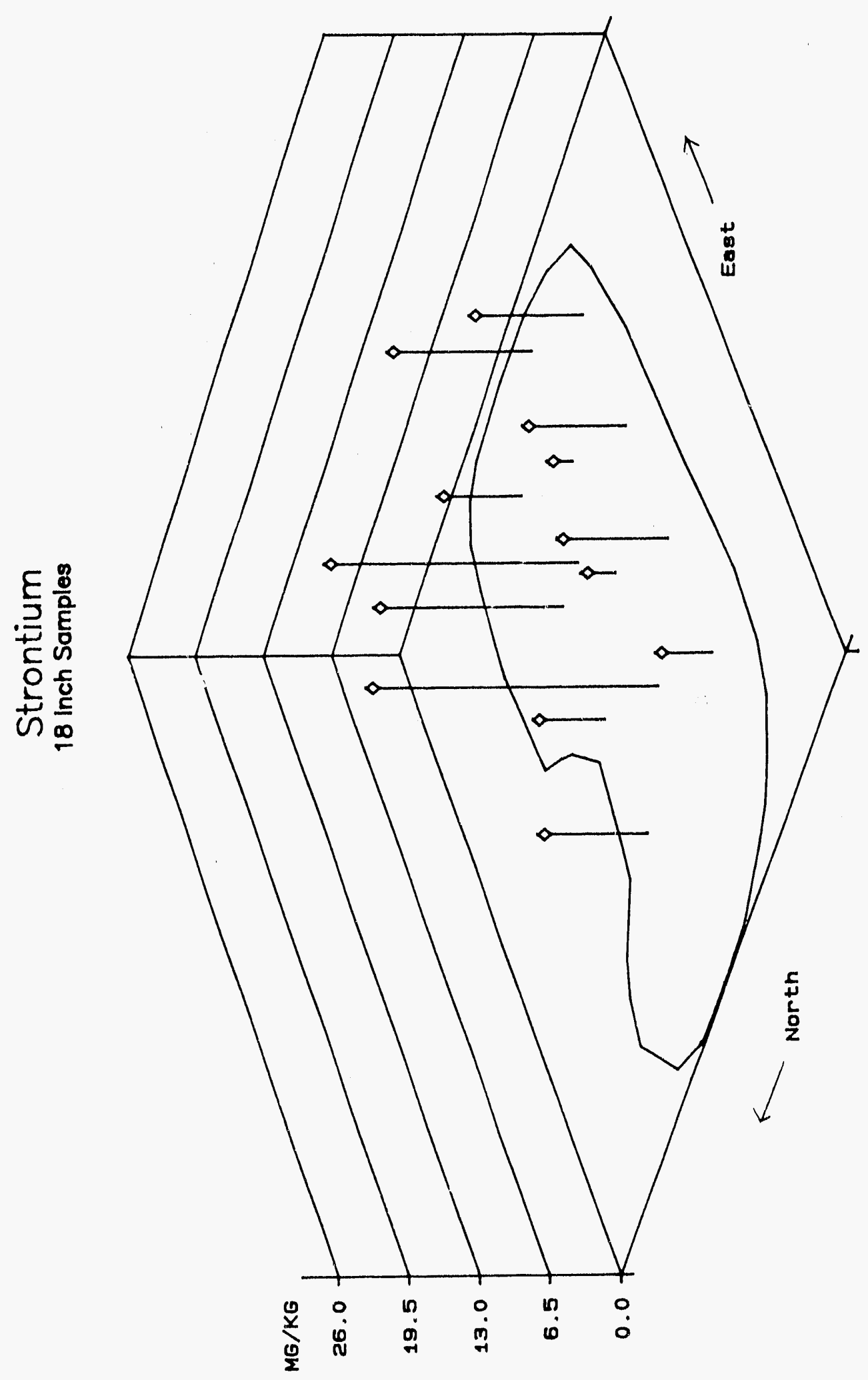

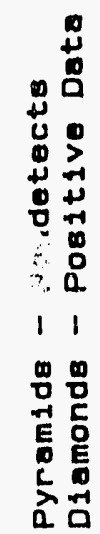




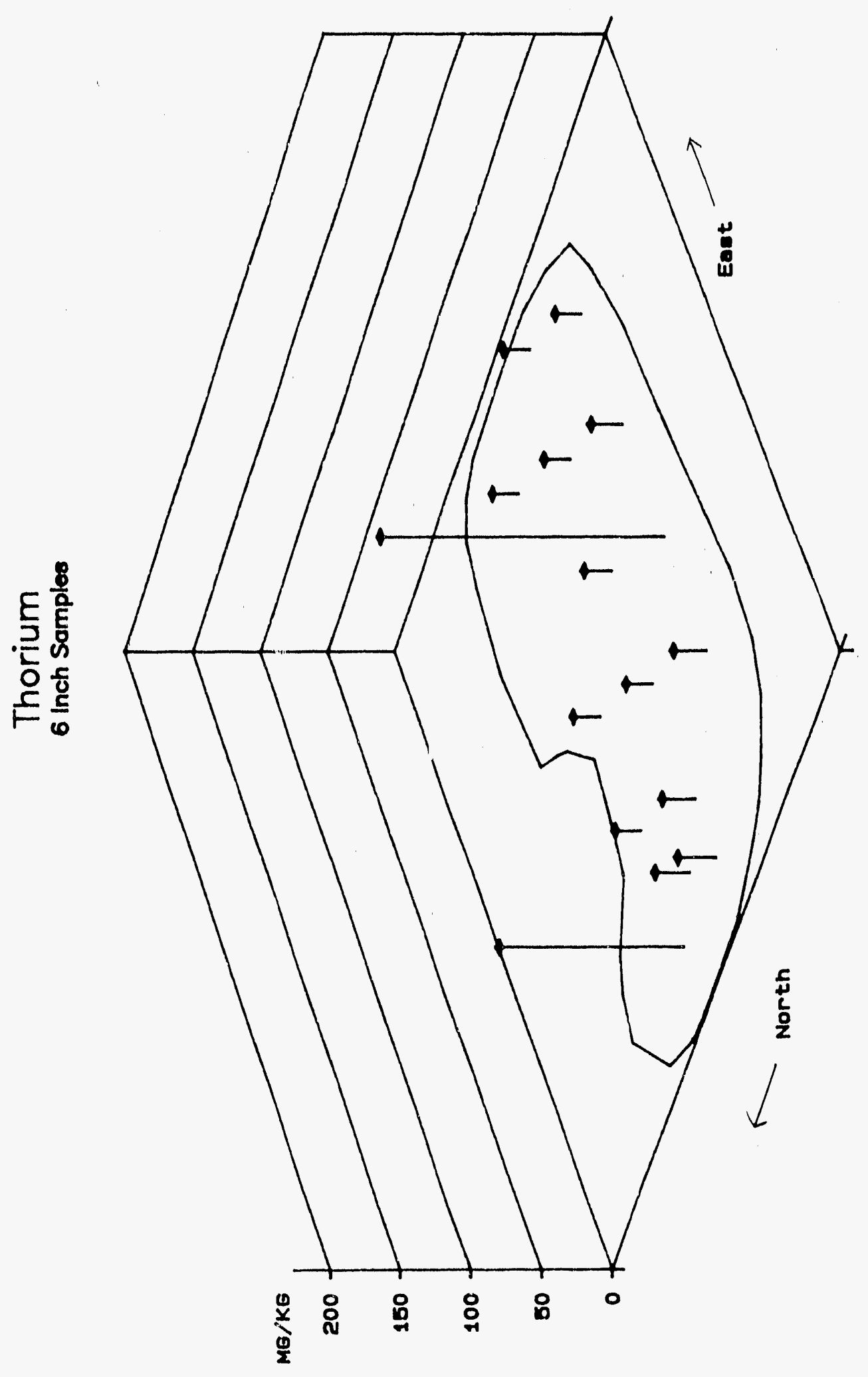

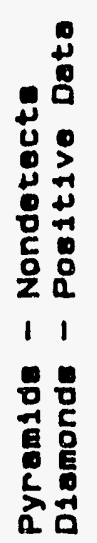




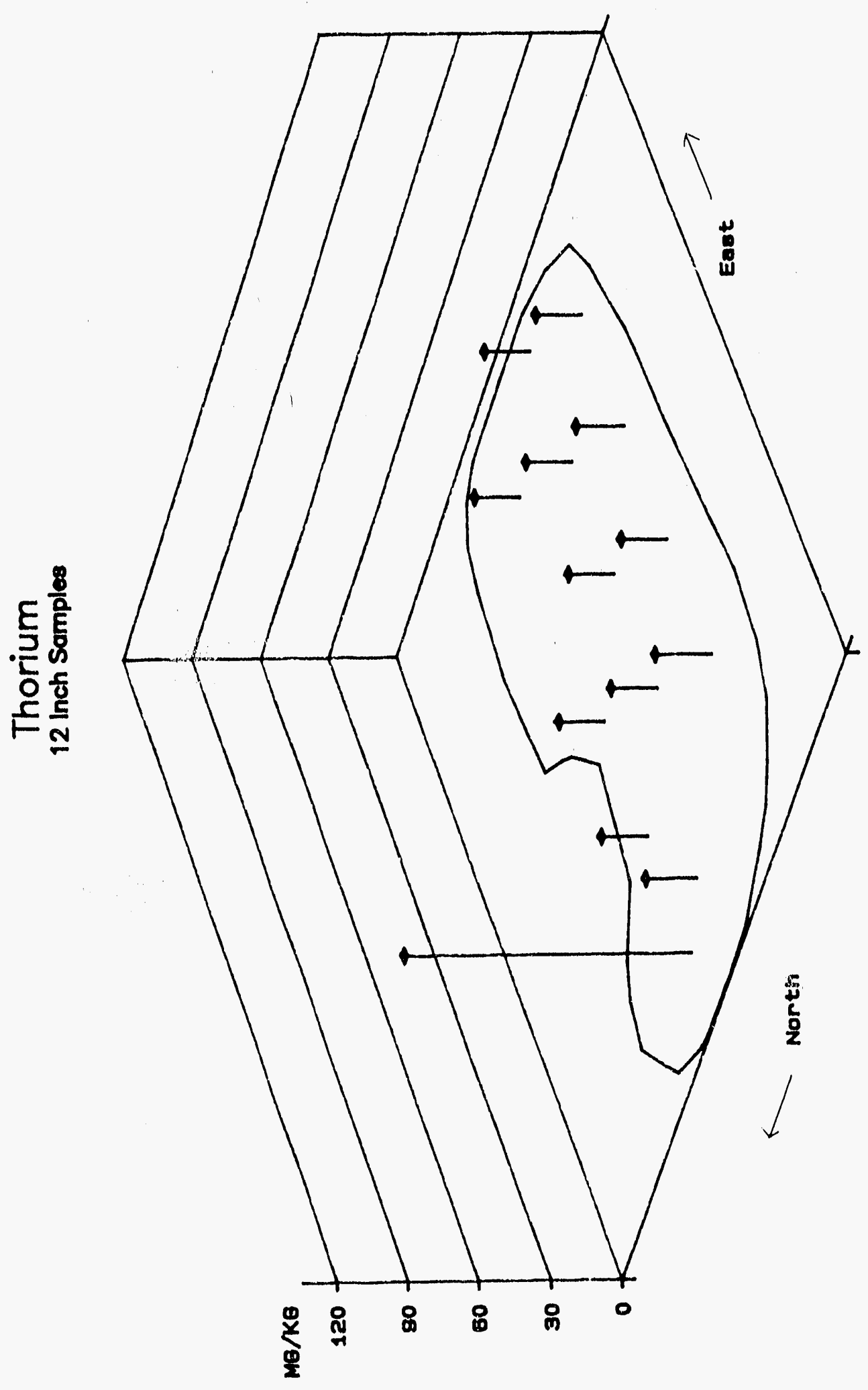

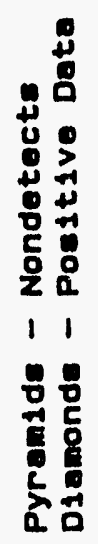




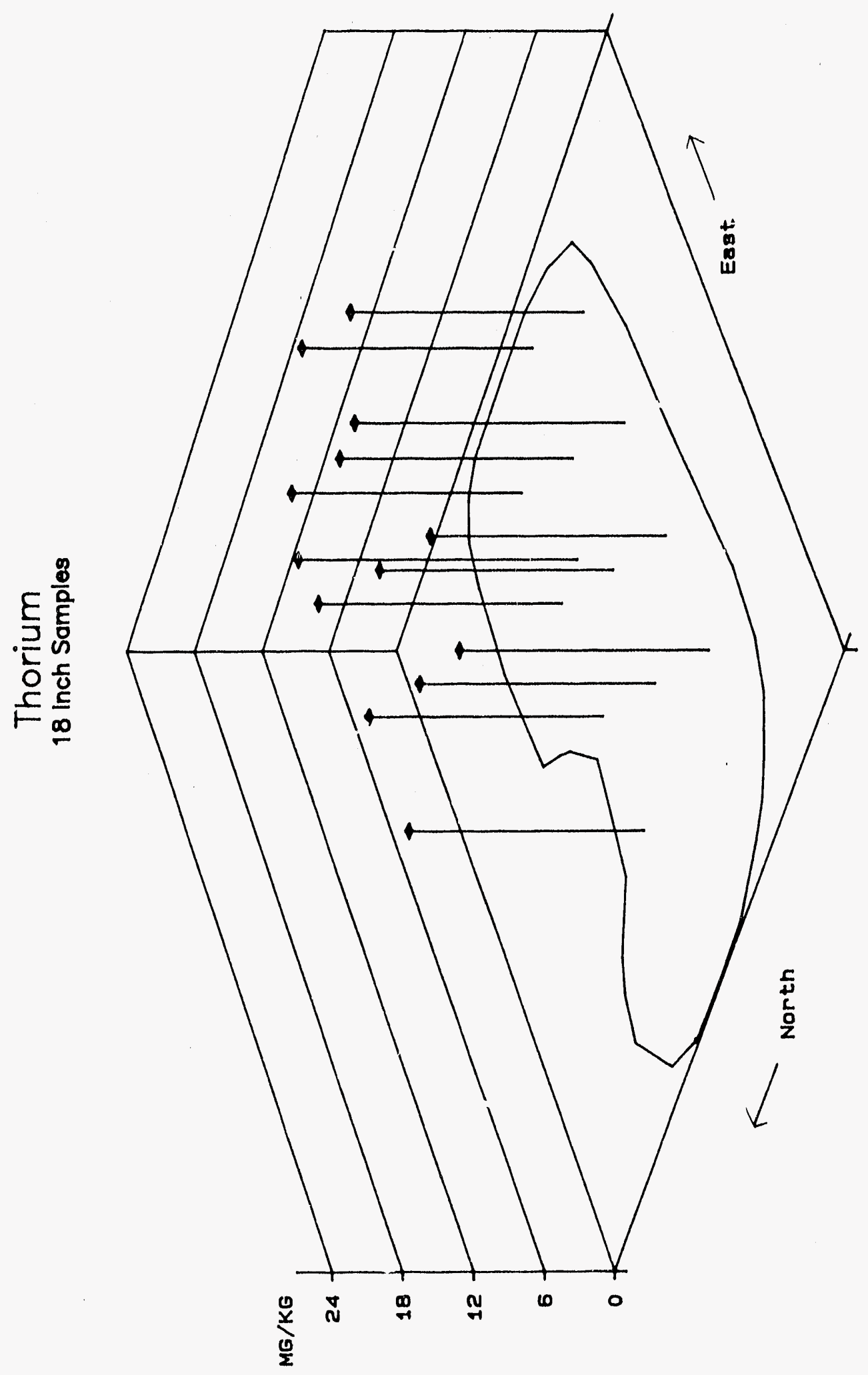

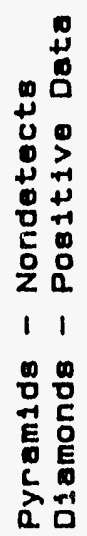




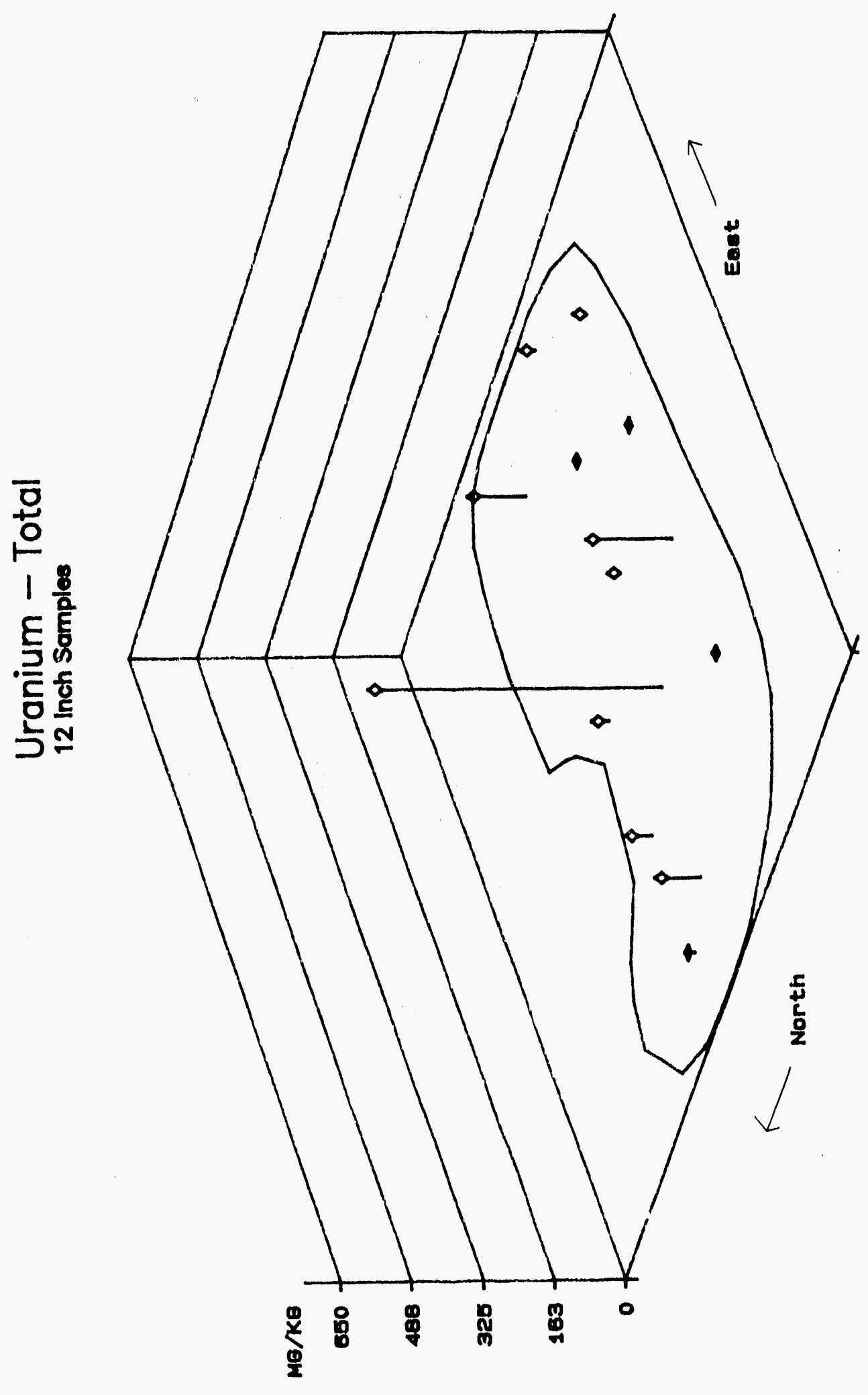

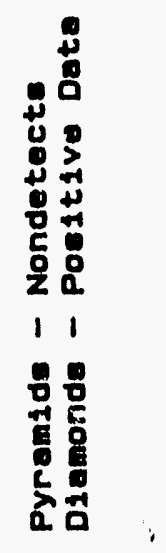




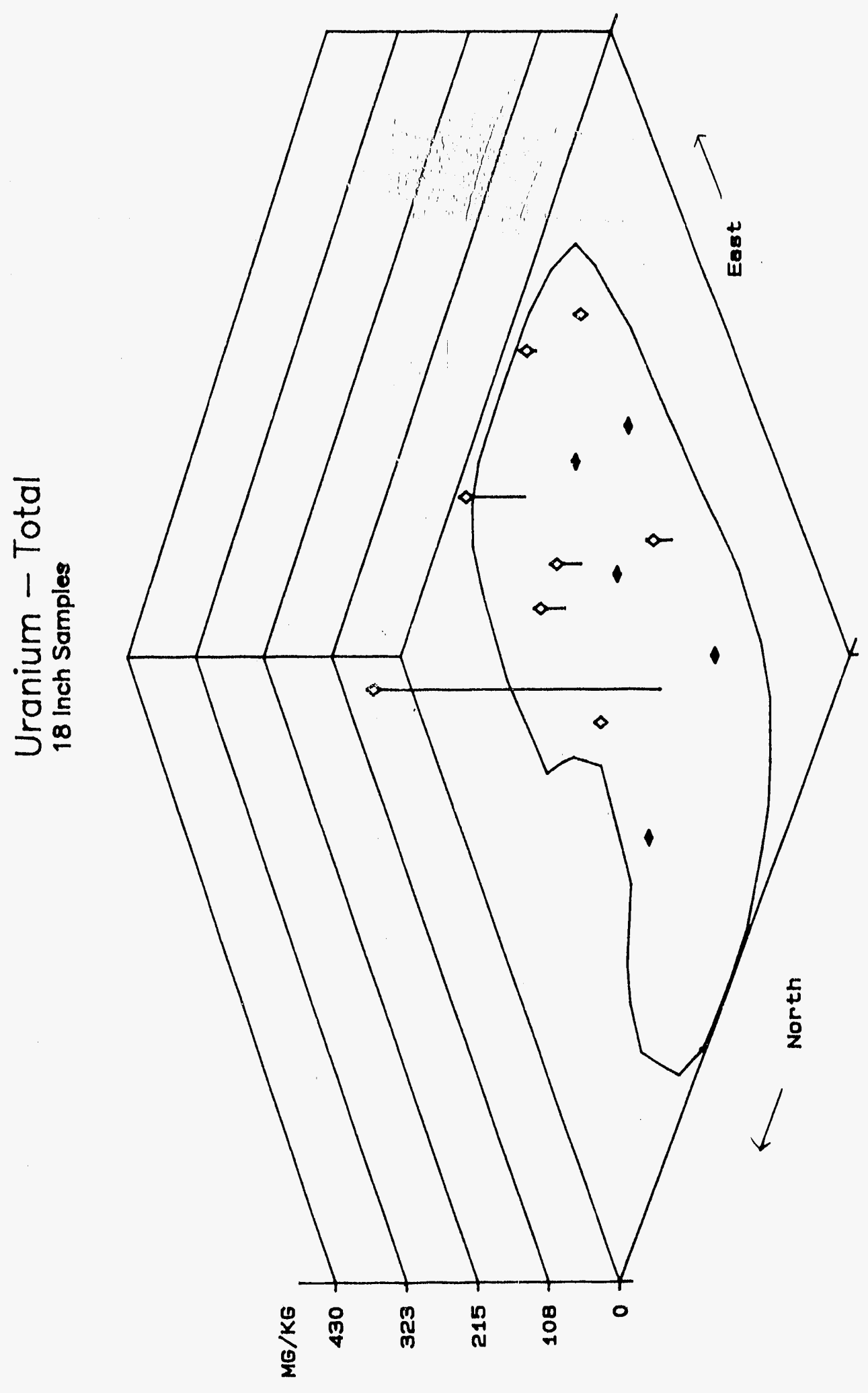

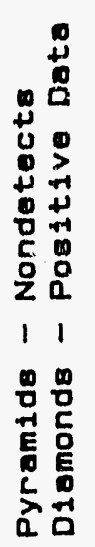




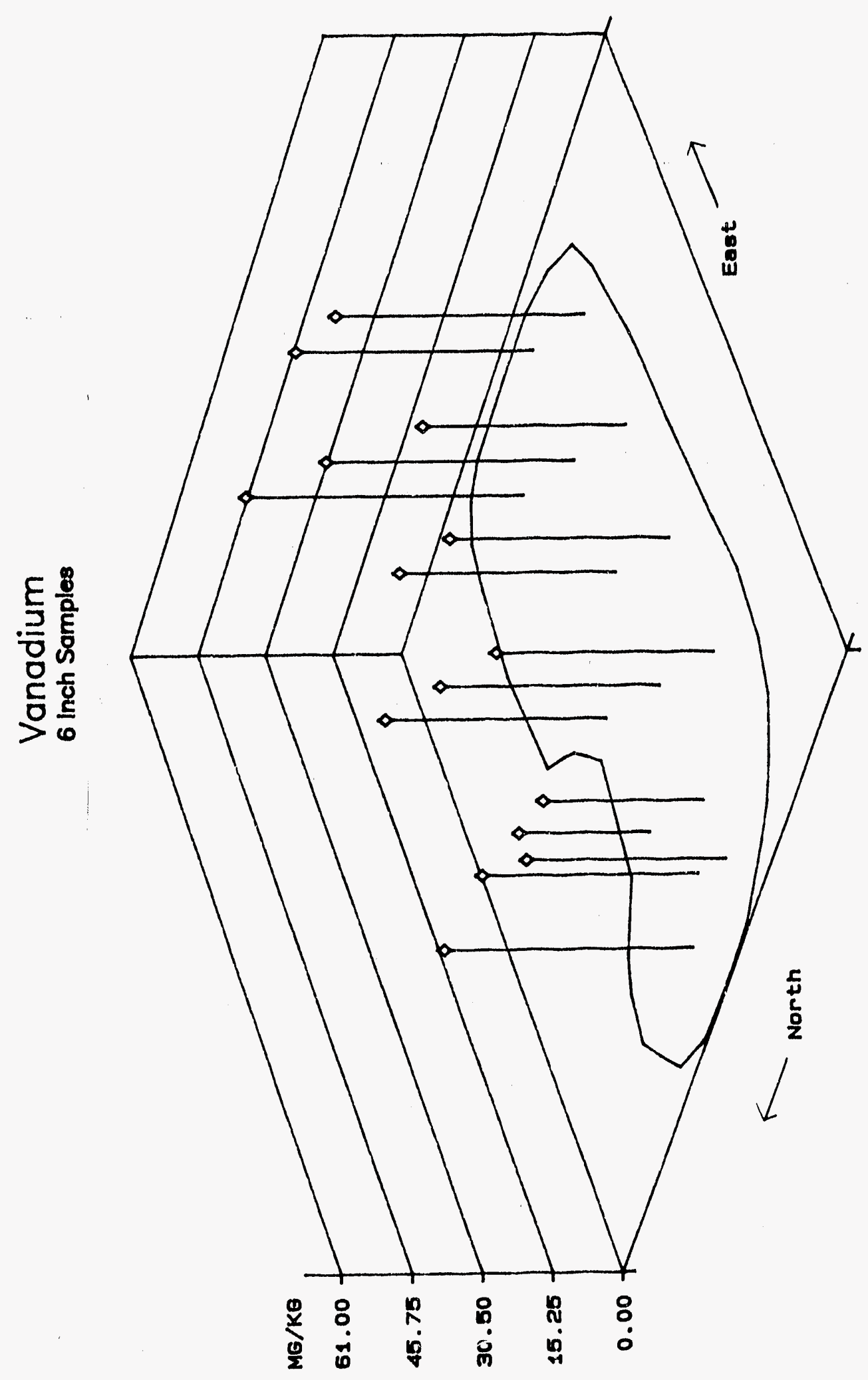

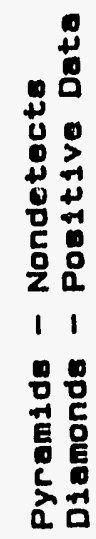




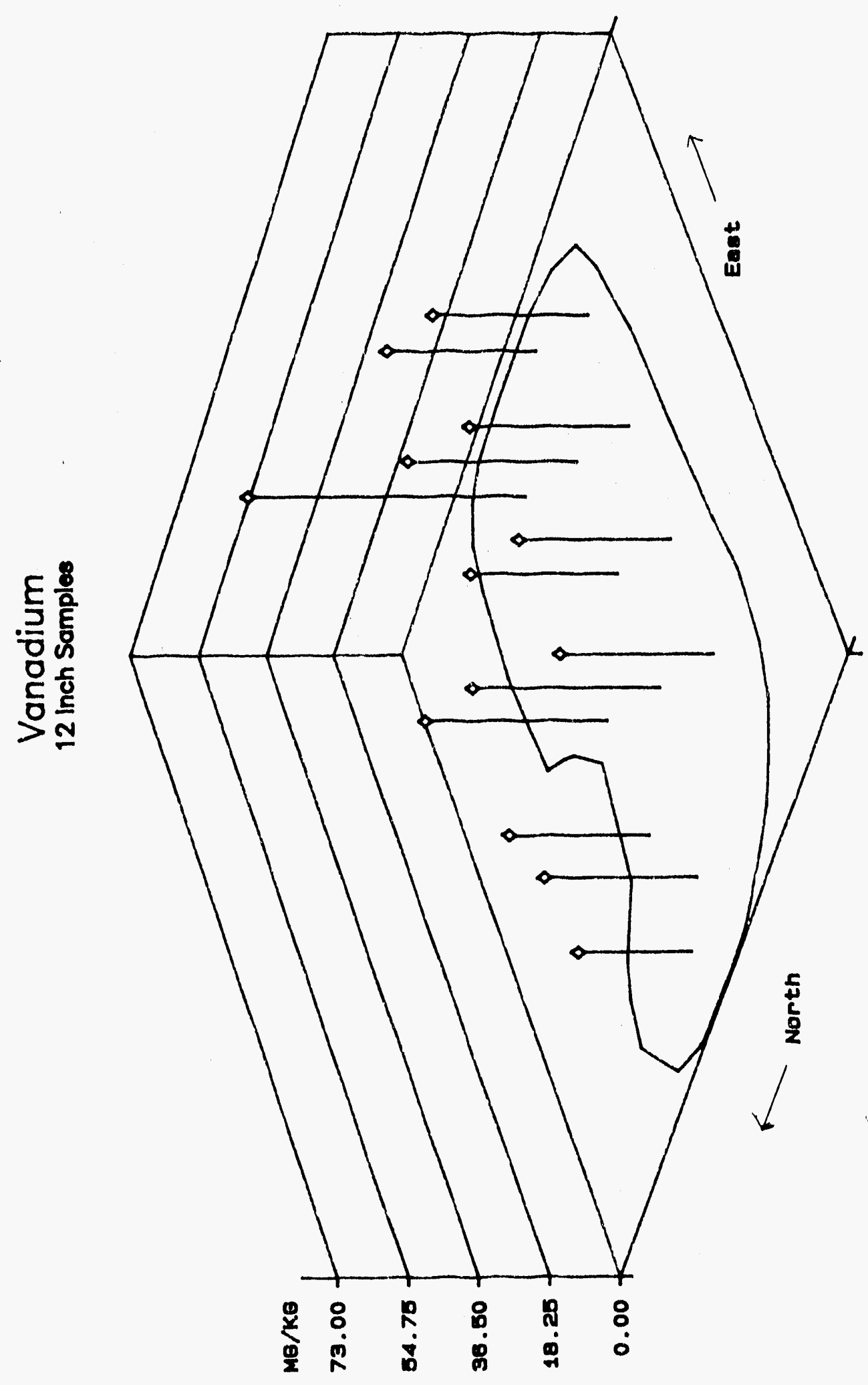

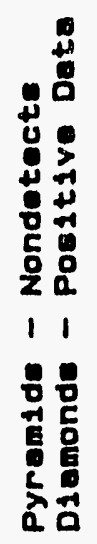




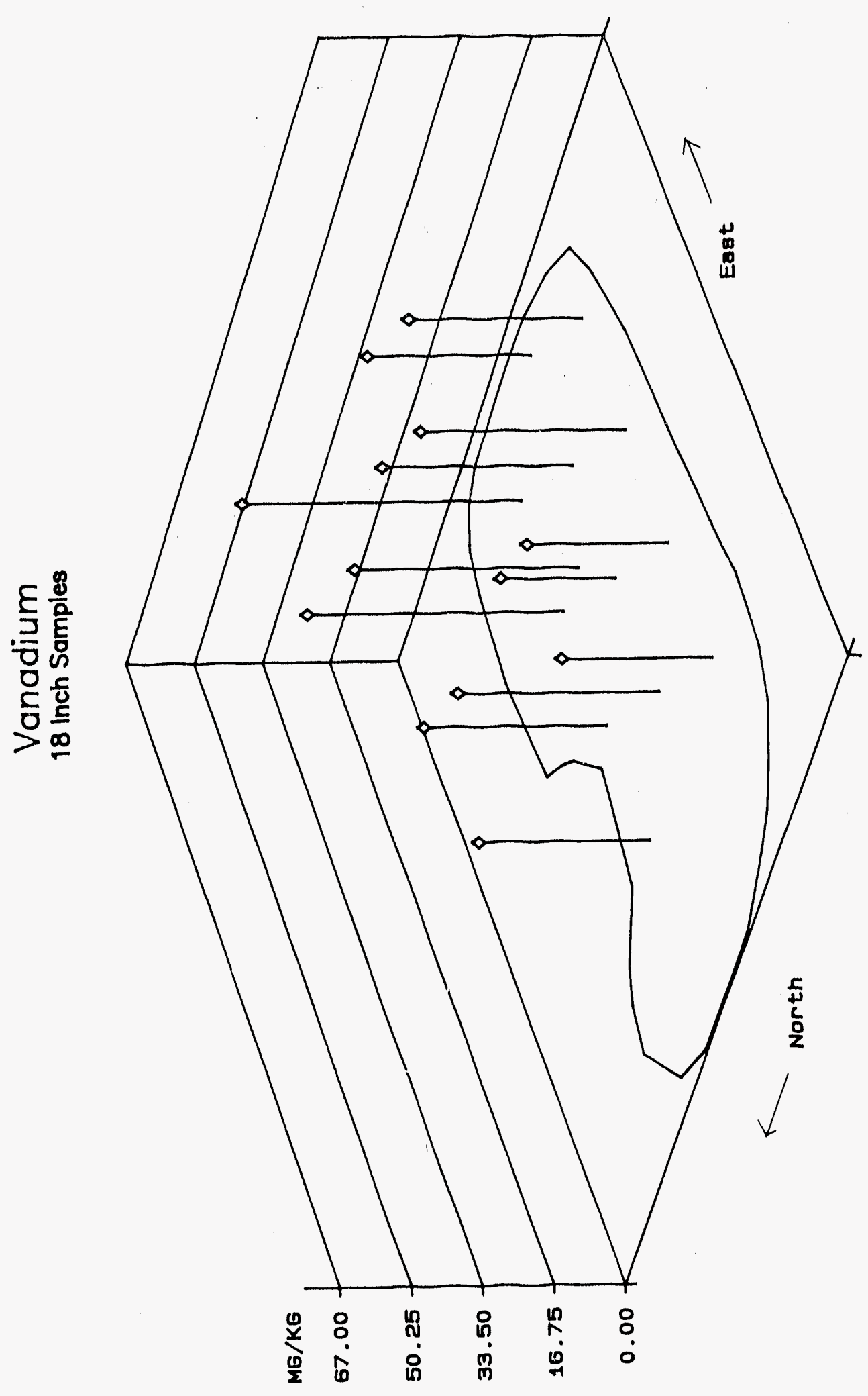

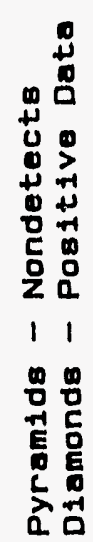




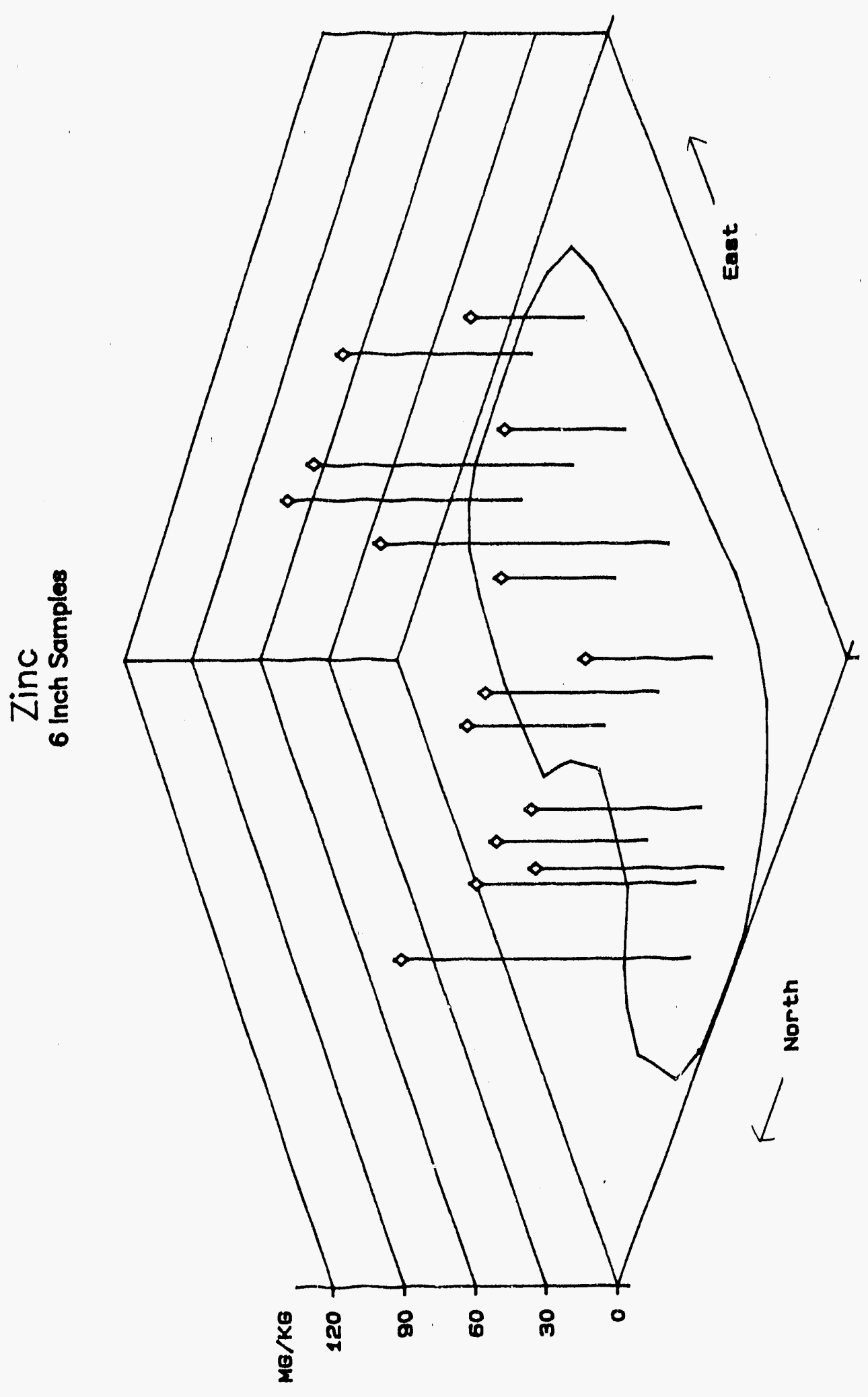

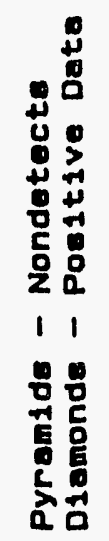




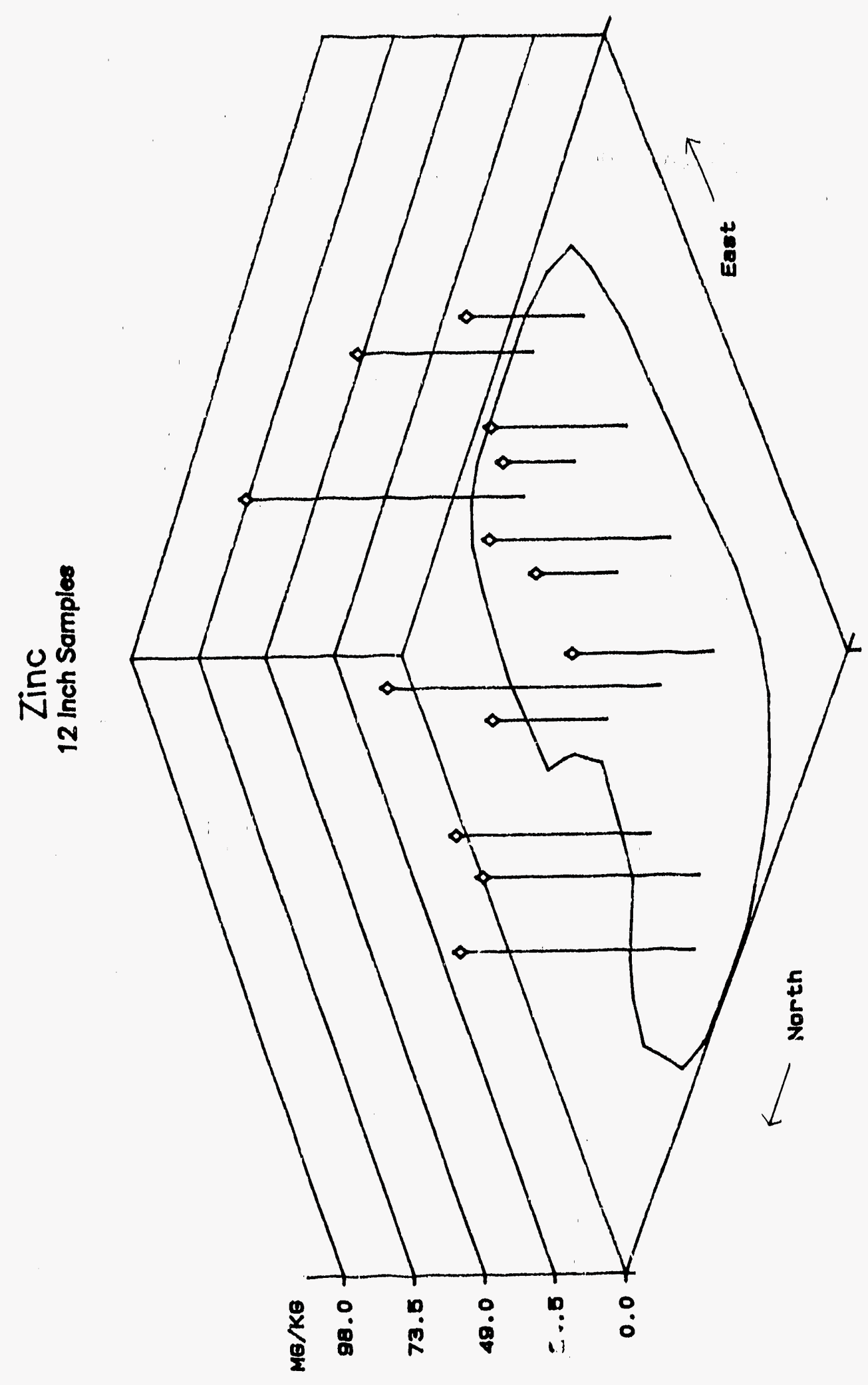

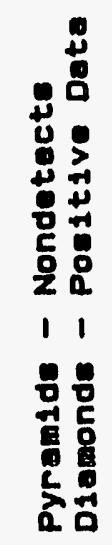




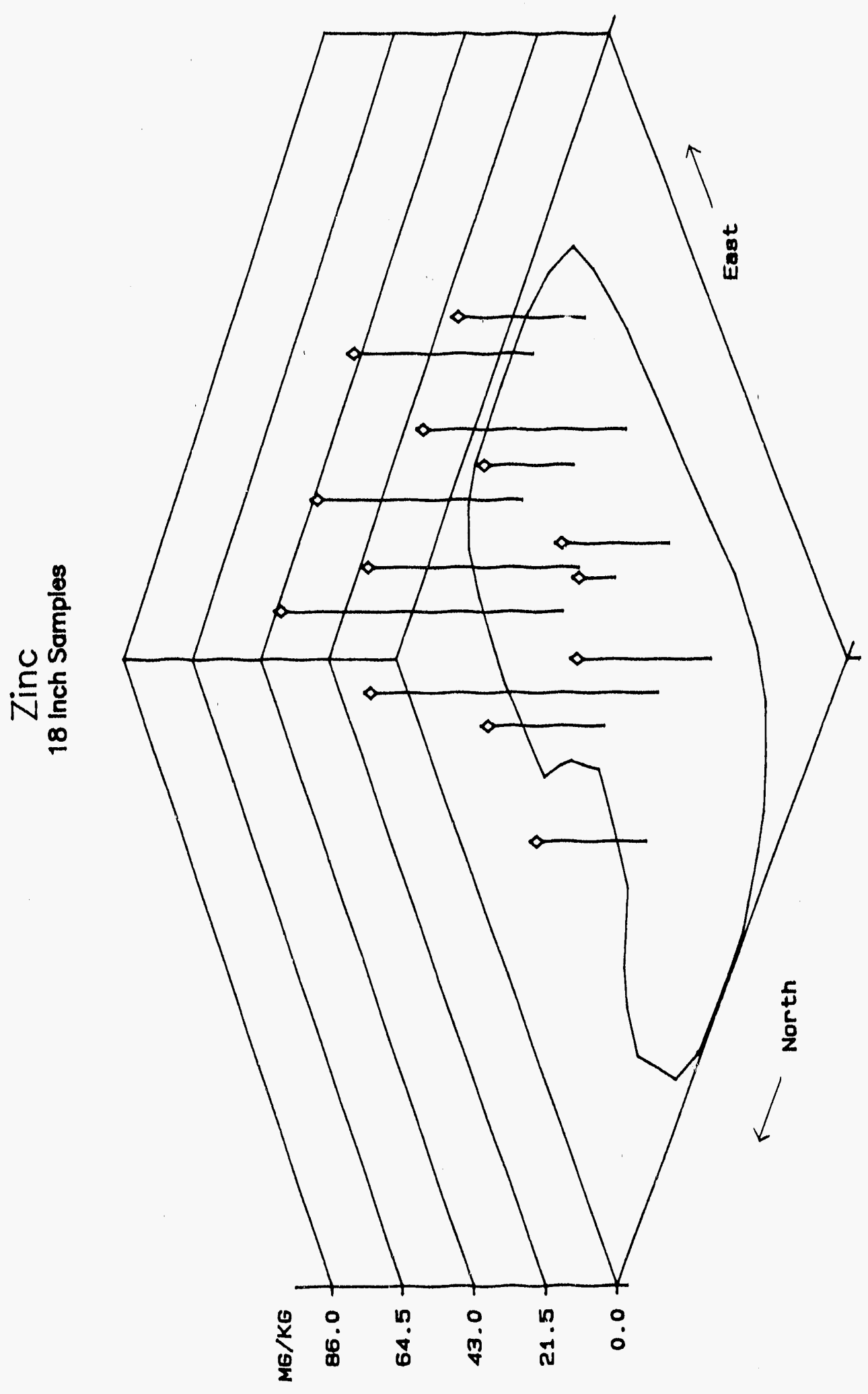

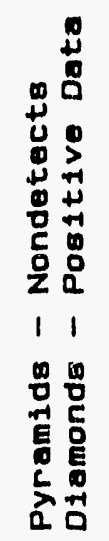




\section{DISTRIBUTION}

1. J. M. Asher

2. M. Baer

3. L. D. Bates

4. D. J. Beal

5. S. C. Bieniek

6. J. L. Bock

7. T. A. Bowers

8. S. N. Burman

9. T. K. Cothron

10. V. G. Davis

11. N. W. Durfee

12. P. L. Goddard

13. C. D. Goins

14. T. L. Hatmaker

15. J. L. Haymore

16. J. Holbert

17. R. K. Holmes

18. K. W. Keever

19. R. H. Ketelle

20. A. J. Kuhaida, Jr.

21. D. A. Kucsmas

22. D. C. Landguth

23. L. W. Long
24. C. W. McGinn

25. W. E. Manrod

26. R. P. Migun

27. W. E. Miller

28. R. W. Oliver

29-32. P. T. Owen

33. A. S. Quist

34. J. R. Rickaway

35. G. E. Rymer

36. R. B. Sackett

37. C. S. Satterwhite, Jr.

38. R. L. Schmoyer

39. L. G. Shipe

40. J. V. Spence

41. D. W. Swindle, Jr.

42. B. D. Walker

43. P. D. White

44. R. K. White

45. Applied Technology Library

46-50. ER Document Management Center

51. ORNL Laboratory Records

52. K-25 Site Records

53. P. H. Edmunds, Radian Corporation, 120 South Jefferson Circle, Oak Ridge, TN 37830

54-55. S. S. Perkins, DOE Field Office, Oak Ridge, Information Resource Center, 105 Broadway, Oak Ridge, TN 37830

56-59. W. E. Murphie, Department of Energy, Office of Environmental Restoration, Eastern Area D\&D Branch, EM-423 (GTN), Washington, DC 20545

60-61. Office of Scientific and Technical Information, P.O. Box 62, Oak Ridge, TN 37831

62. R. C. Sleeman, DOE Field Office, Oak Ridge, P.O. Box 2001, Oak Ridge, TN 37831-8541

63-64. M. A. Travaglini, DOE Field Office, Oak Ridge, P.O. Box 2001, Oak Ridge, TN 37831-854i 

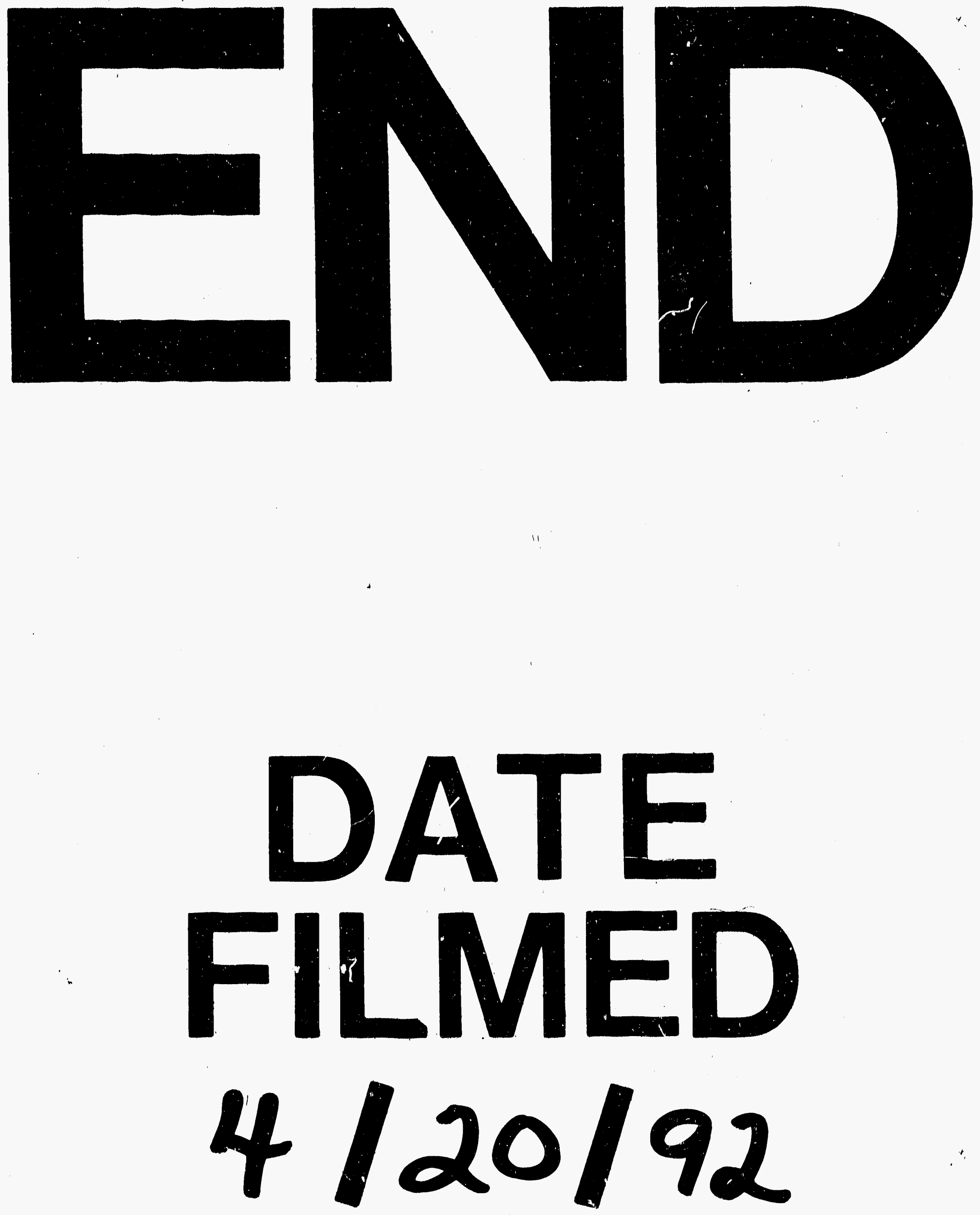

1 